JULIANA KEIKO SAGAWA

\title{
SISTEMA AUTOMATIZADO PARA A MEDIÇÃO DE DESVIOS DE FORMA E ORIENTAÇÃO
}

Dissertação apresentada à Escola de Engenharia de São Carlos da Universidade de São Paulo, para obtenção do título de Mestre em Engenharia Mecânica.

ORIENTADOR: PROF. DR. BENEDITO DI GIACOMO

São Carlos

2008 
AUTORIZO A REPRODUÇÃO E DIVULGAÇÃO TOTAL OU PARCIAL DESTE TRABALHO, POR QUALQUER MEIO CONVENCIONAL OU ELETRONNICO, PARA FINS DE ESTUDO E PESQUISA, DESDE QUE CITADA A FONTE.

Ficha catalográfica preparada pela Seção de Tratamento da Informação do Serviço de Biblioteca - EESCIUSP

S129a

Sagawa, Juliana Keiko

Sistema automatizado para a mediça de desvios de forma e orientaça / Juliana Keiko Sagawa ; orientador Benedito Di Giacomo. -- Sao Carlos, 2008.

Dissertaça Mestrado-Programa de Pơs-Graduação em Engenharia Mecânica e Area de Concentraçăo em Projeto Mecanico) - Escola de Engenharia de Sa Carlos da Universidade de sao Paulo, 2008.

1. Metrologia. 2. Automação da medição. 3. Desvio de planicidade. 4. Desvio de perpendicularismo. 5. Separaça de erros. 6. Métodos de sensores múltiplos. I. Titulo. 


\section{FOLHA DE JULGAMENTO}

Candidata: Engenheira JULLANA KEIKO SAGAWA

Dissertação defendida e julgada em $1209 / 2008$ perante a Comissão Julgadora:

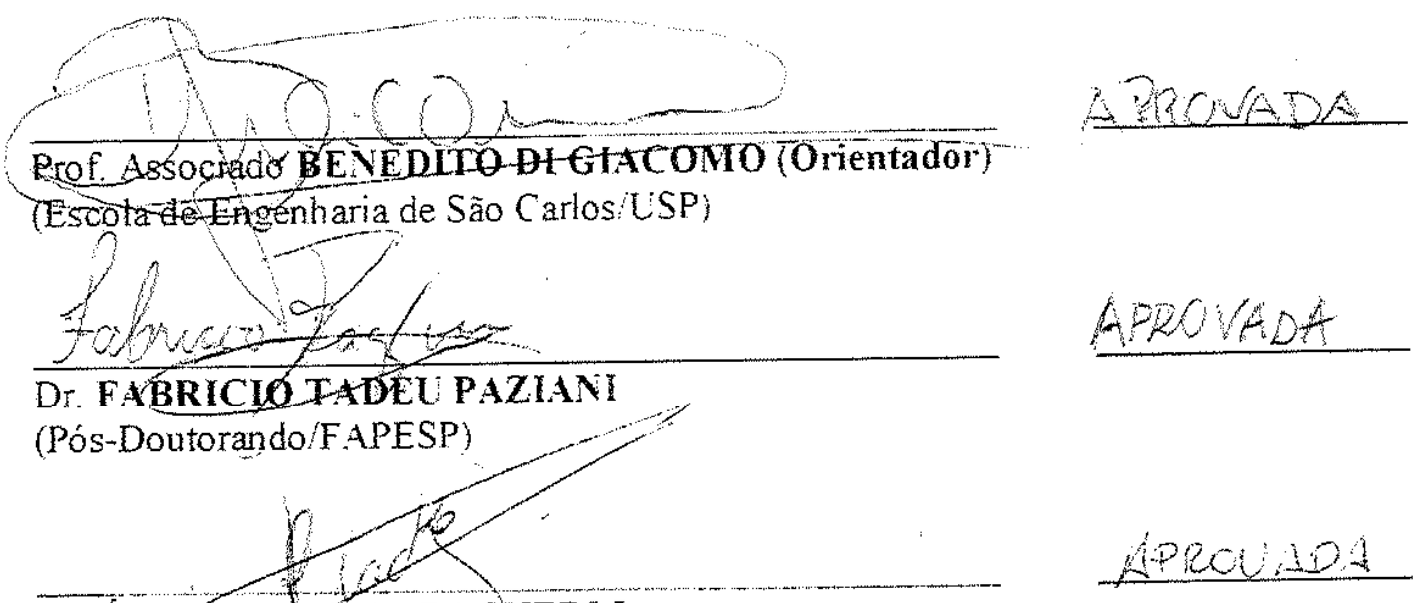

Dr. ALYARO NOSE ABACKERLI

(Instituto de Tescuisa Techológica do Estado de Săo Paulo/IPTESP)

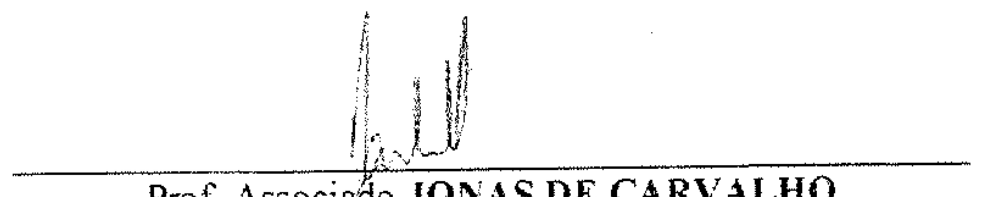

Prof. Associado JONAS DE CARV ALHO

Coordenador dó Programa de Pós-Graduação em

Engenharia Mecânica

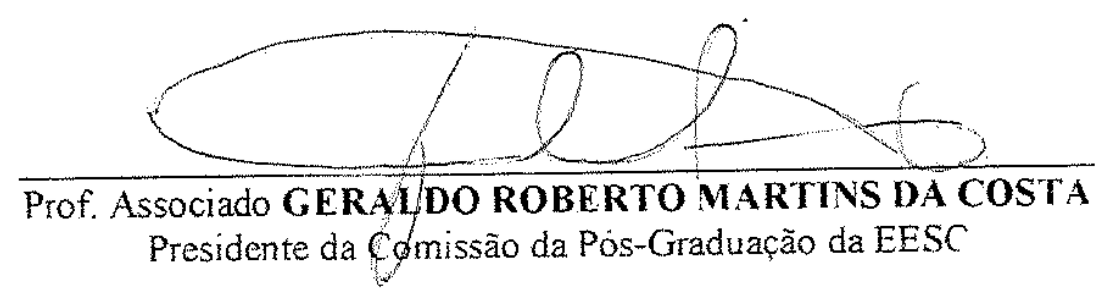



Aos meus queridos pais, Ana e Jorge, meus protetores nesta vida.

Com amor. 



\section{Agradecimentos}

A Deus, Grande Pai, pela minha vida e por tudo que me dá, a cada instante.

Ao querido professor Benedito di Giacomo, mais que um orientador. Agradeço por seus conselhos, apoio incondicional e amizade.

Ao Dr. Fabrício Paziani e ao professor Roberto Tsunaki pelas valiosas contribuições. Ao Luiz Neves, pelo auxílio na parte experimental deste trabalho. Ao José Otoboni pelo auxílio com os desenhos.

Aos colegas de laboratório: ao Alessandro (Fio), por sua alegria e amizade especial, ao Alessandro (Calango), Fabrício e Luizinho pela amizade e auxílio, e à Rita, Guilherme, Helena, Paulo, Pedro, Wagner e Larissa pelos bons momentos durante nossa convivência.

Aos técnicos do laboratório de Metrologia e do LAMAFE.

Ao José Cláudio (Claudinho) pela amizade e companhia nos horários nãoconvencionais.

À FAPESP pelo apoio financeiro concedido durante parte do desenvolvimento deste trabalho.

Ao meu chefe Mario Stefani e colegas de trabalho (também amigos) da Opto Eletrônica S.A.

Aos meus pais Ana e Jorge, pelo seu amor e apoio em todos os momentos. Ao meu irmão Fernando, grande companheiro.

Aos meus padrinhos Maria Aparecida e José Figueiredo e à minha família.

À Vandinha, amiga de muitas peripécias. Aos amigos: Gilmour, Artur, Humberto, Jeff, Mariana, pelos bons momentos. Aos amigos que estão longe e que não vejo há algum um tempo.

Ao Branco, pelo carinho e companheirismo em tantos momentos.

Aos meus guias e amigos de fé.

Aos todos que não puderam ser citados aqui, mas que fazem parte da minha vida, trazendo-me felicidade e aprendizado. 

Quando o homem deixa morrer a sua consciência, deixa de amar e passa para o ódio, [...], aí sim, ele está morto.

Pai João de Aruanda

Senhor, fazei de mim um instrumento de vossa paz.

Oração de São Francisco 



\section{Resumo}

SAGAWA, J. K. (2008). Sistema automatizado para a medição de desvios de forma e orientação. Dissertação (Mestrado) - Escola de Engenharia de São Carlos, Universidade de São Paulo, São Carlos, 2008.

O modo de produção vigente exige cada vez mais rapidez, precisão e eficiência nos processos. Em resposta a essas tendências, constituem-se desafios à área de Metrologia a obtenção de sistemas de medição e algoritmos de avaliação de erros mais precisos; a avaliação de incertezas com precisão; e a execução de medições com rapidez. Neste trabalho apresenta-se um Sistema Automatizado de medição para avaliação dos desvios de forma e orientação de componentes. O sistema é baseado na utilização de um robô industrial com seis graus de liberdade e sensores de deslocamento do tipo LVDT. O emprego de sistemas como o proposto para a avaliação de desvios geométricos está condicionado à utilização de um modelo matemático de separação de erros, uma vez que a acuracidade de posicionamento e a repetibilidade dos robôs disponíveis atualmente não são adequadas à medição de grandezas micrométricas. Além da aplicação do modelo de separação de erros, este trabalho inclui a elaboração modelos e rotinas de processamento de dados para a avaliação de desvios geométricos. Sistemas similares desenvolvidos foram aplicados principalmente à medição de desvios de retilineidade, e em alguns casos, circularidade. Neste trabalho, buscou-se o escopo de aplicações deste tipo de sistema, de forma a abranger não só a avaliação dos desvios de retilineidade, mas também a avaliação dos desvios de planicidade e perpendicularismo. Além disso, o enfoque da pesquisa foi dirigido à avaliação do desempenho do sistema e do modelo de separação de erros, por meio da realização de testes experimentais com três peças distintas e por meio de análise comparativa com sistemas convencionais de medição. Os resultados obtidos comprovaram a eficiência do sistema proposto, que destacou-se também por apresentar boa repetibilidade.

Palavras-chave: Automação da Medição, Desvio de planicidade, Desvio de perpendicularismo, Separacão de erros, Métodos de sensores múltiplos 



\section{Abstract}

SAGAWA, J. K. (2008). Automated system for measuring form and orientation deviations. Dissertation (Master) - Escola de Engenharia de São Carlos, Universidade de São Paulo, São Carlos, 2008.

The current production system demands fast, efficient and precise processes. In order to address these issues, most of the research efforts in the Metrology area have been focused into the development of faster and more accurate measuring systems as well as into the definition of methods to better evaluate uncertainties in measurement. This work presents an automated system for the evaluation of form and orientation deviations of mechanical components. A six-degree-of-freedom industrial robot and LVDT sensors are used to take the measurements. The implementation of the proposed system depends on the application of a mathematical model for error separation since the accuracy of positioning and repeatability presented by the currently available industrial robots are not suitable for measuring micrometric deviations. Besides the application of the error separation model, this work also includes the development of data processing algorithms for the evaluation of geometrical deviations. Few similar systems to the proposed one were developed and applied mainly for straightness and, in some cases, roundness measurements. This work aimed at broadening the range of applications of this kind of measuring systems, making them suitable for the evaluation of flatness and orthogonality deviations. Additionally, the focus of the research was set to the performance evaluation of the system and the error separation model. In order to do that, experimental tests with three different parts were carried out. The values found were compared to the values of the deviations measured with conventional GD\&T practice. The obtained results showed the efficiency of the proposed system, which also presented good repeatability.

Keywords: Automation of measuring, Flatness deviation, Perpendicularity Deviation, Error separation techniques, Multi-probe methods. 



\section{Lista de Figuras}

Figura 2.1 - Método da Reversão do Nível Eletrônico ................................... 35

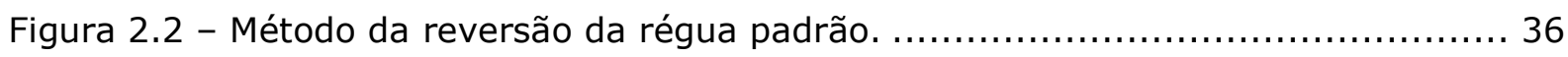

Figura 2.3 - Método da reversão da esfera-padrão de Donaldson ......................... 38

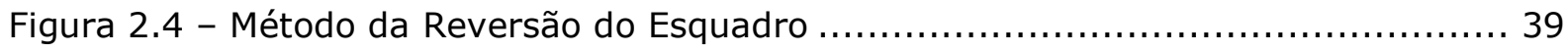

Figura 2.5 - Método da Reversão para Medição de Paralelismo do eixo árvore............ 40

Figura 2.6 - Método da Reversão para detecção do erro de batida axial do eixo árvore 41

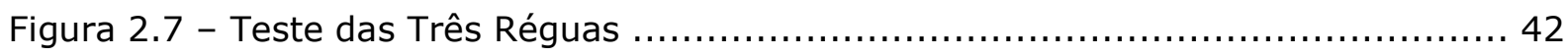

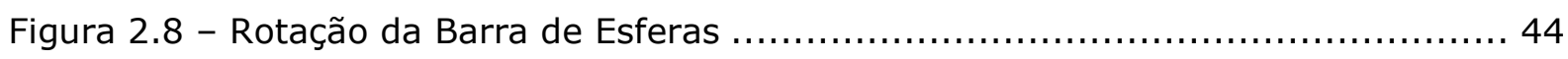

Figura 2.9 - Esquema da medição do desvio de retilineidade utilizando o interferômetro

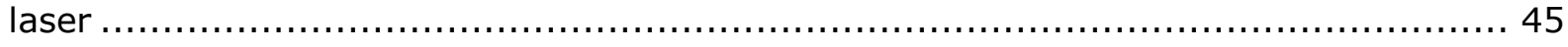

Figura 2.10 - Efeito dos desvios de planicidade do refletor na reflexão dos feixes ....... 46

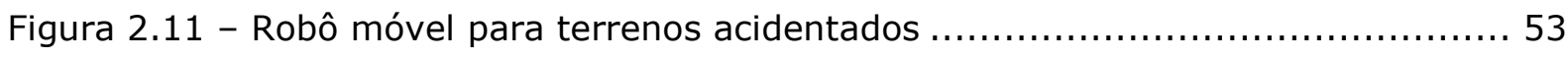

Figura 2.12 - Princípio de medição do robô móvel .......................................... 53

Figura 2.13 - Princípio de funcionamento dos sensores de varredura a laser. ........... 57

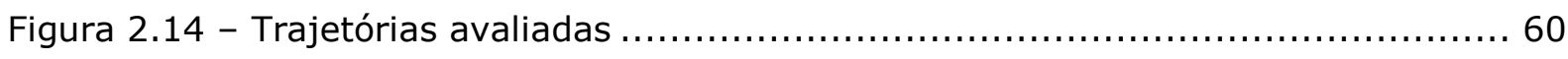

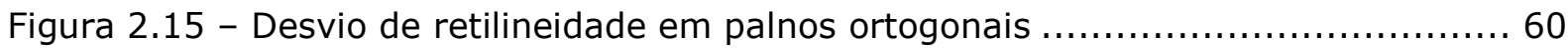

Figura 3.1 - Representação do desvio de retilineidade................................ 64

Figura 3.2 - Tolerância ou desvio de paralelismo de uma reta no plano vertical.......... 67

Figura 3.3 - Tolerância ou desvio de paralelismo de uma reta no plano horizontal ...... 67

Figura 3.4 - Campo cilíndrico tolerância ou desvio de paralelismo.....................67

Figura 3.5 - Campo de tolerância ou desvio de paralelismo especificado em duas direções 68

Figura 3.6 - Tolerância ou desvio de paralelismo em relação a um plano de referência. 68

Figura 3.7 - Desvio de paralelismo de uma superfície em relação a uma reta de

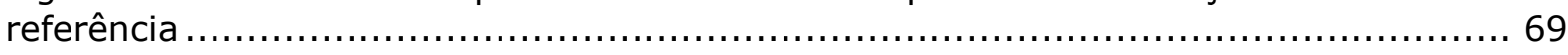

Figura 3.8 - Representação do desvio de perpendicularismo (norma JIS B 0621)....... 70

Figura 3.9 - Princípio do Método dos Dois Pontos Sucessivos ......................... 74

Figura 3.10 - Representação do Método dos Três Pontos ............................... 77

Figura 5.1 - Dispositivo porta-sensores acoplado ao punho do manipulador.............100 
Figura 5.2 - Peça 1.

Figura 5.3 - Peça 3.

Figura 5.4 - Montagem para avaliação do desvio de perpendicularismo - Peça 3. 102

Figura 5.5 - Montagem para avaliação do erro de perpendicularismo - Peça 2. 103

Figura 5.6 - Montagem para avaliação do erro de perpendicularismo utilizando-se sistema convencional de medição.

Figura 5.7 - Esquema representativo da medição das peças 1 e 2 . 107

Figura 5.8 - Coluna de Medição. 108

Figura 5.9 - Fluxograma da rotina de medição.

Figura 5.10 - Mapa de medição da Peça 1 e Peça 2.

Figura 5.11 - Diagrama do modelo de separação de erros. 116

Figura 5.12 - Erros no perfil da peça, reta de referência e posições de medição.

Figura 5.13 - Representação do erro translacional do manipulador.

Figura 5.14 - Representação do erro de inclinação do dispositivo porta-sensores.

Figura 5.15 - Erro de alinhamento inicial dos sensores.

Figura 6.1 - Perfis de superfície da Peça 1 obtidos com o Sistema Automatizado (a) e com o sistema convencional (b). 133

Figura 6.2 - Comparação entre os perfis da geratriz 1 da Peça 2. 138

Figura 6.3 - Perfis de superfície da Peça 2 obtidos com o Sistema Automatizado (a) e o sistema convencional (b). 138

Figura 6.4 - Perfis de superfície da Peça 3 obtidos com o Sistema Automatizado (a) e o sistema convencional (b). 143

Figura 6.5 - Comparação entre os desvios planicidade da Peça 1 (ajustagem Minimax). 170

Figura 6.6 - Comparação entre os desvios de perpendicularismo da Peça 1 (ajustagem Minimax)..... 171

Figura 6.7 - Comparação entre os desvios de perpendicularismo da Peça 1 considerandose 3 amostras do plano de referência (ajustagem Minimax). 171

Figura 6.8 - Comparação entre os desvios planicidade da Peça 1 (ajustagem de Mínimos Quadrados) 173

Figura 6.9 - Comparação entre os desvios de perpendicularismo da Peça 1 (ajustagem de Mínimos Quadrados) 
Figura 6.10 - Comparação entre os desvios de perpendicularismo da Peça 1 considerando-se 3 amostras do plano de referência (ajustagem de Mínimos Quadrados).

Figura 6.11 - Comparação entre os desvios de planicidade da Peça 2 (ajustagem Minimax)

Figura 6.12 - Comparação entre os desvios de perpendicularismo da peça 2 (ajustagem Minimax).

Figura 6.13 - Comparação entre os desvios de perpendicularismo considerando-se 3 amostras do plano de referência (ajustagem Minimax).

Figura 6.14 - Comparação entre os desvios de planicidade da Peça 2 (ajustagem de Mínimos Quadrados). ........................................................................... 178

Figura 6.15 - Comparação entre os desvios de perpendicularismo da Peça 2 (ajustagem de Mínimos Quadrados).

Figura 6.16 - Comparação entre os desvios de perpendicularismo da Peça 2 considerando-se 3 amostras do plano de referência (ajustagem de Mínimos Quadrados)

Figura 6.17 - Comparação entre os desvios de planicidade da Peça 3 (ajustagem Minimax).

Figura 6.18 - Comparação entre os desvios de planicidade da Peça 3 (ajustagem de Mínimos Quadrados).

Figura 6.19 - Comparação entre os desvios de perpendicularismo da peça 3 (ajustagem Minimax)

Figura 6.20 - Comparação entre os desvios de perpendicularismo da peça 3 considerando-se 3 amostras do plano de referência (ajustagem de Mínimos Quadrados)

Figura 6.21 - Comparação entre os desvios de perpendicularismo da Peça 3 (ajustagem de Mínimos Quadrados).....

Figura 6.22 - Comparação entre os desvios de perpendicularismo da Peça 3 considerando-se 3 amostras do plano de referência (ajustagem de Mínimos Quadrados).

Figura 6.23 - Desvios de planicidade da Peça 1 - Comparação entre métodos. 186

Figura 6.24 - Desvios de perpendicularismo da Peça 1 - Comparação entre métodos. .186

Figura 6.25 - Desvios de planicidade da Peça 2 - Comparação entre métodos.

Figura 6.26 - Desvios de perpendicularismo da Peça 2 - Comparação entre métodos. .187

Figura 6.27 - Desvios de planicidade da Peça 3 - Comparação entre métodos. 188

Figura 6.28 - Desvios de perpendicularismo da Peça 3 - Comparação entre métodos. . 188 



\section{Lista de Tabelas}

Tabela 2.1 - Principais aplicações de robôs e manipuladores na indústria automotiva

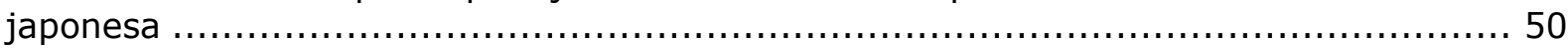

Tabela 5.1 - Características das superfícies medidas.................................. 101

Quadro 5.2 - Entradas e saídas analógicas de comunicação entre manipulador e

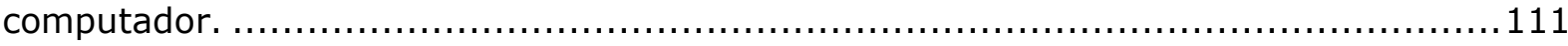

Quadro 5.3 - Rotinas de medição executadas em paralelo pelo microcomputador e pelo manipulador.

Tabela 6.1 - Perfis das geratrizes da Peça 1, medidos com o Sistema Automatizado...130

Tabela 6.2 - Perfis das retas transversais da Peça 1, medidos com o Sistema

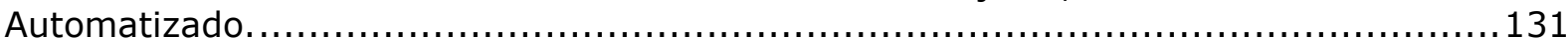

Tabela 6.3 - Perfil da superfície da Peça 1, medido com o sistema convencional.........132

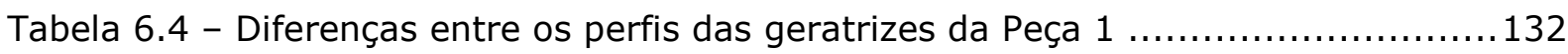

Tabela 6.5 - Desvio de planicidade da peça 1 (ajustagem Minimax) ......................134

Tabela 6.6 - Desvio de planicidade da peça 1 (ajustagem de Mínimos Quadrados) .....134

Tabela 6.7 - Desvio de planicidade da peça 1 (medição convencional) ....................134

Tabela 6.8 - Perfis das geratrizes da Peça 2, medidos com o Sistema Automatizado...136

Tabela 6.9 - Perfis das transversais da Peça 2, medidos com o Sistema Automatizado. 136

Tabela 6.10 - Perfil da superfície da Peça 2, medido com o sistema convencional.......137

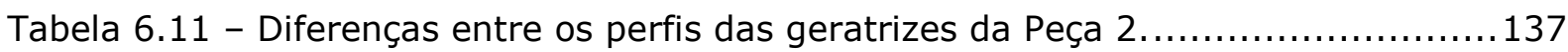

Tabela 6.12 - Desvio de planicidade da Peça 2 (ajustagem Minimax) ....................139

Tabela 6.13 - Desvio de planicidade da Peça 2 (ajustagem de Mínimos Quadrados)....139

Tabela 6.14 - Desvio de planicidade da Peça 2 (Medição Convencional). ...................139

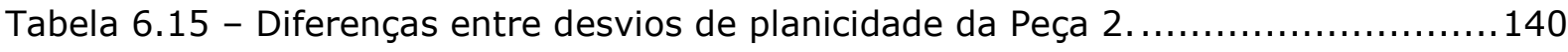

Tabela 6.16 - Perfis das geratrizes da Peça 3 medidos com o Sistema Automatizado. .140

Tabela 6.17 - Perfis das transversais da Peça 3, medidos com o Sistema Automatizado.

Tabela 6.18 - Perfis das geratrizes da Peça 3, medidos com o sistema convencional...141

Tabela 6.19 - Diferenças entre os perfis das geratrizes da Peça $3 \ldots \ldots \ldots \ldots \ldots \ldots \ldots \ldots \ldots 1$

Tabela 6.20 - Desvios de planicidade da peça 3 (ajustagem Minimax) ...................142 
Tabela 6.21 - Desvio de planicidde da peça 3 (ajustagem de Mínimos Quadrados). ....142

Tabela 6.22 - Desvio de planicidade da peça 3 (Medição Convencional).

Tabela 6.23 - Perfis das geratrizes da Peça 1, medidos com o Sistema Automatizado. 144

Tabela 6.24 - Perfis das transversais da Peça 1, medidos com o Sistema Automatizado. 144

Tabela 6.25 - Perfil de superfície da Peça 1 (com inclinação). 145

Tabela 6.26 - Coeficientes dos planos ajustados aos perfis da Peça 1 (ajustagem Minimax). 145

Tabela 6.27 - Coeficientes dos planos ajustados aos perfis da Peça 1 (ajustagem de Mínimos Quadrados).

Tabela 6.28 - Coeficientes dos planos ajustados aos perfis do artefato de referência (ajustagem Minimax).

Tabela 6.29 - Coeficientes dos planos ajustados aos perfis do artefato de referência (ajustagem de Mínimos Quadrados)..... 146

Tabela 6.30 - Desvios de perpendicularismo da peça 1 (Sistema Automatizado e ajustagem Minimax).

Tabela 6.31 - Valores médios do desvio de perpendicularismo da Peça 1 (ajustagem Minimax)....

Tabela 6.32 - Desvios de perpendicularismo da Peça 1 (Sistema Automatizado e ajustagem de Mínimos Quadrados). 150

Tabela 6.33 - Perfil da superfície da Peça 1 (medição convencional). 152

Tabela 6.34 - Coeficientes dos planos ajustados aos perfis da Peça 1 (medição convencional). 152

Tabela 6.35 - Desvio de perpendicularismo da Peça 1 (medição convencional). 153

Tabela 6.36 - Comparação entre os valores do desvio de perpendicularismo da Peça 1.

Tabela 6.37 - Perfis das geratrizes da Peça 2 medidos com o Sistema Automatizado. . 154

Tabela 6.38 - Perfis das transversais da Peça 2 medidos com o Sistema Automatizado. 154

Tabela 6.39 - Perfil de superfície da Peça 2. 155

Tabela 6.40 - Coeficientes dos planos ajustados aos perfis da Peça 2 (ajustagem Minimax) 155

Tabela 6.41 - Coeficientes ajustados aos perfis da Peça 2 (ajustagem de Mínimos Quadrados). 155

Tabela 6.42 - Desvios de perpendicularismo da Peça 2 (Sistema Automatizado e ajustagem Minimax). 156 
Tabela 6.43 - Resultados médios para o desvio de perpendicularismo da Peça 2 (ajustagem Minimax)

Tabela 6.44 - Desvios de perpendicularismo da Peça 2 (Sistema Automatizado e ajustagem de Mínimos Quadrados). .................................................... 158

Tabela 6.45 - Perfil da superfície da Peça 2 (método convencional). .....................159

Tabela 6.46 - Desvio de perpendicularismo da peça 2 (método convencional)............159

Tabela 6.47 - Perfis das geratrizes da Peça 3 medidos com o Sistema Automatizado. .160

Tabela 6.48 - Perfis das transversais da Peça 3, medidos com o Sistema Automatizado. 160

Tabela 6.49 - Perfil de superfície da Peça 3

Tabela 6.50 - Coeficientes dos planos ajustados aos perfis da Peça 3 (ajustagem Minimax)

Tabela 6.51 - Coeficientes ajustados aos perfis da Peça 3 (ajustagem de Mínimos Quadrados)....

Tabela 6.52 - Desvios de perpendicularismo da Peça 3 (Sistema Automatizado e ajustagem Minimax).

Tabela 6.53 - Resultados médios para o desvio de perpendicularismo da Peça 3 (ajustagem Minimax).

Tabela 6.54 - Desvios de perpendicularismo da Peça 3 (Sistema Automatizado e ajustagem de Mínimos Quadrados).

Tabela 6.55 - Perfil da superfície da Peça 3 medido com o sistema convencional. 165

Tabela 6.56 - Desvios de perpendicularismo da Peça 3 (medição convencional). 165

Tabela 6.57 - Tempos de medição. 166

Tabela 6.58 - Desvios geométricos da Peça 1 - Sistema Automatizado e Ajustagem Minimax. 168

Tabela 6.59 - Desvios geométricos da Peça 1 - Sistema Automatizado e Ajustagem de Mínimos Quadrados.

Tabela 6.60 - Tabela comparativa - desvios geométricos da Peça 1 (ajustagem Minimax). 170

Tabela 6.61 - Tabela comparativa - desvios geométricos da Peça 1 (ajustagem de Mínimos Quadrados).

Tabela 6.62 - Desvios geométricos da Peça 2 - Sistema Automatizado e Ajustagem Mnimax. 175

Tabela 6.63 - Desvios geométricos da Peça 2 - Sistema Automatizado e Ajustagem de Mínimos Quadrados. 
Tabela 6.64 - Tabela comparativa - desvios geométricos da Peça 2 (ajustagem Minimax). 176

Tabela 6.65 - Tabela comparativa - desvios geométricos da Peça 2 (ajustagem de

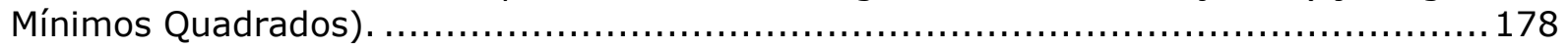

Tabela 6.66 - Desvios geométricos da Peça 3 - Sistema Automatizado e Ajustagem MInimax... 180

Tabela 6.67 - Desvios geométricos da Peça 3 - Sistema Automatizado e Ajustagem de Mínimos Quadrados. 181

Tabela 6.68 - Tabela comparativa - desvios geométricos da Peça 3 (ajustagem Minimax). 181

Tabela 6.69 - Tabela comparativa dos resultados obtidos para a Peça 3 utilizando-se o método de ajustagem de Mínimos Quadrados. 184 


\section{Sumário}

1. Introdução .

2. Separação de Erros e Sistemas Automatizados de Medição...33 2.1. Métodos de Separação de Erros Baseados em Múltiplas Orientações

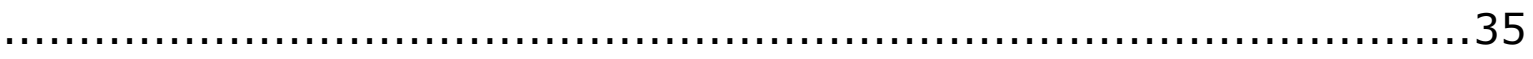

2.1.1. Reversão do Nível Eletrônico ......................................35

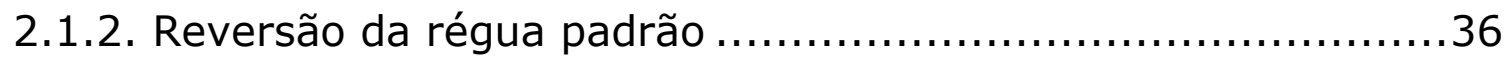

2.1.3. Reversão da esfera padrão......................................... 38

2.1.4. Reversão de esquadro ........................................... 39

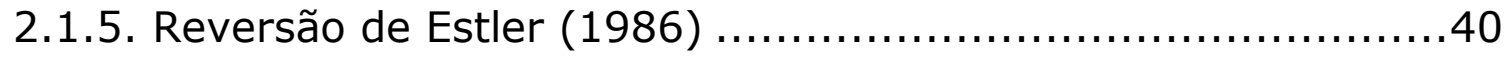

2.1.6. Teste das três réguas ...........................................42

2.1.7. Separação de erros utilizando artefatos de referência em

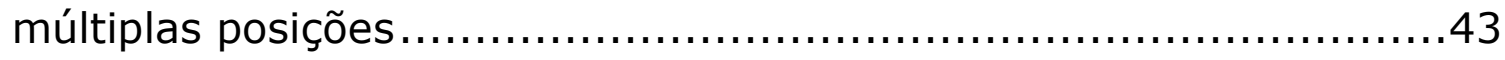

2.1.8. Reversão do refletor do interferômetro para medição de

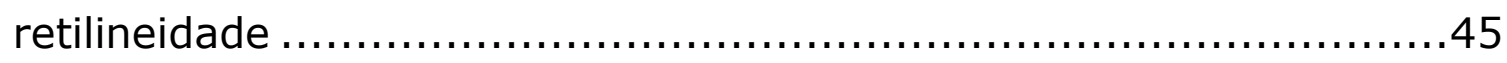

2.2. Automação da medição e aplicações de robôs industriais............46

2.2.1. Sistemas Automatizados Integrados a Máquinas de Medição a Três Coordenadas ....................................................48

2.2.2. Medições executadas por robôs industriais .........................50

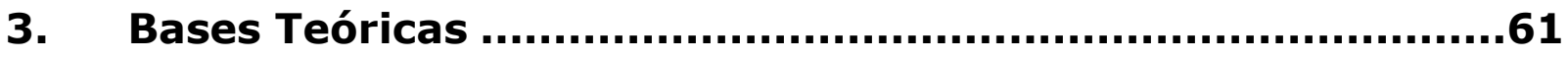

3.1. Tolerâncias e Desvios Geométricos ...................................62

3.1.1. Tolerância e desvio de retilineidade ...............................63

3.1.2. Tolerância e desvio de planicidade ..............................64

3.1.3. Tolerância e desvio de paralelismo................................66

3.1.4. Tolerância e desvio de perpendicularismo .......................69

3.1.5. Tolerâncias e Desvios .......................................... 70

3.2. Métodos de Separação de Erros baseados em Múltiplos Sensores .72

3.2.1. Método dos Dois Pontos Sucessivos (Two Successive Points)..73

3.2.2. Método dos Três Pontos........................................ 76 
3.2.3. Solução do Método dos Três Pontos: o método diferencial (Gao et al, 2002a) ....................................................... 77

3.2.4. Método dos Três Pontos Combinado................................ 79

3.2.5. Método dos Três Pontos e a influência do erro de desalinhamento dos sensores........................................ 82

3.3. Modelo de otimização para a avaliação de desvios de forma e orientação

\section{O Sistema Automatizado para a Medição de Desvios de Forma} e Orientação. 91

4.1. Escolha e adaptação do modelo de separação de erros ............... 94

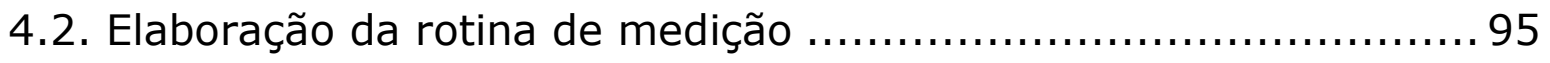

4.3. Desenvolvimento do procedimento de pré-processamento dos dados e das rotinas de avaliação dos desvios geométricos ................. 96

4.4. Medições e aplicação das rotinas.................................... 97

4.5. Avaliação do sistema por análise comparativa ....................... 98

5. Desenvolvimento do Sistema Automatizado para a Medição dos Desvios de Forma e Orientação.............................................. 99

5.1. Equipamentos de medição, peças e dispositivos auxiliares ......... 99

5.2. Programa de Aquisição de Dados ................................. 108

5.3. Rotinas de Pré-Processamento dos dados para obtenção de perfis

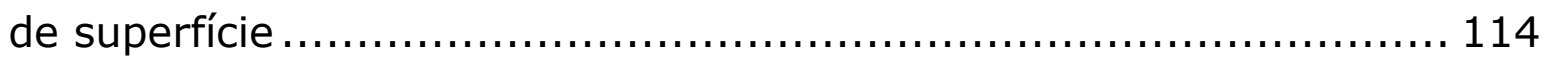

5.4. Modelo e Rotina para a Separação de Erros........................... 116

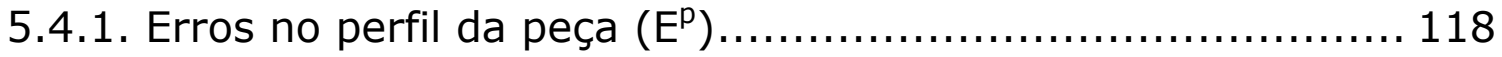

5.4.2. Erros de movimentação translacional do robô $\left(E^{R}\right) \ldots \ldots \ldots \ldots 120$

5.4.3. Erros devido à inclinação do porta-sensores $\left(E^{\delta}\right) \ldots \ldots \ldots \ldots . \ldots 121$

5.4.4. Erro de alinhamento axial dos sensores........................ 122

5.4.5. Equações do modelo de separação de erros ...................... 124

5.5. Solução do Modelo .................................................. 125

5.6. Aplicação do modelo para a avaliação dos desvios de forma e orientação .............................................................. 126

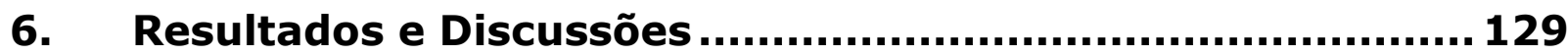

6.1. Resultados da Avaliação do Desvio de Planicidade................... 130 


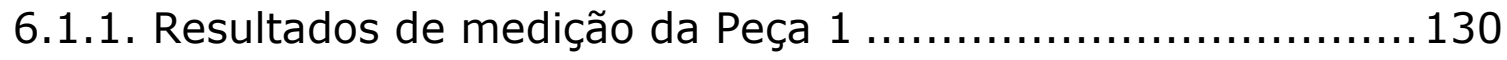

6.1.2. Resultados de medição da Peça 2 ................................. 135

6.1.3. Resultados de medição da Peça 3 ............................... 140

6.2. Resultados da Avaliação do Desvio de Perpendicularismo .......... 143

6.2.1. Resultados de medição da Peça 1 .................................. 143

6.2.2. Resultados de medição da Peça 2 ............................... 153

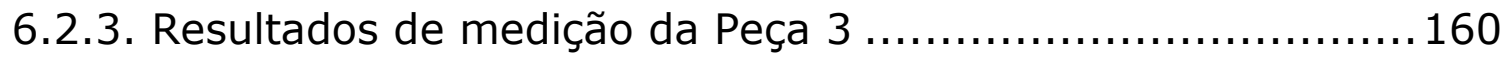

6.3. Tempos de Medição ...................................................... 165

6.4. Resumo dos Resultados e Discussões ..............................168

7. Conclusões e sugestões para trabalhos futuros..................199 Referências Bibliográficas .........................................................207 APÊNDICE 1 ............................................ Erro! Indicador não definido.

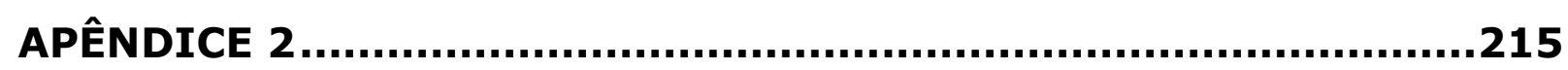

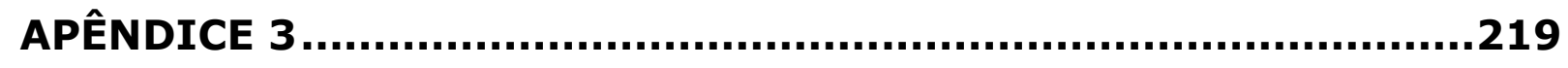

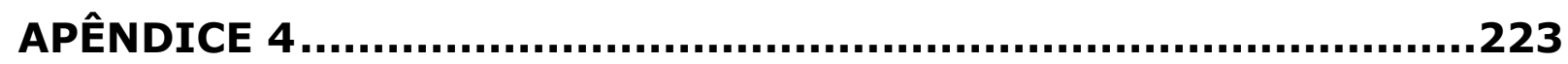

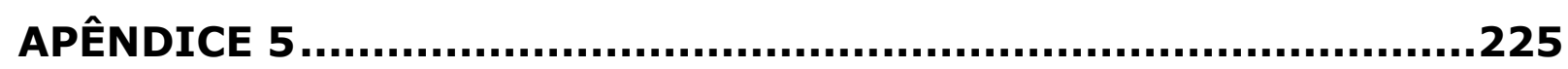

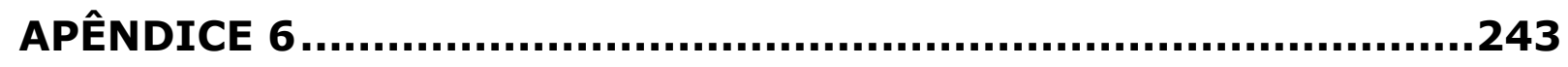

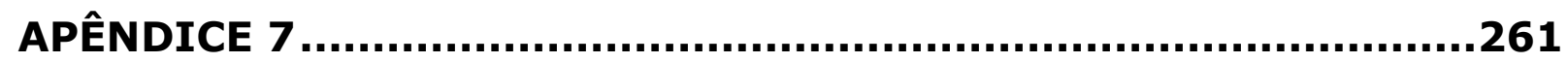





\section{Capítulo 1}

\section{Introdução}

A óptica do modo de produção vigente prima o ganho financeiro. 0 conjunto de valores derivados dessa perspectiva inclui a intensificação da competitividade e a busca, às vezes frenética, por eficiência, rapidez, flexibilidade, entre outros. Em geral, é necessário atender a estes requisitos para que o crescimento econômico ocorra. O poder econômico influi na política e o capital, se bem empregado, é o detentor do poder de gerar benefícios sociais. O setor industrial, por sua vez, tem importância elevada para a geração do crescimento econômico.

Dentro desse contexto geral, é essencial para o desenvolvimento industrial que se concentrem esforços e investimentos no setor metalmecânico. Isto se justifica pelo fato de este setor estar ligado tanto à produção de bens de consumo quanto à produção de bens de capital. Estes últimos alavancam o crescimento das indústrias de bens de consumo, que por sua vez realimentam o crescimento das próprias indústrias de bens de capital. Além disso, o valor agregado de um bem é, em geral, proporcional ao grau de tecnologia aplicada, sendo este valor para produtos industrializados muito superior ao valor dos produtos primários, que são, em sua maioria commodities. Sendo assim, é importante que a pesquisa acadêmica desenvolva soluções para os setores produtivos industriais e, em especial, para o setor metal-mecânico, pelos motivos já citados acima. Por outro lado, a questão não se trata de concentrar todos os esforços nessa área, uma vez que a pesquisa básica nas diversas áreas como humanidades, biologia, medicina, educação, arte, etc., também tem inegável valor na construção da sociedade e formação de cada ser humano. 
Os processos e máquinas de fabricação mecânica têm apresentado maiores velocidades e capabilidades. Alguns conceitos e técnicas atuais desenvolvidos nesta área de fabricação incluem usinagem de alta velocidade, correção dos parâmetros de corte e monitoramento do desgaste de ferramentas em processo, trocas rápidas de ferramentas, entre outros. Esses fatores conferem rapidez significativa aos processos de fabricação. Diante desse cenário, é essencial que os processos de medição sejam capazes de oferecer rapidez e eficiência compatíveis com os processos de manufatura.

Alguns teóricos equivocadamente classificam as inspeções como processos que não agregam valor ao produto, diretamente. O Diagrama de Kano, utilizado nas áreas de Qualidade e Desenvolvimento de Produtos, divide os requisitos do produto quanto a sua contribuição para a satisfação do cliente em básicos, de desempenho esperado e de excitação. $O$ atendimento do produto às suas funcionalidades principais se enquadraria no segundo grupo. Isso demonstra que esse requisito já é esperado pelos clientes, sendo, portanto, obrigatório para a obtenção de um produto minimamente competitivo. A obtenção desse requisito, o atendimento à funcionalidade, por sua vez, está diretamente ligada à capacidade de medição adequada de componentes e sistemas, para garantir que atendam às especificações.

É fato que os custos da qualidade com inspeções finais podem ser reduzidos enfocando-se na detecção antecipada de defeitos por meio de Controle Estatístico de Processos entre outros. As tendências atuais apontam para o desenvolvimento e uso de sistemas de medição em processo. Além disso, é incontestável que, por mais capazes que sejam as máquinas-ferramentas, é indispensável que se avaliem os resultados do processo, comparando os produtos obtidos a padrões. A área de Metrologia, ao contrário de ter sua importância diminuída, passa a requerer um contínuo desenvolvimento para responder aos desafios de se obter sistemas de medição e padrões com acuracidade ainda maior, 
algoritmos de avaliação de erros mais apurados, exatidão na avaliação de incertezas e acentuada rapidez e agilidade na medição.

A escolha do grau de flexibilidade e tipo de sistema de medição, ou seja, a seleção entre sistemas universais ou dedicados, automatizados ou não, está condicionada a fatores como o nível de tolerâncias das peças medidas, a geometria mais ou menos complexa dos componentes e a quantidade a ser avaliada. A inspeção total pode ser requerida em algumas situações, por questões de segurança, por exemplo, em que se deve garantir que nenhum componente defeituoso seja utilizado na montagem. Nesses casos, a utilização de sistemas dedicados e automáticos é muito mais eficiente. A rapidez também é fator importante quando o objetivo da medição é o monitoramento e correção dos processos de fabricação. Uma vantagem adicional da utilização de sistemas de medição automatizados é a minimização da influência do operador nas medições.

Com base no contexto apresentado, o objetivo principal deste trabalho consiste na aplicação de um Sistema Automatizado para medição de desvios de forma e orientação utilizando um robô articulado com seis graus de liberdade.

Os robôs são em geral destinados à execução de tarefas como soldagem, pintura, transporte, montagem, entre outros, que exigem menor acuracidade quando comparadas a processos de medição. A acuracidade de posição dos robôs apresenta-se em torno de 0,1 mm. Assim, o uso do posicionamento dos robôs como sistema de referência para as medições é restrito e deve ser feito cuidadosamente (DI GIACOMO; TSUNAKI; PAZIANI, 2005). Para que os erros geométricos dos componentes sejam avaliados adequadamente, é essencial desacoplá-los dos erros de posicionamento e movimentação do sistema. Dessa forma, o primeiro desdobramento do objetivo geral deste trabalho é o estudo e implementação de algoritmos de separação de erros.

Os métodos de reversão são historicamente utilizados para o desacoplamento de erros, mas sua utilização não é recomendada nos 
casos em que os erros induzidos pelo sistema de medição não apresentam repetibilidade satisfatória. Esta é a situação com a qual se depara quando robôs articulados são utilizados como manipuladores, para a execução de medições. Diante disso, serão utilizados neste trabalho métodos de separação de erros que se baseiam na utilização de sensores múltiplos e no princípio da redundância de dados, que são mais adequados. Alguns trabalhos têm se destacado recentemente nesta área, como os de Gao et al. (2002a), Gao e Kiyono (1997), e Paziani, Di Giacomo, Tsunaki (2007), mas, certamente, ainda há questões a serem dirimidas. Métodos de multisensores apresentam a vantagem adicional de evitarem a manipulação da peça, quando comparados com os métodos de reversão. (DI GIACMO; TSUNAKI; PAZIANI, 2005).

Os objetivos finais deste trabalho consistem na utilização do Sistema Automatizado para a avaliação dos desvios geométricos de planicidade, paralelismo e perpendicularismo dos componentes, e na análise do desempenho do sistema. A implementação dos modelos de separação de erros é uma etapa intermediária imprescindível à medição dos desvios de forma e orientação utilizando-se o Sistema Automatizado. Além da aplicação do modelo de separação de erros, para a avaliação dos desvios de forma e orientação dos componentes foram implementadas rotinas de ajustagem de formas geométricas de referência ao conjunto de dados medidos.

No capítulo 2 deste trabalho apresenta-se uma revisão bibliográfica sobre métodos históricos de separação de erros, baseados no princípio da reversão. Além disso, também são apresentados alguns desenvolvimentos recentes na área de automação, destacando-se os sistemas aplicados à execução de medições.

Os aspectos teóricos que fornecem embasamento ao trabalho desenvolvido são abordados no capítulo 3. Assim, o capítulo se inicia com a definição das tolerâncias e desvios geométricos, seguida pela discussão dos métodos de separação de erros baseados em múltiplos sensores e da apresentação dos modelos de equações associados a estes métodos. Além 
disso, neste capítulo, busca-se analisar criticamente os resultados obtidos por alguns autores que realizaram a aplicação dos métodos de separação de erros apresentados.

No capítulo 4 expõe-se a proposta de trabalho em linhas gerais, enumerando-se as principais etapas de seu desenvolvimento. O Sistema Automatizado para avaliação de desvios de forma e orientação é apresentado, e suas principais características são discutidas. Uma descrição geral do fluxo de dados e informações no sistema também é realizada.

Os desenvolvimentos realizados em cada etapa do trabalho, necessários ao funcionamento do Sistema Automatizado, são detalhados no capítulo 5. Assim, este capítulo contém uma descrição dos equipamentos utilizados, das peças medidas e dos dispositivos de interface e fixação. Além disso, o programa de medição e as rotinas desenvolvidas para pré-processamento e processamento dos dados são apresentados. Por fim, discutem-se o equacionamento do modelo de separação de erros aplicado aos dados medidos e o modelo matemático elaborado para a avaliação de desvios de forma e orientação.

Os resultados da avaliação dos desvios geométricos de cada peça, medidos com o Sistema Automatizado, são apresentados no capítulo 6 . Este capítulo também contém uma análise comparativa entre os valores de desvio fornecidos pelo sistema proposto e os valores obtidos por meio da medição convencional das peças, bem como uma discussão dos resultados obtidos e do desempenho do sistema.

Finalmente, no capítulo 7, apresentam-se as principais conclusões alcançadas e sugestões para trabalhos futuros. 


\section{Capítulo 2}

\section{Separação de Erros e Sistemas Automatizados de Medição}

Os métodos convencionais de medição, em que se utilizam apalpadores, desempeno e os princípios de GD\&T, Geometrical Dimensioning and Tolerancing, nem sempre possuem flexibilidade para atender certas necessidades de medição. Tais métodos apresentam limitações diante do tamanho dos componentes a serem medidos, do formato desses componentes, da ausência de dispositivos de fixação adequados, entre outros. Whitehouse (1976) destaca a necessidade de medição in situ de erros geométricos de peças grandes, no caso em que não é possível utilizar um desempeno que forneça uma referência física para as medições e não se dispõe de máquinas de medir com características adequadas.

A medição de dimensões ou erros geométricos de componentes em processo, ou nos intervalos da seqüência de operações de usinagem, com a peça ainda fixa na própria máquina-ferramenta, também figura entre as tendências atuais. Tal procedimento visa fornecer dados para a correção dos parâmetros de usinagem durante o processo. O problema com o qual se depara neste procedimento é que o sistema de referência da própria máquina-ferramenta, em geral, não apresenta acuracidade suficiente para servir como referência de medição.

Para ambos os casos citados, isto é, para a medição de peças grandes e para medição em processo, um sistema de medição já relativamente difundido consiste no uso de sensores de deslocamento ou inclinação, fixados sobre um carro porta-sensores que é deslocado numa direção conveniente para a medição. Nesta situação, os desvios a serem 
medidos são, em geral, da mesma ordem de grandeza dos erros de movimentação do dispositivo porta-sensores. Uma regra prática sugere que os sistemas de medição apresentem uma resolução no mínimo 10 vezes superior à ordem de grandeza dos desvios que se pretende medir.

Historicamente, outros sistemas de medição foram desenvolvidos em que a mesma situação se verificava, isto é, a ausência de uma referência absoluta de medição e a limitada acuracidade de posicionamento dos elementos que realizam as leituras. A utilização de sistemas como estes citados depende do desenvolvimento e aplicação de métodos de separação de erros, ou seja, de modelos que realizam o desacoplamento dos erros do mensurando dos erros do sistema de medição.

Os métodos de separação de erros podem ser divididos em basicamente dois tipos: os que utilizam múltiplas orientações e os que utilizam múltiplos sensores. Whitehouse (1976) destaca que os primeiros se aplicam à remoção de erros sistemáticos e os segundos, à separação de erros variáveis ou aleatórios. Os erros sistemáticos são repetitivos, e, uma vez identificados, podem ser compensados dos resultados de medição. Erros variáveis podem ser tratados estatisticamente ou mediante a aplicação de métodos de remoção instantânea. Os métodos que utilizam múltiplas orientações, também conhecidos como método de reversão, têm sido historicamente desenvolvidos e utilizados para a avaliação de desvios geométricos e dimensionais ou a calibração de sistemas de medição. O desenvolvimento destes métodos antecede cronologicamente o surgimento dos métodos baseados em múltiplos sensores. Este capítulo se destina a apresentar este histórico de desenvolvimento e discutir os principais métodos de reversão. Além disso, são mostradas também algumas tendências atuais de automatização de medição, e são apresentados alguns exemplos de sistemas automatizados desenvolvidos recentemente. 


\subsection{Métodos de Separação de Erros Baseados em Múltiplas Orientações}

O princípio básico dos métodos de separação de erros baseados em múltiplas orientações consiste na manipulação mecânica de artefatos utilizados no procedimento de medição e na repetição das medições. Tais métodos também são bastante conhecidos pelo nome de Métodos de Reversão. Ao se realizar a reversão do artefato, o efeito de uma das fontes de erro sobre a leitura total em cada medição, antes e depois da reversão, torna-se inverso. Algebricamente, isso se traduz na inversão do sinal de um dos termos em uma ou mais equações do modelo de separação de erros.

\subsubsection{Reversão do Nível Eletrônico}

Segundo Evans, Hocken e Estler (1996), a aplicação do método de reversão ao nível eletrônico permite medir a inclinação absoluta de uma superfície.

Um esquema representativo deste método é apresentado na Figura 2.1.
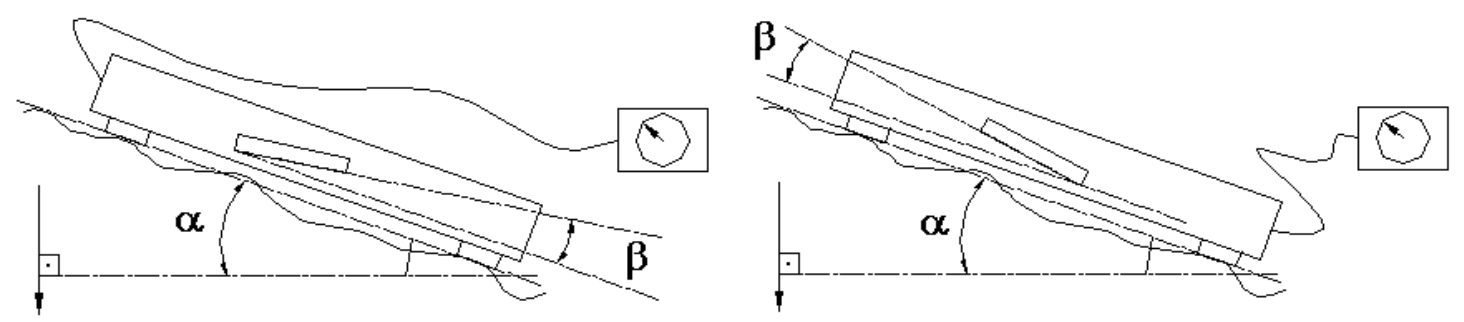

Figura 2.1 - Método da Reversão do Nível Eletrônico

Assumindo que a superfície está inclinada de um ângulo $\alpha$ com relação à horizontal e que o nível eletrônico foi zerado de modo que seu pêndulo esteja inclinado de um ângulo $\beta$ com relação à base de referência do instrumento, obtêm-se o seguinte equacionamento para as leituras realizadas com e sem reversão: 


$$
\begin{aligned}
& l_{1}=\alpha-\beta \\
& l_{2}=\alpha+\beta
\end{aligned}
$$

onde $l_{1}$ e $l_{2}$ são as leituras do nível eletrônico com e sem reversão, respectivamente.

\subsubsection{Reversão da régua padrão}

O método da reversão da régua padrão na medição de retilineidade é bastante conhecido. Segundo Evans, Hocken e Estler (1996), as referências da aplicação deste método datam de pelo menos 1941.

O sistema de medição constitui-se de uma guia com um carro deslizante, ao qual um sensor de deslocamento é fixado, e uma régua padrão. Nesta posição inicial, realiza-se o rastreamento do perfil de retilineidade da régua padrão. Após a reversão da régua e do sensor, o perfil é medido novamente. As leituras resultantes são uma composição de deslocamentos devido ao erro de retilineidade da régua e ao erro de retilineidade do deslocamento do carro. A Figura 2.2 apresenta um esquema do sistema de medição. O modelo matemático é mostrado nas esquações 2.3 e 2.4 .
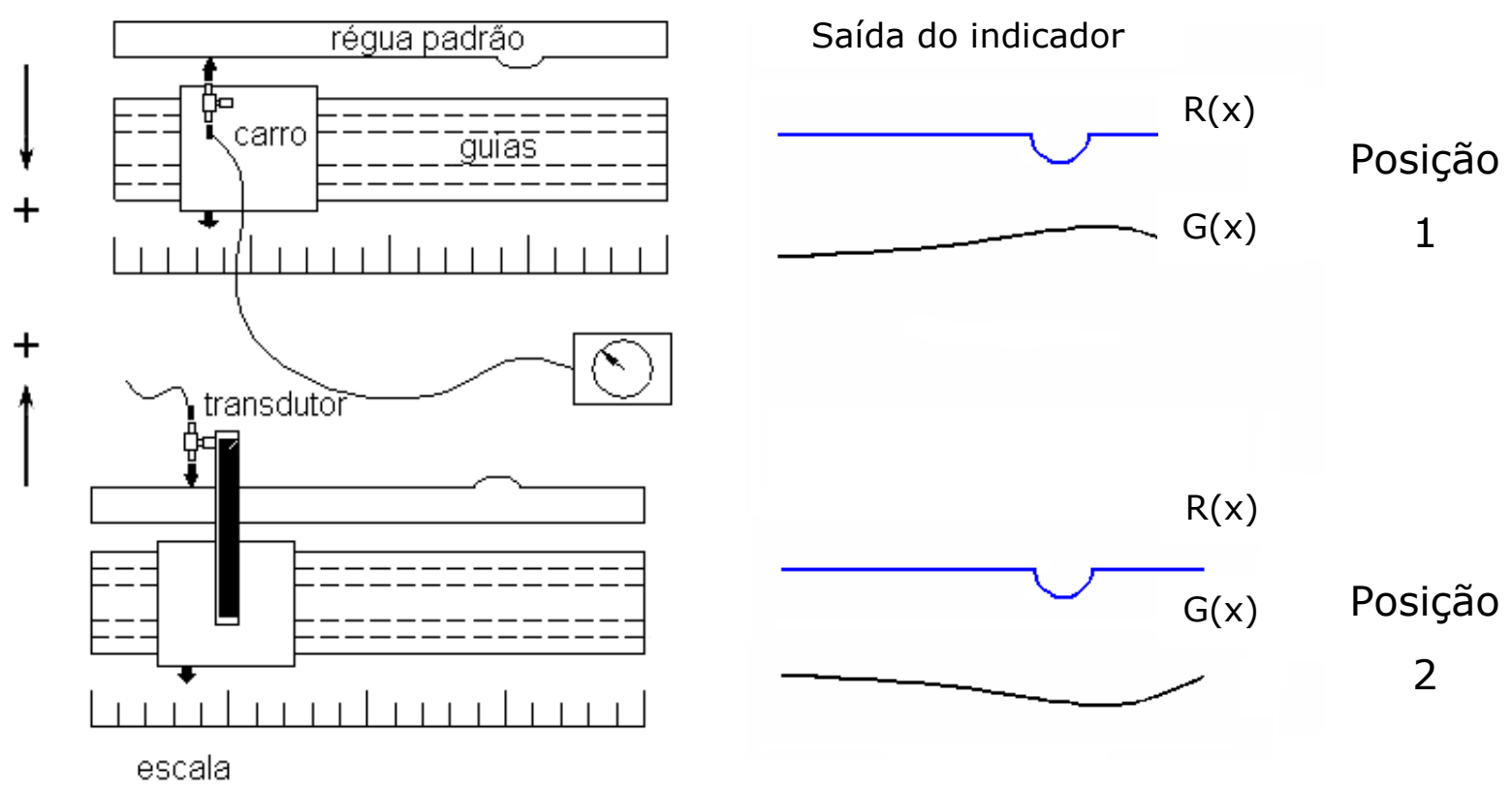

Figura 2.2 - Método da reversão da régua padrão. 


$$
\begin{aligned}
& l_{1}(x)=G(x)+R(x) \\
& l_{2}(x)=-G(x)+R(x)
\end{aligned}
$$

Nas equações apresentadas, $G(x)$ é a função discreta que representa o perfil de retilineidade do deslocamento do carro e $R(x)$ é a função que representa o perfil de retilineidade da régua. Estas componentes de erro são facilmente obtidas por meio da solução do sistema apresentado nas equações 2.5 e 2.6.

$$
\begin{aligned}
& G(x)=\frac{l_{1}(x)-l_{2}(x)}{2} \\
& R(x)=\frac{l_{1}(x)+l_{2}(x)}{2}
\end{aligned}
$$

Segundo Evans, Hocken e Estler (1996), a parcela mais significativa de incerteza no método da reversão provém de efeitos ambientais. Em ambientes bem controlados, o reposicionamento da régua e do sensor após a reversão constituem uma fonte de incerteza que deve ser considerada. Neste caso, pode-se reescrever o modelo incluindo-se um erro de posicionamento relativo $\Delta x$, na direção $x$, tomando-se como referência o posicionamento do carro da máquina.

$$
\begin{gathered}
l_{1}(x)=G(x)+R(x) \\
l_{2}(x)=-G(x)+R(x+\Delta x)
\end{gathered}
$$

Dessa forma, o perfil de retilineidade do deslocamento do carro pode ser escrito como na equação 2.9 .

$$
G(x)-\delta_{x}=\frac{l_{1}(x)-l_{2}(x)}{2},
$$

onde a variável $\delta_{x}$ é definida em função das inclinações do perfil de retilineidade da régua, conforme apresentado na equação 2.10 .

$$
\delta_{x}=\frac{R(x)-R(x+\Delta x)}{2}=-\frac{1}{2} \Delta x \frac{d}{d x} R(x)
$$

Utilizando a inclinação máxima do perfil $R(x)$ determinada por meio da equação 2.6 , é possível definir um limite para $\Delta x$ que resulte num erro $\delta_{x}$ aceitável. Um erro análogo aparecerá quando se consideram erros de 
set-up, $\Delta y$, na direção ortogonal ao plano definido pelo eixo $x$ e pela direção de sensibilidade dos sensores.

Neste modelo, o efeito de um erro de set-up, isto é, de posicionamento relativo entre carro e régua, é uma função das amplitudes e comprimentos de onda do erro de retilineidade da régua. Tais erros de posicionamento não devem ser confundidos com o erro de alinhamento, ou seja, com o erro de inclinação entre a geratriz da régua e o eixo de deslocamento do carro porta-sensores. O erro de alinhamento ocorre na direção $z$, isto é, a direção de sensiblidade dos sensores, ao passo que os erros de set-up são, na verdade, incertezas de posicionamento nas direções secundárias, $x$ e $y$. Recomenda-se que a inclinação entre o artefato e o eixo de deslocamento do porta-sensores seja removida antes das medições alinhando-se os pontos extremos da régua à guia, isto é, garantindo-se leituras iguais nestes pontos.

\subsubsection{Reversão da esfera padrão}

Este método é exatamente análogo à reversão da régua padrão, e foi inicialmente apresentado por Donaldson (1972). No modelo, o erro radial de movimentação do eixo árvore é representado por $R(\theta)$, enquanto $B(\theta)$ representa o desvio de circularidade da esfera. A variável $\theta$ representa a posição angular dos pontos medidos. A Figura 2.3 apresenta o esquema básico do procedimento de reversão.

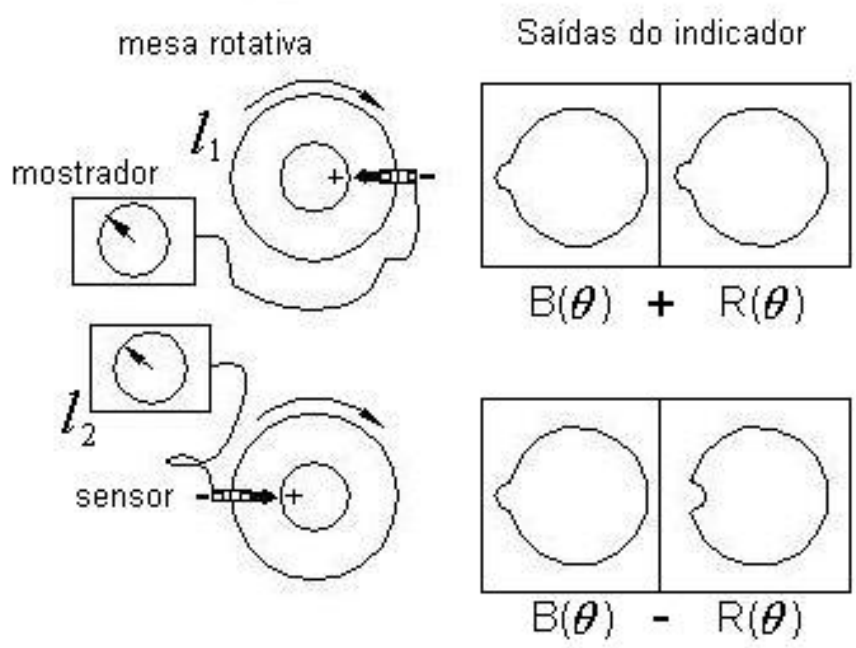

Figura 2.3 - Método da reversão da esfera-padrão de Donaldson 
As equações do modelo são análogas às do modelo de reversão da régua padrão:

$$
\begin{array}{r}
l_{1}(\theta)=R(\theta)+B(\theta) \\
l_{2}(\theta)=-R(\theta)+B(\theta)
\end{array}
$$

Assim como a inclinação na reversão da régua-padrão, a excentricidade entre eixo e esfera também deve ser removida para que o modelo apresentado seja aplicado.

\subsubsection{Reversão de esquadro}

A versão mais simples deste modelo de reversão resulta num sistema de equações idêntico ao modelo da reversão do nível, apresentado nas equações 2.1 e 2.2 (EVANS; HOCKEN; ESTLER, 1996). O princípio deste sistema é apresentado na Figura 2.4. Se um sensor de deslocamentos for utilizado, deve-se ajustar uma reta ou plano aos pontos coletados utilizando-se o Método dos Mínimos Quadrados ou outro com função equivalente, para que as leituras medidas sejam convertidas em valores de inclinação, $l_{1}$ e $I_{2}$. A seguir, calculam-se os ângulos $\alpha$ e $\beta$.
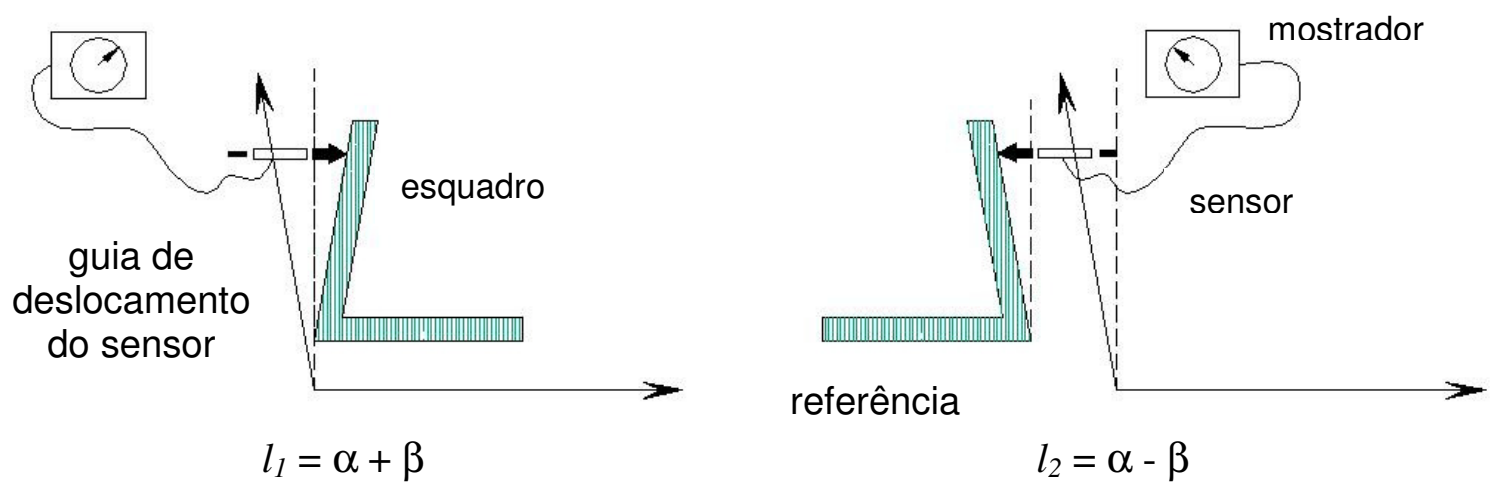

Figura 2.4 - Método da Reversão do Esquadro

Uma variação deste teste permite medir o paralelismo de um eixo árvore de uma máquina-ferramenta, por exemplo. Para tanto, uma régua padrão deve ser fixada no eixo de tal forma que ela possa ser rotacionada de $180^{\circ}$. Neste caso, a régua, ao ser rotacionada, forma um tronco de um 
cone oblíquo cuja geratriz está inclinada de um ângulo $\gamma$ com relação ao eixo do cone. Este eixo, por sua vez, apresenta uma inclinação $\beta$ com relação ao eixo de rotação do eixo-árvore. Além disso, a guia de deslocamento do carro porta-sensores apresenta um desalinhamento $\alpha$ com relação a esse eixo de rotação (EVANS; HOCKEN; ESTLER, 1996). A Figura 2.5 mostra o sistema de medição e as equações de 2.13 a 2.16 apresentam o modelo matemático proposto pelos autores citados.
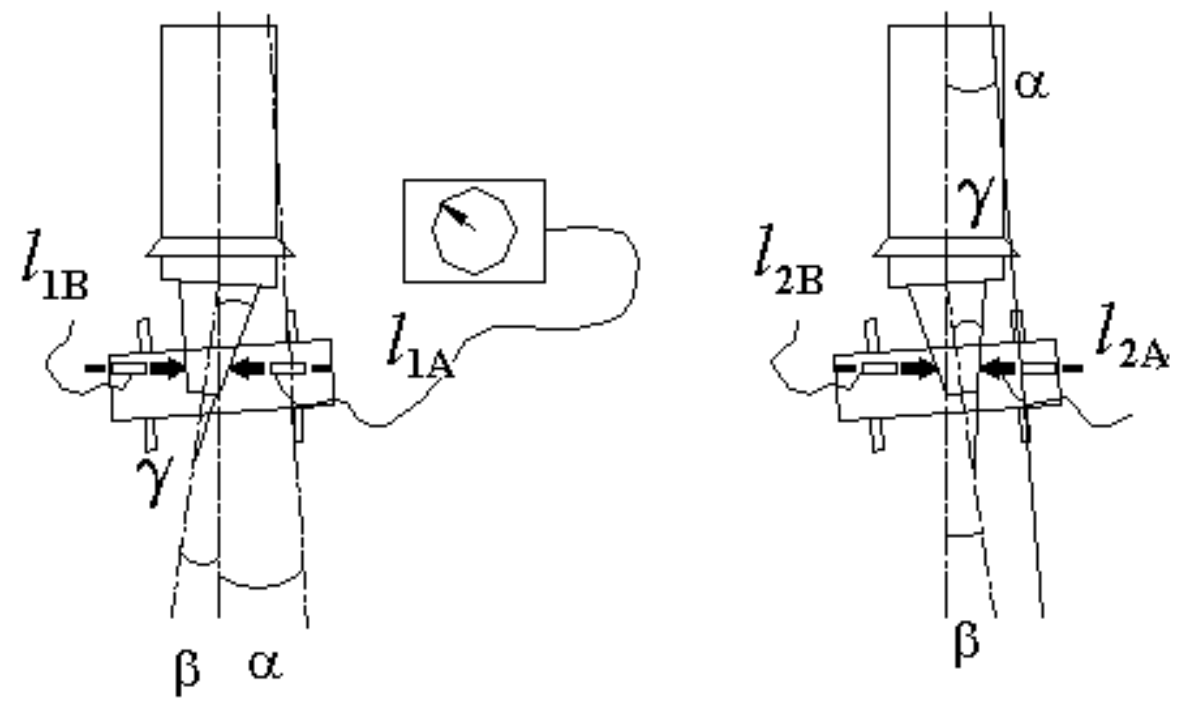

Figura 2.5 - Método da Reversão para Medição de Paralelismo do eixo árvore

$$
\begin{aligned}
& l_{1 A}=\alpha+\beta+\gamma \\
& l_{1 B}=\alpha+\beta-\gamma \\
& l_{2 A}=\alpha-\beta+\gamma \\
& l_{2 B}=\alpha-\beta-\gamma
\end{aligned}
$$

As equações apresentadas podem ser facilmente resolvidas para se obter os valores dos ângulos de interesse.

\subsubsection{Reversão de Estler (1986)}

Este método de reversão permite separar os erros de inclinação e de movimentação axial de um eixo-árvore do erro de planicidade de um plano padrão (EVANS; HOCKEN; ESTLER, 1996). O plano é fixado sobre a 
face do eixo-árvore e dois sensores de deslocamento são fixados perpendicularmente ao plano, sendo um deles alinhado ao eixo de rotação do eixo-árvore e o outro posicionado próximo a uma das extremidades do plano padrão. A reversão é realizada rotacionando-se o sensor excêntrico e o artefato em $180^{\circ}$. O procedimento básico de medição é apresentado na Figura 2.6.
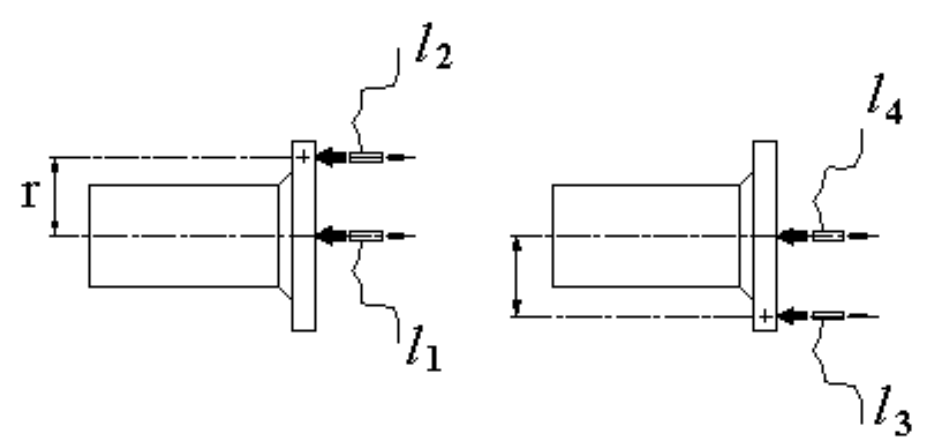

Figura 2.6 - Método da Reversão para detecção do erro de batida axial do eixo árvore

De acordo com o modelo, a leitura do sensor alinhado ao eixo de rotação corresponde somente ao erro de movimentação axial do eixoárvore, representado por $A(\theta)$ na equação 2.17. Na segunda etapa da medição, não é necessário utilizar o sensor central. Contudo, segundo os autores citados, o deslocamento axial pode ser determinado com base em uma média entre as duas leituras deste sensor, conforme apresentado na equação 2.18. Quando o eixo árvore é rotacionado, as leituras do sensor excêntrico, antes e após a reversão, contêm o perfil de planicidade do plano padrão $P(\theta)$, o deslocamento axial $A(\theta)$ e um erro de inclinação do eixo-árvore, $T(\theta)$. Assim, as leituras do sensor excêntrico correspondem à combinação linear de erros mostrada nas equações 2.19 e 2.20.

$$
\begin{gathered}
l_{1}=l_{4}=A(\theta) \\
A(\theta)=\frac{l_{1}+l_{4}}{2} \\
l_{2}=P(\theta)+r \cdot T(\theta)+A(\theta) \\
l_{3}=P(\theta)-r \cdot T(\theta)+A(\theta)
\end{gathered}
$$

As variáveis apresentadas podem ser determinadas em função das leituras dos sensores solucionando-se o sistema acima. 


\subsubsection{Teste das três réguas}

Neste teste são utilizadas 3 réguas-padrão, as quais são comparadas duas a duas. São medidos os deslocamentos resultantes da combinação dos perfis das duas réguas-padrão que estão sendo avaliadas a cada vez. Um esquema representativo deste método é apresentado na Figura 2.7. Este método resulta num sistema bastante simples, apresentado nas equações 2.21 a 2.23 .
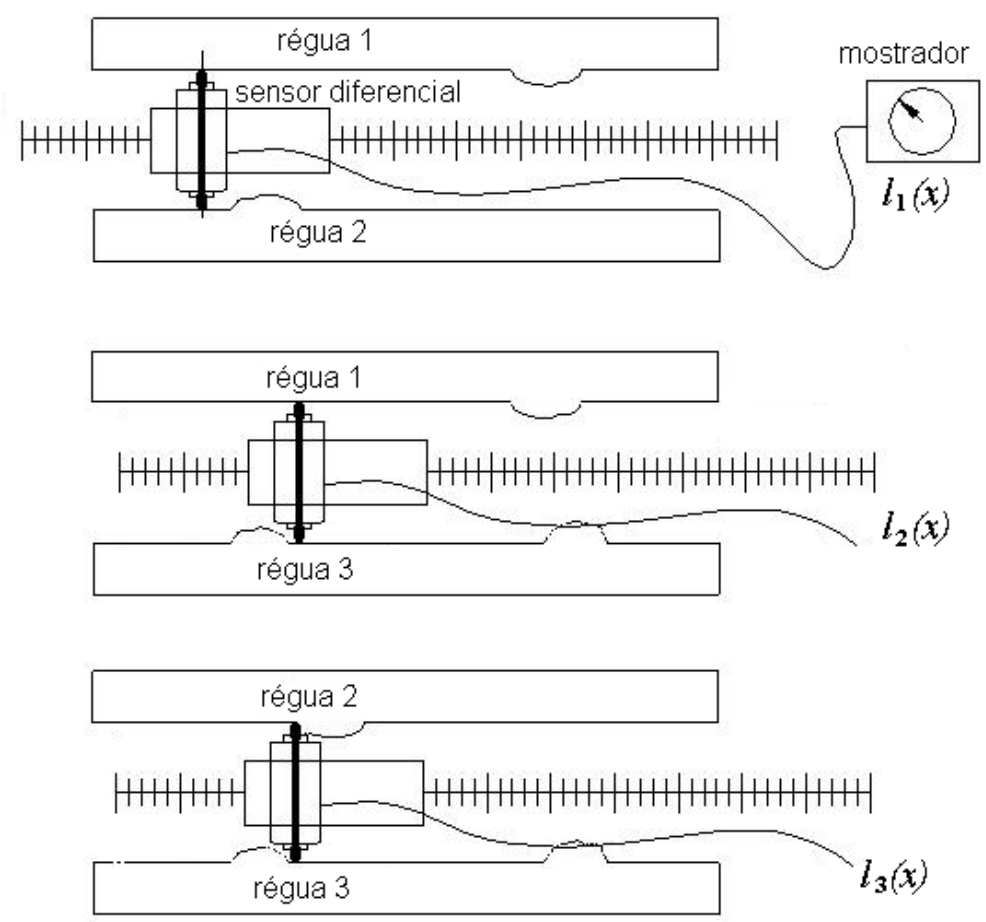

Figura 2.7 - Teste das Três Réguas

$$
\begin{aligned}
& l_{1}(x)=R_{1}(x)+R_{2}(x) \\
& l_{2}(x)=R_{1}(x)+R_{3}(x) \\
& l_{3}(x)=R_{2}(x)+R_{3}(x)
\end{aligned}
$$

O teste das três réguas não se baseia exatamente no mesmo princípio da reversão, porém, também está sujeito a erros de reposicionamento dos artefatos. Evans, Hocken e Estler (1996) apresentam variações deste 
método, como o teste dos três planos, demonstrando a similaridade entre estes tipos de teste e o método da reversão.

\subsubsection{Separação de erros utilizando artefatos de referência em múltiplas posições}

Um conceito semelhante ao princípio da reversão pode ser aplicado para a determinação de erros geométricos de máquinas de medição com múltiplos graus de liberdade. Esta técnica consiste na medição de um artefato não calibrado em posições múltiplas dentro do volume de trabalho do sistema de medição. Obtém-se, desta forma, um conjunto de dados redundantes. Há certas relações geométricas teóricas entre as posições medidas, antes e depois do reposicionamento do artefato, as quais podem ser expressas por meio de um conjunto de equações. Solucionando-se esse sistema, é possível determinar, separadamente, as parcelas de erro devido a imperfeições da máquina e as propriedades geométricas dos artefatos medidos.

O procedimento citado é aplicado especialmente na modelagem e avaliação de erros em máquinas de medir a três coordenadas. Em geral, os artefatos utilizados são barras, esquadros ou placas de esferas.

Para exemplificar os princípios desta técnica, Evans, Hocken e Estler (1996) apresentam um caso simplificado, em que uma barra de esferas é medida em uma máquina de medição de duas dimensões. Assume-se que a máquina contenha apenas erros de posicionamento e de perpendicularismo. A representação geométrica da medição é mostrada na Figura 2.8. Por simplicidade, uma das esferas é colocada na origem do sistema de coordenadas. As coordenadas da segunda esfera são medidas na posição 1 , fornecendo $X_{1}$ e $Y_{1}$. Em seguida, realiza-se uma rotação de $90^{\circ}$ na barra, e as novas coordenadas são coletadas. A modelagem da medição é apresentada nas equações 2.24 a 2.27. No modelo, as coordenadas medidas são relacionadas a um sistema de coordenadas ideal, representado por $X$ e $Y$, que seria válido caso a máquina não apresentasse erros. As distâncias $a$ e $b$ mostram a relação geométrica que 
deve existir entre as duas posições medidas antes e após a rotação. $O$ erro de perpendicularismo da máquina é representado pela variável $\alpha$. A variável $\gamma$ representa um erro incremental nos comprimentos medidos.

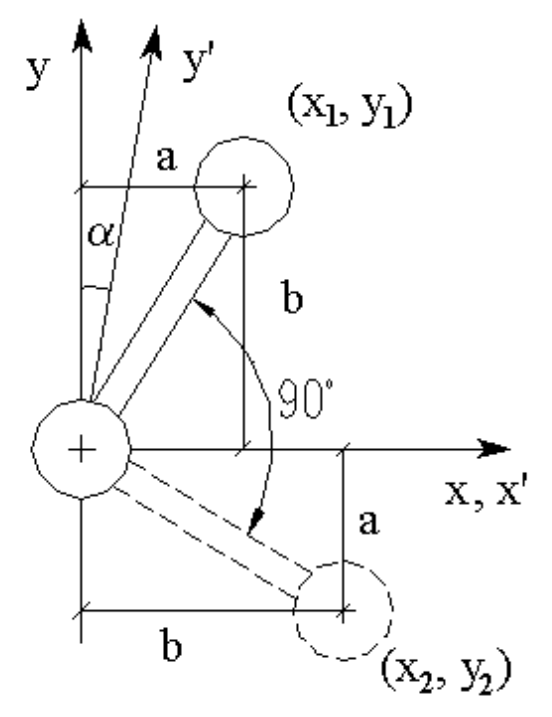

Figura 2.8 - Rotação da Barra de Esferas

$$
\begin{aligned}
& X_{1}=(1+\gamma) X+\alpha Y \\
& Y_{1}=Y \\
& X_{2}=(1+\gamma) Y+\alpha X \\
& Y_{2}=-X
\end{aligned}
$$

Solucionando-se este sistema, obtêm-se os valores dos erros da máquina, apresentados nas equações 2.28 e 2.29 .

$$
\begin{aligned}
& \gamma=\frac{\left(X_{2}-Y_{1}\right) Y_{1}+\left(X_{1}-Y_{2}\right) Y_{2}}{Y_{1}^{2}+Y_{2}^{2}} \\
& \alpha=\frac{X_{1} Y_{1}+X_{2} Y_{2}}{Y_{1}^{2}+Y_{2}^{2}}
\end{aligned}
$$

Conforme já destacado, este sistema é simplificado, uma vez que uma rotação pura de exatamente $90^{\circ}$ é difícil de ser obtida. Por outro lado, a utilização de mais esferas permite a inclusão de outros parâmetros de erro, como o erro de rotação da barra e outros movimentos no eixo de rotação. Sistemas mais abrangentes, com várias componentes de erro, exigem artefatos adequados, maior variação das posições e orientações de medição, bem como modelos matemáticos mais complexos. 


\subsubsection{Reversão do refletor do interferômetro para medição de retilineidade}

A aplicação de interferômetros laser para a medição de retilineidade já é bastante consolidada. O princípio de medição deste sistema é apresentado na Figura 2.9. Movimentos relativos entre duas ópticas, o prisma de Wollaston e o refletor de retilineidade, na direção $Y$, fazem com que os feixes 1 e 2 percorram caminhos ópticos diferentes. Esta diferença fornece um padrão de interferência que pode ser relacionado à movimentação ocorrida. Na figura apresentada, $\delta_{y}(X)$ é o deslocamento na direção y do prisma de Wollaston para cada coordenada $x$ percorrida. Se este prisma for acoplado a um carro que se move na direção $\mathrm{x}$ sobre uma guia, é possível se obter o desvio de retilineidade em y da movimentação do carro, o qual é correspondente ao deslocamento do prisma, $\delta_{\mathrm{y}}(\mathrm{X})$.

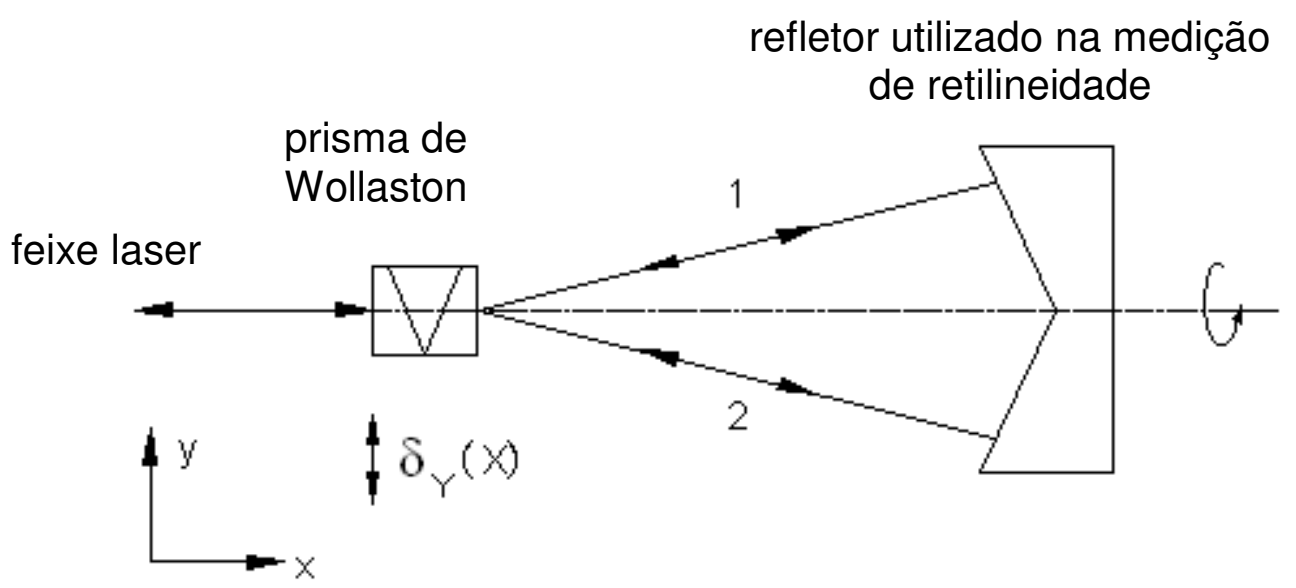

Figura 2.9 - Esquema da medição do desvio de retilineidade utilizando o interferômetro laser

Os desvios de planicidade dos espelhos do refletor geram modificações indesejadas no caminho óptico percorrido pelos feixes, ou seja, introduzem erros nas leituras fornecidas pelo interferômetro. A Figura 2.10 demonstra esse efeito. 


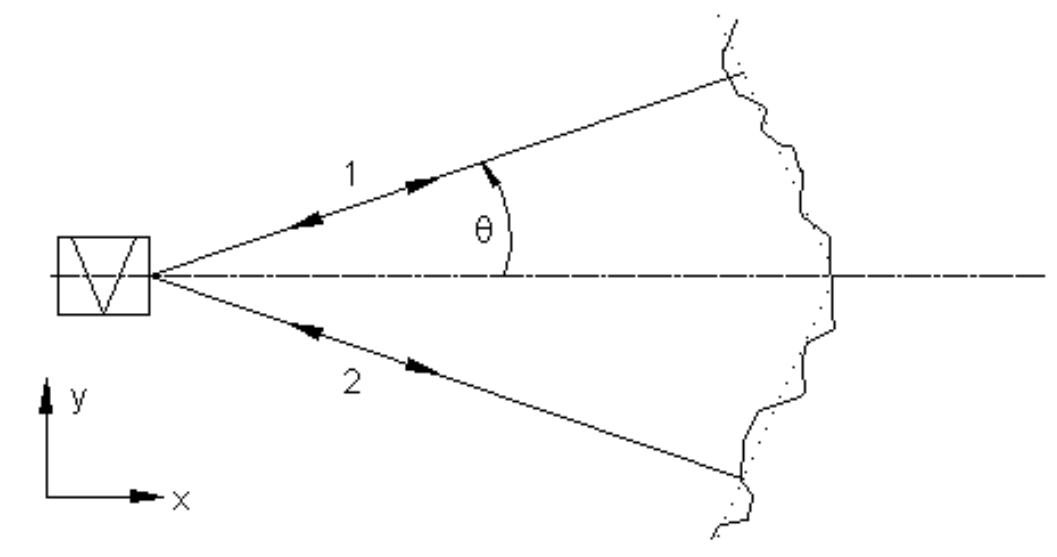

Figura 2.10 - Efeito dos desvios de planicidade do refletor na reflexão dos feixes

Estes erros causados pelo desvio de planicidade dos espelhos podem ser removidos com a aplicação de uma reversão simples, em que o refletor de retilineidade é rotacionado $180^{\circ}$ em torno de sua linha de centro. As leituras fornecidas pelo interferômetro são compostas por uma parcela correspondente à diferença de caminho óptico dos feixes devido ao deslocamento relativo entre o prisma e o refletor e uma parcela correspondente à diferença de caminho óptico devido aos desvios de planicidade do refletor. Como as posições dos espelhos foram invertidas, 0 efeito dos desvios de planicidade dos espelhos é oposto em cada caso, antes e após a reversão. Assim, a combinação das equações das medições normal e reversa fornecerá o perfil de retilineidade sem a influência dos erros do refletor. O equacionamento é análogo ao da reversão da régua padrão. Em geral, os espelhos dos refletores apresentam erros de planicidade bem pequenos. Assim, para avaliar se a reversão será necessária, deve-se analisar se tais erros são significativos diante da acuracidade desejada na medição de retilineidade.

\subsection{Automação da medição e aplicações de robôs industriais}

Por serem intimamente relacionados aos processos de fabricação, os processos de medição acompanharam as tendências de redução de 
tempos e automação. Historicamente, observa-se que estas duas áreas tendem a se desenvolver em paralelo.

É fato que as medições constituem-se operações essenciais para a garantia da qualidade. A década de 60 foi marcada por uma mudança significativa nos conceitos e na avaliação da qualidade com a introdução da metodologia de Controle Estatístico de Processos. Para atender a esta metodologia, os sistemas devem possuir a capacidade de realizar medições e fornecer avaliações a uma taxa adequada para que o processo seja corrigido a tempo de evitar a produção de quantidades significativas de refugo. Por outro lado, em algumas aplicações, como montagem seletiva, a inspeção de $100 \%$ das peças é requerida. Em ambos os casos, os processos de medição devem ser eficientes para que se consigam reduções no tempo total de processamento do produto, principalmente quando etapas subseqüentes da produção dependem de medições.

Do ponto de vista histórico e semântico, a palavra automação, que é um sinônimo de automatização, pode ser definida como um "sistema em que os processos operacionais em fábricas, estabelecimentos comerciais, hospitais, telecomunicações, etc. são controlados e executados por meio de dispositivos mecânicos ou eletrônicos, substituindo o trabalho humano" (HOUAISS; VILLAR, 2001). Este vocábulo pode ser considerado recente. A data estimada do seu primeiro registro é 1976, e a de seu sinônimo "automatização" é 1949. Entretanto, o princípio da automatização é bem mais antigo. Tal fato pode ser verificado observando-se que a data de registro da palavra autômato, da qual as formas citadas derivam, é 1712 . Esta palavra, por sua vez, deriva do radical grego autômatos que significa "que se move por si próprio" e foi trazido à língua portuguesa pelo latim automătus. O segundo elemento desse radical, -mato, prende-se a uma raiz *men-, que significa "pensar". Assim, é possível observar que o termo automação possui um significado bastante abrangente. Mais especificamente, na área de metrologia e inspeção, há uma infinidade de sistemas e dispositivos diversos que concorrem para a automatização de processos de medição, o que torna difícil o estabelecimento de uma linha 
de estudos específica. Neste trabalho, entretanto, o enfoque será restrito a aplicações que utilizam robôs industriais para medições diversas e a alguns sistemas de automação integrados a máquinas de medir controladas numericamente.

\subsubsection{Sistemas Automatizados Integrados a Máquinas de Medição a Três Coordenadas}

As máquinas de medir por coordenadas com controle numérico são largamente utilizadas no setor industrial metal-mecânico. Para a medição de um lote utilizando-se tais máquinas, é necessário que o operador colete manualmente, em cada peça, apenas as coordenadas de alguns pontos iniciais, os quais devem permitir o estabelecimento de um primeiro sistema de referência sobre a peça a ser medida. Os comandos subseqüentes de medição são executados automaticamente, com base nas coordenadas nominais de cada ponto de medição em relação ao sistema de referência. Este processo de medição é relativamente eficiente quando há um volume pequeno ou médio de peças de mesmo tipo a ser medido, ao mesmo tempo em que apresenta flexibilidade para realizar medições de tipos diversos de componentes. Contudo, para medições muito repetitivas e de alto volume, sistemas mais dedicados são, em geral, bem mais eficientes.

Uma desvantagem das máquinas de medir automatizadas convencionais é a exigência de operação em ambientes com temperatura e umidade muito controladas. A necessidade de transporte dos componentes para a sala de medição e de tempo de espera até a estabilização da temperatura dificulta que tais sistemas sejam utilizados para medições em processo e para controle estatístico do processo de fabricação.

Para que os benefícios de um sistema de medição a três coordenadas, bem como de outros sistemas de medição, sejam maximizados, alguns fatores devem ser considerados, buscando 0 
atendimento aos requisitos de inspeção e manufatura de cada empresa. Dentre esses fatores, pode-se citar o ambiente de operação, os tempos de ciclo de medição requeridos, os dispositivos de manipulação e fixação da peça, a interface com sistemas CAD/CAM, a utilização de dispositivos de reconhecimento e posicionamento do componente, a interface de controle, etc.

Uma das tendências atuais de automatização consiste na integração das máquinas de medir com dispositivos automáticos de transporte e posicionamento das peças, com o intuito de reduzir o tempo de ciclo das medições e possibilitar a incorporação de tais sistemas de medição à linha de produção. Estes sistemas automatizados incluem robôs ou outros dispositivos para transporte, carregamento e descarregamento dos componentes a serem medidos, além de sensores ou dispositivos de reconhecimento e posicionamento das peças. Um sistema de automação integrado a máquinas de medir CNC geralmente inclui esteiras ou roletes movidos por motores elétricos para o transporte de paletes de componentes. Estes paletes, por sua vez, são capazes de realizar o posicionamento de peças e de, por exemplo, criar um plano de referência de medição apoiando o componente por três pontos não colineares. Os carros podem movimentar-se de forma linear ou rotativa, realizando a integração com estações de troca ou carregamento e descarregamento de peças. Programas computacionais de interface com usuário, rotinas de baixo nível e controles eletrônicos são utilizados para processar as informações necessárias ao transporte e medição automáticos das peças. Algumas características destes sistemas automatizados de medição são apresentados em DEA (2007).

Estas soluções são alternativas que têm sido adotadas por algumas empresas, em geral de grande porte e que possuem volume e diversidade de medições que justificam os altos custos de implementação de tais sistemas. 


\subsubsection{Medições executadas por robôs industriais}

As aplicações de robôs industriais, segundo Yagi (2002), podem ser divididas em dois grupos: operações de transporte e operações de usinagem. O primeiro grupo é bastante abrangente e, inclui, além de robôs que realizam o transporte de componentes, também os manipuladores que carregam ferramentas em suas extremidades e utilizam equipamentos periféricos de maneira similar a operadores humanos. Assim, também fazem parte deste grupo robôs que realizam solda a ponto e a arco, pintura, manipulação de materiais, entre outros. A grande maioria das aplicações de robôs está inserida neste primeiro grupo, conforme pode ser visualizado na Tabela 2.1, que apresenta as principais aplicações de robôs e manipuladores na indústria automotiva japonesa, no ano de 2001 e uma média das porcentagens dessas aplicações nos anos de 1988 a 1997.

Tabela 2.1 - Principais aplicações de robôs e manipuladores na indústria automotiva japonesa

Fonte: Adaptado de Yagi (2002)

\begin{tabular}{|l|l|l|}
\hline Anos & $\mathbf{1 9 8 8 - 9 7}$ & $\mathbf{2 0 0 1}$ \\
\hline Solda a ponto & $20,3 \%$ & $43,7 \%$ \\
\hline Solda a arco & $21,4 \%$ & $21,4 \%$ \\
\hline Manuseio de Materiais & $6,1 \%$ & $10,6 \%$ \\
\hline Montagem & $10 \% \%$ & $9,9 \%$ \\
\hline Carregamento/Descarregamento & $14,4 \%$ & $4,8 \%$ \\
\hline Fundição & $5,0 \%$ & $2,0 \%$ \\
\hline Prensa & $2,8 \%$ & $1,4 \%$ \\
\hline Pintura & $2,4 \%$ & $1,4 \%$ \\
\hline Outros & $12,7 \%$ & $24 \%$ \\
\hline
\end{tabular}

O autor citado destaca que inicialmente, os robôs do segundo grupo, dedicados a operações de usinagem, podiam apenas mover componentes ao redor de máquinas dedicadas. Recentemente, a melhoria do controle de movimentos, a integração do controle dos dispositivos e ferramentas ao controle dos robôs, a melhoria da acuracidade de posicionamento, o controle da força e diminuição das vibrações, permitiram que os robôs passassem a realizar a usinagem propriamente dita. 
Um terceiro grupo a ser destacado é aquele no qual robôs industriais são utilizados em operações de medição e inspeção. É interessante observar, que, na tabela apresentada não há informações específicas quanto à porcentagem de utilização dos robôs para a realização destas operações. As aplicações dos manipuladores em atividades de medição estariam incluídas no grupo "outros", demonstrando que os manipuladores têm sido pouco empregados para realizar medições. De 2001 até os tempos atuais, foram desenvolvidas poucas aplicações em que robôs industriais executam atividades de inspeção.

Mesmo quando os manipuladores realizam tarefas para a finalidade citada, eles geralmente são programados mais para desempenhar funções de transporte e posicionamento de componentes a serem medidos do que para executar as medições propriamente ditas. É de interesse para este trabalho, entretanto, analisar aplicações diversas em que robôs industriais são utilizados para realizar medições. Nos tópicos subseqüentes serão fornecidos alguns exemplos destas aplicações.

\subsubsection{Utilização de robôs para a análise de soldas em linhas de produção}

Robôs industriais têm sido muito utilizados em operações de soldagem automatizada, conforme demonstrado no item anterior. Nesse contexto, é por vezes necessário que um conjunto de dados críticos seja coletado e analisado visando o controle de qualidade do processo, correção de parâmetros em tempo real e detecção de peças e montagens com defeitos graves. Assim, a aplicação de robôs industriais na medição e análise de cordões de solda automatizada tem se destacado na indústria metal mecânica, em especial no ramo automobilístico. Boillot e Uota (2002) apresentam um sistema de medição que utiliza uma câmera de varredura a laser conectada em um manipulador industrial. A câmera é fixada juntamente com a ferramenta de soldagem e posicionada antes do ponto de solda. Utilizando o princípio de triangulação a laser, o sistema é capaz de medir a geometria e dimensões das componentes, bem como 
localizar os pontos a serem soldados. Com base nessas informações e por meio da comunicação com o robô, é possível controlar o posicionamento das ferramentas em tempo real e corrigir a posição da fonte de calor durante a operação.

O sistema proposto permite análise de perfis de superfícies, a obtenção de informações detalhadas de juntas, furos, rebites, etc., e a medição de diâmetros de furos ou outras características planas.

Os autores citados destacam algumas limitações do sistema descrito. Quando robôs movimentam instrumentos de medição para medir distâncias, a acuracidade de medição depende da desempenho dos manipuladores, especialmente no que tange à acuracidade de posicionamento e repetibilidade. Gradientes de temperatura e outras grandezas de influência relacionadas ao ambiente também são fontes de erro e incerteza relevantes para o sistema descrito, assim como para os sistemas de medição em geral.

\subsubsection{Sistema de Medição 3D para robôs móveis}

Este é um exemplo de aplicação em que um robô móvel realiza medições da dimensão e forma básica de objetos. Contudo, neste caso, a medição em si não é o objetivo final do robô, mas sim uma função secundária, de apoio, para que este possa realizar sua função principal de locomoção.

Há atualmente alguns tipos de robôs que se locomovem em terrenos acidentados e podem ser utilizados, por exemplo, para a realização de resgates ou outras tarefas que impõem riscos ao ser humano. Para estes robôs, a obtenção de informações sobre o ambiente é uma função indispensável, visto que, na maioria dos casos, o terreno no qual se movem é desconhecido. Higasa et al. (2004) apresentaram um robô móvel composto por cinco segmentos planos conectados entre si, em série, sendo que cada segmento possui duas esteiras para locomoção. As esteiras são movidas por motores elétricos que atuam independentemente em cada uma das duas extremidades dos segmentos. Sobre um destes 
segmentos há uma unidade de medição que contém um sensor a laser de medição de distâncias. O objetivo desta unidade é a obtenção da distância, formato e dimensões básicas dos obstáculos. A Figura 2.11 abaixo apresenta o robô descrito. Um esquema representativo da estratégia de medição proposta pelos autores citados é mostrado na Figura 2.12.

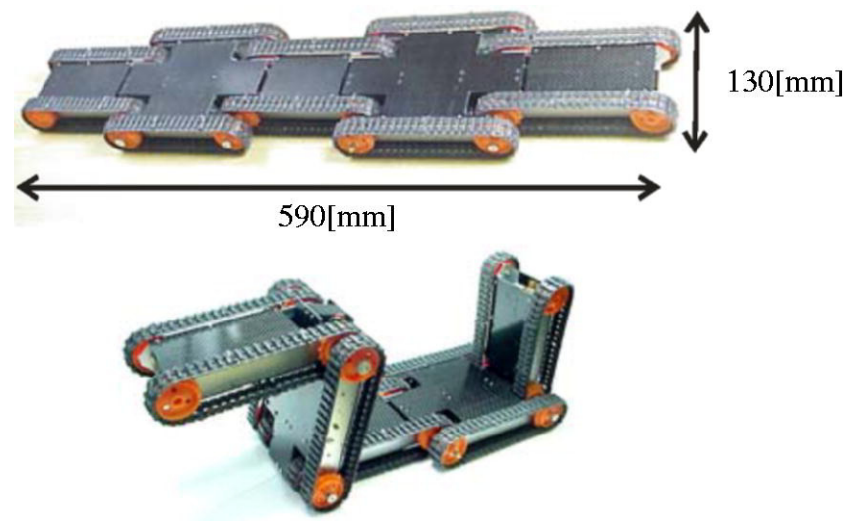

Figura 2.11 - Robô móvel para terrenos acidentados Fonte: Higasa et al. (2004)

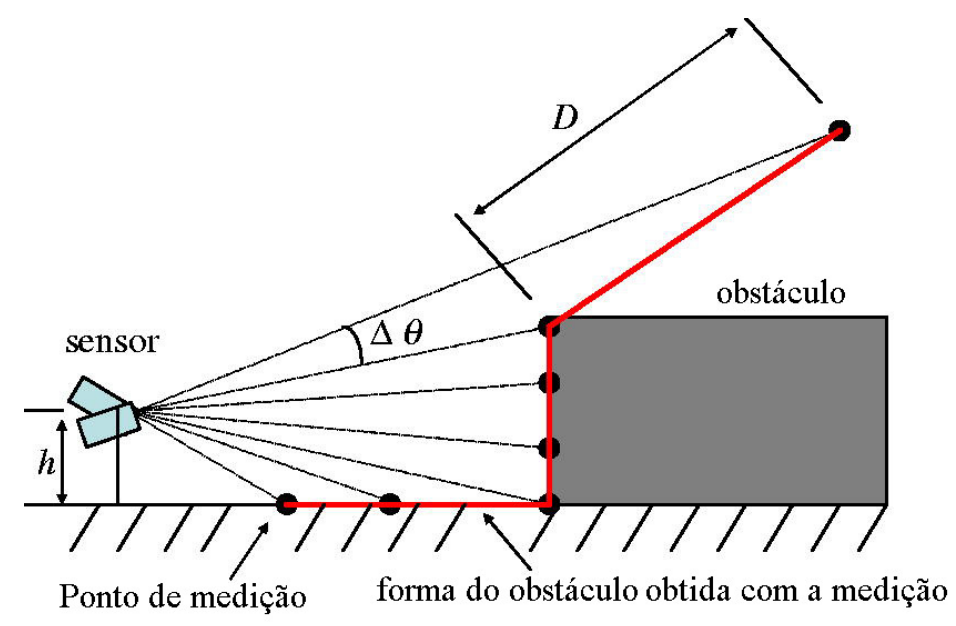

Figura 2.12 - Princípio de medição do robô móvel Fonte: adaptado de Yokota et al. (2007)

Yokota et al. (2007) destacam o fato de que em muitos robôs móveis, braços ou mastros ajustáveis são utilizados para posicionar os sensores para realizar as medições. O sistema de medição apresentado explora os graus de liberdade do mecanismo dos robôs de forma mais efetiva, utilizando-os tanto para movimentação quanto para medição. Assim, medição é realizada por meio da combinação entre o movimento dessa unidade sensora e o movimento do próprio robô. Os eixos de 
movimentação e locomoção do robô são utilizados para elevar a unidade sensora caso um objeto maior que o campo de varredura desta unidade seja detectado.

Buscando analisar o desempenho do sistema proposto, os autores colocaram obstáculos de dimensões conhecidas na trajetória a ser percorrida pelo robô. O valor máximo obtido para as diferenças entre as dimensões medidas e as dimensões reais do obstáculo foi de 0,037 m. Segundo os autores, este resultado é satisfatório diante da acuracidade requerida para o sistema, visto que a função primária do robô não é a medição, mas sim a locomoção.

Neste caso, pode-se supor que os erros de posicionamento do robô e da unidade sensora ao medir cada ponto do obstáculo não influem significativamente no valor das leituras obtidas, uma vez que a ordem de grandeza das dimensões medidas é muito superior à ordem de grandeza dos erros do robô. Assim, conclui-se que a acuracidade e a repetibilidade de posicionamento apresentados pelo robô sejam, neste caso, adequados diante da acuracidade requerida na medição da distância e dimensões dos objetos.

\subsection{2 . Medição Automatizada de Placas de Semicondutores}

As fábricas de semicondutores têm se apoiado em processos automatizados de fabricação e medição de placas a fim de obter reduções significativas nos tempos de ciclo de produção e reduzir a quantidade de material refugado ou comprometido por erros de fabricação e inspeção. Chain (1996) apresenta um sistema em linha, automatizado, utilizado para a medição da dimensão crítica e outras características de placas de semicondutores em uma das plantas da Motorola. As medições são feitas utilizando-se o microscópio eletrônico por varredura, Scanning Electron Microscope, SEM.

A autora apresenta as etapas do procedimento de medição e destaca que, enquanto o modo de operação manual requer que o operador execute o alinhamento global da placa, a localização da região a 
ser medida e a medição propriamente dita, o Sistema Automatizado requer apenas que a placa seja inserida no sistema e a rotina de medição seja carregada. A vantagem desse sistema, conforme destacado por Chain (1996), é que as máquinas e robôs são mais eficientes na execução de tarefas simples e repetitivas, como o posicionamento da placa no mesmo local, a cada vez, e o armazenamento de valores em um banco de dados. Nesta aplicação, em que a inspeção de grandes lotes é requerida, a redução do tempo de ciclo de medição é um fator importante. Além disso, no Sistema Automatizado proposto, as medições são baseadas no reconhecimento e comparação de padrões, enquanto no modo convencional, são mais dependentes do julgamento do operador.

No trabalho citado também se apresenta um sistema de monitoramento da automação que funciona conjuntamente ao próprio sistema de medição. As falhas do Sistema Automatizado devem ser identificadas e reportadas para que o processo seja corrigido ou, em casos críticos, possa seja executado manualmente. Para tanto, são armazenadas informações relativas ao sucesso ou falência na execução de cada etapa do procedimento de medição. Tais informações são registradas na forma de códigos de erro correspondentes às falhas possíveis do sistema. Esta coleta de dados de desempenho do sistema ocorre concomitantemente à medição de um lote.

Neste exemplo de automação, em que são medidos grandes lotes de componentes, a capacidade de monitoramento do sistema e de rastreabilidade das falhas ocorridas deve ser destacada como um aspecto importante para o sucesso da aplicação.

\subsubsection{Medição de Superficie de turbinas}

Um Sistema Automatizado e dedicado à medição do desgaste das superfícies de rotores de turbinas hidráulicas é apresentado por Bonacorso, Dutra e Gonçalves Jr. (2006). Neste sistema, utiliza-se um sensor óptico a laser e um robô não-convencional. O sistema de medição é utilizado para coletar pontos sobre a peça, os quais serão usados para 
se obter um modelo matemático que representa a geometria das superfícies medidas. O conhecimento dos parâmetros dessa geometria permite a realização de uma estimativa de quantidades, orientações e dimensões dos cordões de solda a serem aplicados.

Um robô não-convencional é utilizado devido à limitação da área de trabalho no rotor da turbina. O sensor óptico é acoplado a uma das extremidades do robô enquanto na outra extremidade é montada uma pistola de soldagem manual, com alimentação automática, a qual será utilizada no processo automatizado de deposição.

Após a coleta de pontos sobre a superfície, um plano de Mínimos Quadrados é gerado com base nos pontos da área não-destruída, visando delimitar grosseiramente a região que sofreu desgaste e a determinar uma orientação e posições de referência. A superfície erodida é gerada por meio da utilização de técnicas de interpolação e da aplicação de modelos matemáticos. Discussões sobre estes modelos são apresentadas nos trabalhos de Gonçalves Jr. e Hrebabetzky (2001).

Tendo em vista o objetivo deste trabalho, é interessante destacar alguns aspectos relativos aos sensores utilizados no sistema exposto e algumas considerações sobre os dados obtidos por meio deste sistema.

O princípio básico de medição dos sensores de varredura a laser utilizados no sistema de medição apresentado consiste na projeção de um feixe de laser sobre a superfície a ser medida e na captura da imagem deste feixe com uma câmera CCD alinhada em uma direção diferente da direção da fonte laser. A Figura 2.13 apresenta este princípio de forma simplificada. No caso do sensor proposto pelos autores, são projetadas simultaneamente três feixes ao invés de um, mas o princípio de medição é o mesmo do sensor de feixe único.

O sistema proposto pelos autores realiza a medição das distâncias dos pontos da superfície em relação ao sensor, isto é, a referência para a medição é o sistema de coordenadas do sensor. Para que se obtenham dados do perfil da superfície medida, é necessário obter o valor das coordenadas dos pontos medidos segundo um mesmo sistema de 
referência, um sistema de coordenadas global. Isto requer o conhecimento da posição e orientação do sensor ao medir cada ponto, em relação a este sistema de coordenadas global. Os valores medidos dependem, portanto da acuracidade com que o manipulador posiciona o sensor. Na medição de cada ponto, a distância dos sensores em relação à superfície medida varia, pois o manipulador que conduz o sensor apresenta erros de posicionamento e repetibilidade. Gonçalves Jr. e Hrebabetzky (2001) não mencionam a utilização de métodos de separação de erros para eliminar os erros de posicionamento do manipulador dos valores lidos. Deve-se ressaltar que, em alguns casos, quando esses métodos de separação não são utilizados, a acuracidade de posicionamento e a repetibilidade do manipulador não são suficientes para que se obtenha a precisão requerida para a adequada medição da superfície.

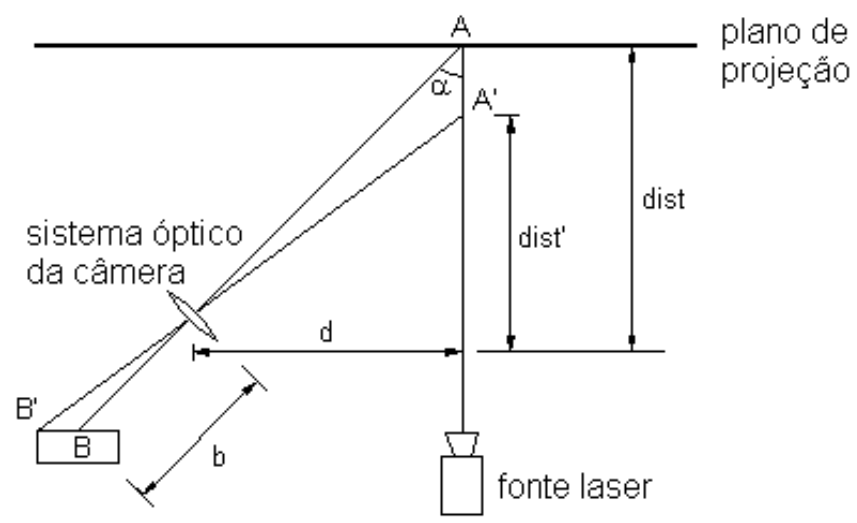

Figura 2.13 - Princípio de funcionamento dos sensores de varredura a laser. Fonte: Adaptado de Gonçalves Jr. e Hrebabetzky (2001).

Com o intuito de avaliar a desempenho do sensor, Gonçalves Jr. e Hrebabetzky (2001) realizaram uma série de testes experimentais utilizando uma régua de seno e blocos padrões para a geração de ângulos de referência. Segundo os autores, o erro máximo obtido foi de $0,5^{\circ}$. Este erro, de aproximadamente 0,0087 radianos, representa uma altura de cerca de $15 \mu \mathrm{m}$ em um comprimento total de $100 \mathrm{~mm}$.

Algumas aplicações requerem a medição de erros dimensionais, de forma e orientação, por exemplo, da ordem de unidades ou dezenas de micrometros. Nestes casos, os sistemas de medição como o proposto não 
apresentam acuracidade suficiente. Segundo dados apresentados por Boillol e Uota (2002) robôs industriais comuns de 6 eixos apresentam repetibilidade de cerca de $150 \mu \mathrm{m}$, enquanto há robôs de medição com repetibilidade de até $35 \mu \mathrm{m}$. Assim sendo, tais valores de acuracidade de posicionamento e repetibilidade dos robôs seriam impeditivos ao uso de sistemas automatizados para a medição de erros de centésimos de milímtero, por exemplo. Tais níveis de acuracidade poderiam ser obtidos com o emprego de técnicas de separação de erros.

Gonçalves Jr. e Hrebabetzky (2001) não deixam claro se as medições das inclinações da régua de seno foram realizadas com o sensor estático ou com o sensor acoplado ao robô e conduzido a diferentes locais de medição. Este é um aspecto importante a ser esclarecido para a análise da validade dos resultados apresentados. Caso as medições tenham sido feitas com o sensor acoplado ao robô, sendo de fato conduzido aos diferentes pontos de medição, deve-se ressaltar que os resultados apresentados, ou seja, inclinações menores do que $0,5^{\circ}$, são questionáveis, uma vez que os robôs disponíveis atualmente não apresentam acuracidade suficiente para garantir este resultado e os autores não mencionam a utilização de técnicas de separação de erros.

No trabalho citado, há indícios de que o valor de erro apresentado corresponda apenas ao erro do sensor, o que significa que as medições foram feitas em um único ponto, utilizando-se um sistema estático ou algum outro dispositivo de posicionamento do sensor, com acuracidade melhor do que a do robô. Neste caso, o resultado apresentado pelos autores não é significativo como medida do desempenho do sistema, uma vez que a acuracidade final deste deverá ser bem pior do que a apresentada, devido aos erros de posicionamento e repetibilidade do robô, que devem ser da ordem de $100 \mu \mathrm{m}$ ou mais.

Além disso, os autores declaram que, com a utilização do método e sensor propostos, "a incerteza da inclinação não depende muito fortemente do erro de posicionamento do robô". Esta afirmação é sustentada provavelmente porque, utilizando-se o sensor desenvolvido 
pelos autores, é possível coletar em cada posição de medição uma nuvem de pontos simultaneamente e não um único ponto. Assim, segundo o método proposto pelos autores citados, uma inclinação local relativa é calculada a partir destes pontos, e esta inclinação provavelmente não depende da acuracidade de posicionamento do robô, já que o erro do robô é o mesmo, neste caso, para todos os pontos coletados. Entretanto, no cálculo do perfil de toda a superfície, e não de uma pequena área local, são considerados pontos coletados em diferentes posições de medição. Neste segundo caso, não se pode afirmar que os resultados obtidos não dependem do erro de posicionamento do robô. Se for necessário que o robô se movimente para realizar as medições, então os valores medidos dependem de sua acuracidade de posicionamento, fato que não é discutido pelos autores citados.

\subsubsection{Determinação dos erros de retilineidade de um robô industrial utilizado em célula de soldagem}

Piratelli-Fillho, Di Giacomo e Siqueira (2000) investigaram a retilineidade da movimentação de um robô industrial utilizado em uma célula de soldagem. Neste caso, o robô não é utilizado para executar medições de desvios geométricos de componentes ou de dimensões de objetos: as medições são realizadas para avaliar os erros de movimentação do próprio manipulador. Tais erros estão diretamente ligados à qualidade final da solda obtida, pois nos processos de solda a arco, por exemplo, os desvios em relação à trajetória retilínea causam variações na distância entre a pistola de solda e a peça, e a conseqüente instabilidade elétrica gerada por esta variação resulta em defeitos no cordão de solda produzido.

No trabalho citado, foram avaliados os desvios de retilineidade do movimento da extremidade do manipulador ao longo trajetórias distintas, distribuídas em diferentes regiões de seu volume de trabalho. Estas trajetórias são mostradas na Figura 2.14. Os desvios foram medidos utilizando-se uma régua-padrão de granito, como artefato de referência, e 
um relógio comparador com resolução de 10 micrometros e incerteza de 50 micrometros acoplado à extremidade do manipulador. A régua-padrão foi alinhada a um dos eixos $x, y$ ou $z$ do robô, dependendo da trajetória analisada. Avaliou-se a retilineidade em relação a dois planos ortogonais que interceptam cada trajetória considerada, conforme apresenta a Figura 2.15 .

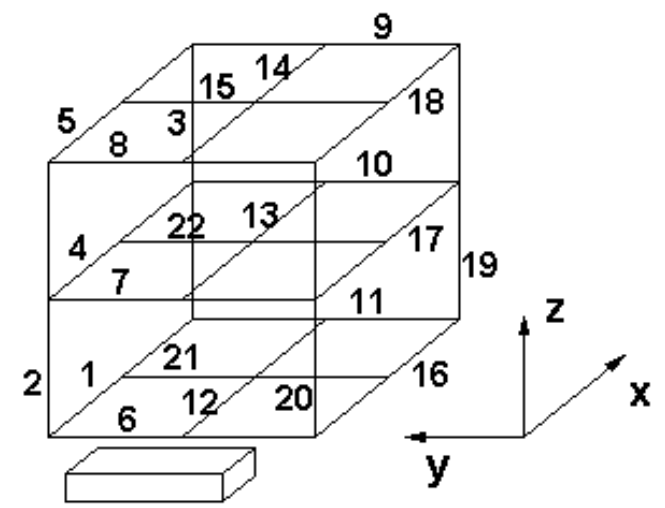

posição do robô

Figura 2.14 - Trajetórias avaliadas

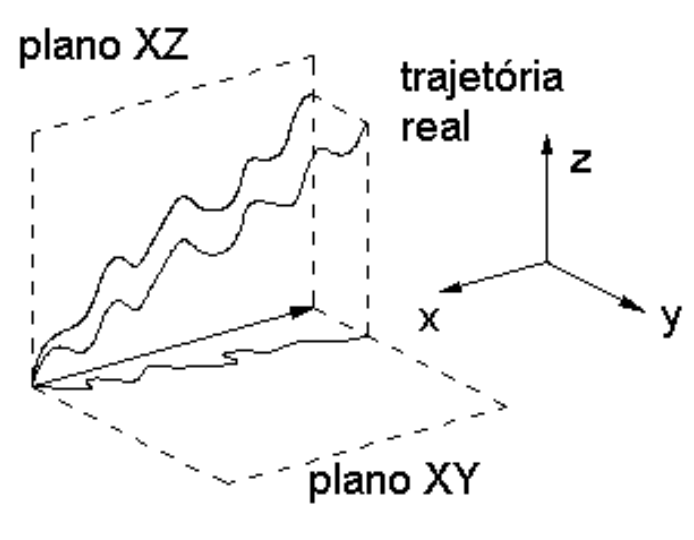

Figura 2.15 - Desvio de retilineidade em palnos ortogonais

Fonte: Piratelli-Filho, Di Giacomo e Siqueira (2000)

A partir dos resultados obtidos foi possível definir, no caso analisado, quais são as melhores e as piores trajetórias a serem seguidas para a realização de operações de soldagem. Segundo os autores citados, o robô apresentou uma repetibilidade constante de cerca de 100 micrometros em todos os pontos do volume de trabalho. Os desvios de retilineidade observados nas várias trajetórias e em relação a diferentes planos, entretanto, variaram consideravelmente: de cerca de 180 micrometros até 1700 micrometros. No contexto do desenvolvimento do Sistema Automatizado proposto neste trabalho, os resultados obtidos por Piratelli-Fillho, Di Giacomo e Siqueira (2000) demonstram, novamente, a necessidade da aplicação de modelos de separação de erros quando robôs industriais são empregados na realização de medições de desvios geométricos de componentes, uma vez que os erros de retilineidade do movimento do robô são significativos e certamente afetarão os valores medidos. 


\section{Capítulo 3}

\section{Bases Teóricas}

Neste capítulo são discutidos os conceitos e modelos matemáticos que fornecem o embasamento teórico para o desenvolvimento do Sistema Automatizado de medição. Conforme os objetivos estabelecidos para este trabalho, apresentados no capítulo 1, propõe-se a aplicação um Sistema Automatizado de medição para a avaliação dos desvios de planicidade, paralelismo e perpendicularismo. Assim, julgou-se relevante iniciar as discussões deste capítulo com as definições de tolerâncias e desvios geométricos de forma e orientação citados.

Além disso, devido às características do sistema proposto, para que se obtenha uma acuracidade adequada às medições dos desvios geométricos, é necessária a utilização de um modelo matemático que realize o desacoplamento entre os desvios do componente e os demais erros de medição. Diante disso, abordar-se-ão as principais técnicas de separação de erros baseadas na utilização de múltiplos sensores, as quais são aplicáveis ao Sistema Automatizado proposto. O equacionamento e as características de cada modelo serão apresentados e discutidos.

Como resultado da aplicação dos modelos de separação de erros, obtêm-se conjuntos de pontos que representam a superfície do componente, a qual possui desvios de forma e orientação. Para que estes desvios sejam avaliados, isto é, para que se obtenha um valor que quantifique um dado desvio, faz-se necessária a ajustagem de formas geométricas de referência, como planos e retas, aos pontos medidos. Tal ajustagem, por sua vez, pode ser realizada utilizando-se diferentes métodos, os quais se baseiam em critérios distintos de minimização dos resíduos da ajustagem. Tradicionalmente, utiliza-se o Método dos Mínimos 
Quadrados. Uma alternativa a este método é a modelagem da avaliação dos desvios de forma como um problema de Programação Linear, o qual pode ser resolvido pelo Método Simplex ou outros métodos de otimização. Tal modelagem será discutida ao final deste capítulo.

\subsection{Tolerâncias e Desvios Geométricos}

Tendo em vista a proposta deste trabalho, são apresentadas nesta seção as definições das tolerâncias de forma e orientação. Tais definições limitam campos ou espaços geométricos nos quais o elemento avaliado do componente, por exemplo, uma face ou linha de centro, deve estar contido. O entendimento destas geometrias, por sua vez, é importante para a correta medição dos principais desvios geométricos de forma e orientação apresentados pelos componentes.

Segundo a norma ASME Y14.5M (1994), tolerâncias de forma e orientação devem ser especificadas nos casos em que as tolerâncias dimensionais e de localização não garantem o suficiente controle das características geométricas de um componente. Certas características como a planicidade ou paralelismo de componentes podem ser críticas para seu desempenho funcional ou intercambiabilidade. Tolerâncias de forma e orientação podem ser especificadas mesmo quando não são estabelecidas tolerâncias dimensionais, como no caso do controle de planicidade após a montagem de um conjunto, por exemplo. A norma citada também estabelece a relação entre tolerâncias de forma e tolerâncias dimensionais aplicadas ao componente. A Condição de Máximo Material deve ser considerada na aplicação das tolerâncias de forma.

Tolerâncias de forma controlam retilineidade, planicidade, circularidade, cilindricidade, forma de uma linha qualquer e forma de uma superfície qualquer, enquanto tolerâncias de orientação controlam a inclinação, paralelismo e perpendicularismo de elementos geométricos dos componentes. As tolerâncias de forma, de orientação e de posição de um elemento geométrico (ponto linha, superfície ou plano mediano) definem 
campos em cujo interior deve ficar situado o elemento sendo avaliado (NBR 6409, 1980). Estes campos podem ser o espaço interior de um círculo, a coroa circular, o espaço entre duas linhas paralelas ou retas paralelas, o espaço interior de uma esfera, o espaço interior de um cilindro ou o espaço entre dois cilindros coaxiais, o espaço entre duas superfícies paralelas ou dos planos paralelos e o espaço interior de um paralelepípedo.

Em geral, as normas existentes tratam mais das definições das tolerâncias geométricas do que das definições dos desvios. A norma JIS B 0621 (1984) destaca-se por trazer as definições dos desvios, as quais também serão apresentadas nos itens seguintes.

\subsubsection{Tolerância e desvio de retilineidade}

"Quando aplicada a uma linha sobre uma superfície ou a uma aresta, a zona de tolerância de retilineidade é a área entre duas retas paralelas contidas no plano que contém a linha considerada" (BSI PD 7304, 1982). Segundo a norma NBR 6409 (1980), o campo de tolerância de retilineidade também pode ser limitado por um cilindro de diâmetro " $t$ ". Alternativamente, "o campo de tolerância fica limitado ao espaço dentro de um paralelepídedo se a tolerância de retilineidade for aplicada a dois planos perpendiculares entre si" (NBR 6409, 1980).

O desvio de retilineidade pode ser simplesmente definido como 0 valor da distância entre duas retas paralelas que contém os desvios apresentados pelo componente avaliado. Essa distância não pode ultrapassar " $t$ ", o qual representa um valor-limite prático.

Segundo a norma JIS B 0621 (1984), o desvio de retilineidade significa a quantidade de desvio que a linha sob avaliação apresenta com relação a uma reta ideal, exata, do ponto de vista geométrico.

Da mesma forma que no caso da representação das tolerâncias, a representação dos desvios geométricos varia, pois diferentes campos de desvios podem ser estabelecidos. As definições dos campos do desvio de retilineidade são muito similares às definições dos campos de tolerância, 
ou seja, os mesmos campos definidos acima para as tolerâncias se aplicam aos desvios, entretanto, nas representações dos desvios, as distâncias consideradas devem ser mínimas. Assim, a norma JIS B 0621 (1984, p. 1132) estabelece que:

o desvio de retilineidade de uma reta, isto é, do elemento sendo considerado, $[\ldots]$ deve ser representado pela distância $(f)$ entre duas retas ideais no caso em que a distância entre as duas retas paralelas torna-se mínima e o elemento considerado ( $L$ ) está contido entre essas duas retas paralelas ideais.

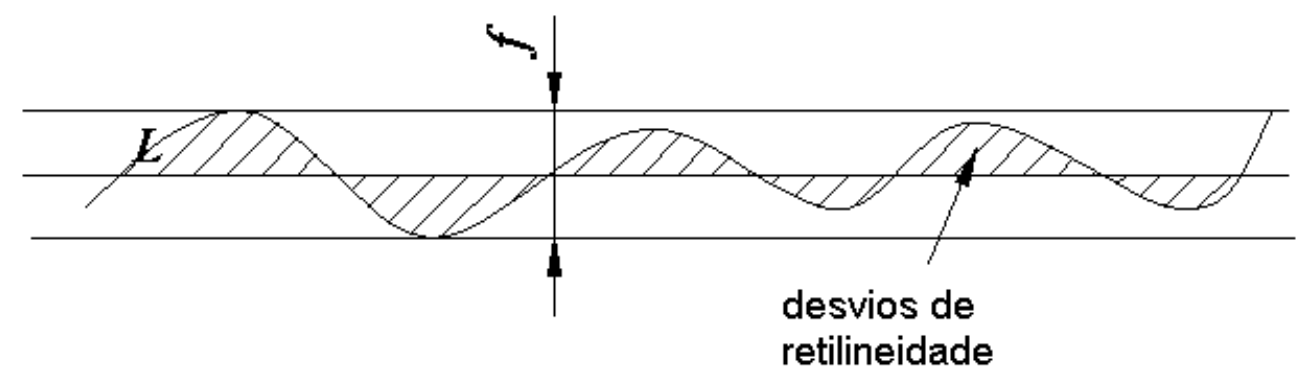

Figura 3.1 - Representação do desvio de retilineidade

Esta definição apresentada se aplica ao desvio de retilineidade de um elemento contido em uma superfície. As representações para o caso em que se considera o desvio em duas direções ou para o caso em que o campo definido para o desvio é cilíndrico são semelhantes às discutidas acima para as tolerâncias, lembrando-se que o desvio corresponde sempre à distância mínima entre os elementos geométricos estabelecidos.

\subsubsection{Tolerância e desvio de planicidade}

"A tolerância de planicidade especifica um campo definido por dois planos paralelos entre os quais a superfície deve estar contida" (ASME Y14.5M - 1994).

A norma NBR 6409 (1980) traz uma definição praticamente idêntica à apresentada, estabelecendo que "o campo de tolerância de planicidade é limitado por dois planos paralelos, distantes de " $t$ ", entre os quais deve 
estar a superfície em consideração". Outras normas como a BSI PD 7304 (1982) e a JIS B 0021 (1984), apresentam definições muito semelhantes.

Deve-se ressaltar que, nas normas em geral, existe uma ausência significativa de instrução quanto a métodos de medição e algoritmos a serem utilizados na avaliação dos erros de forma e orientação. Até mesmo o conceito de desvio é pouco mencionado. A norma ASME Y14.5.1M (1994) é uma das únicas que contraria esta tendência e apresenta uma definição mais completa das tolerâncias e desvios de forma, incluindo as expressões matemáticas correspondentes à definição. O trecho desta norma que define a tolerância de planicidade é transcrito abaixo:

(a) Definição. A tolerância de planicidade especifica que todos os pontos da superfície devem estar contidos em uma zona limitada por dois planos paralelos, os quais estão separados por uma distância correspondente ao valor da tolerância especificada.

O campo de planicidade é um volume composto por todos os pontos definidos pelos vetores $\vec{P}$ que satisfazem à condição:

$|\hat{T} \cdot(\vec{P}-\vec{A})| \leq \frac{t}{2}$

Onde:

$\hat{T}$ é o vetor de direção dos planos paralelos que definem o campo de planicidade

$\vec{A}$ é um vetor de posição localizando o plano médio do campo de planicidade

$t$ é a distância de separação entre os planos paralelos

(b) Conformidade. Um elemento medido atende a uma tolerância de planicidade $t_{0}$ se todos os pontos do elemento estiverem contidos no campo definido acima, $\operatorname{com} t=t_{0}$. Em outras palavras, existe $\hat{T}$ e $\vec{A}$ tal que, com $t=t_{0}$, todos os pontos do elemento estão contidos no campo de planicidade.

(c) Valor verdadeiro. O valor verdadeiro de planicidade de uma superfície é equivalente ao menor campo de planicidade à qual a superfície atende (ASME Y14.5.1M, 1994, p. 36).

É interessante observar que no item (c) define-se o desvio de planicidade de uma superfície, isto é, o valor verdadeiro medido, e a definição apresentada inclui o termo "menor". Assim, tal definição é equivalente à afirmação de que o desvio de planicidade é a menor 
distância entre dois planos paralelos que contém o perfil medido. Esta definição também é apresentada na norma JIS B 0621 (1984), e sinaliza que, na medição do desvio, deve-se buscar ajustar um plano médio ao conjunto de pontos do perfil de tal forma que a distância entre os planos paralelos a este plano médio seja mínima. Dessa forma, estar-se-ia obtendo o "valor verdadeiro" de planicidade da superfície.

\subsubsection{Tolerância e desvio de paralelismo}

Tolerâncias de inclinação, paralelismo e perpendicularismo controlam a orientação de certas partes ou elementos do componente com relação a outros elementos. Na especificação destas tolerâncias e na avaliação destes desvios, a característica considerada é relacionada a um ou mais elementos de referência.

O paralelismo é a condição de uma superfície cujos pontos são eqüidistantes de um plano de referência; ou a condição de um eixo eqüidistante ao longo de seu comprimento de um ou mais planos de referência ou de uma reta de referência (ASME Y14.5M).

Pode-se estabelecer um campo de tolerância de paralelismo ou desvio de paralelismo de uma linha ou superfície com relação a uma reta de referência, ou de linha ou superfície com relação a uma superfície de referência.

No primeiro caso, quando a tolerância é estabelecida entre uma linha e uma reta de referência, "a zona de tolerância, quando projetada sobre um plano horizontal ou vertical, é a região contida entre as duas retas paralelas à reta de referência e a uma distância ' $t$ ' entre si' (JIS B 0021, 1984). A Figura 3.2 apresenta a representação da tolerância ou do desvio de paralelismo de uma reta projetada sobre o plano vertical e a respectiva indicação da tolerância no desenho, segundo a norma NBR 6409. Já na Figura 3.3, segundo a indicação do desenho, o campo de tolerância ou de desvio da reta considerada deve ser projetado no plano horizontal. 
Quando o símbolo $\phi$ antecede o valor numérico da tolerância, a zona de tolerância é a região limitada por um cilindro de diâmetro ' $t$ ' paralelo à reta de referência (NBR 6409, 1980 e JIS B 0021, 1984). Esta zona de tolerância é mostrada na Figura 3.4, juntamente com a respectiva indicação no desenho. A definição do desvio que consta na norma JIS B 0621 (1984) é equivalente à definição da zona de tolerância, sendo que, neste caso, o diâmetro do cilindro é representado pela letra ' $f$ '.
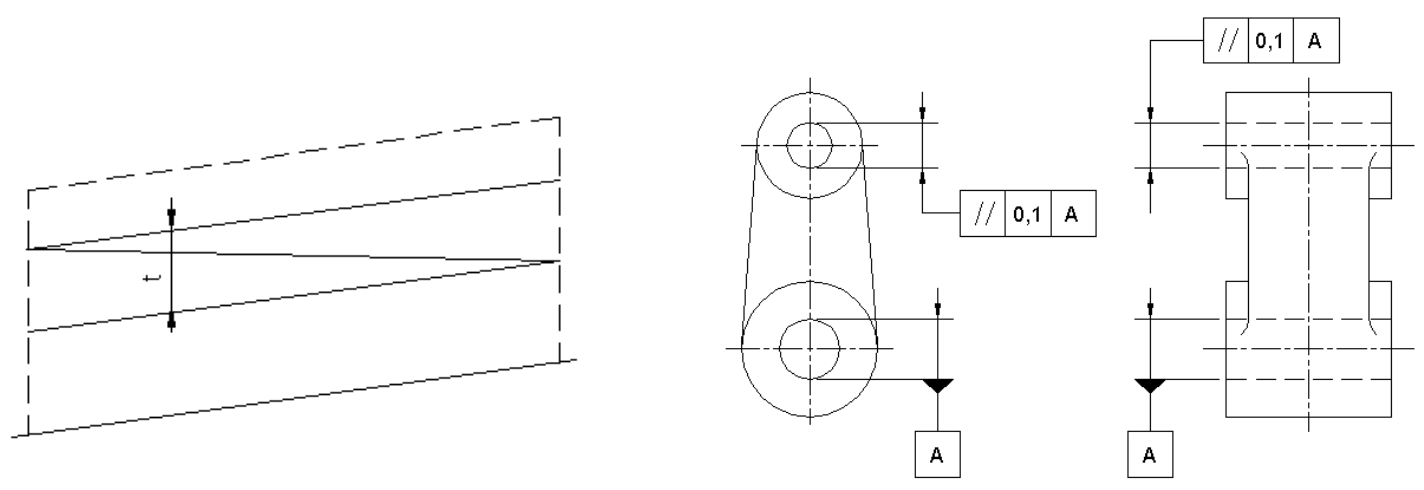

Figura 3.2 - Tolerância ou desvio de paralelismo de uma reta no plano vertical
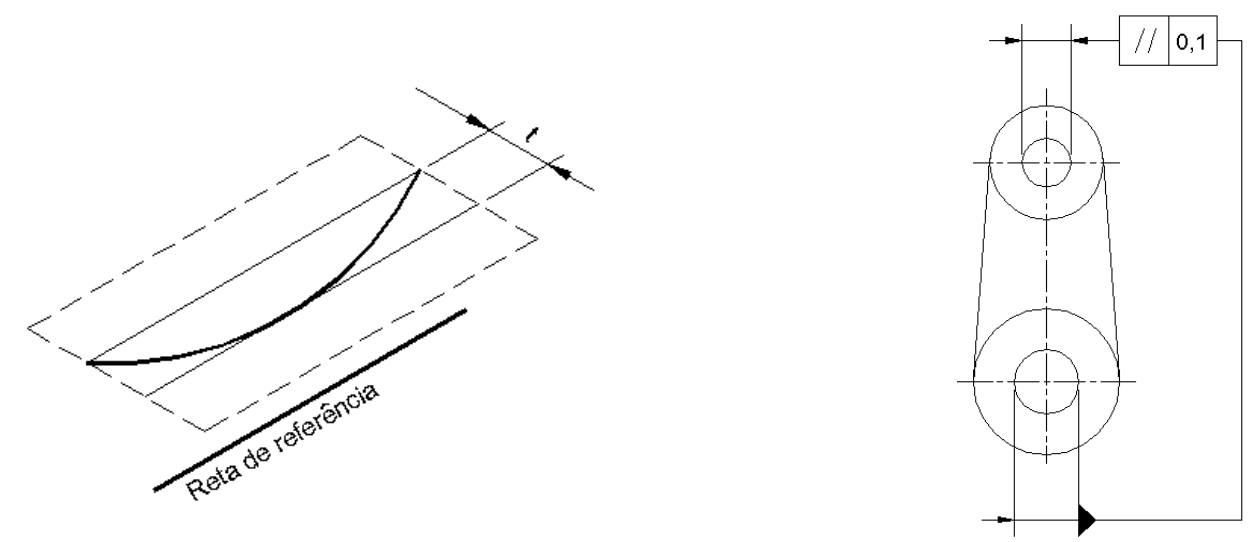

Figura 3.3 - Tolerância ou desvio de paralelismo de uma reta no plano horizontal
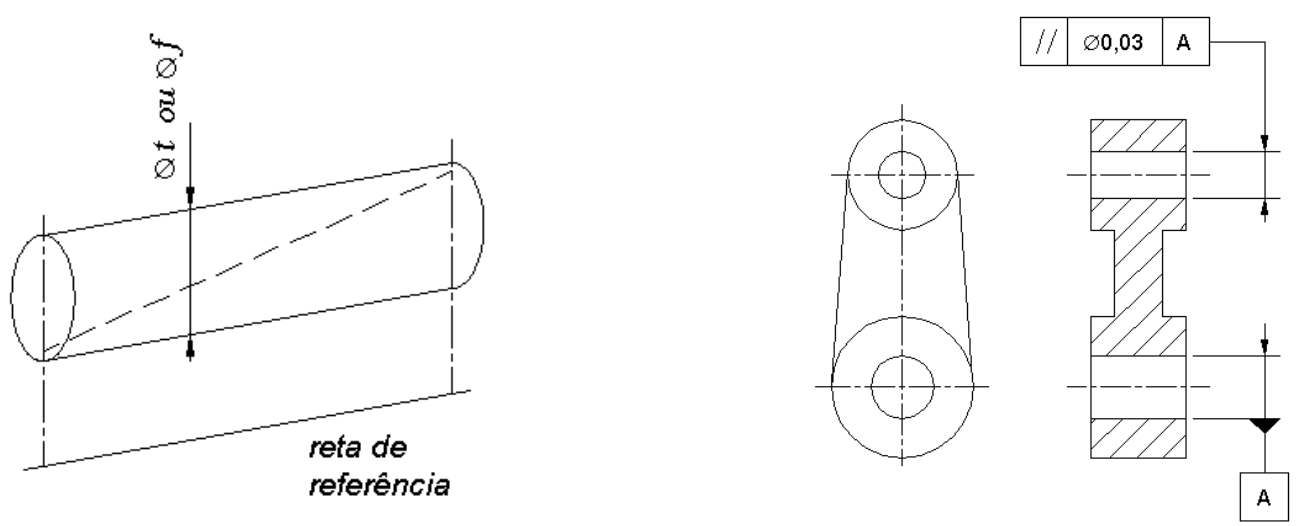

Figura 3.4 - Campo cilíndrico tolerância ou desvio de paralelismo 
Quando a tolerância é especificada em dois planos perpendiculares entre si, a zona de tolerância é um paralelepípedo retangular de seção ' $t_{1}$ $x t_{2}{ }^{\prime}$ paralelo à reta de referência (NBR 6409, 1980 e JIS B 0021, 1984). Este caso é mostrado na Figura 3.5.
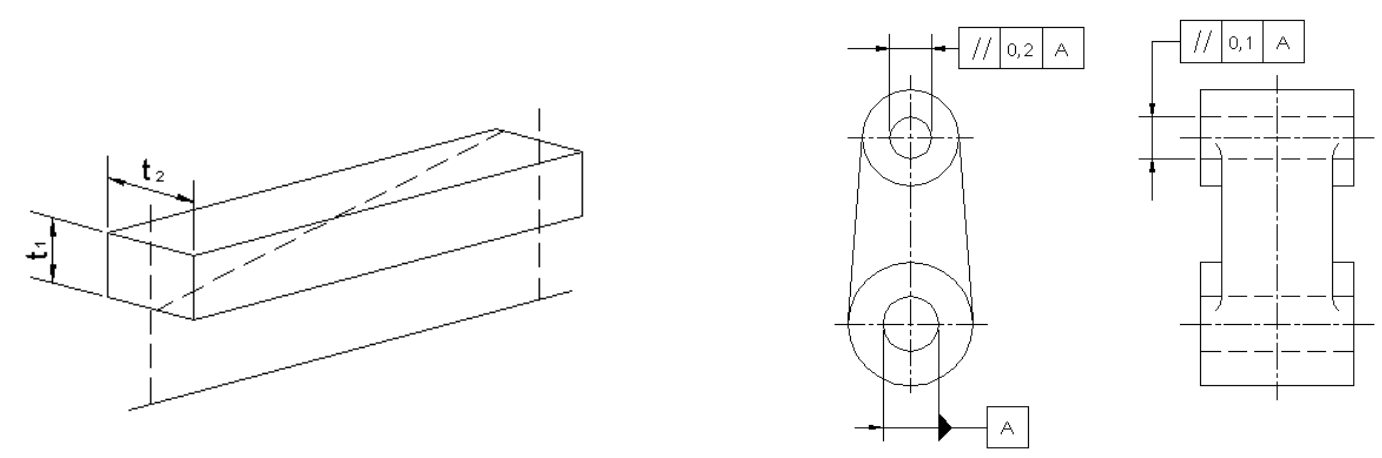

Figura 3.5 - Campo de tolerância ou desvio de paralelismo especificado em duas direções

Conforme dito anteriormente, a relação de paralelismo especificada também pode ser entre uma linha ou uma superfície com relação a um plano de referência. Segundo as normas NBR 6409 (1980), ASME Y14.5M (1994) e JIS B 0021 (1984), nestes dois casos citados, o campo de tolerância, ou de desvio, é limitado por dois planos paralelos distantes de ' $t$ ' e paralelos à reta ou plano de referência. A representação da tolerância ou desvio de paralelismo de uma reta em relação a um plano de referência é mostrada na Figura 3.6. Nesta figura são também apresentadas duas formas possíveis de indicação desta tolerância nos desenhos.
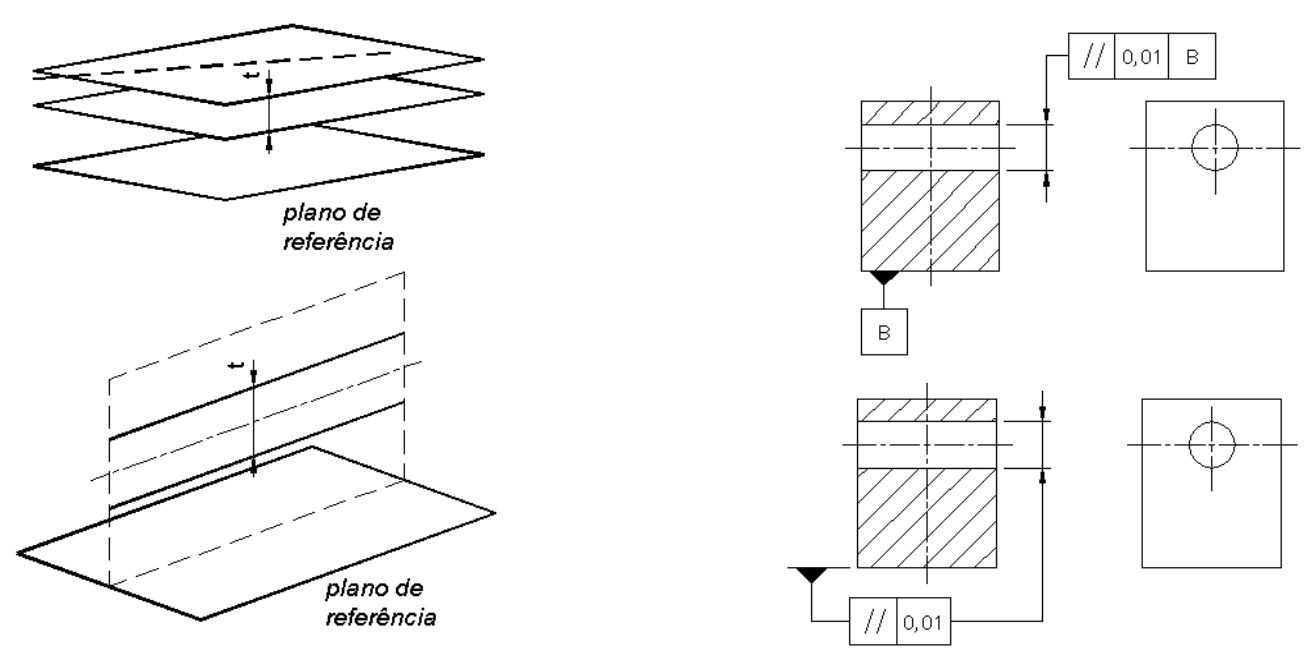

Figura 3.6 - Tolerância ou desvio de paralelismo em relação a um plano de referência 
Por fim, pode-se especificar valores de tolerância de paralelismo de uma superfície com relação a uma reta de referência. De forma similar ao caso anterior, o campo de tolerância, nesse caso, também é limitado por dois planos paralelos distantes de ' $t$ ' e paralelos à reta de referência, conforme estabelecem as três normas citadas acima.

As representações dos desvios de paralelismo são equivalentes às discutidas acima para as tolerâncias. No entanto, ressalta-se novamente que o desvio deve corresponder à distância mínima entre os elementos geométricos citados nas várias situações apresentadas acima. Por exemplo, a norma JIS B 0621 (1984), define o desvio de paralelismo de um plano em relação a uma reta de referência $\left(L_{D}\right)$ como sendo a mínima distância $(f)$ entre dois planos paralelos ideais que contém o perfil da superfície plana avaliada $(P)$.

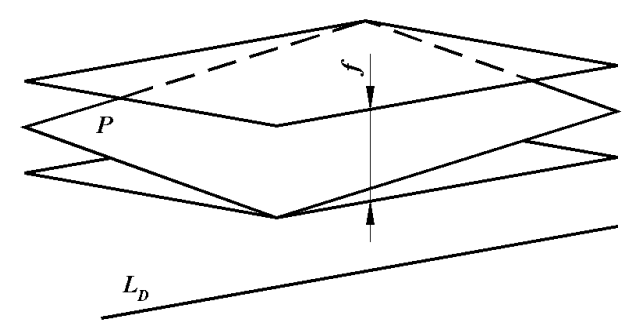

Figura 3.7 - Desvio de paralelismo de uma superfície em relação a uma reta de referência

\subsubsection{Tolerância e desvio de perpendicularismo}

A perpendicularidade é a condição em que uma superfície ou eixo forma um ângulo reto com o plano ou eixo de referência (ASME Y14.5M 1994). Da mesma forma que no caso da tolerância de paralelismo, podese especificar valores de tolerância de perpendicularismo para algumas combinações de elementos geométricos: uma linha ou uma superfície com relação a uma reta de referência e uma linha ou superfície com relação a um plano de referência.

Nestes casos citados, segundo a norma ASME Y14.5M, uma tolerância ou o desvio de perpendicularismo são representados por um dos campos listados abaixo:

(a) um campo de tolerância ou desvio definido por dois planos 
paralelos que devem conter a superfície sob consideração e que são perpendiculares a um plano ou reta de referência;

(b) um campo de tolerância ou desvio definido por dois planos paralelos e perpendiculares a uma reta de referência, dentre os quais a linha ou eixo considerados devem estar contidos;

(c) um campo de tolerância ou desvio definido por um cilindro perpendicular a um plano de referência e que deve conter o eixo sendo considerado;

(d) um campo de tolerância definido por duas retas paralelas e perpendiculares a um plano ou reta de referência. A linha sob consideração deve estar contida entre as duas retas.

Adicionalmente, quando a tolerância de perpendicularismo é especificada em duas direções perpendiculares entre si, o campo de tolerância é limitado por um paralelepípedo retangular de seção 't1xt2' perpendicular ao plano de referência (NBR6409, 1980 e JIS B0021, 1984).

Assim como no caso dos demais desvios geométricos discutidos, a norma JIS B 0621 (1984), utiliza o termo "distância mínima" ou "diâmetro mínimo" também nas definições do desvio de perpendicularismo. Por exemplo, esta norma define que o desvio pendicularismo de uma reta, quando nenhuma direção é especificada, deve corresponder ao valor do menor diâmetro $(f)$ de um cilindro normal ao plano de referência $\left(P_{D}\right)$ e que contém a reta avaliada $(L)$.

Figura 3.8 - Representação do desvio de perpendicularismo (norma JIS B 0621).

\subsubsection{Tolerâncias e Desvios}

Ainda que as normas técnicas mencionem mais freqüentemente 0 termo "tolerância" do que "desvio", observa-se que as definições dos campos geométricos que representam os desvios ou tolerâncias são idênticas, exceto por se incluir, implícita ou explicitamente, a condição de distância mínima na definição dos desvios. Na verdade, ambos os conceitos, de tolerância e desvio, estão diretamente inter-relacionados. O 
conceito de tolerância refere-se aos valores especificados em projeto para determinadas características das peças, sejam estas características dimensionais, de forma, posição ou orientação. As tolerâncias especificam valores-limite para os erros que os componentes podem apresentar. Já os desvios, ou erros, são os valores observados quando os componentes são medidos. Deve-se ressaltar, no entanto, que tanto as tolerâncias quanto os desvios são apenas valores numéricos. Quando características geométricas e não apenas dimensionais das peças estão sendo consideradas, é necessário entender as relações entre os entes geométricos envolvidos para a especificação adequada das tolerâncias e para a medição correta dos desvios. Assim, seja no caso das tolerâncias, seja no caso dos desvios, este é o aspecto mais importante estabelecido nas normas: a definição das relações geométricas entre os elementos dos componentes, e esta definição é válida tanto para o conceito de tolerância quanto para o conceito de desvio.

Por outro lado, nas normas, há uma completa ausência de informações quanto a procedimentos e métodos de medição, algoritmos ou instrumentos que podem ser utilizados para a avaliação dos desvios. Algumas destas informações são encontradas em outras fontes bibliográficas da área, como livros e artigos. Este é um campo de estudos aberto a novas propostas e aperfeiçoamento de métodos já existentes.

As normas citadas também não fazem referências, ou fazem apenas breves citações, quanto a valores recomendados para tolerâncias de forma, posição e orientação. A especificação desses valores não é tarefa trivial, e depende, entre outros fatores, do conhecimento dos processos de usinagem e da capabilidade das máquinas utilizadas. Além disso, para a especificação adequada dessas tolerâncias, deve-se considerar a aplicação definida para o componente sob análise, a funcionalidade que ele deve desempenhar, e o efeito dos desvios geométricos sobre seu desempenho e sobre o desempenho de outros componentes a ele relacionados. Este último fator, isto é, o efeito dos desvios em relação ao desempenho esperado, em geral, não é facilmente estimável. 


\subsection{Métodos de Separação de Erros baseados em Múltiplos Sensores}

A medição de desvios de forma e orientação pode ser realizada utilizando-se sistemas e métodos convencionais GD\&T, em que são utilizadas referências físicas, como o desempeno, e dispositivos de alinhamento. Neste caso, os valores dos desvios são lidos diretamente nos instrumentos, como por exemplo, os relógios comparadores ou apalpadores. Vários equipamentos ou sistemas de medição, entretanto, requerem, para a avaliação de desvios geométricos, a utilização de modelos matemáticos e algoritmos. Alguns sistemas necessitam, ainda, que modelos de separação de erros sejam aplicados aos dados medidos para que então seja possível realizar a avaliação dos desvios.

Conforme apresentado no capítulo 2, pode-se dividir os métodos de separação de erros em dois tipos, os métodos baseados em múltiplas orientações e aqueles que utilizam múltiplos sensores.

Os modelos multi-sensores baseiam-se no fato de que a leitura total apresentada por um sensor, conduzido por um carro porta-sensores ou outro dispositivo de movimentação, ao medir o desvio em um ponto sobre a superfície de uma peça, contém, além do erro da peça, erros de movimentação e posicionamento do sensor. Nos métodos de reversão, entre leituras distintas, há mudança no sinal de uma ou mais parcelas que compõem estas leituras, enquanto nos métodos de sensores múltiplos, há mudanças de fase destas parcelas de erro.

Sob a perspectiva matemática, para que estes erros sejam separados, é necessário que se utilize redundância de dados. De acordo com este princípio, comparam-se leituras diferentes realizadas num mesmo ponto, admitindo-se a hipótese fundamental que a parcela correspondente ao erro da peça apresenta o mesmo valor em todas as leituras realizadas no ponto determinado. Assim, as diferenças observadas nas leituras, nesse caso, devem-se à variabilidade dos erros de movimentação e posicionamento dos sensores. 
Nos modelos, admite-se o princípio da superposição, segundo o qual a leitura observada é a combinação linear das parcelas que representam o desvio da peça e os desvios de movimentação e posicionamento dos sensores. Além disso, assume-se que estas parcelas sejam independentes, isto é, não apresentem correlação.

Resumindo, os princípios básicos que estruturam os modelos são o da unicidade do valor do desvio do componente em cada ponto, o da combinação linear de diferentes desvios na composição da leitura total e o da independência entre esses desvios. A seguir são apresentados os principais métodos de separação de erros em que são utilizados múltiplos sensores.

\subsubsection{Método dos Dois Pontos Sucessivos (Two Successive Points)}

Neste método, obtêm-se dados redundantes por meio da utilização de dois sensores de deslocamento que percorrem a superfície de uma peça. Os sensores são fixados sobre o carro porta-ferramentas de uma máquina, e este carro é deslocado na direção perpendicular à direção de medição, com um passo correspondente à distância entre os sensores. Os desvios de retilineidade da peça e do movimento do dispositivo portasensores são obtidos por meio das diferenças entre as leituras dos sensores em cada ponto. Este método foi inicialmente aplicado por Tanaka et al (1981) para a obtenção dos desvios de retilineidade do carro portaferramentas de uma fresadora e mandriladora horizontal de grandes dimensões.

O esquema apresentado na Figura 3.9 demonstra o princípio do Método dos Dois Pontos Sucessivos.

A modelagem matemática proposta pelos autores é apresentada nas equações de 3.1 a 3.5. Neste equacionamento, os pontos do perfil de retilineidade da movimentação do porta-ferramentas são denotados por $U_{i}$, os pontos do perfil da peça são denotados por $V_{i}$, e as leituras são representadas por $D_{i}$. $O$ índice $i$ indica a posição dos pontos medidos. 


$$
\begin{gathered}
D_{0, B}-D_{0, A}=V_{1} \\
D_{1, A}-D_{0, A}=V_{1}-U_{1} \\
D_{1, B}-D_{0, B}=\left(V_{2}-V_{1}\right)-U_{1} \\
D_{2, A}-D_{0, A}=V_{2}-U_{2} \\
D_{2, B}-D_{0, B}=\left(V_{3}-V_{1}\right)-U_{2}
\end{gathered}
$$

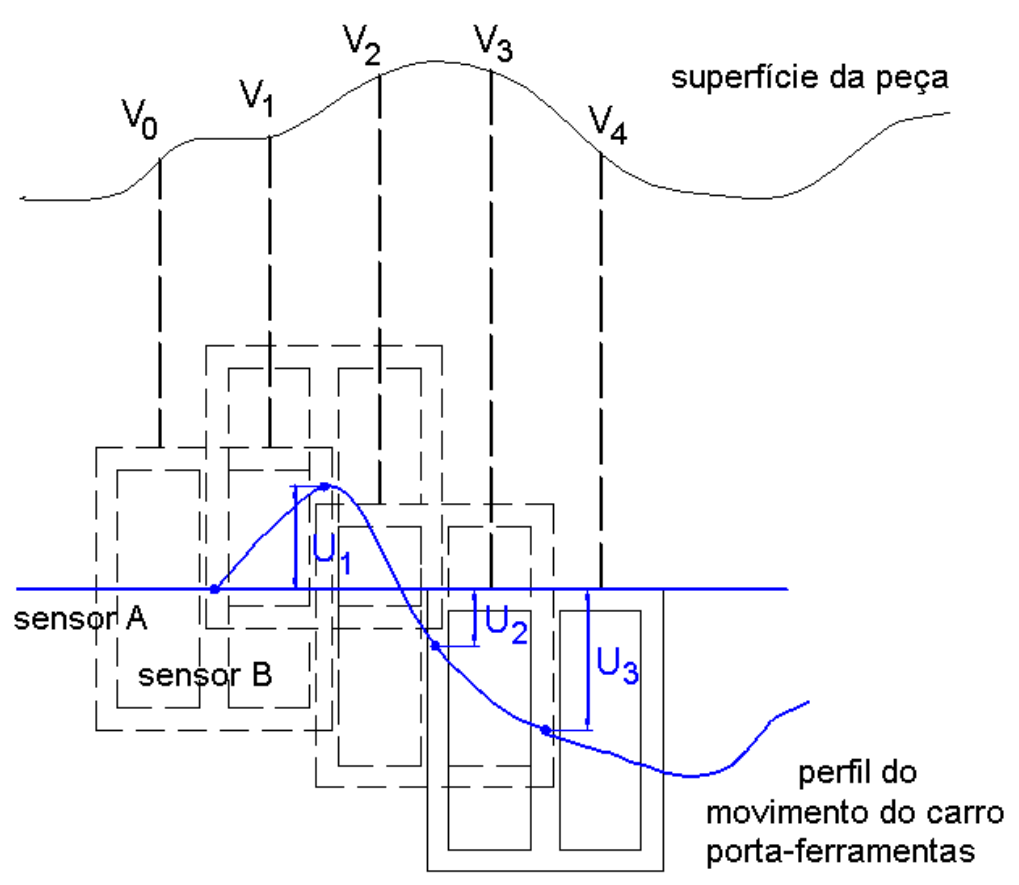

Figura 3.9 - Princípio do Método dos Dois Pontos Sucessivos

As leituras de cada sensor $D_{i}$ correspondem ao deslocamento relativo, na direção de medição, entre o carro porta-ferramentas e a peça. Assim, por exemplo, a leitura $D_{1, B}$ possui uma componente $V_{2}$ relativa ao erro de retilineidade da peça e uma componente $U_{1}$ devido ao erro de retilineidade no movimento do carro porta-ferramentas. De forma semelhante, a leitura $D_{0, B}$ é composta pelas componentes $V_{1}$ e $U_{0}$. Como um pressuposto do modelo, assume-se que o erro de posicionamento inicial do carro, representado por $U_{0}$, e o erro de retilineidade da peça no ponto inicial, isto é, $V_{0}$, tomados como referência, são nulos. Assim, a diferença entre as leituras $D_{1, B}$ e $D_{0, B}$ resulta na equação 3.3. Como se pode observar, cada equação do sistema é obtida por meio da diferença 
entre a leitura de um sensor no i-ésimo ponto e a leitura deste mesmo sensor no ponto inicial, isto é, no ponto zero. Portanto, para cada sensor, tais diferenças podem ser escritas genericamente nas formas apresentadas nas equações 3.6 e 3.7 .

$$
\begin{gathered}
D_{(i-1), B}-D_{0, B}=\left(V_{i}-V_{1}\right)-U_{i-1} \\
D_{i, A}-D_{0, A}=V_{i}-U_{i}
\end{gathered}
$$

Resolvendo-se o sistema de equações 3.6 e 3.7 para $U_{i}$, e utilizandose a equação 3.1 , que fornece o valor de $V_{1}$, obtém-se a equação 3.8 , que estabelece o valor dos desvios de retilineidade do movimento do carro porta-ferramentas em função das leituras dos sensores. Uma vez que estes desvios são calculados, é possível obter o perfil real da peça, ou seja, o valor do desvio de retilineidade da peça em cada ponto, conforme mostra a equação 3.9 .

$$
\begin{gathered}
U_{i}=U_{i-1}+D_{(i-1), B}-D_{i, A} \\
V_{i}=U_{i}+D_{i, A}-D_{0, A}
\end{gathered}
$$

Dentre os métodos que utilizam múltiplos sensores, o Método dos Dois Pontos, é o mais simples, sendo capaz de eliminar a influência dos erros de posicionamento dos sensores. Contudo, as leituras obtidas sofrem a influência do erro de inclinação ou rotação do dispositivo portasensores em torno do eixo perpendicular a um plano que contém os deslocamentos medidos e o eixo ao longo do qual o carro se movimenta. Tal influência não é considerada neste modelo. A influência deste erro nas leituras obtidas deve ser avaliada por meio de testes adicionais que objetivam verificar quais são as inclinações máximas que os sensores experimentam durante o processo de medição. Os ângulos obtidos devem ser multiplicados pela distância entre os sensores, para uma estimativa do deslocamento máximo que seria obtido em função da inclinação. O acréscimo de um terceiro sensor no sistema de medição permite que a influência do erro de inclinação do dispositivo porta-sensores seja considerada. Tal procedimento dá origem ao Método dos Três Pontos, apresentado a seguir. 


\subsubsection{Método dos Três Pontos}

Este método, como o próprio nome estabelece, utiliza 3 sensores de deslocamento alinhados que se movimentam ao longo de uma direção de medição perpendicular aos desvios medidos na superfície do componente. As amostras são coletadas em intervalos regulares. Se o passo de medição corresponde à distância entre os sensores, o método é denominado Método dos Três Pontos Seqüencial. Uma variação deste modelo é o Método dos Três Pontos Generalizado, em que o passo de medição é menor do que a distância entre os sensores.

O equacionamento apresentado para este método no trabalho de Gao et al (2002a) considera que as leituras dos sensores são compostas por: uma parcela de deslocamento relativa ao perfil da peça; por uma parcela que representa o erro translacional do carro porta-sensores, na direção dos deslocamentos medidos; e, finalmente, por uma parcela de erro que se deve à inclinação yaw do porta-sensores. Assume-se, neste caso, que esta inclinação seja gerada por uma rotação que ocorre em torno do ponto central do dispositivo porta-sensores. Dessa forma, tal rotação se reflete em um deslocamento relativo entre os sensores das extermidades e a peça, na direção dos desvios medidos, o qual pode ser calculado pela multiplicação do valor do ângulo de rotação pela distância entre sensores.

O modelo apresentado por Gao et al (2002a) foi aplicado ao cálculo do desvio de retilineidade da geratriz de um cilindro. Representando cada ponto do perfil da geratriz em $\theta=0^{\circ}$ como uma função $f\left(x_{i}, 0^{\circ}\right)$ da posição de medição $x_{i}$, e definindo as saídas ou leituras de cada sensor como sendo $m_{1}\left(x_{i}\right), m_{2}\left(x_{i}\right)$ e $m_{3}\left(x_{i}\right)$, os autores citados estabelecem as equações $3.10,3.11$ e 3.12 .

$$
\begin{gathered}
m_{1}\left(x_{i}\right)=f\left(x_{i}-L, 0^{\circ}\right)+e_{Z}\left(x_{i}\right)-L . e_{y a w}\left(x_{i}\right) \\
m_{2}\left(x_{i}\right)=f\left(x_{i}, 0^{\circ}\right)+e_{Z}\left(x_{i}\right)
\end{gathered}
$$




$$
m_{3}\left(x_{i}\right)=f\left(x_{i}+L, 0^{\circ}\right)+e_{Z}\left(x_{i}\right)+\text { L.e yaw }\left(x_{i}\right),
$$

onde $L$ é a distância entre os sensores, $N$ é o número de medições em todo o comprimento, $e_{Z}\left(x_{i}\right)$ é o erro de retilineidade, na direção $Z$, do movimento do dispositivo porta-sensores e $e_{\text {yaw }}\left(x_{i}\right)$ é o erro de rotação (yaw) do carro porta sensores na posição $x_{i}$, ou seja, é o erro de rotação do carro em torno do eixo $y$.

Um esquema do sistema proposto pelos autores é mostrado na Figura 3.10.

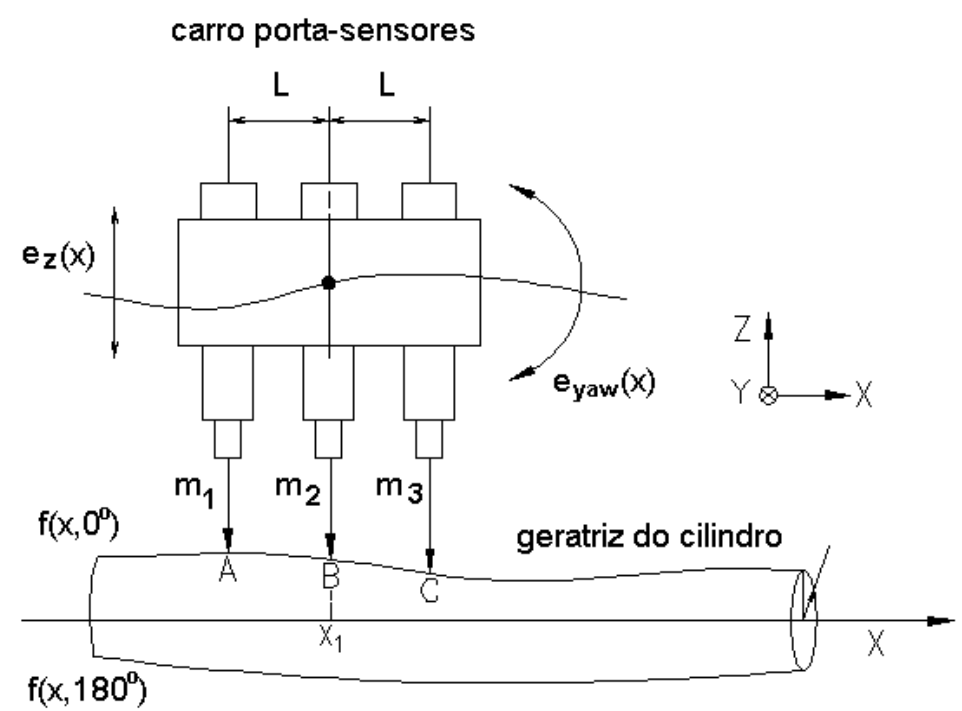

Figura 3.10 - Representação do Método dos Três Pontos

\subsubsection{Solução do Método dos Três Pontos: o método diferencial (Gao et al, 2002a)}

Para a solução do modelo apresentado, Gao et al. (2002a) propõem o cálculo de um diferencial que consiste numa combinação linear das leituras dos sensores. Esta combinação é feita de forma que as componentes de erro de movimentação se cancelem. Tal diferencial é apresentado na equação 3.13 .

$$
\begin{aligned}
& m_{s}\left(x_{i}\right)=\frac{m_{3}\left(x_{i}\right)-2 m_{2}\left(x_{i}\right)+m_{1}\left(x_{i}\right)}{L^{2}}=\frac{\left(m_{3}\left(x_{i}\right)-m_{2}\left(x_{i}\right)\right)-\left(m_{2}\left(x_{i}\right)-m_{1}\left(x_{i}\right)\right)}{L^{2}}= \\
& =\left[\frac{\left(f\left(x_{i}+L, 0^{\circ}\right)-f\left(x_{i}, 0^{\circ}\right)\right)-\left(f\left(x_{i}, 0^{\circ}\right)-f\left(x_{i}-L, 0^{\circ}\right)\right)}{L}\right] \cdot \frac{1}{L} \approx f^{\prime \prime}\left(x_{i}, 0^{\circ}\right), \quad(i=1, \ldots, N)
\end{aligned}
$$


O diferencial apresentado na equação 3.13 pode ser considerado como uma aproximação para a derivada segunda da função do perfil de retilineidade $f\left(x_{i}\right)$, calculada discretamente, por diferenças finitas, sem a aplicação matemática do limite. Dessa forma, uma aproximação desse perfil, representado por $z\left(x_{i}\right)$, pode ser obtida por meio da dupla integração discreta de $m_{s}\left(x_{i}\right)$ :

$$
z\left(x_{i}\right)=\sum_{k=1}^{i}\left(\sum_{j=1}^{k}\left(m_{s}\left(x_{j}\right) s\right) s\right), \text { sendo que } z\left(x_{1}\right)=0,
$$

onde $s$ denota o passo de medição.

Neste método, não é necessário que o passo de medição seja igual à distância entre os sensores. Em outras palavras, esta modelagem pode ser aplicada ao método dos Três Pontos Generalizado, assim como ao método dos Três Pontos Seqüencial, substituindo a o parâmetro $s$ por $L$ na equação 3.14 .

Deve-se ressaltar que há uma diferença entre $z\left(x_{i}\right)$ e $f\left(x_{i}, 0\right)$, denominada por Gao et al. (2002a) de erro de processamento de dados. Esta diferença é causada principalmente pela realização de operações discretas de integração e pela aproximação das derivadas por diferenciais finitos para se obter a solução do método. O fato de a distância entre os sensores ser significativa, faz com que as diferenças apresentadas na equação 3.13 não sejam boas aproximações para as derivadas de primeira e segunda ordem da função do perfil. Em outras palavras, as inclinações das retas secantes podem não ser boas aproximações para a tangente $f^{\prime \prime}\left(x_{i}\right)$. Gao e Kyono (1997) apresentam uma técnica de filtragem digital para a avaliação deste erro de processamento de dados.

Gao et al (2002b) também aplicam o Método dos Três Pontos e esta solução integral para o cálculo do desvio de planicidade de placas de silício para utilizadas na confecção de placas de circuito integrado. Neste caso, os autores utilizam sensores angulares baseado no princípio da autocolimação. A modelagem matemática, entretanto, é muito similar à apresentada. 


\subsubsection{Método dos Três Pontos Combinado}

Conforme definido por Gao e Kyono (1997), este método combina a aplicação do Método dos Três Pontos Seqüenciais e a aplicação do Método dos Três Pontos Generalizado.

Conforme mencionado na seção anterior, os autores citados constataram que o perfil de retilineidade obtido pela integração do diferencial $m_{s}\left(x_{j}\right)$ apresenta um erro com relação ao perfil real $f\left(x_{i}\right)$. Após a aplicação de técnicas de filtragem digital, os autores puderam observar que o erro de processamento de dados é uma função da distância $L$ entre os sensores e do passo de medição ou intervalo de amostragem $s$. Adicionalmente, tal erro está relacionado ao comprimento de onda dos erros presentes no perfil, de modo que o erro de processamento de dados é muito pequeno para superfícies com erros com comprimento de onda grande. Ao contrário, este erro passa a ser significativo para superfícies com erros com comprimento de onda pequeno, isto é, abaixo de $10 \mathrm{~mm}$, segundo afirmam os autores citados. Mais importante que isso, ainda, é o fato de que o erro de processamento de dados é geralmente nulo quando o passo de medição é equivalente à distância entre os sensores (GAO; KYONO, 1997).

Por outro lado, apesar de as alturas do perfil de retilineidade medidas por meio do Método dos Três Pontos Seqüenciais apresentarem baixos erros de processamento, o número de pontos coletados, em alguns casos, pode não ser suficiente para avaliar o perfil do componente com acuracidade, principalmente se o componente possui erros de alta freqüência. O nível de acuracidade da avaliação depende, dentre outros fatores, das dimensões do componente e dos comprimentos de onda dos erros predominantes. Diante desses fatos, os autores propõem a combinação dos métodos citados. As principais etapas do método combinado são resumidas nos tópicos seguintes.

a) Coleta de pontos do perfil utilizando o Método dos Três Pontos Seqüenciais 
Para que a quantidade de dados obtidos aumente, devem ser coletados vários conjuntos discretos de pontos do perfil, defasados entre si de um passo de medição $s$, sendo que esse passo deve ser menor do que a distância entre os sensores. Assim, serão obtidos $M$ conjuntos de pontos, onde $M$ é o resultado inteiro da divisão do valor da distância entre os sensores, $L$, pelo micro-passo de medição, denotado por $s$. Sendo N o número total de pontos coletados, então cada conjunto conterá N/M pontos.

b) Avaliação do perfil $z_{n}\left(x_{n}\right)$ utilizando o Método dos Três Pontos Generalizado

Tal perfil é obtido com base em todos os pontos coletados, aplicando as equações 3.13 e 3.14. Conforme já discutido, as partes do perfil $z_{n}$ nas quais erros de alta freqüência não são predominantes podem ser obtidas com acuracidade utilizando-se o Método Generalizado.

c) Avaliação do perfil $p_{i j}$ utilizando o Método dos Três Pontos Seqüenciais

Inicialmente, define-se um índice $i$ que representa cada conjunto de dados. Assim, i varia de acordo com a equação (3.15).

$$
i=0,1,2, \ldots M-1
$$

Para cada $i$, um perfil discreto $p_{i j}$ pode ser obtido aplicando-se 0 método dos pontos seqüenciais a cada conjunto de dados coletado. 0 equacionamento desta etapa é semelhante ao apresentado no item 3.2.2. Segundo os autores, as alturas relativas entre os dados de cada conjunto podem ser determinadas exatamente. Contudo, como a inclinação e a altura do ponto inicial de cada conjunto são indeterminadas, as alturas dos primeiros e segundos pontos de cada conjunto são definidas como nulas.

d) Avaliação do perfil $f_{\mathrm{ij}}$ utilizando o Método Combinado

Nesta etapa, aplica-se o Método Combinado propriamente dito. O princípio deste método consiste em utilizar aqueles pontos do perfil $z_{i j}$ que representam o perfil do componente com alta acuracidade como pontos de referência para estabelecer uma "área-padrão". Esta área, por sua vez, é 
utilizada para determinar a relação entre os grupos de dados obtidos por meio do Método dos Três Pontos Seqüenciais (GAO; KYONO, 1997).

Os autores citados definem uma função $f_{i j}$ que expressa o perfil da peça utilizando como base os dados oriundos do Método dos Três Pontos Sequenciais. Esta função possui três graus de liberdade, $c_{i 0}, c_{i 1}$ e $c_{i 2}$, que são determinados com a aplicação do Método dos Mínimos Quadrados, MMQ. Em outras palavras, os coeficientes $c_{i}$ são determinados de forma que a diferença entre os pontos do perfil obtidos com a aplicação do método generalizado e os pontos obtidos com a aplicação do método seqüencial seja minimizada. A equação 3.16 apresenta a função $f$, que representa o perfil da peça, e a equação 3.17 apresenta a aplicação do Método dos Mínimos Quadrados.

$$
\begin{gathered}
E_{i}=\sum_{j}\left(z_{i j}-f_{i j}\right)^{2}, \\
\frac{\partial E_{i}}{\partial c_{i 0}}=0, \frac{\partial E_{i}}{\partial c_{i 0}}=0, \frac{\partial E_{i}}{\partial c_{i 0}}=0
\end{gathered}
$$

A acuracidade do Método Combinado está relacionada à escolha dos pontos de referência para a "área padrão". Esta escolha é feita por meio de um processo iterativo. Inicialmente, todos os pontos do perfil são selecionados como pontos de referência para a área-padrão. $\mathrm{Na}$ seqüência, os coeficientes $c_{i}$ são calculados por MMQ e utilizados para corrigir os valores de $f_{i j}$. $O$ valor máximo $e_{i T}$ das diferenças entre $z_{i j}$ e $f_{i j}$ deve ser comparado com um valor limite. Caso essa diferença seja maior que o nível definido, o ponto $x_{i T}$ é removido do conjunto de pontos que forma a área padrão.

Por meio de simulações e experimentos, Gao e Kyono (1997) verificaram que o Método Combinado possibilita a avaliação de perfis com erros de freqüência mais baixa e também erros de alta freqüência. Contudo, o método dos Três Pontos, Seqüencial ou Generalizado, está está sujeito a uma influência deletéria do erro de desalinhamento inicial dos sensores, a qual será discutida no próximo item. 


\subsubsection{Método dos Três Pontos e a influência do erro de desalinhamento dos sensores}

Gao et al. (2002a) destacam a presença de um fator muito significativo a ser considerado no Método dos Três Pontos: o erro de posicionamento relativo da referência, isto é, do ponto zero de cada um dos sensores. A maioria dos transdutores executa medições relativas, de deslocamento com relação a alguma referência, não sendo possível determinar um valor zero absoluto. Dessa forma, as equações de 3.10 a 3.12 devem ser reescritas adicionando-se as componentes de erro relativas à ajustagem do ponto de referência dos sensores, representadas por $e_{m 1}, e_{m 2}$ e $e_{m 3}$.

Nesse caso, o diferencial é definido segundo a equação 3.18 .

$$
\begin{aligned}
& m_{s}=\left[\frac{f\left(x_{i}+L, 0^{\circ}\right)+e_{z}\left(x_{i}\right)+L \cdot e_{\text {yaw }}\left(x_{i}\right)+e_{m 3}-2 f\left(x_{i}, 0^{\circ}\right)-2 e_{z}\left(x_{i}\right)-2 e_{m 2}+f\left(x_{i}-L, 0^{\circ}\right)+e_{z}\left(x_{i}\right)-L \cdot e_{\text {yav }}\left(x_{i}\right)-e_{m 1}}{L}\right] \cdot \frac{1}{L} \\
& \approx f^{\prime \prime}\left(x_{i}, 0^{\circ}\right)+\frac{\alpha}{L^{2}}, \quad(i=1, \ldots, N)
\end{aligned}
$$

onde $\alpha=e_{m 3}-2 e_{m 2}+e_{m 1}=\left(e_{m 3}-e_{m 2}\right)-\left(e_{m 2}-e_{m 1}\right)$

Os autores citados demonstram que, após o equacionamento do diferencial e a integração dupla, os erros de posicionamento dos sensores resultam numa componente de erro parabólica com relação ao comprimento de medição, conforme apresentado na equação 3.19. O fato de essa relação ser quadrática implica o aparecimento de erros acentuados de avaliação do perfil, especialmente quando os componentes são longos.

$$
z\left(x_{i}\right)=\sum_{k=1}^{i}\left(\sum_{j=1}^{k}\left(m_{s}\left(x_{j}\right) s\right) s\right)+\frac{\alpha}{2 L^{2}} x_{i}^{2}=f\left(x_{i}, 0\right)+\frac{\alpha}{2 L^{2}} x_{i}^{2}, \quad(i=2, \ldots, N)
$$

Assim, a solução apresentada não consegue determinar e isolar a influência do erro devido ao desalinhamento dos sensores sobre o perfil final calculado. Magalhães (2006) demonstra que esta influência é significativa, isto é, deteriora muito os resultados finais obtidos, inviabilizando a utilização do método de solução proposto. 
Gao et al. (2002a) afirmam que, para que se obtenha uma acuracidade de $0.18 \mu \mathrm{m}$ no ajuste da referência dos sensores, seria necessária a utilização de um plano de referência com planicidade de 10 $\mathrm{nm}$ por um comprimento de $100 \mathrm{~mm}$, o que tornaria esta técnica impraticável.

Em resposta a esta questão, os autores citados propõem que primeiramente se adicione outra unidade de 3 sensores ao sistema, montada sobre o mesmo carro, de forma que a retilineidade de duas geratrizes seja medida simultaneamente, obtendo-se $f\left(x_{i}, 0^{\circ}\right)$ e $f\left(x_{i}, 180^{\circ}\right)$. Assim, equações similares às equações de 3.10 a 3.12 seriam geradas considerando-se a função $f\left(x_{i}, 180^{\circ}\right)$, conforme exposto nas equações 3.20 a 3.21. Novamente são inseridas 3 componentes de erro devido ao ajuste da referência dos sensores, $e_{n 1}, e_{n 2}$ e $e_{n 3}$, distintas das componentes relacionadas a $f\left(x_{i}, 0^{\circ}\right)$.

$$
\begin{gathered}
n_{1}\left(x_{i}\right)=f\left(x_{i}-L, 180^{\circ}\right)+e_{Z}\left(x_{i}\right)-L \cdot e_{\text {yaw }}\left(x_{i}\right)+e_{n 1} \\
n_{2}\left(x_{i}\right)=f\left(x_{i}, 180^{\circ}\right)+e_{Z}\left(x_{i}\right)+e_{n 2} \\
n_{3}\left(x_{i}\right)=f\left(x_{i}+L, 180^{\circ}\right)+e_{Z}\left(x_{i}\right)+L \cdot e_{\text {yaw }}\left(x_{i}\right)+e_{n 3}
\end{gathered}
$$

Deve-se notar, porém, que estando ambas as unidades de sensores sobre o mesmo carro, devem ambas estar submetidas ao mesmo erro de translação do carro na direção $Z$ e também ao mesmo erro angular $e_{\text {yaw }}\left(x_{i}\right)$.

Após este primeiro conjunto de $\mathrm{N}$ medições, Gao et al. (2002a) sugerem a execução de um tipo de reversão, em que o cilindro medido deve ser rotacionado de $180^{\circ}$ ao redor de seu eixo preferencial, e mais um conjunto de medições deve ser realizado. Dessa forma, para este novo conjunto de equações, os erros devidos à movimentação do carro são os mesmos para as 6 novas equações, mas distintos dos erros de movimentação das 6 equações do primeiro conjunto. Os erros de ajustagem da referência de cada sensor, por outro lado, se mantêm no primeiro e segundo conjunto de medições, já que alinhamento inicial entre 
84

os sensores não foi alterado. As equações do sistema após a reversão são apresentadas nas equações de 3.23 a 3.28 .

$$
\begin{aligned}
& m_{1 r}\left(x_{i}\right)= f\left(x_{i}-L, 180^{\circ}\right)+e_{z r}\left(x_{i}\right)-L \cdot e_{r_{\text {yaw }}}\left(x_{i}\right)+e_{m 1} \\
& m_{2 r}\left(x_{i}\right)=f\left(x_{i}, 180^{\circ}\right)+e_{z r}\left(x_{i}\right)+e_{m 2} \\
& m_{3 r}\left(x_{i}\right)= f\left(x_{i}+L, 180^{\circ}\right)+e_{z r}\left(x_{i}\right)+L \cdot e_{\text {ryaw }}\left(x_{i}\right)+e_{m 3} \\
& n_{1 r}\left(x_{i}\right)= f\left(x_{i}-L, 0^{\circ}\right)+e_{z r}\left(x_{i}\right)-L \cdot e_{r y a w}\left(x_{i}\right)+e_{n 1} \\
& n_{2 r}\left(x_{i}\right)=f\left(x_{i}, 0^{\circ}\right)+e_{z r}\left(x_{i}\right)+e_{n 2} \\
& n_{3 r}\left(x_{i}\right)= f\left(x_{i}+L, 0^{\circ}\right)+e_{z r}\left(x_{i}\right)+L \cdot e_{r_{\text {yaw }}}\left(x_{i}\right)+e_{n 3}
\end{aligned}
$$

Utilizando o sistema de 12 equações apresentado, é possível obter os valores do erro de ajustagem da referência dos sensores. Para tanto, deve-se calcular os diferenciais das equações 3.20 a 3.28, obtendo-se uma expressão similar à apresentada na equação 3.18. Além disso, define-se uma variável $\beta$ similar a $\alpha$, segundo a equação 3.29. Assim, obtém-se o sistema de equações envolvendo $\alpha$ e $\beta$, conforme mostrado nas equações 3.30 a 3.33 .

$$
\begin{aligned}
& \beta= e_{n 3}-2 e_{n 2}+e_{n 1}=\left(e_{n 3}-e_{n 2}\right)-\left(e_{n 2}-e_{n 1}\right) \\
& m_{s}\left(x_{i}\right) \approx f^{\prime \prime}\left(x_{i}, 0^{\circ}\right)+\frac{\alpha}{L^{2}}, \quad(i=1, \ldots, N) \\
& n_{s}\left(x_{i}\right) \approx f^{\prime \prime}\left(x_{i}, 180^{\circ}\right)+\frac{\beta}{L^{2}}, \quad(i=1, \ldots, N) \\
& m_{s r}\left(x_{i}\right) \approx f^{\prime \prime}\left(x_{i}, 180^{\circ}\right)+\frac{\alpha}{L^{2}}, \quad(i=1, \ldots, N) \\
& n_{s r}\left(x_{i}\right) \approx f^{\prime \prime}\left(x_{i}, 0^{\circ}\right)+\frac{\beta}{L^{2}}, \quad(i=1, \ldots, N)
\end{aligned}
$$

Subtraindo-se a eq. 3.30 da eq. 3.33 e subtraindo-se a equação 3.32 da equação 3.31 , obtém-se:

$$
\begin{aligned}
& \frac{\beta-\alpha}{L^{2}}=n_{s r}\left(x_{i}\right)-m_{s}\left(x_{i}\right) \\
& \frac{\beta-\alpha}{L^{2}}=n_{s}\left(x_{i}\right)-m_{s r}\left(x_{i}\right)
\end{aligned}
$$


Considerando-se as equações apresentadas, observa-se que a diferença $\beta$ - $\alpha$ pode ser calculada em função dos diferenciais em um dado ponto $x_{i}$. Alternativamente, para o cálculo dessa diferença, pode-se realizar uma média dos diferenciais calculados para todos os pontos coletados. Esta operação, segundo Gao et al (2002a), diminui significativamente a influência de erros aleatórios nas leituras das sondas, reduzindo também a influência dos erros de posicionamento das amostras coletadas, ao longo da direção de translação dos porta-sensores. Assim, considerando-se todas as medições realizadas nas duas etapas, antes e após a reversão, manipulando-se as equações do modelo, obtém-se a expressão para a diferença $\beta$ - $\alpha$ mostrada na equação 3.36 .

$$
\beta-\alpha=\frac{\left.\sum_{i=1}^{N}\left\{n_{3}\left(x_{i}\right)-2 n_{2}\left(x_{i}\right)+n_{1}\left(x_{i}\right)+2 m_{2}\left(x_{i}\right)+m_{1}\left(x_{i}\right)\right]-\left[m_{3 r}\left(x_{i}\right)-2 m_{2 r}\left(x_{i}\right)+n_{1 r}\left(x_{i}\right)+m_{1 r}\left(x_{i}\right)\right]\right\}}{2 N}
$$

Realizando-se outras manipulações algébricas no mesmo conjunto de equações apresentado, obtém-se também uma expressão para a soma $\alpha+\beta$. Conseqüentemente, a solução desse sistema de duas equações em função das variáveis $\alpha$ e $\beta$, permite determinar o valor do erro parabólico mostrado na equação 3.10. Os valores $\alpha$ e $\beta$ do desalinhamento inicial dos sensores podem ser descontados dos valores dos diferenciais apresentados nas equações 3.30 a 3.33 e o perfil de retilineidade pode ser avaliado com acuracidade.

Uma desvantagem deste método é a utilização de um conjunto adicional de 3 sensores. Além disso, a rotação do cilindro para a aquisição de mais uma série de dados do perfil caracteriza um procedimento de reversão. Assim, o modelo apresentado pelos autores pode ser classificado como um método de separação de erros misto, em que se utilizam múltiplos sensores e múltiplas orientações. Dessa forma, em tese, este método também apresentaria as desvantagens de um método de reversão apontadas pelos próprios autores.

Algumas melhorias podem ser introduzidas no método apresentado para o cálculo da componente de erro devido à diferença de ajuste da 
referência dos sensores. Diferentemente da forma de amostragem do método proposto, em que o cilindro permanece fixo durante cada passo de medição, no método modificado, o cilindro é rotacionado num dispositivo entre-pontos. A cada posição $x_{i}$ ao longo do eixo $x_{\text {, são }}$ coletados pontos de várias geratrizes do cilindro à medida que este executa uma revolução. Assumindo que as posições de medição ao longo da circunferência sejam $\theta_{j}(\mathrm{j}=1,2, \ldots, \mathrm{K})$, as leituras do sensor 1 de cada conjunto de sensores são dadas por:

$$
\begin{gathered}
m_{1}\left(x_{i}, \theta_{j}\right)=f\left(x_{i}-L, \theta_{j}\right)+e_{z}\left(x_{i}, \theta_{j}\right)-L \cdot e_{\text {yaw }}\left(x_{i}, \theta_{j}\right)+e_{m 1} \\
n_{1}\left(x_{i}, \theta_{j}\right)=f\left(x_{i}-L, \theta_{j+K / 2}\right)+e_{Z}\left(x_{i}, \theta_{j}\right)-L \cdot e_{y a w}\left(x_{i}, \theta_{j}\right)+e_{n 1},
\end{gathered}
$$

onde $o$ índice $j+K / 2$ indica que as posições de medição de cada sensor são diametralmente opostas. As quatro equações restantes para os sensores 2 e 3 seguem o modelo apresentado, incluindo a variável $\theta_{j}$. Elas foram omitidas devido à sua similaridade com as equações 3.37 e 3.38 .

Deve-se notar que $e_{z}\left(x_{i}, \theta_{j}\right)$ é uma combinação do erro de translação do carro porta-sensores na direção $z$ e do erro de batida radial do cilindro. De forma similar, o erro $e_{\text {yaw }}\left(x_{i}, \theta_{j}\right)$ é uma combinação do erro de inclinação do porta sensores mais o erro angular do eixo de rotação. Realizando-se a reversão do artefato, escrevendo-se as 12 equações do modelo e aplicando-se as mesmas manipulações apresentadas para o modelo original, obtém-se uma expressão para a diferença entre as variáveis $\alpha$ e $\beta$ que é análoga à equação 3.36. Por meio do cálculo dos diferenciais, de forma similar às equações 3.30 a 3.33, e de manipulações algébricas, pode-se também obter a expressão para $\alpha+\beta$.

$$
\beta\left(x_{i}\right)-\alpha\left(x_{i}\right)=\frac{\sum_{j=1}^{K / 2}\left\{n_{3 r}\left(x_{i}, \theta_{j}\right)-2 n_{2 r}\left(x_{i}, \theta_{j}\right)-2 m_{2}\left(x_{i} \theta_{j}\right)+n_{1 r}\left(x_{i}, \theta_{j}, \theta_{j}\right)\right]-\left[n _ { 3 } \left(x_{i r}, \theta_{j+K / 2}\left(x_{i}, \theta_{j+K / 2}\right)-2 n_{2}\left(x_{i}, \theta_{j+K / 2}\left(x_{i}, \theta_{j+K / 2}\right)+n_{1}\left(x_{i}, \theta_{j+K / 2}\left(x_{i}, \theta_{j+K / 2}\right)\right]\right\}\right.\right.}{K}
$$

Este modelo modificado apresenta a vantagem de fornecer valores de $\alpha$ e $\beta$, isto é, do erro de ajuste inicial dos sensores, para cada ponto $x_{i}$, ao mesmo tempo em que possibilita que este cálculo seja feito a partir de uma média de valores, o que diminui a influência de erros aleatórios. 
Assim, o erro devido ao ajuste dos sensores pode ser compensado pontualmente e a variação deste erro causada por influência de diferenças de temperatura durante a medição pode ser monitorada. Em última análise, os autores afirmam que isto pode aumentar significativamente a acuracidade na medição dos desvios de retilineidade das geratrizes do artefato cilíndrico.

\subsection{Modelo de otimização para a avaliação de desvios de forma e orientação}

Os modelos utilizados na avaliação dos desvios de forma e orientação baseiam-se nas diferenças observadas entre os desvios de um perfil medido e a forma geométrica ideal esperada para o elemento sendo avaliado. Assim, para a avaliação dos desvios, é necessário ajustar o ente geométrico de referência ao conjunto de dados medidos, isto é, é necessário determinar os parâmetros desta forma geométrica de referência. O princípio fundamental da aproximação de funções discretas ou da ajustagem de formas geométricas a um conjunto de pontos é a minimização do conjunto de resíduos de cada ponto medido com relação ao ponto correspondente pertencente à curva ou forma de referência. Assim, os resíduos de ajustagem $r_{i}$ correspondem à diferença entre os pontos medidos, isto é, os pontos da função discreta $f\left(x_{i}\right)$, e as imagens da função $g\left(x_{i}\right)$ utilizada na aproximação, conforme mostrado na equação 3.40 .

$$
r_{i}\left(a, x_{i}\right)=f\left(x_{i}\right)-\sum_{j}\left[a_{j} g_{j}\left(x_{i}\right)\right]
$$

O resíduo total dos pontos pode ser avaliado segundo diferentes critérios mediante a aplicação de normas matemáticas. Usualmente são utilizadas as normas L1, L2 e L $\infty$. A norma L2 origina o tradicional Método dos Mínimos Quadrados, em que os minimiza-se a somatória dos quadrados dos resíduos. O princípio da norma Lo, também denominada Norma Chebyshev, é a minimização do resíduo dos pontos mais distantes 
da forma de referência ajustada, isto é, a minimização dos pontos máximos. Por este motivo, essa ajustagem também pode ser denominada Minimax. Nesse caso, o modelo de ajustagem pode ser escrito como um problema de Programação Linear, PPL, cuja função-objetivo é apresentada na equação 3.41 .

$$
\operatorname{Minimizar}\left(\max \left|r_{i}\right| ; i=1,2, \ldots m^{*} n\right)
$$

Se em um conjunto de pontos alguns resíduos são máximos com relação à forma de referência, é possível afirmar que todos os pontos do conjunto apresentam valores de desvio que são menores ou iguais a estes resíduos máximos. Estabelecendo-se a mudança de variável apresentada na equação 3.42, converte-se esta última afirmação na expressão dada na equação 3.43, que representa o conjunto de restrições do modelo de Programação Linear. Realizando-se as manipulações necessárias e considerando-se a equação 3.40 , de definição do desvio, obtém-se a forma final das restrições, mostrada na equação 3.44 .

$$
\begin{gathered}
h=\max \left|r_{i}\right| ; i=1,2, \ldots m * n \\
\left|r_{i}\right| \leq h ; \quad h \geq 0 \\
-h \leq f\left(x_{i}\right)-\sum_{j}\left[a_{j} g_{j}\left(x_{i}\right)\right] \leq h ; \quad h \geq 0
\end{gathered}
$$

Geometricamente, o resíduo máximo representa a distância dos pontos mais afastados à forma de referência ajustada. Estes pontos localizam-se em lados opostos em relação a esta referência e definem a localização de formas geométricas paralelas à referência que abrangem todos os pontos do perfil. Se a forma de referência é um plano, por exemplo, há pelo menos um ponto que apresenta distância máxima em relação a esta referência localizado acima do plano e outro ponto a esta mesma distância máxima localizado abaixo do plano.

O Simplex e outros algoritmos utilizados para a solução de PPLs requerem que as variáveis envolvidas assumam somente valores nãonegativos. Os parâmetros da forma geométrica de referência são variáveis 
livres, sendo necessário escrevê-las como uma diferença entre variáveis positivas, de acordo com a equação 3.45 .

$$
a_{j}=\left(a_{j}^{+}-a_{j}^{-}\right), j=0,1, \ldots k-1
$$

Assim, a forma final do modelo de ajustagem é:

Minimizar $h$

Sujeito a $\left\{\begin{array}{l}-h \leq f\left(x_{i}\right)-\sum_{j}\left[\left(a_{j}^{+}-a_{j}^{-}\right) g_{j}\left(x_{i}\right)\right] \leq h \\ h, a_{j}^{+}, a_{j}^{-} \geq 0\end{array}\right.$

Outras modelagens que se baseiam em Programação Linear ou outros métodos de otimização são apresentadas por Chetwynd (1985), Burdekin and Pahk (1989), Huang et al. (1993), Carr e Ferreira (1995) e Portman et al. (2003). Segundo estes autores, este tipo de modelagem se aproxima do critério de mínima zona, no qual a distância entre as formas geométricas que estabelecem o valor dos desvios de forma e orientação é mínima. 


\section{Capítulo 4}

\section{O Sistema Automatizado para a Medição de Desvios de Forma e Orientação}

As tendências atuais de produção demandam sistemas de medição ágeis e que apresentem, entretanto, alta acuracidade, sendo capazes de realizar medições da ordem de unidades de micrometros.

Os sistemas dedicados, eficientes para medições de alto volume são, em geral, pouco flexíveis. Um sistema ideal é aquele que apresenta a rapidez de um sistema dedicado, especializado na realização de medições repetitivas, e a flexibilidade dos equipamentos universais, permitindo que sua configuração seja rapidamente adaptada para a medição de componentes com características bem distintas. Buscando atender a estes requisitos, desenvolveu-se neste trabalho um sistema de medição automatizado para medição de erros de forma e orientação.

O sistema proposto é composto por um robô industrial com 6 graus de liberdade, um microcomputador, uma coluna eletrônica de medição, sensores de deslocamento e dispositivos auxiliares de fixação dos sensores e das peças a serem medidas. As figuras 4.1 e 4.2 apresentam, respectivamente, um esquema simplificado e uma foto do Sistema Automatizado de medição.

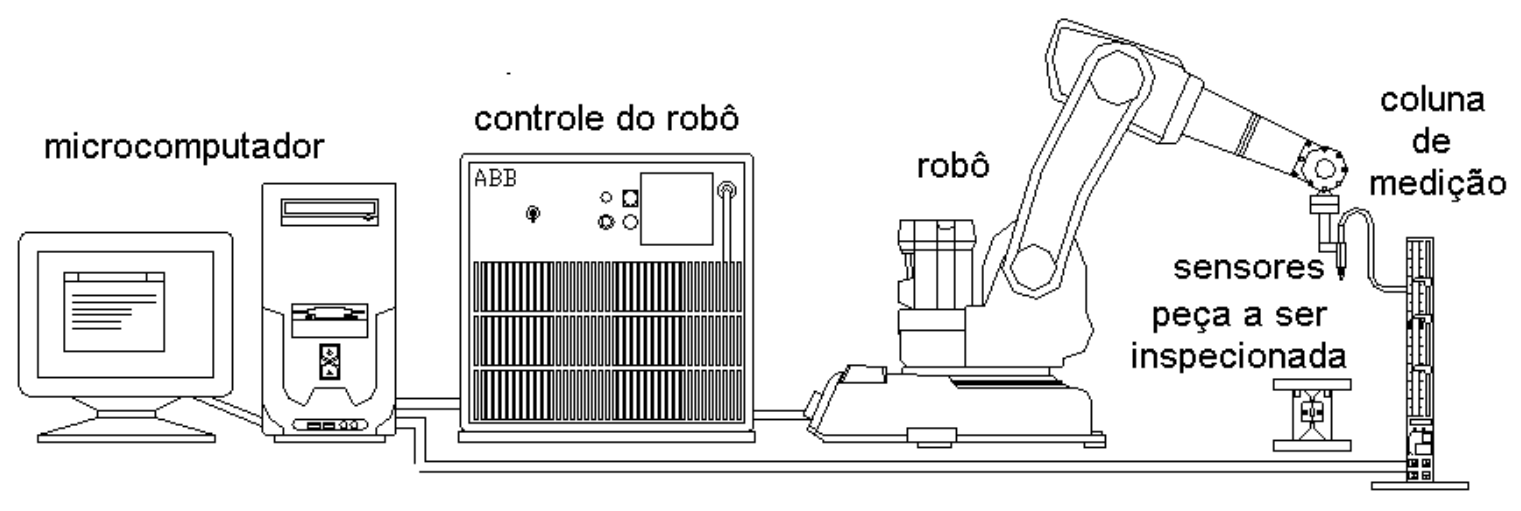

Figura 4.1 - Diagrama do Sistema de Medição Proposto 
No sistema apresentado, um dispositivo de fixação é acoplado à extremidade do robô, e neste dispositivo são colocados três sensores de deslocamento que farão a leitura dos pontos do perfil da peça a ser medida. Tal dispositivo, denominado, por simplicidade, porta-sensores, é movido pelo manipulador em uma direção perpendicular ao eixo dos sensores. A coluna eletrônica de medição capta os sinais analógicos dos sensores e os envia ao microcomputador que fará o tratamento dos dados. A interface entre os equipamentos de medição e as rotinas de análise de dados é feita por meio de uma placa de aquisição na qual foram implementados módulos de conversão analógico-digital, $A / D$, e digitalanalógico, D/A.

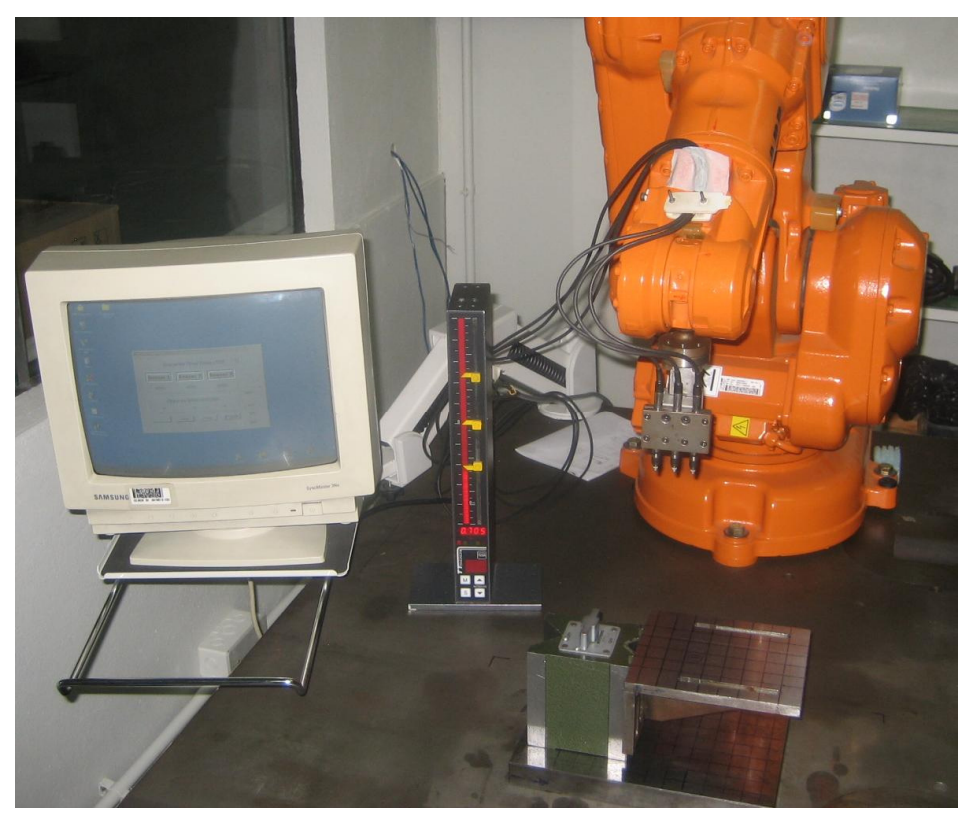

Figura 4.2 - Foto do Sistema de Medição

A utilização deste sistema de medição para a avaliação de desvios geométricos de componentes requer a elaboração e implementação de modelos matemáticos e algoritmos de processamento de dados. Assim, além dos equipamentos e dispositivos descritos, o Sistema Automatizado inclui um programa de aquisição de dados e várias rotinas de implementação de modelos matemáticos e algoritmos. A seqüência do processamento de dados é mostrada na Figura 4.3. 
A aquisição de dados é realizada utilizando-se o Sistema Automatizado de medição e as rotinas de movimentação do robô e coleta de dados, conforme mostra o bloco B1. São medidas várias retas sobre a superfície da peça, dispostas segundo uma malha ortogonal. O arquivo eletrônico gerado pelo programa de aquisição contém dados destas retas geratrizes e trasnversais, os quais devem ser separados em subconjuntos para possibilitar a aplicação do modelo de separação de erros. Estas etapas são mostradas nos blocos B3 e B4. Após a separação dos erros, executa-se um pré-processamento dos perfis das retas para a obtenção de perfis de superfície. A estas superfícies obtidas, são ajustados planos médios, conforme exibido no bloco B6. A partir dos parâmetros destes planos e dos resultados fornecidos pelos métodos de ajustagem, é possível calcular os valores dos desvios de forma e orientação. Os blocos apresentados na Figura 4.3 serão discutidos com mais detalhes nos itens seguintes deste capítulo e no capítulo 5 .
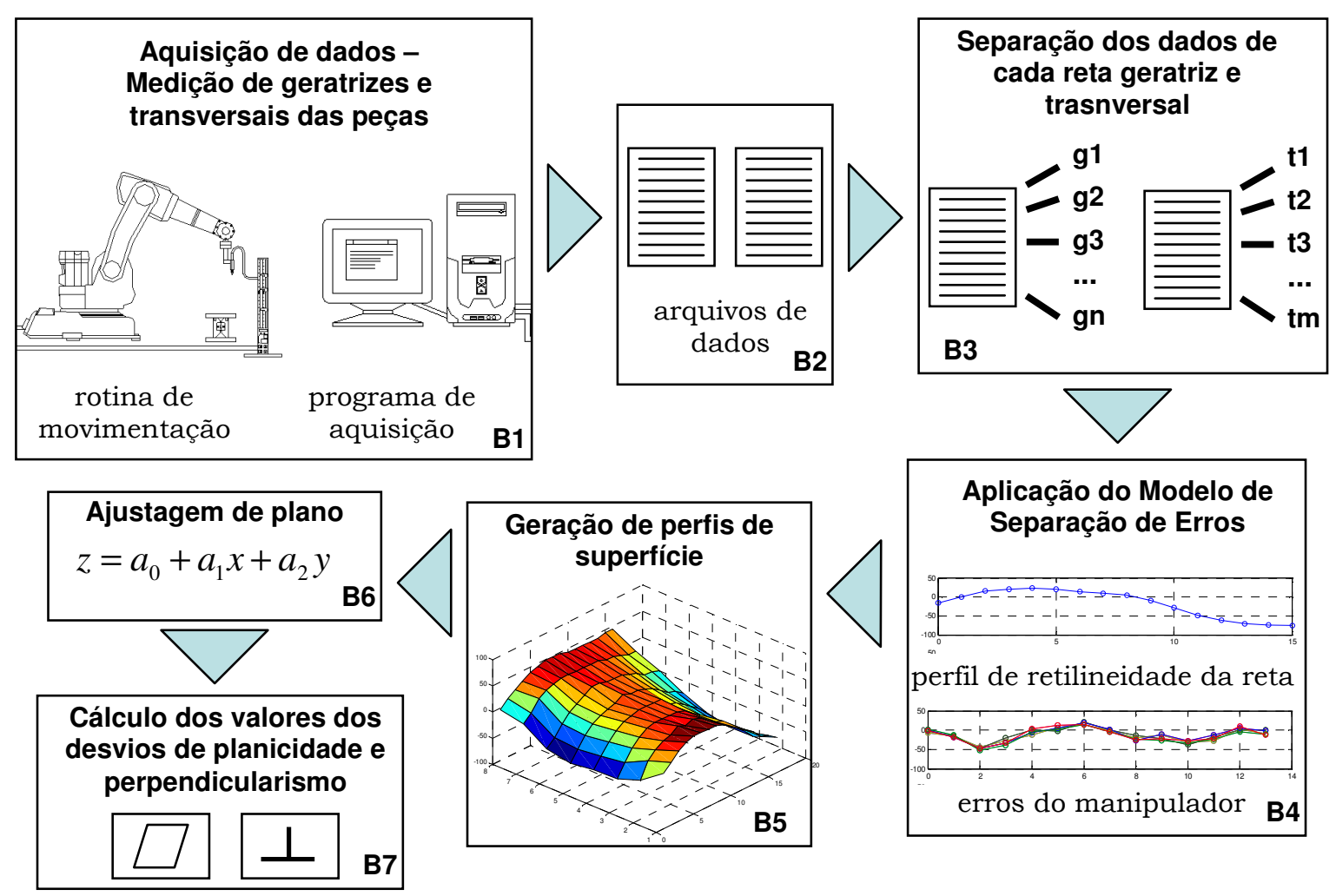

Figura 4.3 - Fluxo de dados e informações no Sistema Automatizado 
O objetivo deste trabalho, conforme enunciado, consiste no desenvolvimento e validação do Sistema Automatizado de medição para a avaliação de desvios de forma e orientação, abordando-se mais especificamente, os desvios de planicidade e perpendicularismo. Este desenvolvimento e validação, por sua vez, incluem a implementação dos modelos matemáticos e sua avaliação por meio de testes experimentais. Na seqüência, são apresentadas as linhas gerais do trabalho desenvolvido e as etapas necessárias ao alcance dos objetivos estabelecidos. O detalhamento destas etapas é realizado no capítulo 5 .

\subsection{Escolha e adaptação do modelo de separação de erros}

As leituras do perfil de uma peça coletadas com auxílio de um robô são afetadas por erros de movimentação deste. Como regra prática, recomenda-se que a resolução do sistema de medição seja de no mínimo uma ordem de grandeza melhor do que a resolução requerida na medição dos desvios. Os erros de posicionamento do robô são muito significativos diante dos valores de desvios geométricos que comumente são medidos, e não podem, desta forma, ser desconsiderados. Assim, é necessário aplicar um modelo de separação de erros aos dados medidos para que a acuracidade desejada seja obtida. Conforme discutido no capítulo 2, os métodos de separação de erros baseados no princípio da reversão devem ser utilizados quando os erros de movimentação do sistema de medição são repetitivos. Os métodos multi-sensoriais não apresentam esta restrição, podendo ser também utilizados para a remoção de erros variáveis.

Para o desenvolvimento deste trabalho, realizou-se inicialmente um estudo sobre os modelos existentes de separação de erros baseados em múltiplos sensores, buscando-se avaliar seu desempenho, vantagens e desvantagens. Optou-se pela utilização de um modelo apresentado por Paziani (2005) e aplicado à avaliação do desvio de retilineidade. Para que fosse possível utilizar este modelo na avaliação do desvio de planicidade e 
perpendicularismo, foi necessário elaborar rotinas para dividir os dados coletados em subconjuntos, cada qual contendo os dados de uma das geratrizes ou transversais medidas. Além disso, alguns dos parâmetros do modelo foram modificados para a aplicação deste à avaliação do desvio de perpendicularismo de componentes.

No modelo empregado assume-se que as leituras fornecidas pelos sensores contém, além dos desvios do perfil da peça, os quais se deseja medir, os seguintes erros: erros de translação do manipulador na direção de medição, ao conduzir o dispositivo porta-sensores; erros de inclinação do porta-sensores; e os erros provenientes do desalinhamento inicial dos sensores. A hipótese fundamental da modelagem é a de que a parcela correspondente aos desvios do perfil da peça, presente nas leituras de cada um dos sensores ao medir um dado ponto, é sempre a mesma.

\subsection{Elaboração da rotina de medição}

Obtém-se um procedimento automatizado de medição a partir do funcionamento integrado de duas rotinas: uma delas contendo as instruções de movimentação do manipulador e a outra, as subrotinas de aquisição de dados.

As instruções de movimentação foram escritas na linguagem do robô (RAPID), e o programa de aquisição utilizado foi escrito em linguagem Delphi. A integração entre estes programas foi conseguida por meio da troca de sinais analógicos entre o manipulador e o microcomputador. Assim, ambas as rotinas possuem instruções de leitura e envio de sinais analógicos. A placa de conversão A/D é utilizada tanto para o estabelecimento deste canal de comunicação quanto para o recebimento e leitura dos sinais analógicos enviados pelos sensores de medição. 


\subsection{Desenvolvimento do procedimento de pré-processamento dos dados e das rotinas de avaliação dos desvios geométricos}

Após a aplicação do modelo de separação de erros e antes que se possa proceder com a avaliação propriamente dita do desvio geométrico, é necessário realizar um procedimento de pré-processamento dos dados para a obtenção de perfis de superfície.

Os conjuntos de dados das geratrizes medidas sobre a peça não formam imediatamente um perfil de superfície porque, da forma como os dados são coletados, não se pode definir o posicionamento relativo entre estas geratrizes. Para se obter um perfil de superfície, é necessário combinar os dados do conjunto destas retas com o perfil de uma reta transversal. Nesta etapa do trabalho, planilhas eletrônicas foram préprogramadas para realizar este pré-processamento dos dados.

A avaliação dos desvios de forma e orientação requer a ajustagem de formas geométricas de referência ao conjunto final de pontos do perfil. Assim, para o tratamento dos dados também foi necessário implementar, além do modelo de separação de erros, os algoritmos de ajustagem destas formas de referência, que no caso são planos. Há vários métodos de aproximação de funções baseados em diferentes princípios. Um dos mais utilizados para a avaliação de desvios de forma e orientação é o Método dos Mínimos Quadrados. Além deste, outro método utilizado é a ajustagem Minimax, que se baseia, como o nome sugere, na minimização dos desvios máximos em relação à curva de referência apresentados por alguns pontos. A ajustagem, neste caso, é modelada como um problema de Programação Linear, o qual pode ser resolvido com o método Simplex ou outros métodos iterativos de otimização similares a ele.

Assim, para a avaliação dos desvios geométricos, foram elaboradas rotinas de implementação dos métodos de ajustagem citados. Tais rotinas são responsáveis por fornecer, a partir de matrizes de pontos dos perfis de superfície geradas na etapa de pré-processamento, os parâmetros dos 
planos de referência utilizados na avaliação dos desvios de forma e orientação.

\subsection{Medições e aplicação das rotinas}

O sistema de medição proposto foi montado, e os procedimentos de aquisição e preparação dos dados, bem como os algoritmos matemáticos de processamento, foram implementados e testados. O algoritmo de separação de erros havia sido inicialmente avaliado por Paziani (2005), por meio de testes simulados e testes experimentais. $O$ algoritmo de avaliação de erros de forma e orientação, por sua vez, foi validado por meio de testes prospectivos nos quais foram utilizados dados apresentados por outros pesquisadores e se verificou a semelhança dos resultados obtidos com os resultados apresentados nos artigos.

Estando os algoritmos validados, realizou-se a medição de 3 superfícies de peças prismáticas e da superfície de um plano de referência. Três amostras de dados de cada peça foram tratadas segundo o procedimento apresentado na Figura 4.3. Assim, inicialmente, os dados de uma amostra gravados em um único arquivo, foram divididos em subconjuntos de dados relativos a cada reta medida sobre a peça. Em seguida, o algoritmo de separação de erros foi aplicado em cada subconjunto e os perfis resultantes, de cada reta, foram transferidos para planilhas a fim de gerar perfis de superfície. A estes perfis foram ajustados planos de referência, o que possibilitou, enfim, o cálculo do desvio de planicidade e perpendicularismo das peças. Informações detalhadas sobre o aparato experimental e o procedimento de aquisição e de processamento dos dados são apresentadas no capítulo 5. 


\subsection{Avaliação do sistema por análise comparativa}

Buscou-se avaliar o desempenho do Sistema Automatizado por meio de comparações entre os resultados obtidos utilizando-se este sistema e os valores obtidos por meio de métodos convencionais de medição.

Segundo o Vocabulário Internacional de Metrologia, INMETRO (2007), define-se "classe de exatidão" (ou classe de acuracidade) de um instrumento ou sistema de medição, como a aptidão desse instrumento ou sistema para dar respostas próximas a um valor verdadeiro. Este valor verdadeiro, na maioria dos casos, é um valor verdadeiro convencional, ou seja, um "valor atribuído a uma grandeza específica e aceito, às vezes por convenção, como tendo uma incerteza apropriada para uma dada finalidade" (INMETRO, 2007). Neste trabalho, foram adotados como referência os valores resultantes da medição com o método convencional. No documento supracitado, a acuracidade é denominada exatidão de medição e definida como um conceito qualitativo. Entretanto, julgou-se importante avaliar as diferenças quantitativas entre os resultados obtidos com o Sistema Automatizado e o sistema convencional. A validação do Sistema Automatizado é baseada na análise dessas diferenças.

Além da acuracidade, avaliou-se o desempenho do sistema com relação a outros aspectos, tais como repetibilidade, tempos de medição e tempos de processamento de dados. 


\section{Capítulo 5}

\section{Desenvolvimento do Sistema Automatizado para a Medição dos Desvios de Forma e Orientação}

Neste capítulo, cada uma das partes integrantes do sistema de medição proposto são apresentadas e discutidas. Assim, são abordados aspectos como: o manipulador utilizado na medição, os sensores, os dispositivos de fixação, as peças medidas, o programa computacional de aquisição, a interface de transferência de dados, os algoritmos de separação de erro, os algoritmos de avaliação dos erros de forma, e os programas computacionais nos quais os algoritmos desenvolvidos são implementados.

\subsection{Equipamentos de medição, peças e dispositivos auxiliares}

O manipulador utilizado na medição é um robô industrial com 6 graus de liberdade, classificado, em função de sua configuração mecânica, como antropomórfico. Estes graus de liberdade são conferidos pela atuação de 6 eixos de rotação independentes.

São utilizados na medição três sensores do tipo LVDT (Linear Variable Differential Transformer), fixados em um dispositivo portasensores, o qual, por sua vez, é acoplado ao punho do manipulador. Este dispositivo de fixação foi desenvolvido especificamente para a aplicação proposta e posiciona os sensores paralelamente, com uma distância de 18 $\mathrm{mm}$ entre si.

Os LVDTs são transdutores ou sensores indutivos bastante conhecidos e utilizados, dotados basicamente de um entre-ferro e conjuntos de bobinas. Seu princípio de funcionamento baseia-se na 
geração de uma determinada diferença de potencial na saída das bobinas quando certo deslocamento é imposto ao entre-ferro. O termo "diferencial" refere-se aos circuitos diferenciais utilizados, que permitem que o valor da tensão de saída não seja afetado por flutuações na tensão de alimentação das bobinas. Foram utilizados LVDTs TESA com resolução $0,1 \mu \mathrm{m}$ e faixa de operação total de $4.200 \mu \mathrm{m}$.
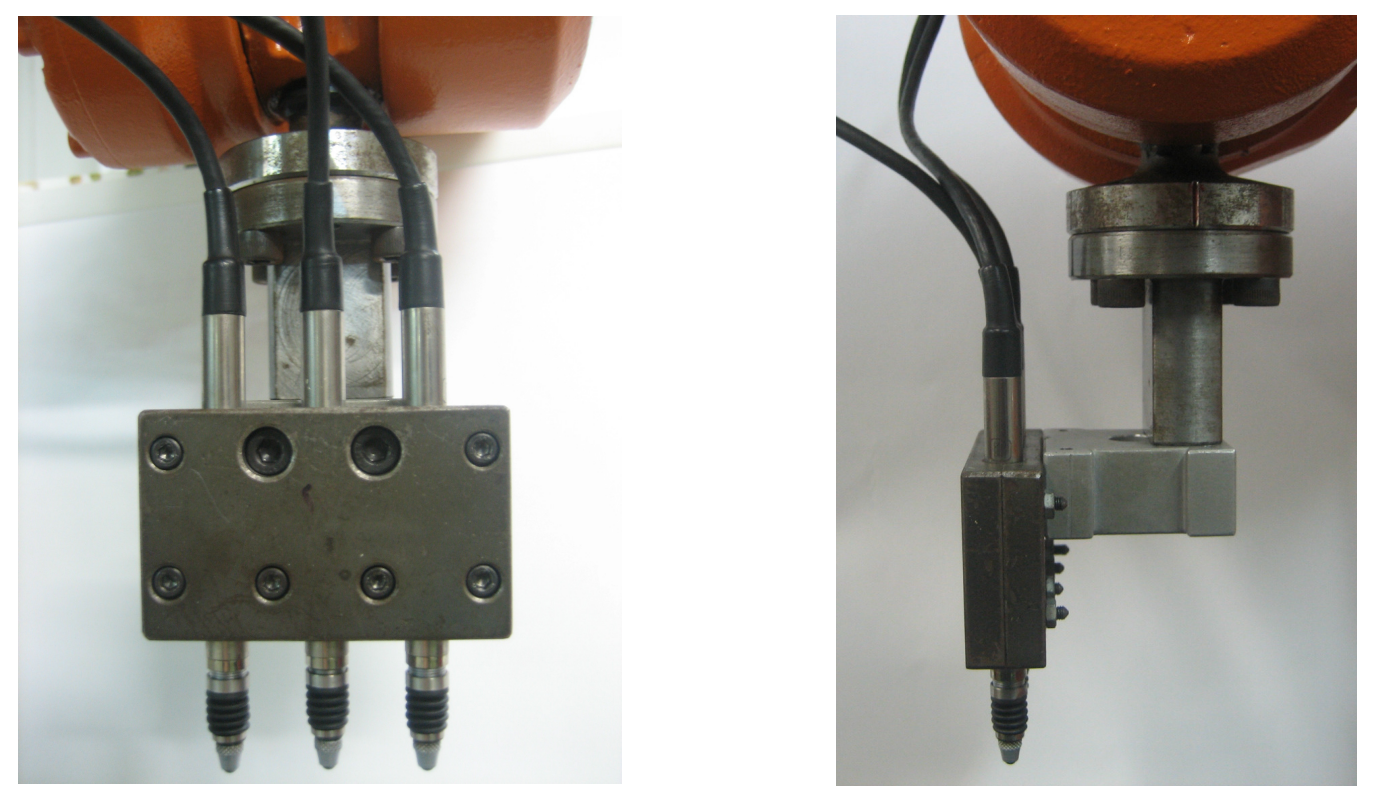

Figura 5.1 - Dispositivo porta-sensores acoplado ao punho do manipulador.

Para que o sistema proposto pudesse ser testado, dois componentes foram usinados: um bloco prismático plano e uma cantoneira. Realizou-se a medição de três superfícies distintas, ou seja, foram medidas duas superfícies opostas do bloco prismático e uma superfície da cantoneira. Cada uma dessas três superfícies ou elementos foram denominados, por simplicidade, Peça 1, Peça 2 e Peça 3. Sobre cada superfície traçou-se uma malha ortogonal de medição com espaçamento de $18 \mathrm{~mm}$ entre os pontos. Dessa forma, a área de medição de cada elemento ou superfície ficou dividida em um determinado número de geratrizes e transversais. A Tabela 5.1. apresenta as dimensões das áreas de medição, o número de retas geratrizes e transversais traçadas sobre cada superfície, e o número de posições de medição, $N$, em cada reta. A avaliação do desvio perpendicularismo por meio do sistema proposto requer que um artefato de referência, no caso um plano, seja medido. As características deste 
artefato de referência também são apresentadas na Tabela 5.1. Nas figuras 5.2 e 5.3 são mostradas a Peça 1 e a Peça 3.

Tabela 5.1 - Características das superfícies medidas.

\begin{tabular}{|c|c|c|c|c|}
\hline \multicolumn{5}{|c|}{ Plano de referência } \\
\cline { 1 - 4 } Geratrizes & \multicolumn{2}{c|}{ Transversais } & Dimensões \\
\cline { 1 - 4 } $\begin{array}{c}\text { No. de posições } \\
\text { de medição (N) }\end{array}$ & $\begin{array}{c}\text { No. de } \\
\text { geratrizes }\end{array}$ & $\begin{array}{c}\text { No. de posições de } \\
\text { medição (N) }\end{array}$ & $\begin{array}{c}\text { No. De } \\
\text { transversais }\end{array}$ & \multirow{2}{*}{$\begin{array}{c}254 \mathrm{~mm} x \\
151 \mathrm{~mm}\end{array}$} \\
\hline 12 & 8 & 6 & 5 & \\
\hline
\end{tabular}

\begin{tabular}{|c|c|c|c|c|}
\hline \multicolumn{6}{|c|}{ Peça 1 e Peça 2 } \\
\cline { 1 - 4 } Geratrizes & \multicolumn{2}{c|}{ Transversais } & Dimensões \\
\cline { 1 - 4 } $\begin{array}{c}\text { No. de posições } \\
\text { de medição }(\mathrm{N})\end{array}$ & $\begin{array}{c}\text { No. de } \\
\text { geratrizes }\end{array}$ & $\begin{array}{c}\text { No. de posições de } \\
\text { medição }(\mathrm{N})\end{array}$ & $\begin{array}{c}\text { No. De } \\
\text { transversais }\end{array}$ & \multirow{2}{*}{$\begin{array}{c}300 \mathrm{~mm} \mathrm{x} \\
150 \mathrm{~mm}\end{array}$} \\
\hline 14 & 8 & 6 & 6 & \\
\hline
\end{tabular}

\begin{tabular}{|c|c|c|c|c|}
\hline \multicolumn{5}{|c|}{ Peça 3 } \\
\hline \multicolumn{2}{|c|}{ Geratrizes } & \multicolumn{2}{c|}{ Transversais } & Dimensões \\
\cline { 1 - 4 } $\begin{array}{c}\text { No. de posições } \\
\text { de medição (N) }\end{array}$ & $\begin{array}{c}\text { No. de } \\
\text { geratrizes }\end{array}$ & $\begin{array}{c}\text { No. de posições de } \\
\text { medição (N) }\end{array}$ & $\begin{array}{c}\text { No. De } \\
\text { transversais }\end{array}$ & $\begin{array}{c}159 \mathrm{~mm} x \\
133 \mathrm{~mm}\end{array}$ \\
\hline 6 & 5 & 3 & 4 & \\
\hline
\end{tabular}

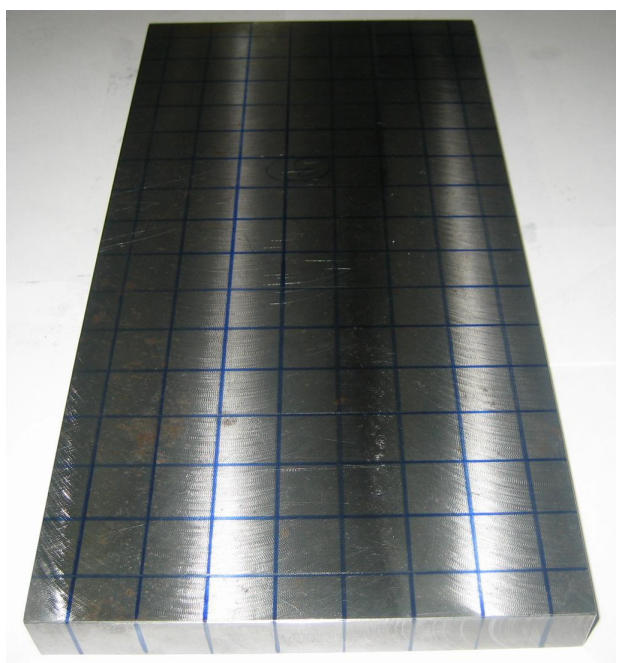

Figura 5.2 - Peça 1.

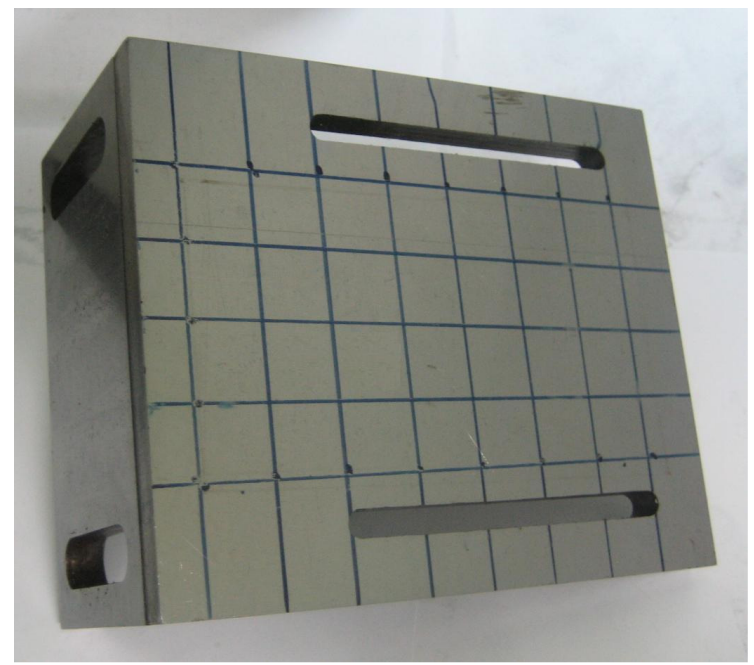

Figura 5.3 - Peça 3.

Novamente, deve-se esclarecer que as peças designadas como Peça 1 e Peça 2 na Tabela 5.1 são, na verdade, faces distintas de um mesmo bloco prismático. Assim, as superfícies a serem medidas possuem mesmas dimensões, mas características bem distintas especialmente no que concerne ao erro de planicidade, já que uma superfície foi fresada e a outra foi retificada, possuindo assim melhor qualidade superficial. Alguns 
parâmetros de usinagem foram controlados para que, em cada peça, fossem produzidos desvios geométricos de características e grandezas bem conhecidas. Este aspecto auxilia na validação dos resultados obtidos com o sistema proposto. Sendo a face de medição das peças retangular, são denominadas geratrizes as linhas de maior comprimento da malha. Optou-se por considerar a direção das geratrizes como direção principal de medição, e a direção ortogonal a esta, como direção secundária de medição.

No sistema automatizado para a medição dos desvios de forma e orientação, os sensores, movidos pelo manipulador, lêem os desvios ou variações de altura que compõe o perfil das geratrizes e transversais que formam a superfície das peças. A partir desses dados, realiza-se uma seqüência de processamento para a obtenção dos valores de desvio de perpendicularismo e planicidade dos componentes.

A montagem experimental para a medição da Peça 3 é apresentada na Figura 5.4. A peça foi fixada por uma de suas laterais, utilizando a base magnética, a qual foi colocada sobre o plano de referência. Utilizando-se esta montagem, é possível medir o desvio de planicidade da face superior da peça e o desvio de perpendicularismo desta face superior em relação à face que está em contato com a base magnética.

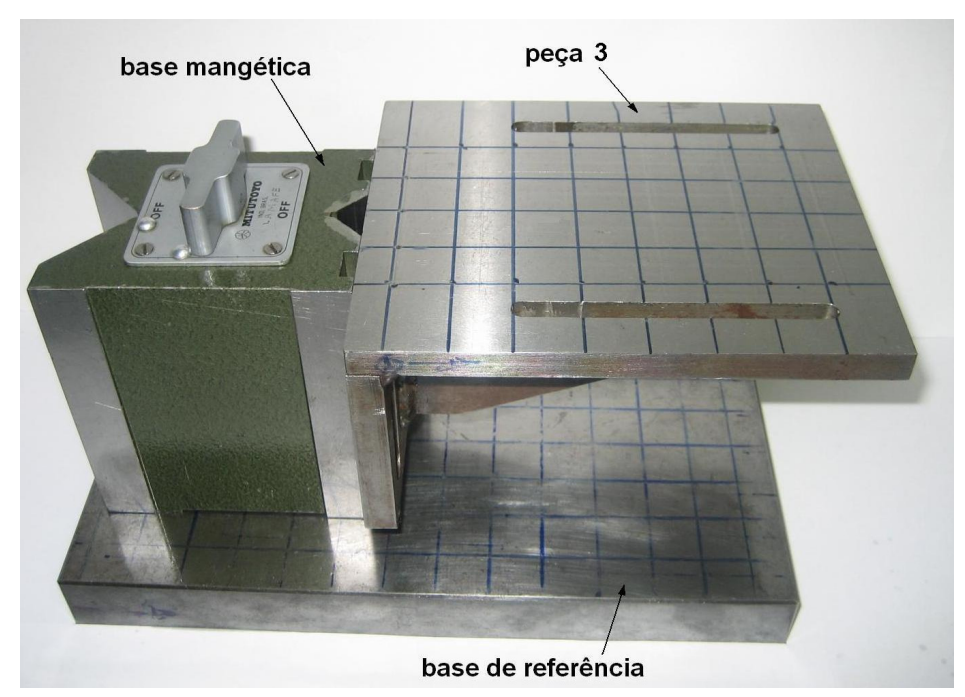

Figura 5.4 - Montagem para avaliação do desvio de perpendicularismo - Peça 3. 
Para a avaliação do perpendicularismo da Peça 2, realiza-se a montagem experimental mostrada na Figura 5.5. Para a Peça 1 utilizou-se uma montagem muito similar.

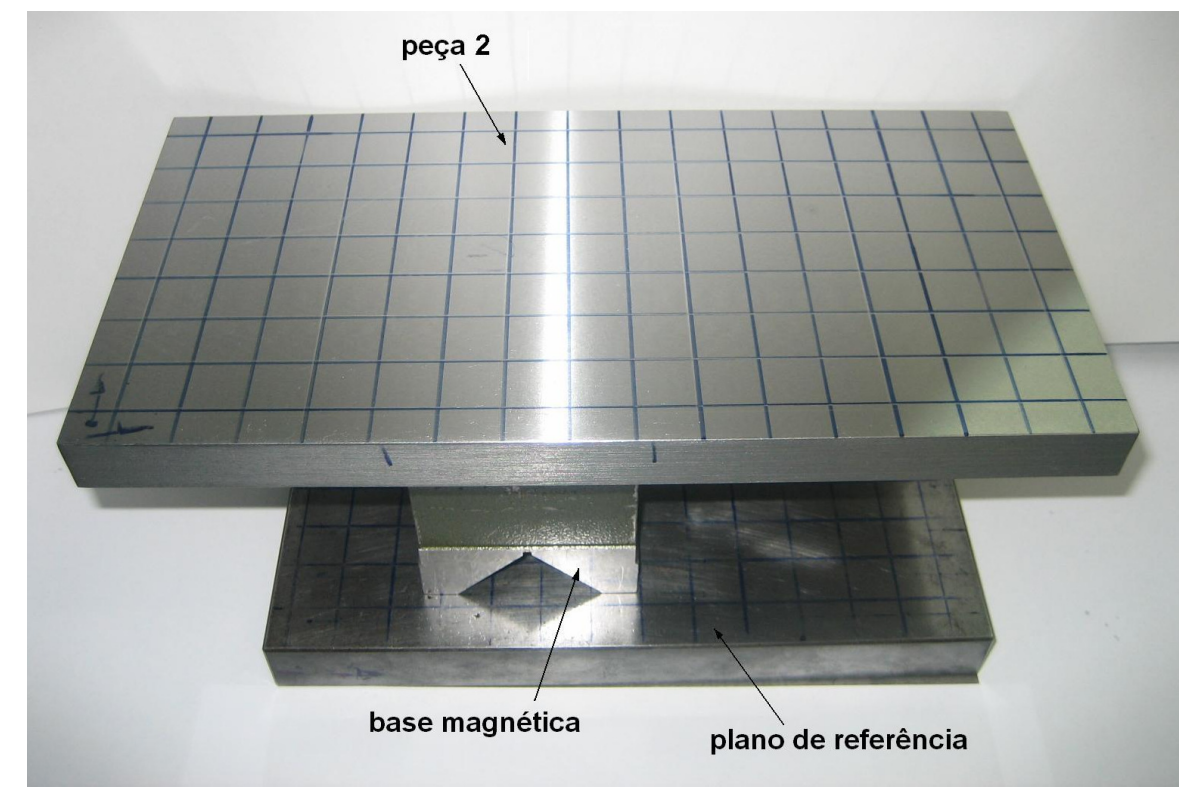

Figura 5.5 - Montagem para avaliação do erro de perpendicularismo - Peça 2.

O aparato experimental da Figura 5.5 é montado da forma mostrada para que seja possível avaliar o desvio de perpendicularismo da face superior da peça em relação a uma das faces verticais da base magnética. Tal montagem simula a mesma situação mostrada para a Peça 3, em que uma das faces de uma peça que possui duas faces supostamente ortogonais é colocada em contato com uma base magnética, em posição vertical, para se medir o desvio de perpendicularismo entre estas faces. Tal desvio de perpendicularismo, nas montagens apresentadas para as peças 2 e 3, é medido indiretamente, por meio da avaliação do desvio de paralelismo da face superior das peças com relação ao plano de referência. Este procedimento é uma prática de oficina, sendo, assim, bastante corriqueiro. Na maioria dos casos, mesmo com a utilização de diferentes sistemas de medição, o desvio de perpendicularismo é avaliado desta forma, ou seja, por meio da avaliação do desvio de paralelismo. Optou-se por realizar a montagem mostrada na Figura 5.5 porque, dessa forma, o bloco prismático pode ser rotacionado e sua outra face, oposta, também pode ser medida. Este procedimento permite que se obtenha 
uma estratégia adicional de avaliação e validação das medições, a qual será mostrada na Figura 5.7 e discutida com mais detalhes adiante.

Assim como no caso das medições dos desvios de orientação realizadas por meio de técnicas convencionais, as medições destes desvios por meio do sistema proposto também requerem a utilização de uma superfície plana de referência. As montagens necessárias para a medição dos desvios de orientação utilizando-se o sistema proposto são muito similares às montagens empregadas nas medições destes desvios com sistemas convencionais. A Figura 5.6 apresenta a montagem empregada na medição convencional.

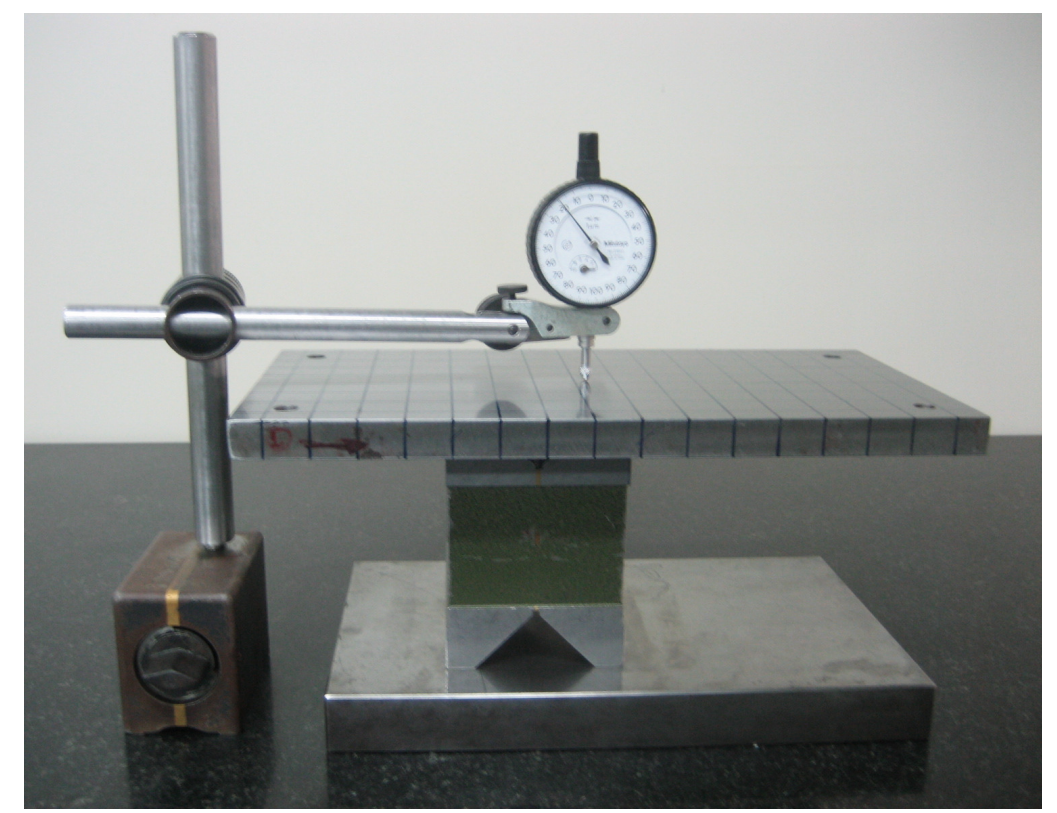

Figura 5.6 - Montagem para avaliação do erro de perpendicularismo utilizando-se sistema convencional de medição.

Como pode ser observado, na medição convencional, as leituras dos apalpadores fornecem a variação das alturas relativas dos pontos da superfície medida, uma vez que o desempeno serve como referência para todas as leituras. Convencionalmente, o desempeno é considerado uma superfície plana ideal, de referência, pois seus desvios forma são muito pequenos e podem ser desconsiderados. Similarmente, a base magnética também é artefato auxiliar de referência. Assume-se que suas faces opostas, neste caso em contato com o desempeno e o componente a ser medido, sejam idealmente paralelas e que suas faces adjacentes sejam 
perfeitamente perpendiculares. Esta é uma premissa necessária para garantir a validade dos resultados absolutos e é comumente adotada ao se realizar medições em oficinas e laboratórios. Uma vez que esta premissa é atendida, pode-se considerar que a face do componente apoiada sobre a base magnética seja paralela ao desempeno. Em última análise, a inclinação medida sobre a superfície do componente, isto é, a máxima diferença entre as alturas medidas pelos apalpadores representa o erro de paralelismo entre as faces do mesmo. Esta inclinação também pode ser entendida como o desvio de perpendicularismo entre a face superior da superfície da peça e uma das faces da base magnética perpendiculares ao plano de referência. Este é o caso que será avaliado. O tipo de montagem apresentado é bastante conhecido e tradicionalmente utilizado na medição convencional do desvio de perpendicularismo e paralelismo de componentes.

Ainda que a base magnética apresente erros de forma e orientação relativamente significativos, isto não inviabilizaria os resultados, uma vez que o enfoque da avaliação é comparativo e a mesma base magnética foi utilizada em todas as medições, realizadas tanto com o sistema automatizado quanto com o método convencional.

$\mathrm{Na}$ montagem convencional apresentada, deve-se salientar que a base de fixação do apalpador estabelece fisicamente a referência para as medições. Assim, a utilização desta base faz com que todas as variações de altura sobre a peça sejam medidas em relação ao desempeno. No caso do Sistema Automatizado, não é possível estabelecer esta referência de forma física, ou seja, não é possível garantir que o manipulador conduza os sensores segundo trajetórias retilíneas e paralelas à superfície de referência. Assim, para a avaliação de perpendicularismo, o manipulador inicialmente movimenta os sensores para possibilitar a coleta dos valores das variações de altura dos pontos sobre a superfície de referência. Com base neste perfil medido, será estabelecido, por meio de ajustagem matemática, um plano médio de referência para a avaliação do desvio de orientação. Cada peça é então colocada sobre a base magnética de 
precisão e apoiada sobre o plano de referência, para que as variações de alturas dos pontos de sua superfície sejam medidas pelo sistema proposto.

Assim, para a avaliação dos desvios de orientação por meio do sistema proposto, é necessário realizar uma varredura inicial de uma superfície de referência, conforme mencionado. No caso do desvio de planicidade, o próprio plano médio ajustado aos pontos da superfície servirá de referência para a avaliação do desvio.

O procedimento de medição descrito deve ainda ser associado à aplicação de técnicas de separação de erros porque o manipulador utilizado não possui um sistema próprio que apresente acuracidade suficiente para servir de referência para as medições, como é o caso das máquinas de medir coordenadas, em que guias e escalas ópticas determinam este sistema de referência.

A medição de faces distintas de uma mesma peça foi realizada propositalmente, como uma estratégia para avaliar o comportamento do Sistema Automatizado. Uma das faces do bloco prismático recebeu a denominação de Peça 1. Em uma primeira montagem, mediu-se o perpendicularismo desta face do bloco em relação à face vertical da base magnética. Em seguida, o bloco foi rotacionado em torno de um eixo central paralelo à direção principal de medição, isto é, paralelo às geratrizes, para que a outra face, denominada Peça 2, pudesse ser medida. Um esquema representativo desta estratégia é apresentado na Figura 5.7.

Espera-se observar valores bem distintos para o desvio de planicidade para as peças 1 e 2, já que cada uma das faces do bloco sofreu processos de usinagem bem distintos, isto é, uma das faces foi fresada e a outra, retificada. Os valores de inclinação medidos na direção das geratrizes, entretanto, devem ser muito próximos, ou seja, não devem se alterar após a rotação realizada. Além disso, se o sistema for robusto e consistente, as diferentes amplitudes e freqüências dos erros de 
planicidade de cada uma das faces não devem afetar a medição da inclinação, isto é, do desvio de perpendicularismo.

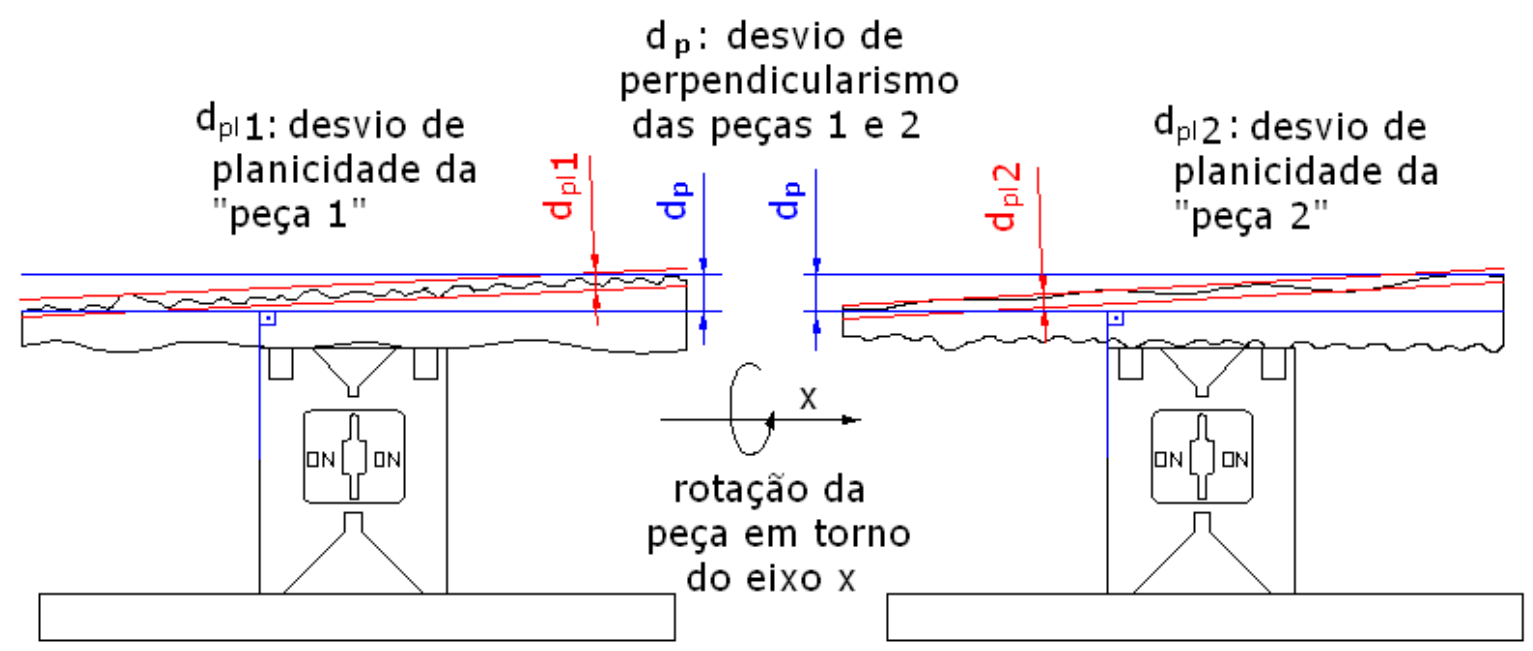

Figura 5.7 - Esquema representativo da medição das peças 1 e 2 .

No sistema automatizado de medição, os sinais analógicos de tensão dos três sensores LVDTs são enviados ao microcomputador que realiza a aquisição dos dados por intermédio de uma coluna de medição TESA. Esta coluna possui quatro entradas para os transdutores e quatro respectivas saídas analógicas DC independentes. A Figura 5.8 apresenta a coluna de medição.

Para o interfaceamento entre a coluna de medição e o microcomputador são utilizadas três saídas analógicas de tensão da coluna. Cada uma dessas saídas transmite o sinal de um transdutor. É necessário converter estes sinais analógicos dos transdutores em dados digitais para que estes valores sejam armazenados e manipulados matematicamente. Esta conversão analógico-digital, $A / D$, é realizada por circuitos integrados implementados numa placa de aquisição AQB11/12. Por meio desta placa, uma tensão analógica é convertida em um número de 12 bits. O fundo de escala deste sistema permite uma tensão de entrada correspondente a uma faixa de $-300 \mu \mathrm{m}$ a $+300 \mu \mathrm{m}$. Assim, a faixa de utilização dos sensores foi reduzida, uma vez que a faixa total, conforme citado, é de $4200 \mu \mathrm{m}$. Por outro lado, obtém-se uma melhor resolução na conversão: sendo cada número digital de 12 bits, dispõe-se de um total de 4096 números $A / D$, isto é, $2^{12}$ números, para uma faixa de 
$600 \mu \mathrm{m}$, o que fornece uma resolução de aproximadamente $0,15 \mu \mathrm{m}$ por número $A / D$. Tal resolução é bem próxima da resolução do próprio LVDT, que segundo o fabricante, é de 0,1 $\mathrm{mm}$.

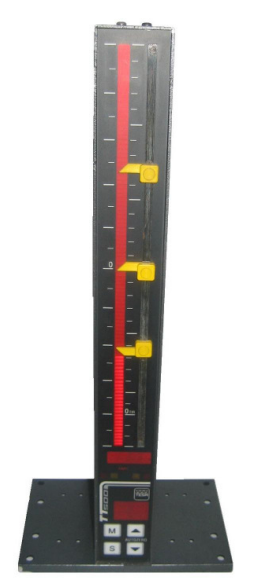

Figura 5.8 - Coluna de Medição.

$\mathrm{Na}$ placa de aquisição utilizada, há ainda um conversor digitalanalógico, D/A, que realiza a conversão de números digitais de 12 bits em uma faixa sinais analógicos de $0 \mathrm{~V}$ a $10 \mathrm{~V}$. A comunicação entre 0 microcomputador e o manipulador, necessária para a implementação do Sistema Automatizado, também requer a utilização desta conversão D/A. O programa de aquisição envia à placa de conversão um número digital de 12 bits, o qual é transformado em um sinal analógico de tensão e enviado ao manipulador. É desta forma, por exemplo, que o programa de aquisição informa ao manipulador que a valor da leitura de determinado ponto de medição já foi armazenado. Ao receber esta informação, o robô move-se para o próximo ponto de medição. Observa-se, assim, a importância das conversões $A / D$ e D/A no contexto da aquisição e armazenamento de dados.

\subsection{Rotina de Medição}

Conforme mencionado no capítulo 4, a rotina completa de medição desenvolvida para o Sistema Automatizado é obtida com o funcionamento integrado de duas rotinas: o programa de aquisição de dados e a rotina de 
movimentação do manipulador. Um fluxograma geral dessa rotina é apresentado na Figura 5.9.

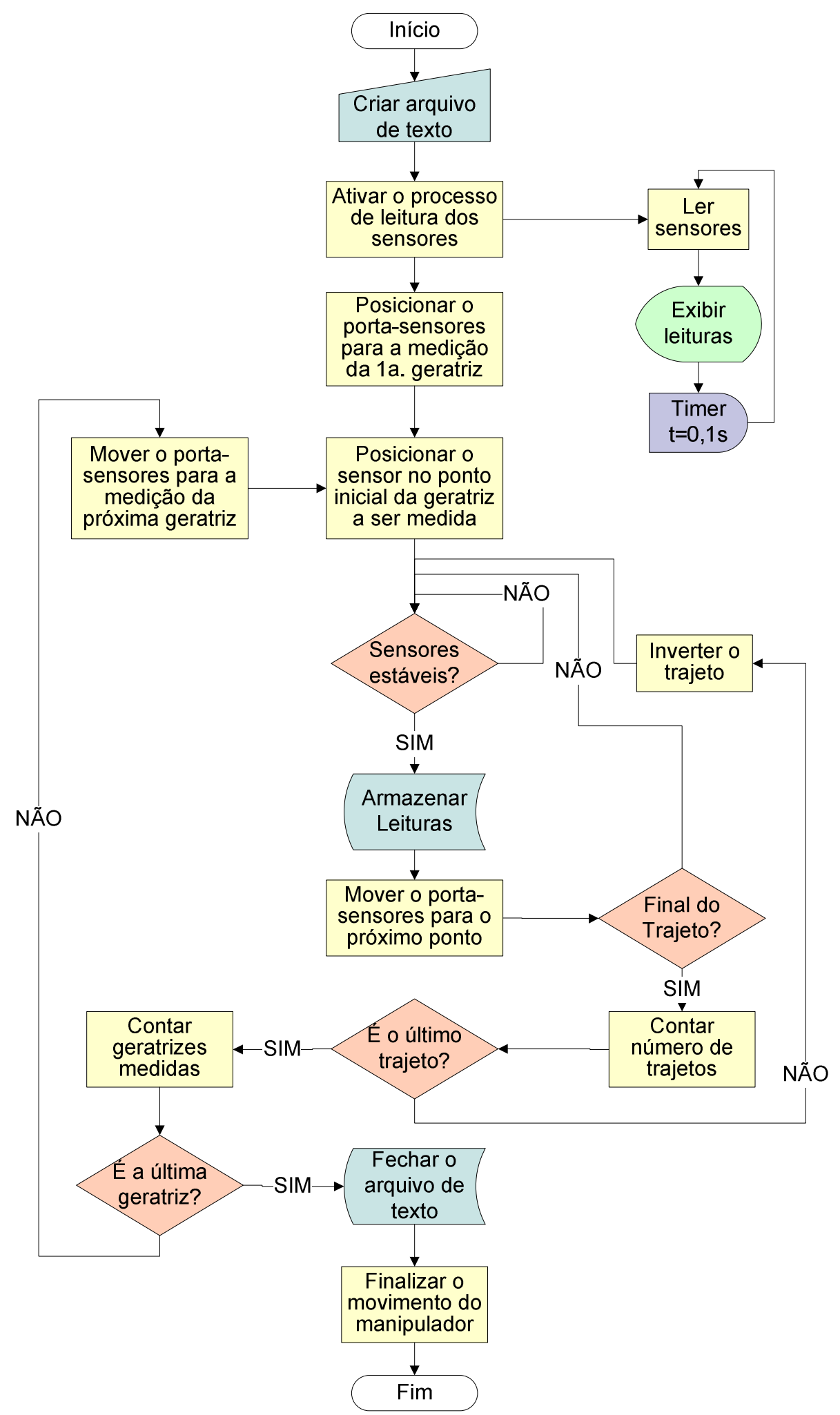

Figura 5.9 - Fluxograma da rotina de medição. 
No diagrama apresentado, pode-se observar que, uma vez ativado, o processo de leitura dos sensores é executado repetidamente e com alta freqüência durante todo o processo de aquisição. Assim, as leituras exibidas na tela são constantemente atualizadas. Paralelamente ao processo de leitura, o robô recebe comandos para posicionar os sensores nos pontos de medição. Assim, primeiramente, o manipulador é programado para se posicionar no ponto inicial da primeira geratriz a ser medida. A leitura deste ponto é armazenada e o manipulador move-se para o próximo ponto de medição sobre esta mesma geratriz. Estes passos são repetidos até que o manipulador posicione os sensores no último ponto da geratriz que está sendo medida. Na seqüência, inicia-se o trajeto de volta e todo o processo é repetido. Uma mesma reta geratriz é medida múltiplas vezes e os valores lidos durante os trajetos de ida e volta são armazenados.

Depois que o manipulador executou o um número requerido de repetições da medição de uma geratriz, o programa de movimentação envia comandos ao robô para que os sensores sejam conduzidos à geratriz seguinte e percorram todos os pontos de medição desta. Os passos descritos são repetidos até que a última geratriz seja medida.

Antes que um dado valor lido seja armazenado, realiza-se uma verificação da estabilidade dos sensores por meio da comparação de médias de subconjuntos de leituras tomadas em intervalos de tempo consecutivos.

O fluxograma apresentado se aplica também à medição das retas transversais.

O programa de aquisição de dados utilizado neste trabalho foi inicialmente desenvolvido por Paziani (2005). Este programa, contudo, originalmente elaborado para a coleta de dados do perfil de uma única reta, foi adaptado para a coleta de dados do perfil de múltiplas retas geratrizes. Estes dados, em última análise, serão utilizados para a obtenção de pontos do perfil de superfícies, e não apenas retas. Outras alterações menores também foram realizadas, para ajuste da 
comunicação entre robô e microcomputador. O programa foi escrito em linguagem Delphi, o que permitiu a inclusão de diversos elementos gráficos como botões e rótulos, tornando a interface amigável ao usuário.

Conforme observado, para que uma medição seja executada e os dados sejam coletados, é necessário haver um sistema de comunicação entre o programa de aquisição de dados e a rotina de movimentação do manipulador. Esta comunicação é realizada por meio de 3 canais analógicos. No Quadro 5.2 são exibidas as saídas e entradas destes canais, presentes na placa de aquisição de dados e no manipulador.

Quadro 5.2 - Entradas e saídas analógicas de comunicação entre manipulador e computador.

\begin{tabular}{|cc|cc|}
\hline Placa de Aquisição de dados no PC & & ROBô \\
\hline Saída Analógica - Canal 0 & & $\longrightarrow$ & Entrada Analógica - AI 1 \\
\hline Entrada Analógica - Canal 6 & & & Saída Analógica - AO 1 \\
\hline Saída Analógica - Canal 1 & & $\longrightarrow$ & Entrada Analógica - AI 2 \\
\hline
\end{tabular}

O Quadro 5.3 a seguir apresenta a execução em paralelo das principais instruções da rotina de movimentação do manipulador e do programa de aquisição de dados. Com esta abordagem, busca-se demonstrar o inter-relacionamento entre estas duas rotinas, bem como a comunicação entre estes dois componentes do sistema de medição: microcomputador e manipulador. Cada instrução da rotina executada pelo computador e pelo robô é designada, respectivamente, pelas letras $\mathrm{C}$ e R.

O manipulador é comandado para mover-se ao próximo ponto de medição do trajeto e para posicionar-se em cada geratriz utilizando-se sub-rotinas de repetição do tipo "for", sendo que a cada repetição, as coordenadas de posicionamento recebem incrementos de valor equivalente ao passo de medição. No quadro, tais instruções foram simplificadas para que o enfoque fosse dado à execução paralela das duas rotinas. Assim, os laços de repetição não foram apresentados com detalhes, sendo apenas designados por "sub-rotina de movimentação" e representados pela instrução R7. 


\section{2}

Quadro 5.3 - Rotinas de medição executadas em paralelo pelo microcomputador e pelo manipulador.

\begin{tabular}{|c|c|c|c|}
\hline \multicolumn{2}{|r|}{ PC } & \multicolumn{2}{|r|}{ ROBÔ } \\
\hline $\mathrm{C} 1$ & Inicialização da placa de Aquisição & R1 & $\begin{array}{l}\text { O robô zera suas entradas analógicas } \\
\text { e zera a saída anaógica } A O 1\end{array}$ \\
\hline C2 & $\begin{array}{l}\text { Envio do número } 0 \text { (em formato de } \\
\text { número A/D de } 12 \text { bits), que, após a } \\
\text { conversão D/A, corresponde a uma } \\
\text { tensão nula. Esta tensão aparece no } \\
\text { Canal } 0 \text { de saída analógica do PC }\end{array}$ & R2 & $\begin{array}{l}\text { Espera até que a entrada analógica } \mathrm{AI} \\
1 \text { receba um valor de tensão entre } 1 \mathrm{~V} \\
\text { e } 1,5 \mathrm{~V}\end{array}$ \\
\hline C3 & $\begin{array}{l}\text { A função "timer" do programa começa } \\
\text { a ler os Canais digitais } 0,2 \text { e } 4 \text {, que } \\
\text { recebem os sinais dos sensores LVDT. } \\
\text { Tais leituras são realizadas durante } \\
\text { toda a execução do programa, com } \\
\text { uma freqüência de } 0,1 \mathrm{~s} \text {, sendo } \\
\text { continuamente atualizadas e exibidas } \\
\text { na tela. }\end{array}$ & & \\
\hline C4 & $\begin{array}{l}\text { Criação e inicialização de um arquivo } \\
\text { de texto para armazenar os dados } \\
\text { (usuário pressiona o botão SALVAR) }\end{array}$ & & \\
\hline C5 & O botão INICIAR é habilitado & & \\
\hline C6 & $\begin{array}{l}\text { Início do ciclo de medição (quando o } \\
\text { usuário pressiona o botão INICIAR) }\end{array}$ & & \\
\hline C7 & $\begin{array}{l}\text { Envio do número } 0 \text { no canal de saída } \\
\text { analógica } 1 \text {. Este é um procedimento } \\
\text { de set-up incial, para que o } \\
\text { manipulador aguarde instruções do } \\
\text { computador }\end{array}$ & & \\
\hline \multirow[t]{8}{*}{$\mathrm{C} 8$} & 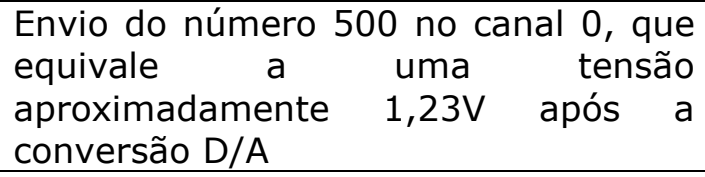 & & \\
\hline & & R3 & $\begin{array}{l}\text { Leitura da tensão de } 1,23 \mathrm{~V} \text { na entrada } \\
\text { AI } 1 \text { e início da movimentação }\end{array}$ \\
\hline & & R4 & $\begin{array}{l}\text { Movimentação para o ponto próximo } \\
\text { da peça (ponto de aproximação) }\end{array}$ \\
\hline & & R5 & $\begin{array}{l}\text { Movimentação para o primeiro ponto } \\
\text { de medição }\end{array}$ \\
\hline & & R6 & Sub-rotina de Movimentação \\
\hline & & R7 & $\begin{array}{l}\begin{array}{l}\text { Movimentação para } 0 \\
\text { medição }\end{array} \\
\end{array}$ \\
\hline & & R8 & $\begin{array}{l}\text { Início da sub-rotina de } \\
\text { Armazenagem }\end{array}$ \\
\hline & & R9 & $\begin{array}{l}\text { - Ativa a saída analógica } A O 1 \text { e envia } \\
\text { um sinal que corresponde a um } \\
\text { número de } 12 \text { bits }>2500\end{array}$ \\
\hline C9 & $\begin{array}{l}\text { Leitura do canal } 6 \text { (entrada analógica). } \\
\text { Se este canal recebe uma tensão } \\
\text { correspondente a um número }>2500 \text {, } \\
\text { enviada pelo robô, e os sensores } \\
\text { estão estáveis, inicia-se a sub-rotina } \\
\text { de armazenagem. A leitura do canal } 6 \\
\text { está relacionada à função "timer", }\end{array}$ & R10 & $\begin{array}{l}\text { - Espera até que a entrada analógica } \\
\text { AI } 2 \text { seja } \geq 1 \mathrm{~V} \text {. Este canal até então } \\
\text { está lendo uma tensão em torno de } \\
0 \mathrm{~V} \text {, devido à instrução } \mathrm{C} 7 \text { executada } \\
\text { pelo microcomputador ou devido à } \\
\text { instrução C18, caso o ciclo de } \\
\text { movimentação esteja sendo repetido. }\end{array}$ \\
\hline
\end{tabular}




\begin{tabular}{|c|c|c|c|}
\hline & 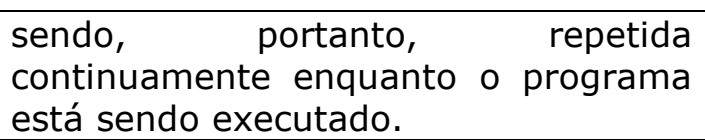 & & \\
\hline $\mathrm{C} 10$ & $\begin{array}{l}\text { Verificação da estabilidade dos } \\
\text { sensores, mediante a comparação de } \\
\text { leituras consecutivas realizadas com } \\
\text { uma determinada freqüência } \\
\text { (utilizando a função "timer") }\end{array}$ & & \\
\hline C11 & $\begin{array}{lll}\text { Início da sub-rotina } & \text { de } \\
\text { Armazenagem } & & \end{array}$ & & \\
\hline $\mathrm{C} 12$ & $\begin{array}{l}\text { - As leituras dos canais } 0,2 \text { e } 4, \\
\text { correspondentes aos LVDTs, são } \\
\text { truncadas e armazenadas em } 3 \\
\text { vetores distintos }\end{array}$ & & \\
\hline $\mathrm{C} 13$ & $\begin{array}{l}\text { - os valores armazenados em cada } \\
\text { vetor são escritos no arquivo de texto }\end{array}$ & & \\
\hline $\mathrm{C} 14$ & $\begin{array}{l}\text { - os dados armazenados no arquivo } \\
\text { são exibidos na tela }\end{array}$ & & \\
\hline $\mathrm{C} 15$ & $\begin{array}{l}\text { - Um sinal de tensão bem maior do } \\
\text { que } 1 V \text { (aproximadamente } 7,3 \mathrm{~V} \text { ) é } \\
\text { enviado no Canal } 1 \text {, para sinalizar ao } \\
\text { robô que o dado já foi armazenado }\end{array}$ & & \\
\hline \multirow[t]{3}{*}{ C16 } & $\begin{array}{l}\text { - Leitura contínua do canal } 6 \text { e } \\
\text { espera até que o robô abaixe a } \\
\text { tensão neste canal, o que ocorrerá } \\
\text { na instrução R12 }\end{array}$ & R11 & $\begin{array}{l}\text { Leitura da tensão enviada pelo } \\
\text { microcomputador em C15, } \\
\text { recebida na entrada AI } 2\end{array}$ \\
\hline & & R12 & $\begin{array}{l}\text { Envio de uma tensão nula na } \\
\text { saída analógica AO } 1\end{array}$ \\
\hline & & R13 & $\begin{array}{l}\text { Fim da sub-rotina de } \\
\text { Armazenagem }\end{array}$ \\
\hline C17 & $\begin{array}{l}\text { - Percepção da queda de tensão no } \\
\text { canal } 6 \text { (executada em R12) }\end{array}$ & R14 & $\begin{array}{l}\text { Tempo de espera com duração } \\
\text { ajustada, para que o PC possa } \\
\text { executar a instrucão C18 }\end{array}$ \\
\hline C18 & $\begin{array}{l}\text { - Envio de tensão nula por meio do } \\
\text { canal } 1 \text {. Este sinal será lido pela } \\
\text { rotina do robô em R10 e garantirá } \\
\text { que o robô pare no próximo ponto } \\
\text { de medição. }\end{array}$ & R15 & $\begin{array}{l}\text { Retorno ao início da sub-rotina de } \\
\text { Movimentação (R6) }\end{array}$ \\
\hline \multirow[t]{3}{*}{ C19 } & $\begin{array}{l}\text { Fim da sub-rotina de } \\
\text { Armazenagem }\end{array}$ & R16 & $\begin{array}{l}\text { Fim da Sub-rotina } \\
\text { Movimentação }\end{array}$ \\
\hline & & R17 & $\begin{array}{llll}\text { Movimentação para } & \text { um } \\
\text { afastado da peca }\end{array}$ \\
\hline & & & Fim da rotina do Robô \\
\hline $\mathrm{C20}$ & Fechamento do arquivo de dados & & \\
\hline \multirow[t]{2}{*}{$\mathrm{C} 21$} & $\begin{array}{l}\text { Mensagem ao usuário: Aquisição } \\
\text { Finalizada }\end{array}$ & & \\
\hline & Fim da rotina do $\mathbf{P C}$ & & \\
\hline
\end{tabular}




\subsection{Rotinas de Pré-Processamento dos dados para obtenção de perfis de superfície}

Por meio das rotinas apresentadas, realiza-se a medição do perfil das várias retas geratrizes e transversais que compõem uma determinada superfície de uma peça. Para que o desvio de planicidade ou a inclinação de uma superfície sejam calculados, é necessário primeiramente obter-se, a partir dos dados do perfil das retas, conjuntos de pontos que representem o perfil desta superfície. Isto implica conhecer a altura relativa entre as geratrizes, combinando os dados de geratrizes com os dados do perfil de uma reta transversal. Esta transversal será utilizada como reta-base, e o valor de altura medido sobre esta reta-base em um dado ponto de intersecção com uma dada geratriz deve ser adicionado às alturas de todos os pontos desta geratriz. Assim, aos valores do conjunto de pontos de cada geratriz será adicionado um valor altura de altura determinado, que difere de geratriz para geratriz. Tal valor é que define a altura relativa entre as geratrizes do perfil. A Figura 5.10 apresenta o mapa de medição da Peça 1 e Peça 2. As geratrizes e retas-base foram destacadas.

Segundo o pré-processamento definido, o valor de altura medido sobre a reta transversal T1 no ponto zero deverá ser somado ao perfil da geratriz $\mathrm{G} 1$, enquanto que o valor medido no ponto 1 da reta $T 1$ será adicionado a todos as alturas da geratriz G2, e assim sucessivamente.

Este procedimento de inter-relacionamento de dados em direções ortogonais ou procedimentos similares são tradicionalmente utilizados para a obtenção de perfis de superfícies, e sua utilização é necessária quando se emprega a maioria dos métodos de avaliação de desvios de forma e orientação que envolvem planos. Assim, de acordo com o método citado, mediante a combinação de perfis de retas-base distintas com um mesmo conjunto de geratrizes, obtêm-se vários perfis que representam cada superfície medida. No caso da figura, esta combinação, utilizando-se as 6 retas transversais destacadas, dará origem a 6 perfis da superfície. 


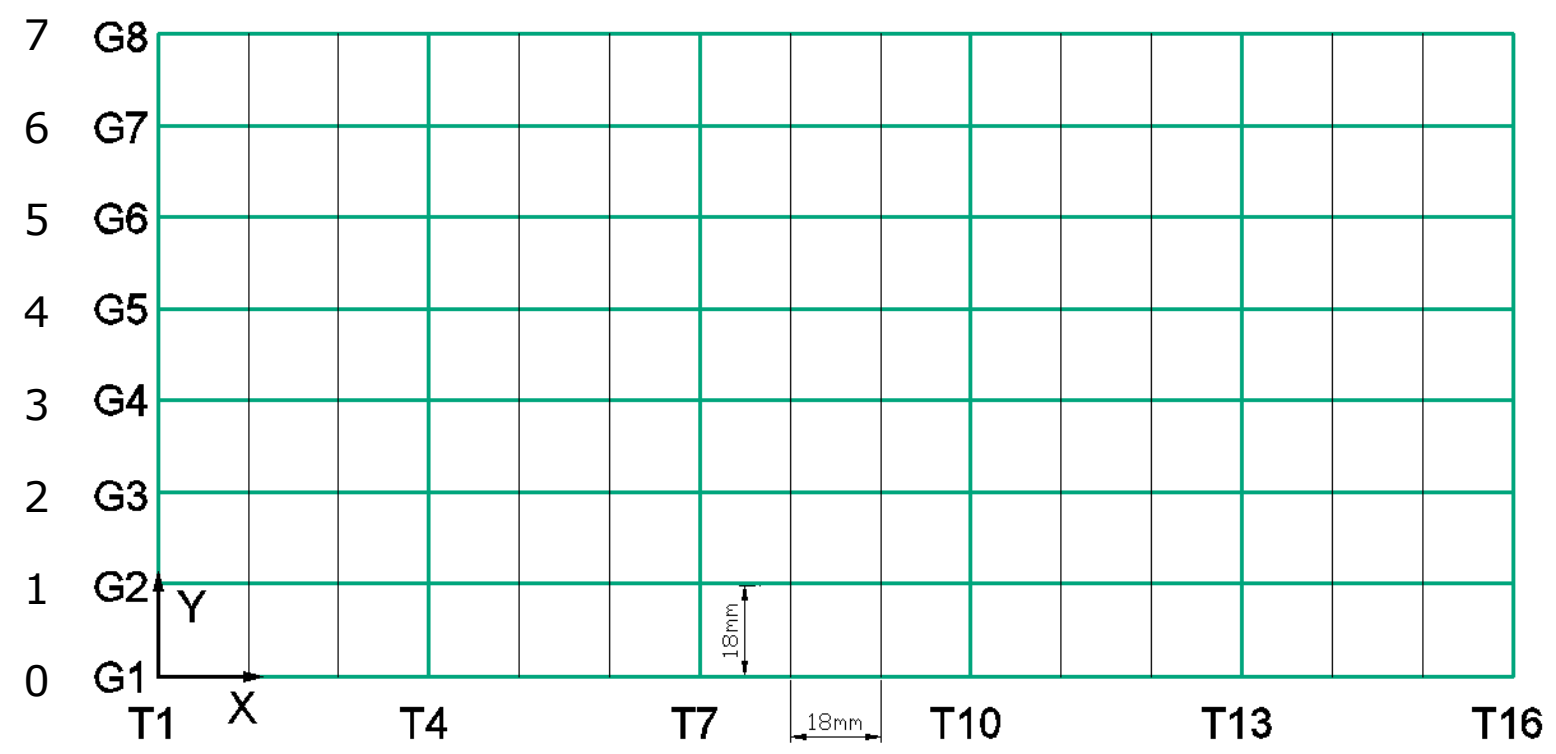

Figura 5.10 - Mapa de medição da Peça 1 e Peça 2.

Para a obtenção do perfil destas retas-base, também é necessário aplicar-se o modelo de separação de erros aos dados coletados pelo manipulador na direção secundária de medição, isto é, na direção transversal. O procedimento global para a obtenção do perfil de superfícies e avaliação de sua inclinação é apresentado abaixo. Como se pode observar, este procedimento inclui a aplicação do algoritmo de separação de erros e dos algoritmos de avaliação de erros de forma, os quais serão discutidos posteriormente.

1. Coletar leituras dos pontos das geratrizes;

2. Coletar leituras dos pontos das transversais;

3. Aplicar o modelo de separação de erros nos conjuntos de dados de cada reta geratriz, obtendo-se um perfil para cada uma destas retas;

4. Aplicar o modelo de separação de erros nos conjuntos de dados de cada reta transversal, obtendo-se um perfil para cada uma destas retas;

5. Combinar dados do perfil das geratrizes com dados das transversais, obtendo perfis de superfície; 
6. Aplicar algoritmos de ajustagem da forma geométrica de referência, que neste caso é um plano, ao conjunto de pontos do perfil;

7. Calcular os desvios de forma e orientação com base nos parâmetros do plano ajustado.

\subsection{Modelo e Rotina para a Separação de Erros}

O modelo de separação de erros adotado neste trabalho baseia-se no Método dos Três Pontos, apresentado no capítulo 3. Assim sendo, o modelo aplica-se a sistemas de medição que utilizam três sensores alinhados e utiliza o princípio da redundância de dados. Optou-se pela utilização do método Seqüencial, no qual o passo de medição é igual à distância entre os sensores. Tal modelo foi inicialmente proposto por Paziani (2005) para a avaliação do desvio de retilineidade, e é apresentado na Figura 5.11. A direção de avanço ou varredura corresponde ao eixo $x$, enquanto que a medição é realizada na direção do eixo $z$.

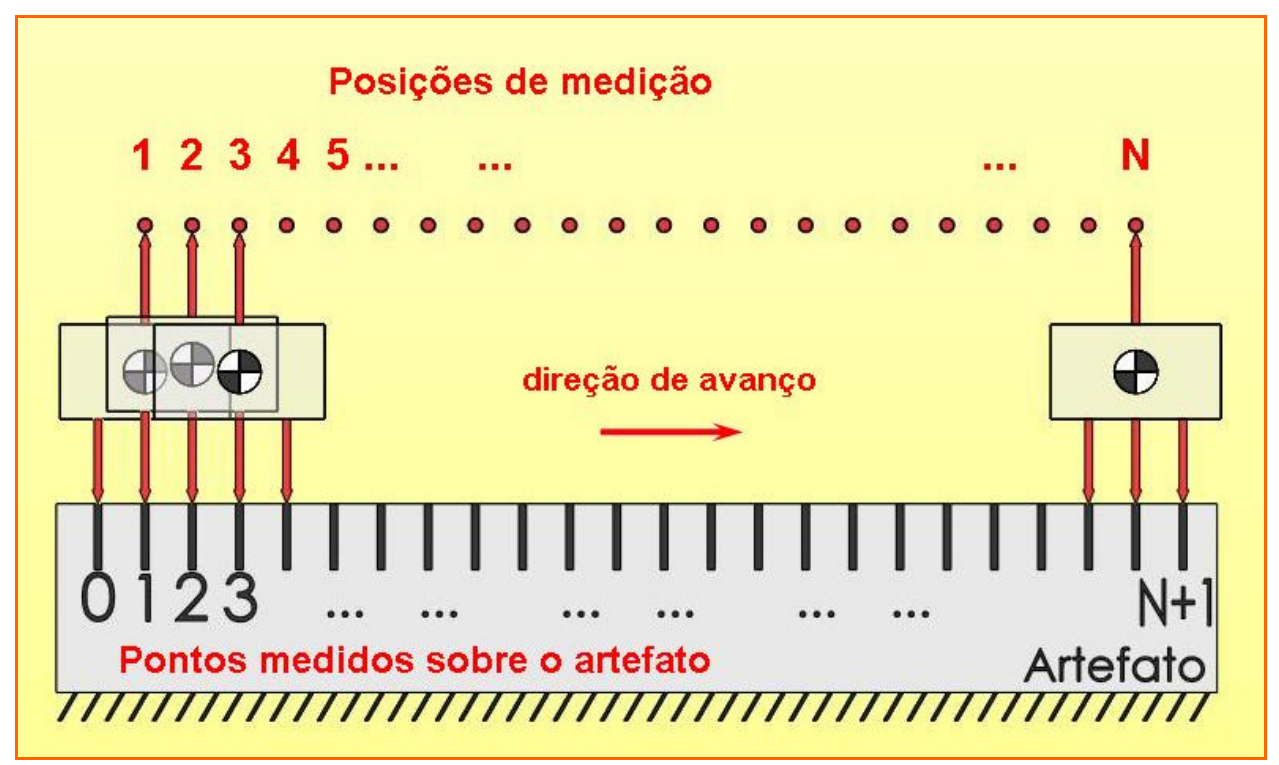

Figura 5.11 - Diagrama do modelo de separação de erros.

Alguns autores propõem como solução para este modelo a integração de um diferencial obtido a partir das leituras medidas, conforme exposto no capítulo 3. O trabalho de Magalhães (2006) 
demonstra que o componente parabólico de erro presente nesta solução distorce os resultados de forma muito significativa, não permitindo que os valores do perfil do componente sejam obtidos com acuracidade. Assim, esta solução baseada em um diferencial de leituras mostrou-se inviável. Diante desses fatos, Paziani, Di Giacomo e Tsunaki (2007) propuseram um modelo que se traduz em um sistema linear que pode ser resolvido diretamente. Para que o sistema tenha solução direta, é necessária a obtenção de linhas extras de equações e dados, as quais, por sua vez, são conseguidas por meio da realização de múltiplas medições de cada ponto.

A adoção deste modelo e da solução direta do sistema linear estabelece a continuidade de uma linha de pesquisa em desenvolvimento no Laboratório de Metrologia da Escola de Engenharia de São Carlos, USP. Assim, o trabalho aqui proposto estende as aplicações do modelo de separação de erros e do método de solução dos autores supracitados, aplicando tais modelos para a avaliação de erros de planicidade, paralelismo e perpendicularismo.

O desenvolvimento do modelo apóia-se no reconhecimento de quatro fontes de erro principais presentes no sistema de medição: os desvios no perfil da peça, os erros de movimentação translacional do robô, os erros devido à inclinação do dispositivo porta-sensores e os erros devido ao desalinhamento inicial entre os sensores. Admite-se como hipótese que estes erros são independentes, isto é, não se influenciam mutuamente. Além disso, assume-se que as leituras fornecidas por cada sensor sejam uma combinação linear de valores representativos destas quatro fontes de erro citadas. A conjunto de equações 5.1. traduz estas afirmações.

$$
\left\{\begin{array}{c}
L_{A i}=E_{A i}^{P}+E_{A i}^{R}+E_{A i}^{\delta}+E_{A i}^{s} \\
L_{B i}=E_{B i}^{P}+E_{B i}^{R}+E_{B i}^{\delta}+E_{B i}^{s} \\
L_{C i}=E_{C i}^{P}+E_{C i}^{R}+E_{C i}^{\delta}+E_{C i}^{s} \\
i=1,2,3, \ldots, N,
\end{array}\right.
$$

onde $L_{A i} L_{B i}$ e $L_{C i}$ são as leituras de cada sensor na i-ésima posição de medição; $E^{P}$ é o erro do perfil da peça lido por cada um dos sensores, A, B 
e $C ; E_{i}^{R}$ é a componente do erro de translação do robô na i-ésima posição; $E^{\delta}{ }_{i}$ é o erro de inclinação do porta sensores na posição de medição $i$ e $E^{s}$ é a componente de erro devido ao desalinhamento entre os sensores. $O$ índice $i$ define uma posição de medição, enquanto $\mathrm{N}$ é o número total de posições de medição, definido pelo número de vezes em que o manipulador posiciona os sensores para realizar medições. No próximo item, este índice será definido com mais detalhes.

\subsubsection{Erros no perfil da peça $\left(E^{p}\right)$}

Estes erros correspondem às variações de altura que se deseja medir sobre a peça, ou seja, constituem-se desvios com relação a um perfil ideal definido. No caso de avaliação da retilineidade, este perfil ideal é uma reta.

Uma hipótese importante do modelo é que o erro da peça em um dado ponto é o mesmo em todas as medições deste ponto. Em outras palavras, as variações nos valores lidos em um mesmo ponto por um mesmo sensor ou por diferentes sensores se devem às variações de posicionamento do manipulador, às variações na inclinação do dispositivo porta-sensores e no alinhamento entre os sensores. Assume-se que a parcela das leituras correspondente ao perfil real da peça em um dado ponto permaneça constante em todas as medições daquele ponto. Isto é bastante razoável já que os desvios em relação a um perfil ideal são características intrínsecas da peça sendo medida. Além disso, pode-se assumir que as pequenas diferenças na posição em que um ponto é coletado em cada medição, isto é, as pequenas variações nas coordenadas de posicionamento $x$ e $y$, não geram variações significativas no valor dos desvios pontuais medidos. Do ponto de vista mecânico, nos casos ordinários, estas variações da superfície da peça, resultantes da usinagem, são suaves, de gradientes bem pequenos.

O desvio de um ponto da peça com relação ao perfil ideal pode ser definido no modelo como: 


$$
\left\{\begin{array}{c}
E_{A i}^{P}=R_{i-1}^{P}+\left(C A_{P}+A_{P .} x_{i-1}\right) \\
E_{B i}^{P}=R_{i}^{P}+\left(C A_{P}+A_{P} \cdot x_{i}\right) \\
E_{C i}^{P}=R_{i+1}^{P}+\left(C A_{P}+A_{P .} x_{i+1}\right) \\
i=1,2,3, \ldots, N,
\end{array}\right.
$$

onde o perfil da peça, ou seja, as variações de altura em um dado ponto são representadas pela variável $R^{P}$, sendo que tais variações são medidas com relação a uma reta de referência, definida pelos parâmetros $C A_{p}$ e $A_{p}$.

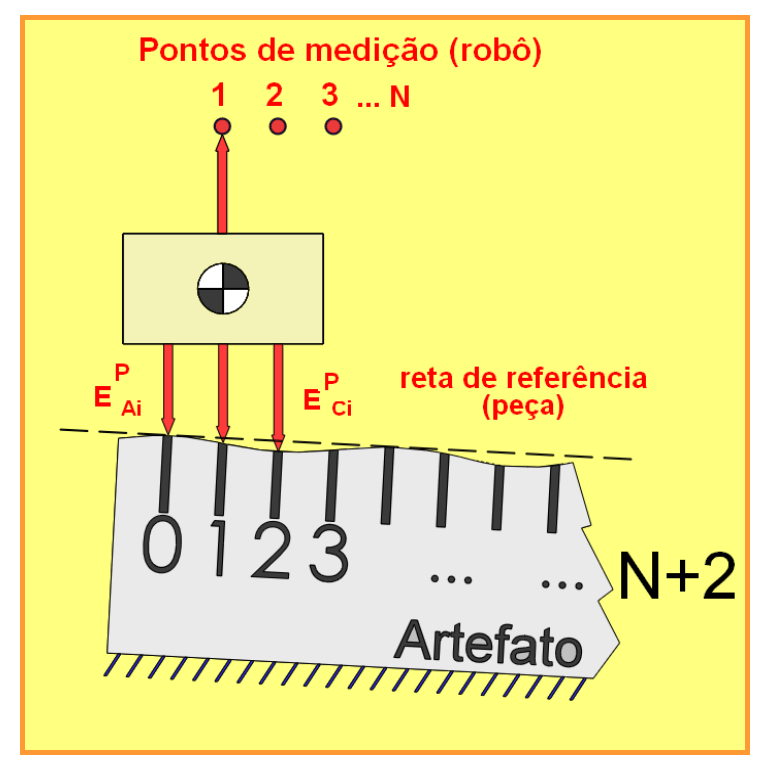

Figura 5.12 - Erros no perfil da peça, reta de referência e posições de medição.

O índice $i$ utilizado nas equações determina um ponto de medição ou uma posição de medição, assumida a cada vez que o manipulador posiciona os sensores sobre o artefato para realizar leituras. Tal índice é diferente dos índices que representam a posição de um ponto medido sobre o artefato. Quando o robô move-se para a posição de medição i, três pontos distintos são medidos: o sensor $A$ mede o ponto de coordenada $x_{i-1}$, o sensor B mede o ponto de coordenada $x_{i}$ e o sensor C mede o ponto seguinte, de coordenada $x_{i+1}$. Se o número total de posições de medição é $\mathrm{N}$, isto significa que cada sensor tocou o artefato $\mathrm{N}$ vezes, e o número de pontos medidos sobre o artefato é $\mathrm{N}+2$, conforme apresentado na Figura 5.12. É devido a esta estrutura de índices que os valores das alturas $\mathrm{R}^{\mathrm{P}}$ medidas pelos sensores $\mathrm{A}, \mathrm{B}$ e $\mathrm{C}$ recebem os índices $i-1, i$ e $i+1$ respectivamente, conforme exposto na equação 5.2 . 


\subsubsection{Erros de movimentação translacional do robô $\left(E^{R}\right)$}

No modelo proposto foram incluídos erros associados à translação do conjunto de sensores em cada medição. Estes erros advêm da acuracidade limitada de posicionamento do robô. Greenway (2000) definiu a acuracidade dos robôs como sendo o máximo erro de posição ou orientação apresentado pelo robô ao mover-se para qualquer ponto no espaço cartesiano. Sabe-se que o manipulador apresenta erros de posicionamento ao atingir um determinado ponto coordenado no espaço, isto é, há diferenças entre os valores das coordenadas da posição real assumida e os valores das coordenadas nominais da posição estabelecida. Além disso, o robô também apresenta erros de repetibilidade, ou seja, apresenta certos desvios de posição e orientação ao retornar a um determinado ponto várias vezes. Assim, a cada vez que o dispositivo porta-sensores é conduzido a um dado ponto de medição, os erros de posicionamento e repetibilidade do manipulador causam uma variação do posicionamento dos sensores. A componente desta variação na direção $z$, isto é, na direção de sensibilidade dos sensores modifica significativamente o valor lido. Esta parcela de erro, portanto, deve ser quantificada e descontada do valor das leituras. O erro de movimentação translacional do manipulador é modelado de forma semelhante ao erro do perfil da peça:

$$
\left\{\begin{array}{c}
E^{R}{ }_{A i}=R^{R}{ }_{i}+\left(C A_{R}+A_{R \cdot} \cdot x_{i}\right) \\
E^{R}{ }_{B i}=R^{R}{ }_{i}+\left(C A_{R}+A_{R} \cdot x_{i}\right) \\
E^{R}{ }_{C i}=R^{R}{ }_{i}+\left(C A_{R}+A_{R .} x_{i}\right) \\
i=1,2,3, \ldots, N,
\end{array}\right.
$$

onde $R^{R}$ é o erro translacional do robô ao assumir uma posição de medição $i$, e $C A_{R}$ e $A_{R}$ são os parâmetros de uma reta de referência para a movimentação do manipulador.

No modelo pode-se considerar que os três sensores, quando posicionados num ponto de medição $i$, estão sujeitos a um mesmo erro translacional do robô, $E^{R}{ }_{i}$. A Figura 5.13 mostra uma representação do 
erro de movimentação translacional do robô e a reta de referência dessa movimentação.

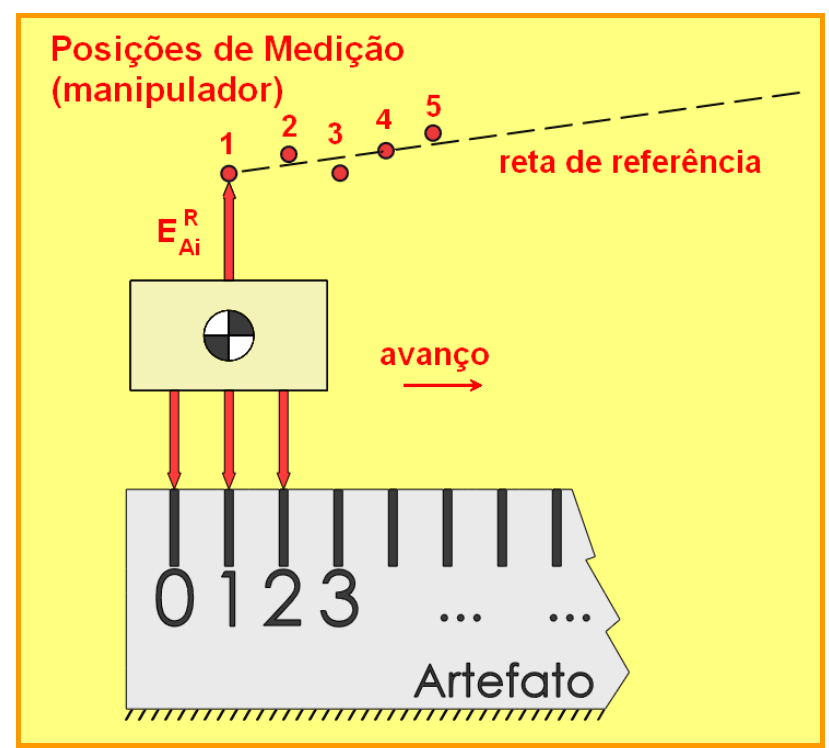

Figura 5.13 - Representação do erro translacional do manipulador.

\subsubsection{Erros devido à inclinação do porta-sensores $\left(E^{\delta}\right)$}

Além do erro translacional do robô ao posicionar os sensores, no modelo de separação considera-se a existência de erros de inclinação do dispositivo porta-sensores. Como o dispositivo é simétrico e simetricamente fixado ao punho do manipulador, pode-se admitir que rotações ocorram em torno de um eixo paralelo ao eixo $y$ e que intercepta o eixo do sensor central B, conforme apresentado na Figura 5.14. Assim, segundo o modelo proposto, essas rotações não modificam o valor lido pelo o sensor central e afetam os dois sensores externos de maneira oposta:

$$
\left\{\begin{array}{l}
E_{A i}^{\delta}=-\delta_{i} \\
E_{B i}^{\delta}=0 \\
E_{C i}^{\delta}=\delta i
\end{array}\right.
$$

onde $\delta_{i}$ é o desvio devido à rotação do porta sensores na i-ésima posição, dado por:

$$
\delta i=\theta_{i} \cdot L
$$


onde $\theta_{\mathrm{i}}$ é o ângulo de rotação do porta sensores, em torno de um eixo paralelo ao eixo $y$ (pitch), em radianos, e $L$ é a distância de separação entre os sensores.

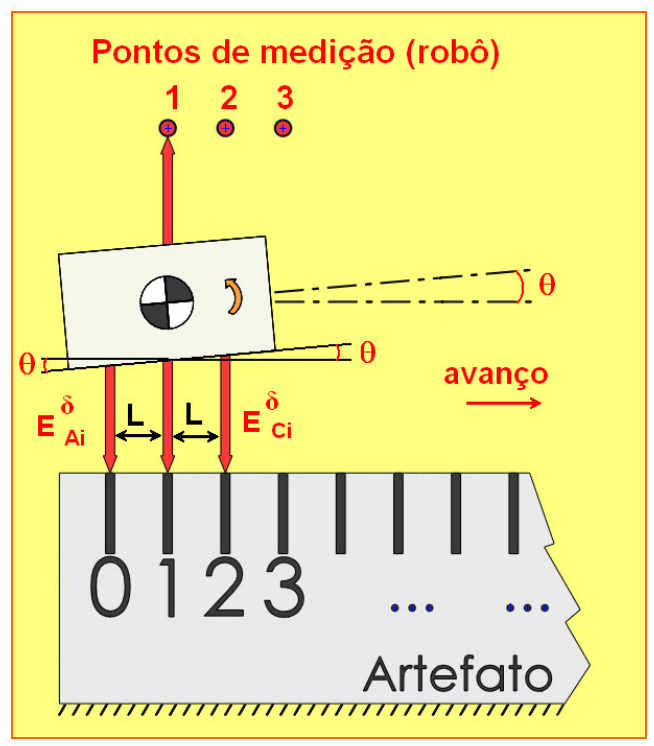

Figura 5.14 - Representação do erro de inclinação do dispositivo porta-sensores.

\subsubsection{Erro de alinhamento axial dos sensores}

$\mathrm{Na}$ exposição das bases teóricas que fundamentam este trabalho, menciona-se a existência de um desalinhamento inicial entre as posições nulas dos sensores de medição utilizados no Método dos Três Pontos, desalinhamento este que contribui de forma significativa para a distorção das leituras dos pontos do perfil. Quando se adota a solução apresentada por Gao e Kyono (1997) para este método, o erro de alinhamento entre os sensores dá origem a um erro parabólico que distorce o perfil resultante de forma muito significativa, a ponto de inviabilizar a utilização desta solução. Tal fato foi constatado no trabalho de Magalhães (2006).

Uma alternativa para diminuir a influência desse erro de alinhamento seria a realização de um procedimento de calibração utilizando-se um plano de referência para obter o alinhamento ideal dos sensores. Contudo, erros inevitáveis envolvidos nesse procedimento experimental impedem a obtenção de um alinhamento físico adequado e com a acuracidade necessária para servir de referência absoluta para os valores a serem lidos. Dessa forma, uma parcela correspondente ao erro 
causado pelo desalinhamento dos sensores deve ser incluída na equação que modela as leituras do perfil. Além disso, é necessário desenvolver soluções capazes de quantificar este erro para que seja possível eliminá-lo dos valores lidos.

No modelo adotado, estabelece-se um sistema de referência a partir das leituras zero dos sensores das extremidades e o desalinhamento entre os sensores é expresso como um erro de posicionamento do sensor central, como pode ser observado na Figura 5.15. Este erro de posicionamento do sensor central é designado por $\mathrm{k}_{\mathrm{B}}$.

Segundo Paziani (2005), escolhendo-se os sensores das extremidades como referência, define-se também a orientação de um sistema de coordenadas. Tal sistema é definido pela reta que passa pelos pontos de referência dos sensores das extremidades, a qual corresponde ao eixo x mostrado na Figura 5.15, e pela reta perpendicular à anterior, denominada eixo $z$. A origem deste sistema de coordenadas coincide com o primeiro ponto do desvio de retilineidade do perfil da peça, que é arbitrariamente definido como zero. Assim, o erro de desalinhamento dos sensores pode ser expresso como:

$$
\left\{\begin{array}{l}
E_{A i}^{S}=0 \\
E_{B i}^{S}=k_{B} \\
E_{C i}^{S}=0
\end{array}\right.
$$

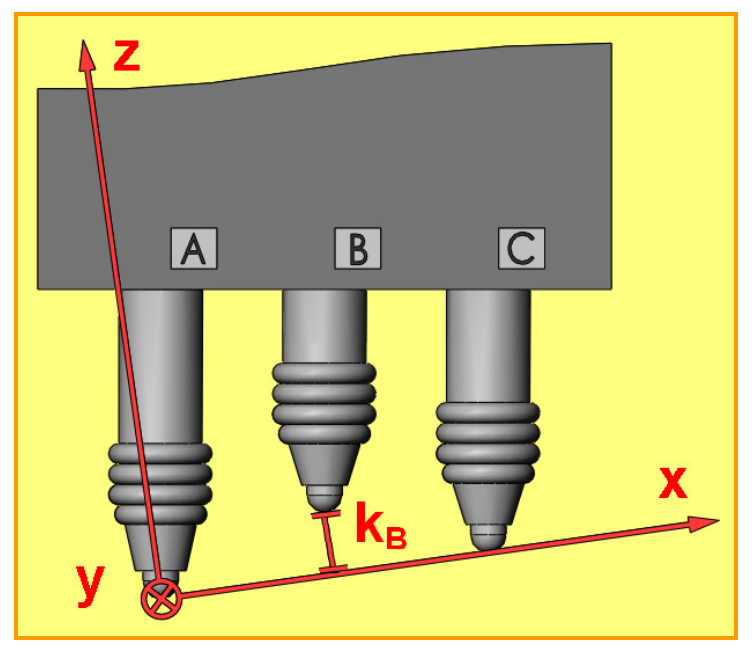

Figura 5.15 - Erro de alinhamento inicial dos sensores. 


\subsubsection{Equações do modelo de separação de erros}

O sistema linear final que representa o modelo de separação de erros aplicado neste trabalho é obtido pela substituição das parcelas da equação 5.1 pelas expressões que definem cada tipo de erro. Assim, obtém-se:

$L_{A i}=R_{i-1}^{P}+\left[C A_{P}+A_{P \cdot} \cdot x_{i-1}\right]+R_{i}^{R}+\left[C A_{R}+A_{R} \cdot x_{i}\right]-\theta_{i} \cdot L$
$L_{B i}=R_{P i}+\left[C A_{P}+A_{P} \cdot x_{i}\right]+R_{R i}+\left[C A_{R}+A_{R} \cdot x_{i}\right]+k_{B}$
$L_{C i}=R_{i+1}^{P}+\left[C A_{P}+A_{P .} x_{i+1}\right]+R_{R i}\left[C A_{R}+A_{R} \cdot x_{i}\right]+\theta_{i} \cdot L$

O passo de medição utilizado para a coleta de dados com o Sistema Automatizado de medição é constante. Assim, realiza-se a medição de um conjunto discreto de pontos regularmente espaçados. É possível simplificar as matrizes correspondentes ao sistema linear apresentado realizando-se uma mudança de coordenadas $x_{i} \rightarrow i$. Os valores das variações de altura que caracterizam o perfil real da peça não são afetados por esta mudança, ou seja, os resultados fornecidos pelo algoritmo de separação de erros não se modificam com a aplicação da referida mudança de coordenadas. O valor obtido para o desvio de planicidade da superfície também não depende da distância horizontal entre os pontos medidos. Esta mudança de coordenadas, contudo, afeta os valores de inclinação das superfícies, ou seja, causa alterações nos valores dos coeficientes de inclinação do plano ajustado ao perfil da superfície. Assim, matrizes com coordenadas verdadeiras devem ser utilizadas nas rotinas de avaliação dos erros de paralelismo e perpendicularismo.

Executando-se a mudança de coordenadas citada, obtém-se o seguinte equacionamento para o modelo de separação de erros:

$$
\begin{aligned}
L_{A i} & =R_{i-1}^{P}+\left[C A_{P}+A_{P \cdot}(i-1)\right]+R_{i}^{R}+\left[C A_{R}+A_{R} \cdot i\right]-\theta_{i} \cdot L \\
L_{B i} & =R_{P i}+\left[C A_{P}+A_{P} \cdot i\right]+R_{R i}+\left[C A_{R}+A_{R} \cdot i\right]+k_{B} \\
L_{C i} & =R_{i+1}^{P}+\left[C A_{P}+A_{P .}(i+1)\right]+\left[C A_{R}+A_{R} \cdot i\right]+\theta_{i} \cdot L
\end{aligned}
$$




\subsection{Solução do Modelo}

Os valores das variações de altura dos pontos do perfil de cada reta medida são obtidos por meio da solução direta do sistema linear apresentado. Entretanto, uma análise do número de equações e incógnitas do sistema demonstra que este possui mais incógnitas do que equações, o que impossibilita sua solução por meio de métodos numéricos convencionais. Tal análise é realizada com detalhes no trabalho de Paziani (2005), que propõe como solução a esta questão a realização de repetições das medições. Se algumas condições de medição forem mantidas, como a temperatura, especialmente, pode-se assumir que os valores das variações de altura que caracterizam o perfil da peça permaneçam inalterados nas múltiplas medições. Assim, realizando-se as repetições é possível aumentar o número de linhas do sistema, e considerando-se a hipótese apresentada, é possível reduzir o número de novas incógnitas introduzidas no sistema devido às linhas adicionais. Seguindo-se esta metodologia, foram realizadas cinco repetições da medição dos pontos do perfil de cada geratriz, sendo que todos estes dados coletados são considerados como pertencentes a um mesmo conjunto, dando origem a uma única amostra. Segundo esta estratégia, cada amostra de pontos, ou cada medição, é composta de 5 repetições, ou 5 subgrupos de pontos que representam o perfil de uma geratriz. Neste caso, admite-se que cada uma das cinco repetições gere linhas de dados linearmente independentes das demais. Uma desvantagem desta metodologia é a necessidade de se realizar várias medições para possibilitar o processamento dos dados. Isto causa um acréscimo significativo no tempo total de medição de uma peça, ou seja, torna o processo de medição pouco eficiente.

A aplicação desta estratégia de redundância de dados permite a solução direta do sistema. Contudo, a matriz de coeficientes obtida é malcondicionada, próxima de uma matriz singular e com rank deficiente. Assim, a solução do sistema por métodos convencionais, como o método 
do escalonamento de Gauss, é inviável. Faz-se ncessária, neste caso, a utilização de métodos, como a decomposição $Q R$ e a decomposição em valores singulares $S V D$, que fornecem a solução de Mínimos Quadrados, mas são mais complexos que os métodos convencionais. Os fundamentos teóricos destes métodos podem ser encontrados em Golub e Van Loan (1996). Atualmente, os aplicativos que fornecem soluções numéricas de problemas matemáticos possuem sub-rotinas prontas que implementam estes algoritmos.

\subsection{Aplicação do modelo para a avaliação dos desvios de forma e orientação}

Neste item, o modelo genérico de otimização para a avaliação dos desvios de forma e orientação, apresentado no capítulo 3, será desenvolvido para ser aplicado à avaliação do desvio de planicidade. Além disso, para o cálculo do desvio de paralelismo e perpendicularismo das peças selecionadas, faz-se necessária a ajustagem de um plano de referência aos pontos dos perfis das superfícies medidas, conforme discutido no item 5.3. Em ambos os casos, pode-se utilizar o mesmo modelo de otimização apresentado, sendo que a forma geométrica a ser ajustada é um plano euclideano. Assim, as funções de ajustagem apresentadas no capítulo 3 devem ser definidas segundo a equação 5.9, para que, no modelo final, obtenha-se a equação cartesiana de um plano.

$$
g_{0}(x, y)=1 ; g_{1}(x, y)=x ; g_{2}(x, y)=y
$$

A função discreta $f\left(x_{s}, y_{t}\right)$ presente no modelo corresponde aos pontos do perfil real da superfície, conforme apresentado na equação 5.10. Como os pontos são medidos sobre uma malha ortogonal retangular, os índices das variáveis devem variar de acordo com a equação 5.11 , onde $m$ é o número de linhas da malha de medição e $n$ é o número de colunas desta malha.

$$
f\left(x_{s}, y_{t}\right)=z_{i},
$$




$$
s=0,1,2, \ldots, m-1 ; \quad t=0,1,2, \ldots, n-1 ; i=1,2, \ldots, m . n
$$

A equação (3.5), apresentada no capítulo 3, definiu o conjunto de restrições do modelo de Programação Linear como sendo:

$$
-h \leq f\left(x_{i}\right)-\sum_{j}\left[a_{j} g_{j}\left(x_{i}\right)\right] \leq h ; \quad h \geq 0
$$

Assim, realizando-se as substituições necessárias e separando-se as desigualdades apresentadas em duas expressões, obtém-se o PPL apresentado na equação 5.12 .

Minimizar $h$

$$
\text { Sujeito a }\left\{\begin{array}{l}
-h+a_{0}^{+}-a_{0}^{-}+a_{1}^{+} x_{s}-a_{1}^{-} x_{s}+a_{2}^{+} y_{t}-a_{2}^{-} y_{t} \leq z_{i} \\
-h-a_{0}^{+}+a_{0}^{-}-a_{1}^{+} x_{s}+a_{1}^{-} x_{s}-a_{2}^{+} y_{t}+a_{2}^{-} y_{t} \leq-z_{i} \\
h, a_{j}^{+}, a_{j}^{-} \geq 0
\end{array}\right.
$$

O resultado deste modelo de otimização consiste num plano de referência para o qual os pontos mais afastados, acima e abaixo deste plano, localizam-se uma distância mínima $h$ deste plano. O plano de referência obtido é eqüidistante dos pontos que apresentam desvio máximo. Segundo o teorema atribuído a de la Valle Poussin, destacado em Golsdstein, Levine e Hereshoff, (1957) e Kelley Jr (1958), existem no mínimo $k+1$ pontos que apresentam o desvio máximo com relação à função ajustada. Portanto, para o plano, são observados no mínimo quatro pontos nestas condições. $O$ erro de planicidade, avaliado segundo a norma $L \infty$, pode ser definido como duas vezes o valor do desvio máximo minimizado, ou seja, duas vezes o valor de $h$ obtido ao final da otimização.

Para a avaliação do desvio de perpendicularismo, planos de referência são ajustados aos pontos do perfil da superfície da peça medida e aos pontos do perfil do artefato de referência utilizando-se o modelo apresentado. O desvio é calculado por meio da diferença entre os coeficientes de inclinação destes planos.

O modelo apresentado foi convertido em forma matricial para ser 
resolvido por ferramentas de otimização disponíveis comercialmente. Um programa computacional e sub-rotinas foram desenvolvidos em ambiente Matlab ${ }^{\circledR}$ para a montagem das matrizes e vetores utilizados na ajustagem. Neste programa, uma das ferramentas de solução de modelos de programação linear contida no software comercial é implementada e gráficos da superfície medida são gerados. Para obter os resultados mencionados, isto é, o valor do desvio de planicidade e dos coeficientes do plano ajustado, é necessário apenas que o usuário forneça como dado de entrada a matriz que contém os pontos do perfil da superfície medida.

Os desvios de forma e orientação também foram avaliados utilizando-se a ajustagem de Mínimos Quadrados. Os princípios que fundamentam este método e as expressões matemáticas que o modelam são tradicionalmente conhecidos e foram intensamente explorados na área de matemática e engenharia, tendo sido empregados para aplicações diversas. Por esse motivo, não se julgou necessário reproduzir neste trabalho o modelo de ajustagem baseado no Método dos Mínimos Quadrados. O desenvolvimento deste modelo para a avaliação de desvios geométricos pode ser encontrado nos trabalhos de Magalhães (2006), Forbes (2006), entre outros. Estes trabalhos citados apresentam, inclusive, o cálculo das incertezas associadas a este método.

As rotinas de aplicação do Método dos Mínimos Quadrados ao conjunto de pontos dos perfis das superfícies medidas também foram implementadas em ambiente Matlab ${ }^{\circledR}$. 


\section{Capítulo 6}

\section{Resultados e Discussões}

Este capítulo é destinado à apresentação dos resultados dos testes experimentais realizados com o objetivo de avaliar o sistema de medição proposto. Conforme exposto no capítulo 5, o Sistema Automatizado para avaliação de erros de forma e orientação foi empregado na medição de três elementos distintos. Assim, as tabelas de resultados fazem menção aos termos Peça 1, Peça 2 e Peça 3. Além disso, realizou-se também a medição do plano de referência. Os resultados obtidos na medição desta referência são necessários para o cálculo do desvio de perpendicularismo das peças, o qual foi avaliado indiretamente, por meio da avaliação do paralelismo de uma das faces das peças em relação ao plano de referência. As características das peças medidas bem como as estratégias de medição estão apresentadas com detalhes no capítulo 5 .

As peças selecionadas também foram medidas utilizando-se um sistema de medição convencional e uma máquina de medir coordenadas. A estratégia adotada para validação do Sistema Automatizado consistiu na comparação entre os resultados obtidos com este sistema e os resultados obtidos com os demais sistemas mencionados.

Nas peças 1 e 2, em cada medição, foram coletados dados de 8 geratrizes e de 6 transversais, conforme o mapa de medição apresentado. Já no caso da Peça 3, foram medidas 5 geratrizes e 4 transversais. Os dados de cada uma das peças foram coletados e processados segundo 0 procedimento apresentado no capítulo 5, item 5.3.

Nos tópicos seguintes são apresentados os dados de medição de cada uma das peças e os resultados de cada etapa de processamento. Ao final do capítulo são apresentadas tabelas contendo um resumo dos 
resultados finais obtidos, e a comparação desses resultados com os resultados obtidos por meio dos métodos convencionais de medição citados.

\subsection{Resultados da Avaliação do Desvio de Planicidade}

\subsubsection{Resultados de medição da Peça 1}

As Tabelas 6.1 e 6.2 apresentam os perfis das retas geratrizes e transversais da Peça 1 obtidos a partir de uma amostra de medição. Estes resultados são obtidos após a aplicação do algoritmo de separação de erros sobre os dados coletados com Sistema Automatizado. Como é possível observar, os perfis das retas não possuem inclinação.

Tabela 6.1 - Perfis das geratrizes da Peça 1, medidos com o Sistema Automatizado.

\begin{tabular}{|r|r|r|r|r|r|r|r|}
\hline \multicolumn{7}{|c|}{ Perfil das Geratrizes da Peça 1 (em $\mu \mathrm{m})$ - Amostra 01 - Sistema } \\
\hline \multicolumn{1}{|c|}{ G1 } & \multicolumn{1}{|c|}{ G2 } & \multicolumn{1}{|c|}{ G3 } & \multicolumn{1}{c|}{ G4 } & \multicolumn{1}{c|}{ G5 } & \multicolumn{1}{c|}{ G6 } & \multicolumn{1}{c|}{ G7 } & \multicolumn{1}{c|}{ G8 } \\
\hline 0 & 0 & 0 & 0 & 0 & 0 & 0 & 0 \\
\hline 17 & 30 & 30 & 24 & 19 & 22 & 20 & 17 \\
\hline 38 & 56 & 54 & 46 & 33 & 40 & 38 & 27 \\
\hline 52 & 72 & 74 & 65 & 48 & 56 & 56 & 31 \\
\hline 61 & 83 & 87 & 84 & 63 & 63 & 67 & 38 \\
\hline 62 & 89 & 85 & 96 & 77 & 64 & 73 & 40 \\
\hline 65 & 88 & 75 & 103 & 81 & 66 & 74 & 41 \\
\hline 68 & 90 & 69 & 103 & 87 & 64 & 72 & 35 \\
\hline 69 & 88 & 60 & 102 & 86 & 58 & 67 & 21 \\
\hline 64 & 77 & 53 & 92 & 79 & 50 & 61 & 9 \\
\hline 59 & 59 & 47 & 85 & 72 & 41 & 48 & 0 \\
\hline 48 & 39 & 37 & 75 & 64 & 31 & 35 & -2 \\
\hline 38 & 25 & 28 & 52 & 51 & 22 & 24 & 1 \\
\hline 26 & 13 & 19 & 34 & 36 & 14 & 13 & 5 \\
\hline 16 & 7 & 9 & 21 & 20 & 5 & 5 & 2 \\
\hline 0 & 0 & 0 & 0 & 0 & 0 & 0 & 0 \\
\hline
\end{tabular}


Tabela 6.2 - Perfis das retas transversais da Peça 1, medidos com o Sistema Automatizado.

\begin{tabular}{|r|r|r|r|r|r|}
\hline \multicolumn{7}{|c|}{ Perfil das Transversais da Peça 1 (em $\mu$ m) - Amostra 01 - } \\
Sistema Automatizado - sem inclinação \\
\hline \multicolumn{1}{|r|}{ T1 } & \multicolumn{1}{|c|}{ T4 } & \multicolumn{1}{c|}{ T7 } & \multicolumn{1}{|c|}{ T10 } & \multicolumn{1}{c|}{ T13 } & \multicolumn{1}{c|}{ T16 } \\
\hline 0 & 0 & 0 & 0 & 0 & 0 \\
\hline-25 & -14 & -11 & -15 & -14 & -25 \\
\hline-40 & -28 & -22 & -24 & -25 & -43 \\
\hline-50 & -35 & -24 & -22 & -24 & -47 \\
\hline-52 & -39 & -26 & -21 & -23 & -43 \\
\hline-45 & -31 & -20 & -13 & -15 & -33 \\
\hline-10 & -8 & -11 & -10 & -10 & -22 \\
\hline 0 & 0 & 0 & 0 & 0 & 0 \\
\hline
\end{tabular}

Os dados obtidos com a medição convencional da Peça 1 são apresentados na Tabela 6.3. O Método dos Pontos Extremos foi aplicado ao conjunto original de dados para que as inclinações dos perfis fossem retiradas, facilitando a comparação com o conjunto de dados obtidos utilizando-se o Sistema Automatizado.

Com o intuito de avaliar a acuracidade do modelo de separação de erros, verificou-se a diferença, ponto a ponto, entre os perfis das geratrizes fornecidos pelos dois sistemas. Tais diferenças são mostradas na Tabela 6.4. As diferenças máximas em cada geratriz estão em destaque.

Para algumas geratrizes, é possível observar diferenças significativas entre as alturas obtidas com cada um dos métodos. Uma hipótese para explicar parte dessas diferenças advém do fato de que, durante o processo de medição, observou-se que podem ocorrer variações de até algumas unidades de milímetros no posicionamento em $\mathrm{x}$ e y de um sensor sobre um dado ponto de medição. Isto é válido especialmente para o sistema convencional, no qual a posição de medição é estabelecida diretamente pelo operador. Assim, no caso da Peça 1, que possui uma qualidade superficial mais grosseira, esta variação de localização dos pontos de medição pode gerar variações significativas nos valores medidos. Segundo alguns testes realizados, no método convencional, foram observadas variações nos valores medidos de até 15 micrometros. 
Diante disso, uma das vantagens do Sistema Automatizado é que o manipulador possui melhor precisão de posicionamento em $\mathrm{x}$ e y do que método convencional.

Tabela 6.3 - Perfil da superfície da Peça 1, medido com o sistema convencional.

\begin{tabular}{|c|c|c|c|c|c|c|c|}
\hline \multicolumn{8}{|c|}{$\begin{array}{l}\text { Perfil das Geratrizes da Peça } 1(\mu \mathrm{m}) \text { - Medição Convencional - sem } \\
\text { inclinação - Amostra } 01\end{array}$} \\
\hline G1 & G2 & G3 & G4 & G5 & G6 & G7 & G8 \\
\hline 0 & 0 & 0 & 0 & 0 & 0 & 0 & 0 \\
\hline 17 & 31 & 25 & 19 & 18 & 12 & 12 & 11 \\
\hline 34 & 47 & 45 & 39 & 35 & 28 & 30 & 18 \\
\hline 46 & 58 & 60 & 53 & 48 & 40 & 37 & 24 \\
\hline 53 & 64 & 70 & 62 & 56 & 47 & 39 & 30 \\
\hline 55 & 75 & 75 & 67 & 58 & 53 & 42 & 32 \\
\hline 57 & 71 & 75 & 71 & 61 & 60 & 39 & 33 \\
\hline 59 & 77 & 75 & 70 & 69 & 57 & 36 & 29 \\
\hline 56 & 73 & 75 & 70 & 61 & 48 & 34 & 26 \\
\hline 48 & 64 & 70 & 69 & 59 & 45 & 31 & 17 \\
\hline 40 & 55 & 60 & 53 & 52 & 42 & 28 & 13 \\
\hline 32 & 51 & 50 & 48 & 44 & 33 & 21 & 10 \\
\hline 24 & 37 & 35 & 37 & 32 & 25 & 18 & 6 \\
\hline 11 & 28 & 25 & 26 & 20 & 12 & 10 & 2 \\
\hline 8 & 14 & 15 & 16 & 12 & 8 & 3 & 4 \\
\hline 0 & 0 & 0 & 0 & 0 & 0 & 0 & 0 \\
\hline
\end{tabular}

Tabela 6.4 - Diferenças entre os perfis das geratrizes da Peça 1

\begin{tabular}{|c|r|r|r|r|r|r|r|r|}
\hline \multicolumn{1}{|c|}{ Diferenças entre os perfis medidos com o sistema proposto e com o sistema } \\
\hline Pontos & G1 & G2 & \multicolumn{1}{|c|}{ G3 } & G4 & G5 & G6 & G7 & G8 \\
\hline 1 & 0 & 0 & 0 & 0 & 0 & 0 & 0 & 0 \\
\hline 2 & 0 & -1 & 5 & 5 & 1 & 10 & 8 & 6 \\
\hline 3 & 4 & 9 & 9 & 7 & -2 & 12 & 9 & 9 \\
\hline 4 & 6 & 14 & 14 & 12 & 0 & 16 & 19 & 7 \\
\hline 5 & 8 & 19 & 17 & 21 & 7 & 16 & 27 & 8 \\
\hline 6 & 7 & 14 & 10 & 29 & 19 & 11 & 31 & 8 \\
\hline 7 & 8 & 17 & 0 & 32 & 20 & 6 & 35 & 8 \\
\hline 8 & 9 & 13 & -6 & 33 & 18 & 7 & 36 & 6 \\
\hline 9 & 13 & 15 & -15 & 32 & 24 & 9 & 33 & -5 \\
\hline 10 & 16 & 13 & -17 & 23 & 20 & 5 & 30 & -8 \\
\hline 11 & 19 & 4 & -13 & 32 & 20 & -1 & 20 & -13 \\
\hline 12 & 16 & -12 & -13 & 27 & 20 & -2 & 14 & -12 \\
\hline 13 & 14 & -12 & -7 & 15 & 19 & -3 & 6 & -5 \\
\hline 14 & 15 & -15 & -6 & 7 & 17 & 3 & 3 & 3 \\
\hline 15 & 8 & -7 & -6 & 6 & 8 & -3 & 3 & -2 \\
\hline 16 & 0 & 0 & 0 & 0 & 0 & 0 & 0 & 0 \\
\hline
\end{tabular}


Conforme apresentado na Tabela 6.2, foram medidas 6 transversais na Peça 1. Dessa forma, aplicando-se o procedimento de préprocessamento de dados, foi possível obter 6 perfis distintos para cada superfície medida uma única vez, mediante a combinação de diferentes retas-base com um mesmo conjunto de geratrizes. A Figura 6.1 apresenta o gráfico de um desses perfis da Peça 1, obtido a partir da combinação das geratrizes com a reta-base T1 e um gráfico do perfil desta peça obtido com a medição convencional, para comparação.

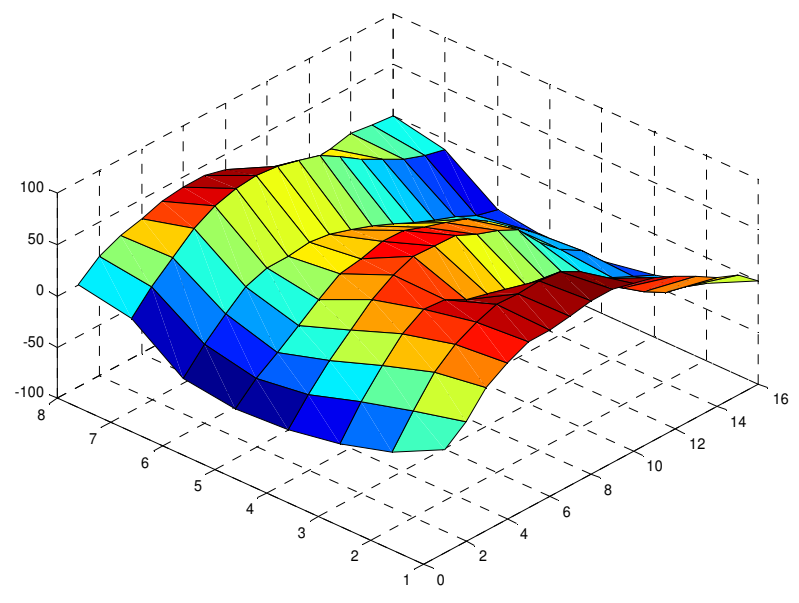

a)

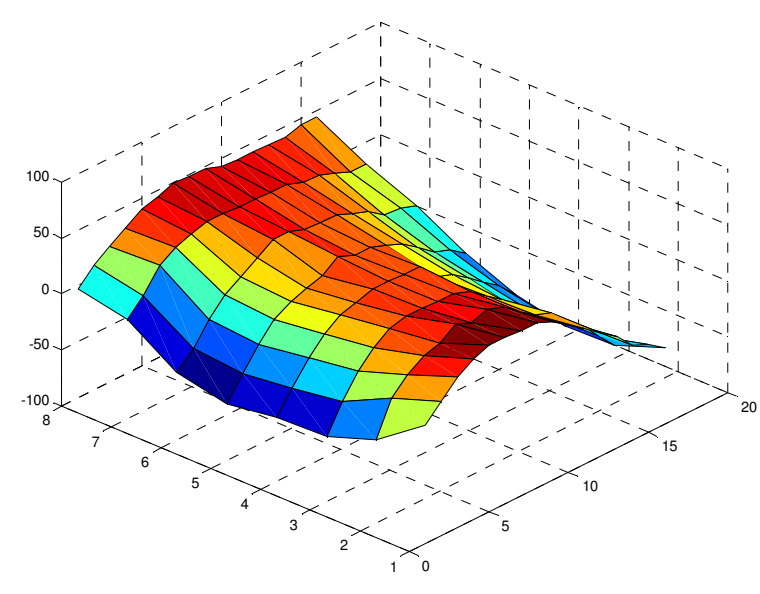

b)

Figura 6.1 - Perfis de superfície da Peça 1 obtidos com o Sistema Automatizado (a) e com o sistema convencional (b)

Nas figuras apresentadas, a inclinação original dos perfis apresentados foi retirada para que as diferenças nos perfis de planicidade obtidos com cada um dos dois sistemas de medição fossem visualizadas com maior clareza. Os gráficos mostram algumas diferenças locais entre as variações de altura medidas em pontos correspondentes, mas o formato de ambos os perfis é similar. Além disso, notam-se algumas diferenças significativas nas alturas relativas entre as geratrizes.

Os perfis da superfície da Peça 1 obtidos com o Sistema Automatizado foram empregados no cálculo do desvio de planicidade desta superfície. Nas tabelas seguintes são apresentados os valores deste desvio e os coeficientes dos planos ajustados aos vários perfis da peça 1 . A Tabela 6.5 apresenta os resultados obtidos com a ajustagem Minimax e a Tabela 6.6, os valores resultantes da ajustagem de Mínimos Quadrados. 
Os resultados da medição convencional da Peça 1 são apresentados na Tabela 6.7.

Tabela 6.5 - Desvio de planicidade da peça 1 (ajustagem Minimax)

\begin{tabular}{|c|c|c|c|c|c|c|c|c|c|c|}
\hline \multicolumn{11}{|c|}{$\begin{array}{c}\text { Peça } 1 \text { - Amostra } 01 \text { - Desvio de planicidade - Medição com Sistema Automatizado - Avaliação com o } \\
\text { Método Minimax }\end{array}$} \\
\hline coefic. & Perfil 1 & Perfil 4 & Perfil 7 & Perfil 10 & Perfil 13 & Perfil 16 & \begin{tabular}{l|} 
Perfil \\
Médio
\end{tabular} & Médias & $\begin{array}{l}\text { Desv. } \\
\text { Padrão }\end{array}$ & $\begin{array}{c}\text { Amplitu- } \\
\text { des }\end{array}$ \\
\hline a0 & 10 & -41 & -60 & -60 & -9 & 16 & -25 & -24 & 31 & 76 \\
\hline a1 & 2.2E-16 & $-3.1 E-15$ & $-6.4 E-15$ & $5.6 \mathrm{E}-15$ & $-1.1 E-15$ & 2.2E-16 & $-1.6 \mathrm{E}-15$ & $-8.9 E-16$ & 3.7E-15 & $1.2 \mathrm{E}-14$ \\
\hline a2 & $-4.9 \mathrm{E}-05$ & $-6.5 \mathrm{E}-05$ & $-3.8 \mathrm{E}-05$ & $2.1 \mathrm{E}-04$ & $-9.7 \mathrm{E}-05$ & $-1.5 \mathrm{E}-04$ & $-4.7 \mathrm{E}-05$ & $-3.5 \mathrm{E}-05$ & $1.1 \mathrm{E}-04$ & $3.6 \mathrm{E}-04$ \\
\hline $\begin{array}{l}\text { Desvio de } \\
\text { planicidade }\end{array}$ & 118 & 117 & 130 & 131 & 123 & 108 & 116 & 120 & 8 & 23 \\
\hline
\end{tabular}

Tabela 6.6 - Desvio de planicidade da peça 1 (ajustagem de Mínimos Quadrados)

\begin{tabular}{|c|c|c|c|c|c|c|c|c|c|c|}
\hline \multicolumn{11}{|c|}{$\begin{array}{l}\text { Peça 1- Amostra } 01 \text { - Desvio de planicidade - Medição com Sistema Automatizado - Avaliação como } \\
\text { Método dos Mínimos Quadrados }\end{array}$} \\
\hline coefic. & Perfil 1 & Perfil 4 & Perfil 7 & Perfil 10 & Perfil 13 & Perfil 16 & $\begin{array}{l}\text { Perfil } \\
\text { Médio }\end{array}$ & Médias & $\begin{array}{c}\text { Desv. } \\
\text { Padrão } \\
\end{array}$ & $\begin{array}{c}\text { Amplitu- } \\
\text { des }\end{array}$ \\
\hline $\mathrm{a} 0$ & 35 & -24 & -35 & -31 & 7 & 36 & -2 & -2 & 30 & 72 \\
\hline a1 & $-8.0 \mathrm{E}-05$ & $-8.0 \mathrm{E}-05$ & $-8.0 \mathrm{E}-05$ & $-8.0 \mathrm{E}-05$ & $-8.0 \mathrm{E}-05$ & $-8.0 \mathrm{E}-05$ & $-8.0 \mathrm{E}-05$ & $-8.0 \mathrm{E}-05$ & $1.5 \mathrm{E}-20$ & $0.0 \mathrm{E}+00$ \\
\hline a2 & $-1.4 \mathrm{E}-04$ & 2.6E-05 & $1.2 \mathrm{E}-05$ & $1.8 \mathrm{E}-04$ & $5.0 \mathrm{E}-05$ & $-1.4 \mathrm{E}-04$ & $-2.9 \mathrm{E}-06$ & $-2.9 \mathrm{E}-06$ & $1.1 \mathrm{E}-04$ & 3.2E-04 \\
\hline $\begin{array}{l}\text { Desvio de } \\
\text { planicidade }\end{array}$ & 130 & 132 & 144 & 141 & 138 & 120 & 130 & 134 & 8 & 24 \\
\hline
\end{tabular}

Tabela 6.7 - Desvio de planicidade da peça 1 (medição convencional)

\begin{tabular}{|c|rr|r|r|r|r|r|}
\cline { 2 - 8 } \multicolumn{1}{c|}{} & \multicolumn{6}{c|}{ Desvio de Planicidade - Peça 1 - Amostra 01 - Medição } \\
\multicolumn{1}{c|}{} & \multicolumn{6}{c|}{ Convencional } \\
\cline { 2 - 8 } \multicolumn{1}{c|}{} & \multicolumn{3}{c|}{ Método Minimax } & \multicolumn{1}{c|}{ Mínimos Quadrados } \\
\hline \multicolumn{2}{|c|}{ Amostra } & \multicolumn{1}{c|}{01} & 02 & \multicolumn{1}{c|}{01} & 02 & \multicolumn{1}{c|}{03} \\
\hline \multirow{3}{*}{ coeficientes } & a0 & 84 & 87 & 92 & 91 & 90 & 91 \\
& a1 & $-5.3 \mathrm{E}-04$ & $-5.3 \mathrm{E}-04$ & $-5.4 \mathrm{E}-04$ & $-5.4 \mathrm{E}-04$ & $-5.4 \mathrm{E}-04$ & $-5.5 \mathrm{E}-04$ \\
& a2 & $7.1 \mathrm{E}-05$ & $4.0 \mathrm{E}-05$ & $-1.5 \mathrm{E}-05$ & $2.3 \mathrm{E}-04$ & $2.3 \mathrm{E}-04$ & $2.1 \mathrm{E}-04$ \\
\hline \multicolumn{2}{|c|}{ Desvio de } \\
planicidade $(\mu \mathrm{m})$
\end{tabular}

Os perfis aos quais as tabelas 6.5 e 6.6 fazem referência são aqueles obtidos pela combinação das transversais da Tabela 6.2 e o conjunto de geratrizes apresentados na Tabela 6.1. O perfil médio é obtido calculando-se a média das variações de altura dos 6 perfis distintos em cada ponto da malha de medição. Os valores médios apresentados na 
tabela consideram os parâmetros dos planos obtidos para os 6 perfis de superfície, e não consideram os resultados do perfil médio. Assim, o desvio de planicidade apresentado na coluna das médias é o desvio médio, que consiste na média dos 6 valores de desvio de planicidade obtidos para cada perfil.

Comparando-se os valores do desvio médio de planicidade, obtidos com o Sistema Automatizado, e os valores obtidos utilizando-se o sistema convencional, tem-se que a diferença máxima, aplicando-se a ajustagem Minimax, é de 22 micrometros. Esta mesma diferença é de 23 micrometros quando o Método dos Mínimos Quadrados é utilizado. Em termos relativos, estas diferenças representam em torno de 20 a $22 \%$ do desvio da peça, considerando como valores de referência para este desvio a média dos resultados do método convencional. Uma diferença positiva e de amplitude da ordem de 20 micrometros era esperada em função das diferenças observadas entre os perfis das geratrizes.

Além da amostra apresentada, foram coletadas outras 2 amostras de dados para a Peça 1 utilizando-se o Sistema Automatizado. Os resultados referentes a estas amostras são apresentados no Apêndice 1. Os perfis das retas obtidos com o processamento destas amostras adicionais são muito similares aos já apresentados, sendo que as diferenças entre os desvios de pontos correspondentes em geral são inferiores a 10 micrometros. No item 6.4. discute-se com mais detalhes a comparação entre os resultados finais obtidos utilizando-se os diferentes sistemas de medição citados, considerando-se todas as amostras coletadas para a Peça 1 e demais peças.

\subsubsection{Resultados de medição da Peça 2}

O mesmo procedimento de medição e análise de dados apresentado para a Peça 1 foi aplicado à Peça 2. Assim, as tabelas e dados apresentados a seguir são análogos aos apresentados no item anterior. Os dados do perfil das geratrizes e transversais da Peça 2, calculados com 
base na primeira amostra de dados coletados, são mostrados nas tabelas 6.8 e 6.9 .

O perfil da Peça 2 também foi avaliado por meio da medição convencional. Os resultados, após a aplicação do método dos Pontos Extremos, são mostrados na Tabela 6.10.

As diferenças, ponto a ponto, entre as variações de altura medidas utilizando-se o sistema proposto e o convencional são apresentadas na Tabela 6.11. A Figura 6.2 apresenta gráficos dos perfis da geratriz G1 obtidos com cada um dos sistemas.

Tabela 6.8 - Perfis das geratrizes da Peça 2, medidos com o Sistema Automatizado.

\begin{tabular}{|c|c|c|c|c|c|c|c|}
\hline \multicolumn{8}{|c|}{$\begin{array}{c}\text { Perfil das Geratrizes da Peça } 2(\mu \mathrm{m}) \text { - Amostra } 01 \text { - Sistema } \\
\text { Automatizado - sem inclinação }\end{array}$} \\
\hline G1 & G2 & G3 & G4 & G5 & G6 & G7 & G8 \\
\hline 0 & 0 & 0 & 0 & 0 & 0 & 0 & 0 \\
\hline-3 & -5 & -4 & -6 & -1 & -3 & -1 & -1 \\
\hline-9 & -9 & -8 & -11 & -5 & -7 & -6 & -4 \\
\hline-14 & -13 & -12 & -18 & -10 & -11 & -11 & -7 \\
\hline-20 & -16 & -16 & -23 & -15 & -16 & -15 & -10 \\
\hline-23 & -18 & -19 & -29 & -20 & -20 & -20 & -14 \\
\hline-25 & -20 & -22 & -32 & -24 & -25 & -23 & -18 \\
\hline-27 & -22 & -24 & -34 & -28 & -28 & -25 & -20 \\
\hline-27 & -23 & -26 & -32 & -28 & -30 & -26 & -19 \\
\hline-26 & -23 & -26 & -30 & -26 & -29 & -25 & -17 \\
\hline-24 & -22 & -24 & -25 & -21 & -26 & -22 & -15 \\
\hline-19 & -20 & -20 & -19 & -16 & -22 & -19 & -11 \\
\hline-14 & -16 & -14 & -15 & -11 & -16 & -15 & -8 \\
\hline-9 & -11 & -10 & -10 & -6 & -10 & -9 & -5 \\
\hline-4 & -5 & -6 & -5 & -2 & -5 & -5 & -3 \\
\hline 0 & 0 & 0 & 0 & 0 & 0 & 0 & 0 \\
\hline
\end{tabular}

Tabela 6.9 - Perfis das transversais da Peça 2, medidos com o Sistema Automatizado.

\begin{tabular}{|} 
Perfil das Transversais da Peça 2 $(\mu \mathrm{m})-$ \\
Amostra 01 - Sistema Automatizado - sem \\
inclinação \\
\hline T1 & \multicolumn{1}{|c|}{ T4 } & \multicolumn{1}{|c|}{ T7 } & \multicolumn{1}{c|}{ T10 } & \multicolumn{1}{c|}{ T13 } & \multicolumn{1}{c|}{ T16 } \\
\hline 0 & 0 & 0 & 0 & 0 & 0 \\
\hline 0 & -1 & 0 & -3 & -2 & 0 \\
\hline 0 & -2 & -2 & -6 & -4 & -1 \\
\hline-1 & -3 & -1 & -7 & -5 & -2 \\
\hline-4 & -1 & 0 & -8 & -5 & -3 \\
\hline-3 & 0 & 0 & -6 & -4 & 0 \\
\hline-2 & 0 & 0 & -3 & -2 & 0 \\
\hline 0 & 0 & 0 & 0 & 0 & 0 \\
\hline
\end{tabular}


Tabela 6.10 - Perfil da superfície da Peça 2, medido com o sistema convencional.

\begin{tabular}{|r|r|r|r|r|r|r|r|}
\hline \multicolumn{10}{|c|}{ Perfil das Geratrizes da Peça 2 $(\mu \mathrm{m})$ - Medição Convencional - } \\
\hline \multicolumn{1}{|r|}{ G1 } & \multicolumn{1}{|c|}{ G2 } & \multicolumn{1}{|c|}{ G3 } & \multicolumn{1}{c|}{ G4 } & \multicolumn{1}{c|}{ G5 } & \multicolumn{1}{c|}{ G6 } & \multicolumn{1}{c|}{ G7 } & \multicolumn{1}{c|}{ G8 } \\
\hline 0 & 0 & 0 & 0 & 0 & 0 & 0 & 0 \\
\hline-7 & -7 & -4 & -7 & -4 & -4 & -6 & -6 \\
\hline-9 & -11 & -10 & -10 & -8 & -10 & -13 & -13 \\
\hline-16 & -15 & -14 & -15 & -15 & -13 & -17 & -14 \\
\hline-18 & -20 & -19 & -19 & -17 & -19 & -20 & -20 \\
\hline-25 & -23 & -22 & -23 & -24 & -23 & -27 & -25 \\
\hline-27 & -25 & -25 & -25 & -25 & -25 & -28 & -28 \\
\hline-29 & -27 & -27 & -27 & -27 & -26 & -29 & -29 \\
\hline-26 & -26 & -26 & -28 & -26 & -26 & -31 & -31 \\
\hline-23 & -25 & -25 & -25 & -26 & -28 & -27 & -27 \\
\hline-20 & -22 & -21 & -22 & -22 & -23 & -23 & -23 \\
\hline-17 & -16 & -18 & -18 & -19 & -19 & -20 & -17 \\
\hline-14 & -13 & -13 & -12 & -15 & -13 & -16 & -11 \\
\hline-11 & -9 & -10 & -7 & -8 & -10 & -9 & -7 \\
\hline-8 & -3 & -3 & -5 & -4 & -6 & -4 & -4 \\
\hline 0 & 0 & 0 & 0 & 0 & 0 & 0 & 0 \\
\hline
\end{tabular}

Tabela 6.11 - Diferenças entre os perfis das geratrizes da Peça 2.

\begin{tabular}{|c|r|r|r|r|r|r|r|r|}
\hline \multicolumn{10}{|c|}{ Diferenças entre os perfis medidos com o sistema proposto e com o } \\
\hline Pontos & \multicolumn{1}{|c|}{ G1 } & \multicolumn{1}{|c|}{ G2 } & G3 & \multicolumn{1}{|c|}{ G4 } & \multicolumn{1}{c|}{ G5 } & \multicolumn{1}{c|}{ G6 } & \multicolumn{1}{c|}{ G7 } & \multicolumn{1}{c|}{ G8 } \\
\hline 1 & 0 & 0 & 0 & 0 & 0 & 0 & 0 & 0 \\
\hline 2 & 4 & 2 & -1 & 1 & 3 & 1 & 5 & 5 \\
\hline 3 & 0 & 2 & 2 & -1 & 3 & 4 & 7 & 8 \\
\hline 4 & 2 & 2 & 2 & -3 & 5 & 2 & 6 & 7 \\
\hline 5 & -2 & 4 & 3 & -4 & 2 & 3 & 5 & 10 \\
\hline 6 & 2 & 5 & 2 & -6 & 4 & 3 & 7 & 11 \\
\hline 7 & 2 & 5 & 4 & -7 & 1 & 0 & 5 & 10 \\
\hline 8 & 2 & 5 & 3 & -7 & -1 & -2 & 4 & 10 \\
\hline 9 & -1 & 4 & 0 & -4 & -2 & -4 & 5 & 12 \\
\hline 10 & -3 & 2 & -2 & -5 & 0 & -1 & 2 & 10 \\
\hline 11 & -4 & -1 & -2 & -3 & 1 & -3 & 1 & 9 \\
\hline 12 & -2 & -3 & -2 & 0 & 3 & -3 & 1 & 5 \\
\hline 13 & 0 & -3 & -2 & -3 & 4 & -3 & 1 & 3 \\
\hline 14 & 2 & -2 & -1 & -3 & 2 & 0 & 0 & 3 \\
\hline 15 & 4 & -2 & -2 & 0 & 2 & 1 & -1 & 1 \\
\hline 16 & 0 & 0 & 0 & 0 & 0 & 0 & 0 & 0 \\
\hline
\end{tabular}


Comparação entre os perfis de uma das geratrizes da Peça 2 Amostra 01

Posições (mm)

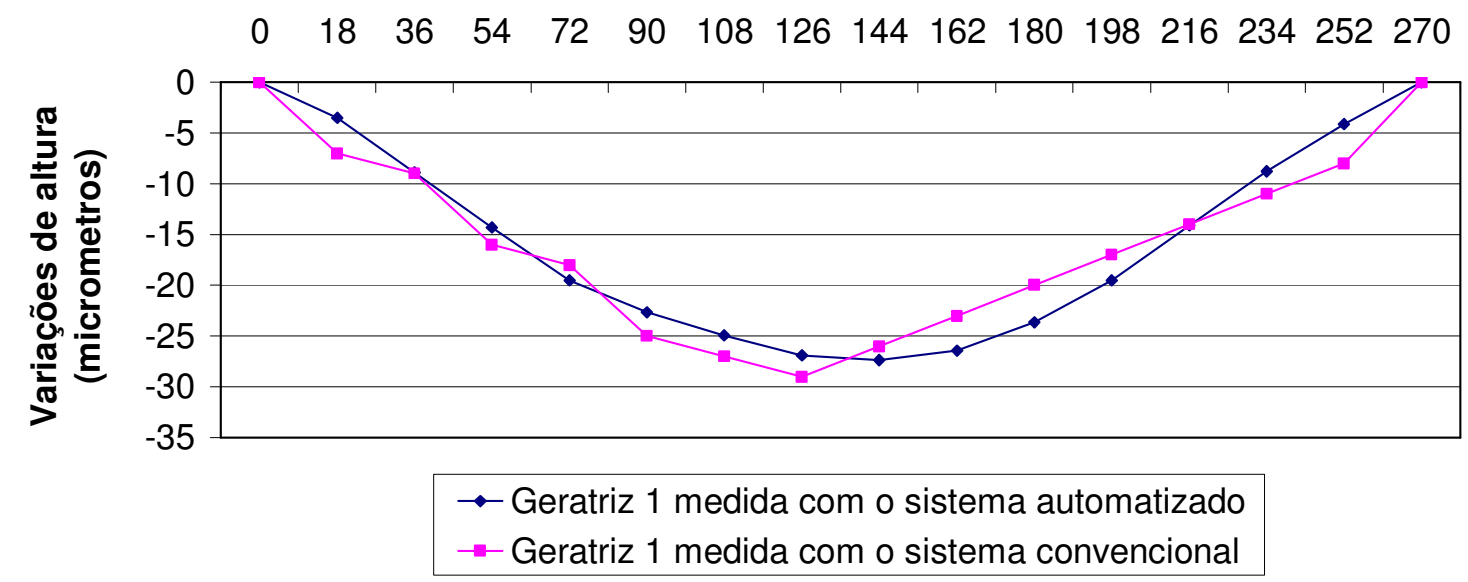

Figura 6.2 - Comparação entre os perfis da geratriz 1 da Peça 2.

De forma análoga à Peça 1, a combinação das 6 transversais medidas na Peça 2 com o conjunto de geratrizes dá origem a 6 perfis distintos que representam a superfície desta peça. $O$ perfil obtido utilizando-se a primeira transversal como reta-base é apresentado na Figura 6.3.

Os resultados da avaliação do desvio de planicidade e os parâmetros do plano ajustado aos perfis da peça 2 são apresentados nas tabelas 6.12 , 6.13 e 6.14 .

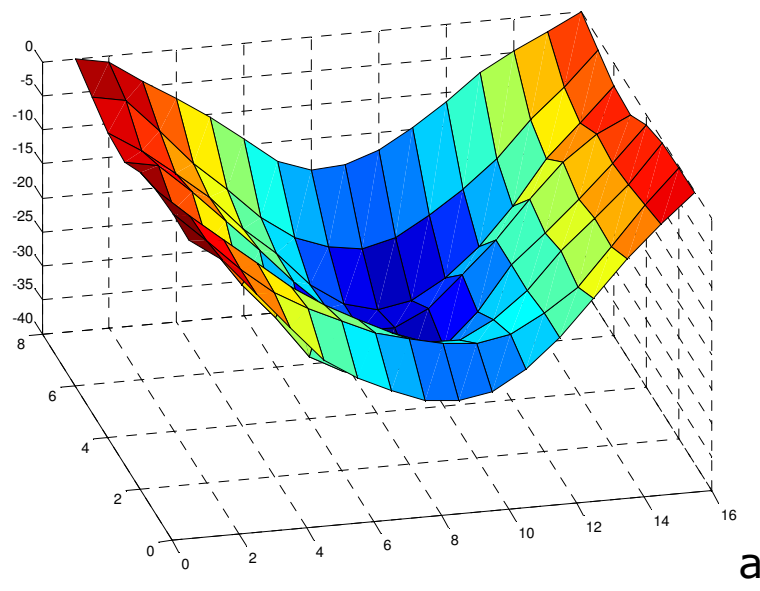

a)

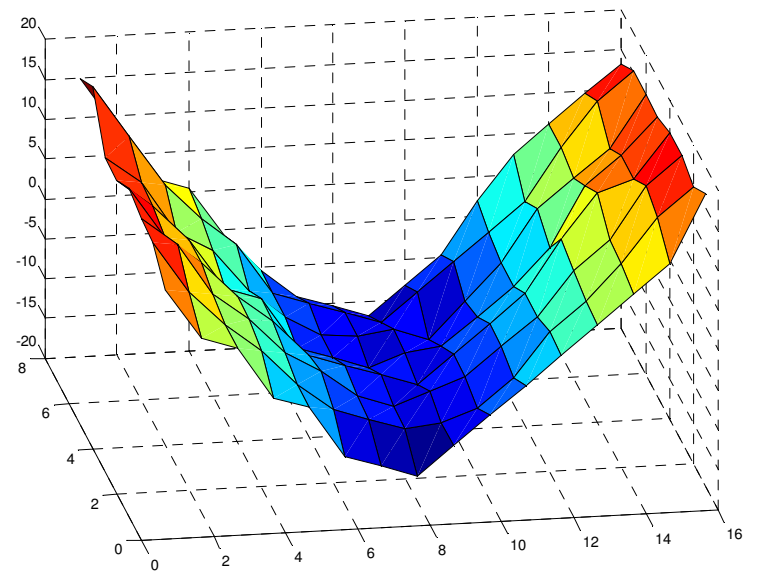

Figura 6.3 - Perfis de superfície da Peça 2 obtidos com o Sistema Automatizado (a) e o b) sistema convencional (b). 
Tabela 6.12 - Desvio de planicidade da Peça 2 (ajustagem Minimax).

\begin{tabular}{|c|c|c|c|c|c|c|c|c|c|c|}
\hline \multicolumn{11}{|c|}{$\begin{array}{c}\text { Peça } 2 \text { - Amostra } 01 \text { - Desvio de planicidade - Medição com Sistema Automatizado - Avaliação com } \\
\text { Método Minimax }\end{array}$} \\
\hline coefic. & Perfil 1 & Perfil 4 & Perfil 7 & Perfil 10 & Perfil 13 & Perfil 16 & \begin{tabular}{c|} 
Perfil \\
Médio \\
\end{tabular} & Médias & $\begin{array}{l}\text { Desv. } \\
\text { Padrão }\end{array}$ & $\begin{array}{c}\text { Amplitu- } \\
\text { des }\end{array}$ \\
\hline $\mathrm{a} 0$ & -18 & 2 & 12 & 9 & -4 & -18 & -3 & -3 & 12 & 29 \\
\hline a1 & $3.1 \mathrm{E}-14$ & $0.0 \mathrm{E}+00$ & $-4.4 E-16$ & $-8.0 \mathrm{E}-14$ & 8.7E-14 & $1.8 \mathrm{E}-15$ & $-7.8 E-13$ & $-1.1 E-13$ & $3.0 \mathrm{E}-13$ & 8.7E-13 \\
\hline a2 & $5.2 \mathrm{E}-14$ & $-7.3 \mathrm{E}-05$ & $2.5 \mathrm{E}-05$ & $-4.3 E-05$ & $-2.4 \mathrm{E}-05$ & $-9.3 \mathrm{E}-07$ & $-2.1 \mathrm{E}-05$ & $-1.9 \mathrm{E}-05$ & $3.2 \mathrm{E}-05$ & $9.8 \mathrm{E}-05$ \\
\hline $\begin{array}{l}\text { Desvio de } \\
\text { planicidade }\end{array}$ & 35 & 34 & 37 & 35 & 38 & 36 & 34 & 35 & 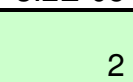 & 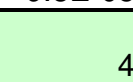 \\
\hline
\end{tabular}

Tabela 6.13 - Desvio de planicidade da Peça 2 (ajustagem de Mínimos Quadrados).

\begin{tabular}{|c|c|c|c|c|c|c|c|c|c|c|}
\hline \multicolumn{11}{|c|}{$\begin{array}{c}\text { Peça } 2 \text { - Amostra } 01 \text { - Desvio de planicidade - Medição com Sistema Automatizado - Avaliação com } \\
\text { Método dos Mínimos Quadrados }\end{array}$} \\
\hline coefic. & Perfil 1 & Perfil 4 & Perfil 7 & Perfil 10 & Perfil 13 & Perfil 16 & \begin{tabular}{c|} 
Perfil \\
Médio \\
\end{tabular} & Médias & \begin{tabular}{c|} 
Desv. \\
Padrão \\
\end{tabular} & $\begin{array}{c}\text { Amplitu- } \\
\text { des }\end{array}$ \\
\hline $\mathrm{a} 0$ & -16 & -2 & 9 & 8 & -2 & -16 & -3 & -3 & 10 & 25 \\
\hline a1 & $-5.8 \mathrm{E}-06$ & $-5.8 \mathrm{E}-06$ & $-5.8 \mathrm{E}-06$ & $-5.8 \mathrm{E}-06$ & $-5.8 \mathrm{E}-06$ & $-5.8 \mathrm{E}-06$ & $-5.8 \mathrm{E}-06$ & $-5.8 \mathrm{E}-06$ & $9.1 \mathrm{E}-22$ & $0.0 \mathrm{E}+00$ \\
\hline a2 & $1.5 \mathrm{E}-05$ & $-1.1 \mathrm{E}-05$ & $1.3 \mathrm{E}-05$ & $-8.5 E-06$ & $-8.3 \mathrm{E}-06$ & $2.9 \mathrm{E}-05$ & $4.8 \mathrm{E}-06$ & $4.8 \mathrm{E}-06$ & $1.5 \mathrm{E}-05$ & $4.0 \mathrm{E}-05$ \\
\hline $\begin{array}{l}\text { Desvio de } \\
\text { planicidade }\end{array}$ & 37 & 35 & 38 & 37 & 39 & 38 & 35 & 37 & 1 & 4 \\
\hline
\end{tabular}

Tabela 6.14 - Desvio de planicidade da Peça 2 (Medição Convencional).

\begin{tabular}{|c|c|c|c|c|c|c|c|}
\hline & \multicolumn{6}{|c|}{$\begin{array}{c}\text { Desvio de Planicidade - Peça } 2 \text { - Amostra } 01 \text { - Medição } \\
\text { Convencional }\end{array}$} \\
\hline & & \multicolumn{3}{|c|}{ Método Minimax } & \multicolumn{3}{|c|}{ Mínimos Quadrados } \\
\hline & Amostra & 01 & 02 & 03 & 01 & 02 & 03 \\
\hline \multirow{3}{*}{ coeficientes } & $\mathrm{a} 0$ & 52 & 50 & 46 & 47 & 47 & 42 \\
\hline & a1 & $-4.8 E-04$ & $-4.7 E-04$ & $-4.7 E-04$ & $-4.6 \mathrm{E}-04$ & $-4.6 \mathrm{E}-04$ & $-4.6 E-04$ \\
\hline & a2 & 1.1E-04 & 1.1E-04 & 1.1E-04 & $1.1 \mathrm{E}-04$ & 1.1E-04 & $1.3 \mathrm{E}-04$ \\
\hline \multicolumn{2}{|c|}{$\begin{array}{l}\text { Desvio de } \\
\text { planicidade }(\mu \mathrm{m})\end{array}$} & 33 & 32 & 32 & 36 & 34 & 35 \\
\hline
\end{tabular}

O perfil médio e o desvio médio apresentados nas tabelas foram calculados da mesma forma que no caso da Peça 1. Comparando-se o desvio médio de planicidade da Peça 2, medido com o Sistema Automatizado, com os valores resultantes das medições convencionais, observa-se que as diferenças obtidas são mínimas. 
Tabela 6.15 - Diferenças entre desvios de planicidade da Peça 2.

\begin{tabular}{|c|c|c|c|c|c|c|}
\hline \multicolumn{7}{|c|}{$\begin{array}{c}\text { Comparação entre desvios de planicidade }(\mu \mathrm{m}) \text { - Peça } 2 \text { - Método proposto e } \\
\text { medição convencional }\end{array}$} \\
\hline & \multicolumn{3}{|c|}{ Minimax } & \multicolumn{3}{|c|}{$\mathrm{MMQ}$} \\
\hline Amostra & 01 & 02 & 03 & 01 & 02 & 03 \\
\hline Medição convencional & 33 & 32 & 32 & 36 & 34 & 35 \\
\hline Método proposto (desvio médio) & \multicolumn{3}{|c|}{35} & \multicolumn{3}{|c|}{37} \\
\hline Diferenças & 2 & 3 & 3 & $\overline{1}$ & 3 & 2 \\
\hline
\end{tabular}

Os resultados obtidos para esta amostra são satisfatórios. Contudo, a repetibilidade do sistema proposto também deve ser avaliada. Duas medições adicionais da Peça 2 foram realizadas com este objetivo. Os resultados obtidos em cada etapa de processamento dos dados destas medições são apresentados no Apêndice 2. As diferenças entre os perfis das geratrizes obtidos a partir das amostras adicionais e os perfis apresentados nesta seção são menores do que 5 micrometros para a maioria dos pontos, o que demonstra que o sistema possui boa repetibilidade.

\subsubsection{Resultados de medição da Peça 3}

Para a avaliação dos desvios de planicidade e perpendicularismo da Peça 3, foram medidas as variações de altura dos perfis de 5 geratrizes e 4 transversais, conforme exposto no capítulo 5. Os resultados do processamento dos dados para a avaliação do desvio de planicidade são apresentados abaixo.

Tabela 6.16 - Perfis das geratrizes da Peça 3 medidos com o Sistema Automatizado.

\begin{tabular}{|r|r|r|r|r|}
\hline \multicolumn{6}{|c|}{$\begin{array}{l}\text { Perfil das Geratrizes da Peça 3 }(\mu \mathrm{m}) \text { - } \\
\text { Amostra 01 - Sistema Automatizado - } \\
\text { sem inclinação }\end{array}$} \\
\hline \multicolumn{1}{|r|r|r|}{ G1 } & \multicolumn{1}{|c|}{ G3 } & \multicolumn{1}{c|}{ G4 } & \multicolumn{1}{c|}{ G5 } \\
\hline 0 & 0 & 0 & 0 & 0 \\
\hline 1 & 1 & 1 & 1 & 2 \\
\hline 1 & 1 & 1 & 2 & 3 \\
\hline 1 & 1 & 3 & 2 & 3 \\
\hline 0 & 2 & 3 & 3 & 2 \\
\hline 1 & 3 & 3 & 2 & 2 \\
\hline 1 & 2 & 2 & 2 & 1 \\
\hline 0 & 0 & 0 & 0 & 0 \\
\hline
\end{tabular}


Tabela 6.17 - Perfis das transversais da Peça 3, medidos com o Sistema Automatizado.

\begin{tabular}{|c|c|c|c|}
\hline \multicolumn{4}{|c|}{$\begin{array}{l}\text { Perfil das Transversais da Peça } \\
\mathbf{3}(\mu \mathrm{m}) \text { - Amostra } 01 \text { - Sistema } \\
\text { Automatizado - sem inclinação }\end{array}$} \\
\hline T1 & T3 & T5 & T7 \\
\hline 0 & 0 & 0 & 0 \\
\hline-4 & -4 & -1 & -2 \\
\hline-6 & -5 & -3 & -3 \\
\hline-5 & -3 & -2 & -2 \\
\hline 0 & 0 & 0 & 0 \\
\hline
\end{tabular}

Tabela 6.18 - Perfis das geratrizes da Peça 3, medidos com o sistema convencional.

\begin{tabular}{|r|r|r|r|r|}
\hline \multicolumn{6}{|c|}{$\begin{array}{c}\text { Perfil das Geratrizes da Peça 3 }(\mu \mathrm{m}) \text { - } \\
\text { Amostra 01 - Sistema Convencional - } \\
\text { sem inclinação }\end{array}$} \\
\hline \multicolumn{1}{|r|}{ G1 } & \multicolumn{1}{|c|}{ G2 } & \multicolumn{1}{|c|}{ G3 } & \multicolumn{1}{c|}{ G4 } & \multicolumn{1}{c|}{ G5 } \\
\hline 0 & 0 & 0 & 0 & 0 \\
\hline 2 & 1 & -2 & 0 & 1 \\
\hline 2 & 1 & -1 & 0 & -1 \\
\hline 3 & 1 & 0 & 2 & 2 \\
\hline 5 & 0 & -1 & 1 & 0 \\
\hline 5 & 0 & 0 & 1 & 1 \\
\hline 3 & 1 & 0 & 1 & 0 \\
\hline 0 & 0 & 0 & 0 & 0 \\
\hline
\end{tabular}

Tabela 6.19 - Diferenças entre os perfis das geratrizes da Peça 3

\begin{tabular}{|r|r|r|r|r|}
\hline $\begin{array}{c}\text { Diferenças entre os perfis medidos com } \\
\text { o sistema proposto e com o sistema } \\
\text { convencional }(\mu \mathrm{m}) \text { - Peça 3 }\end{array}$ \\
\hline \multicolumn{1}{|r|r|}{ G1 } & \multicolumn{1}{|c|}{ G2 } & \multicolumn{1}{|c|}{ G3 } & \multicolumn{1}{c|}{ G4 } & \multicolumn{1}{c|}{ G5 } \\
\hline 0 & 0 & 0 & 0 & 0 \\
\hline-1 & -1 & 3 & 1 & 1 \\
\hline-1 & 0 & 3 & 2 & 4 \\
\hline-2 & 0 & 3 & 0 & 1 \\
\hline-5 & 2 & 5 & 2 & 2 \\
\hline-4 & 2 & 3 & 1 & 2 \\
\hline-2 & 2 & 2 & 1 & 1 \\
\hline 0 & 0 & 0 & 0 & 0 \\
\hline
\end{tabular}

A combinação dos perfis de geratrizes e transversais medidos com o Sistema Automatizado deu origem a 4 perfis de superfície para cada amostra de dados da peça. A avaliação destes perfis forneceu os valores de desvio de planicidade mostrados nas tabelas 6.20 e 6.21. Os resultados obtidos com a medição convencional da Peça 3 também são apresentados. 
Tabela 6.20 - Desvios de planicidade da peça 3 (ajustagem Minimax)

\begin{tabular}{|c|c|c|c|c|c|c|c|c|}
\hline \multicolumn{9}{|c|}{$\begin{array}{c}\text { Peça } 3 \text { - Amostra } 01 \text { - Desvio de planicidade - Medição com Sistema Automatizado - Avaliação } \\
\text { com Método Minimax }\end{array}$} \\
\hline coeficientes & Perfil 1 & Perfil 3 & Perfil 5 & Perfil 7 & Perfil Médio & Médias & $\begin{array}{l}\text { Desv. } \\
\text { Padrão } \\
\end{array}$ & Amplitudes \\
\hline $\mathrm{a} 0$ & -3 & -3 & -2 & -3 & -3 & -3 & 0 & 1 \\
\hline a1 & $-8.9 E-16$ & 2.7E-15 & $4.4 \mathrm{E}-16$ & $0.0 \mathrm{E}+00$ & $1.8 \mathrm{E}-12$ & 3.6E-13 & $7.3 E-13$ & $1.8 \mathrm{E}-12$ \\
\hline a2 & 2.7E-05 & $8.9 \mathrm{E}-16$ & $-5.6 \mathrm{E}-06$ & 2.7E-05 & $1.2 \mathrm{E}-05$ & $1.2 \mathrm{E}-05$ & $1.4 \mathrm{E}-05$ & 3.3E-05 \\
\hline $\begin{array}{l}\text { Desvio de } \\
\text { planicidade }\end{array}$ & 8 & 6 & 7 & 6 & 7 & 7 & 1 & 2 \\
\hline
\end{tabular}

Tabela 6.21 - Desvio de planicidde da peça 3 (ajustagem de Mínimos Quadrados).

\begin{tabular}{|l|l|r|r|r|r|r|r|r|}
\hline \multicolumn{2}{|c|}{ Peça 3 - Amostra 01 - Desvio de planicidade - Medição com Sistema Automatizado - Método dos } \\
Mínimos Quadrados \\
\hline coeficientes & Perfil 1 & Perfil 3 & Perfil 5 & Perfil 7 & Perfil Médio & Médias & $\begin{array}{c}\text { Desv. } \\
\text { Padrão }\end{array}$ & Amplitudes \\
\hline a0 & -2 & -2 & -1 & -2 & -2 & -2 & 0 & 1 \\
a1 & $2.6 \mathrm{E}-06$ & $2.6 \mathrm{E}-06$ & $2.6 \mathrm{E}-06$ & $2.6 \mathrm{E}-06$ & $2.6 \mathrm{E}-06$ & $2.6 \mathrm{E}-06$ & $0.0 \mathrm{E}+00$ & $0.0 \mathrm{E}+00$ \\
a2 & $1.2 \mathrm{E}-05$ & $-1.6 \mathrm{E}-05$ & $-2.1 \mathrm{E}-05$ & $1.8 \mathrm{E}-05$ & $-1.7 \mathrm{E}-06$ & $-1.7 \mathrm{E}-06$ & $1.5 \mathrm{E}-05$ & $3.9 \mathrm{E}-05$ \\
\hline Desvio de & & & & & & & & \\
planicidade & 9 & 7 & 8 & 6 & 7 & 7 & 1 & 3 \\
\hline
\end{tabular}

Tabela 6.22 - Desvio de planicidade da peça 3 (Medição Convencional).

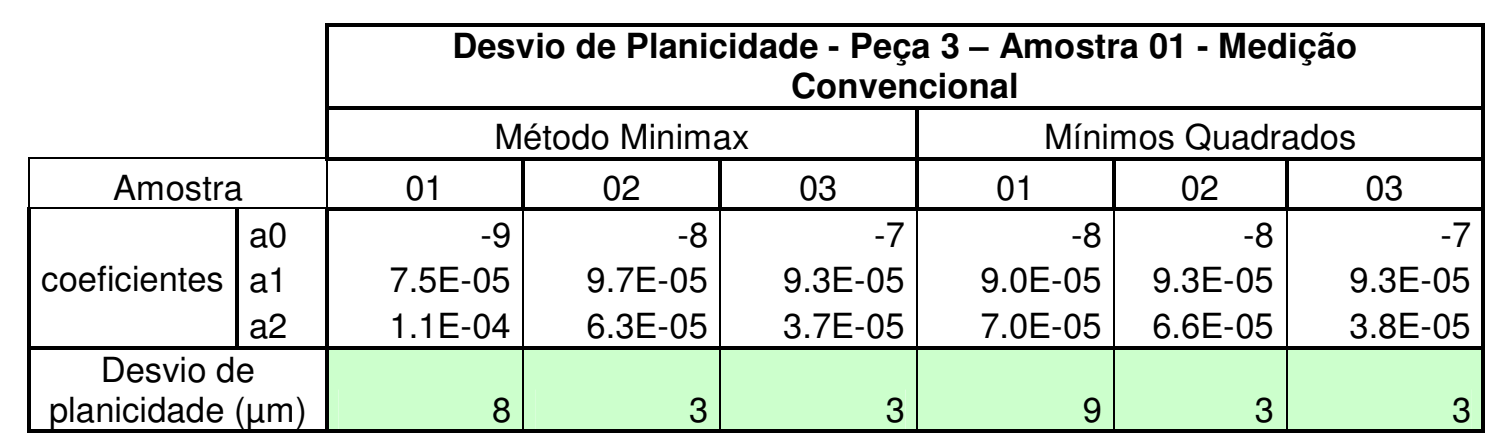

No caso da Peça 3, deve-se ressaltar que número de pontos coletados sobre as geratrizes e especialmente sobre as transversais, é muito reduzido. No caso das transversais, por exemplo, é possível coletar dados em apenas 3 posições de medição. Assim, é possível que a disponibilidade limitada de dados redundantes comprometa o desempenho do modelo de separação de erros. 
Os erros de avaliação do Sistema Automatizado podem ser visualizados ao se comparar os perfis da Peça 3 obtidos por meio de cada um dos sistemas.
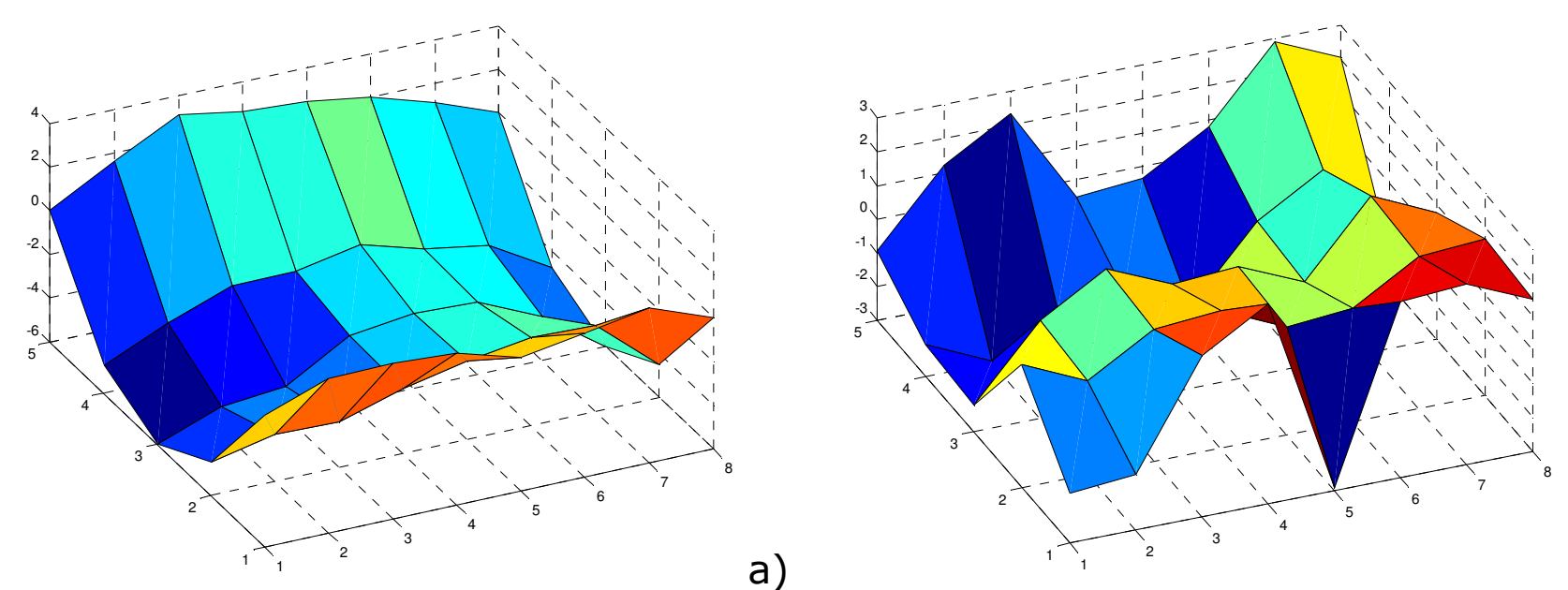

a)

b)

Figura 6.4 - Perfis de superfície da Peça 3 obtidos com o Sistema Automatizado (a) e o sistema convencional (b).

Ainda que sejam notadas diferenças entre os perfis avaliados, quando os resultados médios obtidos com o Sistema Automatizado, ou seja, valores de desvio de planicidade de $7 \mu \mathrm{m}$, são comparados com os valores resultantes da medição convencional, observa-se uma diferença máxima de $4 \mu \mathrm{m}$. Assim, a princípio, o sistema proposto foi capaz de fornecer resultados com boa acuracidade mesmo dispondo de uma quantidade reduzida de pontos de medição.

\subsection{Resultados da Avaliação do Desvio de Perpendicularismo}

\subsubsection{Resultados de medição da Peça 1}

As leituras de medição das geratrizes e transversais, coletadas com o Sistema Automatizado, constituem-se dados de entrada tanto para a avaliação do desvio de planicidade quanto para a avaliação do desvio de paralelismo e, consequentemente, perpendicularismo. Nesta seção são apresentados os resultados do processamento destes dados para a avaliação do perpendicularismo. As tabelas 6.23 e 6.24 apresentam os dados do perfil das geratrizes e transversais da Peça 1 , medidas com o 
Sistema Automatizado. Nesse caso, a inclinação dos dados foi preservada, já que se deseja exatamente calcular a inclinação da superfície plana ajustada a estes dados. Desta inclinação derivará o valor do desvio de perpendicularismo.

Tabela 6.23 - Perfis das geratrizes da Peça 1, medidos com o Sistema Automatizado.

\begin{tabular}{|r|r|r|r|r|r|r|r|}
\hline \multicolumn{8}{|c|}{ Perfil das Geratrizes da Peça 1 $(\mu \mathrm{m})$ - Amostra 01 - Sistema } \\
\hline \multicolumn{1}{|r|}{ G1 } & \multicolumn{1}{|c|}{ G2 } & G3 & \multicolumn{1}{|c|}{ G4 } & \multicolumn{1}{c|}{ G5 } & G6 & G7 & G8 \\
\hline 33 & -16 & -63 & -50 & -73 & -88 & -63 & -90 \\
\hline 29 & 1 & -34 & -44 & -63 & -73 & -61 & -81 \\
\hline 33 & 16 & -10 & -38 & -56 & -61 & -59 & -76 \\
\hline 31 & 21 & 8 & -33 & -47 & -50 & -54 & -76 \\
\hline 26 & 23 & 19 & -26 & -38 & -47 & -53 & -72 \\
\hline 16 & 21 & 16 & -24 & -30 & -47 & -55 & -72 \\
\hline 9 & 14 & 3 & -24 & -30 & -46 & -59 & -72 \\
\hline 6 & 10 & -6 & -29 & -28 & -47 & -64 & -76 \\
\hline 1 & 5 & -17 & -34 & -32 & -51 & -69 & -88 \\
\hline-7 & -9 & -28 & -44 & -40 & -55 & -72 & -96 \\
\hline-13 & -29 & -38 & -50 & -49 & -59 & -80 & -100 \\
\hline-22 & -48 & -51 & -57 & -57 & -61 & -85 & -96 \\
\hline-29 & -62 & -66 & -75 & -70 & -63 & -86 & -86 \\
\hline-36 & -71 & -80 & -85 & -83 & -61 & -84 & -72 \\
\hline-38 & -73 & -95 & -87 & -98 & -59 & -76 & -65 \\
\hline-44 & -75 & -110 & -96 & -115 & -52 & -63 & -55 \\
\hline
\end{tabular}

Tabela 6.24 - Perfis das transversais da Peça 1, medidos com o Sistema Automatizado.

\begin{tabular}{|r|r|r|r|r|r|}
\hline \multicolumn{6}{|c|}{$\begin{array}{c}\text { Perfil das Transversais da Peça 1 }(\mu \mathrm{m})- \\
\text { Amostra 01 - Sistema Automatizado - com } \\
\text { inclinação }\end{array}$} \\
\hline \multicolumn{1}{|c|}{ T1 } & \multicolumn{1}{|c|}{ T4 } & \multicolumn{1}{c|}{ T7 } & \multicolumn{1}{c|}{ T10 } & \multicolumn{1}{c|}{ T13 } & \multicolumn{1}{c|}{ T16 } \\
\hline 45 & 64 & 82 & 48 & 19 & -41 \\
\hline 26 & 56 & 82 & 57 & 26 & -38 \\
\hline 8 & 40 & 74 & 59 & 28 & -35 \\
\hline-15 & 27 & 66 & 58 & 33 & -25 \\
\hline-40 & 11 & 50 & 43 & 29 & -16 \\
\hline-65 & 1 & 33 & 22 & 22 & -6 \\
\hline-72 & 1 & 10 & -18 & 3 & -2 \\
\hline-113 & -19 & -18 & -63 & -21 & 5 \\
\hline
\end{tabular}

Conforme já citado, a combinação do conjunto de geratrizes medidas com cada reta-base dá origem a vários perfis para a superfície da Peça 1. Um destes perfis é apresentado na Tabela 6.25. 
Os parâmetros dos planos ajustados a estes perfis de superfície utilizando-se o Método Minimax e o Método dos Mínimos Quadrados são apresentados, respectivamente, nas tabelas 6.26 e 6.27 .

Tabela 6.25 - Perfil de superfície da Peça 1 (com inclinação).

\begin{tabular}{|r|r|r|r|r|r|r|r|r|r|r|r|r|r|r|r|r|}
\hline \multicolumn{1}{|c|}{ Perfil da superfície da Peça $1(\mu \mathrm{m})$ - Amostra 01 - Plano 01, obtido utilizando-se a reta-base T1 } \\
\hline 0 & -3 & 1 & -2 & -6 & -16 & -24 & -27 & -31 & -39 & -46 & -55 & -62 & -68 & -70 & -77 \\
\hline-19 & -2 & 13 & 19 & 21 & 18 & 11 & 8 & 2 & -12 & -31 & -51 & -64 & -74 & -76 & -78 \\
\hline-37 & -7 & 16 & 35 & 46 & 42 & 29 & 21 & 9 & -1 & -11 & -25 & -39 & -54 & -68 & -83 \\
\hline-60 & -55 & -49 & -44 & -37 & -34 & -35 & -40 & -44 & -55 & -61 & -68 & -85 & -95 & -97 & -107 \\
\hline-85 & -74 & -68 & -59 & -50 & -41 & -41 & -39 & -43 & -52 & -60 & -69 & -82 & -95 & -109 & -127 \\
\hline-110 & -95 & -83 & -72 & -69 & -69 & -68 & -69 & -73 & -77 & -81 & -84 & -85 & -83 & -81 & -74 \\
\hline-117 & -115 & -112 & -108 & -107 & -109 & -112 & -117 & -123 & -126 & -133 & -139 & -140 & -137 & -129 & -117 \\
\hline-158 & -148 & -144 & -144 & -140 & -140 & -139 & -144 & -155 & -164 & -167 & -163 & -153 & -139 & -132 & -122 \\
\hline
\end{tabular}

Tabela 6.26 - Coeficientes dos planos ajustados aos perfis da Peça 1 (ajustagem Minimax).

\begin{tabular}{|l|r|r|r|r|r|r|r|r|}
\hline \multicolumn{7}{|c|}{ Peça 1 - Amostra 01 - Coeficientes dos planos ajustados - Sistema Automatizado - } \\
Avaliação com Método Minimax \\
\hline coeficientes & \multicolumn{1}{|c|}{ Perfil 1 } & \multicolumn{1}{|c|}{ Perfil 4 } & \multicolumn{1}{|c|}{ Perfil 7 } & Perfil 10 & Perfil 13 & Perfil 16 & \multicolumn{1}{c|}{ Média } & Perfil Médio \\
\hline a0 & 54.0 & -38.8 & -9.2 & 53.1 & 82.8 & 97.4 & 39.9 & 46.3 \\
a1 & $-2.8 \mathrm{E}-04$ & $-1.7 \mathrm{E}-04$ & $-1.7 \mathrm{E}-04$ & $-1.8 \mathrm{E}-04$ & $-1.8 \mathrm{E}-04$ & $-1.3 \mathrm{E}-04$ & $-1.9 \mathrm{E}-04$ & $-1.7 \mathrm{E}-04$ \\
a2 & $-1.2 \mathrm{E}-03$ & $-2.0 \mathrm{E}-04$ & $-5.0 \mathrm{E}-04$ & $-8.7 \mathrm{E}-04$ & $-6.3 \mathrm{E}-04$ & $-4.0 \mathrm{E}-04$ & $-6.4 \mathrm{E}-04$ & $-7.4 \mathrm{E}-04$ \\
\hline
\end{tabular}

Tabela 6.27 - Coeficientes dos planos ajustados aos perfis da Peça 1 (ajustagem de Mínimos Quadrados).

\begin{tabular}{|l|r|r|r|r|r|r|r|r|}
\hline \multicolumn{7}{|c|}{ Peça 1 - Amostra 01 - Coeficientes dos planos ajustados - Sistema Automatizado - } \\
Avaliação com Método dos Mínimos Quadrados \\
\hline coeficientes & \multicolumn{1}{|c|}{ Perfil 1 } & \multicolumn{1}{|c|}{ Perfil 4 } & Perfil 7 & Perfil 10 & Perfil 13 & Perfil 16 & \multicolumn{1}{c|}{ Média } & Perfil Médio \\
\hline a0 & 19.7 & -15.1 & 10.3 & 47.5 & 76.7 & 93.0 & 38.7 & 38.7 \\
a1 & $-1.7 \mathrm{E}-04$ & $-1.7 \mathrm{E}-04$ & $-1.7 \mathrm{E}-04$ & $-1.7 \mathrm{E}-04$ & $-1.7 \mathrm{E}-04$ & $-1.7 \mathrm{E}-04$ & $-1.7 \mathrm{E}-04$ & $-1.7 \mathrm{E}-04$ \\
a2 & $-1.0 \mathrm{E}-03$ & $-3.7 \mathrm{E}-04$ & $-6.7 \mathrm{E}-04$ & $-7.6 \mathrm{E}-04$ & $-5.3 \mathrm{E}-04$ & $-2.8 \mathrm{E}-04$ & $-6.0 \mathrm{E}-04$ & $-6.0 \mathrm{E}-04$ \\
\hline
\end{tabular}

O perfil médio, conforme o dito anteriormente, foi calculado a partir da média das alturas dos 6 perfis obtidos, calculada para cada ponto da malha.

O mesmo processamento realizado para a Peça 1 foi aplicado aos dados medidos sobre a superfície de referência. Os resultados são apresentados nas tabelas 6.28 e 6.29 . Neste caso, os vários perfis obtidos para esta superfície foram denominados "Referência 1", "Referência 4", e 
assim por diante. A referência média foi calculada da mesma forma que perfil médio das peças.

Tabela 6.28 - Coeficientes dos planos ajustados aos perfis do artefato de referência (ajustagem Minimax).

\begin{tabular}{|l|r|r|r|r|r|r|r|}
\hline \multicolumn{7}{|c|}{ Coeficientes dos planos ajustados - Plano de Referência - Amostra 02 - Sistema } \\
Automatizado - Avaliação com Método Minimax \\
\hline coeficientes & \multicolumn{1}{|c|}{ Ref. 1 } & \multicolumn{1}{|c|}{ Ref. 4 } & \multicolumn{1}{|c|}{ Ref. 7 } & \multicolumn{1}{c|}{ Ref. 10 } & \multicolumn{1}{c|}{ Ref. 13 } & \multicolumn{1}{c|}{ Médias } & Ref. média \\
\hline a0 & -55.2 & 1.6 & 5.9 & -30.3 & -118.5 & -39.3 & -36.7 \\
a1 (x) & $4.5 \mathrm{E}-04$ & $4.0 \mathrm{E}-04$ & $3.9 \mathrm{E}-04$ & $3.8 \mathrm{E}-04$ & $3.8 \mathrm{E}-04$ & $4.0 \mathrm{E}-04$ & $3.9 \mathrm{E}-04$ \\
a2 (y) & $-1.8 \mathrm{E}-03$ & $-1.6 \mathrm{E}-03$ & $-1.5 \mathrm{E}-03$ & $-1.5 \mathrm{E}-03$ & $-9.0 \mathrm{E}-04$ & $-1.5 \mathrm{E}-03$ & $-1.5 \mathrm{E}-03$ \\
\hline
\end{tabular}

Tabela 6.29 - Coeficientes dos planos ajustados aos perfis do artefato de referência (ajustagem de Mínimos Quadrados).

\begin{tabular}{|l|r|r|r|r|r|r|r|}
\hline \multicolumn{7}{|c|}{$\begin{array}{c}\text { Coeficientes dos planos ajustados - Plano de Referência - Amostra } 02 \text { - com Sistema } \\
\text { Automatizado - Avaliação com Método dos Mínimos Quadrados }\end{array}$} \\
\hline coeficientes & \multicolumn{1}{|c|}{ Ref. 1 } & \multicolumn{1}{|c|}{ Ref. 4 } & \multicolumn{1}{|c|}{ Ref. 7 } & \multicolumn{1}{c|}{ Ref. 10 } & \multicolumn{1}{c|}{ Ref. 13 } & \multicolumn{1}{c|}{ Média } & Ref. média \\
\hline a0 & -33.2 & -13.0 & -14.3 & -43.9 & -107.5 & -42.4 & -42.4 \\
a1 (x) & $3.5 \mathrm{E}-04$ & $3.5 \mathrm{E}-04$ & $3.5 \mathrm{E}-04$ & $3.5 \mathrm{E}-04$ & $3.5 \mathrm{E}-04$ & $3.5 \mathrm{E}-04$ & $3.5 \mathrm{E}-04$ \\
a2 (y) & $-2.0 \mathrm{E}-03$ & $-1.7 \mathrm{E}-03$ & $-1.5 \mathrm{E}-03$ & $-1.6 \mathrm{E}-03$ & $-1.1 \mathrm{E}-03$ & $-1.6 \mathrm{E}-03$ & $-1.6 \mathrm{E}-03$ \\
\hline
\end{tabular}

Com base nos dados obtidos avaliou-se 0 desvio de perpendicularismo das peças na direção $x$, isto é, na direção das geratrizes. Conforme discutido anteriormente, pode-se assumir que o valor deste desvio corresponde à inclinação relativa entre a peça e a referência, na direção x. Tal inclinação, por sua vez, é dada pela diferença entre os coeficientes $a_{1}$ da superfície da peça e do plano de referência, ou seja, o desvio de perpendicularismo $D p$ é dado por:

$$
D p=a_{1} \text { peça }-a_{1} \text { superfície de referência }
$$

A combinação entre valores de inclinação de 6 perfis distintos da Peça 1 e de 5 perfis da superfície de referência resulta num total de 30 valores distintos para o desvio de perpendicularismo. A inclusão dos valores de inclinação do perfil médio e da referência média nas combinações resulta em mais 12 valores. Todas essas combinações são mostradas na Tabela 6.30. Neste caso, todos os valores de inclinação foram calculados utilizando-se o método Minimax, ou seja, a Tabela 6.30 baseia nos resultados das tabelas 6.26 e 6.28 . 
Tabela 6.30 - Desvios de perpendicularismo da peça 1 (Sistema Automatizado e ajustagem Minimax).

\begin{tabular}{|c|c|c|c|c|c|c|c|c|c|c|}
\hline \multicolumn{11}{|c|}{$\begin{array}{c}\text { Desvio de Perpendicularismo - Peça } 1 \text { - Medição com o Sistema Automatizado - } \\
\text { Avaliação com o Método Minimax }\end{array}$} \\
\hline \multicolumn{5}{|c|}{ Amostra de medição da Peça: } & \multirow{2}{*}{$\begin{array}{c}01 \\
\text { R1-P10 }\end{array}$} & \multicolumn{4}{|c|}{$\begin{array}{l}\text { Amostra de medição da superfície } \\
\text { de referência: }\end{array}$} & \multirow{2}{*}{$\begin{array}{c}02 \\
\text { Desvio } \\
\text { padrão }\end{array}$} \\
\hline Comb & inações & $\mathrm{R} 1-\mathrm{P} 1$ & $\mathrm{R} 1-\mathrm{P} 4$ & $\mathrm{R} 1-\mathrm{P} 7$ & & $\mathrm{R} 1-\mathrm{P} 13$ & R1-P16 & R1-PM & $\begin{array}{c}\text { Médias } \\
\text { (R1) }\end{array}$ & \\
\hline \multirow{3}{*}{$\begin{array}{c}\text { Valores } \\
\text { do } \\
\text { desvio }\end{array}$} & radianos & $-7.3 \mathrm{E}-04$ & $-6.2 \mathrm{E}-04$ & $-6.2 \mathrm{E}-04$ & $-6.2 \mathrm{E}-04$ & $-6.3 E-04$ & $-5.8 \mathrm{E}-04$ & $-6.2 E-04$ & $-6.3 \mathrm{E}-04$ & $4.9 \mathrm{E}-05$ \\
\hline & arco-seg & -150 & -128 & -128 & -129 & -131 & -120 & -128 & -131 & 10 \\
\hline & $\mu \mathrm{m}$ & -196 & -167 & -167 & -168 & -171 & -157 & -167 & -171 & 13 \\
\hline
\end{tabular}

\begin{tabular}{|c|r|r|r|r|r|r|r|r|r|r|}
\hline \multicolumn{2}{|c|}{ Combinações } & R4-P1 & \multicolumn{1}{|c|}{ R4-P4 } & R4-P7 & R4-P10 & R4-P13 & R4-P16 & R4-PM & $\begin{array}{c}\text { Médias } \\
\text { (R4) }\end{array}$ & $\begin{array}{l}\text { Desvio } \\
\text { padrão }\end{array}$ \\
\hline \multirow{2}{*}{\begin{tabular}{c} 
Valores $\begin{array}{c}\text { do } \\
\text { desvio }\end{array}$ \\
\cline { 3 - 13 }
\end{tabular}} & radianos & $-6.8 \mathrm{E}-04$ & $-5.7 \mathrm{E}-04$ & $-5.7 \mathrm{E}-04$ & $-5.8 \mathrm{E}-04$ & $-5.9 \mathrm{E}-04$ & $-5.3 \mathrm{E}-04$ & $-5.7 \mathrm{E}-04$ & $-5.9 \mathrm{E}-04$ & $4.9 \mathrm{E}-05$ \\
\cline { 2 - 12 } & $\mu \mathrm{m}$ & -140 & -118 & -118 & -119 & -121 & -110 & -118 & -121 & 10 \\
\hline
\end{tabular}

\begin{tabular}{|c|c|c|c|c|c|c|c|c|c|c|}
\hline \multicolumn{2}{|c|}{ Combinações } & R7-P1 & R7-P4 & $\mathrm{R} 7-\mathrm{P} 7$ & R7-P10 & R7-P13 & R7-P16 & R7-PM & $\begin{array}{c}\text { Médias } \\
\text { (R7) }\end{array}$ & $\begin{array}{l}\text { Desvio } \\
\text { padrão }\end{array}$ \\
\hline \multirow{3}{*}{$\begin{array}{c}\text { Valores } \\
\text { do } \\
\text { desvio }\end{array}$} & radianos & $-6.7 \mathrm{E}-04$ & $-5.7 \mathrm{E}-04$ & $-5.7 E-04$ & $-5.7 \mathrm{E}-04$ & $-5.8 \mathrm{E}-04$ & $-5.3 E-04$ & $-5.5 \mathrm{E}-04$ & $-5.8 \mathrm{E}-04$ & 4.9E-05 \\
\hline & arco-seg & -139 & -117 & -117 & -118 & -120 & -109 & -114 & -120 & 10 \\
\hline & $\mu \mathrm{m}$ & -182 & -153 & -153 & -154 & -157 & -143 & -149 & -157 & 13 \\
\hline
\end{tabular}

\begin{tabular}{|c|c|c|c|c|c|c|c|c|c|c|}
\hline \multicolumn{2}{|c|}{ Combinações } & $\mathrm{R} 10-\mathrm{P} 1$ & R10-P4 & $\mathrm{R} 10-\mathrm{P} 7$ & R10-P10 & $\mathrm{R} 10-\mathrm{P} 13$ & R10-P16 & R10-PM & $\begin{array}{l}\text { Médias } \\
\text { (R10) }\end{array}$ & $\begin{array}{l}\text { Desvio } \\
\text { padrão }\end{array}$ \\
\hline \multirow{3}{*}{$\begin{array}{c}\text { Valores } \\
\text { do } \\
\text { desvio }\end{array}$} & radianos & $-6.6 \mathrm{E}-04$ & $-5.5 \mathrm{E}-04$ & $-5.5 \mathrm{E}-04$ & $-5.6 \mathrm{E}-04$ & $-5.6 \mathrm{E}-04$ & $-5.1 \mathrm{E}-04$ & $-5.5 \mathrm{E}-04$ & $-5.7 \mathrm{E}-04$ & $4.9 \mathrm{E}-05$ \\
\hline & arco-seg & -136 & -114 & -114 & -115 & -117 & -106 & -114 & -117 & 10 \\
\hline & $\mu \mathrm{m}$ & -178 & -149 & -149 & -150 & -153 & -139 & -149 & -153 & 13 \\
\hline
\end{tabular}

\begin{tabular}{|c|r|r|r|r|r|r|r|r|r|r|}
\hline \multicolumn{2}{|c|}{ Combinações } & R13-P1 & R13-P4 & R13-P7 & R13-P10 & R13-P13 & R13-P16 & R13-PM & $\begin{array}{c}\text { Médias } \\
\text { (R13) }\end{array}$ & $\begin{array}{c}\text { Desvio } \\
\text { padrão }\end{array}$ \\
\hline \multirow{2}{*}{\begin{tabular}{c} 
Valores $\begin{array}{c}\text { do } \\
\text { desvio }\end{array}$ \\
\cline { 2 - 11 }
\end{tabular}} & $\begin{array}{l}\text { radianos } \\
\text { arco-seg }\end{array}$ & $-6.6 \mathrm{E}-04$ & $-5.5 \mathrm{E}-04$ & $-5.5 \mathrm{E}-04$ & $-5.6 \mathrm{E}-04$ & $-5.6 \mathrm{E}-04$ & $-5.1 \mathrm{E}-04$ & $-5.5 \mathrm{E}-04$ & $-5.7 \mathrm{E}-04$ & $4.9 \mathrm{E}-05$ \\
\cline { 2 - 11 } & $\mu-114$ & -114 & -115 & -117 & -106 & -114 & -117 & 10 \\
\hline
\end{tabular}

\begin{tabular}{|c|c|c|c|c|c|c|c|c|c|c|}
\hline \multicolumn{2}{|c|}{ Combinações } & RM-P1 & RM-P4 & RM-P7 & RM-P10 & RM-P13 & RM-P16 & RM-PM & $\begin{array}{l}\text { Médias } \\
(\mathrm{RM})\end{array}$ & $\begin{array}{l}\text { Desvio } \\
\text { padrão }\end{array}$ \\
\hline \multirow{3}{*}{$\begin{array}{c}\text { Valores } \\
\text { do } \\
\text { desvio }\end{array}$} & radianos & $-6.7 E-04$ & $-5.7 E-04$ & $-5.7 E-04$ & $-5.7 E-04$ & $-5.8 \mathrm{E}-04$ & $-5.3 E-04$ & $-5.7 \mathrm{E}-04$ & $-5.8 \mathrm{E}-04$ & 4.9E-05 \\
\hline & arco-seg & -139 & -117 & -117 & -118 & -119 & -109 & -117 & -120 & 10 \\
\hline & $\mu \mathrm{m}$ & -182 & -153 & -153 & -154 & -156 & -142 & -153 & -157 & 13 \\
\hline
\end{tabular}

\begin{tabular}{|c|l|r|r|r|r|r|r|r|}
\cline { 2 - 9 } \multicolumn{2}{c|}{} & \multicolumn{1}{c|}{$\mathrm{P} 1$} & \multicolumn{1}{c|}{$\mathrm{P} 4$} & \multicolumn{1}{c|}{$\mathrm{P} 7$} & \multicolumn{1}{c|}{$\mathrm{P} 10$} & \multicolumn{1}{c|}{$\mathrm{P} 13$} & \multicolumn{1}{c|}{ P16 } & \multicolumn{1}{c|}{ Pmédio } \\
\hline \multirow{3}{*}{ Médias } & radianos & $-6.8 \mathrm{E}-04$ & $-5.7 \mathrm{E}-04$ & $-5.7 \mathrm{E}-04$ & $-5.8 \mathrm{E}-04$ & $-5.9 \mathrm{E}-04$ & $-5.3 \mathrm{E}-04$ & $-5.7 \mathrm{E}-04$ \\
\cline { 2 - 9 } & arco-seg & -140 & -118 & -118 & -119 & -121 & -110 & -118 \\
\cline { 2 - 9 } & $\mu \mathrm{m}$ & -183 & -155 & -155 & -156 & -158 & -144 & -154 \\
\hline
\end{tabular}

\begin{tabular}{|c|l|r|r|r|r|r|r|r|}
\cline { 2 - 9 } \multicolumn{2}{c|}{} & \multicolumn{1}{c|}{$\mathrm{P} 1$} & \multicolumn{1}{c|}{$\mathrm{P} 4$} & \multicolumn{1}{c|}{$\mathrm{P} 7$} & \multicolumn{1}{c|}{$\mathrm{P} 10$} & \multicolumn{1}{c|}{$\mathrm{P} 13$} & $\mathrm{P} 16$ & Pmédio \\
\hline \multirow{2}{*}{$\begin{array}{c}\text { Desvios- } \\
\text { padrão }\end{array}$} & $\begin{array}{l}\text { radianos } \\
\text { arco-seg }\end{array}$ & $2.8 \mathrm{E}-05$ & $2.8 \mathrm{E}-05$ & $2.8 \mathrm{E}-05$ & $2.8 \mathrm{E}-05$ & $2.8 \mathrm{E}-05$ & $2.8 \mathrm{E}-05$ & $2.9 \mathrm{E}-05$ \\
\cline { 2 - 9 } & $\mu \mathrm{m}$ & 8 & 6 & 6 & 6 & 6 & 6 & 6 \\
\hline
\end{tabular}


O valor do desvio de perpendicularismo em micrometros resulta da multiplicação do valor em radianos pelo comprimento total da Peça 1 na direção $x$, que é de $270 \mathrm{~mm}$.

A análise da tabela demonstra que, para um mesmo perfil da peça, por exemplo, P1, o valor do desvio de paralelismo não se altera substancialmente quando diferentes perfis de referência, como R1, R4, R7, R10, etc., são utilizados. Em outras palavras, para cada perfil da peça, os valores do desvio de paralelismo são razoavelmente constantes para vários perfis de referência adotados, indicando que o modelo proposto apresenta certa consistência. O desvio padrão neste caso, devido à variação dos perfis de referência, é de 8 micrometros, independentemente do perfil da peça adotado. Na situação oposta, isto é, quando um dado perfil de referência é adotado e variam-se os perfis da peça, observa-se uma variação um pouco maior nos resultados, de 13 micrometros. Todos os valores apresentados em micrometros são relativos ao comprimento total da Peça 1, de $270 \mathrm{~mm}$. A partir dos valores de desvio padrão obtidos pode-se concluir que os perfis das retas transversais do plano de referência são mais similares entre si do que os perfis das retas transversais da peça, ou seja, a diferença observada entre estes valores demonstra que o plano de referência apresenta desvios de forma e orientação mais uniformes e homogêneos do que a Peça 1 medida. A combinação dos perfis das geratrizes com o perfil de cada reta transversal, no caso da Peça 1, resulta em perfis de superfície razoavelmente distintos, o que, por sua vez, reflete-se em um valor maior de desvio padrão. Esta maior homogeneidade observada no plano de referência é um resultado esperado, uma vez que, para exercer a função de referência, selecionou-se propositalmente um artefato que apresentasse desvios de forma e orientação pequenos e regulares.

A primeira coluna da Tabela 6.31 apresenta a média geral das combinações obtidas. Um outro valor médio para o desvio de perpendicularismo pode ser obtido calculando-se a diferença entre a 
média das inclinações dos diferentes perfis de referência e a média das inclinações dos diferentes perfis da peça. Em outras palavras, este desvio médio é dado por:

$$
\bar{D} p=\bar{a}_{1} \text { peça }-\bar{a}_{1} \text { referência }
$$

Uma terceira opção seria, ainda, considerar o valor da diferença entre a inclinação do perfil médio e a inclinação da referência média. A comparação entre os diferentes valores médios é mostrada abaixo.

Tabela 6.31 - Valores médios do desvio de perpendicularismo da Peça 1 (ajustagem Minimax).

\begin{tabular}{|c|c|c|c|c|}
\hline & \multicolumn{4}{|c|}{$\begin{array}{c}\text { Resultados Gerais - Desvio de perpendicularismo - Peça } \\
1 \text { - Sistema Automatizado e Ajustagem Minimax }\end{array}$} \\
\hline & $\begin{array}{l}\text { Média Geral } \\
\text { das } \\
\text { Combinações }\end{array}$ & $\begin{array}{l}\text { D. Padrão } \\
\text { Total }\end{array}$ & \begin{tabular}{l|} 
Perfil Médio - \\
Referência \\
Média \\
\end{tabular} & $\begin{array}{l}\text { Desvio } \\
\text { Médio }\end{array}$ \\
\hline \multirow{2}{*}{$\begin{array}{l}\text { radianos } \\
\text { arco-seg }\end{array}$} & $-5.9 \mathrm{E}-04$ & 5.2E-05 & $-5.7 \mathrm{E}-04$ & $-5.9 \mathrm{E}-04$ \\
\hline & -121 & 11 & -117 & -121 \\
\hline \multirow[t]{3}{*}{ um } & -158 & 14 & -153 & -158 \\
\hline & \multicolumn{3}{|c|}{ Amostra de Medição da Peça } & 01 \\
\hline & \multicolumn{3}{|c|}{$\begin{array}{l}\text { Amostra de Medição da superfície de } \\
\text { Referência }\end{array}$} & 02 \\
\hline
\end{tabular}

A amplitude máxima de variação entre os diferentes valores médios do desvio de perpendicularismo é de 5 micrometros. Além disso, o valor resultante da média das combinações é coincidente com o valor do desvio médio. Assim, observa-se que as diferentes estratégias não fornecem valores muito díspares.

As inclinações dos perfis de superfície também foram calculadas utilizando-se o Método dos Mínimos Quadrados. Os resultados são mostrados na Tabela 6.32. 
Tabela 6.32 - Desvios de perpendicularismo da Peça 1 (Sistema Automatizado e ajustagem de Mínimos Quadrados).

\begin{tabular}{|c|c|c|c|c|c|c|c|c|}
\hline \multicolumn{9}{|c|}{$\begin{array}{c}\text { Desvio de Perpendicularismo - Peça } 1 \text { - Medição com o Sistema Automatizado - } \\
\text { Avaliação com o Método dos Mínimos Quadrados }\end{array}$} \\
\hline \multicolumn{3}{|c|}{$\begin{array}{l}\text { Amostra de medição da } \\
\text { Peça: }\end{array}$} & \multirow{2}{*}{$\frac{01}{\mathrm{R} 1-\mathrm{P} 4}$} & \multicolumn{4}{|c|}{$\begin{array}{l}\text { Amostra de medição da superfície de } \\
\text { referência: }\end{array}$} & \multirow{2}{*}{$\frac{02}{\text { R1-Pmédio }}$} \\
\hline Comb & inações & $\mathrm{R} 1-\mathrm{P} 1$ & & $\mathrm{R} 1-\mathrm{P} 7$ & $\mathrm{R} 1-\mathrm{P} 10$ & $\mathrm{R} 1-\mathrm{P} 13$ & R1-P16 & \\
\hline \multirow{3}{*}{$\begin{array}{l}\text { Valores } \\
\text { do } \\
\text { desvio }\end{array}$} & radianos & $-5.2 E-04$ & $-5.2 \mathrm{E}-04$ & $-5.2 E-04$ & $-5.2 \mathrm{E}-04$ & $-5.2 \mathrm{E}-04$ & $-5.2 \mathrm{E}-04$ & $-5.2 \mathrm{E}-04$ \\
\hline & arco-seg & -108 & -108 & -108 & -108 & -108 & -108 & -108 \\
\hline & $\mu \mathrm{m}$ & -141 & -141 & -141 & -141 & -141 & -141 & -141 \\
\hline
\end{tabular}

\begin{tabular}{|c|l|r|r|r|r|r|r|r|}
\hline \multicolumn{2}{|c|}{ Combinações } & \multicolumn{1}{|c|}{ R4-P1 } & \multicolumn{1}{c|}{ R4-P1 } & \multicolumn{1}{c|}{ R4-P4 } & \multicolumn{1}{c|}{ R4-P7 } & R4-P10 & R4-P13 & \multicolumn{1}{c|}{ R4-P16 } \\
\hline \multirow{2}{*}{\begin{tabular}{c} 
Valores $\begin{array}{c}\text { do } \\
\text { do } \\
\text { desvio }\end{array}$ \\
\cline { 2 - 10 }
\end{tabular}} & arco-seg & $-5.2 \mathrm{E}-04$ & $-5.2 \mathrm{E}-04$ & $-5.2 \mathrm{E}-04$ & $-5.2 \mathrm{E}-04$ & $-5.2 \mathrm{E}-04$ & $-5.2 \mathrm{E}-04$ & $-5.2 \mathrm{E}-04$ \\
\cline { 2 - 10 } & -108 & -108 & -108 & -108 & -108 & -108 & -108 \\
\hline
\end{tabular}

\begin{tabular}{|c|l|r|r|r|r|r|r|r|}
\hline \multicolumn{2}{|c|}{ Combinações } & \multicolumn{1}{|c|}{ R7-P1 } & \multicolumn{1}{c|}{ R7-P1 } & \multicolumn{1}{c|}{ R7-P4 } & \multicolumn{1}{c|}{ R7-P7 } & R7-P10 & R7-P13 & \multicolumn{1}{c|}{ R7-P16 } \\
\hline \multirow{2}{*}{$\begin{array}{c}\text { Valores } \\
\text { do } \\
\text { desvio }\end{array}$} & radianos & $-5.2 \mathrm{E}-04$ & $-5.2 \mathrm{E}-04$ & $-5.2 \mathrm{E}-04$ & $-5.2 \mathrm{E}-04$ & $-5.2 \mathrm{E}-04$ & $-5.2 \mathrm{E}-04$ & $-5.2 \mathrm{E}-04$ \\
\cline { 2 - 10 } & arco-seg & -108 & -108 & -108 & -108 & -108 & -108 & -108 \\
\hline
\end{tabular}

\begin{tabular}{|c|c|c|c|c|c|c|c|c|}
\hline \multicolumn{2}{|c|}{ Combinações } & R10-P1 & R10-P1 & R10-P4 & R10-P7 & R10-P10 & R10-P13 & R10-P16 \\
\hline \multirow{3}{*}{$\begin{array}{c}\text { Valores } \\
\text { do } \\
\text { desvio }\end{array}$} & radianos & $-5.2 E-04$ & $-5.2 E-04$ & $-5.2 E-04$ & $-5.2 E-04$ & $-5.2 E-04$ & $-5.2 E-04$ & $-5.2 E-04$ \\
\hline & arco-se & -108 & -108 & -108 & -108 & -108 & -108 & -108 \\
\hline & $\mu \mathrm{m}$ & -141 & -141 & -141 & -141 & -141 & -141 & -141 \\
\hline
\end{tabular}

\begin{tabular}{|c|c|c|c|c|c|c|c|c|}
\hline \multicolumn{2}{|c|}{ Combinações } & R13-P1 & R13-P1 & R13-P4 & R13-P7 & R13-P10 & R13-P13 & R13-P16 \\
\hline \multirow{3}{*}{$\begin{array}{c}\text { Valores } \\
\text { do } \\
\text { desvio }\end{array}$} & radianos & $-5.2 E-04$ & $-5.2 E-04$ & $-5.2 E-04$ & $-5.2 E-04$ & $-5.2 E-04$ & $-5.2 E-04$ & $-5.2 E-04$ \\
\hline & arco-seg & -108 & -108 & -108 & -108 & -108 & -108 & -108 \\
\hline & $\mu \mathrm{m}$ & -141 & -141 & -141 & -141 & -141 & -141 & -141 \\
\hline
\end{tabular}

\begin{tabular}{|c|c|c|c|c|c|c|c|c|}
\hline \multicolumn{2}{|c|}{ Combinações } & RM-P1 & RM-P1 & RM-P4 & RM-P7 & RM-P10 & RM-P13 & RM-P16 \\
\hline \multirow{3}{*}{$\begin{array}{c}\text { Valores } \\
\text { do } \\
\text { desvio }\end{array}$} & radianos & $-5.2 E-04$ & $-5.2 E-04$ & $-5.2 E-04$ & $-5.2 E-04$ & $-5.2 E-04$ & $-5.2 E-04$ & $-5.2 E-04$ \\
\hline & arco-seg & -108 & -108 & -108 & -108 & -108 & -108 & -108 \\
\hline & $\mu \mathrm{m}$ & -141 & -141 & -141 & -141 & -141 & -141 & -141 \\
\hline
\end{tabular}

É possível notar de imediato que não há variabilidade nos resultados quando são adotados diferentes perfis de superfície da peça ou do plano de referência. Isso demonstra que o Método dos Mínimos Quadrados, quando aplicado à avaliação do desvio de perpendicularismo, é altamente estável, ou seja, é insensível às diferentes combinações entre os perfis da peça e da referência. Além disso, o valor obtido com qualquer uma das combinações coincide com o valor do desvio médio, obtido a partir da 
inclinação média dos perfis da peça e da inclinação média dos perfis da referência, conforme mostrado na equação 6.2.

Os resultados apresentados, obtidos com o Sistema Automatizado, são relativos a uma amostra de pontos da Peça 1 e uma amostra de pontos do artefato de referência. Foram realizadas outras 2 medições da Peça 1 para a avaliação do perpendicularismo. As amostras de dados destas outras medições foram tratadas da mesma forma que a amostra apresentada, isto é, para cada uma das amostras foram gerados vários perfis de superfície, e assim por diante. Os resultados são apresentados nos apêndices. Pode-se observar que as diferenças absolutas entre os perfis das geratrizes e transversais, considerando-se as 3 amostras, são muito maiores do que as diferenças observadas entre os conjuntos de dados sem inclinação, utilizados para o cálculo de planicidade. Entretanto, estas diferenças são aproximadamente constantes para todos os pontos de uma amostra, como é possível se observar comparando a Tabela 6.23 e as tabelas A5.1 e A5.6 do apêndice 5. Isto indica que os perfis obtidos a partir das diferentes amostras são similares, porém estão localizados em alturas diferentes em relação ao sistema coordenadas de medição. De fato, os valores das inclinações médias com relação ao eixo x (coeficiente $a_{1}$ ) obtidos a partir das três amostras são muito próximos, enquanto os valores dos coeficientes $a_{0}$, que representam o ponto em que os planos interceptam o eixo $z$, são distintos, conforme se pode observar nas tabelas 6.28, A5.4 e A5.9. Assim, deve-se ressaltar que o sistema possui boa repetibilidade na avaliação da inclinação da peça na direção $x$, ainda que os perfis obtidos nas três amostras sejam distintos.

Dados de outras 2 medições da superfície de referência também foram processados. Isto permitiu a combinação de resultados de três amostras das peças 1 e resultados de três amostras da superfície de referência, buscando-se verificar a repetibilidade e consistência do sistema proposto. $O$ resumo dos resultados destas combinações é apresentado no tópico 6.4 . 
A seguir são apresentados os resultados obtidos com a medição convencional do desvio de perpendicularismo da Peça 1. A Tabela 6.33 apresenta os perfis das geratrizes medidas.

Tabela 6.33 - Perfil da superfície da Peça 1 (medição convencional).

\begin{tabular}{|r|r|r|r|r|r|r|r|}
\hline \multicolumn{10}{|c|}{ Perfil das Geratrizes da Peça 1 $(\mu \mathrm{m})$ - Medição Convencional - } \\
\hline \multicolumn{1}{|r|}{ G1 } & \multicolumn{1}{|c|}{ G2 } & \multicolumn{1}{c|}{ G3 } & \multicolumn{1}{c|}{ G4 } & \multicolumn{1}{|c|}{ G5 } & \multicolumn{1}{c|}{ G6 } & \multicolumn{1}{c|}{ G7 } & \multicolumn{1}{c|}{ G8 } \\
\hline 90 & 60 & 45 & 45 & 40 & 50 & 80 & 90 \\
\hline 95 & 80 & 60 & 55 & 50 & 55 & 85 & 95 \\
\hline 100 & 85 & 70 & 65 & 60 & 65 & 95 & 95 \\
\hline 100 & 85 & 75 & 70 & 65 & 70 & 95 & 95 \\
\hline 95 & 80 & 75 & 70 & 65 & 70 & 90 & 95 \\
\hline 85 & 80 & 70 & 65 & 60 & 70 & 85 & 90 \\
\hline 75 & 65 & 60 & 60 & 55 & 70 & 75 & 85 \\
\hline 65 & 60 & 50 & 50 & 55 & 60 & 65 & 75 \\
\hline 50 & 45 & 40 & 40 & 40 & 45 & 55 & 65 \\
\hline 30 & 25 & 25 & 30 & 30 & 35 & 45 & 50 \\
\hline 10 & 5 & 5 & 5 & 15 & 25 & 35 & 40 \\
\hline-10 & -10 & -15 & -10 & 0 & 10 & 20 & 30 \\
\hline-30 & -35 & -40 & -30 & -20 & -5 & 10 & 20 \\
\hline-55 & -55 & -60 & -50 & -40 & -25 & -5 & 10 \\
\hline-70 & -80 & -80 & -70 & -55 & -35 & -20 & 5 \\
\hline-90 & -105 & -105 & -95 & -75 & -50 & -30 & -5 \\
\hline
\end{tabular}

Neste caso, não é necessário combinar os dados de retas transversais para se obter o perfil de superfície, uma vez que, no método convencional, os valores das alturas relativas entre as geratrizes já estão embutidos nas leituras do apalpador. Assim, os dados apresentados já constituem um perfil de superfície. As tabelas 6.34 e 6.35 apresentam, respectivamente, os parâmetros dos planos ajustados a três diferentes amostras do perfil da Peça 1 e os valores do desvio de perpendicularismo.

Tabela 6.34 - Coeficientes dos planos ajustados aos perfis da Peça 1 (medição convencional).

\begin{tabular}{|l|r|r|r|r|r|r|}
\hline \multicolumn{4}{|c|}{ Coeficientes dos planos ajustados - Peça 1 - Medição Convencional } \\
\hline \multirow{3}{*}{ coeficientes } & \multicolumn{3}{|c|}{ Método Minimax } & \multicolumn{1}{c|}{ Mínimos Quadrados } \\
\cline { 2 - 7 } & \multicolumn{1}{|c|}{02} & \multicolumn{1}{c|}{03} & \multicolumn{1}{c|}{01} & \multicolumn{1}{c|}{02} & \multicolumn{1}{c|}{03} \\
\hline a0 & 83.9 & 87.3 & 92.2 & 91.0 & 89.7 & 91.3 \\
a1 $(x)$ & $-5.3 \mathrm{E}-04$ & $-5.3 \mathrm{E}-04$ & $-5.4 \mathrm{E}-04$ & $-5.4 \mathrm{E}-04$ & $-5.4 \mathrm{E}-04$ & $-5.5 \mathrm{E}-04$ \\
a2 $(\mathrm{y})$ & $7.1 \mathrm{E}-05$ & $4.0 \mathrm{E}-05$ & $-1.5 \mathrm{E}-05$ & $2.3 \mathrm{E}-04$ & $2.3 \mathrm{E}-04$ & $2.1 \mathrm{E}-04$ \\
\hline
\end{tabular}


Tabela 6.35 - Desvio de perpendicularismo da Peça 1 (medição convencional).

\begin{tabular}{|c|c|c|c|c|c|c|c|}
\hline & \multirow[b]{3}{*}{ Medição } & \multicolumn{6}{|c|}{ Desvio de Perpendicularismo - Peça 1 - Medição Convencional } \\
\hline & & \multicolumn{3}{|c|}{ Método Minimax } & \multicolumn{3}{|c|}{ Mínimos Quadrados } \\
\hline & & 01 & 02 & 03 & 01 & 02 & 03 \\
\hline \multirow{3}{*}{$\begin{array}{c}\text { Valores } \\
\text { do } \\
\text { desvio }\end{array}$} & radianos & $-5.3 E-04$ & $-5.3 \mathrm{E}-04$ & $-5.4 \mathrm{E}-04$ & $-5.4 \mathrm{E}-04$ & $-5.4 \mathrm{E}-04$ & $-5.5 \mathrm{E}-04$ \\
\hline & arco-seg & -109 & -110 & -111 & -112 & -112 & -113 \\
\hline & $\mu \mathrm{m}$ & -142 & -144 & -146 & -147 & -147 & -147 \\
\hline
\end{tabular}

Novamente observa-se que o Método dos Mínimos Quadrados forneceu resultados praticamente constantes, neste caso, não para perfis diferentes pertencentes a uma mesma amostra, mas para amostras diferentes.

A diferença máxima entre os valores do desvio de perpendicularismo obtidos com cada um dos sistemas é de 14 micrometros, o que representa aproximadamente $10 \%$ do valor do desvio. Erros da ordem e dois décimos de milímetro medidos com os dois sistemas apresentaram diferenças de centésimos de milímetro.

Tabela 6.36 - Comparação entre os valores do desvio de perpendicularismo da Peça 1.

\begin{tabular}{|c|c|c|c|c|c|c|}
\hline \multicolumn{7}{|c|}{$\begin{array}{c}\text { Comparação entre desvios de perpendicularismo }(\mathrm{em} \mu \mathrm{m}) \text { - Peça } 1 \text { - Método } \\
\text { proposto e medição convencional }\end{array}$} \\
\hline & \multicolumn{3}{|c|}{ Minimax } & \multicolumn{3}{|c|}{ MMQ } \\
\hline Amostra de medição & 01 & 02 & 03 & 01 & 02 & 03 \\
\hline Medição convencional & -142 & -144 & -146 & -147 & -147 & -147 \\
\hline Método proposto (desvio médio) & \multicolumn{3}{|c|}{-157} & \multicolumn{3}{|c|}{-141} \\
\hline Diferenças & -14 & -13 & -11 & 6 & 6 & 6 \\
\hline
\end{tabular}

A comparação apresentada considera somente uma amostra de dados coletados com o Sistema Automatizado. Uma comparação mais abrangente é apresentada no item 6.4, onde são exibidas tabelas com resultados obtidos a partir das demais amostras de medição coletadas.

\subsubsection{Resultados de medição da Peça 2}

Neste item são apresentados os resultados de cada etapa do processamento dos dados de uma amostra de medição da Peça 2. As tabelas 6.37 e 6.38 apresentam os perfis, com inclinação, das geratrizes e 
transversais da Peça 2 resultantes da medição com o Sistema Automatizado. Os parâmetros dos planos ajustados aos perfis de superfície da Peça 2 são apresentados nas tabelas 6.40 e 6.41. Um destes perfis de superfície, obtido a partir da combinação entre os perfis das geratrizes e a reta transversal T1 é mostrado na tabela 6.39.

Tabela 6.37 - Perfis das geratrizes da Peça 2 medidos com o Sistema Automatizado.

\begin{tabular}{|r|r|r|r|r|r|r|r|}
\hline \multicolumn{10}{|c|}{ Perfil das Geratrizes da Peça $2(\mu \mathrm{m})$ - Amostra 01 - Sistema } \\
\hline \multicolumn{1}{|c|}{ G1 } & \multicolumn{1}{|c|}{ G2 } & G3 & \multicolumn{1}{|c|}{ G4 } & \multicolumn{1}{c|}{ G5 } & \multicolumn{1}{c|}{ G6 } & \multicolumn{1}{c|}{ G7 } & \multicolumn{1}{c|}{ G8 } \\
\hline 14 & 10 & -22 & -13 & -18 & -35 & -26 & -55 \\
\hline-6 & -8 & -31 & -27 & -26 & -45 & -43 & -73 \\
\hline-25 & -24 & -39 & -40 & -38 & -56 & -62 & -91 \\
\hline-43 & -39 & -48 & -54 & -49 & -65 & -79 & -107 \\
\hline-59 & -50 & -56 & -65 & -60 & -75 & -94 & -121 \\
\hline-71 & -61 & -63 & -77 & -71 & -84 & -108 & -134 \\
\hline-80 & -69 & -69 & -84 & -80 & -92 & -118 & -144 \\
\hline-87 & -76 & -75 & -89 & -89 & -98 & -125 & -151 \\
\hline-91 & -81 & -80 & -90 & -93 & -101 & -130 & -154 \\
\hline-92 & -84 & -83 & -90 & -95 & -101 & -130 & -153 \\
\hline-89 & -85 & -84 & -87 & -93 & -99 & -128 & -149 \\
\hline-83 & -82 & -83 & -81 & -92 & -94 & -123 & -143 \\
\hline-74 & -77 & -80 & -77 & -88 & -87 & -116 & -134 \\
\hline-64 & -69 & -78 & -71 & -85 & -78 & -106 & -124 \\
\hline-52 & -60 & -76 & -64 & -83 & -70 & -95 & -113 \\
\hline-39 & -49 & -72 & -57 & -82 & -62 & -82 & -99 \\
\hline
\end{tabular}

Tabela 6.38 - Perfis das transversais da Peça 2 medidos com o Sistema Automatizado.

\begin{tabular}{|c|c|c|c|c|c|}
\hline \multicolumn{6}{|c|}{$\begin{array}{c}\text { Perfil das Transversais da Peça } 2(\mu \mathrm{m})- \\
\text { Amostra } 01 \text { - Sistema Automatizado - com } \\
\text { inclinação }\end{array}$} \\
\hline T1 & T4 & T7 & T10 & T13 & T16 \\
\hline 34 & -10 & -23 & -34 & -9 & -10 \\
\hline 44 & 1 & -8 & -20 & 8 & 9 \\
\hline 45 & 6 & -3 & -14 & 17 & 20 \\
\hline 36 & 4 & -3 & -15 & 17 & 23 \\
\hline 17 & -3 & -11 & -24 & 10 & 21 \\
\hline-9 & -18 & -28 & -39 & -5 & 14 \\
\hline-42 & -40 & -52 & -62 & -29 & -2 \\
\hline-85 & -69 & -85 & -93 & -60 & -26 \\
\hline
\end{tabular}


Tabela 6.39 - Perfil de superfície da Peça 2.

\begin{tabular}{|c|c|c|c|c|c|c|c|c|c|c|c|c|c|c|c|}
\hline \multicolumn{16}{|c|}{$\begin{array}{l}\text { Perfil da superfície da Peça } 2 \text { - Amostra } 01 \text { - Perfil de superfície 01, obtido utilizando-se a reta- } \\
\text { base T1 }\end{array}$} \\
\hline 0 & -19 & -39 & -57 & -72 & -84 & -94 & -101 & -105 & -106 & -103 & -97 & -88 & -77 & -66 & -53 \\
\hline 10 & -7 & -23 & -38 & -50 & -60 & -69 & -75 & -80 & -84 & -84 & -81 & -77 & -69 & -59 & -49 \\
\hline 11 & 2 & -6 & -14 & -22 & -29 & -36 & -42 & -47 & -50 & -51 & -50 & -47 & -45 & -43 & -39 \\
\hline 2 & -12 & -25 & -39 & -50 & -61 & -69 & -74 & -75 & -75 & -72 & -66 & -61 & -56 & -49 & -41 \\
\hline-17 & -25 & -37 & -48 & -59 & -70 & -80 & -88 & -92 & -94 & -93 & -91 & -88 & -85 & -82 & -81 \\
\hline-42 & -53 & -63 & -73 & -83 & -92 & -100 & -106 & -109 & -109 & -107 & -102 & -95 & -86 & -78 & -69 \\
\hline-76 & -93 & -112 & -129 & -144 & -157 & -168 & -175 & -180 & -180 & -178 & -173 & -166 & -156 & -145 & -131 \\
\hline-118 & -136 & -155 & -171 & -185 & -197 & -208 & -215 & -217 & -217 & -213 & -206 & -197 & -188 & -176 & -163 \\
\hline
\end{tabular}

Tabela 6.40 - Coeficientes dos planos ajustados aos perfis da Peça 2 (ajustagem Minimax).

\begin{tabular}{|l|r|r|r|r|r|r|r|r|}
\hline \multicolumn{7}{|c|}{ Peça 2 - Amostra 01 - Coeficientes dos planos ajustados - Sistema Automatizado - } \\
Avaliação com Método Minimax \\
\hline \\
coeficientes & Perfil 1 & Perfil 4 & Perfil 7 & Perfil 10 & Perfil 13 & Perfil 16 & Média & $\begin{array}{r}\text { Perfil } \\
\text { Médio }\end{array}$ \\
\hline a0 & -129.1 & -30.6 & 4.7 & 17.0 & 11.2 & 23.9 & -17.2 & -24.2 \\
a1 & $-1.5 \mathrm{E}-04$ & $-1.6 \mathrm{E}-04$ & $-1.6 \mathrm{E}-04$ & $-1.8 \mathrm{E}-04$ & $-1.9 \mathrm{E}-04$ & $-2.4 \mathrm{E}-04$ & $-1.8 \mathrm{E}-04$ & $-1.8 \mathrm{E}-04$ \\
a2 & $8.9 \mathrm{E}-04$ & $4.6 \mathrm{E}-04$ & $4.8 \mathrm{E}-04$ & $4.8 \mathrm{E}-04$ & $4.4 \mathrm{E}-04$ & $1.6 \mathrm{E}-04$ & $4.8 \mathrm{E}-04$ & $4.9 \mathrm{E}-04$ \\
\hline
\end{tabular}

Tabela 6.41 - Coeficientes ajustados aos perfis da Peça 2 (ajustagem de Mínimos Quadrados).

\begin{tabular}{|l|r|r|r|r|r|r|r|r|}
\hline \multicolumn{7}{|c|}{ Peça 2 - Amostra 01 - Coeficientes dos planos ajustados - Sistema Automatizado - } \\
Avaliação com Método dos Mínimos Quadrados \\
\hline \\
coeficientes & \multicolumn{1}{|c|}{ Perfil 1 } & Perfil 4 & Perfil 7 & Perfil 10 & Perfil 13 & Perfil 16 & Média & $\begin{array}{r}\text { Perfil } \\
\text { Médio }\end{array}$ \\
\hline a0 & -121.5 & -25.4 & 9.9 & 20.5 & 15.5 & 19.4 & -13.6 & -19.1 \\
a1 & $-1.9 \mathrm{E}-04$ & $-1.9 \mathrm{E}-04$ & $-1.9 \mathrm{E}-04$ & $-1.9 \mathrm{E}-04$ & $-1.9 \mathrm{E}-04$ & $-1.9 \mathrm{E}-04$ & $-1.9 \mathrm{E}-04$ & $-1.9 \mathrm{E}-04$ \\
a2 & $9.4 \mathrm{E}-04$ & $4.5 \mathrm{E}-04$ & $4.3 \mathrm{E}-04$ & $4.5 \mathrm{E}-04$ & $4.4 \mathrm{E}-04$ & $2.0 \mathrm{E}-04$ & $4.9 \mathrm{E}-04$ & $5.0 \mathrm{E}-04$ \\
\hline
\end{tabular}

Para o cálculo do desvio de perpendicularismo da Peça 2, foram utilizados, além dos dados das tabelas 6.40 e 6.41 , os valores dos coeficientes do plano de referência apresentados nas tabelas 6.28 e 6.29 do item anterior. Os resultados obtidos são mostrados a seguir. 
Tabela 6.42 - Desvios de perpendicularismo da Peça 2 (Sistema Automatizado e ajustagem Minimax).

\begin{tabular}{|c|c|c|c|c|c|c|c|c|c|c|}
\hline \multicolumn{11}{|c|}{$\begin{array}{c}\text { Desvio de Perpendicularismo - Peça } 2 \text { - Medição com o Sistema Automatizado - } \\
\text { Avaliação com o Método Minimax }\end{array}$} \\
\hline \multicolumn{5}{|c|}{ Amostra de medição da Peça: } & \multirow{2}{*}{$\begin{array}{c}01 \\
R 1-P 10\end{array}$} & \multicolumn{4}{|c|}{$\begin{array}{l}\text { Amostra de medição da superfície } \\
\text { de referência: }\end{array}$} & \multirow{2}{*}{$\begin{array}{c}02 \\
\text { Desvio } \\
\text { padrão }\end{array}$} \\
\hline Comb & nações & $\mathrm{R} 1-\mathrm{P} 1$ & $\mathrm{R} 1-\mathrm{P} 4$ & $\mathrm{R} 1-\mathrm{P} 7$ & & $\mathrm{R} 1-\mathrm{P} 13$ & R1-P16 & R1-PM & $\begin{array}{c}\text { Média } \\
(\mathrm{R} 1)\end{array}$ & \\
\hline \multirow{3}{*}{$\begin{array}{c}\text { Valores } \\
\text { do } \\
\text { desvio }\end{array}$} & radianos & $-5.9 \mathrm{E}-04$ & $-6.0 \mathrm{E}-04$ & $-6.1 \mathrm{E}-04$ & $-6.3 \mathrm{E}-04$ & $-6.4 \mathrm{E}-04$ & $-6.9 \mathrm{E}-04$ & $-6.3 \mathrm{E}-04$ & $-6.3 \mathrm{E}-04$ & $3.3 \mathrm{E}-05$ \\
\hline & arco-seg & -123 & -125 & -126 & -130 & -132 & -141 & -129 & -130 & 7 \\
\hline & $\mu \mathrm{m}$ & -161 & -163 & -165 & -170 & -173 & -185 & -169 & -170 & 9 \\
\hline
\end{tabular}

\begin{tabular}{|c|l|r|r|r|r|r|r|r|r|r|}
\hline \multicolumn{2}{|c|}{ Combinações } & \multicolumn{1}{c|}{ R4-P1 } & \multicolumn{1}{c|}{ R4-P4 } & R4-P7 & R4-P10 & R4-P13 & R4-P16 & R4-PM & $\begin{array}{c}\text { Média } \\
\text { (R4) }\end{array}$ & $\begin{array}{c}\text { Desvio } \\
\text { padrão }\end{array}$ \\
\hline \multirow{2}{*}{$\begin{array}{c}\text { Valores } \\
\text { do } \\
\text { desvio }\end{array}$} & radianos & $-5.5 \mathrm{E}-04$ & $-5.6 \mathrm{E}-04$ & $-5.6 \mathrm{E}-04$ & $-5.8 \mathrm{E}-04$ & $-5.9 \mathrm{E}-04$ & $-6.4 \mathrm{E}-04$ & $-5.8 \mathrm{E}-04$ & $-5.8 \mathrm{E}-04$ & $3.3 \mathrm{E}-05$ \\
\cline { 2 - 12 } & $\mu \mathrm{m}$ & -113 & -115 & -116 & -120 & -122 & -132 & -119 & -120 & 7 \\
\hline
\end{tabular}

\begin{tabular}{|c|c|c|c|c|c|c|c|c|c|c|}
\hline \multicolumn{2}{|c|}{ Combinações } & R7-P1 & R7-P4 & R7-P7 & $\mathrm{R} 7-\mathrm{P} 10$ & $\mathrm{R} 7-\mathrm{P} 13$ & $\mathrm{R} 7-\mathrm{P} 16$ & R7-PM & $\begin{array}{c}\text { Média } \\
\text { (R7) }\end{array}$ & $\begin{array}{l}\text { Desvio } \\
\text { padrão }\end{array}$ \\
\hline \multirow{3}{*}{$\begin{array}{c}\text { Valores } \\
\text { do } \\
\text { desvio }\end{array}$} & radianos & $-5.4 \mathrm{E}-04$ & $-5.5 \mathrm{E}-04$ & $-5.6 \mathrm{E}-04$ & $-5.8 \mathrm{E}-04$ & $-5.9 E-04$ & $-6.3 \mathrm{E}-04$ & $-5.6 \mathrm{E}-04$ & $-5.7 \mathrm{E}-04$ & 3.3E-05 \\
\hline & arco-seg & -112 & -114 & -115 & -119 & -121 & -131 & -115 & -119 & 7 \\
\hline & $\mu \mathrm{m}$ & -146 & -149 & -150 & -156 & -159 & -171 & -151 & -155 & 9 \\
\hline
\end{tabular}

\begin{tabular}{|c|c|c|c|c|c|c|c|c|c|c|}
\hline \multicolumn{2}{|c|}{ Combinações } & $\mathrm{R} 10-\mathrm{P} 1$ & R10-P4 & R10-P7 & R10-P10 & R10-P13 & R10-P16 & R10-PM & $\begin{array}{l}\text { Média } \\
\text { (R10) }\end{array}$ & $\begin{array}{l}\text { Desvio } \\
\text { padrão }\end{array}$ \\
\hline \multirow{3}{*}{$\begin{array}{c}\text { Valores } \\
\text { do } \\
\text { desvio }\end{array}$} & radianos & $-5.3 \mathrm{E}-04$ & $-5.4 \mathrm{E}-04$ & $-5.4 \mathrm{E}-04$ & $-5.6 \mathrm{E}-04$ & $-5.7 \mathrm{E}-04$ & $-6.2 \mathrm{E}-04$ & $-5.6 \mathrm{E}-04$ & $-5.6 \mathrm{E}-04$ & 3.3E-05 \\
\hline & arco-seg & -109 & -111 & -112 & -116 & -118 & -127 & -115 & -116 & 7 \\
\hline & $\mu \mathrm{m}$ & -142 & -145 & -146 & -152 & -155 & -167 & -151 & -151 & 9 \\
\hline
\end{tabular}

\begin{tabular}{|c|c|c|c|c|c|c|c|c|c|c|}
\hline \multicolumn{2}{|c|}{ Combinações } & R13-P1 & R13-P4 & R13-P7 & R13-P10 & R13-P13 & R13-P16 & R13-PM & $\begin{array}{l}\text { Média } \\
\text { (R13) }\end{array}$ & $\begin{array}{l}\text { Desvio } \\
\text { padrão }\end{array}$ \\
\hline \multirow{3}{*}{$\begin{array}{c}\text { Valores } \\
\text { do } \\
\text { desvio }\end{array}$} & radianos & $-5.3 \mathrm{E}-04$ & $-5.4 \mathrm{E}-04$ & $-5.4 \mathrm{E}-04$ & $-5.6 \mathrm{E}-04$ & $-5.7 \mathrm{E}-04$ & $-6.2 \mathrm{E}-04$ & $-5.6 \mathrm{E}-04$ & $-5.6 \mathrm{E}-04$ & 3.3E-05 \\
\hline & arco-seg & -109 & -111 & -112 & -116 & -118 & -127 & -115 & -116 & 7 \\
\hline & $\mu \mathrm{m}$ & -142 & -145 & -146 & -152 & -155 & -167 & -151 & -151 & 9 \\
\hline
\end{tabular}

\begin{tabular}{|c|c|c|c|c|c|c|c|c|c|c|}
\hline \multicolumn{2}{|c|}{ Combinações } & RM-P1 & RM-P4 & RM-P7 & RM-P10 & $\mathrm{RM}-\mathrm{P} 13$ & RM-P16 & RM-PM & $\begin{array}{l}\text { Média } \\
\text { (RM) }\end{array}$ & $\begin{array}{l}\text { Desvio } \\
\text { padrão }\end{array}$ \\
\hline \multirow{3}{*}{$\begin{array}{c}\text { Valores } \\
\text { do } \\
\text { desvio }\end{array}$} & radianos & $-5.4 \mathrm{E}-04$ & $-5.5 \mathrm{E}-04$ & $-5.6 \mathrm{E}-04$ & $-5.8 \mathrm{E}-04$ & $-5.9 \mathrm{E}-04$ & $-6.3 \mathrm{E}-04$ & $-5.7 \mathrm{E}-04$ & $-5.7 \mathrm{E}-04$ & 3.3E-05 \\
\hline & arco-seg & -112 & -114 & -115 & -119 & -121 & -130 & -118 & -118 & 7 \\
\hline & $\mu \mathrm{m}$ & -146 & -149 & -150 & -156 & -158 & -171 & -155 & -155 & 9 \\
\hline
\end{tabular}

\begin{tabular}{|c|l|r|r|r|r|r|r|r|}
\cline { 3 - 9 } \multicolumn{2}{c|}{} & \multicolumn{1}{c|}{$\mathrm{P} 1$} & \multicolumn{1}{c|}{$\mathrm{P} 4$} & \multicolumn{1}{c|}{$\mathrm{P} 7$} & \multicolumn{1}{c|}{$\mathrm{P} 10$} & \multicolumn{1}{c|}{$\mathrm{P} 13$} & \multicolumn{1}{c|}{$\mathrm{P} 16$} & \multicolumn{1}{c|}{ Pmédio } \\
\hline \multirow{3}{*}{ Médias } & radianos & $-5.5 \mathrm{E}-04$ & $-5.6 \mathrm{E}-04$ & $-5.6 \mathrm{E}-04$ & $-5.8 \mathrm{E}-04$ & $-5.9 \mathrm{E}-04$ & $-6.4 \mathrm{E}-04$ & $-5.8 \mathrm{E}-04$ \\
\cline { 2 - 9 } & arco-seg & -113 & -115 & -116 & -120 & -122 & -132 & -119 \\
\cline { 2 - 9 } & (um) & -148 & -151 & -152 & -158 & -160 & -172 & -155 \\
\hline
\end{tabular}

\begin{tabular}{|c|l|r|r|r|r|r|r|r|}
\cline { 2 - 9 } \multicolumn{2}{c|}{} & \multicolumn{1}{c|}{$\mathrm{P} 1$} & \multicolumn{1}{c|}{$\mathrm{P} 4$} & \multicolumn{1}{c|}{$\mathrm{P} 7$} & \multicolumn{1}{c|}{$\mathrm{P} 10$} & \multicolumn{1}{c|}{$\mathrm{P} 13$} & $\mathrm{P} 16$ & Pmédio \\
\hline \multirow{2}{*}{$\begin{array}{c}\text { Desvios- } \\
\text { padrão }\end{array}$} & radianos & $2.8 \mathrm{E}-05$ & $2.8 \mathrm{E}-05$ & $2.8 \mathrm{E}-05$ & $2.8 \mathrm{E}-05$ & $2.8 \mathrm{E}-05$ & $2.8 \mathrm{E}-05$ & $2.9 \mathrm{E}-05$ \\
\cline { 2 - 9 } & arco-seg & 6 & 6 & 6 & 6 & 6 & 6 & 6 \\
\cline { 2 - 9 } & um & 8 & 8 & 8 & 8 & 8 & 8 & 8 \\
\hline
\end{tabular}


Os valores do desvio de perpendicularismo apresentados em micrometros são relativos a um comprimento total da Peça 2, na direção principal de medição, de $270 \mathrm{~mm}$.

Pode-se observar que as médias dos desvios de perpendicularismo da Peça 2 são bastante próximas às médias correspondentes obtidas para a Peça 1, apresentadas na Tabela 6.30. Este resultado é esperado uma vez que estas peças constituem-se faces opostas de uma mesma peça mecânica, conforme exposto no item 5.1. O desvio padrão relativo à variação dos perfis de superfície da Peça 2 é menor do que o observado para a Peça 1, indicando possivelmente que a Peça 2 é mais homogênea e que suas transversais possuem perfis similares. Os valores de desvio padrão relacionados aos diferentes perfis da superfície de referência são os mesmos apresentados na tabela relativa à Peça 1. Isso é natural, visto que, nos cálculos do desvio da Peça 2, utilizou-se a mesma amostra de medição da superfície de referência empregada na avaliação do desvio da Peça 1.

Na Tabela 6.43 são apresentados os valores médios dos desvios de perpendicularismo, calculados segundo os métodos já citados.

Tabela 6.43 - Resultados médios para o desvio de perpendicularismo da Peça 2 (ajustagem Minimax).

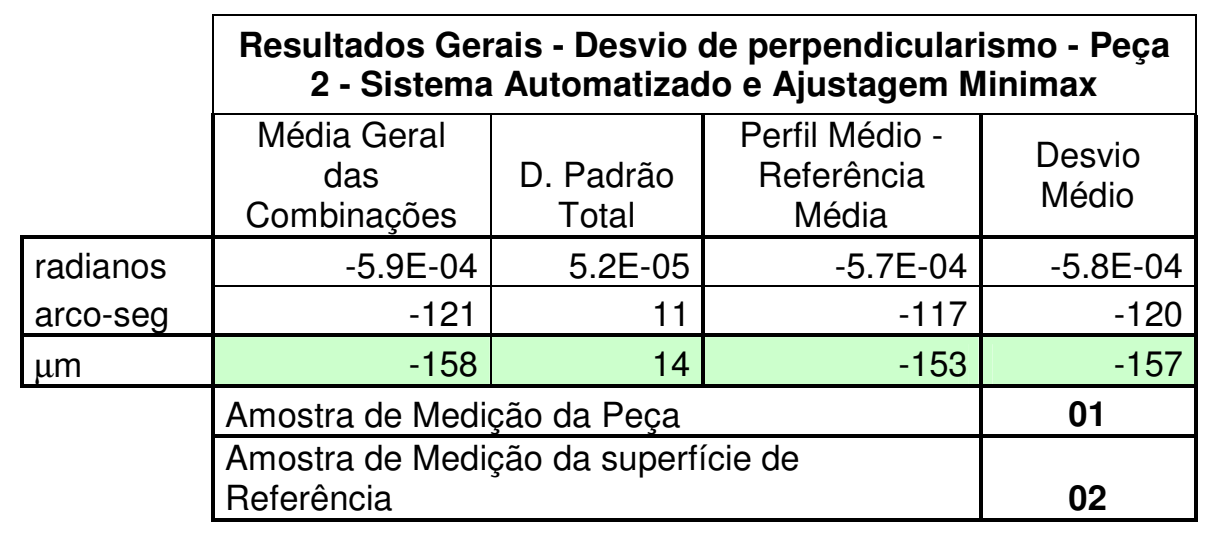

Os valores do desvio de perpendicularismo calculados utilizando-se o Método dos Mínimos Quadrados são apresentados na Tabela 6.44. Embora estes valores tenham sido obtidos mediante a combinação dos diferentes 
perfis da superfície da peça e do artefato de referência, não se observa nenhuma variação entre eles.

Os perfis das geratrizes da Peça 2 medidos com o sistema convencional e os valores finais do desvio de perpendicularismo obtidos a partir destes perfis são apresentados nas tabelas 6.45 e 6.46 .

Tabela 6.44 - Desvios de perpendicularismo da Peça 2 (Sistema Automatizado e ajustagem de Mínimos Quadrados).

\begin{tabular}{|c|c|c|c|c|c|c|c|c|}
\hline \multicolumn{9}{|c|}{$\begin{array}{c}\text { Desvio de Perpendicularismo - Peça } 2 \text { - Medição com o Sistema Automatizado - } \\
\text { Avaliação com o Método dos Mínimos Quadrados }\end{array}$} \\
\hline \multicolumn{2}{|c|}{ Combinações } & $\mathrm{R} 1-\mathrm{P} 1$ & $\mathrm{R} 1-\mathrm{P} 4$ & R1-P7 & $\mathrm{R} 1-\mathrm{P} 10$ & R1-P13 & $\mathrm{R} 1-\mathrm{P} 16$ & R1-Pmédio \\
\hline \multirow{3}{*}{$\begin{array}{c}\text { Valores } \\
\text { do } \\
\text { desvio }\end{array}$} & \multirow{2}{*}{\begin{tabular}{|l|} 
radianos \\
arco-seg
\end{tabular}} & $-5.4 E-04$ & $-5.4 E-04$ & $-5.4 E-04$ & $-5.4 E-04$ & $-5.4 \mathrm{E}-04$ & $-5.4 \mathrm{E}-04$ & $-5.4 \mathrm{E}-04$ \\
\hline & & -112 & -112 & -112 & -112 & -112 & -112 & -112 \\
\hline & $\mu \mathrm{m}$ & -146 & -146 & -146 & -146 & -146 & -146 & -146 \\
\hline
\end{tabular}

\begin{tabular}{|c|l|r|r|r|r|r|r|r|}
\hline \multicolumn{2}{|c|}{ Combinações } & \multicolumn{1}{|c|}{ R4-P1 } & \multicolumn{1}{c|}{ R4-P4 } & \multicolumn{1}{c|}{ R4-P7 } & R4-P10 & R4-P13 & R4-P16 & \multicolumn{1}{c|}{ R4-Pmédio } \\
\hline $\begin{array}{c}\text { Valores } \\
\text { do } \\
\text { desvio }\end{array}$ & radianos & $-5.4 \mathrm{E}-04$ & $-5.4 \mathrm{E}-04$ & $-5.4 \mathrm{E}-04$ & $-5.4 \mathrm{E}-04$ & $-5.4 \mathrm{E}-04$ & $-5.4 \mathrm{E}-04$ & $-5.4 \mathrm{E}-04$ \\
\cline { 2 - 10 } & arco-seg & -112 & -112 & -112 & -112 & -112 & -112 & -112 \\
\cline { 2 - 10 } & $\mu \mathrm{m}$ & -146 & -146 & -146 & -146 & -146 & -146 & -146 \\
\hline
\end{tabular}

\begin{tabular}{|c|l|r|r|r|r|r|r|r|}
\hline \multicolumn{2}{|c|}{ Combinações } & \multicolumn{1}{|c|}{ R7-P1 } & \multicolumn{1}{c|}{ R7-P4 } & \multicolumn{1}{c|}{ R7-P7 } & R7-P10 & R7-P13 & R7-P16 & \multicolumn{1}{c|}{ R7-Pmédio } \\
\hline \multirow{2}{*}{\begin{tabular}{c} 
Valores $\begin{array}{c}\text { do } \\
\text { desvio }\end{array}$ \\
\cline { 2 - 10 }
\end{tabular}} & $\begin{array}{l}\text { radianos } \\
\text { arco-seg }\end{array}$ & $-5.4 \mathrm{E}-04$ & $-5.4 \mathrm{E}-04$ & $-5.4 \mathrm{E}-04$ & $-5.4 \mathrm{E}-04$ & $-5.4 \mathrm{E}-04$ & $-5.4 \mathrm{E}-04$ & $-5.4 \mathrm{E}-04$ \\
\cline { 2 - 10 } & -112 & -112 & -112 & -112 & -112 & -112 & -112 \\
\hline
\end{tabular}

\begin{tabular}{|c|l|r|r|r|r|r|r|r|}
\hline \multicolumn{2}{|c|}{ Combinações } & R10-P1 & R10-P4 & R10-P7 & R10-P10 & R10-P13 & R10-P16 & R10-Pmédio \\
\hline $\begin{array}{c}\text { Valores } \\
\text { do } \\
\text { desvio }\end{array}$ & $\begin{array}{l}\text { radianos } \\
\text { arco-seg }\end{array}$ & $-5.4 \mathrm{E}-04$ & $-5.4 \mathrm{E}-04$ & $-5.4 \mathrm{E}-04$ & $-5.4 \mathrm{E}-04$ & $-5.4 \mathrm{E}-04$ & $-5.4 \mathrm{E}-04$ & $-5.4 \mathrm{E}-04$ \\
\cline { 2 - 10 } & $\mu \mathrm{m}$ & -112 & -112 & -112 & -112 & -112 & -112 & -112 \\
\hline
\end{tabular}

\begin{tabular}{|c|l|r|r|r|r|r|r|r|}
\hline \multicolumn{2}{|c|}{ Combinações } & R13-P1 & R13-P4 & R13-P7 & R13-P10 & R13-P13 & R13-P16 & R13-Pmédio \\
\hline $\begin{array}{c}\text { Valores } \\
\text { do } \\
\text { desvio }\end{array}$ & radianos & $-5.4 \mathrm{E}-04$ & $-5.4 \mathrm{E}-04$ & $-5.4 \mathrm{E}-04$ & $-5.4 \mathrm{E}-04$ & $-5.4 \mathrm{E}-04$ & $-5.4 \mathrm{E}-04$ & $-5.4 \mathrm{E}-04$ \\
\cline { 2 - 10 } & arco-seg & -112 & -112 & -112 & -112 & -112 & -112 & -112 \\
\hline
\end{tabular}

\begin{tabular}{|c|c|c|c|c|c|c|c|c|}
\hline \multicolumn{2}{|c|}{ Combinações } & RM-P1 & RM-P4 & RM-P7 & RM-P10 & RM-P13 & RM-P16 & RM-Pmédio \\
\hline \multirow{3}{*}{$\begin{array}{c}\text { Valores } \\
\text { do } \\
\text { desvio }\end{array}$} & radianos & $-5.4 \mathrm{E}-04$ & $-5.4 \mathrm{E}-04$ & $-5.4 \mathrm{E}-04$ & $-5.4 E-04$ & $-5.4 E-04$ & $-5.4 \mathrm{E}-04$ & $-5.4 \mathrm{E}-04$ \\
\hline & arco-se & -112 & -112 & -112 & -112 & -112 & -112 & -112 \\
\hline & $\mu \mathrm{m}$ & -146 & -146 & -146 & -146 & -146 & -146 & -146 \\
\hline
\end{tabular}


Tabela 6.45 - Perfil da superfície da Peça 2 (método convencional).

\begin{tabular}{|r|r|r|r|r|r|r|r|}
\hline \multicolumn{8}{|c|}{ Perfil das Geratrizes da Peça 2 $(\mu \mathrm{m})$ - Medição Convencional - } \\
\multicolumn{1}{|c|}{ com inclinaça - Amostra 01 } \\
\hline G1 & G2 & \multicolumn{1}{c|}{ G3 } & \multicolumn{1}{c|}{ G4 } & \multicolumn{1}{c|}{ G5 } & \multicolumn{1}{c|}{ G6 } & G7 & \multicolumn{1}{c|}{ G8 } \\
\hline 60 & 65 & 67 & 70 & 70 & 72 & 80 & 80 \\
\hline 45 & 50 & 55 & 55 & 58 & 60 & 65 & 65 \\
\hline 35 & 37 & 40 & 43 & 45 & 45 & 50 & 50 \\
\hline 20 & 25 & 28 & 30 & 30 & 34 & 37 & 40 \\
\hline 10 & 12 & 15 & 18 & 20 & 20 & 25 & 25 \\
\hline-5 & 0 & 4 & 5 & 5 & 8 & 10 & 12 \\
\hline-15 & -10 & -8 & -5 & -5 & -3 & 0 & 0 \\
\hline-25 & -20 & -18 & -15 & -15 & -12 & -10 & -10 \\
\hline-30 & -28 & -25 & -25 & -22 & -20 & -20 & -20 \\
\hline-35 & -35 & -32 & -30 & -30 & -30 & -25 & -25 \\
\hline-40 & -40 & -37 & -35 & -35 & -34 & -30 & -30 \\
\hline-45 & -43 & -42 & -40 & -40 & -38 & -35 & -32 \\
\hline-50 & -48 & -45 & -42 & -44 & -40 & -40 & -35 \\
\hline-55 & -52 & -50 & -45 & -45 & -45 & -42 & -40 \\
\hline-60 & -55 & -52 & -52 & -50 & -50 & -45 & -45 \\
\hline-60 & -60 & -57 & -55 & -54 & -52 & -50 & -50 \\
\hline
\end{tabular}

Tabela 6.46 - Desvio de perpendicularismo da peça 2 (método convencional).

\begin{tabular}{|c|c|c|c|c|c|c|c|}
\hline & & \multicolumn{6}{|c|}{ Desvio de Perpendicularismo - Peça 2 - Medição Convencional } \\
\hline & & \multicolumn{3}{|c|}{ Método Minimax } & \multicolumn{3}{|c|}{ Mínimos Quadrados } \\
\hline & Medição & 01 & 02 & 03 & 01 & 02 & 03 \\
\hline \multirow{3}{*}{$\begin{array}{c}\text { Valores } \\
\text { do } \\
\text { desvio }\end{array}$} & radianos & $-4.8 \mathrm{E}-04$ & $-4.7 E-04$ & $-4.7 E-04$ & $-4.6 \mathrm{E}-04$ & $-4.6 \mathrm{E}-04$ & $-4.6 \mathrm{E}-04$ \\
\hline & arco-seg & -98 & -97 & -97 & -95 & -95 & -94 \\
\hline & $\mu \mathrm{m}$ & -128 & -127 & -127 & -124 & -124 & -124 \\
\hline
\end{tabular}

São observadas diferenças de 17 a 31 micrometros entre os valores obtidos utilizando-se os diferentes sistemas de medição. Deve-se notar também que o sistema convencional forneceu valores bem distintos para o desvio de perpendicularismo das peças 1 e 2 , sendo que, a princípio, estes valores deveriam ser próximos, conforme discutido no capítulo 5. Uma análise comparativa mais aprofundada é apresentada no item 6.4. Resultados obtidos a partir de outras amostras de dados da Peça 2 são apresentados nos apêndices. Analisando-se estes resultados, é possível constatar que o sistema apresentou boa repetibilidade na medição da inclinação da Peça 2, assim como ocorreu para a Peça 1. Mais do que isso, no caso da Peça 2, não se observou uma translação entre os dados das diferentes amostras, como o ocorrido no caso da Peça 1. Estes fatos podem ser constatados a partir da análise das tabelas contendo os perfis 
das geratrizes da peça 2 ou a partir da análise dos coeficientes dos planos ajustados a estes perfis. Em outras palavras, a repetibilidade do sistema na avaliação da Peça 2 foi ainda maior, pois se observou pouca variação tanto entre os valores médios do coeficiente $a_{1}$ relativos às diferentes amostras quanto entre os valores médios do coeficiente $a_{0}$ também obtidos a partir das diferentes amostras. Estes últimos valores, sendo aproximadamente constantes, é que indicam que não houve translação entre os perfis, ou seja, neste caso, os perfis obtidos a partir de diferentes amostras encontram-se em uma mesma altura em relação ao sistema de referência para a medição da peça 2 , além de possuírem as mesmas inclinações médias.

\subsubsection{Resultados de medição da Peça 3}

As tabelas apresentadas neste item são análogas às apresentadas para as demais peças, e contêm os resultados das etapas do processo de avaliação do desvio de perpendicularismo da Peça 3.

Tabela 6.47 - Perfis das geratrizes da Peça 3 medidos com o Sistema Automatizado.

\begin{tabular}{|r|r|r|r|r|}
\hline \multicolumn{6}{|c|}{ Perfil das Geratrizes da Peça 3 $(\mu \mathrm{m})$ - } \\
Amostra 01 - Sistema Automatizado - \\
com inclinação \\
\hline \multicolumn{1}{|c|}{ G1 } & \multicolumn{1}{|c|}{ G2 } & \multicolumn{1}{c|}{ G3 } & \multicolumn{1}{c|}{ G4 } & \multicolumn{1}{c|}{ G5 } \\
\hline 5 & 3 & 20 & 0 & -10 \\
\hline 46 & 45 & 64 & 43 & 34 \\
\hline 79 & 77 & 95 & 77 & 67 \\
\hline 102 & 100 & 115 & 99 & 87 \\
\hline 117 & 113 & 122 & 111 & 97 \\
\hline 125 & 117 & 116 & 112 & 96 \\
\hline 124 & 110 & 97 & 103 & 83 \\
\hline 114 & 91 & 65 & 83 & 60 \\
\hline
\end{tabular}

Tabela 6.48 - Perfis das transversais da Peça 3 medidos com o Sistema Automatizado.

\begin{tabular}{|c|c|c|c|}
\hline \multicolumn{4}{|c|}{$\begin{array}{l}\text { Perfil das Transversais da Peça } \\
3(\mu \mathrm{m}) \text { - Amostra } 01 \text { - Sistema } \\
\text { Automatizado - com inclinação }\end{array}$} \\
\hline T1 & T3 & T5 & $\mathrm{T7}$ \\
\hline 77 & 107 & 124 & 166 \\
\hline 101 & 144 & 164 & 205 \\
\hline 107 & 146 & 164 & 207 \\
\hline 97 & 113 & 127 & 174 \\
\hline 69 & 45 & 51 & 105 \\
\hline
\end{tabular}


O mesmo comentário feito no caso da avaliação do desvio de planicidade da Peça 3 é aplicável neste caso, ou seja, o número de pontos coletados sobre a Peça 3 é pequeno e pode comprometer o desempenho do modelo de separação de erros.

Os parâmetros dos planos ajustados aos perfis de superfície da Peça 3 são apresentados nas tabelas 6.50 e 6.51 . Um destes perfis é mostrado na tabela abaixo.

Tabela 6.49 - Perfil de superfície da Peça 3.

\begin{tabular}{|c|c|c|c|c|c|c|c|}
\hline \multicolumn{8}{|c|}{$\begin{array}{c}\text { Perfil da superfície da Peça } 3 \text { - Amostra } 01 \text { - Perfil de } \\
\text { superfície 01, obtido utilizando-se a reta-base T1 - } \\
\text { Sistema Automatizado }\end{array}$} \\
\hline 0 & 41 & 74 & 97 & 112 & 120 & 119 & 109 \\
\hline 24 & 66 & 98 & 121 & 134 & 137 & 130 & 111 \\
\hline 31 & 75 & 106 & 126 & 133 & 127 & 108 & 76 \\
\hline 20 & 64 & 97 & 119 & 132 & 132 & 124 & 104 \\
\hline-7 & 36 & 69 & 90 & 99 & 98 & 86 & 62 \\
\hline
\end{tabular}

Tabela 6.50 - Coeficientes dos planos ajustados aos perfis da Peça 3 (ajustagem Minimax).

\begin{tabular}{|l|r|r|r|r|r|r|}
\hline \multicolumn{7}{|c|}{ Peça 3 - Amostra 01 - Coeficientes dos planos ajustados - Sistema } \\
\multicolumn{7}{|c|}{ Automatizado - Avaliano com o Método Minimax } \\
\hline coeficientes & \multicolumn{1}{|c|}{ Perfil 1 } & \multicolumn{1}{|c|}{ Perfil 3 } & \multicolumn{1}{c|}{ Perfil 5 } & \multicolumn{1}{|c|}{ Perfil 7 } & \multicolumn{1}{c|}{ Média } & \multicolumn{1}{c|}{ Perfil Médio } \\
\hline a0 & 50.0 & -5.6 & -37.3 & -36.1 & -7.3 & -7.3 \\
a1 & $5.5 \mathrm{E}-04$ & $5.5 \mathrm{E}-04$ & $5.5 \mathrm{E}-04$ & $5.5 \mathrm{E}-04$ & $5.5 \mathrm{E}-04$ & $5.5 \mathrm{E}-04$ \\
a2 & $-1.0 \mathrm{E}-04$ & $-9.0 \mathrm{E}-04$ & $-9.3 \mathrm{E}-04$ & $-4.9 \mathrm{E}-04$ & $-6.1 \mathrm{E}-04$ & $-6.1 \mathrm{E}-04$ \\
\hline
\end{tabular}

Tabela 6.51 - Coeficientes ajustados aos perfis da Peça 3 (ajustagem de Mínimos Quadrados).

\begin{tabular}{|l|r|r|r|r|r|r|}
\hline \multicolumn{6}{|c|}{ Peça 3 - Amostra 01 - Coeficientes dos planos ajustados - Sistema } \\
Automatizado - Avaliação com Método dos Mínimos Quadrados \\
\hline Coeficientes & \multicolumn{1}{|c|}{ Perfil 1 } & \multicolumn{1}{|c|}{ Perfil 3 } & \multicolumn{1}{|c|}{ Perfil 5 } & \multicolumn{1}{|c|}{ Perfil 7 } & \multicolumn{1}{c|}{ Média } & Perfil Médio \\
\hline a0 & 58.0 & 2.5 & -30.9 & -34.3 & -1.1 & -1.1 \\
a1 & $6.3 \mathrm{E}-04$ & $6.3 \mathrm{E}-04$ & $6.3 \mathrm{E}-04$ & $6.3 \mathrm{E}-04$ & $6.3 \mathrm{E}-04$ & $6.3 \mathrm{E}-04$ \\
a2 & $-2.1 \mathrm{E}-04$ & $-1.0 \mathrm{E}-03$ & $-1.1 \mathrm{E}-03$ & $-6.5 \mathrm{E}-04$ & $-7.4 \mathrm{E}-04$ & $-7.4 \mathrm{E}-04$ \\
\hline
\end{tabular}

Uma peculiaridade a ser observada no caso da Peça 3 é que os coeficientes $a_{1}$ dos planos ajustados utilizando-se o Método Minimax não variaram. Para as demais peças, estas variações ocorreram. Além disso, tal estabilidade foi observada apenas nos valores dos coeficientes calculados a partir dos dados da amostra 01, isto é, os valores dos mesmos coeficientes calculados a partir das amostras 02 e 03 da Peça 3, utilizando-se o método Minimax, variaram, da mesma forma como ocorreu 
para as peças 1 e 2 .

Assim como no caso das demais peças, o desvio de perpendicularismo foi calculado por meio da equação 6.1. Os resultados são apresentados na Tabela 6.52. Os coeficientes do plano de referência utilizados no cálculo são aqueles mostrados nas tabelas do item 6.2.1. Os valores do desvio de perpendicularismo apresentados em micrometros representam a máxima variação de altura observada em um comprimento total de $158 \mathrm{~mm}$.

$\mathrm{Na}$ Tabela 6.52 pode-se observar que o desvio-padrão dos valores do desvio de perpendicularismo obtidos a partir dos diferentes perfis é nulo. Em outras palavras, o desvio de perpendicularismo da Peça 3, para um dado perfil da superfície de referência, não varia em função dos diferentes perfis da peça. Estes resultados eram esperados, uma vez que foi possível observar na Tabela 6.50 que todos os perfis da peça apresentavam os mesmos valores de inclinação na direção $x$, ou seja, os mesmos valores para o coeficiente $a_{1}$. Este resultado só foi observado no caso da avaliação da Peça 3, ou seja, não ocorreu para as demais peças. Isto pode indicar que a Peça 3 é bastante homogênea, e os perfis de suas retas transversais são muito similares entre si. Alternativamente, deve-se considerar a hipótese de o algoritmo de separação de erros não ter conseguido avaliar o perfil destas retas com acuracidade suficiente a ponto de reconhecer as diferenças entre os perfis medidos. Neste caso, os resultados da separação de erros convergiriam para um mesmo conjunto de valores para os pontos do perfil de todas as transversais, e as inclinações dos perfis resultantes seriam iguais. O número de pontos coletados sobre a peça pode estar diretamente relacionado a este limite de acuracidade do sistema. Esta peça distingue-se das demais por apresentar uma área de medição mais reduzida. Na direção das transversais, são coletados dados em apenas três posições de medição. Assim, a quantidade de leituras redundantes pode ser insuficiente para que o desacoplamento dos erros seja feito de forma efetiva. 
Tabela 6.52 - Desvios de perpendicularismo da Peça 3 (Sistema Automatizado e ajustagem Minimax).

\begin{tabular}{|c|c|c|c|c|c|c|c|c|}
\hline \multicolumn{9}{|c|}{$\begin{array}{c}\text { Desvio de Perpendicularismo - Peça } 3 \text { - Medição com o Sistema Automatizado - } \\
\text { Avaliação com o Método Minimax }\end{array}$} \\
\hline \multicolumn{4}{|c|}{ Amostra de medição da Peça: } & \multirow{2}{*}{$\frac{01}{\mathrm{R} 1-\mathrm{P} 5}$} & \multicolumn{3}{|c|}{$\begin{array}{l}\text { Amostra de medição da } \\
\text { superfície de referência: }\end{array}$} & \multirow{2}{*}{$\begin{array}{c}02 \\
\text { D. padrão }\end{array}$} \\
\hline Comk & inações & $\mathrm{R} 1-\mathrm{P} 1$ & R1-P3 & & $\mathrm{R} 1-\mathrm{P} 7$ & R1-PM & Médias (R1) & \\
\hline \multirow{3}{*}{$\begin{array}{c}\text { Valores } \\
\text { do } \\
\text { desvio }\end{array}$} & radianos & $1.0 \mathrm{E}-04$ & $1.0 \mathrm{E}-04$ & 1.0E-04 & $1.0 \mathrm{E}-04$ & 1.0E-04 & $1.0 \mathrm{E}-04$ & $0.0 \mathrm{E}+00$ \\
\hline & arco-seg & 22 & 22 & 22 & 22 & 22 & 22 & 0 \\
\hline & $\mu \mathrm{m}$ & 17 & 17 & 17 & 17 & 17 & 17 & 0 \\
\hline
\end{tabular}

\begin{tabular}{|c|l|r|r|r|r|r|r|r|}
\hline \multicolumn{2}{|c|}{ Combinã̃es } & \multicolumn{1}{c|}{ R4-P1 } & R4-P3 & R4-P5 & R4-P7 & R4-PM & Médias (R4) & D. padrão \\
\hline \multirow{2}{*}{$\begin{array}{c}\text { Valores } \\
\text { do } \\
\text { desvio }\end{array}$} & radianos & $1.5 \mathrm{E}-04$ & $1.5 \mathrm{E}-04$ & $1.5 \mathrm{E}-04$ & $1.5 \mathrm{E}-04$ & $1.5 \mathrm{E}-04$ & $1.5 \mathrm{E}-04$ & $0.0 \mathrm{E}+00$ \\
\cline { 2 - 10 } & arco-seg & 31 & 31 & 31 & 31 & 31 & 31 & 0 \\
\cline { 2 - 10 } & & 24 & 24 & 24 & 24 & 24 & 24 & 0 \\
\hline
\end{tabular}

\begin{tabular}{|c|l|r|r|r|r|r|r|r|}
\hline \multicolumn{2}{|c|}{ Combinações } & \multicolumn{1}{|c|}{ R7-P1 } & R7-P3 & R7-P5 & R7-P7 & R7-PM & Médias (R1) & D. padrão \\
\hline \multirow{2}{*}{$\begin{array}{c}\text { Valores } \\
\text { do } \\
\text { desvio }\end{array}$} & radianos & $1.6 \mathrm{E}-04$ & $1.6 \mathrm{E}-04$ & $1.6 \mathrm{E}-04$ & $1.6 \mathrm{E}-04$ & $1.6 \mathrm{E}-04$ & $1.6 \mathrm{E}-04$ & $0.0 \mathrm{E}+00$ \\
\cline { 2 - 9 } & arco-seg & 33 & 33 & 33 & 33 & 33 & 33 & 0 \\
\cline { 2 - 10 } & 25 & 25 & 25 & 25 & 25 & 25 & 0 \\
\hline
\end{tabular}

\begin{tabular}{|c|l|r|r|r|r|r|r|r|}
\hline \multicolumn{2}{|c|}{ Combinações } & R10-P1 & R10-P3 & R10-P5 & R10-P7 & $\begin{array}{c}\text { R10- } \\
\text { PM }\end{array}$ & Médias (R1) & D. padrão \\
\hline \multirow{2}{*}{$\begin{array}{c}\text { Valores } \\
\text { do } \\
\text { desvio }\end{array}$} & radianos & $1.7 \mathrm{E}-04$ & $1.7 \mathrm{E}-04$ & $1.7 \mathrm{E}-04$ & $1.7 \mathrm{E}-04$ & $1.7 \mathrm{E}-04$ & $1.7 \mathrm{E}-04$ & $0.0 \mathrm{E}+00$ \\
\cline { 2 - 10 } & arco-seg & 36 & 36 & 36 & 36 & 36 & 36 & 0 \\
\hline
\end{tabular}

\begin{tabular}{|c|l|r|r|r|r|r|r|r|}
\hline \multicolumn{2}{|c|}{ Combinações } & R13-P1 & R13-P3 & R13-P5 & R13-P7 & $\begin{array}{c}\text { R13- } \\
\text { PM }\end{array}$ & Médias (R1) & D. padrão \\
\hline \begin{tabular}{c} 
Valores $\begin{array}{c}\text { do } \\
\text { do } \\
\text { desvio }\end{array}$ \\
\cline { 2 - 10 }
\end{tabular} & radianos & $1.7 \mathrm{E}-04$ & $1.7 \mathrm{E}-04$ & $1.7 \mathrm{E}-04$ & $1.7 \mathrm{E}-04$ & $1.7 \mathrm{E}-04$ & $1.7 \mathrm{E}-04$ & $0.0 \mathrm{E}+00$ \\
\cline { 2 - 9 } & 36 & 36 & 36 & 36 & 36 & 36 & 0 \\
\hline
\end{tabular}

\begin{tabular}{|c|c|c|c|c|c|c|c|c|}
\hline \multicolumn{2}{|c|}{ Combinações } & RM-P1 & RM-P3 & RM-P5 & RM-P7 & RM-PM & Médias (R1) & D. padrão \\
\hline \multirow{3}{*}{$\begin{array}{c}\text { Valores } \\
\text { do } \\
\text { desvio }\end{array}$} & radianos & $1.6 \mathrm{E}-04$ & $1.6 \mathrm{E}-04$ & $1.6 \mathrm{E}-04$ & 1.6E-04 & 1.6E-04 & $1.6 \mathrm{E}-04$ & $0.0 \mathrm{E}+00$ \\
\hline & arco-seg & 33 & 33 & 33 & 33 & 33 & 33 & 0 \\
\hline & $\mu \mathrm{m}$ & 25 & 25 & 25 & 25 & 25 & 25 & 0 \\
\hline
\end{tabular}

\begin{tabular}{|l|l|r|r|r|r|r|}
\cline { 3 - 7 } \multicolumn{2}{c|}{} & \multicolumn{1}{c|}{$\mathrm{P} 1$} & \multicolumn{1}{c|}{$\mathrm{P} 3$} & \multicolumn{1}{c|}{$\mathrm{P} 5$} & \multicolumn{1}{c|}{$\mathrm{P} 7$} & Pmédio \\
\hline \multirow{3}{*}{ Médias } & radianos & $1.5 \mathrm{E}-04$ & $1.5 \mathrm{E}-04$ & $1.5 \mathrm{E}-04$ & $1.5 \mathrm{E}-04$ & $1.5 \mathrm{E}-04$ \\
\cline { 2 - 7 } & arco-seg & 31 & 31 & 31 & 31 & 31 \\
\cline { 2 - 7 } & $\mu \mathrm{m}$ & 24 & 24 & 24 & 24 & 24 \\
\hline
\end{tabular}

\begin{tabular}{|c|l|r|r|r|r|r|}
\cline { 3 - 7 } \multicolumn{2}{c|}{} & \multicolumn{1}{c|}{$\mathrm{P} 1$} & \multicolumn{1}{c|}{$\mathrm{P} 3$} & \multicolumn{1}{c|}{$\mathrm{P} 5$} & $\mathrm{P} 7$ & Pmédio \\
\hline \multirow{2}{*}{$\begin{array}{c}\text { Desvios- } \\
\text { padrão }\end{array}$} & radianos & $2.8 \mathrm{E}-05$ & $2.8 \mathrm{E}-05$ & $2.8 \mathrm{E}-05$ & $2.8 \mathrm{E}-05$ & $2.8 \mathrm{E}-05$ \\
\cline { 2 - 7 } & arco-seg & 6 & 6 & 6 & 6 & 6 \\
\cline { 2 - 7 } & $\mu \mathrm{m}$ & 4 & 4 & 4 & 4 & 4 \\
\hline
\end{tabular}


O resumo dos resultados do desvio de perpendicularismo para uma amostra de medição da peça é mostrado a seguir.

Tabela 6.53 - Resultados médios para o desvio de perpendicularismo da Peça 3

(ajustagem Minimax).

\begin{tabular}{|c|c|c|c|c|}
\hline & \multicolumn{4}{|c|}{$\begin{array}{c}\text { Resultados Gerais - Desvio de perpendicularismo - Peça } \\
3 \text { - Sistema Automatizado e Ajustagem Minimax }\end{array}$} \\
\hline & $\begin{array}{l}\text { Média Geral } \\
\text { das } \\
\text { Combinações }\end{array}$ & $\begin{array}{l}\text { D. Padrão } \\
\text { Total }\end{array}$ & $\begin{array}{l}\text { Perfil Médio - } \\
\text { Referência } \\
\text { Média }\end{array}$ & $\begin{array}{l}\text { Desvio } \\
\text { Médio }\end{array}$ \\
\hline \multirow{2}{*}{$\begin{array}{l}\text { radianos } \\
\text { arco-seg }\end{array}$} & $1.5 \mathrm{E}-04$ & $2.5 \mathrm{E}-05$ & 1.6E-04 & $1.5 \mathrm{E}-04$ \\
\hline & 31 & 5 & 33 & 31 \\
\hline \multirow{3}{*}{ um } & 24 & 4 & 25 & 24 \\
\hline & \multicolumn{3}{|c|}{ Amostra de Medição da Peça } & 01 \\
\hline & \multicolumn{3}{|c|}{$\begin{array}{l}\text { Amostra de Medição da superfície de } \\
\text { Referência }\end{array}$} & 02 \\
\hline
\end{tabular}

Os resultados da avaliação do perpendicularismo da Peça 3 utilizando-se o Método dos Mínimos Quadrados foram similares aos apresentados para as demais peças, ou seja, obteve-se um valor constante de desvio para todas as combinações de perfis da superfície da peça e do artefato de referência. Deve-se observar, entretanto, que os diferentes métodos de ajustagem, aplicados a um mesmo conjunto de pontos do perfil, forneceram resultados significativamente distintos para 0 valor do desvio de perpendicularismo. A tabela 6.54 apresenta os resultados obtidos utilizando-se o Método dos Mínimos Quadrados.

Os resultados da medição convencional da Peça 3 são mostrados nas tabelas 6.55 e 6.56 .

Tabela 6.54 - Desvios de perpendicularismo da Peça 3 (Sistema Automatizado e ajustagem de Mínimos Quadrados).

\begin{tabular}{|c|c|c|c|c|c|}
\hline \multicolumn{6}{|c|}{$\begin{array}{c}\text { Desvio de Perpendicularismo - Peça } 3 \text { - Medição com o Sistema } \\
\text { Automatizado - Método dos Mínimos Quadrados }\end{array}$} \\
\hline \multicolumn{2}{|c|}{$\begin{array}{l}\text { Amostra de medição da } \\
\text { Peça: }\end{array}$} & \multirow{2}{*}{\multicolumn{2}{|c|}{\begin{tabular}{c|c}
01 & $\begin{array}{c}\text { Amostra de medi } \\
\text { superfície de refe }\end{array}$ \\
Valores observados para todas \\
as combinacõos de perfis
\end{tabular}}} & $\begin{array}{l}\text { da } \\
\text { cia: }\end{array}$ & 02 \\
\hline & & & & Des & Médio \\
\hline \multirow{3}{*}{$\begin{array}{l}\text { Valores do } \\
\text { desvio }\end{array}$} & radianos & & $2.8 \mathrm{E}-04$ & & $2.8 \mathrm{E}-04$ \\
\hline & arco-seg & & 57 & & 57 \\
\hline & um & & 44 & & 44 \\
\hline
\end{tabular}


Tabela 6.55 - Perfil da superfície da Peça 3 (método convencional).

\begin{tabular}{|r|r|r|r|r|r|r|r|}
\hline \multicolumn{1}{|c|}{ Perfil da superfície da Peça 3 - Sistema Convencional - } \\
com inclinãa - Amostra 01 \\
\hline-8 & -6 & -5 & -3 & 0 & 0 & -2 & -4 \\
\hline-7 & -4 & -3 & -1 & 0 & 2 & 4 & 5 \\
\hline-4 & -4 & -2 & 2 & 2 & 5 & 7 & 8 \\
\hline-6 & -4 & -2 & 2 & 2 & 4 & 6 & 7 \\
\hline-5 & -2 & -2 & 3 & 3 & 6 & 7 & 9 \\
\hline
\end{tabular}

Tabela 6.56 - Desvios de perpendicularismo da Peça 3 (medição convencional).

\begin{tabular}{|c|c|c|c|c|c|c|c|}
\hline & \multirow[b]{3}{*}{ Medição } & \multicolumn{6}{|c|}{ Desvio de Perpendicularismo - Peça 3 - Medição Convencional } \\
\hline & & \multicolumn{3}{|c|}{ Método Minimax } & \multicolumn{3}{|c|}{ Mínimos Quadrados } \\
\hline & & 01 & 02 & 03 & 01 & 02 & 03 \\
\hline \multirow{3}{*}{$\begin{array}{c}\text { Valores } \\
\text { do } \\
\text { desvio }\end{array}$} & radianos & $7.5 \mathrm{E}-05$ & 9.7E-05 & 9.3E-05 & 9.0E-05 & 9.3E-05 & $9.3 \mathrm{E}-05$ \\
\hline & arco-seg & 15 & 20 & 19 & 18 & 19 & 19 \\
\hline & um & 20 & 26 & 25 & 24 & 25 & 25 \\
\hline
\end{tabular}

Considerando-se os resultados obtidos a partir da amostra 01, medida com o Sistema Automatizado, observa-se que os valores fornecidos pela ajustagem Minimax aproximaram-se mais dos valores de referência, obtidos por meio da medição convencional. Entretanto, este tipo de ajustagem se mostrou mais instável, uma vez que os resultados obtidos a partir da amostra 02 utilizando-se o Método Minimax, apresentados nos apêndices, apresentaram grande diferença em relação aos valores avaliados a partir da amostra 01. Quando a ajustagem de Mínimos Quadrados foi utilizada, isto não ocorreu, ou seja, a diferença entre desvio médio obtido a partir da amostra 01 e o obtido a partir da amostra 02 foi mínima. Estes aspectos serão discutidos com mais detalhes no próximo item.

\subsection{Tempos de Medição}

Além da análise comparativa entre valores dos desvios geométricos obtidos a partir de diferentes métodos, buscou-se avaliar também a rapidez do Sistema Automatizado na realização das medições. Para tanto, realizou-se uma breve comparação entre os tempos de medição 
associados aos três sistemas empregados: o Sistema Automatizado, o Método Convencional e a medição por coordenadas. Os tempos de cada etapa das medições e os tempos totais, por peça, são apresentados na Tabela 6.57.

Tabela 6.57 - Tempos de medição.

\begin{tabular}{|l|c|c|c|c|}
\cline { 2 - 5 } \multicolumn{1}{c|}{} & \multicolumn{3}{c|}{ Tempos Aproximados de Medição (em minutos) } \\
\cline { 2 - 5 } & $\begin{array}{c}\text { Sistema } \\
\text { Automatizado }\end{array}$ & $\begin{array}{c}\text { Máquina de } \\
\text { Medir (operador } \\
\text { inexperiente) }\end{array}$ & $\begin{array}{c}\text { Máquina de } \\
\text { medir (operador } \\
\text { experiente) }\end{array}$ & $\begin{array}{c}\text { Método } \\
\text { Convencional }\end{array}$ \\
\hline Set-up & 2 & 1.5 & 1.5 & 3 \\
\hline Qualificação sonda & - & 2.5 & 8 & - \\
\hline Medição da referência & 14 & 13 & 10 & 36 \\
\hline $\begin{array}{l}\text { Medição Peça 1 ou } \\
\text { Peça 2 }\end{array}$ & 16 & 15 & 4 & 12 \\
\hline Medição Peça 3 & 4 & 6 & 20.5 & 39 \\
\hline $\begin{array}{l}\text { Total Peça 1 ou Peça 2 } \\
\text { perpendicularismo }\end{array}$ & 32 & 32 & 14.5 & 15 \\
\hline $\begin{array}{l}\text { Total Peça 3 - } \\
\text { perpendicularismo }\end{array}$ & 20 & 23 & 12.5 & 39 \\
\hline $\begin{array}{l}\text { Total Peça 1 ou Peça 2 } \\
\text { planicidade }\end{array}$ & 18 & 19 & 6.5 & 15 \\
\hline $\begin{array}{l}\text { Total Peça 3 - } \\
\text { planicidade }\end{array}$ & 6 & 10 & \multicolumn{2}{|c|}{} \\
\hline
\end{tabular}

Deve-se destacar que os valores apresentados servem como uma referência aproximada dos tempos de medição, pois estes dados não foram obtidos por meio de uma abordagem estatística, pois este não se constitui o enfoque principal do trabalho.

A etapa designada como "set-up" na Tabela 6.57 inclui, principalmente, o tempo de fixação e posicionamento das peças e, no caso do Sistema Automatizado e da Máquina de Medir, também o tempo de carregamento das rotinas de medição. No caso do Método convencional, este tempo de set-up também considera o tempo de regulagem de altura da haste que sustenta o relógio comparador sobre a peça. O tempo de fixação do dispositivo porta-sensores e de alinhamento inicial dos sensores, etapas do procedimento de medição com o Sistema Automatizado, não foram incluídas no tempo de set-up deste sistema pois estas tarefas, uma vez realizadas, não precisam ser repetidas para cada peça a ser medida, ainda que as peças avaliadas sejam bem distintas. Assim, algumas amostras foram coletadas com o Sistema Automatizado 
em ocasiões distintas, sem que o procedimento de fixação e alinhamento dos sensores fosse realizado novamente em cada ocasião.

Os tempos de medição das peças, para o Sistema Automatizado já incluem os tempos de medição das retas geratrizes e das transversais.

Observa-se, na tabela apresentada, que o Sistema Automatizado apresenta uma vantagem, em termos de rapidez, em relação os outros sistemas ou apresenta, no mínimo, tempos de medição equivalentes aos tempos associados aos demais métodos, exceto no caso em que um operador experiente executa a medição com a Máquina de Medir. Neste último caso, a avaliação da rapidez torna-se menos objetiva e mais complexa, pois os tempos de medição dependem diretamente da habilidade do operador. Aliás, o fato de não haver esta dependência em relação ao operador no caso do Sistema Automatizado é uma vantagem deste sistema, pois os tempos de medição são praticamente constantes e a eficiência não diminui em função de fatores externos, como a habilidade ou o cansaço físico.

É importante destacar que, em termos de rapidez absoluta, o desempenho do método automatizado é bastante superior ao desempenho dos demais sistemas. Neste sistema, 1 ponto é coletado em aproximadamente 1,3 segundos, enquanto esta taxa é de 1 ponto em 4 segundos ou 8 segundos, para diferentes operadores utilizando a máquina de medir. No caso do sistema convencional, a eficiência é ainda menor: a taxa de coleta é de aproximadamente 1 ponto a cada 19 segundos.

Em última análise, os tempos totais de medição do Sistema Automatizado apresentados na Tabela 6.57 só não são ainda menores devido a algumas características do procedimento de medição definido. $\mathrm{Na}$ verdade, os tempos de medição de cada peça apresentados na tabela, no caso do Sisetema Automatizado, incluem 5 repetições da medição de cada geratriz e cada transversal. Mesmo assim, este sistema apresenta tempos totais compatíveis ou melhores do que os outros sistemas, salvo alguns casos específicos. Além disso, as taxas de coleta demonstram que a rapidez absoluta do Sistema Automatizado é bem superior em relação aos 
demais sistemas. Isto fornece um alto potencial de melhoria dos tempos finais de medição, bastando apenas que, para tanto, alguns requisitos do procedimento de medição, como a necessidade das repetições da medição, por exemplo, sejam alterados.

\subsection{Resumo dos Resultados e Discussões}

Neste item são apresentadas tabelas contendo os valores finais dos desvios de planicidade e perpendicularismo de cada peça, resultantes da medição com o Sistema Automatizado. Além disso, são apresentados gráficos comparativos dos resultados obtidos com o sistema proposto e com a medição convencional das peças.

Tabela 6.58 - Desvios geométricos da Peça 1 - Sistema Automatizado e Ajustagem Minimax.

\begin{tabular}{|c|c|c|c|c|c|c|c|c|c|c|c|c|}
\hline & \multicolumn{11}{|c|}{ Peça 1 - Sistema Automatizado } \\
\hline & & \multicolumn{3}{|c|}{ Amostra 01} & \multicolumn{3}{|c|}{ Amostra 02} & \multicolumn{3}{|c|}{ Amostra 03} & \multirow[b]{2}{*}{$\begin{array}{c}\text { Amplitude } \\
\text { amostral }\end{array}$} & \multirow{2}{*}{$\begin{array}{c}\text { Desvio. } \\
\text { padrão } \\
\text { amostral }\end{array}$} \\
\hline & & mín & máx & $\begin{array}{l}\text { Desvio } \\
\text { Médio }\end{array}$ & mín & máx & \begin{tabular}{|l|} 
Desvio \\
Médio
\end{tabular} & mín & máx & \begin{tabular}{|l|} 
Desvio \\
Médio \\
\end{tabular} & & \\
\hline \multicolumn{2}{|c|}{ Desvio de planicidade } & 108 & 131 & 120 & 117 & 136 & 124 & 114 & 125 & 120 & 4 & 2 \\
\hline \multirow{8}{*}{$\begin{array}{l}\text { Desvio } \\
\text { de } \\
\text { perpendi- } \\
\text { cularismo }\end{array}$} & Referência & & & & & & & & & & & \\
\hline & Amostra 01 & -133 & -176 & -150 & -119 & -179 & -137 & -122 & -192 & -143 & 13 & 7 \\
\hline & Amostra 02 & -138 & -196 & -158 & -124 & -200 & -145 & -127 & -211 & -151 & 12 & 6 \\
\hline & Amostra 03 & -143 & -183 & -155 & -154 & -186 & -141 & -120 & -198 & -148 & 14 & 7 \\
\hline & Média & & & -154 & & & -141 & & & -147 & & \\
\hline & D. padrão & & & 4 & & & 4 & & & 4 & & \\
\hline & Amplitude & & & 8 & & & 8 & & & 8 & & \\
\hline & \multicolumn{4}{|c|}{ Método de ajustagem dos planos: } & \multicolumn{6}{|c|}{ Minimax } & & \\
\hline
\end{tabular}

Tabela 6.59 - Desvios geométricos da Peça 1 - Sistema Automatizado e Ajustagem de Mínimos Quadrados.

\begin{tabular}{|c|c|c|c|c|c|c|c|c|c|c|c|c|}
\hline & \multicolumn{11}{|c|}{ Peça 1 - Sistema Automatizado } \\
\hline & & \multicolumn{3}{|c|}{ Amostra 01} & \multicolumn{3}{|c|}{ Amostra 02} & \multicolumn{3}{|c|}{ Amostra 03} & \multirow[b]{2}{*}{$\begin{array}{c}\text { Amplitude } \\
\text { amostral }\end{array}$} & \multirow{2}{*}{$\begin{array}{l}\text { Desvio. } \\
\text { padrão } \\
\text { amostral }\end{array}$} \\
\hline & & mín & máx & \begin{tabular}{|l|} 
Desvio \\
Médio \\
\end{tabular} & mín & máx & $\begin{array}{l}\text { Desvio } \\
\text { Médio }\end{array}$ & mín & máx & $\begin{array}{l}\text { Desvio } \\
\text { Médio } \\
\end{array}$ & & \\
\hline \multicolumn{2}{|c|}{ Desvio de planicidade } & 119 & 141 & 134 & 133 & 154 & 140 & 120 & 140 & 134 & 6 & 3 \\
\hline \multirow{8}{*}{$\begin{array}{c}\text { Desvio } \\
\text { de } \\
\text { perpendi- } \\
\text { cularismo }\end{array}$} & Referência & & & & & & & & & & & \\
\hline & Amostra 01 & -152 & -152 & -152 & -146 & -146 & -146 & -146 & -146 & -146 & 6 & 3 \\
\hline & Amostra 02 & -141 & -141 & -141 & -136 & -136 & -136 & -136 & -136 & -136 & 5 & 3 \\
\hline & Amostra 03 & -147 & -147 & -147 & -141 & -141 & -141 & -141 & -141 & -141 & 6 & 3 \\
\hline & Média & & & -147 & & & -141 & & & -141 & & \\
\hline & D. padrão & & & 6 & & & 5 & & & 5 & & \\
\hline & Amplitude & & & 11 & & & 10 & & & 10 & & \\
\hline & \multicolumn{4}{|c|}{ Método de ajustagem dos planos: } & \multicolumn{6}{|c|}{ Mínimos Quadrados } & & \\
\hline
\end{tabular}


Antes que sejam feitas comparações dos resultados apresentados com os resultados do método convencional, deve-se observar que o Sistema Automatizado apresenta boa repetibilidade. As amplitudes e desvios-padrão amostrais apresentados nas tabelas indicam este fato. A variabilidade do desvio de planicidade é menor para os valores ajustados pelo Método Minimax, enquanto a variabilidade do desvio de perpendicularismo é bem menor quando se realiza a ajustagem pelo método dos Mínimos Quadrados. No caso da avaliação do perpendicularismo, foi observado anteriormente que este último método é insensível à variação dos perfis obtidos a partir uma mesma amostra da peça. Além deste fato, a Tabela 6.59 mostra que a ajustagem de Mínimos Quadrados também é menos sensível às variações existentes entre as amostras de medição da peça, isto é, apresenta resultados de desvio de perpendicularismo com menor variabilidade no geral.

Deve-se destacar, ainda, que os valores do desvio de perpendicularismo da Peça 1 obtidos com Sistema Automatizado também apresentam pouca variação em função da escolha de diferentes amostras da superfície de referência. A amplitude máxima dessa variação é de 11 micrometros para a Ajustagem por MMQ. A ajustagem Minimax apresentou melhor desempenho neste quesito, apresentando uma variação máxima de 8 micrometros. Em geral, os valores fornecidos pelo sistema proposto se mostraram pouco sensíveis às variações dos dados da superfície de referência coletados em diferentes medições. Este é um aspecto positivo e demonstra que a avaliação fornecida é consistente. Neste caso, não se está avaliando o impacto da utilização de diferentes perfis da superfície de referência pertencentes a uma mesma amostra, mas sim da utilização de diferentes amostras desta superfície no cálculo do desvio de perpendicularismo.

$\mathrm{Na}$ Tabela 6.60 apresenta-se também a comparação entre os resultados obtidos com a utilização do Sistema Automatizado e os outros dois sistemas citados, o de medição convencional e o de medição por coordenadas. 
Tabela 6.60 - Tabela comparativa - desvios geométricos da Peça 1 (ajustagem Minimax).

\begin{tabular}{|c|c|c|c|c|c|c|c|c|c|}
\hline & \multicolumn{3}{|c|}{$\begin{array}{l}\text { Peça } 1 \text { - Sistema } \\
\text { Automatizado }\end{array}$} & \multicolumn{3}{|c|}{$\begin{array}{l}\text { Peça 1 - Sistema } \\
\text { Convencional }\end{array}$} & \multicolumn{3}{|c|}{ Peça 1 - Máquina de Medir } \\
\hline & $\begin{array}{c}\text { Amostra } \\
01\end{array}$ & $\begin{array}{c}\text { Amostra } \\
02\end{array}$ & $\begin{array}{c}\text { Amostra } \\
03\end{array}$ & \multirow{2}{*}{$\begin{array}{l}\text { Amostra } \\
01\end{array}$} & \multirow{2}{*}{$\begin{array}{l}\text { Amostra } \\
02\end{array}$} & \multirow{2}{*}{$\begin{array}{l}\text { Amostra } \\
03\end{array}$} & \multirow{2}{*}{$\begin{array}{l}\text { Amostra } \\
01\end{array}$} & \multirow{2}{*}{$\begin{array}{c}\text { Amostra } \\
02\end{array}$} & \multirow{2}{*}{$\begin{array}{l}\text { Amostra } \\
03\end{array}$} \\
\hline & D. Médio & D. Médio & D. Médio & & & & & & \\
\hline $\begin{array}{l}\text { Desvio de } \\
\text { planicidade }\end{array}$ & 120 & 124 & 120 & 98 & 100 & 102 & 109 & 106 & 109 \\
\hline \multirow[t]{3}{*}{$\begin{array}{c}\text { Desvio de } \\
\text { perpendicularismo }\end{array}$} & $-154^{\star}$ & $-141^{*}$ & $-147^{\star}$ & -142 & -144 & -146 & -156 & -150 & -156 \\
\hline & \multicolumn{9}{|c|}{${ }^{*}$ Média dos valores obtidos com as 3 referências } \\
\hline & \multicolumn{4}{|c|}{ Método de ajustagem dos planos: } & \multicolumn{5}{|c|}{ Minimax } \\
\hline
\end{tabular}

As diferenças entre os desvios de planicidade obtidos utilizando-se os Sistema Automatizado e o sistema convencional são mostradas no gráfico da Figura 6.5 abaixo. O sistema convencional foi adotado como referência, isto é, dentre os sistemas utilizados, considera-se que este sistema apresente a maior acuracidade.

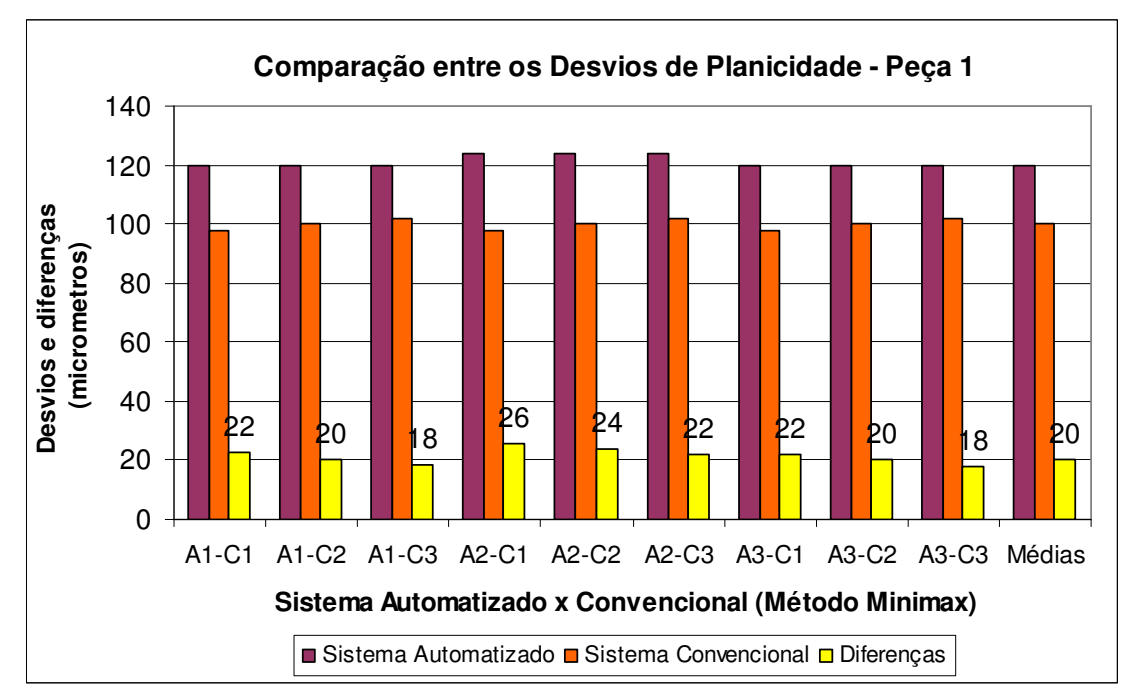

Figura 6.5 - Comparação entre os desvios planicidade da Peça 1 (ajustagem Minimax).

A letra "A" refere-se aos valores de desvio fornecidos pelo Sistema Automatizado, e a letra " $\mathrm{C}$ " aos valores obtidos com o sistema convencional. Os números indicam a amostra de dados a partir da qual os valores do desvio foram calculado. Assim, a expressão A1-C1 indica a diferença entre o valor do desvio obtido a partir amostra 01 coletada com o Sistema Automatizado e o valor obtido a partir da amostra 01 coletada com o sistema convencional.

Os gráficos das figuras 6.6 e 6.7 apresentam os erros do Sistema Automatizado na avaliação do desvio de perpendicularismo. No primeiro 
gráfico, foram consideradas, para o cálculo destes erros, as médias entre os desvios de perpendicularismo avaliados em relação às 3 amostras distintas do plano de referência. Já a Figura 6.7 apresenta os valores desses erros calculados considerando-se todos os valores de perpendicularismo obtidos com o Sistema Automatizado, resultantes da combinação de 3 amostras de medição da peça e 3 amostras de medição da superfície de referência, conforme apresentado na Tabela 6.58.

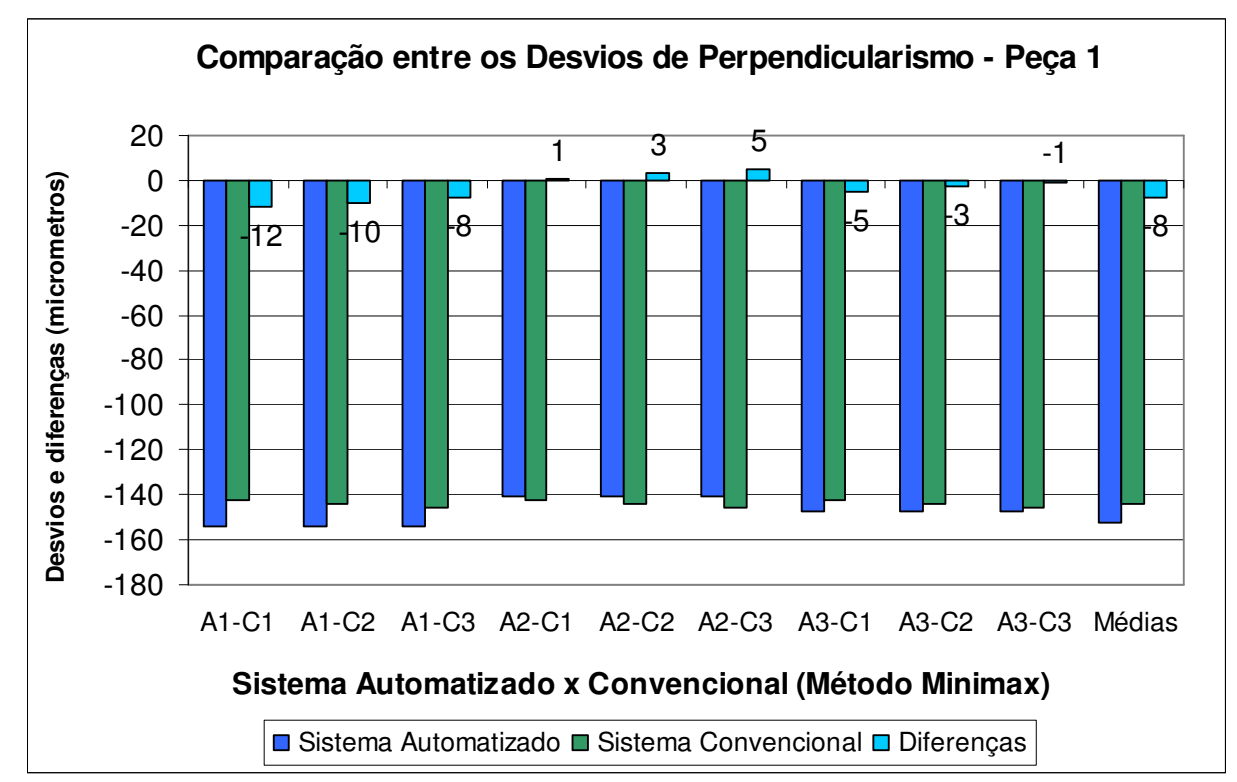

Figura 6.6 - Comparação entre os desvios de perpendicularismo da Peça 1 (ajustagem Minimax)

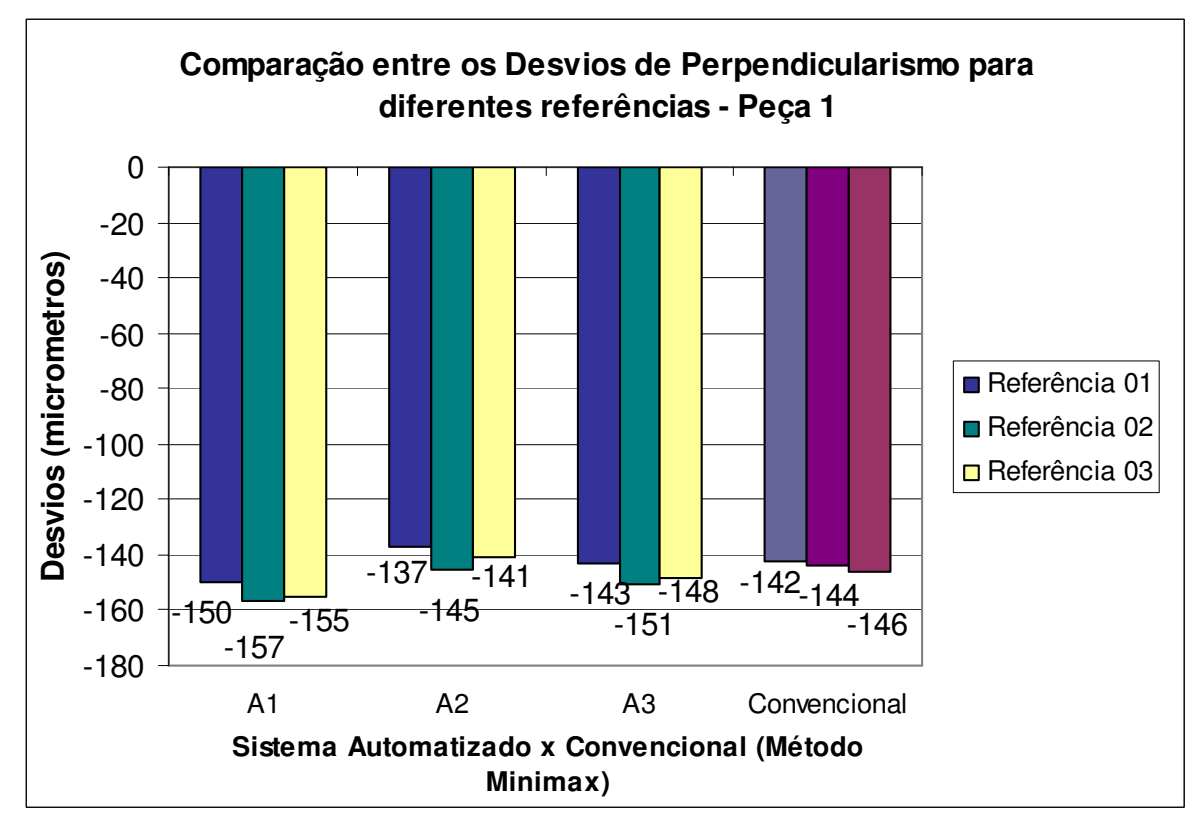

Figura 6.7 - Comparação entre os desvios de perpendicularismo da Peça 1 considerandose 3 amostras do plano de referência (ajustagem Minimax). 
Os gráficos apresentados demonstram que, para a Peça 1, o Sistema Automatizado apresentou melhor desempenho, em termos de acuracidade, ao avaliar o desvio de perpendicularismo do que ao avaliar o desvio de planicidade.

No caso do desvio de planicidade, a princípio, haveria indícios da existência de um erro sistemático na avaliação do desvio, uma vez que os valores obtidos com o Sistema Automatizado são sempre maiores do que os desvios avaliados pelo sistema convencional, e esta diferença é praticamente constante. Este comportamento sistemático, entretanto, não foi verificado na avaliação das outras peças, conforme será mostrado mais adiante. Possivelmente, parte das diferenças entre os resultados de planicidade obtidos para a Peça 1 se deve às variações observadas em cada ponto do perfil quando este é medido com o método convencional. Conforme discutido no item 6.1.1, observou-se que, para este método, pequenas diferenças na localização do sensor sobre a superfície fresada da peça geram diferenças de até 15 micrometros nos desvios medidos em cada ponto. Supõe-se que resultados comparativos mais consistentes para a Peça 1 possam ser obtidos com o desenvolvimento de uma estratégia ou dispositivo para aumentar a exatidão e precisão da localização do sensor sobre a malha de medição nos testes realizados utilizando-se o método convencional. O Sistema Automatizado apresenta melhor acuracidade e repetibilidade na localização dos sensores nos pontos da malha de medição do que o método convencional e a máquina de medir manual, nos quais esta localização é feita pelo operador.

Deve-se ressaltar ainda que o sistema apresentou boa repetibilidade na avaliação dos desvios de planicidade, isto é, a componente aleatória do erro de avaliação, considerando-se as três amostras, é pequena. Este fato pode ser visualizado tanto na Figura 6.5 quanto na Tabela 6.60.

Com relação ao desvio de perpendicularismo da peça, o erro de avaliação do Sistema Automatizado tem uma característica mais aleatória, conforme pode ser visto nas figuras 6.6 e 6.7. A amplitude do intervalo de variação deste erro é de 15 micrometros quando se consideram os 
resultados obtidos para diferentes referências e de 12 micrometros quando se consideram resultados médios.

A seguir apresentam-se as tabelas e gráficos comparativos dos resultados da Peça 1 calculados por meio da ajustagem de Mínimos Quadrados.

Tabela 6.61 - Tabela comparativa - desvios geométricos da Peça 1 (ajustagem de Mínimos Quadrados).

\begin{tabular}{|c|c|c|c|c|c|c|c|c|c|}
\hline & \multicolumn{3}{|c|}{$\begin{array}{l}\text { Peça } 1 \text { - Sistema } \\
\text { Automatizado }\end{array}$} & \multicolumn{3}{|c|}{$\begin{array}{l}\text { Peça } 1 \text { - Sistema } \\
\text { Convencional }\end{array}$} & \multicolumn{3}{|c|}{ Peça 1 - Máquina de Medir } \\
\hline & $\begin{array}{c}\text { Amostra } \\
01\end{array}$ & $\begin{array}{c}\text { Amostra } \\
02\end{array}$ & $\begin{array}{c}\text { Amostra } \\
03\end{array}$ & \multirow{2}{*}{$\begin{array}{c}\text { Amostra } \\
01\end{array}$} & \multirow{2}{*}{$\begin{array}{c}\text { Amostra } \\
02 \\
\end{array}$} & \multirow{2}{*}{$\begin{array}{c}\text { Amostra } \\
03\end{array}$} & \multirow{2}{*}{$\begin{array}{c}\text { Amostra } \\
01\end{array}$} & \multirow{2}{*}{$\begin{array}{c}\text { Amostra } \\
02 \\
\end{array}$} & \multirow{2}{*}{$\begin{array}{c}\text { Amostra } \\
03\end{array}$} \\
\hline & D. Médio & D. Médio & D. Médio & & & & & & \\
\hline $\begin{array}{l}\text { Desvio de } \\
\text { planicidade }\end{array}$ & 134 & 140 & 134 & 111 & 115 & 119 & 126 & 126 & 125 \\
\hline \multirow[t]{3}{*}{$\begin{array}{c}\text { Desvio de } \\
\text { perpendicularismo }\end{array}$} & $-147^{*}$ & $-141^{*}$ & $-141^{*}$ & -147 & -147 & -147 & -161 & -159 & -161 \\
\hline & \multicolumn{9}{|c|}{ os valores obtidos com as 3 referências } \\
\hline & \multicolumn{4}{|c|}{ Método de ajustagem dos planos: } & \multicolumn{5}{|c|}{ Mínimos Quadrados } \\
\hline
\end{tabular}

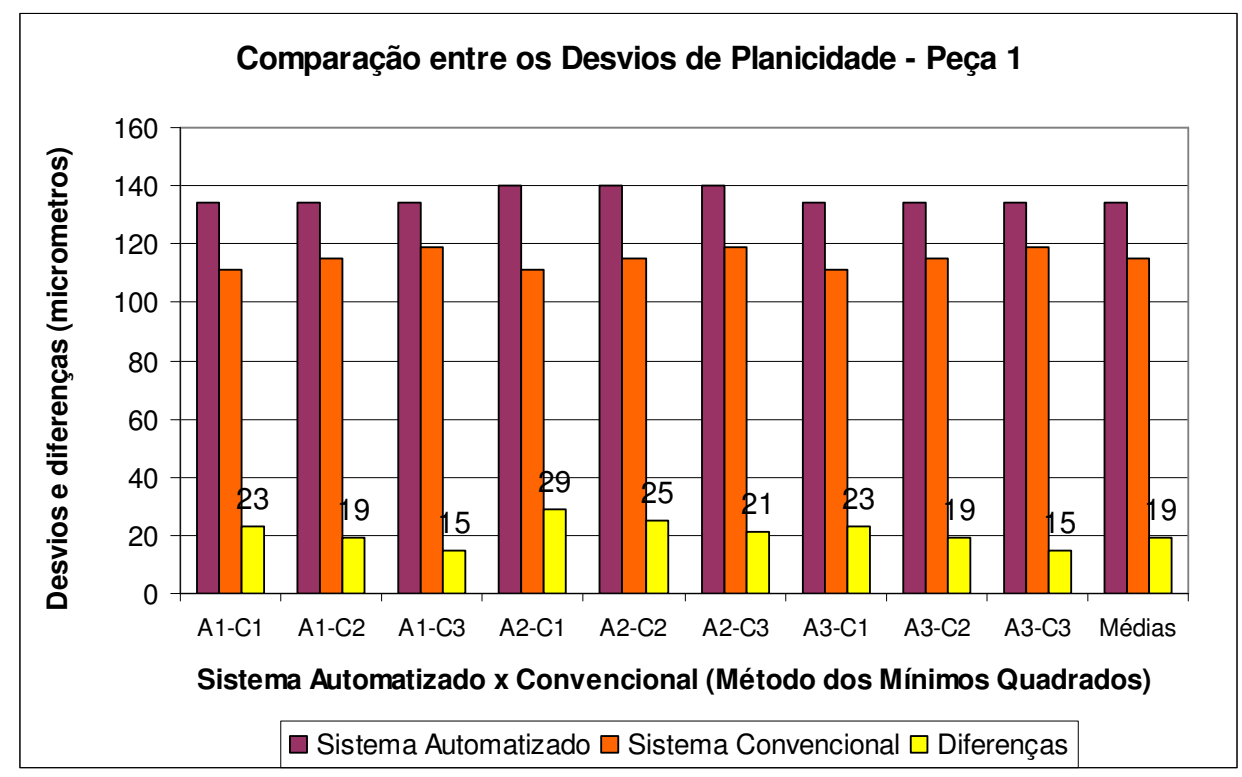

Figura 6.8 - Comparação entre os desvios planicidade da Peça 1 (ajustagem de Mínimos Quadrados) 


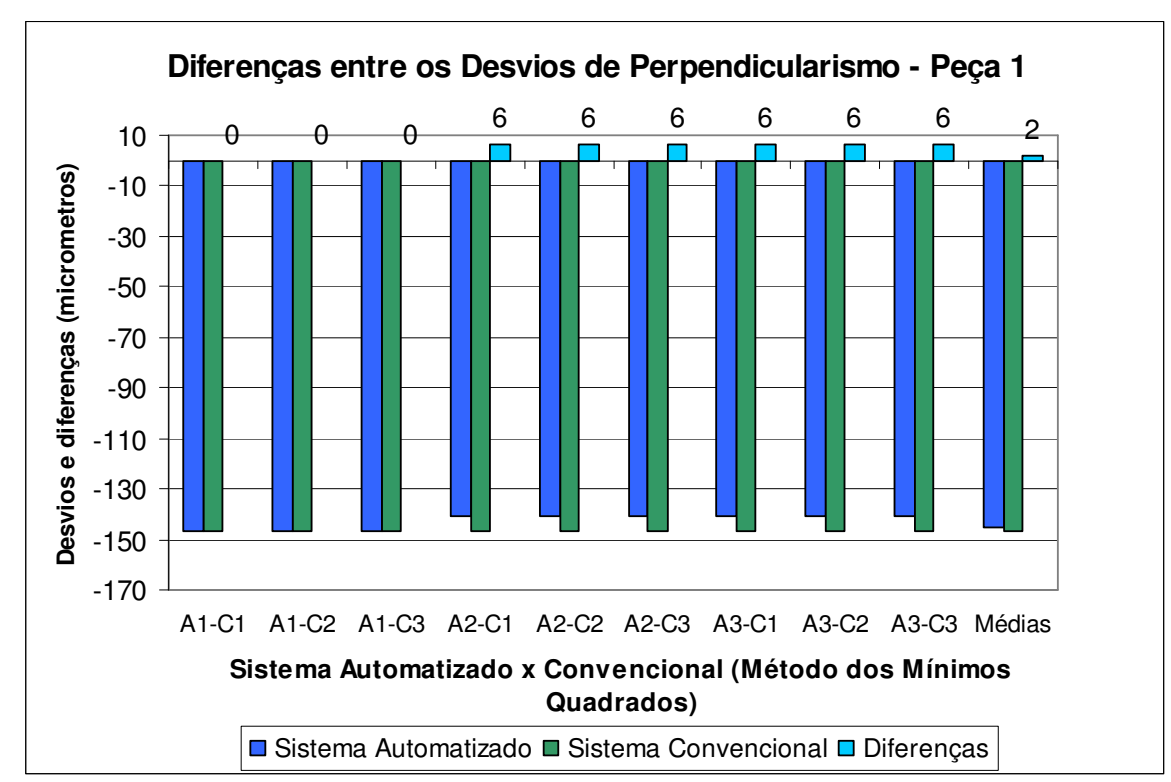

Figura 6.9 - Comparação entre os desvios de perpendicularismo da Peça 1 (ajustagem de Mínimos Quadrados)

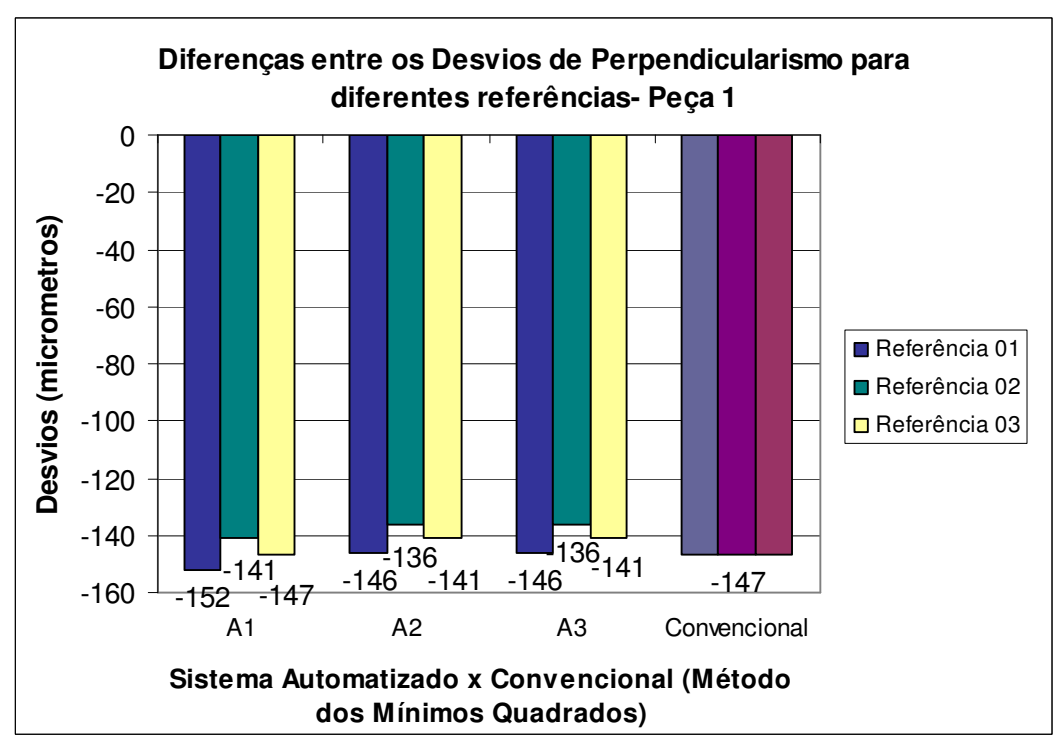

Figura 6.10 - Comparação entre os desvios de perpendicularismo da Peça 1 considerando-se 3 amostras do plano de referência (ajustagem de Mínimos Quadrados).

Pela análise da Figura 6.8 também nota-se a existência de uma componente de erro sistemático na avaliação do desvio de planicidade. A diferença máxima obtida quando os valores são ajustados pelo Método dos Mínimos Quadrados, foi de 29 micrometros, maior do que a obtida com a utilização da ajustagem Minimax, de 26 micrometros. A diferença média, entretanto, manteve-se praticamente constante nos dois casos. Supõe-se que a hipótese apresentada para explicar as diferenças observadas entre os desvios de planicidade da Peça 1 avaliados com o 
Método Minimax também se aplique no caso da avaliação deste desvio com o Método dos Mínimos Quadrados.

A seguir são apresentados os resultados finais das medições da Peça 2. As tabelas e gráficos de resultados são análogos aos apresentados para a Peça 1. O objetivo da análise, neste caso, é observar se o comportamento do sistema proposto e dos métodos de ajustagem é similar ao observado para a Peça 1.

Tabela 6.62 - Desvios geométricos da Peça 2 - Sistema Automatizado e Ajustagem Mnimax.

\begin{tabular}{|c|c|c|c|c|c|c|c|c|c|c|c|c|}
\hline & \multicolumn{11}{|c|}{ Peça 2 - Sistema Automatizado } \\
\hline & & \multicolumn{3}{|c|}{ Amostra 01} & \multicolumn{3}{|c|}{ Amostra 02} & \multicolumn{3}{|c|}{ Amostra 03} & \multirow[b]{2}{*}{$\begin{array}{c}\text { Amplitude } \\
\text { amostral }\end{array}$} & \multirow{2}{*}{$\begin{array}{l}\text { Desvio. } \\
\text { padrão } \\
\text { amostral }\end{array}$} \\
\hline & & mín & máx & $\begin{array}{l}\text { Desvio } \\
\text { Médio }\end{array}$ & mín & máx & $\begin{array}{l}\text { Desvio } \\
\text { Médio }\end{array}$ & mín & máx & \begin{tabular}{|l|} 
Desvio \\
Médio
\end{tabular} & & \\
\hline \multicolumn{2}{|c|}{ Desvio de planicidade } & 35 & 38 & 36 & 33 & 40 & 36 & 30 & 34 & 32 & 4 & 2 \\
\hline \multirow{8}{*}{$\begin{array}{l}\text { Desvio } \\
\text { de } \\
\text { perpendi- } \\
\text { cularismo }\end{array}$} & Referência & & & & & & & & & & & \\
\hline & Amostra 01 & -139 & -161 & -148 & -135 & -162 & -148 & -130 & -159 & -140 & 8 & 5 \\
\hline & Amostra 02 & -144 & -173 & -157 & -140 & -185 & -156 & -134 & -179 & -149 & 8 & 4 \\
\hline & Amostra 03 & -138 & -159 & -153 & -133 & -172 & -152 & -128 & -166 & -145 & 8 & 4 \\
\hline & Média & & & -153 & & & -152 & & & -145 & & \\
\hline & D. padrão & & & 5 & & & 4 & & & 5 & & \\
\hline & Amplitude & & & 9 & & & 8 & & & 9 & & \\
\hline & Método de a & ustage & $\mathrm{m}$ dos & planos: & & & Mini & $\max$ & & & & \\
\hline
\end{tabular}

Tabela 6.63 - Desvios geométricos da Peça 2 - Sistema Automatizado e Ajustagem de Mínimos Quadrados.

\begin{tabular}{|c|c|c|c|c|c|c|c|c|c|c|c|c|}
\hline & \multicolumn{11}{|c|}{ Peça 2 - Sistema Automatizado } \\
\hline & & \multicolumn{3}{|c|}{ Amostra 01} & \multicolumn{3}{|c|}{ Amostra 02} & \multicolumn{3}{|c|}{ Amostra 03} & \multirow[b]{2}{*}{$\begin{array}{c}\text { Amplitude } \\
\text { amostral }\end{array}$} & \multirow{2}{*}{$\begin{array}{l}\text { Desvio. } \\
\text { padrão } \\
\text { amostral }\end{array}$} \\
\hline & & mín & máx & $\begin{array}{l}\text { Desvio } \\
\text { Médio } \\
\end{array}$ & mín & máx & $\begin{array}{l}\text { Desvio } \\
\text { Médio }\end{array}$ & mín & máx & $\begin{array}{l}\text { Desvio } \\
\text { Médio } \\
\end{array}$ & & \\
\hline \multicolumn{2}{|c|}{ Desvio de planicidade } & 37 & 39 & 38 & 34 & 42 & 37 & 31 & 36 & 34 & 4 & 2 \\
\hline \multirow{7}{*}{$\begin{array}{c}\text { Desvio } \\
\text { de } \\
\text { perpendi- } \\
\text { cularismo }\end{array}$} & Referência & & & & & & & & & & & \\
\hline & Amostra 01 & -157 & -157 & -157 & -157 & -157 & -157 & -154 & -154 & -154 & 3 & 2 \\
\hline & Amostra 02 & -146 & -146 & -146 & -147 & -147 & -147 & -144 & -144 & -144 & 3 & 2 \\
\hline & Amostra 03 & -152 & -152 & -152 & -152 & -152 & -152 & -149 & -149 & -149 & 3 & 2 \\
\hline & Média & & & -152 & & & -152 & & & -149 & & \\
\hline & D. padrão & & & 6 & & & 5 & & & 5 & & \\
\hline & Amplitude & & & 11 & & & 10 & & & 10 & & \\
\hline & \multicolumn{4}{|c|}{ Método de ajustagem dos planos: } & \multicolumn{6}{|c|}{ Mínimos Quadrados } & & \\
\hline
\end{tabular}

A análise das tabelas 6.62 e 6.63 demonstra que alguns padrões de resultados observados para a Peça 1 se repetem para a Peça 2 . Novamente, a variabilidade dos resultados considerando-se as diferentes amostras de medição da peça é bem pequena. Este fato pode ser 
constatado mediante a observação dos valores de amplitude e desvio padrão amostrais. Além disso, a variação observada nos valores do desvio de perpendicularismo devido à adoção de diferentes amostras do plano de referência também foi relativamente pequena, não ultrapassando 11 micrometros, como no caso anterior.

Da mesma forma que no caso anterior, a ajustagem de Mínimos Quadrados forneceu resultados para o desvio de perpendicularismo mais estáveis do que aqueles obtidos com a ajustagem Minimax.

As análises comparativas mostradas nas tabelas e gráficos abaixo, entretanto, apresentam alguns resultados diferentes daqueles que foram obtidos para a Peça 1.

Tabela 6.64 - Tabela comparativa - desvios geométricos da Peça 2 (ajustagem Minimax).

\begin{tabular}{|c|c|c|c|c|c|c|c|c|c|}
\hline & \multicolumn{3}{|c|}{$\begin{array}{l}\text { Peça } 2 \text { - Sistema } \\
\text { Automatizado }\end{array}$} & \multicolumn{3}{|c|}{$\begin{array}{l}\text { Peça } 2 \text { - Sistema } \\
\text { Convencional }\end{array}$} & \multicolumn{3}{|c|}{ Peça 2 - Máquina de Medir } \\
\hline & $\begin{array}{c}\text { Amostra } \\
01\end{array}$ & $\begin{array}{c}\text { Amostra } \\
02\end{array}$ & $\begin{array}{l}\text { Amostra } \\
03\end{array}$ & \multirow{2}{*}{$\begin{array}{c}\text { Amostra } \\
01\end{array}$} & \multirow{2}{*}{$\begin{array}{l}\text { Amostra } \\
02\end{array}$} & \multirow{2}{*}{$\begin{array}{l}\text { Amostra } \\
03\end{array}$} & \multirow{2}{*}{$\begin{array}{l}\text { Amostra } \\
01\end{array}$} & \multirow{2}{*}{$\begin{array}{l}\text { Amostra } \\
02\end{array}$} & \multirow{2}{*}{$\begin{array}{l}\text { Amostra } \\
03\end{array}$} \\
\hline & D. Médio & D. Médio & D. Médio & & & & & & \\
\hline $\begin{array}{l}\text { Desvio de } \\
\text { planicidade }\end{array}$ & 36 & 36 & 32 & 33 & 32 & 32 & 38 & 36 & 38 \\
\hline \multirow[t]{3}{*}{$\begin{array}{c}\text { Desvio de } \\
\text { perpendicularismo }\end{array}$} & $-153^{*}$ & $-152^{*}$ & $-145^{*}$ & -128 & -127 & -127 & -143 & -141 & -144 \\
\hline & \multicolumn{9}{|c|}{ * Média dos valores obtidos com as 3 referências } \\
\hline & \multicolumn{4}{|c|}{ Método de ajustagem dos planos: } & \multicolumn{5}{|c|}{ Minimax } \\
\hline
\end{tabular}

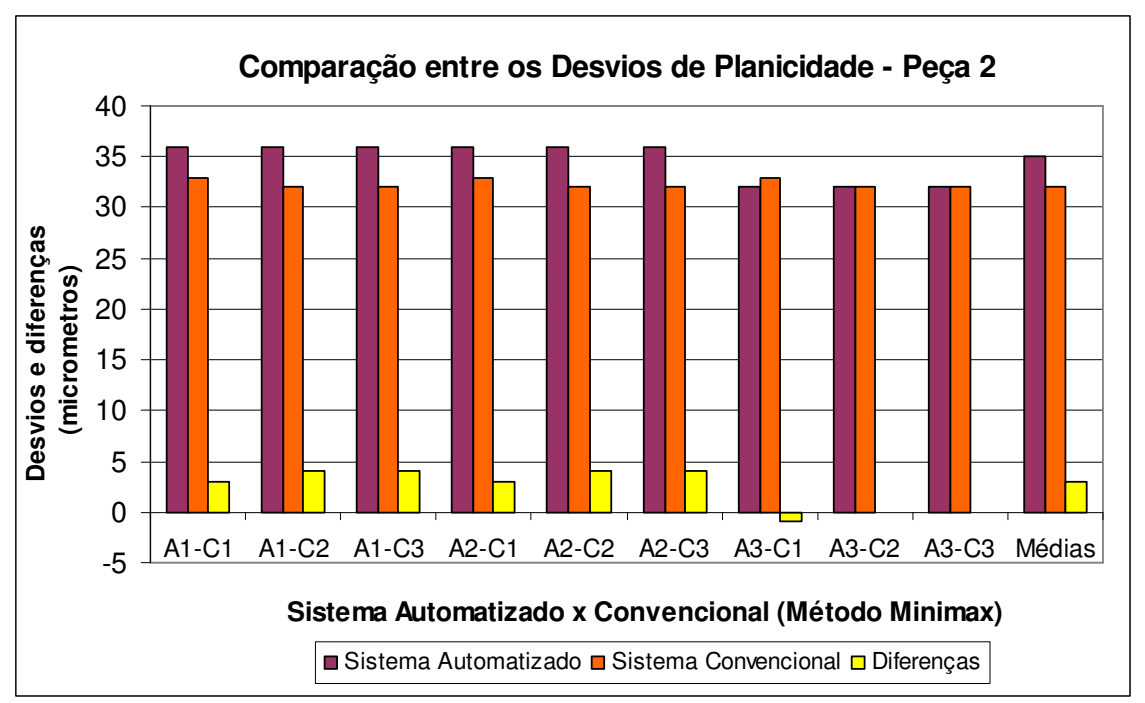

Figura 6.11 - Comparação entre os desvios de planicidade da Peça 2 (ajustagem Minimax).

Conforme pode ser visto na Figura 6.11, a diferença máxima entre os valores do desvio de planicidade obtidos com o sistema proposto e o 
convencional, para a Peça 2, foi de 4 micrometros. Assim, observa-se que desempenho do sistema proposto na avaliação da planicidade desta peça foi bem melhor do que o desempenho na avaliação da Peça 1.

A situação é oposta no caso do desvio de perpendicularismo da Peça 2. As diferenças absolutas observadas na avaliação do perpendicularismo desta peça são maiores do que as observadas no caso da Peça 1, conforme mostram os gráficos das figuras 6.12 e 6.13 . Neste caso observa-se a presença de uma componente de erro sistemático significativa.

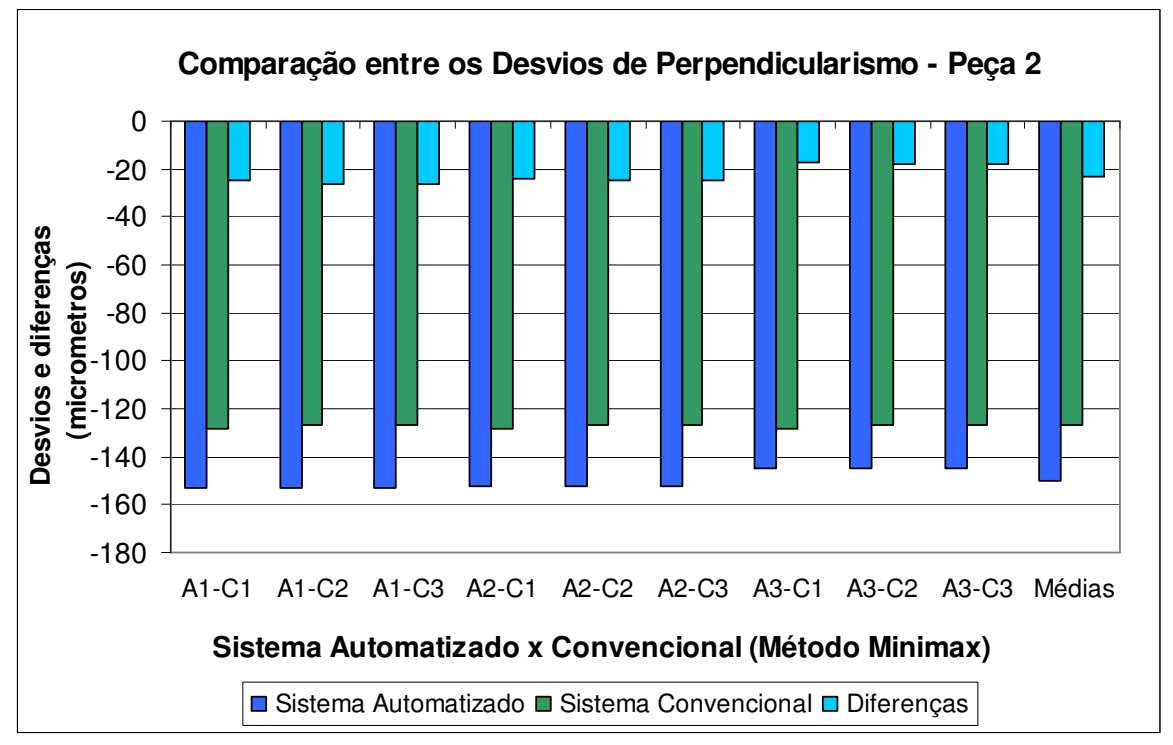

Figura 6.12 - Comparação entre os desvios de perpendicularismo da peça 2 (ajustagem Minimax).

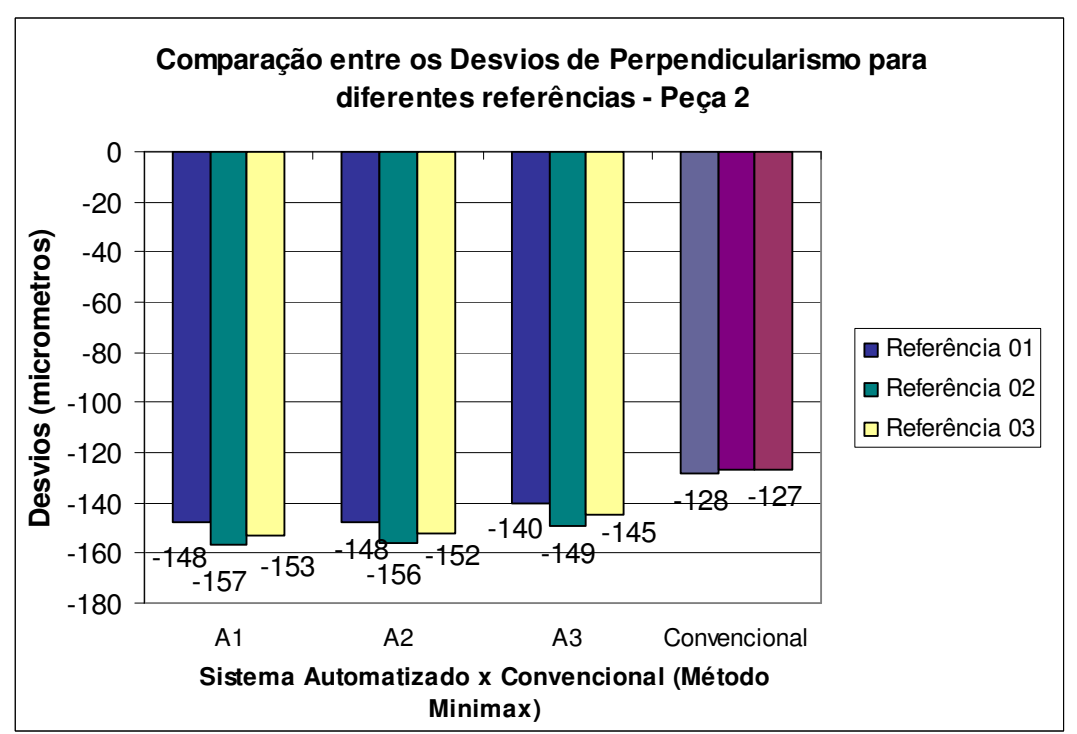

Figura 6.13 - Comparação entre os desvios de perpendicularismo considerando-se 3 amostras do plano de referência (ajustagem Minimax) 
Resultados similares foram observados para a ajustagem de Mínimos Quadrados, conforme mostram a tabela e gráficos a seguir.

Tabela 6.65 - Tabela comparativa - desvios geométricos da Peça 2 (ajustagem de Mínimos Quadrados).

\begin{tabular}{|c|c|c|c|c|c|c|c|c|c|}
\hline & \multicolumn{3}{|c|}{$\begin{array}{c}\text { Peça } 2 \text { - Sistema } \\
\text { Automatizado }\end{array}$} & \multicolumn{3}{|c|}{$\begin{array}{l}\text { Peça } 2 \text { - Sistema } \\
\text { Convencional }\end{array}$} & \multicolumn{3}{|c|}{ Peça 2 - Máquina de Medir } \\
\hline & $\begin{array}{c}\text { Amostra } \\
01\end{array}$ & $\begin{array}{c}\text { Amostra } \\
02 \\
\end{array}$ & \begin{tabular}{|c|} 
Amostra \\
03 \\
\end{tabular} & \multirow{2}{*}{$\begin{array}{c}\text { Amostra } \\
01\end{array}$} & \multirow{2}{*}{$\begin{array}{c}\text { Amostra } \\
02\end{array}$} & \multirow{2}{*}{$\begin{array}{c}\text { Amostra } \\
03\end{array}$} & \multirow{2}{*}{$\begin{array}{c}\text { Amostra } \\
01\end{array}$} & \multirow{2}{*}{$\begin{array}{c}\text { Amostra } \\
02\end{array}$} & \multirow{2}{*}{$\begin{array}{c}\text { Amostra } \\
03\end{array}$} \\
\hline & D. Médio & D. Médio & D. Médio & & & & & & \\
\hline $\begin{array}{l}\text { Desvio de } \\
\text { planicidade }\end{array}$ & 38 & 37 & 34 & 36 & 34 & 35 & 39 & 38 & 39 \\
\hline \multirow[t]{3}{*}{$\begin{array}{c}\text { Desvio de } \\
\text { perpendicularismo }\end{array}$} & $-152^{*}$ & $-152^{*}$ & $-149^{*}$ & -124 & -124 & -124 & -141 & -141 & -141 \\
\hline & \multicolumn{9}{|c|}{ os valores obtidos com as 3 referências } \\
\hline & \multicolumn{4}{|c|}{ Método de ajustagem dos planos: } & \multicolumn{5}{|c|}{ Mínimos Quadrados } \\
\hline
\end{tabular}

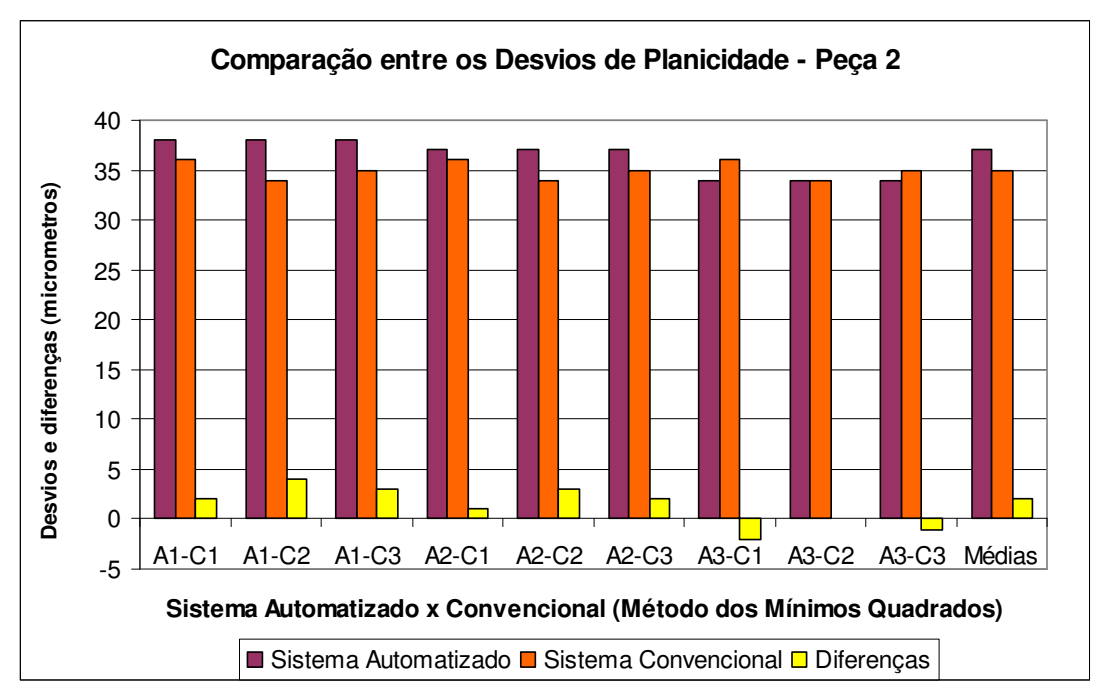

Figura 6.14 - Comparação entre os desvios de planicidade da Peça 2 (ajustagem de Mínimos Quadrados).

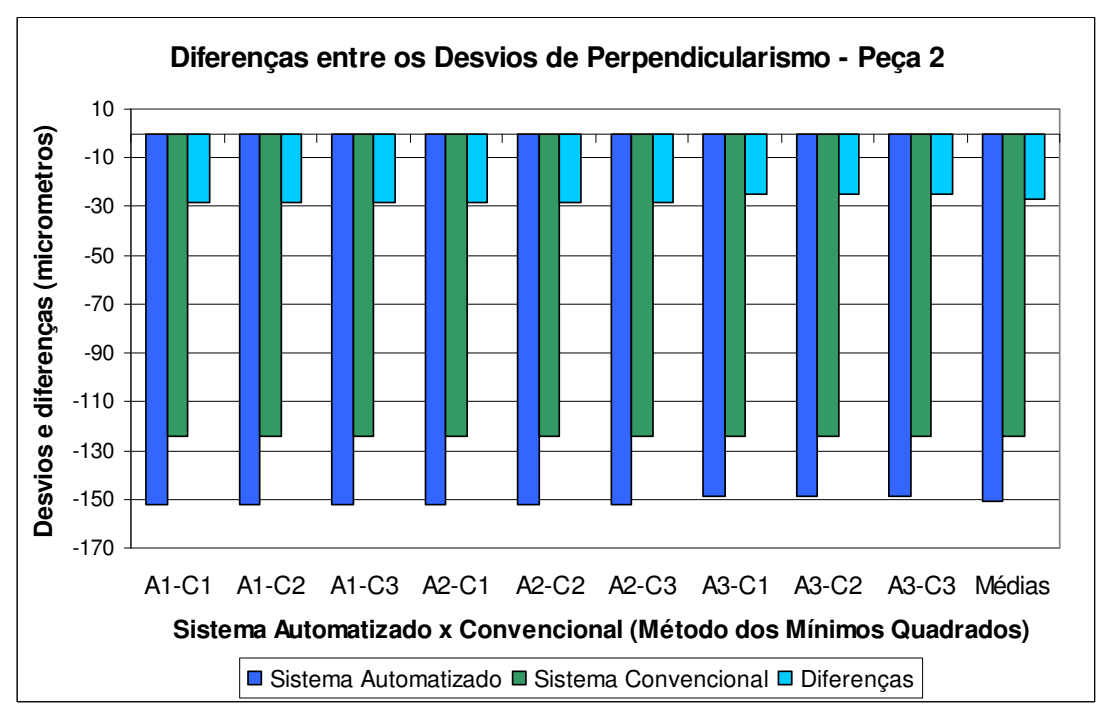

Figura 6.15 - Comparação entre os desvios de perpendicularismo da Peça 2 (ajustagem de Mínimos Quadrados). 


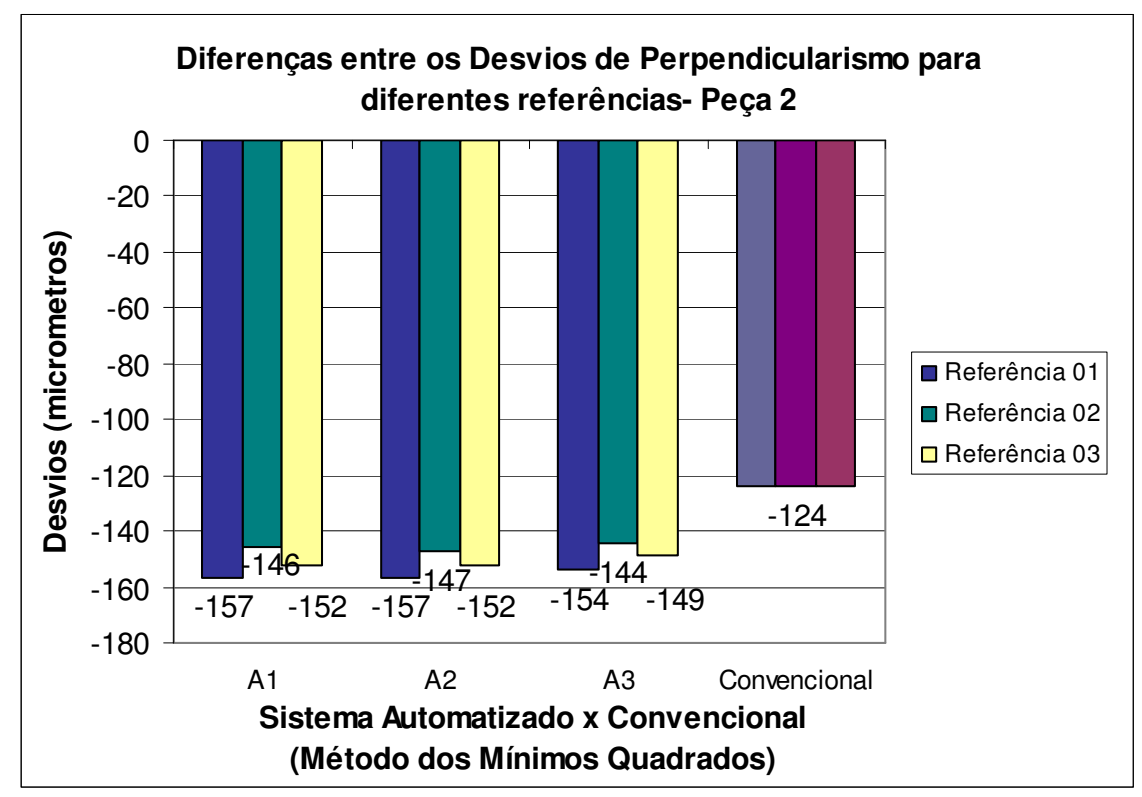

Figura 6.16 - Comparação entre os desvios de perpendicularismo da Peça 2 considerando-se 3 amostras do plano de referência (ajustagem de Mínimos Quadrados)

É importante destacar que os valores do desvio de perpendicularismo da Peça 2, obtidos com o Sistema Automatizado, foram praticamente os mesmos obtidos para a Peça 1. Este é um resultado esperado uma vez que, conforme exposto anteriormente, as peças 1 e 2 são faces opostas de uma mesma peça. Para que as medições fossem realizadas, esta peça foi rotacionada em $180^{\circ}$ ao redor de seu eixo longitudinal, o qual é paralelo às geratizes da peça. Assim, os valores observados para ambas as peças deveriam ser, de fato, muito próximos. Há diferenças significativas, entretanto, nos valores do desvio de planicidade devido à diferença de qualidade superficial de cada uma das faces. Esta estratégia foi apresentada na Figura 5.7 e discutida cm detalhes no item 5.1. Deve-se observar que a avaliação do perpendicularismo pelo sistema convencional foi influenciada por imperfeições superficiais da peça, já que o valor de desvio de perpendicularismo fornecido por este sistema para a Peça 1, que possui com superfície mais grosseira, foi maior do que aquele relativo à Peça 2 . 
Os valores fornecidos pelo sistema proposto, ao contrário, não sofreram variações diante das diferenças na qualidade superficial das faces medidas, indicando que o sistema proposto é mais robusto neste caso.

Assim, as disparidades observadas entre os valores das diferenças de avaliação do perpendicularismo das peças 1 e 2 se devem à variação dos valores de desvio fornecidos pelo método convencional para cada peça. Os valores da medição convencional obtidos para a Peça 2 poderiam ser tomados como referência também para a Peça 1 , pois se supõe que contenham menos ruídos causados por imperfeições superficiais. Neste caso, o mesmo erro obtido na avaliação da Peça 2 seria observado para a Peça 1, isto é, também seriam observadas diferenças de aproximadamente 30 micrometros. Em resumo, pode-se observar que 0 Sistema Automatizado apresentou um comportamento repetitivo e consistente em relação à avaliação do perpendicularismo das duas faces de uma mesma peça.

Finalmente, são apresentadas a seguir as tabelas contendo o resumo dos resultados obtidos com a medição da Peça 3.

Tabela 6.66 - Desvios geométricos da Peça 3 - Sistema Automatizado e Ajustagem MInimax.

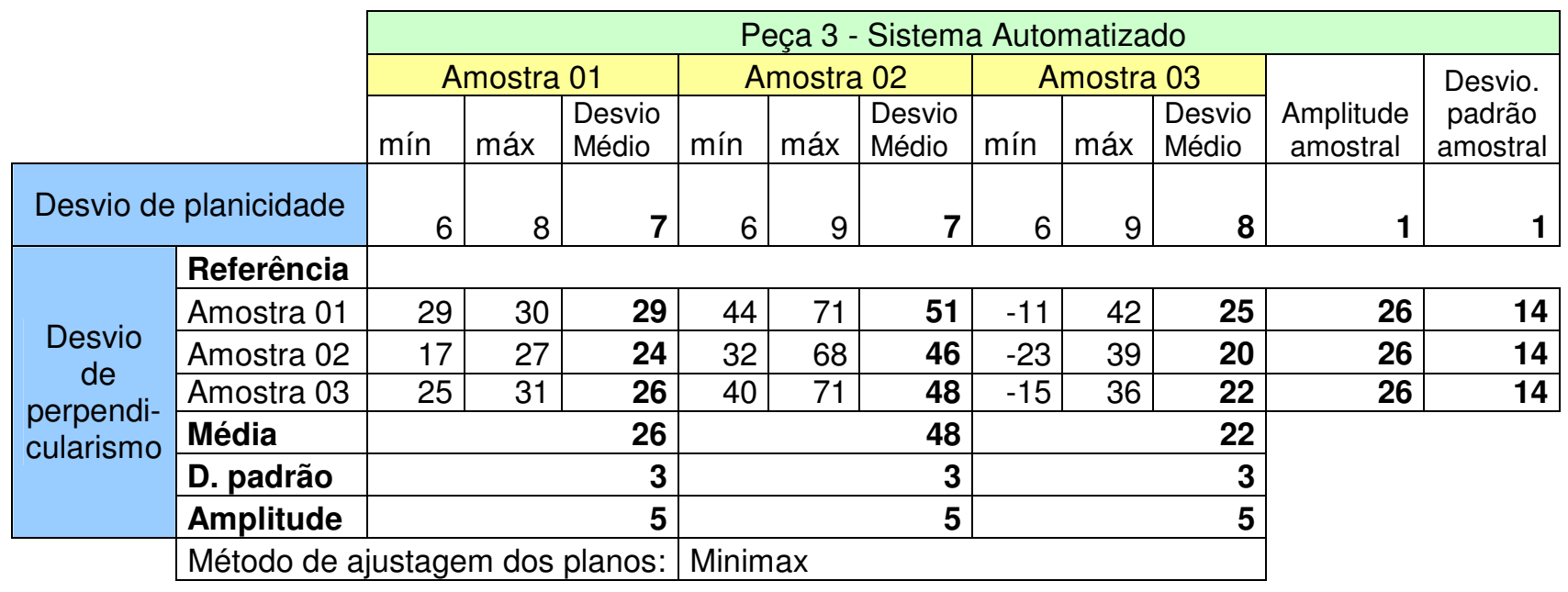


Tabela 6.67 - Desvios geométricos da Peça 3 - Sistema Automatizado e Ajustagem de Mínimos Quadrados.

\begin{tabular}{|c|c|c|c|c|c|c|c|c|c|c|c|c|}
\hline & \multirow{2}{*}{\multicolumn{11}{|c|}{ Peça 3 - Sistema Automatizado }} \\
\hline & & & & & & & & & & & & \\
\hline & & \multicolumn{3}{|c|}{ Amostra 01} & \multicolumn{3}{|c|}{ Amostra 02} & \multicolumn{3}{|c|}{ Amostra 03} & \multirow[b]{2}{*}{$\begin{array}{c}\text { Amplitude } \\
\text { amostral }\end{array}$} & \multirow{2}{*}{\begin{tabular}{|c} 
Desvio. \\
padrão \\
amostral \\
\end{tabular}} \\
\hline & & mín & máx & \begin{tabular}{|l} 
Desvio \\
Médio \\
\end{tabular} & mín & máx & \begin{tabular}{|l} 
Desvio \\
Médio \\
\end{tabular} & mín & máx & \begin{tabular}{|l} 
Desvio \\
Médio \\
\end{tabular} & & \\
\hline \multicolumn{2}{|c|}{ Desvio de planicidade } & 6 & 9 & 7 & 7 & 10 & 8 & 6 & 10 & 8 & 1 & 1 \\
\hline \multirow{8}{*}{$\begin{array}{l}\text { Desvio } \\
\text { de } \\
\text { perpendi- } \\
\text { cularismo }\end{array}$} & Referência & & & & & & & & & & & \\
\hline & Amostra 01 & 38 & 38 & 38 & 37 & 37 & 37 & 27 & 27 & 27 & 11 & 6 \\
\hline & Amostra 02 & 44 & 44 & 44 & 43 & 43 & 43 & 34 & 34 & 34 & 10 & 6 \\
\hline & Amostra 03 & 41 & 41 & 41 & 40 & 40 & 40 & 30 & 30 & 30 & 11 & 6 \\
\hline & Média & & & 41 & & & 40 & & & 30 & & \\
\hline & D. padrão & & & 3 & & & 3 & & & 4 & & \\
\hline & Amplitude & & & 6 & & & 6 & & & 7 & & \\
\hline & \multicolumn{4}{|c|}{ Método de ajustagem dos planos: } & \multicolumn{6}{|c|}{ Mínimos Quadrados } & & \\
\hline
\end{tabular}

Nas tabelas 6.66 e 6.67 , os valores de amplitude e desvio padrão amostral dos resultados referentes ao desvio de perpendicularismo se destacam por serem praticamente 0 dobro do que os valores correspondentes observados para as peças 1 e 2, ou seja, a variação dos resultados, de amostra para amostra, foi significativamente maior no caso da Peça 3 do que no caso das outras peças. Novamente, comparando-se os dois métodos de ajustagem, nota-se que esta variabilidade amostral é menor quando o Método dos Mínimos Quadrados é utilizado, mas, ainda assim, ela é comparativamente maior do que a observada para as demais peças. Isso demonstra que a avaliação do desvio de perpendicularismo da Peça 3 é mais instável do que a avaliação do desvio de perpendicularismo das outras peças. Esta instabilidade pode ser notada também nas tabelas nos gráficos comparativos dos sistemas de medição que se referem à avaliação do erro de perpendicularismo.

Tabela 6.68 - Tabela comparativa - desvios geométricos da Peça 3 (ajustagem Minimax).

\begin{tabular}{|c|c|c|c|c|c|c|c|c|c|}
\hline & \multicolumn{3}{|c|}{$\begin{array}{l}\text { Peça } 3 \text { - Sistema } \\
\text { Automatizado }\end{array}$} & \multicolumn{3}{|c|}{$\begin{array}{l}\text { Peça } 3 \text { - Sistema } \\
\text { Convencional }\end{array}$} & \multicolumn{3}{|c|}{ Peça 3 - Máquina de Medir } \\
\hline & $\begin{array}{c}\text { Amostra } \\
01\end{array}$ & \begin{tabular}{|c|} 
Amostra \\
02 \\
\end{tabular} & $\begin{array}{c}\text { Amostra } \\
03\end{array}$ & \multirow{2}{*}{$\begin{array}{l}\text { Amostra } \\
01\end{array}$} & \multirow{2}{*}{$\begin{array}{c}\text { Amostra } \\
02\end{array}$} & \multirow{2}{*}{$\begin{array}{l}\text { Amostra } \\
03\end{array}$} & \multirow{2}{*}{$\begin{array}{c}\text { Amostra } \\
01\end{array}$} & \multirow{2}{*}{$\begin{array}{c}\text { Amostra } \\
02\end{array}$} & \multirow{2}{*}{$\begin{array}{l}\text { Amostra } \\
03\end{array}$} \\
\hline & D. Médio & D. Médio & D. Médio & & & & & & \\
\hline $\begin{array}{l}\text { Desvio de } \\
\text { planicidade }\end{array}$ & 7 & 6 & 9 & 8 & 3 & 3 & 5 & 6 & 6 \\
\hline \multirow[t]{3}{*}{$\begin{array}{c}\text { Desvio de } \\
\text { perpendicularismo }\end{array}$} & $26^{*}$ & $48^{*}$ & $22^{*}$ & 20 & 26 & 25 & 26 & 28 & 32 \\
\hline & \multicolumn{9}{|c|}{${ }^{*}$ Média dos valores obtidos com as 3 referências } \\
\hline & \multicolumn{5}{|c|}{\begin{tabular}{|l|l} 
Método de ajustagem dos planos: &
\end{tabular}} & \multicolumn{4}{|c|}{ Minimax } \\
\hline
\end{tabular}


Os resultados da avaliação do desvio de planicidade da Peça 3 foram satisfatórios, conforme mostram as figuras 6.17 e 6.18 . Além disso, os resultados obtidos mediante a aplicação de ambos os métodos de ajustagem, isto é, Minimax e Mínimos Quadrados, foram, neste caso, muito semelhantes. A seguir são apresentados os gráficos dos erros observados tanto na avaliação do desvio de planicidade quanto na avaliação do desvio de perpendicularismo da Peça 3.

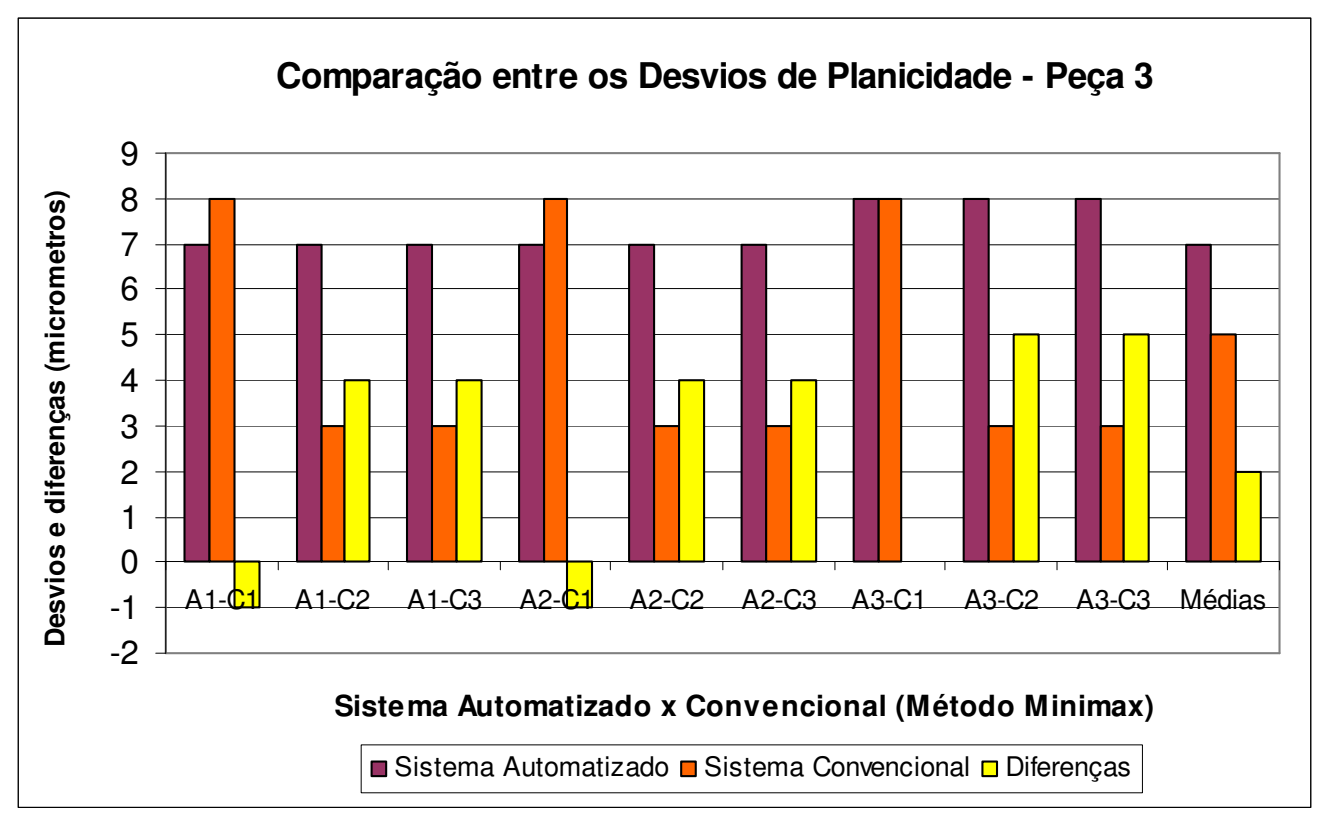

Figura 6.17 - Comparação entre os desvios de planicidade da Peça 3 (ajustagem Minimax).

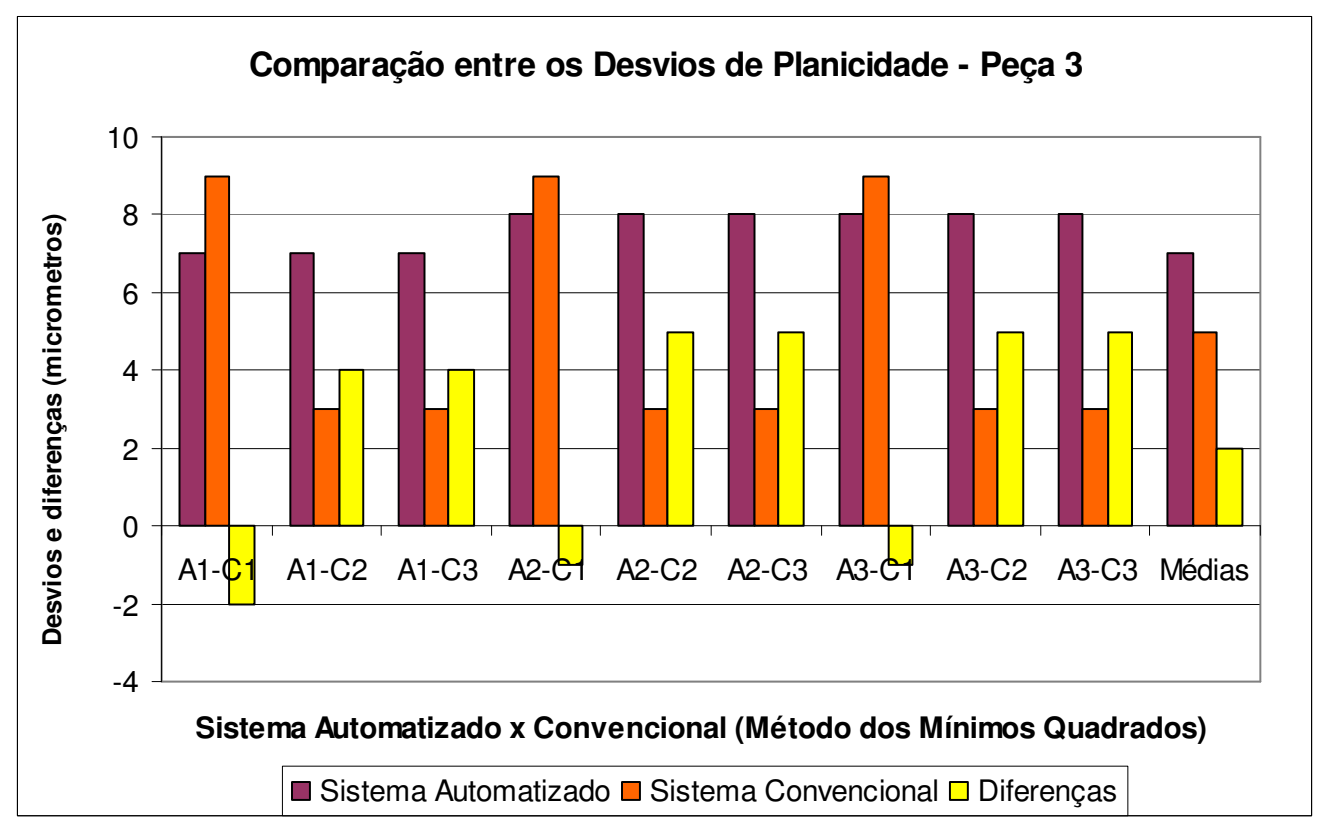

Figura 6.18 - Comparação entre os desvios de planicidade da Peça 3 (ajustagem de Mínimos Quadrados). 


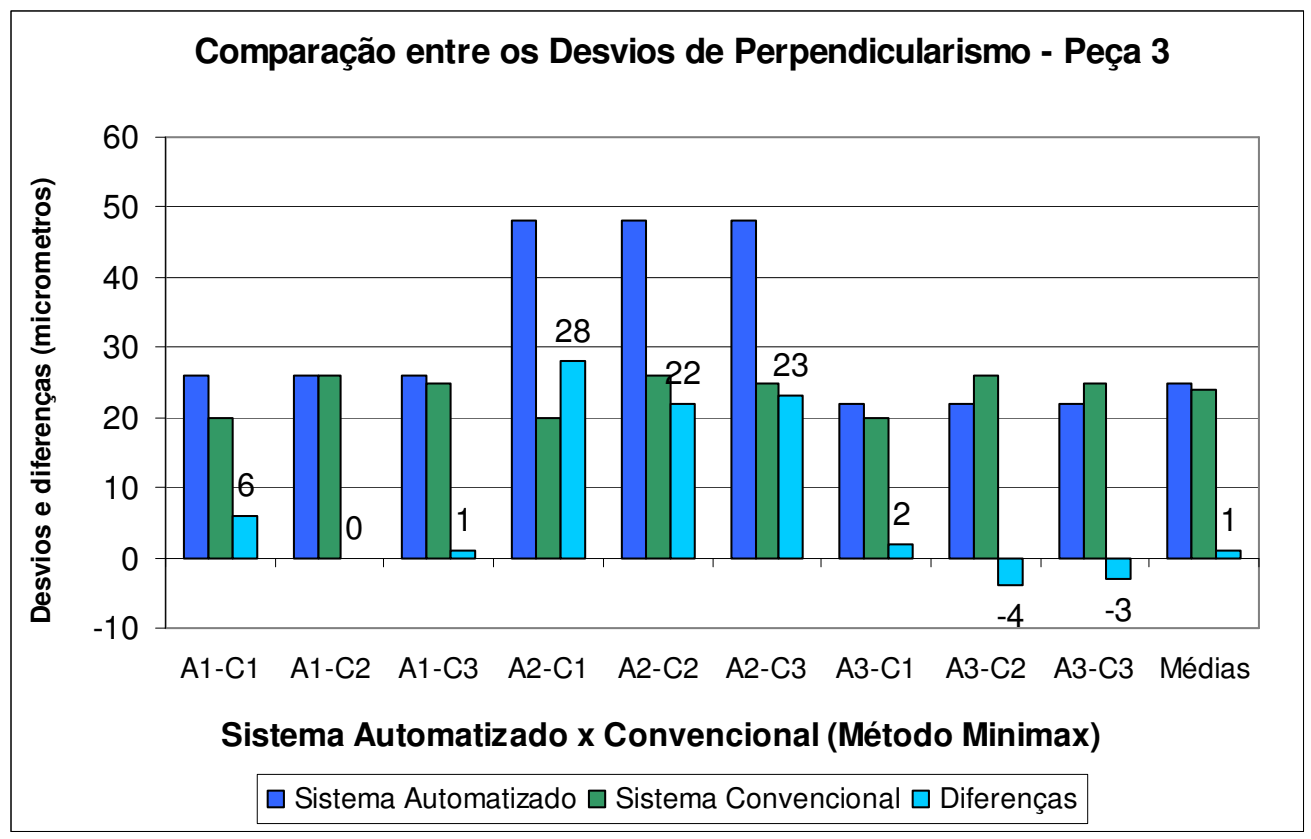

Figura 6.19 - Comparação entre os desvios de perpendicularismo da peça 3 (ajustagem Minimax).

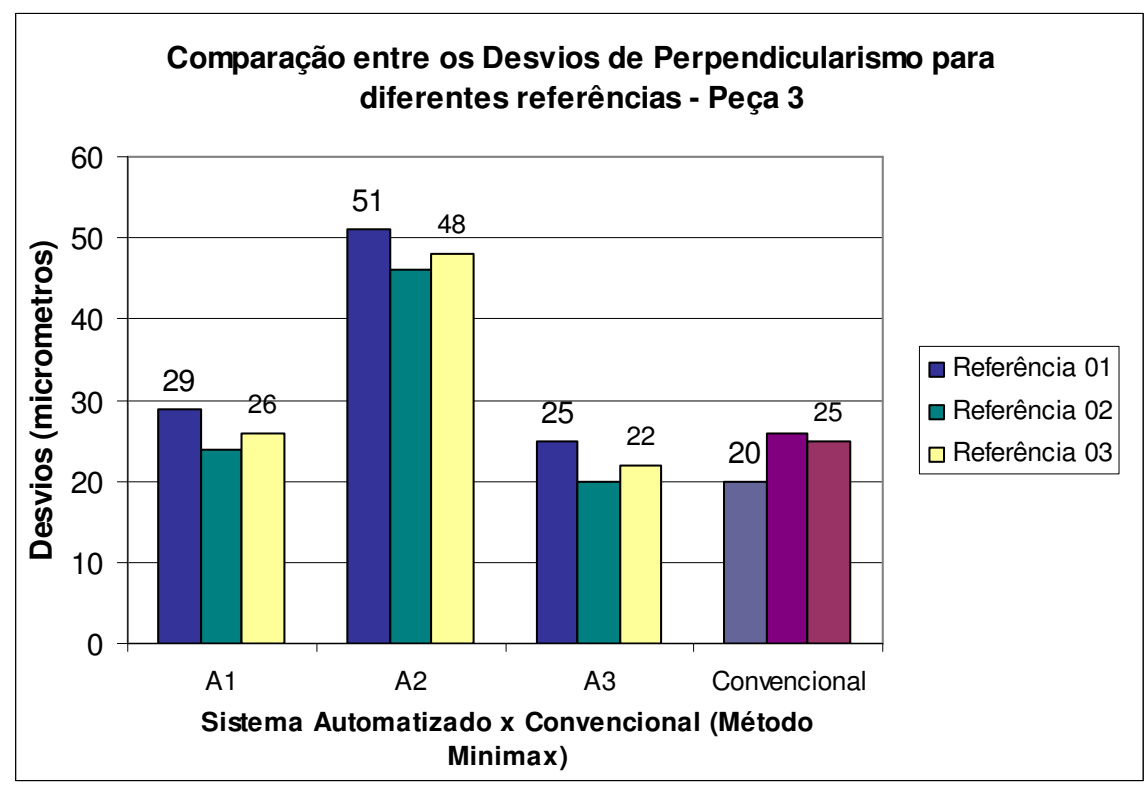

Figura 6.20 - Comparação entre os desvios de perpendicularismo da peça 3 considerando-se 3 amostras do plano de referência (ajustagem de Mínimos Quadrados)

Os resultados da avaliação do perpendicularismo obtidos para as três amostras de dados da Peça 3 apontam que o erro aleatório é grande, ou que a medição da amostra 2 sofreu a influência de causas especiais, as quais geraram uma variação maior que aquela que é natural do processo, definida segundo as teorias de Controle Estatístico de Processos. Segundo o Guia para a Expressão da Incerteza de Medição, ISO GUM (1998), as 
variações em observações repetidas surgem porque as grandezas de influência que podem afetar o resultado de medição não são mantidas completamente constantes. As grandezas de influência, por sua vez, podem estar relacionadas a padrões de medição, materiais, flutuações de curta duração do instrumento e características do ambiente, como temperatura, pressão, etc. Entretanto, é interessante observar que esta diferença significativa entre os valores obtidos a partir das amostras 01 e 02 não ocorre quando se utiliza na ajustagem o Método dos Mínimos Quadrados, conforme é possível observar na Tabela 6.69.

Essa instabilidade e aleatoriedade dos resultados podem estar relacionadas à quantidade de pontos coletados sobre a peça. Esta peça difere das demais por apresentar uma área de medição bem mais reduzida. Assim, na direção transversal, há apenas 3 posições de medição, ou seja, o modelo de separação de erros tem como dados de entrada apenas os pontos coletados em três posições, e isto pode ser insuficiente para que o desacoplamento dos erros seja realizado de forma efetiva.

Quando a ajustagem do desvio de perpendicularismo é realizada pelo método dos Mínimos Quadrados, a amplitude do erro aleatório é menor, conforme foi destacado acima, na análise da Tabela 6.67. Este fato também pode ser observado nas figuras 6.21 e 6.22. Abaixo também é apresentada a Tabela 6.69, na qual se baseiam os gráficos comparativos.

Tabela 6.69 - Tabela comparativa dos resultados obtidos para a Peça 3 utilizando-se o método de ajustagem de Mínimos Quadrados.

\begin{tabular}{|c|c|c|c|c|c|c|c|c|c|}
\hline & \multicolumn{3}{|c|}{$\begin{array}{l}\text { Peça } 3 \text { - Sistema } \\
\text { Automatizado }\end{array}$} & \multicolumn{3}{|c|}{$\begin{array}{l}\text { Peça } 3 \text { - Sistema } \\
\text { Convencional }\end{array}$} & \multicolumn{3}{|c|}{ Peça 3 - Máquina de Medir } \\
\hline & Amostra & Amostra & Amostra & \multirow[b]{2}{*}{$\begin{array}{c}\text { Amostra } \\
01\end{array}$} & \multirow[b]{2}{*}{$\begin{array}{l}\text { Amostra } \\
02\end{array}$} & \multirow[b]{2}{*}{$\begin{array}{c}\text { Amostra } \\
03\end{array}$} & \multirow[b]{2}{*}{$\begin{array}{c}\text { Amostra } \\
01\end{array}$} & \multirow[b]{2}{*}{$\begin{array}{l}\text { Amostra } \\
02\end{array}$} & \multirow[b]{2}{*}{$\begin{array}{l}\text { Amostra } \\
03\end{array}$} \\
\hline & 01 & 02 & 03 & & & & & & \\
\hline $\begin{array}{l}\text { Desvio de } \\
\text { planicidade }\end{array}$ & 7 & 8 & 8 & 9 & 3 & 3 & 6 & 7 & 7 \\
\hline \multirow[t]{3}{*}{$\begin{array}{c}\text { Desvio de } \\
\text { perpendicularismo }\end{array}$} & $41^{*}$ & $40^{*}$ & $30^{*}$ & 24 & 25 & 25 & 29 & 28 & 28 \\
\hline & \multicolumn{9}{|c|}{ * Média dos valores obtidos com as 3 referências } \\
\hline & \multicolumn{5}{|c|}{ Método de ajustagem dos planos: } & \multicolumn{4}{|c|}{ Mínimos Quadrados } \\
\hline
\end{tabular}




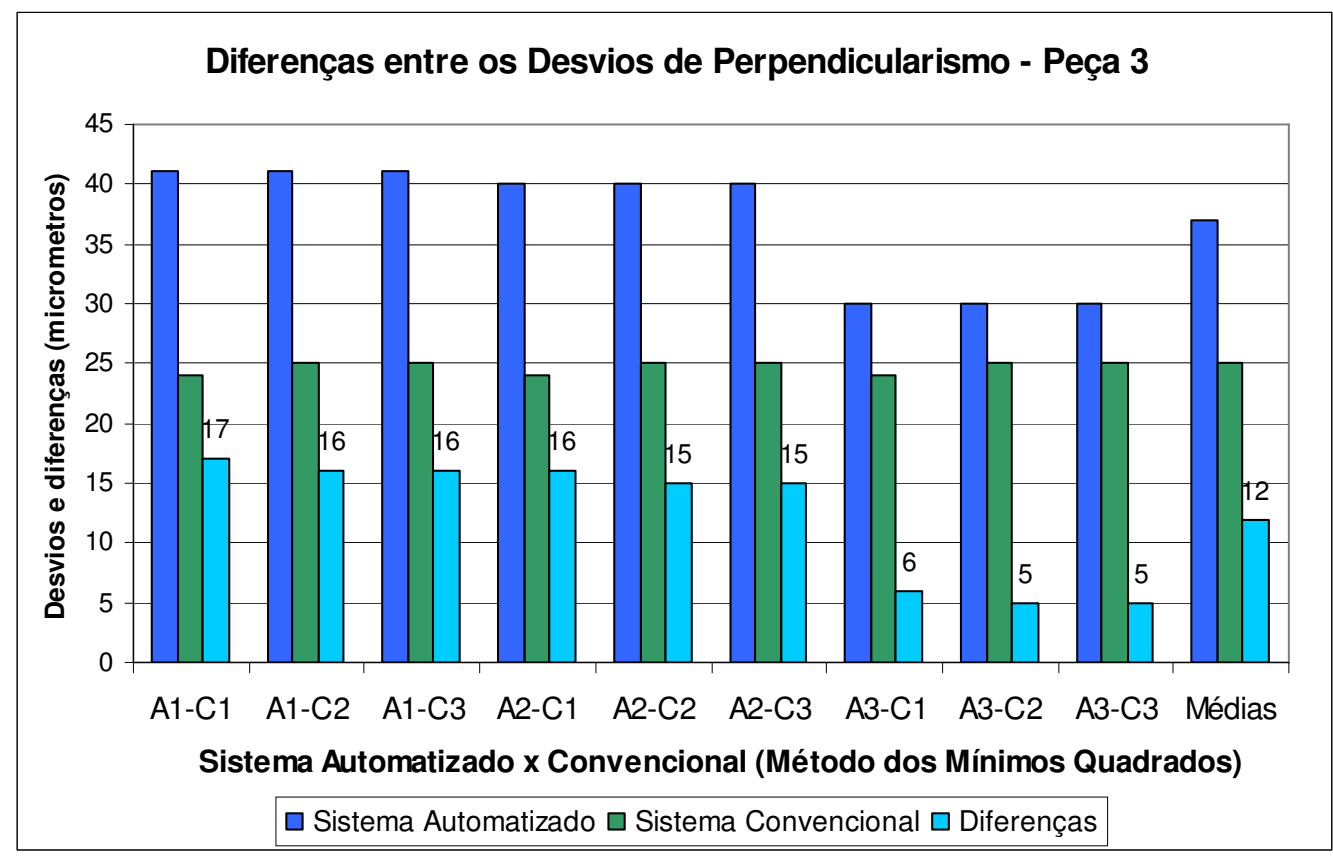

Figura 6.21 - Comparação entre os desvios de perpendicularismo da Peça 3 (ajustagem de Mínimos Quadrados).

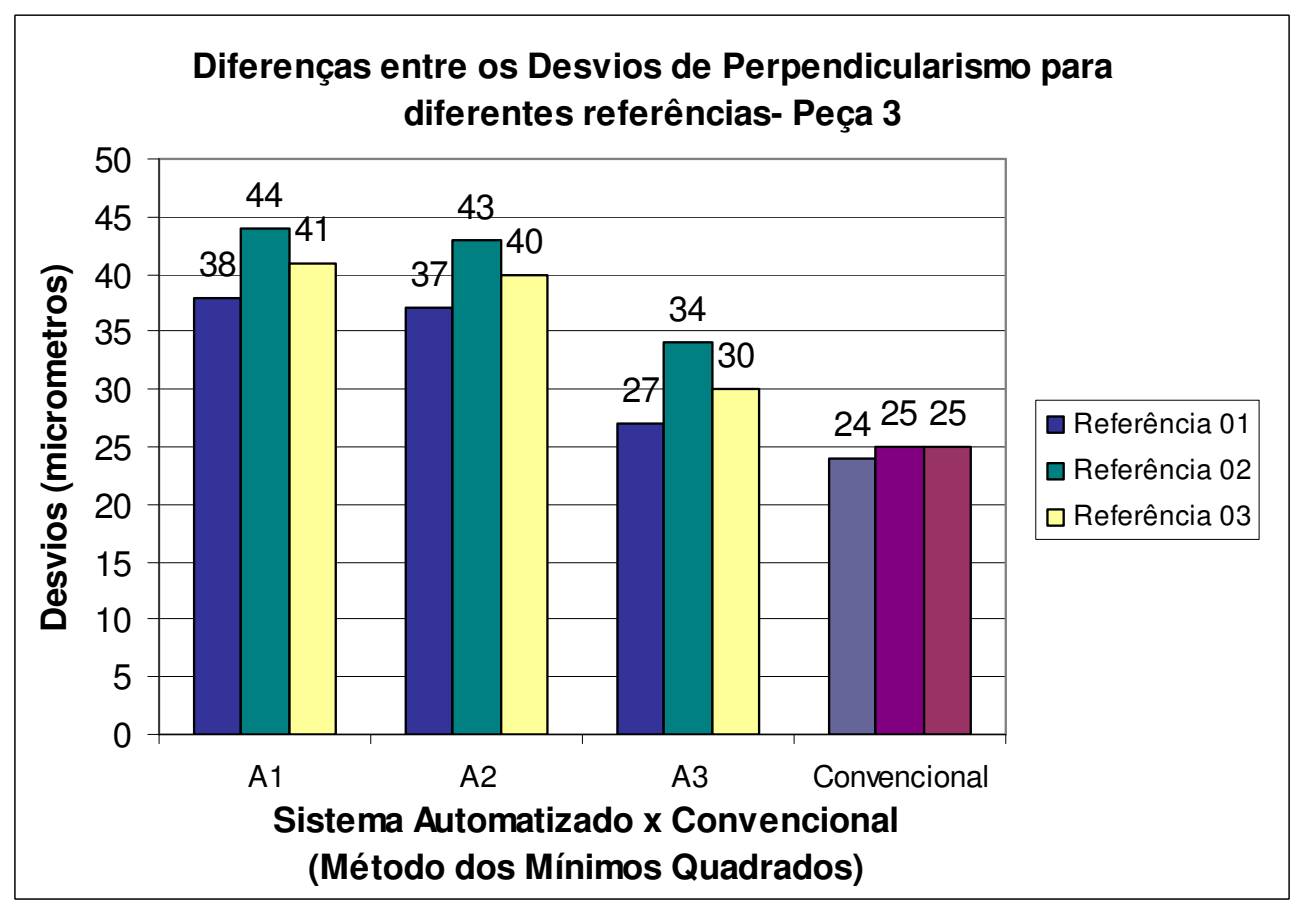

Figura 6.22 - Comparação entre os desvios de perpendicularismo da Peça 3 considerando-se 3 amostras do plano de referência (ajustagem de Mínimos Quadrados).

Estendendo-se a análise comparativa de forma a incluir os resultados obtidos com a máquina de medir por coordenadas, observa-se, em geral, que os valores dos desvios de planicidade e perpendicularismo obtidos com a medição por coordenadas são intermediários em relação 
aos valores fornecidos pelo sistema convencional e pelo Sistema Automatizado. Os resultados observados em dois casos escapam a esta tendência geral. Nestes casos, os desvios resultantes da medição com a máquina de medir foram maiores do que aqueles obtidos com os outros dois sistemas. Os gráficos de barras dos resultados fornecidos pelos três sistemas, são apresentados a seguir.
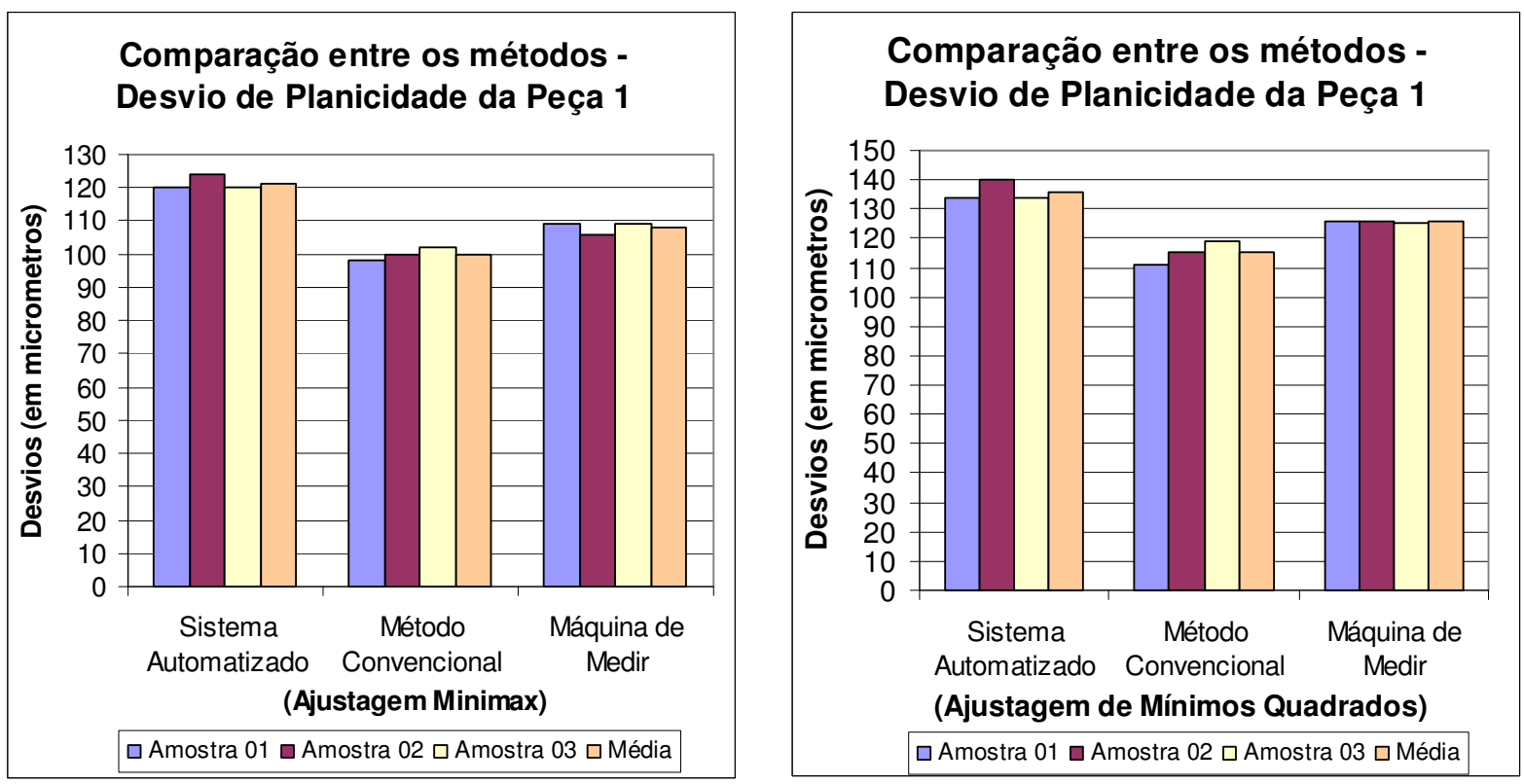

Figura 6.23 - Desvios de planicidade da Peça 1 - Comparação entre métodos.
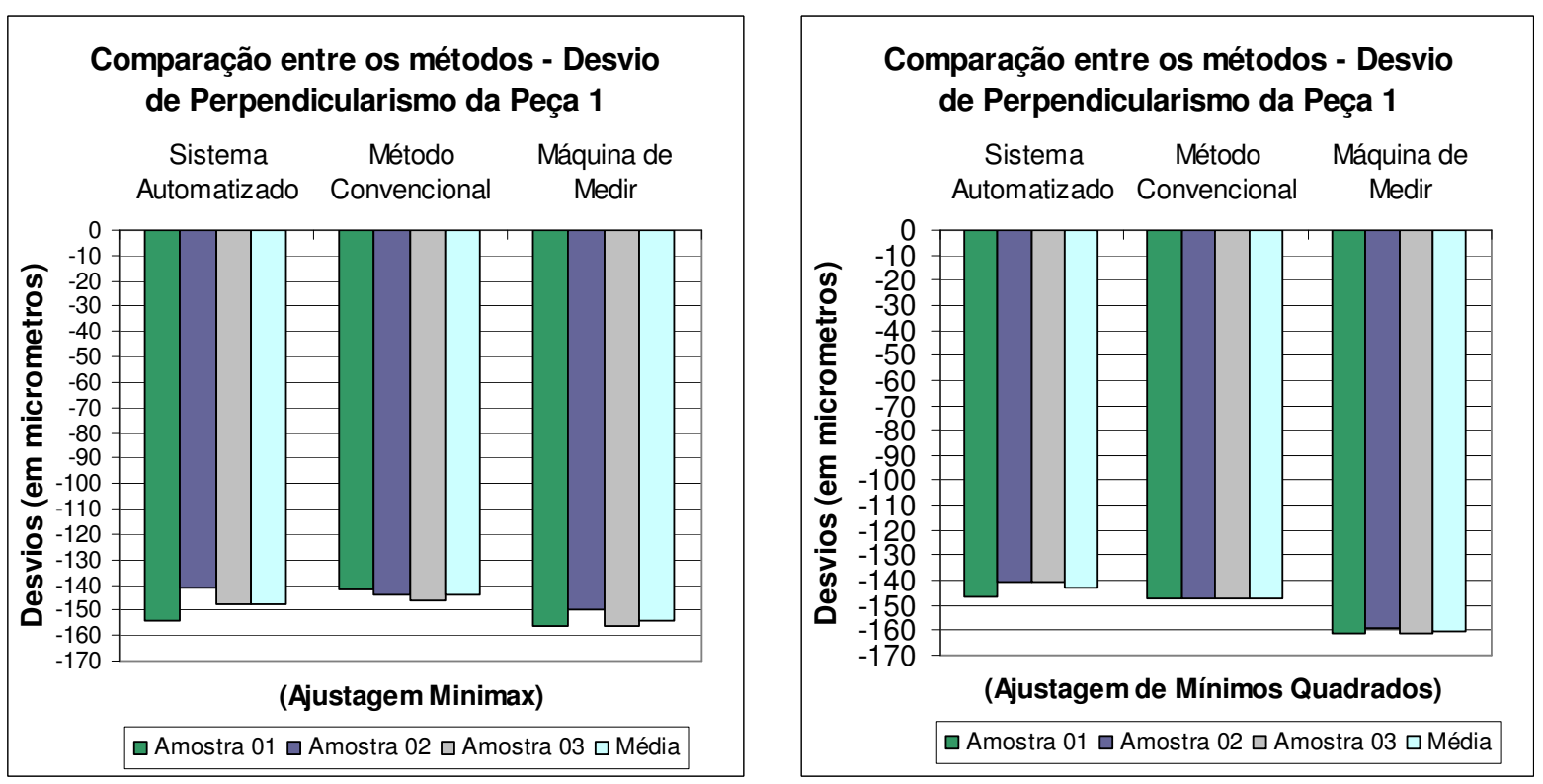

Figura 6.24 - Desvios de perpendicularismo da Peça 1 - Comparação entre métodos. 

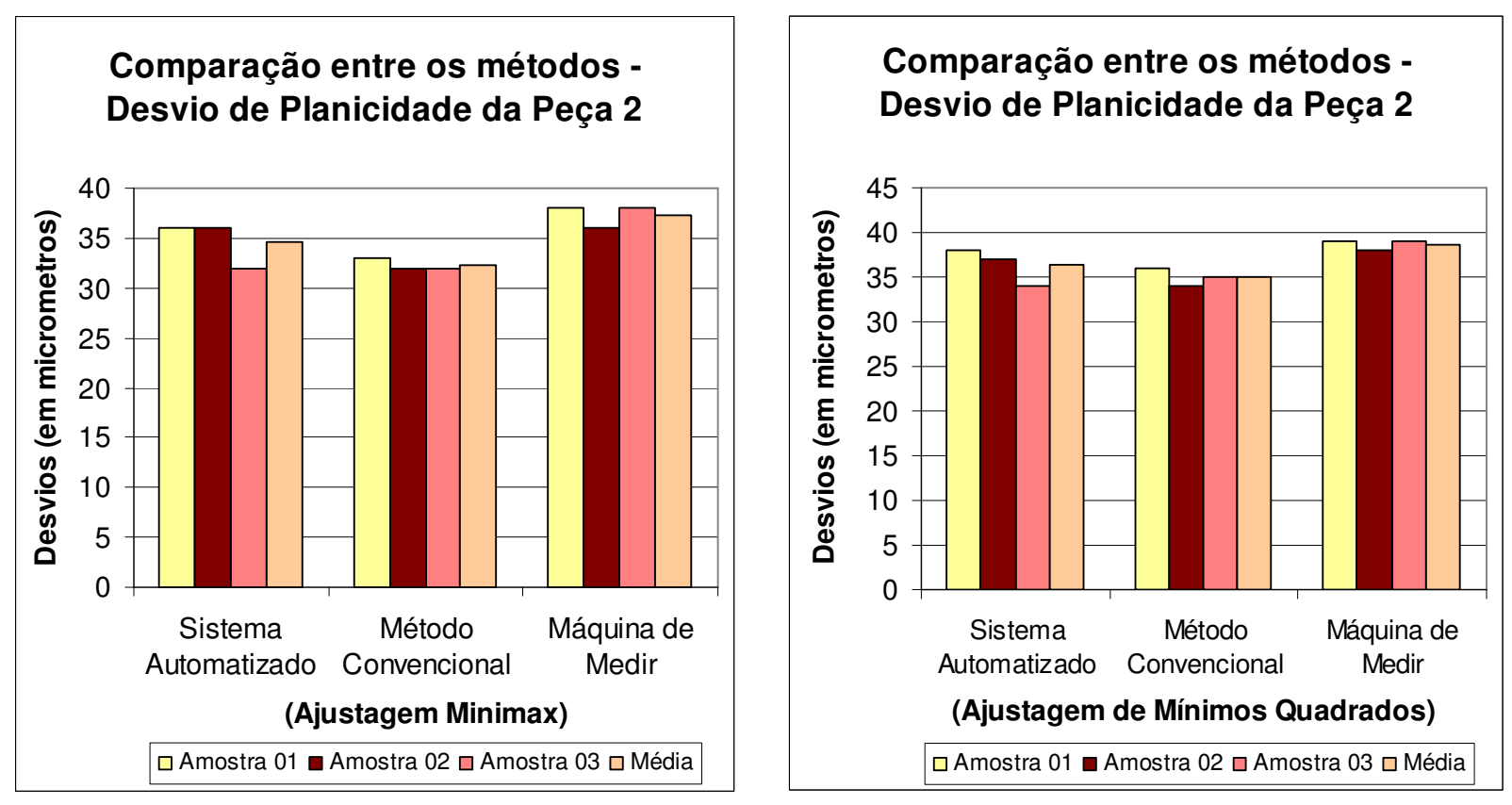

Figura 6.25 - Desvios de planicidade da Peça 2 - Comparação entre métodos.
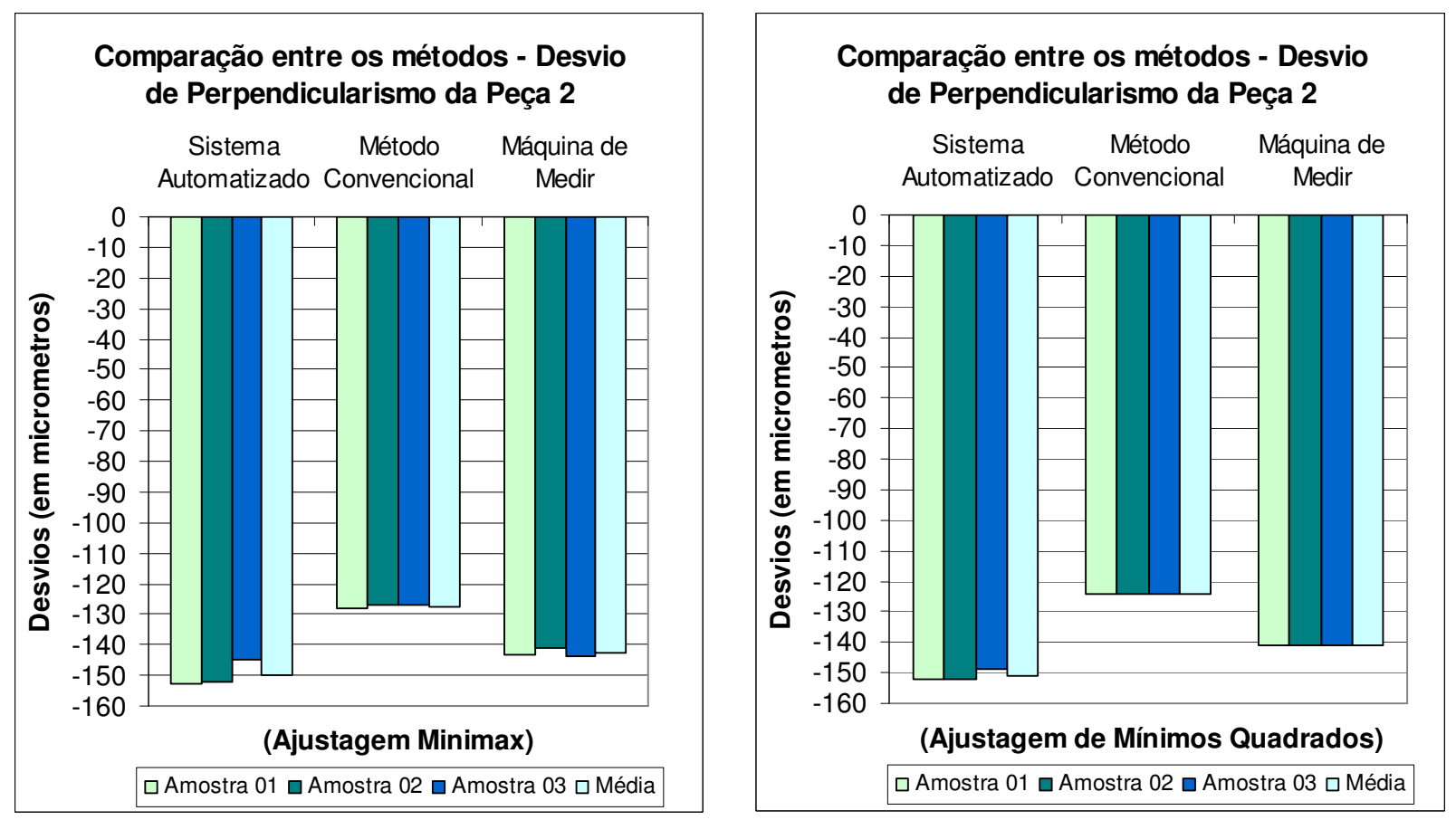

Figura 6.26 - Desvios de perpendicularismo da Peça 2 - Comparação entre métodos. 

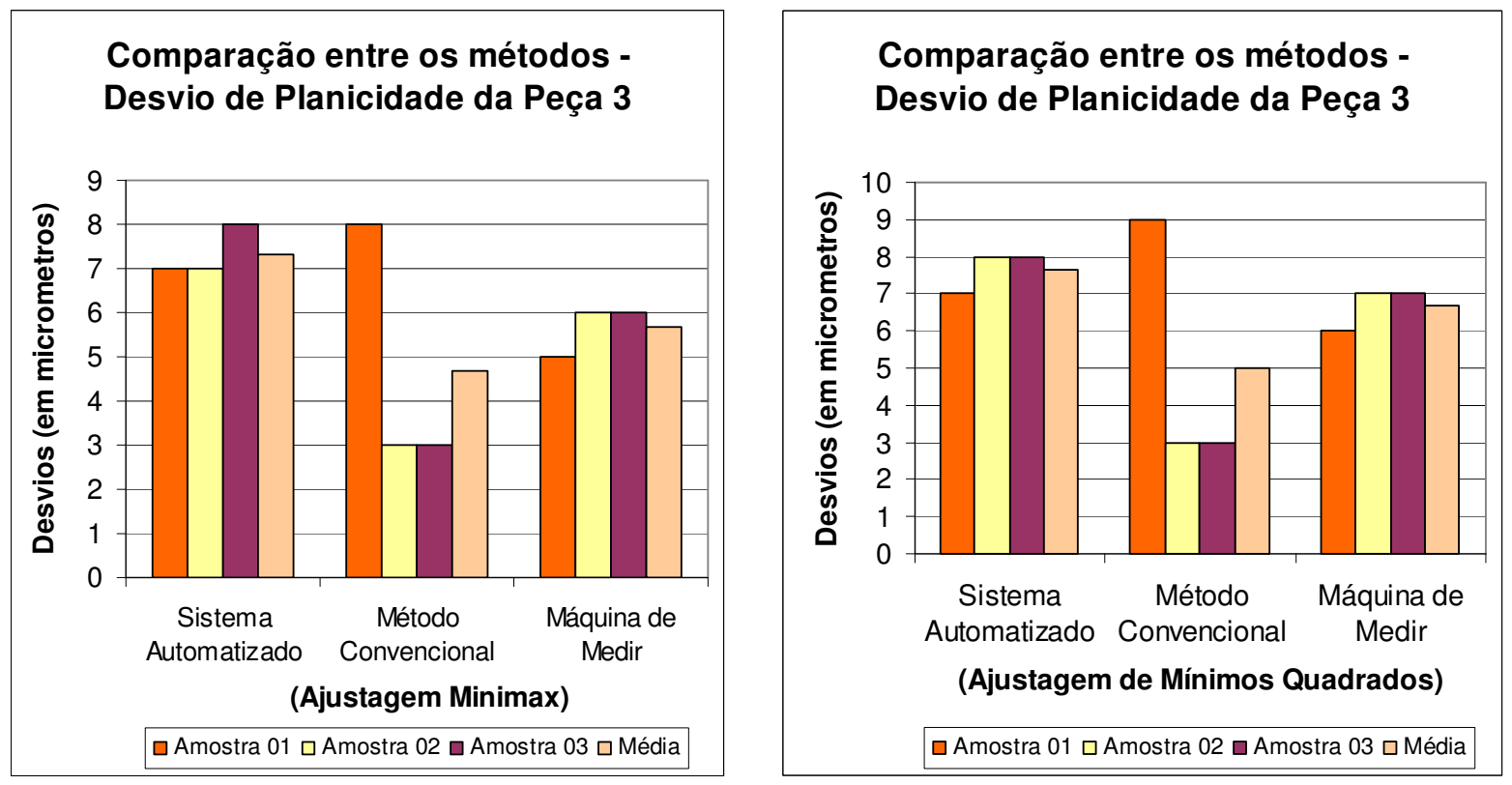

Figura 6.27 - Desvios de planicidade da Peça 3 - Comparação entre métodos.
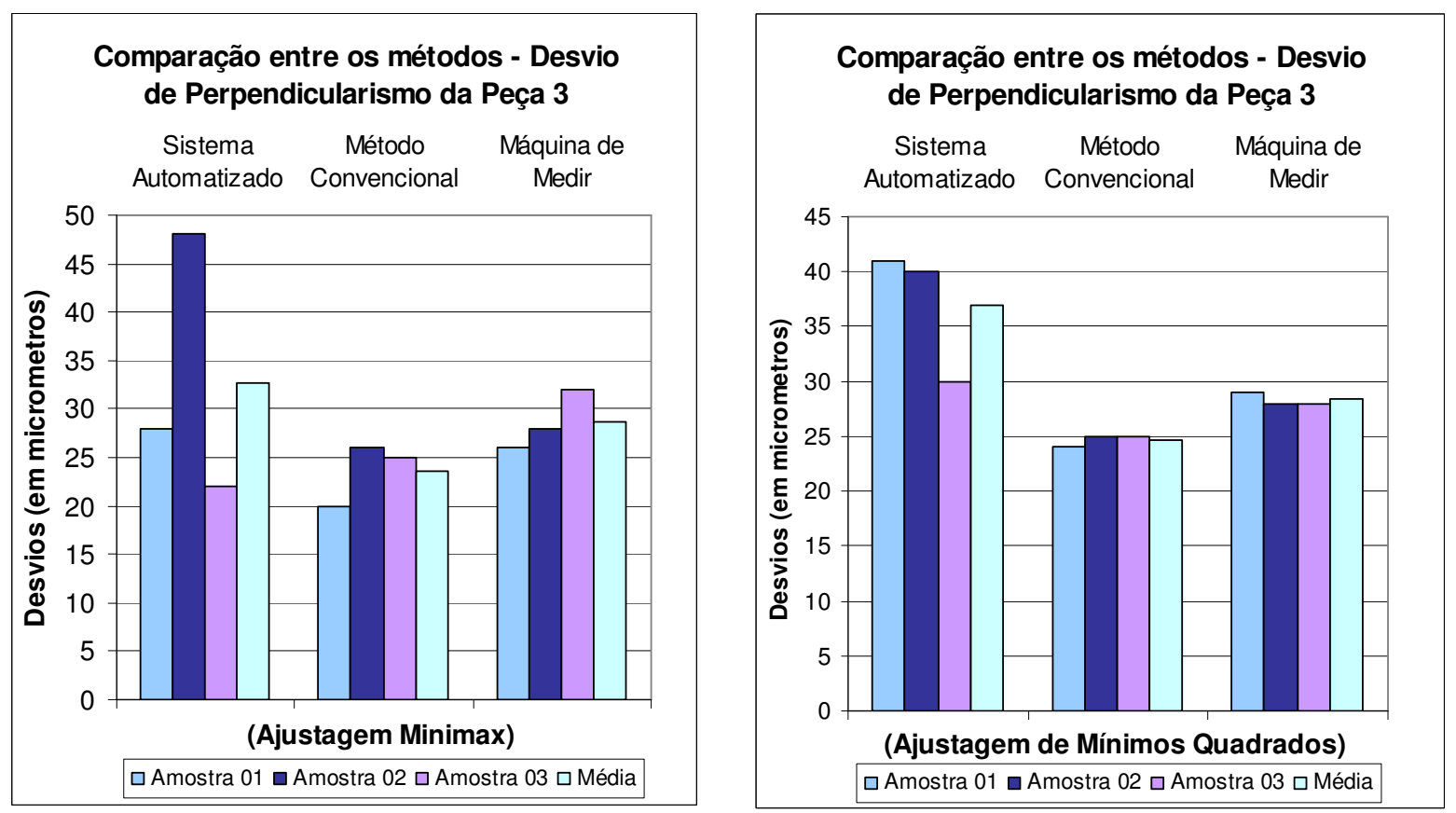

Figura 6.28 - Desvios de perpendicularismo da Peça 3 - Comparação entre métodos.

Nos gráficos apresentados, nota-se que a diferença entre os valores de desvio fornecidos pelo Sistema Automatizado e os valores obtidos com a máquina de medir é menor do que a diferença entre os desvios obtidos com o Sistema Automatizado e os desvios resultantes da medição convencional. Em outras palavras, os valores fornecidos pela máquina de 
medir são mais próximos dos valores obtidos com o sistema proposto do que os valores convencionais. Além disso, tanto o sistema proposto quanto a máquina de medir forneceram desvios sempre maiores em valor absoluto do que os valores absolutos dos desvios obtidos com o sistema convencional.

Esta proximidade entre os resultados obtidos com o Sistema Automatizado e os resultados da medição por coordenadas indica, mais uma vez, que o sistema proposto apresentou resultados coerentes. Assim como ocorreu para o Sistema Automatizado, não houve uma diferença grande entre os valores do desvio de perpendicularismo da Peça 1 e da Peça 2 avaliados com a máquina de medir. No caso da Peça 2, os desvios fornecidos pelos dois sistemas, o automatizado e a máquina de medir, são próximos entre si e maiores do que os obtidos a partir da medição convencional. Isto pode indicar que o valor do desvio de perpendicularismo da Peça 2 fornecido pelo sistema convencional é subestimado.

Analisando-se os resultados de forma geral, é importante salientar, primeiramente, a viabilidade da utilização do Sistema Automatizado em um número considerável de casos, ou seja, nos casos em que não se requer uma acuracidade melhor do que dois centésimos de milímetro nas medições dos desvios de forma e orientação. Em outras palavras o sistema de medição proposto é adequado para ser utilizado em muitas aplicações ordinárias na área de mecânica. Esta estimativa da acuracidade do sistema foi feita com base na observação de que, em praticamente todos os casos, as diferenças entre os resultados obtidos com o Sistema Automatizado e o Método convencional não excederam 20 micrometros.

A repetibilidade do sistema proposto também é um dos aspectos que merece destaque. Os resultados obtidos indicam que o Sistema Automatizado apresenta boa repetibilidade na coleta e processamento de diferentes amostras de dados de uma mesma peça, tanto na avaliação do desvio de planicidade quanto na avaliação do desvio de perpendicularismo. Para que a avaliação apresentada pelo sistema tenha 
consistência, não é necessário que todos os resultados intermediários do processamento sejam próximos, mas sim que os resultados finais sejam repetitivos. Assim, por exemplo, no caso da avaliação de perpendicularismo, as inclinações absolutas do artefato de referência e da superfície da peça não precisam ser as mesmas para todas as amostras coletadas. Entretanto, para que o sistema seja viável, é necessário que as combinações finais entre a inclinação da peça e da referência obtidas a partir de cada amostra sejam repetitivas. O sistema atende não só a esta condição, mas também apresenta repetibilidade na avaliação absoluta das inclinações, isto é, na avaliação das inclinações individuais do artefato de referência e da superfície da peça. Isto é uma vantagem adicional, pois elimina a necessidade de se realizar, a cada medição da peça, uma medição subseqüente do artefato de referência. Na verdade, esta qualidade abre espaço para que, na inspeção de lotes, o plano de referência seja medido apenas uma vez para um determinado número de peças medidas, o que contribui positivamente para um aumento de eficiência do sistema.

No caso do desvio de perpendicularismo, considerando-se a faixa de diferenças médias apresentada, pode-se considerar que o sistema apresentou um comportamento repetitivo não só na avaliação diferentes amostras de uma mesma superfície, mas também na avaliação de diferentes peças ou superfícies. Na avaliação da planicidade, foram observadas diferenças médias tão pequenas quanto 1, 2 ou 3 micrometros para duas das peças medidas, ou seja, o sistema apresentou um ótimo desempenho em termos de acuracidade. Por outro lado, a diferença média obtido para a Peça 1, de cerca de 20 micrometros, indica certa instabilidade na avaliação do desvio de planicidade. Curiosamente, o sistema apresentou piores resultados para esta peça, que possui pior qualidade superficial, do que para as peças que possuem menores desvios de planicidade. Este fato contrariou os resultados esperados. Seria mais natural que o sistema proposto apresentasse um desempenho um pouco inferior na avaliação das peças com qualidade superficial muito boa, da 
ordem de unidades de micrometros, já que, como qualquer outro sistema de medição, ele possui um limite de acuracidade e os desvios apresentados por estas peças poderiam ser inferiores a este limite. Porém, conforme apresentado nas discussões específicas dos resultados de planicidade obtidos para a Peça 1 , no início deste item, o método convencional apresenta deficiências que podem ter ocasionado a diferença média citada.

A adoção do sistema convencional como referência, não o torna absoluto, uma vez que, neste caso, o procedimento de avaliação não se traduz na comparação de um determinado instrumento com um instrumento de referência ou com um padrão pertencentes a uma classe superior de acuracidade. O método convencional executado não está inserido em uma cadeia de rastreabilidade de forma a servir de referência absoluta para a comparação. A continuidade das investigações acerca do comportamento do modelo de separação de erros e do método convencional pode auxiliar a esclarecer melhor esta questão. Deve-se ressaltar novamente que este resultado observado para a Peça 1 não inviabiliza a utilização do Sistema Automatizado em um número considerável de casos, dependendo da acuracidade requerida.

Outro aspecto positivo a ser observado é o fato de que a avaliação do desvio de perpendicularismo se mostrou pouco sensível diante da utilização de diferentes amostras de medição da superfície de referência. A combinação de diferentes amostras da peça medida e da superfície de referência resulta em valores próximos, demonstrando que o sistema está sendo repetitivo tanto na avaliação da inclinação da superfície da peça quanto na avaliação da inclinação da superfície de referência. Esta repetibilidade também pode ser constatada mediante a observação dos valores reduzidos de desvio padrão dos coeficientes de inclinação, $a_{1}$ e $a_{2}$ da superfície das peças e da superfície de referência. É possível supor que esta estabilidade do sistema é conferida, pelo menos em parte, pela eficácia do modelo de separação de erros. Como já discutido, a repetitividade do sistema na avaliação da inclinação do artefato de 
referência permite reduzir a freqüência de medição deste artefato quando um lote de peças é inspecionado, tornando o sistema mais eficiente.

A análise dos resultados para o desvio de perpendicularismo de todas as peças fornece indícios de que o sistema possa apresentar um limite de acuracidade para avaliação deste desvio em torno de 20 micrometros. É possível que esse limite seja intrínseco ao modelo de separação adotado, isto é, seja independente do número de pontos medidos sobre as peças. Assumindo-se que os resultados da medição convencional de perpendicularismo obtidos para a Peça 2 sejam referência também para as medições da Peça 1, a qual é uma outra face de uma mesma peça, e considerando-se a ajustagem de Mínimos Quadrados, então é possível observar que os valores de desvio de perpendicularismo de todas as peças fornecidos pelo Sistema Automatizado apresentaram diferenças médias positivas na faixa de 12 a 28 micrometros em relação ao método convencional. Em outras palavras, a partir dessas diferenças pode-se supor a existência de um erro sistemático, isto é, um erro médio na avaliação do perpendicularismo fornecida pelo Sistema Automatizado. Neste caso, o desempenho do modelo de separação de erros poderia ser melhorado incluindo-se uma constante no equacionamento ou alguma outra variável que represente esta parcela de erro.

Contudo, deve-se lembrar que o Sistema Automatizado apresentou resultados muito mais uniformes para a avaliação do perpendicularismo da Peça 1 e Peça 2 do que o sistema convencional. Uma hipótese importante para explicar as diferenças observadas entre os resultados de perpendicularismo da Peça 2 é que tenha ocorrido um erro de posicionamento do bloco prismático sobre a base magnética quando este foi rotacionado. Pequenas diferenças neste posicionamento podem causar diferenças significativas nas inclinações medidas e, conseqüentemente, no desvio de perpendicularismo das peças. Assim, o erro na avaliação do perpendicularismo das peças pode estar associado às condições experimentais, e cogita-se que melhores resultados possam ser obtidos, 
especialmente na medição da Peça 2, caso se execute um controle mais rigoroso de alguns procedimentos experimentais.

A análise dos valores obtidos para o desvio de perpendicularismo das três peças também demonstra que o Método dos Mínimos Quadrados é bem menos sensível às variações dos dados obtidos em diferentes medições de cada peça, ou seja, variações nos dados de entrada para a avaliação da inclinação das superfícies. Além disso, este método também é insensível às variações dos perfis obtidos a partir de uma mesma amostra de medição de uma dada peça. Isto provavelmente se deve aos diferentes princípios de ajustagem que regem cada um dos métodos utilizados. No método Minimax, a forma geométrica de referência, no caso o plano, é ajustada aos pontos do perfil com base na minimização da distância dos pontos mais afastados em relação a esta forma de referência. Nesse caso, há um conjunto reduzido de pontos do perfil nos quais a ajustagem é baseada. Assim, provavelmente, as diferenças nos perfis obtidos levam a que, para cada perfil, um conjunto de pontos significativamente distinto dos demais defina a ajustagem do plano. Isto resulta em planos com diferentes inclinações para cada perfil avaliado, mesmo que os perfis sejam de uma mesma amostra de medição de uma mesma peça. No método dos Mínimos Quadrados, por outro lado, os quadrados dos desvios individuais de todos os pontos são considerados para se obter a ajustagem. Assim, as variações nas distâncias dos pontos mais afastados da forma de referência são um pouco menos significativas para a ajustagem pois seu efeito dilui-se devido à consideração dos outros desvios intermediários, os quais não sofreram muitas alterações em seu valor. Tal fato provavelmente garante planos com inclinação mais constante para os diferentes perfis e para diferentes amostras, ainda que estes planos estejam posicionados em diferentes alturas em relação ao sistema de coordenadas.

A estabilidade dos resultados avaliados utilizando-se o Método dos Mínimos Quadrados confere uma importante vantagem ao sistema proposto, a qual consiste na possibilidade de se diminuir o tempo e 
volume de processamento de dados, pois, neste caso, é necessário avaliar apenas 1 perfil de superfície, ou seja, não é necessário calcular um desvio médio.

Conforme explicitado anteriormente, o desvio de perpendicularismo das peças é avaliado indiretamente, por meio da avaliação do desvio de paralelismo. Este, por sua vez, é avaliado por meio do cálculo da diferença de inclinação entre o plano ajustado ao perfil da peça e o plano ajustado ao perfil da superfície de referência. Ao calcular-se essa diferença, admitese a premissa de que os valores dos pontos coletados em ambas as superfícies são referentes a um mesmo sistema de coordenadas. Em outras palavras, assume-se a existência de um sistema de referência comum tanto aos pontos do perfil da peça quanto aos pontos do perfil da superfície de referência. Não se deve afirmar a priori que esta premissa seja verdadeira, já que, no sistema proposto, não há dispositivos que fisicamente levem ao estabelecimento desse sistema de referência. Os erros de posicionamento do manipulador ao executar a medição da peça e da superfície de referência provavelmente não são repetitivos, considerando-se que o robô, em cada caso, move-se em regiões distintas do seu volume de trabalho. $O$ algoritmo de separação de erros é aplicado exatamente para eliminar ou minimizar essa influência do manipulador. A aplicação deste algoritmo, a princípio, não garante diretamente que os perfis resultantes sejam referentes a um mesmo sistema de coordenadas. Entretanto, deve-se destacar que o cálculo do desvio de perpendicularismo da forma proposta forneceu bons resultados. Em outras palavras, a análise comparativa de resultados demonstrou que, para as amostras consideradas, a diferença de inclinação entre os planos ajustados à superfície da peça e o artefato de referência forneceu uma boa aproximação para o desvio de perpendicularismo que se desejava medir. Estes resultados, de certa forma, validam o método de cálculo proposto. 
$\mathrm{Na}$ avaliação do desempenho do Sistema Automatizado deve-se considerar, além da acuracidade e repetibilidade, a eficiência e rapidez na realização das medições e no processamento dos dados.

O sistema de aquisição e processamento de dados desenvolvido inclui várias rotinas e etapas distintas. Para implementar o programa de aquisição, as rotinas de pré-processamento para obtenção de perfis de superfície e as rotinas de aplicação dos algoritmos para separação de erros e avaliação dos desvios, foi necessário utilizar linguagens e ambientes diferentes. Cada uma destas rotinas é executada separadamente, mediante comandos de inicialização fornecidos pelo usuário a cada etapa do processamento. A rotina de separação de erros é executada para cada geratriz medida sobre a superfície, separadamente. A rotina de avaliação do desvio é aplicada para cada perfil de superfície gerado. Mesmo considerando-se todo este processamento, a capacidade computacional disponível atualmente confere eficiência ao sistema, uma vez que as rotinas são executadas com muita rapidez. Tal eficiência pode ainda ser aumentada com a otimização desse procedimento de aquisição e tratamento dos dados, buscando torná-lo mais contínuo. Isto pode ser conseguido com a utilização diferentes linguagens e aplicativos e com a implementação de otimizações nas rotinas para que funcionem de forma mais integrada. A melhoria destes aspectos operacionais é relativamente fácil de ser implementada.

Com relação aos perfis de superfície, pode-se optar pela geração de um só perfil se a avaliação do desvio for feita utilizando-se Método dos Mínimos Quadrados, uma vez que este método apresenta um resultado estável para diferentes perfis de uma mesma amostra de medição. Isto minimizaria o tempo de processamento, conforme já discutido.

Os tempos de medição apresentados pelo Sistema Automatizado são menores do que os tempos requeridos para a medição convencional das peças, conforme exposto no item 6.3. Os tempos de execução das medições com o Sistema Automatizado e com a máquina de medir manual 
foram muito próximos. No caso da máquina de medir, os tempos totais de medição variaram significativamente conforme a habilidade do operador.

O método de solução do modelo de separação de erros requer a execução de múltiplas corridas ou séries de medições para gerar equações adicionais que viabilizem a solução direta do sistema linear. Isto diminui um pouco a eficiência do sistema, já que este requisito leva a um aumento no tempo de medição. Mesmo assim, o desempenho do Sistema Automatizado em relação ao tempo total de medição foi compatível ao desempenho dos demais sistemas ou até melhor, conforme dito anteriormente. O tempo de medição por ponto utilizando-se o Sistema Automatizado é quase vinte vezes menor do que o tempo de medição por ponto obtido com o sistema convencional. Para a máquina de medir manual foram observadas taxas intermediárias. Em outras palavras, a eficiência absoluta do Sistema Automatizado é bem superior à eficiência dos demais. Além disso, ao mesmo tempo em que o sistema proposto é dedicado, há flexibilidade, pois as rotinas de movimentação do manipulador podem ser facilmente alteradas para se executar a medição de componentes com tamanhos e geometria variados. O programa de aquisição, nesse caso, não precisa ser alterado. Outra vantagem é que o Sistema Automatizado requer pouca assistência do operador durante o processo de aquisição de dados. A interferência deste é necessária apenas para carregar os programas de aquisição, ao início da inspeção de um lote e para trocar as peças a serem medidas a cada vez. Assim, o Sistema Automatizado pode operar por um longo período de tempo. Além disso, praticamente não há influência do operador nas leituras realizadas. Os valores fornecidos por sistemas manuais, como máquinas de medir controladas manualmente e principalmente o sistema convencional, estão mais vulneráveis a flutuações devido à influência do operador.

Resumindo-se as discussões apresentadas, observa-se que o sistema proposto apresentou um nível de acuracidade de medição maior do que a acuracidade de posicionamento do manipulador. Este nível pode ser compatível ao requerido por algumas medições ordinárias de desvios 
geométricos de componentes. O Sistema Automatizado, quando comparado com os sistemas convencionais, também apresenta algumas vantagens com relação à eficiência, flexibilidade e influência do operador nas medições. 
198 


\section{Capítulo 7}

\section{Conclusões e sugestões para trabalhos futuros}

Neste trabalho apresentou-se um Sistema Automatizado para a medição de desvios geométricos de forma e orientação de componentes mecânicos. No sistema proposto, foram utilizados um robô industrial e sensores de deslocamento. Para que a acuracidade necessária à realização das medições fosse obtida, aplicou-se um modelo de separação de erros baseado no princípio de redundância de dados, conseguida, por sua vez, por meio da utilização de múltiplos sensores.

O desenvolvimento deste tipo de sistema na área da Metrologia é consideravelmente recente. Sistemas similares desenvolvidos foram aplicados principalmente à medição de desvios de retilineidade, e em alguns casos, circularidade. Neste trabalho, ampliou-se o escopo de aplicações deste tipo de sistema, de forma a abranger não só a avaliação dos desvios de retilneidade, mas também a avaliação dos desvios de planicidade e perpendicularismo, sendo este último calculado indiretamente, por meio da medição do desvio de paralelismo. Nesse sentido, o trabalho apresentado caracteriza-se como uma pesquisa exploratória. Além disso, o enfoque desta pesquisa foi dirigido à avaliação do desempenho do sistema, por meio da realização de testes experimentais com três peças distintas e por meio de análise comparativa com sistemas convencionais tradicionalmente adotados para a medição de desvios geométricos. Das avaliações realizadas, as seguintes conclusões podem ser enumeradas:

- O Sistema Automatizado apresentou boa repetibilidade, isto é, as variações observadas nos valores dos desvios de planicidade ou perpendicularismo obtidos a partir de diferentes amostras de 
uma mesma peça foram pequenas. Comparando-se resultados obtidos a partir do mesmo método de ajustagem, observou-se que cerca de dois terços das variações máximas entre amostras são menores ou iguais a $10 \mu \mathrm{m}$. Este resultado é válido tanto para a medição do desvio de planicidade quanto para a medição do desvio de perpendicularismo.

- Em praticamente todos os casos, as diferenças entre os resultados obtidos com o Sistema Automatizado e com o Método Convencional não excederam 20 micrometros. As diferenças observadas ao se comparar os valores fornecidos pelo sistema proposto com os valores obtidos utilizando-se a máquina de medir por coordenadas são ainda menores. Isto indica que o Sistema Automatizado apresentou resultados bastante coerentes, e pode ser utilizado em um número considerável de casos de medição de desvios geométricos, ou seja, nos casos em que não se requer uma acuracidade melhor do que 20 micrometros.

- Considerando todas as medições dos desvios de planicidade e perpendicularismo das peças, tem-se que as diferenças médias observadas entre os resultados obtidos com o Sistema Automatizado e os resultados fornecidos pelo método convencional foram de 11 micrometros, sendo que, para planicidade, estas diferenças foram de 9 micrometros e para perpendicularismo, 13 micrometros. As amplitudes médias dos intervalos de resultados obtidos com o Sistema Automatizado a partir das diferentes amostras foram de 3 micrometros para planicidade e 7 micrometros para perpendicularismo.

- O Sistema Automatizado apresentou comportamento uniforme ao avaliar o desvio de perpendicularismo de peças distintas. Há a possibilidade da existência de um erro sistemático para todas as peças, na avaliação deste desvio. Se este fato for confirmado, deve-se estimar valores de correção a serem aplicados nos resultados obtidos. É possível que este erro sistemático provenha 
de alguma possível deficiência do modelo de separação de erros. Nesse caso, faz-se necessário investigar a existência de uma nova parcela de erro de alguma fonte ainda não considerada. A acuracidade do sistema pode ser melhorada com a inclusão desta nova variável no modelo de separação de erros. Por outro lado, deve-se considerar a hipótese alternativa de que houve um erro de posicionamento do bloco prismático sobre a base magnética quando este foi rotacionado durante as medições. Este erro afetaria as medições das peças 1 e 2, podendo ter sido responsável pelas diferenças observadas na avaliação da Peça 2, por exemplo. Se esta hipótese for comprovada, pode-se dizer que alguns erros de avaliação do perpendicularismo estariam associados ao procedimento experimental.

- Tanto no caso da medição do perpendicularismo das Peças 1 e 2 quanto na medição da planicidade da Peça 1 com o método convencional, é possível supor que resultados mais consistentes sejam obtidos com um controle mais rigoroso dos procedimentos experimentais, como, por exemplo, o controle da localização do sensor sobre a peça, na medição convencional, e o controle mais estrito do posicionamento do bloco prismático sobre a base magnética.

- Com relação à avaliação do desvio de planicidade, o sistema apresentou um desempenho um pouco instável quando diferentes peças foram avaliadas. A repetibilidade dos resultados obtidos a partir de diferentes amostras de uma mesma peça é boa, mas o sistema apresentou um comportamento não muito uniforme ao avaliar o desvio de planicidade das diferentes peças. Para duas dessas peças, não foram observadas diferenças acentuadas entre os resultados obtidos com Sistema Automatizado e o com sistema convencional. Para uma delas, a que possui pior qualidade superficial, observou-se uma diferença sistemática significativa. 
- O Método dos Mínimos Quadrados forneceu resultados mais estáveis para a avaliação do erro de perpendicularismo do que a ajustagem Minimax. Houve muito pouca variação entre os valores de desvio obtidos a partir de diferentes amostras de medição de uma mesma peça quando o método dos Mínimos Quadrados foi utilizado. Quando o mesmo cálculo é feito aplicando-se o Método Minimax, a variação observada nos resultados é bem mais significativa. Além disso, a ajustagem por MMQ é insensível às variações existentes entre os diferentes perfis gerados a partir de uma mesma amostra de uma dada peça. Se esta ajustagem for utilizada, pode-se medir uma única transversal em cada peça e gerar apenas um perfil de superfície, pois se espera que o valor do desvio de perpendicularismo obtido a partir desse perfil seja equivalente ao desvio médio, calculado considerando-se todos os perfis gerados a partir de uma mesma amostra. Este resultado foi observado em todos os testes experimentais. Adotando-se a estratégia citada, obtém-se uma vantagem considerável no que concerne à redução dos tempos de medição e processamento de dados sem que a avaliação dos desvios seja prejudicada em termos de acuracidade.

- O desempenho do sistema, com relação ao tempo de medição, é melhor do que o desempenho dos sistemas convencionais. 0 tempo total necessário para a medição do desvio de perpendicularismo da Peça 1 ou da Peça 2 utilizando-se o Sistema Automatizado é de 32 minutos. Quando o método convencional é utilizado, este tempo é de aproximadamente 40 minutos. Em outras palavras, o tempo de medição associado ao sistema convencional é mais de $20 \%$ maior do que o tempo conseguido com o Sistema Automatizado. As áreas de medição da Peça 1 e da Peça 2 são de $300 \mathrm{~mm} \times 150 \mathrm{~mm}$. Na avaliação da planicidade destas peças, a relação entre os tempos de medição é de 18 minutos e 39 minutos, respectivamente. Assim, neste caso, 
observa-se que a medição com o Sistema Automatizado é cerca de duas vezes mais rápida do que a medição convencional. Esta diferença é mais acentuada porque no caso da avaliação do desvio de planicidade com o Sistema Automatizado não é necessário realizar a medição do plano de referência. Os tempos de medição obtidos com o sistema proposto são praticamente equivalentes aos conseguidos com a medição por coordenadas, quando esta é executada por um operador pouco experiente ou mediano. Se um operador bastante experiente e habilidoso executa a medição, é possível obter tempos um pouco melhores do que os apresentados para o sistema proposto. Entretanto, a vantagem do Sistema Automatizado é que seu desempenho é uniforme, ou seja, não depende da habilidade ou cansaço físico do operador. Além disso, é importante destacar que, em termos de rapidez absoluta, o desempenho do método automatizado é bastante superior ao desempenho dos demais sistemas. Neste sistema, 1 ponto é coletado em aproximadamente 1,3 segundos, enquanto esta taxa é de 1 ponto em 4 segundos ou 8 segundos, para diferentes operadores utilizando a máquina de medir. No caso do sistema convencional, a eficiência é ainda menor: a taxa de coleta é de aproximadamente 1 ponto a cada 19 segundos. Isto demonstra que há um alto potencial de melhoria dos tempos finais de medição utilizando-se o Sistema Autmatizado, bastando apenas que, para tanto, alguns requisitos do procedimento de medição, como a necessidade das repetições da medição, por exemplo, sejam alterados.

- A flexibilidade é uma outra vantagem do sistema proposto, uma vez que as rotinas de movimentação do manipulador podem ser modificadas com certa facilidade para executar a medição de componentes com geometrias variadas.

- Os valores do desvio de perpendicularismo sofreram pouca variação quando diferentes amostras de medição do plano de 
referência foram utilizadas nos cálculos. Isto decorre do fato de o Sistema Automatizado apresentar boa repetibilidade na avaliação da inclinação do plano de referência. No caso da avaliação de perpendicularismo, as inclinações absolutas do artefato de referência e da superfície da peça não precisam ser repetitivas para todas as amostras coletadas. Entretanto, para que o sistema seja viável, é necessário que as combinações finais entre a inclinação da peça e da referência obtidas a partir de cada amostra sejam repetitivas. O sistema atende não só a esta condição, mas também apresenta repetibilidade na avaliação absoluta das inclinações, isto é, na avaliação das inclinações individuais do artefato de referência e da superfície da peça. Isto é uma vantagem adicional, pois elimina a necessidade de se realizar, a cada medição da peça, uma medição subseqüente do artefato de referência.

- A estratégia de avaliação do perpendicularismo por meio da diferença entre as inclinações do plano ajustado ao perfil da peça e do plano ajustado ao perfil do artefato de referência gerou bons resultados para as três peças medidas.

- O erro aleatório de avaliação do desvio de perpendicularismo é maior para a peça com menor área de medição. Isto ocorre porque o modelo de separação de erros provavelmente apresenta um limite de acuracidade em função do número de pontos coletados. Uma menor quantidade de pontos coletados significa que há poucas medições redundantes. Assim, supõe-se que a instabilidade apresentada pelo sistema ao realizar a avaliação do perpendicularismo da peça menor seja, neste caso, devido à disponibilidade de poucos dados redundantes. Isto, por sua vez, faz com que o desempenho do modelo de separação de erros se torne mais instável, especialmente ao realizar o desacoplamento das parcelas de erro das retas transversais medidas sobre a peça menor. Este era um resultado esperado. Em casos como este, em 
que as peças possuem menores dimensões, micro-passos de medição podem ser utilizados. Em outras palavras, aplicando-se o Método dos Três Pontos Generalizado com passo de medição menor do que a distância entre os sensores, aumenta-se o número de pontos medidos e, conseqüentemente, a quantidade de dados redundantes coletados.

Durante o desenvolvimento deste trabalho, surgiram pontos que instigam uma investigação mais profunda. Diante disso, buscou-se levantar as questões que ainda precisam ser dirimidas e algumas melhorias que podem ser implementadas. Para trabalhos futuros, sugerese:

- Realizar ajustes no modelo de separação, buscando aumentar a acuracidade do sistema e tornar seu comportamento mais estável especialmente na avaliação do desvio de planicidade.

- Buscar identificar fontes de erro não consideradas no modelo que podem ser relevantes. Investigar a necessidade de se incluir uma variável adicional no modelo de separação de erros representando a contribuição das fontes de erros identificadas.

- Estudar e aplicar métodos alternativos de solução numérica do modelo, buscando-se eliminar a necessidade de se realizar múltiplas corridas de aquisição de dados.

- Realizar a integração entre o programa de aquisição de dados, os procedimentos de pré-processamento e as rotinas de avaliação dos desvios geométricos, de forma que, se possível, todo o processo possa ser realizado de maneira contínua, em uma só etapa, sem interrupções.

- Calcular a incerteza das medições feitas com o sistema proposto. Para tanto, é necessário não só considerar a acuracidade do Sistema Automatizado, mas também realizar um estudo aprofundado para identificar as grandezas de influência atuantes durante a medição e outras fontes de erro significativas, associadas com o ambiente, o procedimento de 
medição, os algoritmos utilizados no processamento dos dados, os materiais utilizados, entre outros. A partir daí, devese estimar os valores dos coeficientes de sensibilidade, que são fatores de ponderação da influência de cada uma destas fontes de erro na medição. Para a realização dos cálculos, as diretrizes que constam no Guia para a expressão da incerteza de medição, ISO GUM (1998), devem ser seguidas. 


\section{Referências Bibliográficas}

ABNT - NBR 6409 (1980). Tolerâncias de forma e tolerâncias de posição.

ASME - Y14.5M (1994). Dimensioning and Tolerancing.

ASME - Y14.5.1M (1994). Mathematical Definition of Dimensioning and Tolerancing Principles.

BSI PD 7304 (1982). Introduction to Geometrical Tolerancing.

BOILLOT, J.P.; UOTA, K. (2002). Flexible robotic measuring of weldments on production lines. Idustrial Robot: An International Journal, v. 29, n.1, p.43-48.

BONACORSO, N.G.; GONÇALVES JR., A.A.; DUTRA, J.C. (2006). Automation of the processes of surface measurement and of deposition by welding for the recovery of rotors of large-scale hydraulic turbines. Journal of Materials Processing Technology, n.179, p.231-238.

BURDEKIN, M.; PAHK, H.J. (1989). The application of a microcomputer to the online calibration of the flatness of engineering surfaces. Proceedings of the Institution of Mechanical Engineers Part B: Journal of Engineering Manufacture, v.203, p.127-137.

CARR, K; FERREIRA, P. (1995). Verification of form tolerances part I: basic issues, flatness and straightness. Precision Engineering, v.17, n.2, p.131-143.

CHAIN, E.E. (1996). Automated Metrology for increased throughput and reliability. 1996 IEEE/SEMI Advanced Semiconductor Manufacturing Conference, p.347-352.

CHETWYND, B.A. (1985). Applications of linear programming to engineering metrology. Proceedings of the Institution of Mechanical Engineers, v.199, n.B2, p.93-99.

DEA (2007). Applications - Part loading, unloading and palleting. Disponível em: <http://www.dea.it/comuni/applicazioni.php>. Acesso em 4 set.

DONALDSON, R.R. (1972). A simple method for separating spindle error from test ball roundness error. Annals of the CIRP, v.21, n.1, p. 125-126.

DI GIACOMO, B.; TSUNAKI, R.H.; PAZIANI, F.T. (2005). Robot-based dedicated measuring system with data redundancy for profile inspection. In: IEEE/RSJ IROS - International Conference on Intelligent Robots and Systems, Aug. 2-6, 2005, Edmonton, Alberta, Canada, pp. 1646-1649. 
EVANS, C.J.; HOCKEN, R.J.; ESTLER, W.T. (1996). Self-calibration: reversal, redundancy, error separation, and "absolute testing". Annals of the CIRP, v.45, n.2, p.617-634.

FORBES, A.B. (2006). Uncertainty evaluation associated with fitting geometric surfaces to coordinate data. Metrologia, v. 43, p.S282-S290.

GAO, W.; KIYONO, S. (1997). On-machine profile measurement of machined surface using the combined three-point method. JSME International Journal, Series C, v. 40, n.2, p.253-259.

GAO, W. et al. (2002a). Precision measurement of cylinder straightness using a scanning multi-probe system. Precision Engineering, v. 26, n.3, p.279-288.

GAO, W. et al. (2002b). A compact and sensitive two-dimensional angle probe for flatness measurement of large silicon wafers. Precision Engineering, v.26, n.4, p.396-404.

GOldstein, A.A.; LEVINE, N; HERESHOFF, J.B. (1957). On the "best" and "least Qth" approximation of an overdetermined system of linear equations. Journal of ACM, v.4, n.3 (July 1957), p.341-347.

GOLUB, G.H.; VAN LOAN, C.F. (1996). Matrix computations. 3. ed. Baltimore:The Johns Hopkins University Press.

GONÇALVES JR., A.A.; HREBABETZKY, F. (2001). Three-line rangefinder for shape, slope, and local curvature measurement from a robot arm. Proceedings of SPIE, v. 4398, p.134-144.

GREENWAY, B. (2000). Robot Accuracy. Industrial Robot: An International Journal, v.27, n.4, p.257-265.

HIGASA et al. (2004). Construction of the 3-dimensional maps for the collaps environment presentation in rubble by integration of a range sensor and a image sensor. Proceedings of JSME Conference on Robotics and Mechatronics ROBOMEC'04, 2P2-H-23 (2004-2006).

HOUAISS, A.; VILLAR, M.S. (2001). Dicionário Houaiss da Língua Portuguesa. Rio de Janeiro:Editora Objetiva.

HUANG, S.T.; FAN, K.C.; WU, W.H. (1993). A new minimum zone method for evaluating flatness erros. Precision Engineering, v.15, n.1, p.25-32.

INMETRO (2007). Vocabulário internacional de termos fundamentais e gerais de metrologia. 4. ed. revisada. Rio de Janeiro.

ISO GUM (1998). Guia para a expressão da incerteza de medição: Segunda Edição Brasileria do Guide to the Expression of Uncertinty in Measurement. Rio de Janeiro.

JIS B 0021 (1984). Indications of geometrical tolerances on drawings.

JIS B 0621 (1984). Definitions and designations of geometrical deviations. 
KELLEY JR., J.E. (1958). An Application of Linear Programming to Curve Fitting. Journal of the Society for Industrial and Applied Mathematics, v.6, n.1, p.15-22.

MAGALHÃES, R. C. (2006). Sistema para Medição de Erro de Planicidade. Tese de Mestrado, Escola de Engenharia de São Carlos: Universidade de São Paulo, São Carlos - SP, Brasil.

PAZIANI, F.T. (2005). Desenvolvimento de um sistema de medição automatizado e dedicado. Tese de Doutorado, Escola de Engenharia de São Carlos: Universidade de São Paulo, São Carlos - SP, Brasil.

PAZIANI, F. T.; DI GIACOMO, B.; TSUNAKI, R. H. (2007). Development of an automated and dedicated measuring system for straightness evaluation. Journal of the Brazilian Society of Mechanical Sciences and Engineering, v.27, n.3, p. 290-298.

PIRATELLI-FILHO, A.; DI GIACOMO, B.; SIQUEIRA, M. L. (2000). Determination of straightness errors in a welding robot. Proceedings the $16^{\text {th }}$ IMEKO Congress, p. 63-67.

PORTMAN, V.T. et al. (2003). Linear programming-based assessments of geometrical accuracy: standard presentation and application area. International Journal of Machine Tools \& Manufacture, v.43, n.10, p.1023-1033.

TANAKA, H. et al (1981). Application of a New Straightness Measurement Method to Large Machine Tool. Annals of the CIRP, v.30, n.1, p.455-459.

WHITEHOUSE, D.J. (1976). Some theoretical aspects of error separation techniques in surface metrology. Journal of Physics E: Scientific Instruments, v.9, n.7, p.531-536.

YAGI, T. (2002). Recent trends in the robotization of the Japanese automotive industry. Industrial Robot: An International Journal, v.29, n.6, p.495-499.

YOKOTA et al. (2007). 3D measurement sensor system for rough terrain mobile robots. Sensor Review, v.27, n.3, p.224-232. 


\section{APÊNDICE 1 - Resultados dos cálculos do desvio de} planicidade da peça 1 - Amostras adicionais

\section{Dados obtidos utilizando-se o sistema automatizado}

\section{Amostra 02}

Tabela A1.1 - Perfis das geratrizes da Peça 1, medidos com o Sistema Automatizado.

\begin{tabular}{|r|r|r|r|r|r|r|r|}
\hline \multicolumn{8}{|c|}{ Perfil das Geratrizes da Peça 1 $(\mathrm{em} \mu \mathrm{m})$ - Amostra 02 - Sistema } \\
\hline \multicolumn{1}{|c|}{ G1 } & \multicolumn{1}{|c|}{ G2 } & \multicolumn{1}{|c|}{ G3 } & \multicolumn{1}{|c|}{ G4 } & \multicolumn{1}{|c|}{ G5 } & \multicolumn{1}{c|}{ G6 } & \multicolumn{1}{c|}{ G7 } & \multicolumn{1}{c|}{ G8 } \\
\hline 0 & 0 & 0 & 0 & 0 & 0 & 0 & 0 \\
\hline 21 & 29 & 32 & 30 & 19 & 21 & 26 & 13 \\
\hline 40 & 59 & 61 & 55 & 42 & 38 & 47 & 21 \\
\hline 54 & 74 & 80 & 67 & 66 & 51 & 61 & 32 \\
\hline 65 & 83 & 92 & 76 & 80 & 62 & 70 & 38 \\
\hline 77 & 88 & 91 & 85 & 92 & 71 & 81 & 41 \\
\hline 79 & 87 & 88 & 86 & 92 & 72 & 84 & 43 \\
\hline 82 & 86 & 82 & 78 & 91 & 69 & 79 & 39 \\
\hline 79 & 80 & 70 & 75 & 86 & 64 & 68 & 30 \\
\hline 73 & 73 & 58 & 64 & 80 & 56 & 53 & 19 \\
\hline 66 & 62 & 46 & 48 & 62 & 49 & 35 & 19 \\
\hline 57 & 47 & 41 & 38 & 56 & 44 & 23 & 18 \\
\hline 40 & 30 & 29 & 26 & 42 & 36 & 14 & 20 \\
\hline 29 & 14 & 17 & 21 & 31 & 25 & 8 & 16 \\
\hline 10 & 4 & 9 & 10 & 16 & 12 & 5 & 8 \\
\hline 0 & 0 & 0 & 0 & 0 & 0 & 0 & 0 \\
\hline
\end{tabular}

Tabela A1.2 - Perfis das retas transversais da Peça 1, medidos com o Sistema Automatizado.

\begin{tabular}{|r|r|r|r|r|r|}
\hline \multicolumn{7}{|c|}{ Perfil das Transversais da Peça $1(\mathrm{em} \mu \mathrm{m})$ - Amostra 02 - } \\
Sistema Automatizado - sem inclinação \\
\hline \multicolumn{1}{|c|}{ T1 } & \multicolumn{1}{c|}{ T4 } & \multicolumn{1}{c|}{ T7 } & \multicolumn{1}{c|}{ T10 } & \multicolumn{1}{c|}{ T13 } & \multicolumn{1}{c|}{ T16 } \\
\hline 0 & 0 & 0 & 0 & 0 & 0 \\
\hline-26 & -17 & -10 & -15 & -16 & -26 \\
\hline-41 & -32 & -21 & -25 & -27 & -46 \\
\hline-51 & -41 & -22 & -24 & -27 & -51 \\
\hline-53 & -43 & -24 & -23 & -27 & -47 \\
\hline-43 & -34 & -20 & -15 & -21 & -34 \\
\hline-9 & -10 & -12 & -10 & -14 & -23 \\
\hline 0 & 0 & 0 & 0 & 0 & 0 \\
\hline
\end{tabular}


Tabela A1.3 - Desvio de planicidade da Peça 1 (ajustagem Minimax).

\begin{tabular}{|c|c|c|c|c|c|c|c|c|c|c|}
\hline \multicolumn{11}{|c|}{$\begin{array}{l}\text { Peça } 1 \text { - Amostra } 02 \text { - Desvio de planicidade - Medição com Sistema Automatizado - Avaliação com } \\
\text { Método Minimax }\end{array}$} \\
\hline coefic. & Perfil 1 & Perfil 4 & Perfil 7 & Perfil 10 & Perfil 13 & Perfil 16 & \begin{tabular}{c|} 
Perfil \\
Médio \\
\end{tabular} & Médias & \begin{tabular}{c|} 
Desv. \\
Padrão \\
\end{tabular} & $\begin{array}{c}\text { Amplitu- } \\
\text { des }\end{array}$ \\
\hline $\mathrm{a} 0$ & 17 & -40 & -56 & -52 & -18 & 21 & -19 & -21 & 31 & 77 \\
\hline a1 & $0,0 \mathrm{E}+00$ & $1,0 \mathrm{E}-12$ & $2,1 \mathrm{E}-12$ & $-8,9 E-16$ & $-3,6 \mathrm{E}-14$ & $-2,1 \mathrm{E}-13$ & $-2,1 \mathrm{E}-13$ & $3,7 \mathrm{E}-13$ & $8,5 \mathrm{E}-13$ & $2,3 \mathrm{E}-12$ \\
\hline a2 & $-6,0 \mathrm{E}-05$ & $-1,3 \mathrm{E}-04$ & $-2,1 \mathrm{E}-05$ & $1,2 \mathrm{E}-04$ & $1,3 \mathrm{E}-04$ & $-1,9 \mathrm{E}-04$ & $-4,8 \mathrm{E}-05$ & $-2,9 \mathrm{E}-05$ & $1,2 \mathrm{E}-04$ & $3,2 \mathrm{E}-04$ \\
\hline $\begin{array}{l}\text { Desvio de } \\
\text { planicidade }\end{array}$ & 130 & 136 & 117 & 120 & 120 & 122 & 120 & 124 & 7 & 19 \\
\hline
\end{tabular}

Tabela A1.4 - Desvio de planicidade da Peça 1 (ajustagem de Mínimos Quadrados).

\begin{tabular}{|c|c|c|c|c|c|c|c|c|c|c|}
\hline \multicolumn{11}{|c|}{$\begin{array}{l}\text { Peça 1- Amostra } 02 \text { - Desvio de planicidade - Medição com Sistema Automatizado - Avaliação com } \\
\text { Método dos Mínimos Quadrados }\end{array}$} \\
\hline coefic. & Perfil 1 & Perfil 4 & Perfil 7 & Perfil 10 & Perfil 13 & Perfil 16 & \begin{tabular}{c|c|} 
Perfil \\
Médio
\end{tabular} & Médias & \begin{tabular}{c|} 
Desv. \\
Padrão
\end{tabular} & $\begin{array}{c}\text { Amplitu- } \\
\text { des }\end{array}$ \\
\hline a0 & 37 & -29 & -37 & -28 & 13 & 37 & -1 & -1 & 31 & 75 \\
\hline a1 & $-9,6 \mathrm{E}-05$ & $-9,6 \mathrm{E}-05$ & $-9,6 \mathrm{E}-05$ & $-9,6 \mathrm{E}-05$ & $-9,6 \mathrm{E}-05$ & $-9,6 \mathrm{E}-05$ & $-9,6 \mathrm{E}-05$ & $-9,6 \mathrm{E}-05$ & $2,0 \mathrm{E}-08$ & $5,4 \mathrm{E}-08$ \\
\hline a2 & $-1,2 \mathrm{E}-04$ & $5,6 \mathrm{E}-05$ & $3,2 \mathrm{E}-05$ & $1,8 \mathrm{E}-04$ & $-2,1 \mathrm{E}-05$ & $-1,3 \mathrm{E}-04$ & $5,3 \mathrm{E}-07$ & $5,4 \mathrm{E}-07$ & $1,1 \mathrm{E}-04$ & $3,1 \mathrm{E}-04$ \\
\hline $\begin{array}{l}\text { Desvio de } \\
\text { planicidade }\end{array}$ & 143 & 155 & 133 & 137 & 136 & 138 & 136 & 140 & 7 & 22 \\
\hline
\end{tabular}

\section{Amostra 03}

Tabela A1.5 - Perfis das geratrizes da Peça 1, medidos com o Sistema Automatizado.

\begin{tabular}{|r|r|r|r|r|r|r|r|}
\hline \multicolumn{7}{|c|}{ Perfil das Geratrizes da Peça 1 (em $\mu$ m) - Amostra 03 - Sistema } \\
\hline G1 & \multicolumn{1}{|c|}{ G2 } & \multicolumn{1}{|c|}{ G3 } & \multicolumn{1}{|c|}{ G4 } & \multicolumn{1}{|c|}{ G5 } & \multicolumn{1}{c|}{ G6 } & \multicolumn{1}{c|}{ G7 } & \multicolumn{1}{c|}{ G8 } \\
\hline 0 & 0 & 0 & 0 & 0 & 0 & 0 & 0 \\
\hline 19 & 27 & 30 & 28 & 19 & 19 & 27 & 12 \\
\hline 38 & 57 & 58 & 52 & 42 & 35 & 49 & 18 \\
\hline 51 & 73 & 75 & 64 & 66 & 48 & 66 & 28 \\
\hline 61 & 83 & 88 & 75 & 81 & 59 & 75 & 35 \\
\hline 72 & 87 & 88 & 82 & 95 & 67 & 84 & 39 \\
\hline 72 & 87 & 84 & 85 & 96 & 69 & 85 & 42 \\
\hline 73 & 88 & 80 & 77 & 95 & 65 & 79 & 39 \\
\hline 70 & 83 & 70 & 74 & 89 & 59 & 67 & 32 \\
\hline 65 & 75 & 59 & 62 & 79 & 51 & 50 & 22 \\
\hline 57 & 64 & 49 & 47 & 59 & 45 & 34 & 21 \\
\hline 50 & 50 & 41 & 38 & 54 & 40 & 21 & 20 \\
\hline 33 & 31 & 28 & 27 & 41 & 32 & 12 & 21 \\
\hline 24 & 15 & 17 & 22 & 30 & 21 & 6 & 17 \\
\hline 7 & 5 & 9 & 10 & 16 & 10 & 3 & 9 \\
\hline 0 & 0 & 0 & 0 & 0 & 0 & 0 & 0 \\
\hline
\end{tabular}


Tabela A1.6 - Perfis das retas transversais da Peça 1, medidos com o Sistema Automatizado.

\begin{tabular}{|r|r|r|r|r|r|}
\hline \multicolumn{7}{|c|}{ Perfil das Transversais da Peça $1(\mathrm{em} \mu \mathrm{m})$ - Amostra 03 - } \\
Sistema Automatizado - sem inclinação \\
\hline \multicolumn{1}{|c|}{ T1 } & \multicolumn{1}{c|}{ T4 } & \multicolumn{1}{c|}{ T7 } & \multicolumn{1}{|c|}{ T10 } & \multicolumn{1}{c|}{ T13 } & \multicolumn{1}{c|}{ T16 } \\
\hline 0 & 0 & 0 & 0 & 0 & 0 \\
\hline-25 & -15 & -11 & -15 & -15 & -23 \\
\hline-38 & -28 & -23 & -24 & -24 & -42 \\
\hline-49 & -34 & -23 & -23 & -24 & -44 \\
\hline-52 & -35 & -24 & -22 & -24 & -40 \\
\hline-44 & -28 & -20 & -14 & -19 & -29 \\
\hline-11 & -7 & -12 & -10 & -14 & -20 \\
\hline 0 & 0 & 0 & 0 & 0 & 0 \\
\hline
\end{tabular}

Tabela A1.7 - Desvio de planicidade da Peça 1 (ajustagem Minimax).

\begin{tabular}{|c|c|c|c|c|c|c|c|c|c|c|}
\hline \multicolumn{11}{|c|}{$\begin{array}{c}\text { Peça } 1 \text { - Amostra } 03 \text { - Desvio de planicidade - Medição com Sistema Automatizado - Avaliação com } \\
\text { Método Minimax }\end{array}$} \\
\hline coefic. & Perfil 1 & Perfil 4 & Perfil 7 & Perfil 10 & Perfil 13 & Perfil 16 & $\begin{array}{l}\text { Perfil } \\
\text { Médio }\end{array}$ & Médias & \begin{tabular}{|c|} 
Desv. \\
Padrão
\end{tabular} & $\begin{array}{c}\text { Amplitu- } \\
\text { des }\end{array}$ \\
\hline a0 & 12 & -47 & -60 & -33 & 4 & 7 & -21 & -20 & 28 & 72 \\
\hline a1 & $-6,0 \mathrm{E}-13$ & $-6,7 \mathrm{E}-16$ & $-2,2 \mathrm{E}-16$ & $7,0 \mathrm{E}-12$ & $-6,7 \mathrm{E}-16$ & $-2,1 \mathrm{E}-12$ & $1,1 \mathrm{E}-11$ & $2,2 \mathrm{E}-12$ & $4,8 \mathrm{E}-12$ & $1,3 \mathrm{E}-11$ \\
\hline a2 & $-1,1 \mathrm{E}-05$ & $5,9 \mathrm{E}-05$ & $6,9 \mathrm{E}-06$ & $-1,5 \mathrm{E}-04$ & $-1,8 \mathrm{E}-04$ & $7,3 \mathrm{E}-05$ & $-1,1 \mathrm{E}-05$ & $-3,2 \mathrm{E}-05$ & $9,9 \mathrm{E}-05$ & $2,5 \mathrm{E}-04$ \\
\hline $\begin{array}{l}\text { Desvio de } \\
\text { planicidade }\end{array}$ & 125 & 123 & 120 & 120 & 118 & 114 & 117 & 120 & 4 & 12 \\
\hline
\end{tabular}

Tabela A1.8 - Desvio de planicidade da Peça 1 (ajustagem de Mínimos Quadrados).

\begin{tabular}{|l|r|r|r|r|r|r|r|r|r|r|}
\hline \multicolumn{1}{|c|}{ Peça 1- Amostra 03 - Desvio de planicidade - Medição com Sistema Automatizado - Avaliação com } \\
Método dos Mínimos Quadrados \\
\hline coefic. & Perfil 1 & Perfil 4 & Perfil 7 & Perfil 10 & Perfil 13 & Perfil 16 & $\begin{array}{c}\text { Perfil } \\
\text { Médio }\end{array}$ & Médias & $\begin{array}{c}\text { Desv. } \\
\text { Padrão }\end{array}$ & $\begin{array}{c}\text { Amplitu- } \\
\text { des }\end{array}$ \\
\hline a0 & 22 & -17 & -34 & -4 & 11 & 24 & 0 & 0 & 21 & 58 \\
a1 & $-9,4 \mathrm{E}-05$ & $-9,4 \mathrm{E}-05$ & $-9,4 \mathrm{E}-05$ & $-9,4 \mathrm{E}-05$ & $-9,4 \mathrm{E}-05$ & $-9,4 \mathrm{E}-05$ & $-9,4 \mathrm{E}-05$ & $-9,4 \mathrm{E}-05$ & $0,0 \mathrm{E}+00$ & $0,0 \mathrm{E}+00$ \\
a2 & $1,1 \mathrm{E}-04$ & $-6,4 \mathrm{E}-05$ & $-2,5 \mathrm{E}-05$ & $-1,8 \mathrm{E}-04$ & $2,8 \mathrm{E}-05$ & $1,1 \mathrm{E}-04$ & $-3,3 \mathrm{E}-06$ & $-3,3 \mathrm{E}-06$ & $1,0 \mathrm{E}-04$ & $2,9 \mathrm{E}-04$ \\
\hline $\begin{array}{l}\text { Desvio de } \\
\text { planicidade }\end{array}$ & 140 & 139 & 134 & 134 & 135 & 126 & 128 & 134 & 5 & 14 \\
\hline
\end{tabular}




\section{Dados obtidos com a medição convencional}

\section{Amostra 02}

Tabela A1.9 - Perfil da superfície da Peça 1, medido com o sistema convencional.

\begin{tabular}{|r|r|r|r|r|r|r|r|}
\hline \multicolumn{1}{|c|}{ Perfil das Geratrizes da Peça 1 $(\mu \mathrm{m})$ - Medição Convencional - sem } \\
inclinaço - Amostra 02 \\
\hline \multicolumn{1}{|c|}{ G1 G2 } & \multicolumn{1}{c|}{ G3 } & \multicolumn{1}{c|}{ G4 } & \multicolumn{1}{c|}{ G5 } & \multicolumn{1}{c|}{ G6 } & \multicolumn{1}{c|}{ G7 } & \multicolumn{1}{c|}{ G8 } \\
\hline 0 & 0 & 0 & 0 & 0 & 0 & 0 & 0 \\
\hline 22 & 26 & 20 & 19 & 18 & 16 & 13 & 11 \\
\hline 39 & 42 & 41 & 38 & 35 & 28 & 25 & 18 \\
\hline 51 & 58 & 56 & 57 & 43 & 44 & 33 & 24 \\
\hline 58 & 64 & 61 & 66 & 51 & 50 & 41 & 30 \\
\hline 60 & 70 & 72 & 75 & 58 & 57 & 38 & 27 \\
\hline 67 & 76 & 72 & 74 & 66 & 58 & 46 & 33 \\
\hline 64 & 72 & 72 & 73 & 69 & 59 & 39 & 29 \\
\hline 56 & 73 & 73 & 72 & 61 & 51 & 36 & 26 \\
\hline 53 & 64 & 68 & 66 & 59 & 47 & 29 & 17 \\
\hline 45 & 55 & 58 & 60 & 47 & 38 & 27 & 13 \\
\hline 37 & 41 & 44 & 49 & 39 & 35 & 24 & 10 \\
\hline 24 & 32 & 34 & 38 & 32 & 26 & 17 & 6 \\
\hline 21 & 23 & 24 & 27 & 20 & 12 & 15 & 7 \\
\hline 8 & 14 & 10 & 16 & 12 & 4 & 7 & 4 \\
\hline 0 & 0 & 0 & 0 & 0 & 0 & 0 & 0 \\
\hline
\end{tabular}

\section{Amostra 03}

Tabela A1.10 - Perfil da superfície da Peça 1, medido com o sistema convencional.

\begin{tabular}{|r|r|r|r|r|r|r|r|}
\hline \multicolumn{2}{|c|}{ Perfil das Geratrizes da Peça 1 $(\mu \mathrm{m})$ - Medição Convencional - sem } \\
inclinação - Amostra 03 \\
\hline \multicolumn{1}{|r|}{ G1 } & \multicolumn{1}{|c|}{ G2 } & \multicolumn{1}{c|}{ G3 } & \multicolumn{1}{c|}{ G4 } & \multicolumn{1}{c|}{ G5 } & \multicolumn{1}{c|}{ G6 } & \multicolumn{1}{c|}{ G7 } & \multicolumn{1}{c|}{ G8 } \\
\hline 0 & 0 & 0 & 0 & 0 & 0 & 0 & 0 \\
\hline 17 & 21 & 16 & 19 & 18 & 17 & 12 & 6 \\
\hline 35 & 38 & 36 & 33 & 30 & 33 & 20 & 18 \\
\hline 47 & 54 & 52 & 52 & 43 & 45 & 32 & 24 \\
\hline 54 & 60 & 58 & 61 & 51 & 52 & 39 & 30 \\
\hline 62 & 72 & 68 & 65 & 58 & 58 & 37 & 27 \\
\hline 69 & 73 & 79 & 74 & 66 & 65 & 44 & 28 \\
\hline 61 & 69 & 70 & 68 & 64 & 57 & 36 & 24 \\
\hline 59 & 71 & 70 & 67 & 61 & 53 & 29 & 21 \\
\hline 56 & 62 & 66 & 61 & 59 & 50 & 26 & 17 \\
\hline 43 & 53 & 57 & 50 & 52 & 42 & 23 & 13 \\
\hline 36 & 40 & 47 & 39 & 39 & 33 & 21 & 10 \\
\hline 23 & 36 & 33 & 33 & 32 & 30 & 13 & 6 \\
\hline 15 & 22 & 19 & 22 & 20 & 22 & 10 & 7 \\
\hline 8 & 14 & 14 & 11 & 12 & 13 & 3 & 4 \\
\hline 0 & 0 & 0 & 0 & 0 & 0 & 0 & 0 \\
\hline
\end{tabular}




\section{APÊNDICE 2- Resultados dos cálculos do desvio de planicidade da peça 2 - Amostras adicionais}

\section{Dados obtidos utilizando-se o sistema automatizado Amostra 02}

Tabela A2.1 - Perfis das geratrizes da Peça 2, medidos com o Sistema Automatizado.

\begin{tabular}{|r|r|r|r|r|r|r|r|}
\hline \multicolumn{7}{|c|}{ Perfil das Geratrizes da Peça $2(e m \mu m)-$ Amostra 02 - Sistema } \\
\hline \multicolumn{1}{|r|}{ G1 } & \multicolumn{1}{|c|}{ G2 } & \multicolumn{1}{|c|}{ G3 } & \multicolumn{1}{|c|}{ G4 } & \multicolumn{1}{|c|}{ G5 } & \multicolumn{1}{c|}{ G6 } & \multicolumn{1}{c|}{ G7 } & \multicolumn{1}{c|}{ G8 } \\
\hline 0 & 0 & 0 & 0 & 0 & 0 & 0 & 0 \\
\hline-3 & -3 & -3 & -4 & -1 & -1 & -3 & -2 \\
\hline-8 & -8 & -7 & -8 & -4 & -4 & -8 & -7 \\
\hline-14 & -12 & -12 & -14 & -7 & -9 & -12 & -11 \\
\hline-21 & -14 & -16 & -20 & -10 & -13 & -17 & -13 \\
\hline-26 & -18 & -18 & -24 & -14 & -19 & -22 & -17 \\
\hline-30 & -21 & -21 & -26 & -18 & -24 & -28 & -21 \\
\hline-31 & -22 & -23 & -30 & -21 & -26 & -31 & -22 \\
\hline-30 & -22 & -25 & -30 & -20 & -28 & -33 & -21 \\
\hline-26 & -22 & -25 & -29 & -18 & -27 & -33 & -18 \\
\hline-21 & -19 & -23 & -24 & -14 & -24 & -31 & -14 \\
\hline-16 & -15 & -20 & -19 & -10 & -20 & -27 & -10 \\
\hline-12 & -11 & -16 & -14 & -7 & -15 & -21 & -8 \\
\hline-7 & -7 & -11 & -9 & -3 & -9 & -14 & -6 \\
\hline-3 & -3 & -6 & -5 & -1 & -4 & -7 & -4 \\
\hline 0 & 0 & 0 & 0 & 0 & 0 & 0 & 0 \\
\hline
\end{tabular}

Tabela A2.2 - Perfis das transversais da Peça 2, medidos com o Sistema Automatizado.

\begin{tabular}{|r|r|r|r|r|r|}
\hline \multicolumn{7}{|c|}{ Perfil das Transversais da Peça $2(e m \mu m)$ - Amostra 02 - } \\
Sistema Automatizado - sem inclinação \\
\hline T1 & \multicolumn{1}{|c|}{ T4 } & \multicolumn{1}{c|}{ T7 } & \multicolumn{1}{c|}{ T10 } & \multicolumn{1}{c|}{ T13 } & \multicolumn{1}{c|}{ T16 } \\
\hline 0 & 0 & 0 & 0 & 0 & 0 \\
\hline 1 & 2 & 0 & -3 & -5 & -2 \\
\hline 0 & 3 & 0 & -7 & -7 & -4 \\
\hline 0 & 2 & 0 & -7 & -9 & -6 \\
\hline-2 & 1 & 1 & -8 & -9 & -5 \\
\hline-2 & 0 & 0 & -7 & -8 & -4 \\
\hline-2 & 0 & 1 & -4 & -5 & -2 \\
\hline 0 & 0 & 0 & 0 & 0 & 0 \\
\hline
\end{tabular}


Tabela A2.3 - Desvio de planicidade da Peça 2 (ajustagem Minimax).

\begin{tabular}{|c|c|c|c|c|c|c|c|c|c|c|}
\hline \multicolumn{11}{|c|}{$\begin{array}{l}\text { Peça } 2 \text { - Amostra } 02 \text { - Desvio de planicidade - Medição com Sistema Automatizado - Avaliação com } \\
\text { Método Minimax }\end{array}$} \\
\hline coefic. & fil 1 & Perfil 4 & & Perfil 10 & Perfil 13 & & \begin{tabular}{c|c|} 
Perfil \\
Médio \\
\end{tabular} & & \begin{tabular}{c|} 
Desv. \\
Padrão \\
\end{tabular} & $\begin{array}{c}\text { Amplitu- } \\
\text { des }\end{array}$ \\
\hline $\mathrm{a} 0$ & -18 & -4 & 11 & 10 & -3 & -18 & -3 & -4 & 12 & 30 \\
\hline a1 & $-1,9 \mathrm{E}-06$ & $-5,2 \mathrm{E}-14$ & $-3,8 \mathrm{E}-14$ & $-1,1 \mathrm{E}-13$ & $3 E-14$ & OE-15 & $-3,5 E-13$ & $-2,7 \mathrm{E}-07$ & $7,3 \mathrm{E}-07$ & $1,9 \mathrm{E}-06$ \\
\hline a2 & $1,2 \mathrm{E}-05$ & $3,8 \mathrm{E}-05$ & $1,5 \mathrm{E}-05$ & $-2,7 \mathrm{E}-05$ & $-4,0 \mathrm{E}-05$ & $7,1 \mathrm{E}-15$ & $1,3 \mathrm{E}-06$ & $4,3 \mathrm{E}-08$ & $2,6 \mathrm{E}-05$ & $7,8 \mathrm{E}-05$ \\
\hline & & 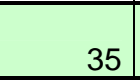 & 33 & & 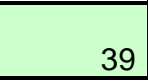 & 37 & 34 & 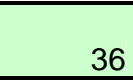 & & \\
\hline
\end{tabular}

Tabela A2.4 - Desvio de planicidade da Peça 2 (ajustagem de Mínimos Quadrados).

\begin{tabular}{|c|c|c|c|c|c|c|c|c|c|c|}
\hline \multicolumn{11}{|c|}{$\begin{array}{c}\text { Peça } 2 \text { - Amostra } 02 \text { - Desvio de planicidade - Medição com Sistema Automatizado - Avaliação com } \\
\text { Método Minimax }\end{array}$} \\
\hline coefic. & Perfil 1 & Perfil 4 & Perfil 7 & Perfil 10 & Perfil 13 & Perfil 16 & $\begin{array}{l}\text { Perfil } \\
\text { Médio } \\
\end{array}$ & Médias & $\begin{array}{c}\text { Desv. } \\
\text { Padrão } \\
\end{array}$ & $\begin{array}{c}\text { Amplitu- } \\
\text { des }\end{array}$ \\
\hline $\mathrm{a} 0$ & -14 & -2 & 10 & 7 & -5 & -15 & -3 & -3 & 10 & 25 \\
\hline a1 & $-6,1 E-06$ & $-6,1 \mathrm{E}-06$ & $-6,1 \mathrm{E}-06$ & $-6,1 E-06$ & $-6,1 \mathrm{E}-06$ & $-6,1 \mathrm{E}-06$ & $-6,1 E-06$ & $-6,1 \mathrm{E}-06$ & $7,6 \mathrm{E}-11$ & $2,0 \mathrm{E}-10$ \\
\hline $\mathrm{a} 2$ & $8,8 \mathrm{E}-06$ & 3,1E-05 & $9,6 \mathrm{E}-06$ & $-1,4 \mathrm{E}-06$ & $-1,4 \mathrm{E}-05$ & $-1,0 \mathrm{E}-05$ & $3,9 \mathrm{E}-06$ & $3,9 \mathrm{E}-06$ & $1,5 \mathrm{E}-05$ & $4,5 \mathrm{E}-05$ \\
\hline $\begin{array}{c}\text { Desvio de } \\
\text { planicidade }\end{array}$ & 36 & 36 & 34 & 40 & 42 & 38 & 35 & 37 & 3 & 2 \\
\hline
\end{tabular}

\section{Amostra 03}

Tabela A2.5 - Perfis das geratrizes da Peça 2, medidos com o Sistema Automatizado.

\begin{tabular}{|c|c|c|c|c|c|c|c|}
\hline \multicolumn{8}{|c|}{$\begin{array}{c}\text { Perfil das Geratrizes da Peça } 2(\text { em } \mu \mathrm{m}) \text { - Amostra } 03 \text { - Sistema } \\
\text { Automatizado - Sem inclinação }\end{array}$} \\
\hline G1 & G2 & G3 & G4 & G5 & G6 & G7 & G8 \\
\hline 0 & 0 & 0 & 0 & 0 & 0 & 0 & 0 \\
\hline-5 & -6 & -2 & -4 & -1 & -3 & -1 & -2 \\
\hline-11 & -11 & -7 & -9 & -4 & -7 & -4 & -6 \\
\hline-16 & -16 & -12 & -15 & -6 & -10 & -7 & -10 \\
\hline-21 & -19 & -16 & -19 & -9 & -13 & -12 & -15 \\
\hline-24 & -22 & -20 & -23 & -12 & -17 & -16 & -20 \\
\hline-27 & -26 & -24 & -26 & -16 & -20 & -21 & -24 \\
\hline-28 & -27 & -26 & -28 & -18 & -23 & -24 & -26 \\
\hline-27 & -27 & -28 & -28 & -18 & -25 & -24 & -24 \\
\hline-23 & -25 & -28 & -27 & -18 & -25 & -23 & -22 \\
\hline-20 & -22 & -27 & -22 & -16 & -23 & -21 & -20 \\
\hline-15 & -17 & -23 & -18 & -14 & -19 & -19 & -16 \\
\hline-11 & -13 & -19 & -13 & -11 & -13 & -16 & -12 \\
\hline-6 & -8 & -13 & -8 & -6 & -9 & -10 & -8 \\
\hline-3 & -4 & -6 & -4 & -2 & -5 & -5 & -5 \\
\hline 0 & 0 & 0 & 0 & 0 & 0 & 0 & 0 \\
\hline
\end{tabular}


Tabela A2.6 - Perfis das transversais da Peça 2, medidos com o Sistema Automatizado.

\begin{tabular}{|r|r|r|r|r|r|}
\hline \multicolumn{6}{|c|}{ Perfil das Transversais da Peça $1(\mathrm{em} \mu \mathrm{m})$ - Amostra 03 - } \\
\hline S1 & \multicolumn{1}{|c|}{ T4 } & \multicolumn{1}{|c|}{ T7 } & \multicolumn{1}{|c|}{ T10 } & \multicolumn{1}{c|}{ T13 } & \multicolumn{1}{c|}{ T16 } \\
\hline 0 & 0 & 0 & 0 & 0 & 0 \\
\hline-1 & 2 & 0 & -2 & -1 & -2 \\
\hline-3 & 2 & -1 & -4 & -2 & -4 \\
\hline-4 & 1 & -1 & -5 & -2 & -6 \\
\hline-4 & 0 & -1 & -6 & -3 & -6 \\
\hline-3 & 0 & -2 & -5 & -2 & -5 \\
\hline-2 & 0 & -1 & -3 & -2 & -2 \\
\hline 0 & 0 & 0 & 0 & 0 & 0 \\
\hline
\end{tabular}

Tabela A2.7 - Desvio de planicidade da Peça 2 (ajustagem Minimax).

\begin{tabular}{|l|r|r|r|r|r|r|r|r|r|r|}
\hline \multicolumn{1}{|c|}{ Peça 2 - Amostra 03 - Desvio de planicidade - Medição com Sistema Automatizado - Avaliação com } \\
Método Minimax \\
\hline coefic. & Perfil 1 & Perfil 4 & Perfil 7 & Perfil 10 & Perfil 13 & Perfil 16 & $\begin{array}{r}\text { Perfil } \\
\text { Médio }\end{array}$ & Médias & $\begin{array}{r}\text { Desv. } \\
\text { Padrão }\end{array}$ & $\begin{array}{c}\text { Amplitu- } \\
\text { des }\end{array}$ \\
\hline a0 & -16 & -3 & 8 & 7 & 0 & -17 & -4 & -3 & 10 & 25 \\
a1 & $3,5 \mathrm{E}-13$ & $0,0 \mathrm{E}+00$ & $-1,3 \mathrm{E}-15$ & $0,0 \mathrm{E}+00$ & $1,7 \mathrm{E}-14$ & $2,6 \mathrm{E}-13$ & $-1,3 \mathrm{E}-05$ & $-1,8 \mathrm{E}-06$ & $4,9 \mathrm{E}-06$ & $1,3 \mathrm{E}-05$ \\
a2 & $6,7 \mathrm{E}-14$ & $4,1 \mathrm{E}-05$ & $1,9 \mathrm{E}-05$ & $2,4 \mathrm{E}-05$ & $-8,5 \mathrm{E}-06$ & $3,9 \mathrm{E}-13$ & $1,8 \mathrm{E}-06$ & $1,1 \mathrm{E}-05$ & $1,7 \mathrm{E}-05$ & $4,9 \mathrm{E}-05$ \\
\hline $\begin{array}{c}\text { Desvio de } \\
\text { planicidade }\end{array}$ & 32 & 31 & 32 & 30 & 34 & 34 & 33 & 32 & 1 & 4 \\
\hline
\end{tabular}

Tabela A2.8 - Desvio de planicidade da Peça 2 (ajustagem de Mínimos Quadrados).

\begin{tabular}{|c|c|c|c|c|c|c|c|c|c|c|}
\hline \multicolumn{11}{|c|}{$\begin{array}{c}\text { Peça } 2 \text { - Amostra } 03 \text { - Desvio de planicidade - Medição com Sistema Automatizado - Avaliação com } \\
\text { Método Minimax }\end{array}$} \\
\hline coefic. & Perfil 1 & Perfil 4 & Perfil 7 & Perfil 10 & Perfil 13 & Perfil 16 & $\begin{array}{l}\text { Perfil } \\
\text { Médio } \\
\end{array}$ & Médias & $\begin{array}{c}\text { Desv. } \\
\text { Padrão } \\
\end{array}$ & $\begin{array}{c}\text { Amplitu- } \\
\text { des }\end{array}$ \\
\hline $\mathrm{a} 0$ & -14 & -4 & 8 & 7 & 1 & -15 & -4 & -3 & 9 & 23 \\
\hline a1 & $-5,9 \mathrm{E}-06$ & $-5,9 E-06$ & $-5,9 \mathrm{E}-06$ & $-5,9 E-06$ & $-5,9 E-06$ & $-5,9 E-06$ & $-9,7 \mathrm{E}-06$ & $-6,5 \mathrm{E}-06$ & $1,4 \mathrm{E}-06$ & $3,8 \mathrm{E}-06$ \\
\hline a2 & $-1,8 \mathrm{E}-05$ & $5,1 \mathrm{E}-05$ & 2,2E-05 & $1,0 \mathrm{E}-05$ & $-2,5 E-05$ & $-2,3 E-05$ & $-1,0 \mathrm{E}-05$ & $9,9 \mathrm{E}-07$ & $2,8 \mathrm{E}-05$ & 7,6E-05 \\
\hline Desvio de & & & & & & & & & & \\
\hline planicidade & 34 & 32 & 33 & 31 & 35 & 36 & 34 & 34 & 2 & 5 \\
\hline
\end{tabular}




\section{Dados obtidos com a medição convencional}

\section{Amostra 02}

Tabela A2.9 - Perfil da superfície da Peça 2, medido com o sistema convencional.

\begin{tabular}{|r|r|r|r|r|r|r|r|}
\hline \multicolumn{1}{|c|}{ Perfil das Geratrizes da Peça 2 $(\mu \mathrm{m})$ - Medição Convencional - sem } \\
inclinaço - Amostra 02 \\
\hline \multicolumn{1}{|c|}{ G1 } & \multicolumn{1}{|c|}{ G2 } & \multicolumn{1}{c|}{ G3 } & \multicolumn{1}{c|}{ G4 } & \multicolumn{1}{c|}{ G5 } & \multicolumn{1}{c|}{ G6 } & \multicolumn{1}{c|}{ G7 } & \multicolumn{1}{c|}{ G8 } \\
\hline 0 & 0 & 0 & 0 & 0 & 0 & 0 & 0 \\
\hline-7 & -7 & -3 & -7 & -5 & -2 & -2 & -6 \\
\hline-11 & -11 & -9 & -10 & -8 & -8 & -8 & -13 \\
\hline-16 & -15 & -15 & -15 & -15 & -15 & -15 & -14 \\
\hline-19 & -22 & -17 & -20 & -17 & -17 & -19 & -20 \\
\hline-24 & -23 & -21 & -23 & -23 & -21 & -23 & -27 \\
\hline-26 & -27 & -24 & -25 & -25 & -25 & -25 & -28 \\
\hline-28 & -27 & -28 & -27 & -27 & -27 & -27 & -29 \\
\hline-25 & -28 & -24 & -28 & -27 & -26 & -28 & -31 \\
\hline-25 & -25 & -23 & -25 & -25 & -26 & -25 & -27 \\
\hline-22 & -22 & -21 & -22 & -22 & -22 & -22 & -23 \\
\hline-18 & -18 & -17 & -18 & -18 & -17 & -18 & -20 \\
\hline-12 & -15 & -13 & -15 & -15 & -14 & -15 & -14 \\
\hline-9 & -9 & -8 & -10 & -10 & -9 & -9 & -7 \\
\hline-6 & -3 & -5 & -5 & -5 & -4 & -3 & -4 \\
\hline 0 & 0 & 0 & 0 & 0 & 0 & 0 & 0 \\
\hline
\end{tabular}

\section{Amostra 03}

Tabela A2.10 - Perfil da superfície da Peça 2, medido com o sistema convencional.

\begin{tabular}{|r|r|r|r|r|r|r|r|}
\hline \multicolumn{2}{|c|}{ Perfil das Geratrizes da Peça $2(\mu \mathrm{m})$ - Medição Convencional - sem } \\
inclinac̃o - Amostra 03 \\
\hline \multicolumn{1}{|r|}{ G1 } & \multicolumn{1}{|c|}{ G2 } & \multicolumn{1}{c|}{ G3 } & \multicolumn{1}{c|}{ G4 } & \multicolumn{1}{c|}{ G5 } & \multicolumn{1}{c|}{ G6 } & \multicolumn{1}{c|}{ G7 } & \multicolumn{1}{c|}{ G8 } \\
\hline 0 & 0 & 0 & 0 & 0 & 0 & 0 & 0 \\
\hline-5 & -7 & -2 & -7 & -7 & -4 & -5 & -6 \\
\hline-9 & -13 & -9 & -8 & -13 & -10 & -11 & -10 \\
\hline-16 & -15 & -14 & -15 & -20 & -17 & -16 & -17 \\
\hline-17 & -20 & -17 & -20 & -21 & -18 & -19 & -21 \\
\hline-22 & -23 & -19 & -23 & -25 & -25 & -25 & -25 \\
\hline-26 & -25 & -23 & -25 & -27 & -26 & -27 & -29 \\
\hline-28 & -27 & -25 & -27 & -29 & -28 & -29 & -30 \\
\hline-25 & -26 & -25 & -25 & -27 & -29 & -22 & -31 \\
\hline-25 & -25 & -22 & -23 & -26 & -26 & -22 & -28 \\
\hline-21 & -22 & -19 & -22 & -23 & -22 & -18 & -25 \\
\hline-18 & -18 & -16 & -18 & -19 & -19 & -15 & -21 \\
\hline-12 & -12 & -12 & -12 & -13 & -15 & -11 & -15 \\
\hline-9 & -9 & -9 & -7 & -10 & -9 & -8 & -9 \\
\hline-4 & -3 & -4 & -3 & -6 & -3 & -4 & -6 \\
\hline 0 & 0 & 0 & 0 & 0 & 0 & 0 & 0 \\
\hline
\end{tabular}




\section{APÊNDICE 3 - Resultados dos cálculos do desvio de planicidade da peça 3 - Amostras adicionais}

\section{Dados obtidos utilizando-se o sistema automatizado Amostra 02}

Tabela A3.1 - Perfis das geratrizes da Peça 3 medidos com o Sistema Automatizado.

\begin{tabular}{|r|r|r|r|r|}
\hline \multicolumn{6}{|c|}{$\begin{array}{c}\text { Perfil das Geratrizes da Peça 3 }(\mu \mathrm{m}) \text { - } \\
\text { Amostra 02 - Sistema Automatizado - } \\
\text { sem inclinação }\end{array}$} \\
\hline \multicolumn{1}{|r|r|}{ G1 } & \multicolumn{1}{|c|}{ G2 } & \multicolumn{1}{|c|}{ G3 } & \multicolumn{1}{c|}{ G4 } & \multicolumn{1}{c|}{ G5 } \\
\hline 0 & 0 & 0 & 0 & 0 \\
\hline 0 & 0 & 2 & 1 & 1 \\
\hline-1 & 0 & 2 & 1 & 2 \\
\hline-1 & 1 & 2 & 1 & 3 \\
\hline-1 & 1 & 3 & 2 & 3 \\
\hline 0 & 2 & 3 & 3 & 3 \\
\hline 0 & 2 & 2 & 2 & 2 \\
\hline 0 & 0 & 0 & 0 & 0 \\
\hline
\end{tabular}

Tabela A3.2 - Perfis das transversais da Peça 3, medidos com o Sistema Automatizado.

\begin{tabular}{|c|c|c|c|}
\hline \multicolumn{4}{|c|}{$\begin{array}{l}\text { Perfil das Transversais da Peça } \\
3(\mu \mathrm{m}) \text { - Amostra } 02 \text { - Sistema } \\
\text { Automatizado - sem inclinação }\end{array}$} \\
\hline T1 & T3 & T5 & T7 \\
\hline 0 & 0 & 0 & 0 \\
\hline-5 & -4 & -2 & -3 \\
\hline-7 & -5 & -2 & -4 \\
\hline-6 & -4 & -2 & -3 \\
\hline 0 & 0 & 0 & 0 \\
\hline
\end{tabular}

Tabela A3.3 - Desvios de planicidade da Peça 3 (ajustagem Minimax).

\begin{tabular}{|c|c|c|c|c|c|c|c|c|}
\hline \multicolumn{9}{|c|}{$\begin{array}{c}\text { Peça } 3 \text { - Amostra } 02 \text { - Desvio de planicidade - Medição com Sistema Automatizado - Avaliação com } \\
\text { Método Minimax }\end{array}$} \\
\hline coeficientes & Perfil 1 & Perfil 3 & Perfil 5 & Perfil 7 & $\begin{array}{l}\text { Perfil } \\
\text { Médio }\end{array}$ & Médias & $\begin{array}{l}\text { Desv. } \\
\text { Padrão }\end{array}$ & Amplitudes \\
\hline $\mathrm{a} 0$ & -4 & -3 & -2 & -3 & -3 & -3 & 1 & 2 \\
\hline a1 & $7,1 \mathrm{E}-15$ & $2,3 \mathrm{E}-13$ & $-6,2 \mathrm{E}-13$ & $-1,8 \mathrm{E}-15$ & $-8,4 \mathrm{E}-15$ & $-7,7 \mathrm{E}-14$ & $3,2 \mathrm{E}-13$ & $8,5 \mathrm{E}-13$ \\
\hline $\mathrm{a} 2$ & $4,0 \mathrm{E}-05$ & $4,9 \mathrm{E}-06$ & $-1,3 E-05$ & 2,0E-05 & 1,3E-05 & 1,3E-05 & $2,0 \mathrm{E}-05$ & 5,3E-05 \\
\hline $\begin{array}{l}\text { Desvio de } \\
\text { planicidade }\end{array}$ & 9 & 8 & 6 & 6 & 7 & 7 & 1 & 3 \\
\hline
\end{tabular}


Tabela A3.4 - Desvio de planicidade da Peça 3 (ajustagem de Mínimos Quadrados).

\begin{tabular}{|c|c|c|c|c|c|c|c|c|}
\hline \multicolumn{9}{|c|}{$\begin{array}{c}\text { Peça } 3 \text { - Amostra } 02 \text { - Desvio de planicidade - Medição com Sistema Automatizado - Método dos } \\
\text { Mínimos Quadrados }\end{array}$} \\
\hline coeficientes & Perfil 1 & Perfil 3 & Perfil 5 & Perfil 7 & Perfil Médio & Médias & Desv. Padrão & Amplitudes \\
\hline $\mathrm{a} 0$ & -4 & -2 & -2 & -3 & -3 & -3 & 1 & 2 \\
\hline a1 & 5,3E-06 & $5,3 E-06$ & $5,3 \mathrm{E}-06$ & $5,3 \mathrm{E}-06$ & $5,3 E-06$ & $5,3 \mathrm{E}-06$ & $0,0 \mathrm{E}+00$ & $E+00$ \\
\hline $\mathrm{a} 2$ & 2E-05 & $-1,0 \mathrm{E}-05$ & $-2,3 E-05$ & 5,7E-06 & $-1,3 \mathrm{E}-06$ & $-1,3 \mathrm{E}-06$ & E-05 & 4,4E-05 \\
\hline $\begin{array}{l}\text { Desvio de } \\
\text { planicidade }\end{array}$ & 10 & 9 & 7 & 7 & 8 & 8 & 1 & 3 \\
\hline
\end{tabular}

\section{Amostra 03}

Tabela A3.5 - Perfis das geratrizes da Peça 3 medidos com o Sistema Automatizado.

\begin{tabular}{|r|r|r|r|r|}
\hline \multicolumn{6}{|c|}{$\begin{array}{l}\text { Perfil das Geratrizes da Peça 3 }(\mu \mathrm{m}) \text { - } \\
\text { Amostra 03 - Sistema Automatizado - } \\
\text { sem inclinação }\end{array}$} \\
\hline \multicolumn{1}{|r|r|r|r|}{ G1 } & \multicolumn{1}{|c|}{ G3 } & \multicolumn{1}{c|}{ G4 } & \multicolumn{1}{c|}{ G5 } \\
\hline 0 & 0 & 0 & 0 & 0 \\
\hline 1 & 1 & 2 & 1 & 3 \\
\hline 2 & 2 & 3 & 2 & 5 \\
\hline 2 & 2 & 4 & 1 & 5 \\
\hline 3 & 2 & 3 & 0 & 5 \\
\hline 3 & 1 & 2 & 0 & 4 \\
\hline 3 & 2 & 1 & 0 & 3 \\
\hline 0 & 0 & 0 & 0 & 0 \\
\hline
\end{tabular}

Tabela A3.6 - Perfis das transversais da Peça 3, medidos com o Sistema Automatizado.

\begin{tabular}{|c|c|c|c|}
\hline \multicolumn{4}{|c|}{$\begin{array}{l}\text { Perfil das Transversais da Peça } \\
3(\mu \mathrm{m}) \text { - Amostra } 03 \text { - Sistema } \\
\text { Automatizado - sem inclinação }\end{array}$} \\
\hline T1 & T3 & T5 & T7 \\
\hline 0 & 0 & 0 & 0 \\
\hline-3 & -4 & -3 & -3 \\
\hline-4 & -5 & -3 & -4 \\
\hline-3 & -3 & -3 & -2 \\
\hline 0 & 0 & 0 & 0 \\
\hline
\end{tabular}

Tabela A3.7 - Desvios de planicidade da Peça 3 (ajustagem Minimax).

\begin{tabular}{|c|c|c|c|c|c|c|c|c|}
\hline \multicolumn{9}{|c|}{$\begin{array}{c}\text { Peça } 3 \text { - Amostra } 03 \text { - Desvio de planicidade - Medição com Sistema Automatizado - Avaliação } \\
\text { com Método Minimax }\end{array}$} \\
\hline coeficientes & Perfil 1 & Perfil 3 & Perfil 5 & Perfil 7 & $\begin{array}{l}\text { Perfil } \\
\text { Médio } \\
\end{array}$ & Médias & $\begin{array}{l}\text { Desv. } \\
\text { Padrão }\end{array}$ & Amplitudes \\
\hline $\mathrm{a} 0$ & -1 & -3 & -3 & -3 & -3 & -3 & 1 & 2 \\
\hline a1 & $2,1 \mathrm{E}-14$ & $-4,5 \mathrm{E}-14$ & $-2,6 \mathrm{E}-13$ & $-1,8 \mathrm{E}-15$ & $0,0 \mathrm{E}+00$ & $-5,8 E-14$ & $1,2 \mathrm{E}-13$ & $2,9 \mathrm{E}-13$ \\
\hline a2 & $3,2 \mathrm{E}-05$ & $-8,0 \mathrm{E}-06$ & 7,1E-07 & 3,8E-05 & 1,6E-05 & 1,6E-05 & $2,0 \mathrm{E}-05$ & 4,6E-05 \\
\hline $\begin{array}{l}\text { Desvio de } \\
\text { planicidade }\end{array}$ & 9 & 9 & 7 & 6 & 8 & 8 & 1 & 3 \\
\hline
\end{tabular}


Tabela A3.8 - Desvio de planicidade da Peça 3 (ajustagem de Mínimos Quadrados).

\begin{tabular}{|l|r|r|r|r|r|r|r|r|}
\hline \multicolumn{7}{|c|}{ Peça 3 - Amostra 03 - Desvio de planicidade - Medição com Sistema Automatizado - Método dos } \\
Mínimos Quadrados \\
\hline coeficientes & \multicolumn{1}{|c|}{ Perfil 1 } & \multicolumn{1}{|c|}{ Perfil 3 } & \multicolumn{1}{c|}{ Perfil 5 } & Perfil 7 & Perfil Médio & Médias & Desv. Padrão & Amplitudes \\
\hline a0 & -1 & -3 & -3 & -3 & -2 & -2 & 1 & 2 \\
a1 & $1,7 \mathrm{E}-08$ & $1,7 \mathrm{E}-08$ & $1,7 \mathrm{E}-08$ & $1,7 \mathrm{E}-08$ & $1,7 \mathrm{E}-08$ & $1,7 \mathrm{E}-08$ & $2,2 \mathrm{E}-16$ & $0,0 \mathrm{E}+00$ \\
a2 & $1,3 \mathrm{E}-05$ & $-1,7 \mathrm{E}-05$ & $-2,6 \mathrm{E}-06$ & $2,2 \mathrm{E}-05$ & $3,8 \mathrm{E}-06$ & $3,8 \mathrm{E}-06$ & $1,5 \mathrm{E}-05$ & $4,0 \mathrm{E}-05$ \\
\hline Desvio de & & & & & & & & \\
planicidade & 9 & 9 & 7 & 6 & 8 & 8 & 1 & 3 \\
\hline
\end{tabular}

\section{Dados obtidos com a medição convencional}

\section{Amostra 02}

Tabela A3.9 - Perfis das geratrizes da Peça 3, medidos com o sistema convencional.

\begin{tabular}{|r|r|r|r|r|}
\multicolumn{6}{|c|}{ Perfil das Geratrizes da Peça 3 $(\mu \mathrm{m})$ - } \\
Amostra 02 - Sistema Convencional - \\
sem inclinação \\
\hline \multicolumn{1}{|r|r|}{ G1 } & \multicolumn{1}{|c|}{ G2 } & \multicolumn{1}{|c|}{ G3 } & \multicolumn{1}{c|}{ G4 } & \multicolumn{1}{c|}{ G5 } \\
\hline 0 & 0 & 0 & 0 & 0 \\
\hline 0 & 0 & -1 & -1 & -3 \\
\hline 0 & 0 & -1 & -1 & -2 \\
\hline 1 & -1 & -1 & 1 & -2 \\
\hline 0 & -1 & -1 & -1 & -2 \\
\hline 0 & 0 & 1 & 0 & 1 \\
\hline 1 & 0 & 1 & 0 & 1 \\
\hline 0 & 0 & 0 & 0 & 0 \\
\hline
\end{tabular}

\section{Amostra 03}

Tabela A3.10 - Perfis das geratrizes da Peça 3, medidos com o sistema convencional.

\begin{tabular}{|r|r|r|r|r|}
\hline \multicolumn{6}{|c|}{$\begin{array}{c}\text { Perfil das Geratrizes da Peça 3 }(\mu \mathrm{m}) \text { - } \\
\text { Amostra 03 - Sistema Convencional - } \\
\text { sem inclinação }\end{array}$} \\
\hline \multicolumn{1}{|c|}{ G1 } & \multicolumn{1}{|c|}{ G2 } & \multicolumn{1}{|c|}{ G3 } & \multicolumn{1}{c|}{ G4 } & \multicolumn{1}{c|}{ G5 } \\
\hline 0 & 0 & 0 & 0 & 0 \\
\hline 1 & 0 & -1 & -2 & 0 \\
\hline-1 & 1 & 0 & -2 & -1 \\
\hline 0 & 0 & -1 & -1 & -1 \\
\hline-1 & 0 & 0 & -1 & 0 \\
\hline 0 & 0 & 1 & -1 & 1 \\
\hline 0 & 1 & 0 & -1 & -2 \\
\hline 0 & 0 & 0 & 0 & 0 \\
\hline
\end{tabular}


222 


\section{APÊNDICE 4 - Resultados das medições do artefato de referência}

\section{Dados obtidos utilizando-se o sistema automatizado}

\section{Amostra 01}

Tabela A4.1 - Coeficientes dos planos ajustados aos perfis do artefato de referência (ajustagem Minimax).

\begin{tabular}{|c|c|c|c|c|c|}
\hline \multicolumn{6}{|c|}{$\begin{array}{c}\text { Coeficientes dos planos ajustados - Plano de Referência - } \\
\text { Amostra } 01 \text { - Sistema Automatizado - Avaliação com Método } \\
\text { Minimax }\end{array}$} \\
\hline coeficientes & Ref. 1 & Ref. 3 & Ref. 5 & Médias & Ref. média \\
\hline $\mathrm{a} 0$ & -134 & -108 & -82 & -108 & \\
\hline $\mathrm{a} 1(\mathrm{x})$ & 3.7E-04 & 3.6E-04 & 3.6E-04 & 3.7E-04 & \\
\hline a2 (y) & 6.7E-04 & $5.0 \mathrm{E}-04$ & $2.8 \mathrm{E}-04$ & $4.8 \mathrm{E}-04$ & \\
\hline
\end{tabular}

Tabela A4.2 - Coeficientes dos planos ajustados aos perfis do artefato de referência (ajustagem de Mínimos Quadrados).

\begin{tabular}{|l|r|r|r|r|r|}
\hline \multicolumn{5}{|c|}{$\begin{array}{c}\text { Coeficientes dos planos ajustados - Plano de Referência - } \\
\text { Amostra 01 - com Sistema Automatizado - Avaliação com } \\
\text { Método dos Mínimos Quadrados }\end{array}$} \\
\hline coeficientes & \multicolumn{1}{|c|}{ Ref. 1 } & \multicolumn{1}{c|}{ Ref. 3 } & \multicolumn{1}{c|}{ Ref. 5} & \multicolumn{1}{c|}{ Médias } & Ref. Média \\
\hline a0 & -138 & -109 & -82 & -109 & \\
a1 (x) & $3.9 \mathrm{E}-04$ & $3.9 \mathrm{E}-04$ & $3.9 \mathrm{E}-04$ & $3.9 \mathrm{E}-04$ & \\
a2 (y) & $7.0 \mathrm{E}-04$ & $5.1 \mathrm{E}-04$ & $2.9 \mathrm{E}-04$ & $5.0 \mathrm{E}-04$ & \\
\hline
\end{tabular}

\section{Amostra 03}

Tabela A4.3 - Coeficientes dos planos ajustados aos perfis do artefato de referência (ajustagem Minimax).

\begin{tabular}{|l|r|r|r|r|r|r|r|}
\hline \multicolumn{7}{|c|}{ Coeficientes dos planos ajustados - Plano de Referência - Amostra 03 - Sistema } \\
Automatizado - Avaliação com Método Minimax \\
\hline coeficientes & \multicolumn{1}{|c|}{ Ref. 1 } & \multicolumn{1}{c|}{ Ref. 4 } & \multicolumn{1}{c|}{ Ref. 7 } & Ref. 10 & Ref. 13 & \multicolumn{1}{c|}{ Médias } & Ref. média \\
\hline a0 & -267 & -201 & -178 & -232 & -260 & -227 & -228 \\
a1 (x) & $4.0 \mathrm{E}-04$ & $4.0 \mathrm{E}-04$ & $3.8 \mathrm{E}-04$ & $4.0 \mathrm{E}-04$ & $3.6 \mathrm{E}-04$ & $3.9 \mathrm{E}-04$ & $4.0 \mathrm{E}-04$ \\
a2 (y) & $1.9 \mathrm{E}-03$ & $1.6 \mathrm{E}-03$ & $1.4 \mathrm{E}-03$ & $1.6 \mathrm{E}-03$ & $1.2 \mathrm{E}-03$ & $1.5 \mathrm{E}-03$ & $1.5 \mathrm{E}-03$ \\
\hline
\end{tabular}


Tabela A4.4 - Coeficientes dos planos ajustados aos perfis do artefato de referência (ajustagem de Mínimos Quadrados).

\begin{tabular}{|l|r|r|r|r|r|r|r|}
\hline \multicolumn{7}{|c|}{$\begin{array}{c}\text { Coeficientes dos planos ajustados - Plano de Referência - Amostra 03 - com Sistema } \\
\text { Automatizado - Avaliação com Método dos Mínimos Quadrados }\end{array}$} \\
\hline coeficientes & \multicolumn{1}{|c|}{ Ref. 1 } & \multicolumn{1}{|c|}{ Ref. 4 } & \multicolumn{1}{c|}{ Ref. 7 } & \multicolumn{1}{c|}{ Ref. 10 } & \multicolumn{1}{l|}{ Ref. 13 } & \multicolumn{1}{c|}{ Média } & Ref. média \\
\hline a0 & -274 & -215 & -199 & -246 & -267 & -240 & -240 \\
a1 (x) & $3.7 \mathrm{E}-04$ & $3.7 \mathrm{E}-04$ & $3.7 \mathrm{E}-04$ & $3.7 \mathrm{E}-04$ & $3.7 \mathrm{E}-04$ & $3.7 \mathrm{E}-04$ & $3.7 \mathrm{E}-04$ \\
a2 (y) & $1.9 \mathrm{E}-03$ & $1.6 \mathrm{E}-03$ & $1.3 \mathrm{E}-03$ & $1.6 \mathrm{E}-03$ & $1.4 \mathrm{E}-03$ & $1.6 \mathrm{E}-03$ & $1.6 \mathrm{E}-03$ \\
\hline
\end{tabular}

Obs.: Os resultados referentes à amostra 02 de medição do artefato de referência foram apresentados no capítulo 6 deste trabalho, item 6.2. 


\section{APÊNDICE 5 - Resultados dos cálculos do desvio de perpendicularismo da peça 1 - Amostras Adicionais}

\section{Dados obtidos utilizando-se o sistema automatizado}

\section{Amostra 02}

Tabela A5.1 - Perfis das geratrizes da Peça 1 medidos com o Sistema Automatizado.

\begin{tabular}{|r|r|r|r|r|r|r|r|}
\hline \multicolumn{7}{|c|}{ Perfil das Geratrizes da Peça 1 $(\mu m)-$ Amostra 02 - Sistema } \\
\hline G1 & \multicolumn{1}{c}{ G2 } & G3 & \multicolumn{1}{c|}{ G4 } & G5 & \multicolumn{1}{c|}{ G6 } & G7 & G8 \\
\hline-59 & -100 & -158 & -155 & -171 & -145 & -138 & -149 \\
\hline-59 & -83 & -129 & -133 & -159 & -138 & -132 & -147 \\
\hline-58 & -64 & -102 & -114 & -142 & -134 & -127 & -149 \\
\hline-60 & -59 & -84 & -108 & -124 & -131 & -126 & -146 \\
\hline-62 & -59 & -74 & -103 & -114 & -129 & -128 & -146 \\
\hline-62 & -62 & -77 & -98 & -105 & -124 & -124 & -147 \\
\hline-69 & -70 & -81 & -99 & -108 & -126 & -125 & -147 \\
\hline-74 & -76 & -89 & -109 & -110 & -130 & -132 & -152 \\
\hline-83 & -86 & -102 & -114 & -115 & -133 & -141 & -160 \\
\hline-92 & -97 & -116 & -124 & -122 & -137 & -152 & -167 \\
\hline-100 & -111 & -129 & -139 & -138 & -137 & -162 & -162 \\
\hline-108 & -126 & -135 & -146 & -143 & -133 & -165 & -156 \\
\hline-122 & -143 & -148 & -155 & -153 & -130 & -160 & -146 \\
\hline-128 & -158 & -161 & -157 & -160 & -127 & -149 & -140 \\
\hline-139 & -166 & -170 & -163 & -170 & -123 & -134 & -135 \\
\hline-139 & -167 & -180 & -166 & -181 & -116 & -116 & -129 \\
\hline
\end{tabular}

Tabela A5.2 - Perfis das transversais da Peça 1 medidos com o Sistema Automatizado.

\begin{tabular}{|c|r|r|r|r|r|}
\hline \multicolumn{6}{|c|}{$\begin{array}{c}\text { Perfil das Transversais da Peça 1 }(\mu \mathrm{m})- \\
\text { Amostra 02 - Sistema Automatizado - com } \\
\text { inclinação }\end{array}$} \\
\hline \multicolumn{1}{|c|}{ T1 } & \multicolumn{1}{|c|}{ T4 } & \multicolumn{1}{c|}{ T7 } & \multicolumn{1}{c|}{ T10 } & \multicolumn{1}{c|}{ T13 } & \multicolumn{1}{c|}{ T16 } \\
\hline-47 & -9 & -14 & -49 & -65 & -116 \\
\hline-63 & -18 & -12 & -39 & -58 & -111 \\
\hline-78 & -32 & -17 & -35 & -55 & -108 \\
\hline-100 & -47 & -19 & -32 & -50 & -96 \\
\hline-124 & -63 & -30 & -40 & -54 & -82 \\
\hline-148 & -74 & -41 & -51 & -62 & -68 \\
\hline-156 & -77 & -54 & -78 & -79 & -61 \\
\hline-202 & -102 & -70 & -110 & -97 & -50 \\
\hline
\end{tabular}


Tabela A5.3 - Perfil de superfície da Peça 1.

\begin{tabular}{|r|r|r|r|r|r|r|r|r|r|r|r|r|r|r|r|}
\hline \multicolumn{2}{|c|}{ Perfil da superfície da Peça $1(\mu \mathrm{m})$ - Amostra 02 - Perfil 1, obtido utilizando-se a reta-base T1 } \\
\hline 0 & 0 & 1 & -1 & -3 & -3 & -11 & -15 & -24 & -33 & -41 & -49 & -63 & -69 & -80 & -81 \\
\hline-16 & 1 & 20 & 25 & 25 & 23 & 14 & 9 & -2 & -13 & -26 & -42 & -59 & -74 & -82 & -83 \\
\hline-32 & -2 & 25 & 43 & 52 & 50 & 45 & 38 & 24 & 11 & -2 & -9 & -22 & -34 & -44 & -54 \\
\hline-54 & -31 & -13 & -7 & -2 & 3 & 2 & -8 & -13 & -23 & -38 & -45 & -54 & -56 & -61 & -65 \\
\hline-78 & -66 & -49 & -31 & -21 & -12 & -15 & -17 & -22 & -29 & -45 & -50 & -60 & -67 & -77 & -88 \\
\hline-101 & -95 & -91 & -88 & -85 & -81 & -83 & -87 & -90 & -94 & -94 & -90 & -86 & -83 & -79 & -73 \\
\hline-110 & -103 & -99 & -97 & -99 & -95 & -97 & -103 & -112 & -123 & -133 & -136 & -131 & -120 & -105 & -87 \\
\hline-155 & -153 & -155 & -152 & -151 & -152 & -153 & -157 & -165 & -173 & -168 & -162 & -152 & -145 & -141 & -135 \\
\hline
\end{tabular}

Tabela A5.4 - Coeficientes dos planos ajustados aos perfis da Peça 1 (ajustagem Minimax).

\begin{tabular}{|l|r|r|r|r|r|r|r|r|}
\hline \multicolumn{7}{|c|}{ Peça 1 - Amostra 02 - Coeficientes dos planos ajustados - Sistema Automatizado - } \\
Avaliação com Método Minimax
\end{tabular}

Tabela A5.5 - Coeficientes dos planos ajustados aos perfis da Peça 1 (ajustagem de Mínimos Quadrados).

\begin{tabular}{|l|r|r|r|r|r|r|r|r|}
\hline \multicolumn{7}{|c|}{ Peça 1 - Amostra 02 - Coeficientes dos planos ajustados - Sistema Automatizado - } \\
Avaliação com Método dos Mínimos Quadrados \\
\hline coeficientes & \multicolumn{1}{|c|}{ Perfil 1 } & Perfil 4 & Perfil 7 & Perfil 10 & Perfil 13 & Perfil 16 & Média & $\begin{array}{c}\text { Perfil } \\
\text { Médio }\end{array}$ \\
\hline a0 & 30 & -70 & -4 & -3 & 74 & 62 & 15 & 34 \\
a1 & $-1.5 \mathrm{E}-04$ & $-1.5 \mathrm{E}-04$ & $-1.5 \mathrm{E}-04$ & $-1.5 \mathrm{E}-04$ & $-1.5 \mathrm{E}-04$ & $-1.5 \mathrm{E}-04$ & $-1.5 \mathrm{E}-04$ & $-1.5 \mathrm{E}-04$ \\
$\mathrm{a} 2$ & $-1.1 \mathrm{E}-03$ & $4.2 \mathrm{E}-04$ & $-2.4 \mathrm{E}-04$ & $3.0 \mathrm{E}-04$ & $-5.3 \mathrm{E}-04$ & $2.0 \mathrm{E}-04$ & $-1.6 \mathrm{E}-04$ & $-4.6 \mathrm{E}-04$ \\
\hline
\end{tabular}




\section{Amostra 03}

Tabela A5.6 - Perfis das geratrizes da Peça 1, medidos com o Sistema Automatizado.

\begin{tabular}{|c|c|c|c|c|c|c|c|}
\hline \multicolumn{8}{|c|}{$\begin{array}{c}\text { Perfil das Geratrizes da Peça } 1(\mu \mathrm{m}) \text { - Amostra } 03 \text { - Sistema } \\
\text { Automatizado - com inclinação }\end{array}$} \\
\hline G1 & G2 & G3 & G4 & G5 & G6 & G7 & G8 \\
\hline-26 & -78 & -129 & -129 & -141 & -125 & -112 & -139 \\
\hline-28 & -63 & -99 & -109 & -130 & -120 & -102 & -135 \\
\hline-27 & -45 & -72 & -92 & -115 & -115 & -94 & -136 \\
\hline-30 & -38 & -56 & -86 & -97 & -111 & -90 & -131 \\
\hline-34 & -37 & -44 & -81 & -86 & -108 & -90 & -128 \\
\hline-35 & -40 & -46 & -77 & -76 & -104 & -87 & -126 \\
\hline-44 & -46 & -51 & -77 & -78 & -105 & -91 & -124 \\
\hline-51 & -50 & -57 & -87 & -80 & -109 & -100 & -127 \\
\hline-60 & -58 & -69 & -91 & -87 & -113 & -111 & -132 \\
\hline-69 & -67 & -82 & -102 & -96 & -117 & -125 & -139 \\
\hline-78 & -79 & -95 & -116 & -114 & -116 & -137 & -135 \\
\hline-85 & -93 & -105 & -123 & -117 & -112 & -141 & -130 \\
\hline-99 & -109 & -121 & -130 & -126 & -108 & -141 & -122 \\
\hline-104 & -122 & -136 & -130 & -132 & -106 & -134 & -117 \\
\hline-115 & -127 & -147 & -136 & -140 & -101 & -122 & -115 \\
\hline-114 & -126 & -160 & -139 & -148 & -93 & -108 & -113 \\
\hline
\end{tabular}

Tabela A5.7 - Perfis das transversais da Peça 1, medidos com o Sistema Automatizado.

\begin{tabular}{|r|r|r|r|r|r|}
\hline \multicolumn{6}{|c|}{$\begin{array}{c}\text { Perfil das Transversais da Peça 1 }(\mu \mathrm{m})- \\
\text { Amostra 03- Sistema Automatizado - com } \\
\text { inclinação }\end{array}$} \\
\hline \multicolumn{1}{|c|}{ T1 } & \multicolumn{1}{|c|}{ T4 } & \multicolumn{1}{c|}{ T7 } & \multicolumn{1}{c|}{ T10 } & \multicolumn{1}{c|}{ T13 } & \multicolumn{1}{c|}{ T16 } \\
\hline-28 & -1 & 22 & -24 & -46 & -103 \\
\hline-46 & -9 & 23 & -15 & -39 & -96 \\
\hline-62 & -22 & 14 & -12 & -35 & -93 \\
\hline-85 & -33 & 9 & -9 & -30 & -79 \\
\hline-109 & -47 & -6 & -18 & -32 & -64 \\
\hline-132 & -58 & -25 & -32 & -37 & -49 \\
\hline-139 & -61 & -48 & -60 & -50 & -42 \\
\hline-178 & -84 & -76 & -94 & -63 & -31 \\
\hline
\end{tabular}

Tabela A5.8 - Perfil de superfície da Peça 1.

\begin{tabular}{|r|r|r|r|r|r|r|r|r|r|r|r|r|r|r|r|}
\hline \multicolumn{1}{|c|}{ Perfil da superfície da Peça $1(\mu \mathrm{m})$ - Amostra 03 - Perfil 1, obtido utilizando-se a reta-base T1 } \\
\hline 0 & -1 & 0 & -3 & -7 & -9 & -18 & -25 & -33 & -43 & -52 & -59 & -73 & -78 & -88 & -87 \\
\hline-18 & -3 & 16 & 22 & 23 & 20 & 14 & 10 & 3 & -7 & -19 & -32 & -49 & -62 & -67 & -66 \\
\hline-35 & -5 & 22 & 38 & 50 & 48 & 44 & 37 & 25 & 12 & -1 & -11 & -27 & -41 & -53 & -66 \\
\hline-53 & -33 & -17 & -11 & -5 & -2 & -2 & -12 & -16 & -27 & -41 & -47 & -54 & -55 & -60 & -64 \\
\hline-71 & -60 & -45 & -27 & -16 & -6 & -8 & -10 & -17 & -26 & -44 & -47 & -56 & -62 & -70 & -78 \\
\hline-86 & -82 & -77 & -73 & -70 & -66 & -67 & -71 & -75 & -79 & -78 & -74 & -70 & -68 & -63 & -55 \\
\hline-84 & -74 & -66 & -61 & -62 & -59 & -63 & -71 & -83 & -96 & -108 & -113 & -112 & -106 & -94 & -80 \\
\hline-112 & -108 & -109 & -104 & -101 & -99 & -97 & -100 & -106 & -112 & -108 & -103 & -95 & -91 & -88 & -86 \\
\hline
\end{tabular}


Tabela A5.9 - Coeficientes dos planos ajustados aos perfis da Peça 1 (ajustagem Minimax).

\begin{tabular}{|l|r|r|r|r|r|r|r|r|}
\hline \multicolumn{7}{|c|}{ Peça 1 - Amostra 03 - Coeficientes dos planos ajustados - Sistema Automatizado - } \\
Avaliação com Método Minimax \\
\hline coeficientes & Perfil 1 & Perfil 4 & Perfil 7 & Perfil 10 & Perfil 13 & Perfil 16 & \multicolumn{1}{c|}{ Média } & Perfil Médio \\
\hline a0 & 59 & -41 & -26 & 19 & 65 & 96 & 29 & 26 \\
a1 & $-3.4 \mathrm{E}-04$ & $-1.1 \mathrm{E}-04$ & $-1.1 \mathrm{E}-04$ & $-8.9 \mathrm{E}-05$ & $-1.3 \mathrm{E}-04$ & $-1.8 \mathrm{E}-04$ & $-1.6 \mathrm{E}-04$ & $-1.2 \mathrm{E}-04$ \\
a2 & $-1.2 \mathrm{E}-03$ & $-1.7 \mathrm{E}-04$ & $-3.1 \mathrm{E}-04$ & $-3.1 \mathrm{E}-04$ & $-4.0 \mathrm{E}-04$ & $-2.3 \mathrm{E}-04$ & $-4.3 \mathrm{E}-04$ & $-3.8 \mathrm{E}-04$ \\
\hline
\end{tabular}

Tabela A5.10 - Coeficientes dos planos ajustados aos perfis da Peça 1 (ajustagem de Mínimos Quadrados).

\begin{tabular}{|l|r|r|r|r|r|r|r|r|}
\hline \multicolumn{7}{|c|}{ Peça 1 - Amostra 03 - Coeficientes dos planos ajustados - Sistema Automatizado - } \\
\hline Coeficientes & \multicolumn{1}{|c|}{ Perfil 1 } & Perfil 4 & \multicolumn{1}{c|}{ Perfil 7 } & Perfil 10 & Perfil 13 & Perfil 16 & \multicolumn{1}{c|}{ Média } & Perfil Médio \\
\hline a0 & 24 & -16 & 4 & 37 & 71 & 82 & 34 & 34 \\
a1 & $-1.5 \mathrm{E}-04$ & $-1.5 \mathrm{E}-04$ & $-1.5 \mathrm{E}-04$ & $-1.5 \mathrm{E}-04$ & $-1.5 \mathrm{E}-04$ & $-1.5 \mathrm{E}-04$ & $-1.5 \mathrm{E}-04$ & $-1.5 \mathrm{E}-04$ \\
a2 & $-9.9 \mathrm{E}-04$ & $-3.5 \mathrm{E}-04$ & $-6.1 \mathrm{E}-04$ & $-4.0 \mathrm{E}-04$ & $-4.1 \mathrm{E}-04$ & $-5.3 \mathrm{E}-05$ & $-4.7 \mathrm{E}-04$ & $-4.7 \mathrm{E}-04$ \\
\hline
\end{tabular}

\section{Dados obtidos com a medição convencional}

\section{Amostra 02}

Tabela A5.11 - Perfil das geratrizes da Peça 2 (método convencional).

\begin{tabular}{|r|r|r|r|r|r|r|r|}
\hline \multicolumn{7}{|c|}{ Perfil das Geratrizes da Peça 2 $(\mu \mathrm{m})$ - Medição Convencional - } \\
\multicolumn{1}{|r|}{ com inclinação - Amostra 02 } \\
\hline \multicolumn{1}{|c|}{ G1 } & \multicolumn{1}{c|}{ G2 } & \multicolumn{1}{c|}{ G4 } & \multicolumn{1}{c|}{ G5 } & \multicolumn{1}{c|}{ G6 } & \multicolumn{1}{c|}{ G7 } & G8 \\
\hline 85 & 60 & 50 & 40 & 40 & 45 & 80 & 90 \\
\hline 95 & 75 & 60 & 50 & 50 & 55 & 85 & 95 \\
\hline 100 & 80 & 70 & 60 & 60 & 60 & 90 & 95 \\
\hline 100 & 85 & 75 & 70 & 60 & 70 & 90 & 95 \\
\hline 95 & 80 & 70 & 70 & 60 & 70 & 90 & 95 \\
\hline 85 & 75 & 70 & 70 & 60 & 70 & 80 & 85 \\
\hline 80 & 70 & 60 & 60 & 60 & 65 & 80 & 85 \\
\hline 65 & 55 & 50 & 50 & 55 & 60 & 65 & 75 \\
\hline 45 & 45 & 40 & 40 & 40 & 45 & 55 & 65 \\
\hline 30 & 25 & 25 & 25 & 30 & 35 & 40 & 50 \\
\hline 10 & 5 & 5 & 10 & 10 & 20 & 30 & 40 \\
\hline-10 & -20 & -20 & -10 & -5 & 10 & 20 & 30 \\
\hline-35 & -40 & -40 & -30 & -20 & -5 & 5 & 20 \\
\hline-50 & -60 & -60 & -50 & -40 & -25 & -5 & 15 \\
\hline-75 & -80 & -85 & -70 & -55 & -40 & -20 & 5 \\
\hline-95 & -105 & -105 & -95 & -75 & -50 & -35 & -5 \\
\hline
\end{tabular}




\section{Amostra 03}

Tabela A6.12 - Perfil das geratrizes da Peça 2 (método convencional).

\begin{tabular}{|c|c|c|c|c|c|c|c|}
\hline \multicolumn{8}{|c|}{$\begin{array}{c}\text { Perfil das Geratrizes da Peça } 2(\mu \mathrm{m}) \text { - Medição Convencional - } \\
\text { com inclinação - Amostra } 03\end{array}$} \\
\hline G1 & G2 & G3 & G4 & G5 & G6 & G7 & G8 \\
\hline 90 & 65 & 55 & 45 & 40 & 45 & 80 & 90 \\
\hline 95 & 75 & 60 & 55 & 50 & 55 & 85 & 90 \\
\hline 100 & 80 & 70 & 60 & 55 & 65 & 85 & 95 \\
\hline 100 & 85 & 75 & 70 & 60 & 70 & 90 & 95 \\
\hline 95 & 80 & 70 & 70 & 60 & 70 & 90 & 95 \\
\hline 90 & 80 & 70 & 65 & 60 & 70 & 80 & 85 \\
\hline 85 & 70 & 70 & 65 & 60 & 70 & 80 & 80 \\
\hline 65 & 55 & 50 & 50 & 50 & 55 & 65 & 70 \\
\hline 50 & 45 & 40 & 40 & 40 & 45 & 50 & 60 \\
\hline 35 & 25 & 25 & 25 & 30 & 35 & 40 & 50 \\
\hline 10 & 5 & 5 & 5 & 15 & 20 & 30 & 40 \\
\hline-10 & -20 & -15 & -15 & -5 & 5 & 20 & 30 \\
\hline-35 & -35 & -40 & -30 & -20 & -5 & 5 & 20 \\
\hline-55 & -60 & -65 & -50 & -40 & -20 & -5 & 15 \\
\hline-75 & -80 & -80 & -70 & -55 & -35 & -20 & 5 \\
\hline-95 & -105 & -105 & -90 & -75 & -55 & -30 & -5 \\
\hline
\end{tabular}




\section{Valores do Desvio de Perpendicularismo da Peça 1 - combinações entre as amostras de dados da peça e as amostras de dados do plano de referência}

Tabela A5.13 - Desvios de perpendicularismo da Peça 1 (Sistema Automatizado e ajustagem Minimax) - Amostras 01 e 01.

\begin{tabular}{|c|c|c|c|c|c|c|c|c|c|c|}
\hline \multicolumn{11}{|c|}{$\begin{array}{c}\text { Desvio de Perpendicularismo - Peça } 1 \text { - Medição com o Sistema Automatizado - } \\
\text { Avaliação com o Método Minimax }\end{array}$} \\
\hline \multicolumn{4}{|c|}{ Amostra de medição da Peça: } & \multirow{2}{*}{$\begin{array}{c}01 \\
\mathrm{R} 1-\mathrm{P} 7\end{array}$} & \multicolumn{5}{|c|}{$\begin{array}{l}\text { Amostra de medição da superfície de } \\
\text { referência: }\end{array}$} & \multirow{2}{*}{$\begin{array}{c}01 \\
\text { Desvio } \\
\text { padrão }\end{array}$} \\
\hline Comb & hações & $\mathrm{R} 1-\mathrm{P} 1$ & $\mathrm{R} 1-\mathrm{P} 4$ & & $\mathrm{R} 1-\mathrm{P} 10$ & $\mathrm{R} 1-\mathrm{P} 13$ & $\mathrm{R} 1-\mathrm{P} 16$ & R1-PM & $\begin{array}{c}\text { Média } \\
\text { (R1) }\end{array}$ & \\
\hline \multirow{3}{*}{$\begin{array}{c}\text { Valores } \\
\text { do } \\
\text { desvio }\end{array}$} & radianos & $-6.5 \mathrm{E}-04$ & $-5.4 \mathrm{E}-04$ & $-5.4 \mathrm{E}-04$ & $-5.5 \mathrm{E}-04$ & $-5.6 \mathrm{E}-04$ & $-5.1 \mathrm{E}-04$ & $-5.4 \mathrm{E}-04$ & $-5.6 \mathrm{E}-04$ & 4.9E-05 \\
\hline & arco-seg & -134 & -112 & -112 & -113 & -115 & -104 & -112 & -115 & 10 \\
\hline & $\mu \mathrm{m}$ & -176 & -147 & -147 & -148 & -151 & -137 & -147 & -151 & 13 \\
\hline
\end{tabular}

\begin{tabular}{|c|l|r|r|r|r|r|r|r|r|r|}
\hline \multicolumn{2}{|c|}{ Combinações } & \multicolumn{1}{c|}{ R3-P1 } & R3-P4 & R3-P7 & R3-P10 & R3-P13 & R3-P16 & R3-PM & $\begin{array}{c}\text { Média } \\
\text { (R3) }\end{array}$ & $\begin{array}{c}\text { Desvio } \\
\text { padrão }\end{array}$ \\
\hline \multirow{2}{*}{\begin{tabular}{c} 
Valores $\begin{array}{c}\text { do } \\
\text { do } \\
\text { desvio }\end{array}$ \\
\cline { 2 - 12 }
\end{tabular}} & arco-seg & $-6.4 \mathrm{E}-04$ & $-5.3 \mathrm{E}-04$ & $-5.3 \mathrm{E}-04$ & $-5.4 \mathrm{E}-04$ & $-5.5 \mathrm{E}-04$ & $-4.9 \mathrm{E}-04$ & $-5.3 \mathrm{E}-04$ & $-5.5 \mathrm{E}-04$ & $4.9 \mathrm{E}-05$ \\
\cline { 2 - 11 } & -132 & -110 & -110 & -111 & -113 & -102 & -110 & -113 & 10 \\
\hline
\end{tabular}

\begin{tabular}{|c|c|c|c|c|c|c|c|c|c|c|}
\hline \multicolumn{2}{|c|}{ Combinações } & & R5-P4 & & & & & & $\begin{array}{c}\text { Média } \\
\text { (R5) }\end{array}$ & $\begin{array}{l}\text { Desvio } \\
\text { padrão }\end{array}$ \\
\hline \multirow{3}{*}{$\begin{array}{c}\text { Valores } \\
\text { do } \\
\text { desvio }\end{array}$} & radianos & $-6.4 \mathrm{E}-04$ & $-5.4 \mathrm{E}-04$ & $-5.4 \mathrm{E}-04$ & $-5.4 \mathrm{E}-04$ & $-5.5 \mathrm{E}-04$ & $-5.0 \mathrm{E}-04$ & $-5.4 \mathrm{E}-04$ & $-5.5 \mathrm{E}-04$ & $4.9 \mathrm{E}-05$ \\
\hline & arco-seg & -132 & -110 & -110 & -111 & -113 & -102 & -110 & -113 & 10 \\
\hline & $\mu \mathrm{m}$ & -173 & -145 & -145 & -146 & -148 & -134 & -145 & -148 & 13 \\
\hline
\end{tabular}

\begin{tabular}{|c|l|r|r|r|r|r|r|r|}
\cline { 3 - 9 } \multicolumn{2}{c|}{} & \multicolumn{1}{c|}{$\mathrm{P} 1$} & \multicolumn{1}{c|}{$\mathrm{P} 4$} & \multicolumn{1}{c|}{$\mathrm{P} 7$} & \multicolumn{1}{c|}{$\mathrm{P} 10$} & \multicolumn{1}{c|}{$\mathrm{P} 13$} & \multicolumn{1}{c|}{$\mathrm{P} 16$} & \multicolumn{1}{c|}{ Pmédio } \\
\hline \multirow{3}{*}{ Médias } & radianos & $-6.4 \mathrm{E}-04$ & $-5.4 \mathrm{E}-04$ & $-5.4 \mathrm{E}-04$ & $-5.4 \mathrm{E}-04$ & $-5.5 \mathrm{E}-04$ & $-5.0 \mathrm{E}-04$ & $-5.4 \mathrm{E}-04$ \\
\cline { 2 - 9 } & arco-seg & -133 & -111 & -111 & -112 & -114 & -103 & -111 \\
\cline { 2 - 9 } & $\mu \mathrm{m}$ & -174 & -145 & -145 & -146 & -149 & -135 & -145 \\
\hline
\end{tabular}

\begin{tabular}{|c|c|c|c|c|c|c|c|c|}
\hline & & P1 & P4 & P7 & P10 & $\mathrm{P} 13$ & P16 & Pmédio \\
\hline \multirow{3}{*}{$\begin{array}{l}\text { Desvios- } \\
\text { padrão }\end{array}$} & \multirow{2}{*}{$\begin{array}{l}\text { radianos } \\
\text { arco-seg }\end{array}$} & $6.2 \mathrm{E}-06$ & $6.2 \mathrm{E}-06$ & $6.2 \mathrm{E}-06$ & $6.2 \mathrm{E}-06$ & $6.2 \mathrm{E}-06$ & $6.2 \mathrm{E}-06$ & $6.2 \mathrm{E}-06$ \\
\hline & & 1 & 1 & 1 & 1 & 1 & 1 & 1 \\
\hline & $\mu \mathrm{m}$ & 2 & 2 & 2 & 2 & 2 & 2 & 2 \\
\hline
\end{tabular}

Obs.: Os valores do desvio resultantes da combinação entre a amostra 01 de dados da peça e a amostra 02 de dados do artefato de referência são apresentados no capítulo 6 deste trabalho, item 6.2.1. 
Tabela A5.14 - Desvios de perpendicularismo da Peça 1 (Sistema Automatizado e ajustagem Minimax) - Amostras 01 e 03.

\begin{tabular}{|c|c|c|c|c|c|c|c|c|c|c|}
\hline \multicolumn{11}{|c|}{$\begin{array}{c}\text { Desvio de Perpendicularismo - Peça } 1 \text { - Medição com o Sistema Automatizado - } \\
\text { Avaliação com o Método Minimax }\end{array}$} \\
\hline \multicolumn{5}{|c|}{ Amostra de medição da Peça: } & \multirow{2}{*}{$\begin{array}{c}01 \\
\mathrm{R} 1-\mathrm{P} 10\end{array}$} & \multicolumn{4}{|c|}{$\begin{array}{l}\text { Amostra de medição da superfície } \\
\text { de referência: }\end{array}$} & \multirow{2}{*}{$\begin{array}{c}\mathbf{0 3} \\
\text { Desvio } \\
\text { padrão }\end{array}$} \\
\hline Comb & nações & $\mathrm{R} 1-\mathrm{P} 1$ & $\mathrm{R} 1-\mathrm{P} 4$ & $\mathrm{R} 1-\mathrm{P} 7$ & & $\mathrm{R} 1-\mathrm{P} 13$ & R1-P16 & R1-PM & $\begin{array}{c}\text { Médias } \\
\text { (R1) }\end{array}$ & \\
\hline \multirow{3}{*}{$\begin{array}{c}\text { Valores } \\
\text { do } \\
\text { desvio }\end{array}$} & radianos & $-6.8 \mathrm{E}-04$ & $-5.7 \mathrm{E}-04$ & $-5.7 \mathrm{E}-04$ & $-5.7 \mathrm{E}-04$ & $-5.8 \mathrm{E}-04$ & $-5.3 \mathrm{E}-04$ & $-5.7 \mathrm{E}-04$ & $-5.8 \mathrm{E}-04$ & 4.9E-05 \\
\hline & arco-seg & -139 & -117 & -117 & -118 & -120 & -109 & -117 & -120 & 10 \\
\hline & $\mu \mathrm{m}$ & -182 & -154 & -154 & -155 & -157 & -143 & -154 & -157 & 13 \\
\hline
\end{tabular}

\begin{tabular}{|c|r|r|r|r|r|r|r|r|r|r|}
\hline \multicolumn{2}{|c|}{$\begin{array}{c}\text { Combinações } \\
\text { R4-P1 }\end{array}$} & \multicolumn{1}{|c|}{ R4-P4 } & R4-P7 & R4-P10 & R4-P13 & R4-P16 & R4-PM & $\begin{array}{c}\text { Médias } \\
\text { (R4) }\end{array}$ & $\begin{array}{c}\text { Desvio } \\
\text { padrão }\end{array}$ \\
\hline \multirow{2}{*}{\begin{tabular}{c} 
Valores $\begin{array}{c}\text { do } \\
\text { desvio }\end{array}$ \\
\cline { 3 - 12 }
\end{tabular}} & radianos & $-6.8 \mathrm{E}-04$ & $-5.7 \mathrm{E}-04$ & $-5.7 \mathrm{E}-04$ & $-5.7 \mathrm{E}-04$ & $-5.8 \mathrm{E}-04$ & $-5.3 \mathrm{E}-04$ & $-5.7 \mathrm{E}-04$ & $-5.8 \mathrm{E}-04$ & $4.9 \mathrm{E}-05$ \\
\cline { 2 - 11 } & $\mu \mathrm{m}$ & -139 & -117 & -117 & -118 & -120 & -109 & -117 & -120 & 10 \\
\hline
\end{tabular}

\begin{tabular}{|c|c|c|c|c|c|c|c|c|c|c|}
\hline \multicolumn{2}{|c|}{ Combinações } & R7-P1 & R7-P4 & R7-P7 & R7-P10 & R7-P13 & R7-P16 & R7-PM & $\begin{array}{l}\text { Médias } \\
\text { (R7) }\end{array}$ & $\begin{array}{l}\text { Desvio } \\
\text { padrão }\end{array}$ \\
\hline \multirow{3}{*}{$\begin{array}{c}\text { Valores } \\
\text { do } \\
\text { desvio }\end{array}$} & radianos & $-6.6 \mathrm{E}-04$ & $-5.6 E-04$ & $-5.6 E-04$ & $-5.6 \mathrm{E}-04$ & $-5.7 E-04$ & $-5.2 E-04$ & $-5.7 E-04$ & $-5.7 \mathrm{E}-04$ & $4.9 \mathrm{E}-05$ \\
\hline & arco-seg & -137 & -115 & -115 & -115 & -117 & -107 & -117 & -118 & 10 \\
\hline & $\mu \mathrm{m}$ & -179 & -150 & -150 & -151 & -154 & -140 & -154 & -154 & 13 \\
\hline
\end{tabular}

\begin{tabular}{|c|r|r|r|r|r|r|r|r|r|r|}
\hline \multicolumn{2}{|c|}{ Combinações } & R10-P1 & R10-P4 & R10-P7 & R10-P10 & R10-P13 & R10-P16 & R10-PM & $\begin{array}{c}\text { Médias } \\
\text { (R10) }\end{array}$ & $\begin{array}{c}\text { Desvio } \\
\text { padrão }\end{array}$ \\
\hline \multirow{2}{*}{\begin{tabular}{c} 
Valores $\begin{array}{c}\text { Ro } \\
\text { do } \\
\text { desvio }\end{array}$ \\
\cline { 2 - 12 }
\end{tabular}} & radianos & $-6.8 \mathrm{E}-04$ & $-5.7 \mathrm{E}-04$ & $-5.7 \mathrm{E}-04$ & $-5.7 \mathrm{E}-04$ & $-5.8 \mathrm{E}-04$ & $-5.3 \mathrm{E}-04$ & $-5.7 \mathrm{E}-04$ & $-5.8 \mathrm{E}-04$ & $4.9 \mathrm{E}-05$ \\
\cline { 2 - 11 } & $\mu \mathrm{m}$ & -139 & -117 & -117 & -118 & -120 & -109 & -117 & -120 & 10 \\
\hline
\end{tabular}

\begin{tabular}{|c|c|c|c|c|c|c|c|c|c|c|}
\hline \multicolumn{2}{|c|}{ Combinações } & R13-P1 & R13-P4 & R13-P7 & R13-P10 & R13-P13 & R13-P16 & R13-PM & $\begin{array}{l}\text { Médias } \\
\text { (R13) }\end{array}$ & $\begin{array}{l}\text { Desvio } \\
\text { padrão }\end{array}$ \\
\hline \multirow{3}{*}{$\begin{array}{l}\text { Valores } \\
\text { do } \\
\text { desvio }\end{array}$} & radianos & $-6.4 \mathrm{E}-04$ & $-5.3 \mathrm{E}-04$ & $-5.3 E-04$ & $-5.3 \mathrm{E}-04$ & $-5.4 \mathrm{E}-04$ & $-4.9 \mathrm{E}-04$ & $-5.3 E-04$ & $-5.4 \mathrm{E}-04$ & $4.9 \mathrm{E}-05$ \\
\hline & arco-seg & -131 & -109 & -109 & -110 & -112 & -101 & -109 & -112 & 10 \\
\hline & $\mu \mathrm{m}$ & -171 & -143 & -143 & -144 & -146 & -132 & -143 & -147 & 13 \\
\hline
\end{tabular}

\begin{tabular}{|c|c|c|c|c|c|c|c|c|c|c|}
\hline \multicolumn{2}{|c|}{ Combinações } & RM-P1 & RM-P4 & RM-P7 & RM-P10 & RM-P13 & RM-P16 & RM-PM & $\begin{array}{l}\text { Médias } \\
(\mathrm{RM})\end{array}$ & $\begin{array}{l}\text { Desvio } \\
\text { padrão }\end{array}$ \\
\hline \multirow{3}{*}{$\begin{array}{c}\text { Valores } \\
\text { do } \\
\text { desvio }\end{array}$} & radianos & $-6.8 \mathrm{E}-04$ & $-5.7 \mathrm{E}-04$ & $-5.7 \mathrm{E}-04$ & $-5.7 \mathrm{E}-04$ & $-5.8 \mathrm{E}-04$ & $-5.3 \mathrm{E}-04$ & $-5.7 \mathrm{E}-04$ & $-5.8 \mathrm{E}-04$ & $4.9 \mathrm{E}-05$ \\
\hline & arco-seg & -139 & -117 & -117 & -118 & -120 & -109 & -117 & -120 & 10 \\
\hline & $\mu \mathrm{m}$ & -182 & -154 & -154 & -155 & -157 & -143 & -154 & -157 & 13 \\
\hline
\end{tabular}

\begin{tabular}{|c|l|r|r|r|r|r|r|r|}
\cline { 3 - 9 } \multicolumn{2}{c|}{} & \multicolumn{1}{c|}{$\mathrm{P} 1$} & \multicolumn{1}{c|}{$\mathrm{P} 4$} & \multicolumn{1}{c|}{$\mathrm{P} 7$} & \multicolumn{1}{c|}{$\mathrm{P} 10$} & \multicolumn{1}{c|}{$\mathrm{P} 13$} & \multicolumn{1}{c|}{$\mathrm{P} 16$} & \multicolumn{1}{c|}{ Pmédio } \\
\hline \multirow{3}{*}{ Médias } & radianos & $-6.6 \mathrm{E}-04$ & $-5.6 \mathrm{E}-04$ & $-5.6 \mathrm{E}-04$ & $-5.6 \mathrm{E}-04$ & $-5.7 \mathrm{E}-04$ & $-5.2 \mathrm{E}-04$ & $-5.6 \mathrm{E}-04$ \\
\cline { 2 - 9 } & arco-seg & -137 & -115 & -115 & -116 & -118 & -107 & -116 \\
\cline { 2 - 9 } & $\mu \mathrm{m}$ & -180 & -151 & -151 & -152 & -154 & -140 & -152 \\
\hline
\end{tabular}

\begin{tabular}{|c|l|r|r|r|r|r|r|r|}
\cline { 2 - 9 } \multicolumn{2}{c|}{} & \multicolumn{1}{c|}{$\mathrm{P} 1$} & $\mathrm{P} 4$ & $\mathrm{P} 7$ & \multicolumn{1}{c|}{$\mathrm{P} 10$} & $\mathrm{P} 13$ & $\mathrm{P} 16$ & Pmédio \\
\hline \multirow{2}{*}{$\begin{array}{c}\text { Desvios- } \\
\text { padrão }\end{array}$} & $\begin{array}{l}\text { radianos } \\
\text { arco-seg }\end{array}$ & $1.8 \mathrm{E}-05$ & $1.8 \mathrm{E}-05$ & $1.8 \mathrm{E}-05$ & $1.8 \mathrm{E}-05$ & $1.8 \mathrm{E}-05$ & $1.8 \mathrm{E}-05$ & $1.8 \mathrm{E}-05$ \\
\cline { 2 - 9 } & $\mu \mathrm{m}$ & 4 & 4 & 4 & 4 & 4 & 4 & 4 \\
\hline
\end{tabular}


Tabela A5.15 - Desvios de perpendicularismo da Peça 1 (Sistema Automatizado e ajustagem Minimax) - Amostras 02 e 01.

\begin{tabular}{|c|c|c|c|c|c|c|c|c|c|c|}
\hline \multicolumn{11}{|c|}{$\begin{array}{c}\text { Desvio de Perpendicularismo - Peça } 1 \text { - Medição com o Sistema Automatizado - } \\
\text { Avaliação com o Método Minimax }\end{array}$} \\
\hline \multicolumn{4}{|c|}{ Amostra de medição da Peça: } & \multirow{2}{*}{$\begin{array}{c}02 \\
\mathrm{R} 1-\mathrm{P} 7\end{array}$} & \multicolumn{5}{|c|}{$\begin{array}{l}\text { Amostra de medição da superfície de } \\
\text { referência: }\end{array}$} & \multirow{2}{*}{$\begin{array}{c}01 \\
\text { Desvio } \\
\text { padrão }\end{array}$} \\
\hline Comb & nações & $\mathrm{R} 1-\mathrm{P} 1$ & $\mathrm{R} 1-\mathrm{P} 4$ & & $\mathrm{R} 1-\mathrm{P} 10$ & $\mathrm{R} 1-\mathrm{P} 13$ & R1-P16 & R1-PM & $\begin{array}{c}\text { Média } \\
\text { (R1) }\end{array}$ & \\
\hline \multirow{3}{*}{$\begin{array}{c}\text { Valores } \\
\text { do } \\
\text { desvio }\end{array}$} & radianos & $-6.7 \mathrm{E}-04$ & $-4.7 \mathrm{E}-04$ & $-4.5 \mathrm{E}-04$ & $-5.0 \mathrm{E}-04$ & $-5.0 \mathrm{E}-04$ & $-4.7 \mathrm{E}-04$ & $-4.9 \mathrm{E}-04$ & $-5.1 \mathrm{E}-04$ & $7.8 \mathrm{E}-05$ \\
\hline & arco-seg & -137 & -97 & -93 & -103 & -102 & -98 & -101 & -105 & 16 \\
\hline & $\mu \mathrm{m}$ & -180 & -127 & -122 & -134 & -134 & -128 & -133 & -138 & 21 \\
\hline
\end{tabular}

\begin{tabular}{|c|r|r|r|r|r|r|r|r|r|r|}
\hline \multicolumn{2}{|c|}{$\begin{array}{c}\text { Combinações } \\
\text { R3-P1 }\end{array}$} & \multicolumn{1}{c|}{ R3-P4 } & \multicolumn{1}{c|}{ R3-P7 } & R3-P10 & R3-P13 & R3-P16 & R3-PM & $\begin{array}{c}\text { Média } \\
\text { (R3) }\end{array}$ & $\begin{array}{c}\text { Desvio } \\
\text { padrão }\end{array}$ \\
\hline \multirow{2}{*}{$\begin{array}{c}\text { Valores } \\
\text { do } \\
\text { desvio }\end{array}$} & $\begin{array}{l}\text { radianos } \\
\text { arco-seg }\end{array}$ & $-6.5 \mathrm{E}-04$ & $-4.6 \mathrm{E}-04$ & $-4.4 \mathrm{E}-04$ & $-4.9 \mathrm{E}-04$ & $-4.8 \mathrm{E}-04$ & $-4.6 \mathrm{E}-04$ & $-4.8 \mathrm{E}-04$ & $-5.0 \mathrm{E}-04$ & $7.8 \mathrm{E}-05$ \\
\cline { 2 - 11 } & $\mu \mathrm{m}$ & -176 & -124 & -91 & -100 & -100 & -95 & -99 & -103 & 16 \\
\hline
\end{tabular}

\begin{tabular}{|c|r|r|r|r|r|r|r|r|r|r|}
\hline \multicolumn{2}{|c|}{ Combinações } & \multicolumn{1}{|c|}{ R5-P1 } & R5-P4 & R5-P7 & R5-P10 & R5-P13 & R5-P16 & R5-PM & $\begin{array}{c}\text { Média } \\
\text { (R5) }\end{array}$ & $\begin{array}{c}\text { Desvio } \\
\text { padrão }\end{array}$ \\
\hline \multirow{2}{*}{$\begin{array}{c}\text { Valores } \\
\text { do } \\
\text { desvio }\end{array}$} & $\begin{array}{l}\text { radianos } \\
\text { arco-seg }\end{array}$ & $-6.6 \mathrm{E}-04$ & $-4.6 \mathrm{E}-04$ & $-4.4 \mathrm{E}-04$ & $-4.9 \mathrm{E}-04$ & $-4.9 \mathrm{E}-04$ & $-4.7 \mathrm{E}-04$ & $-4.8 \mathrm{E}-04$ & $-5.0 \mathrm{E}-04$ & $7.8 \mathrm{E}-05$ \\
\cline { 2 - 11 } & $\mu \mathrm{m}$ & -135 & -95 & -92 & -101 & -100 & -96 & -99 & -103 & 16 \\
\hline
\end{tabular}

\begin{tabular}{|c|l|r|r|r|r|r|r|r|}
\cline { 3 - 9 } \multicolumn{2}{c|}{} & \multicolumn{1}{c|}{$\mathrm{P} 1$} & \multicolumn{1}{c|}{$\mathrm{P} 4$} & \multicolumn{1}{c|}{$\mathrm{P} 7$} & \multicolumn{1}{c|}{$\mathrm{P} 10$} & \multicolumn{1}{c|}{$\mathrm{P} 13$} & \multicolumn{1}{c|}{$\mathrm{P} 16$} & \multicolumn{1}{c|}{ Pmédio } \\
\hline \multirow{3}{*}{ Médias } & radianos & $-6.6 \mathrm{E}-04$ & $-4.6 \mathrm{E}-04$ & $-4.5 \mathrm{E}-04$ & $-4.9 \mathrm{E}-04$ & $-4.9 \mathrm{E}-04$ & $-4.7 \mathrm{E}-04$ & $-4.8 \mathrm{E}-04$ \\
\cline { 2 - 9 } & arco-seg & -136 & -96 & -92 & -101 & -101 & -96 & -100 \\
\cline { 2 - 9 } & $\mu \mathrm{m}$ & -178 & -125 & -120 & -132 & -132 & -126 & -131 \\
\hline
\end{tabular}

\begin{tabular}{|c|l|r|r|r|r|r|r|r|}
\cline { 3 - 9 } \multicolumn{2}{c|}{} & \multicolumn{1}{c|}{$\mathrm{P} 1$} & \multicolumn{1}{c|}{$\mathrm{P} 4$} & \multicolumn{1}{c|}{$\mathrm{P} 7$} & \multicolumn{1}{c|}{$\mathrm{P} 10$} & \multicolumn{1}{c|}{$\mathrm{P} 13$} & \multicolumn{1}{c|}{$\mathrm{P} 16$} & Pmédio \\
\hline \multirow{2}{*}{$\begin{array}{c}\text { Desvios- } \\
\text { padrão }\end{array}$} & radianos & $6.2 \mathrm{E}-06$ & $6.2 \mathrm{E}-06$ & $6.2 \mathrm{E}-06$ & $6.2 \mathrm{E}-06$ & $6.2 \mathrm{E}-06$ & $6.2 \mathrm{E}-06$ & $6.2 \mathrm{E}-06$ \\
\cline { 2 - 9 } & \begin{tabular}{r} 
arco-seg \\
\cline { 2 - 8 }
\end{tabular} & 1 & 1 & 1 & 1 & 1 & 1 & 1 \\
\hline
\end{tabular}


Tabela A5.16 - Desvios de perpendicularismo da Peça 1 (Sistema Automatizado e ajustagem Minimax) - Amostras 02 e 02.

\begin{tabular}{|c|c|c|c|c|c|c|c|c|c|c|}
\hline \multicolumn{11}{|c|}{$\begin{array}{c}\text { Desvio de Perpendicularismo - Peça } 1 \text { - Medição com o Sistema Automatizado - } \\
\text { Avaliação com o Método Minimax }\end{array}$} \\
\hline \multicolumn{5}{|c|}{ Amostra de medição da Peça: } & \multirow{2}{*}{$\begin{array}{c}02 \\
R 1-P 10\end{array}$} & \multicolumn{4}{|c|}{$\begin{array}{l}\text { Amostra de medição da superfície } \\
\text { de referência: }\end{array}$} & \multirow{2}{*}{$\begin{array}{c}02 \\
\text { Desvio } \\
\text { padrão }\end{array}$} \\
\hline Comk & inações & $\mathrm{R} 1-\mathrm{P} 1$ & $\mathrm{R} 1-\mathrm{P} 4$ & R1-P7 & & R1-P13 & $\mathrm{R} 1-\mathrm{P} 16$ & R1-PM & $\begin{array}{c}\text { Médias } \\
(\mathrm{R} 1)\end{array}$ & \\
\hline \multirow{3}{*}{$\begin{array}{c}\text { Valores } \\
\text { do } \\
\text { desvio }\end{array}$} & radianos & $-7.4 \mathrm{E}-04$ & $-5.5 \mathrm{E}-04$ & $-5.3 \mathrm{E}-04$ & $-5.7 \mathrm{E}-04$ & $-5.7 \mathrm{E}-04$ & $-5.5 \mathrm{E}-04$ & $-5.7 E-04$ & $-5.8 \mathrm{E}-04$ & $7.8 \mathrm{E}-05$ \\
\hline & arco-seg & -153 & -113 & -109 & -118 & -118 & -113 & -117 & $-1.2 \mathrm{E}+02$ & 1.6E +01 \\
\hline & $\mu \mathrm{m}$ & -200 & -147 & -143 & -155 & -154 & -148 & -153 & -158 & 21 \\
\hline
\end{tabular}

\begin{tabular}{|c|c|c|c|c|c|c|c|c|c|c|}
\hline \multicolumn{2}{|c|}{ Combinacões } & R4-P1 & R4-P4 & R4-P7 & R4-P10 & R4-P13 & R4-P16 & R4-PM & $\begin{array}{c}\text { Médias } \\
(\mathrm{R} 4)\end{array}$ & $\begin{array}{l}\text { Desvio } \\
\text { padrão }\end{array}$ \\
\hline \multirow{3}{*}{$\begin{array}{c}\text { Valores } \\
\text { do } \\
\text { desvio }\end{array}$} & radianos & $-6.9 \mathrm{E}-04$ & $-5.0 \mathrm{E}-04$ & $-4.8 \mathrm{E}-04$ & $-5.3 \mathrm{E}-04$ & $-5.2 E-04$ & $-5.0 \mathrm{E}-04$ & $-5.2 E-04$ & $-5.4 \mathrm{E}-04$ & $7.8 \mathrm{E}-05$ \\
\hline & arco-seg & -143 & -103 & -99 & -108 & -108 & -104 & -107 & -110.8 & 16.1 \\
\hline & $\mu \mathrm{m}$ & -187 & -134 & -130 & -142 & -141 & -136 & -140 & -145 & 21 \\
\hline
\end{tabular}

\begin{tabular}{|c|c|c|c|c|c|c|c|c|c|c|}
\hline \multicolumn{2}{|c|}{ Combinacões } & R7-P1 & R7-P4 & R7-P7 & R7-P10 & R7-P13 & R7-P16 & R7-PM & $\begin{array}{c}\text { Médias } \\
\text { (R7) }\end{array}$ & $\begin{array}{l}\text { Desvio } \\
\text { padrão }\end{array}$ \\
\hline \multirow{3}{*}{$\begin{array}{c}\text { Valores } \\
\text { do } \\
\text { desvio }\end{array}$} & radianos & $-6.9 \mathrm{E}-04$ & $-4.9 \mathrm{E}-04$ & $-4.8 \mathrm{E}-04$ & $-5.2 \mathrm{E}-04$ & $-5.2 \mathrm{E}-04$ & $-5.0 \mathrm{E}-04$ & $-5.0 \mathrm{E}-04$ & $-5.3 E-04$ & $7.8 \mathrm{E}-05$ \\
\hline & arco-seg & -142 & -102 & -98 & -107 & -107 & -102 & -103 & -109.6 & 16.1 \\
\hline & $\mu \mathrm{m}$ & -186 & -133 & -128 & -140 & -140 & -134 & -135 & -144 & 21 \\
\hline
\end{tabular}

\begin{tabular}{|c|c|c|c|c|c|c|c|c|c|c|}
\hline \multicolumn{2}{|c|}{ Combinações } & R10-P1 & R10-P4 & R10-P7 & R10-P10 & R10-P13 & R10-P16 & R10-PM & $\begin{array}{l}\text { Médias } \\
\text { (R10) }\end{array}$ & $\begin{array}{l}\text { Desvio } \\
\text { padrão }\end{array}$ \\
\hline \multirow{3}{*}{$\begin{array}{c}\text { Valores } \\
\text { do } \\
\text { desvio }\end{array}$} & radianos & $-6.7 \mathrm{E}-04$ & $-4.8 \mathrm{E}-04$ & $-4.6 \mathrm{E}-04$ & $-5.0 \mathrm{E}-04$ & $-5.0 \mathrm{E}-04$ & $-4.8 \mathrm{E}-04$ & $-5.0 \mathrm{E}-04$ & $-5.2 \mathrm{E}-04$ & $7.8 \mathrm{E}-05$ \\
\hline & arco-seg & -139 & -99 & -95 & -104 & -104 & -99 & -103 & -106.6 & 16.1 \\
\hline & $\mu \mathrm{m}$ & -182 & -129 & -124 & -136 & -136 & -130 & -135 & -140 & 21 \\
\hline
\end{tabular}

\begin{tabular}{|c|c|c|c|c|c|c|c|c|c|c|}
\hline \multicolumn{2}{|c|}{ Combinações } & R13-P1 & R13-P4 & R13-P7 & $\mathrm{R} 13-\mathrm{P} 10$ & R13-P13 & R13-P16 & R13-PM & $\begin{array}{l}\text { Médias } \\
\text { (R13) }\end{array}$ & $\begin{array}{l}\text { Desvio } \\
\text { padrão }\end{array}$ \\
\hline \multirow{3}{*}{$\begin{array}{c}\text { Valores } \\
\text { do } \\
\text { desvio }\end{array}$} & \multirow{2}{*}{\begin{tabular}{|l|} 
radianos \\
arco-seg
\end{tabular}} & $-6.7 \mathrm{E}-04$ & $-4.8 \mathrm{E}-04$ & $-4.6 \mathrm{E}-04$ & $-5.0 \mathrm{E}-04$ & $-5.0 \mathrm{E}-04$ & $-4.8 \mathrm{E}-04$ & $-5.0 \mathrm{E}-04$ & $-5.2 \mathrm{E}-04$ & $7.8 \mathrm{E}-05$ \\
\hline & & -139 & -99 & -95 & -104 & -104 & -99 & -103 & -106.6 & 16.1 \\
\hline & $\mu \mathrm{m}$ & -182 & -129 & -124 & -136 & -136 & -130 & -135 & -140 & 21 \\
\hline
\end{tabular}

\begin{tabular}{|c|c|c|c|c|c|c|c|c|c|c|}
\hline \multicolumn{2}{|c|}{ Combinações } & RM-P1 & RM-P4 & RM-P7 & RM-P10 & RM-P13 & RM-P16 & RM-PM & $\begin{array}{c}\text { Médias } \\
\text { (RM) }\end{array}$ & $\begin{array}{l}\text { Desvio } \\
\text { padrão }\end{array}$ \\
\hline \multirow{3}{*}{$\begin{array}{c}\text { Valores } \\
\text { do } \\
\text { desvio }\end{array}$} & radianos & $-6.9 \mathrm{E}-04$ & $-4.9 \mathrm{E}-04$ & $-4.7 \mathrm{E}-04$ & $-5.2 \mathrm{E}-04$ & $-5.2 \mathrm{E}-04$ & $-5.0 \mathrm{E}-04$ & $-5.1 \mathrm{E}-04$ & $-5.3 \mathrm{E}-04$ & 7.8E-05 \\
\hline & arco-seg & -142 & -101 & -98 & -107 & -107 & -102 & -106 & -109.5 & 16.1 \\
\hline & $\mu \mathrm{m}$ & -185 & -133 & -128 & -140 & -140 & -134 & -138 & -143 & 21 \\
\hline
\end{tabular}

\begin{tabular}{|l|l|r|r|r|r|r|r|r|}
\cline { 3 - 9 } \multicolumn{2}{c|}{} & \multicolumn{1}{c|}{$\mathrm{P} 1$} & \multicolumn{1}{c|}{$\mathrm{P} 4$} & \multicolumn{1}{c|}{$\mathrm{P} 7$} & \multicolumn{1}{c|}{$\mathrm{P} 10$} & \multicolumn{1}{c|}{$\mathrm{P} 13$} & \multicolumn{1}{c|}{$\mathrm{P} 16$} & \multicolumn{1}{c|}{ Pmédio } \\
\hline \multirow{3}{*}{ Médias } & radianos & $-6.9 \mathrm{E}-04$ & $-5.0 \mathrm{E}-04$ & $-4.8 \mathrm{E}-04$ & $-5.3 \mathrm{E}-04$ & $-5.2 \mathrm{E}-04$ & $-5.0 \mathrm{E}-04$ & $-5.2 \mathrm{E}-04$ \\
\cline { 2 - 9 } & arco-seg & -143 & -103 & -99 & -108 & -108 & -104 & -106 \\
\cline { 2 - 9 } & $\mu \mathrm{m}$ & -187 & -135 & -130 & -142 & -141 & -136 & -139 \\
\hline
\end{tabular}

\begin{tabular}{|c|l|r|r|r|r|r|r|r|}
\cline { 2 - 9 } \multicolumn{2}{c|}{} & \multicolumn{1}{c|}{$\mathrm{P} 1$} & \multicolumn{1}{c|}{$\mathrm{P} 4$} & \multicolumn{1}{c|}{$\mathrm{P} 7$} & \multicolumn{1}{c|}{$\mathrm{P} 10$} & \multicolumn{1}{c|}{$\mathrm{P} 13$} & $\mathrm{P} 16$ & Pmédio \\
\hline \multirow{2}{*}{$\begin{array}{c}\text { Desvios- } \\
\text { padrão }\end{array}$} & $\begin{array}{l}\text { radianos } \\
\text { arco-seg }\end{array}$ & $2.8 \mathrm{E}-05$ & $2.8 \mathrm{E}-05$ & $2.8 \mathrm{E}-05$ & $2.8 \mathrm{E}-05$ & $2.8 \mathrm{E}-05$ & $2.8 \mathrm{E}-05$ & $2.9 \mathrm{E}-05$ \\
\cline { 2 - 9 } & $4 \mathrm{~m}$ & 6 & 6 & 6 & 6 & 6 & 6 & 6 \\
\hline
\end{tabular}


Tabela A5.17 - Desvios de perpendicularismo da Peça 1 (Sistema Automatizado e ajustagem Minimax) - Amostras 02 e 03.

\begin{tabular}{|c|r|r|r|r|r|r|r|r|r|}
\hline \multicolumn{8}{|c|}{$\begin{array}{c}\text { Desvio de Perpendicularismo - Peça 1 - Medição com o Sistema Automatizado - } \\
\text { Avaliação com o Método Minimax }\end{array}$} \\
\hline \multicolumn{8}{|c|}{ Amostra de medição da Peça: } & \multicolumn{1}{c|}{$\mathbf{0 2}$} & \multicolumn{3}{c|}{ Amostra de medição da superfície } \\
de referência:
\end{tabular}

\begin{tabular}{|c|r|r|r|r|r|r|r|r|r|r|}
\hline \multicolumn{2}{|c|}{ Combinações } & \multicolumn{1}{|c|}{ R4-P1 } & \multicolumn{1}{|c|}{ R4-P4 } & R4-P7 & R4-P10 & R4-P13 & R4-P16 & R4-PM & $\begin{array}{c}\text { Médias } \\
\text { (R4) }\end{array}$ & $\begin{array}{c}\text { Desvio } \\
\text { padrão }\end{array}$ \\
\hline \multirow{2}{*}{\begin{tabular}{c} 
Valores $\begin{array}{c}\text { do } \\
\text { desvio }\end{array}$ \\
\cline { 2 - 12 }
\end{tabular}} & \begin{tabular}{l} 
radianos \\
\cline { 2 - 11 }
\end{tabular} & $-6.9 \mathrm{E}-04$ & $-5.0 \mathrm{E}-04$ & $-4.8 \mathrm{E}-04$ & $-5.2 \mathrm{E}-04$ & $-5.2 \mathrm{E}-04$ & $-5.0 \mathrm{E}-04$ & $-5.2 \mathrm{E}-04$ & $-5.3 \mathrm{E}-04$ & $7.8 \mathrm{E}-05$ \\
\cline { 2 - 11 } & -142 & -102 & -99 & -108 & -107 & -103 & -106 & -110.2 & 16.1 \\
\hline
\end{tabular}

\begin{tabular}{|c|c|c|c|c|c|c|c|c|c|c|}
\hline \multicolumn{2}{|c|}{ Combinações } & R7-P1 & R7-P4 & R7-P7 & R7-P10 & R7-P13 & R7-P16 & R7-PM & $\begin{array}{c}\text { Médias } \\
\text { (R7) }\end{array}$ & $\begin{array}{l}\text { Desvio } \\
\text { padrão }\end{array}$ \\
\hline \multirow{3}{*}{$\begin{array}{l}\text { Valores } \\
\text { do } \\
\text { desvio }\end{array}$} & radianos & $-6.8 \mathrm{E}-04$ & $-4.8 \mathrm{E}-04$ & $-4.6 \mathrm{E}-04$ & $-5.1 \mathrm{E}-04$ & $-5.1 \mathrm{E}-04$ & $-4.9 E-04$ & $-5.2 E-04$ & $-5.2 E-04$ & $7.8 \mathrm{E}-05$ \\
\hline & arco-seg & -140 & -99 & -96 & -105 & -105 & -100 & -106 & -107.4 & 16.1 \\
\hline & $\mu \mathrm{m}$ & -183 & -130 & -125 & -137 & -137 & -131 & -139 & -141 & 21 \\
\hline
\end{tabular}

\begin{tabular}{|c|r|r|r|r|r|r|r|r|r|r|}
\hline \multicolumn{2}{|c|}{ Combinações } & R10-P1 & R10-P4 & R10-P7 & R10-P10 & R10-P13 & R10-P16 & R10-PM & $\begin{array}{c}\text { Médias } \\
\text { (R10) }\end{array}$ & $\begin{array}{c}\text { Desvio } \\
\text { padrão }\end{array}$ \\
\hline \multirow{2}{*}{$\begin{array}{c}\text { Valores } \\
\text { do } \\
\text { desvio }\end{array}$} & $\begin{array}{l}\text { radianos } \\
\text { arco-seg }\end{array}$ & $-6.9 \mathrm{E}-04$ & $-4.9 \mathrm{E}-04$ & $-4.8 \mathrm{E}-04$ & $-5.2 \mathrm{E}-04$ & $-5.2 \mathrm{E}-04$ & $-5.0 \mathrm{E}-04$ & $-5.2 \mathrm{E}-04$ & $-5.3 \mathrm{E}-04$ & $7.8 \mathrm{E}-05$ \\
\cline { 2 - 12 } & $\mu \mathrm{m}$ & -186 & -102 & -98 & -108 & -107 & -103 & -106 & -110.1 & 16.1 \\
\hline
\end{tabular}

\begin{tabular}{|c|l|r|r|r|r|r|r|r|r|r|}
\hline \multicolumn{2}{|c|}{ Combinações } & R13-P1 & R13-P4 & R13-P7 & R13-P10 & R13-P13 & R13-P16 & R13-PM & $\begin{array}{c}\text { Médias } \\
\text { (R13) }\end{array}$ & $\begin{array}{c}\text { Desvio } \\
\text { padrão }\end{array}$ \\
\hline \multirow{2}{*}{$\begin{array}{c}\text { Valores } \\
\text { do } \\
\text { desvio }\end{array}$} & $\begin{array}{l}\text { radianos } \\
\text { arco-seg }\end{array}$ & $-6.5 \mathrm{E}-04$ & $-4.5 \mathrm{E}-04$ & $-4.4 \mathrm{E}-04$ & $-4.8 \mathrm{E}-04$ & $-4.8 \mathrm{E}-04$ & $-4.6 \mathrm{E}-04$ & $-4.7 \mathrm{E}-04$ & $-4.9 \mathrm{E}-04$ & $7.8 \mathrm{E}-05$ \\
\cline { 2 - 11 } & $\mu \mathrm{m}$ & -175 & -94 & -90 & -99 & -99 & -95 & -98 & -101.8 & 16.1 \\
\hline
\end{tabular}

\begin{tabular}{|c|c|c|c|c|c|c|c|c|c|c|}
\hline \multicolumn{2}{|c|}{ Combinações } & RM-P1 & RM-P4 & RM-P7 & RM-P10 & RM-P13 & RM-P16 & RM-PM & $\begin{array}{c}\text { Médias } \\
(\mathrm{RM})\end{array}$ & $\begin{array}{l}\text { Desvio } \\
\text { padrão }\end{array}$ \\
\hline \multirow{3}{*}{$\begin{array}{c}\text { Valores } \\
\text { do } \\
\text { desvio }\end{array}$} & radianos & $-6.9 \mathrm{E}-04$ & $-4.9 \mathrm{E}-04$ & $-4.8 \mathrm{E}-04$ & $-5.2 \mathrm{E}-04$ & $-5.2 \mathrm{E}-04$ & $-5.0 \mathrm{E}-04$ & $-5.2 \mathrm{E}-04$ & $-5.3 \mathrm{E}-04$ & $7.8 \mathrm{E}-05$ \\
\hline & arco-seg & -142 & -102 & -98 & -108 & -107 & -103 & -106 & -110.1 & 16.1 \\
\hline & $\mu \mathrm{m}$ & -186 & -134 & -129 & -141 & -140 & -135 & -139 & -144 & 21 \\
\hline
\end{tabular}

\begin{tabular}{|l|l|r|r|r|r|r|r|r|}
\cline { 3 - 9 } \multicolumn{2}{c|}{} & \multicolumn{1}{c|}{$\mathrm{P} 1$} & \multicolumn{1}{c|}{$\mathrm{P} 4$} & \multicolumn{1}{c|}{$\mathrm{P} 7$} & \multicolumn{1}{c|}{$\mathrm{P} 10$} & \multicolumn{1}{c|}{$\mathrm{P} 13$} & \multicolumn{1}{c|}{$\mathrm{P} 16$} & \multicolumn{1}{c|}{ Pmédio } \\
\hline \multirow{3}{*}{ Médias } & radianos & $-6.8 \mathrm{E}-04$ & $-4.8 \mathrm{E}-04$ & $-4.7 \mathrm{E}-04$ & $-5.1 \mathrm{E}-04$ & $-5.1 \mathrm{E}-04$ & $-4.9 \mathrm{E}-04$ & $-5.1 \mathrm{E}-04$ \\
\cline { 2 - 9 } & arco-seg & -140 & -100 & -96 & -105 & -105 & -101 & -105 \\
\cline { 2 - 9 } & $\mu \mathrm{m}$ & -183 & -131 & -126 & -138 & -138 & -132 & -137 \\
\hline
\end{tabular}

\begin{tabular}{|c|l|r|r|r|r|r|r|r|}
\cline { 2 - 9 } \multicolumn{2}{c|}{} & \multicolumn{1}{c|}{$\mathrm{P} 1$} & $\mathrm{P} 4$ & $\mathrm{P} 7$ & $\mathrm{P} 10$ & $\mathrm{P} 13$ & $\mathrm{P} 16$ & Pmédio \\
\hline \multirow{2}{*}{$\begin{array}{c}\text { Desvios- } \\
\text { padrão }\end{array}$} & $\begin{array}{l}\text { radianos } \\
\text { arco-seg }\end{array}$ & $1.8 \mathrm{E}-05$ & $1.8 \mathrm{E}-05$ & $1.8 \mathrm{E}-05$ & $1.8 \mathrm{E}-05$ & $1.8 \mathrm{E}-05$ & $1.8 \mathrm{E}-05$ & $1.8 \mathrm{E}-05$ \\
\cline { 2 - 9 } & $\mu \mathrm{m}$ & 5 & 4 & 4 & 4 & 4 & 4 & 4 \\
\hline
\end{tabular}


Tabela A5.18 - Desvios de perpendicularismo da Peça 1 (Sistema Automatizado e ajustagem Minimax) - Amostras 03 e 01.

\begin{tabular}{|c|c|c|c|c|c|c|c|c|c|c|}
\hline \multicolumn{11}{|c|}{$\begin{array}{c}\text { Desvio de Perpendicularismo - Peça } 1 \text { - Medição com o Sistema Automatizado - } \\
\text { Avaliação com o Método Minimax }\end{array}$} \\
\hline \multicolumn{4}{|c|}{ Amostra de medição da Peça: } & \multirow{2}{*}{$\begin{array}{c}03 \\
\mathrm{R} 1-\mathrm{P} 7\end{array}$} & \multicolumn{5}{|c|}{$\begin{array}{l}\text { Amostra de medição da superfície de } \\
\text { referência: }\end{array}$} & \multirow{2}{*}{$\begin{array}{c}01 \\
\text { Desvio } \\
\text { padrão }\end{array}$} \\
\hline Comk & nações & $\mathrm{R} 1-\mathrm{P} 1$ & $\mathrm{R} 1-\mathrm{P} 4$ & & $\mathrm{R} 1-\mathrm{P} 10$ & $\mathrm{R} 1-\mathrm{P} 13$ & $\mathrm{R} 1-\mathrm{P} 16$ & R1-PM & \begin{tabular}{|c|}
$\begin{array}{c}\text { Média } \\
\text { (R1) }\end{array}$ \\
\end{tabular} & \\
\hline \multirow{3}{*}{$\begin{array}{c}\text { Valores } \\
\text { do } \\
\text { desvio }\end{array}$} & radianos & $-7.1 \mathrm{E}-04$ & $-4.9 \mathrm{E}-04$ & $-4.9 \mathrm{E}-04$ & $-4.6 \mathrm{E}-04$ & $-5.0 \mathrm{E}-04$ & $-5.5 \mathrm{E}-04$ & $-4.9 \mathrm{E}-04$ & $-5.3 \mathrm{E}-04$ & $9.1 \mathrm{E}-05$ \\
\hline & arco-seg & -146 & -100 & -100 & -95 & -104 & -113 & -102 & -110 & 19 \\
\hline & $\mu \mathrm{m}$ & -191 & -131 & -131 & -125 & -136 & -148 & -133 & -144 & 25 \\
\hline
\end{tabular}

\begin{tabular}{|c|c|c|c|c|c|c|c|c|c|c|}
\hline \multicolumn{2}{|c|}{ Combinações } & R3-P1 & R3-P4 & R3-P7 & R3-P10 & R3-P13 & R3-P16 & R3-PM & $\begin{array}{c}\text { Média } \\
\text { (R3) }\end{array}$ & $\begin{array}{l}\text { Desvio } \\
\text { padrão }\end{array}$ \\
\hline \multirow{3}{*}{$\begin{array}{c}\text { Valores } \\
\text { do } \\
\text { desvio }\end{array}$} & radianos & $-7.0 \mathrm{E}-04$ & $-4.7 E-04$ & $-4.7 \mathrm{E}-04$ & $-4.5 \mathrm{E}-04$ & $-4.9 \mathrm{E}-04$ & $-5.4 \mathrm{E}-04$ & $-4.8 \mathrm{E}-04$ & $-5.2 E-04$ & 9.1E-05 \\
\hline & arco-seg & -144 & -98 & -98 & -93 & -101 & -111 & -99 & -107 & 19 \\
\hline & $\mu \mathrm{m}$ & -188 & -128 & -128 & -122 & -132 & -145 & -130 & -141 & 25 \\
\hline
\end{tabular}

\begin{tabular}{|c|c|c|c|c|c|c|c|c|c|c|}
\hline \multicolumn{2}{|c|}{ Combinações } & R5-P1 & R5-P4 & R5-P7 & R5-P10 & $\mathrm{R} 5-\mathrm{P} 13$ & R5-P16 & R5-PM & $\begin{array}{c}\text { Média } \\
\text { (R5) }\end{array}$ & $\begin{array}{l}\text { Desvio } \\
\text { padrão }\end{array}$ \\
\hline \multirow{3}{*}{$\begin{array}{c}\text { Valores } \\
\text { do } \\
\text { desvio }\end{array}$} & radianos & $-7.0 \mathrm{E}-04$ & $-4.8 \mathrm{E}-04$ & $-4.8 \mathrm{E}-04$ & $-4.5 \mathrm{E}-04$ & $-4.9 \mathrm{E}-04$ & $-5.4 \mathrm{E}-04$ & $-4.8 \mathrm{E}-04$ & $-5.2 E-04$ & $9.1 \mathrm{E}-05$ \\
\hline & arco-seg & -144 & -98 & -98 & -93 & -102 & -111 & -100 & -108 & 19 \\
\hline & $\mu \mathrm{m}$ & -189 & -129 & -129 & -122 & -133 & -146 & -131 & -141 & 25 \\
\hline
\end{tabular}

\begin{tabular}{|c|l|r|r|r|r|r|r|r|}
\cline { 3 - 9 } \multicolumn{2}{c|}{} & \multicolumn{1}{c|}{$\mathrm{P} 1$} & \multicolumn{1}{c|}{$\mathrm{P} 4$} & \multicolumn{1}{c|}{$\mathrm{P} 7$} & \multicolumn{1}{c|}{$\mathrm{P} 10$} & \multicolumn{1}{c|}{$\mathrm{P} 13$} & \multicolumn{1}{c|}{$\mathrm{P} 16$} & \multicolumn{1}{c|}{ Pmédio } \\
\hline \multirow{3}{*}{ Médias } & radianos & $-7.0 \mathrm{E}-04$ & $-4.8 \mathrm{E}-04$ & $-4.8 \mathrm{E}-04$ & $-4.6 \mathrm{E}-04$ & $-5.0 \mathrm{E}-04$ & $-5.4 \mathrm{E}-04$ & $-4.9 \mathrm{E}-04$ \\
\cline { 2 - 9 } & arco-seg & -145 & -99 & -99 & -94 & -102 & -112 & -100 \\
\cline { 2 - 9 } & $\mu \mathrm{m}$ & -190 & -129 & -129 & -123 & -134 & -146 & -131 \\
\hline
\end{tabular}

\begin{tabular}{|c|l|r|r|r|r|r|r|r|}
\cline { 2 - 8 } \multicolumn{2}{c|}{} & \multicolumn{1}{c|}{$\mathrm{P} 1$} & \multicolumn{1}{c|}{$\mathrm{P} 4$} & $\mathrm{P} 7$ & \multicolumn{1}{c|}{$\mathrm{P} 10$} & \multicolumn{1}{c|}{$\mathrm{P} 13$} & \multicolumn{1}{c|}{$\mathrm{P} 16$} & Pmédio \\
\hline \multirow{2}{*}{$\begin{array}{c}\text { Desvios- } \\
\text { padrão }\end{array}$} & $\begin{array}{l}\text { radianos } \\
\text { arco-seg }\end{array}$ & $6.2 \mathrm{E}-06$ & $6.2 \mathrm{E}-06$ & $6.2 \mathrm{E}-06$ & $6.2 \mathrm{E}-06$ & $6.2 \mathrm{E}-06$ & $6.2 \mathrm{E}-06$ & $6.2 \mathrm{E}-06$ \\
\cline { 2 - 9 } & $\mu \mathrm{m}$ & 1 & 1 & 1 & 1 & 1 & 1 & 1 \\
\hline
\end{tabular}


Tabela A5.19 - Desvios de perpendicularismo da Peça 1 (Sistema Automatizado e ajustagem Minimax) - Amostras 03 e 02.

\begin{tabular}{|c|c|c|c|c|c|c|c|c|c|c|}
\hline \multicolumn{11}{|c|}{$\begin{array}{c}\text { Desvio de Perpendicularismo - Peça } 1 \text { - Medição com o Sistema Automatizado - } \\
\text { Avaliação com o Método Minimax }\end{array}$} \\
\hline \multicolumn{5}{|c|}{ Amostra de medição da Peça: } & \multirow{2}{*}{$\begin{array}{c}03 \\
\text { R1-P10 }\end{array}$} & \multicolumn{4}{|c|}{$\begin{array}{l}\text { Amostra de medição da superfície } \\
\text { de referência: }\end{array}$} & \multirow{2}{*}{$\begin{array}{c}02 \\
\text { Desvio } \\
\text { padrão }\end{array}$} \\
\hline Comb & nações & $\mathrm{R} 1-\mathrm{P} 1$ & $\mathrm{R} 1-\mathrm{P} 4$ & R1-P7 & & $\mathrm{R} 1-\mathrm{P} 13$ & R1-P16 & R1-PM & $\begin{array}{c}\text { Médias } \\
(\mathrm{R} 1)\end{array}$ & \\
\hline \multirow{3}{*}{$\begin{array}{l}\text { Valores } \\
\text { do } \\
\text { desvio }\end{array}$} & radianos & $-7.8 \mathrm{E}-04$ & $-5.6 \mathrm{E}-04$ & $-5.6 \mathrm{E}-04$ & $-5.4 \mathrm{E}-04$ & $-5.8 \mathrm{E}-04$ & $-6.2 \mathrm{E}-04$ & $-5.7 \mathrm{E}-04$ & $-6.1 \mathrm{E}-04$ & $9.1 \mathrm{E}-05$ \\
\hline & arco-seg & -162 & -116 & -116 & -111 & -119 & -129 & -117 & $-1.3 \mathrm{E}+02$ & $1.9 \mathrm{E}+01$ \\
\hline & $\mu \mathrm{m}$ & -212 & -152 & -152 & -145 & -156 & -169 & -153 & -164 & 25 \\
\hline
\end{tabular}

\begin{tabular}{|c|c|c|c|c|c|c|c|c|c|c|}
\hline \multicolumn{2}{|c|}{ Combinações } & $\mathrm{R} 4-\mathrm{P} 1$ & R4-P4 & R4-P7 & R4-P10 & $\mathrm{R} 4-\mathrm{P} 13$ & R4-P16 & R4-PM & $\begin{array}{c}\text { Média } \\
(\mathrm{R} 4)\end{array}$ & $\begin{array}{l}\text { Desvio } \\
\text { padrão }\end{array}$ \\
\hline \multirow{3}{*}{$\begin{array}{c}\text { Valores } \\
\text { do } \\
\text { desvio }\end{array}$} & radianos & $-7.4 \mathrm{E}-04$ & $-5.1 E-04$ & $-5.1 E-04$ & $-4.9 E-04$ & $-5.3 E-04$ & $-5.8 E-04$ & $-5.2 E-04$ & $-5.6 E-04$ & 9.1E-05 \\
\hline & arco-seg & -152 & -106 & -106 & -101 & -109 & -119 & -107 & -115.5 & 18.8 \\
\hline & $\mu \mathrm{m}$ & -199 & -139 & -139 & -132 & -143 & -156 & -140 & -151 & 25 \\
\hline
\end{tabular}

\begin{tabular}{|c|r|r|r|r|r|r|r|r|r|r|}
\hline \multicolumn{2}{|c|}{ Combinações } & \multicolumn{1}{|c|}{ R7-P1 } & \multicolumn{1}{c|}{ R7-P4 } & R7-P7 & R7-P10 & R7-P13 & R7-P16 & R7-PM & $\begin{array}{c}\text { Média } \\
\text { (R7) }\end{array}$ & \multicolumn{1}{c|}{$\begin{array}{c}\text { Desvio } \\
\text { padrão }\end{array}$} \\
\hline \multirow{2}{*}{$\begin{array}{c}\text { Valores } \\
\text { do } \\
\text { desvio }\end{array}$} & $\begin{array}{l}\text { radianos } \\
\text { arco-seg }\end{array}$ & $-7.3 \mathrm{E}-04$ & $-5.1 \mathrm{E}-04$ & $-5.1 \mathrm{E}-04$ & $-4.8 \mathrm{E}-04$ & $-5.2 \mathrm{E}-04$ & $-5.7 \mathrm{E}-04$ & $-5.0 \mathrm{E}-04$ & $-5.5 \mathrm{E}-04$ & $9.1 \mathrm{E}-05$ \\
\cline { 2 - 11 } & $\mu \mathrm{m}$ & -197 & -137 & -105 & -100 & -108 & -118 & -103 & -114.4 & 18.8 \\
\hline
\end{tabular}

\begin{tabular}{|c|r|r|r|r|r|r|r|r|r|r|}
\hline \multicolumn{2}{|c|}{ Combinações } & R10-P1 & R10-P4 & R10-P7 & R10-P10 & R10-P13 & R10-P16 & R10-PM & $\begin{array}{c}\text { Média } \\
\text { (R10) }\end{array}$ & \multicolumn{1}{c|}{$\begin{array}{c}\text { Desvio } \\
\text { padrão }\end{array}$} \\
\hline \multirow{2}{*}{$\begin{array}{c}\text { Valores } \\
\text { do } \\
\text { desvio }\end{array}$} & $\begin{array}{l}\text { radianos } \\
\text { arco-seg }\end{array}$ & $-7.2 \mathrm{E}-04$ & $-4.9 \mathrm{E}-04$ & $-4.9 \mathrm{E}-04$ & $-4.7 \mathrm{E}-04$ & $-5.1 \mathrm{E}-04$ & $-5.6 \mathrm{E}-04$ & $-5.0 \mathrm{E}-04$ & $-5.4 \mathrm{E}-04$ & $9.1 \mathrm{E}-05$ \\
\cline { 2 - 11 } & $\mu \mathrm{m}$ & -194 & -102 & -102 & -97 & -105 & -115 & -103 & -111.4 & 18.8 \\
\hline
\end{tabular}

\begin{tabular}{|c|l|r|r|r|r|r|r|r|r|r|}
\hline \multicolumn{2}{|c|}{ Combinações } & \multicolumn{1}{|c|}{ R13-P1 } & R13-P4 & R13-P7 & R13-P10 & R13-P13 & R13-P16 & R13-PM & $\begin{array}{c}\text { Média } \\
\text { (R13) }\end{array}$ & $\begin{array}{c}\text { Desvio } \\
\text { padrão }\end{array}$ \\
\hline \multirow{2}{*}{$\begin{array}{c}\text { Valores } \\
\text { do } \\
\text { desvio }\end{array}$} & $\begin{array}{l}\text { radianos } \\
\text { arco-seg }\end{array}$ & $-7.2 \mathrm{E}-04$ & $-4.9 \mathrm{E}-04$ & $-4.9 \mathrm{E}-04$ & $-4.7 \mathrm{E}-04$ & $-5.1 \mathrm{E}-04$ & $-5.6 \mathrm{E}-04$ & $-5.0 \mathrm{E}-04$ & $-5.4 \mathrm{E}-04$ & $9.1 \mathrm{E}-05$ \\
\cline { 2 - 11 } & $\mu \mathrm{m}$ & -194 & -102 & -102 & -97 & -105 & -115 & -103 & -111.4 & 18.8 \\
\hline
\end{tabular}

\begin{tabular}{|c|c|c|c|c|c|c|c|c|c|c|}
\hline \multicolumn{2}{|c|}{ Combinações } & RM-P1 & RM-P1 & RM-P4 & RM-P7 & RM-P10 & RM-P13 & RM-P16 & RM-PM & $\begin{array}{l}\text { Média } \\
\text { (RM) }\end{array}$ \\
\hline \multirow{3}{*}{$\begin{array}{c}\text { Valores } \\
\text { do } \\
\text { desvio }\end{array}$} & radianos & $-7.3 \mathrm{E}-04$ & $-5.1 \mathrm{E}-04$ & $-5.1 \mathrm{E}-04$ & $-4.8 \mathrm{E}-04$ & $-5.2 \mathrm{E}-04$ & $-5.7 \mathrm{E}-04$ & $-5.1 \mathrm{E}-04$ & $-5.5 \mathrm{E}-04$ & $9.1 \mathrm{E}-05$ \\
\hline & arco-seg & -151 & -105 & -105 & -100 & -108 & -118 & -106 & -114.3 & 18.8 \\
\hline & $\mu \mathrm{m}$ & -197 & -137 & -137 & -131 & -141 & -154 & -139 & -150 & 25 \\
\hline
\end{tabular}

\begin{tabular}{|l|l|r|r|r|r|r|r|r|}
\cline { 3 - 9 } \multicolumn{2}{c|}{} & \multicolumn{1}{c|}{$\mathrm{P} 1$} & \multicolumn{1}{c|}{$\mathrm{P} 4$} & \multicolumn{1}{c|}{$\mathrm{P} 7$} & \multicolumn{1}{c|}{$\mathrm{P} 10$} & \multicolumn{1}{c|}{$\mathrm{P} 13$} & \multicolumn{1}{c|}{$\mathrm{P} 16$} & \multicolumn{1}{c|}{ Pmédio } \\
\hline \multirow{3}{*}{ Médias } & radianos & $-7.4 \mathrm{E}-04$ & $-5.1 \mathrm{E}-04$ & $-5.1 \mathrm{E}-04$ & $-4.9 \mathrm{E}-04$ & $-5.3 \mathrm{E}-04$ & $-5.8 \mathrm{E}-04$ & $-5.2 \mathrm{E}-04$ \\
\cline { 2 - 9 } & arco-seg & -152 & -106 & -106 & -101 & -109 & -119 & -107 \\
\cline { 2 - 9 } & $\mu \mathrm{m}$ & -199 & -139 & -139 & -132 & -143 & -156 & -140 \\
\hline
\end{tabular}

\begin{tabular}{|c|l|r|r|r|r|r|r|r|}
\cline { 2 - 9 } \multicolumn{2}{c|}{} & \multicolumn{1}{c|}{$\mathrm{P} 1$} & \multicolumn{1}{c|}{$\mathrm{P} 4$} & $\mathrm{P} 7$ & $\mathrm{P} 10$ & $\mathrm{P} 13$ & $\mathrm{P} 16$ & Pmédio \\
\hline \multirow{2}{*}{$\begin{array}{c}\text { Desvios- } \\
\text { padrão }\end{array}$} & radianos & $2.8 \mathrm{E}-05$ & $2.8 \mathrm{E}-05$ & $2.8 \mathrm{E}-05$ & $2.8 \mathrm{E}-05$ & $2.8 \mathrm{E}-05$ & $2.8 \mathrm{E}-05$ & $2.9 \mathrm{E}-05$ \\
\cline { 2 - 9 } & & 6 & 6 & 6 & 6 & 6 & 6 & 6 \\
\cline { 2 - 9 } & & 8 & 8 & 8 & 8 & 8 & 8 & 8 \\
\hline
\end{tabular}


Tabela A5.20 - Desvios de perpendicularismo da Peça 1 (Sistema Automatizado e ajustagem Minimax) - Amostras 03 e 03.

\begin{tabular}{|c|c|c|c|c|c|c|c|c|c|c|}
\hline \multicolumn{11}{|c|}{$\begin{array}{c}\text { Desvio de Perpendicularismo - Peça } 1 \text { - Medição com o Sistema Automatizado - } \\
\text { Avaliação com o Método Minimax }\end{array}$} \\
\hline \multicolumn{5}{|c|}{ Amostra de medição da Peça: } & \multirow{2}{*}{$\begin{array}{c}03 \\
R 1-P 10\end{array}$} & \multicolumn{4}{|c|}{$\begin{array}{l}\text { Amostra de medição da superfície } \\
\text { de referência: }\end{array}$} & \multirow{2}{*}{$\begin{array}{c}03 \\
\text { Desvio } \\
\text { padrão }\end{array}$} \\
\hline Comb & nações & $\mathrm{R} 1-\mathrm{P} 1$ & $\mathrm{R} 1-\mathrm{P} 4$ & $\mathrm{R} 1-\mathrm{P} 7$ & & $\mathrm{R} 1-\mathrm{P} 13$ & $\mathrm{R} 1-\mathrm{P} 16$ & R1-PM & $\begin{array}{c}\text { Médias } \\
\text { (R1) }\end{array}$ & \\
\hline \multirow{3}{*}{$\begin{array}{l}\text { Valores } \\
\text { do } \\
\text { desvio }\end{array}$} & radianos & $-7.3 \mathrm{E}-04$ & $-5.1 \mathrm{E}-04$ & $-5.1 \mathrm{E}-04$ & $-4.9 \mathrm{E}-04$ & $-5.3 \mathrm{E}-04$ & $-5.7 \mathrm{E}-04$ & $-5.2 \mathrm{E}-04$ & $-5.6 \mathrm{E}-04$ & $9.1 \mathrm{E}-05$ \\
\hline & arco-seg & -151 & -105 & -105 & -100 & -109 & -118 & -107 & $-1.1 \mathrm{E}+02$ & $1.9 \mathrm{E}+01$ \\
\hline & $\mu \mathrm{m}$ & -198 & -138 & -138 & -131 & -142 & -155 & -140 & -150 & 25 \\
\hline
\end{tabular}

\begin{tabular}{|c|r|r|r|r|r|r|r|r|r|r|}
\hline \multicolumn{2}{|c|}{ Combinações } & \multicolumn{1}{|c|}{ R4-P1 } & \multicolumn{1}{|c|}{ R4-P4 } & R4-P7 & R4-P10 & R4-P13 & R4-P16 & R4-PM & $\begin{array}{c}\text { Média } \\
\text { (R4) }\end{array}$ & $\begin{array}{c}\text { Desvio } \\
\text { padrão }\end{array}$ \\
\hline \multirow{2}{*}{\begin{tabular}{c} 
Valores $\begin{array}{c}\text { do } \\
\text { desvio }\end{array}$ \\
\cline { 3 - 12 }
\end{tabular}} & radianos & $-7.3 \mathrm{E}-04$ & $-5.1 \mathrm{E}-04$ & $-5.1 \mathrm{E}-04$ & $-4.9 \mathrm{E}-04$ & $-5.3 \mathrm{E}-04$ & $-5.7 \mathrm{E}-04$ & $-5.2 \mathrm{E}-04$ & $-5.6 \mathrm{E}-04$ & $9.1 \mathrm{E}-05$ \\
\cline { 2 - 11 } & $\mu \mathrm{m}$ & -151 & -105 & -105 & -100 & -109 & -118 & -107 & -114.9 & 18.8 \\
\hline
\end{tabular}

\begin{tabular}{|c|r|r|r|r|r|r|r|r|r|r|}
\hline \multicolumn{2}{|c|}{ Combinações } & \multicolumn{1}{|c|}{ R7-P1 } & \multicolumn{1}{c|}{ R7-P4 } & R7-P7 & R7-P10 & R7-P13 & R7-P16 & R7-PM & $\begin{array}{c}\text { Média } \\
\text { (R7) }\end{array}$ & $\begin{array}{c}\text { Desvio } \\
\text { padrão }\end{array}$ \\
\hline \multirow{2}{*}{\begin{tabular}{c} 
Valores $\begin{array}{c}\text { do } \\
\text { desvio }\end{array}$ \\
\cline { 3 - 12 }
\end{tabular}} & radianos & $-7.2 \mathrm{E}-04$ & $-5.0 \mathrm{E}-04$ & $-5.0 \mathrm{E}-04$ & $-4.7 \mathrm{E}-04$ & $-5.1 \mathrm{E}-04$ & $-5.6 \mathrm{E}-04$ & $-5.2 \mathrm{E}-04$ & $-5.4 \mathrm{E}-04$ & $9.1 \mathrm{E}-05$ \\
\cline { 2 - 12 } & $\mu \mathrm{m}$ & -149 & -103 & -103 & -98 & -106 & -116 & -107 & -112.1 & 18.8 \\
\hline
\end{tabular}

\begin{tabular}{|c|r|r|r|r|r|r|r|r|r|r|}
\hline \multicolumn{2}{|c|}{ Combinações } & R10-P1 & R10-P4 & R10-P7 & R10-P10 & R10-P13 & R10-P16 & R10-PM & $\begin{array}{c}\text { Média } \\
\text { (R10) }\end{array}$ & $\begin{array}{c}\text { Desvio } \\
\text { padrão }\end{array}$ \\
\hline \multirow{2}{*}{\begin{tabular}{c} 
Valores $\begin{array}{c}\text { do } \\
\text { desvio }\end{array}$ \\
\cline { 3 - 12 }
\end{tabular}} & \begin{tabular}{r} 
adianos \\
\cline { 2 - 11 }
\end{tabular} & $-7.3 \mathrm{E}-04$ & $-5.1 \mathrm{E}-04$ & $-5.1 \mathrm{E}-04$ & $-4.9 \mathrm{E}-04$ & $-5.3 \mathrm{E}-04$ & $-5.7 \mathrm{E}-04$ & $-5.2 \mathrm{E}-04$ & $-5.6 \mathrm{E}-04$ & $9.1 \mathrm{E}-05$ \\
\cline { 2 - 11 } & -151 & -105 & -105 & -100 & -109 & -118 & -107 & -114.9 & 18.8 \\
\hline
\end{tabular}

\begin{tabular}{|c|r|r|r|r|r|r|r|r|r|r|}
\hline \multicolumn{2}{|c|}{$\begin{array}{c}\text { Combinações } \\
\text { R13-P1 }\end{array}$} & R13-P4 & R13-P7 & R13-P10 & R13-P13 & R13-P16 & R13-PM & $\begin{array}{c}\text { Média } \\
\text { (R13) }\end{array}$ & $\begin{array}{c}\text { Desvio } \\
\text { padrão }\end{array}$ \\
\hline \multirow{2}{*}{\begin{tabular}{c} 
Valores $\begin{array}{c}\text { do } \\
\text { desvio }\end{array}$ \\
\cline { 2 - 12 }
\end{tabular}} & \begin{tabular}{l} 
ardianos \\
\cline { 2 - 11 }
\end{tabular} & $-6.9 \mathrm{E}-04$ & $-4.7 \mathrm{E}-04$ & $-4.7 \mathrm{E}-04$ & $-4.5 \mathrm{E}-04$ & $-4.9 \mathrm{E}-04$ & $-5.3 \mathrm{E}-04$ & $-4.8 \mathrm{E}-04$ & $-5.2 \mathrm{E}-04$ & $9.1 \mathrm{E}-05$ \\
\cline { 2 - 11 } & -143 & -97 & -97 & -92 & -100 & -110 & -98 & -106.5 & 18.8 \\
\hline
\end{tabular}

\begin{tabular}{|c|c|c|c|c|c|c|c|c|c|c|}
\hline \multicolumn{2}{|c|}{ Combinações } & RM-P1 & RM-P4 & RM-P7 & RM-P10 & RM-P13 & RM-P16 & RM-PM & $\begin{array}{l}\text { Média } \\
\text { (RM) }\end{array}$ & $\begin{array}{l}\text { Desvio } \\
\text { padrão }\end{array}$ \\
\hline \multirow{3}{*}{$\begin{array}{c}\text { Valores } \\
\text { do } \\
\text { desvio }\end{array}$} & radianos & $-7.3 \mathrm{E}-04$ & $-5.1 \mathrm{E}-04$ & $-5.1 E-04$ & $-4.9 \mathrm{E}-04$ & $-5.3 E-04$ & $-5.7 E-04$ & $-5.2 E-04$ & $-5.6 \mathrm{E}-04$ & $9.1 \mathrm{E}-05$ \\
\hline & arco-seg & -151 & -105 & -105 & -100 & -109 & -118 & -107 & -114.9 & 18.8 \\
\hline & $\mu \mathrm{m}$ & -198 & -138 & -138 & -131 & -142 & -155 & -140 & -150 & 25 \\
\hline
\end{tabular}

\begin{tabular}{|l|l|r|r|r|r|r|r|r|}
\cline { 3 - 9 } \multicolumn{2}{c|}{} & \multicolumn{1}{c|}{$\mathrm{P} 1$} & \multicolumn{1}{c|}{$\mathrm{P} 4$} & \multicolumn{1}{c|}{$\mathrm{P} 7$} & \multicolumn{1}{c|}{$\mathrm{P} 10$} & \multicolumn{1}{c|}{$\mathrm{P} 13$} & \multicolumn{1}{c|}{$\mathrm{P} 16$} & \multicolumn{1}{c|}{ Pmédio } \\
\hline \multirow{3}{*}{ Médias } & radianos & $-7.2 \mathrm{E}-04$ & $-5.0 \mathrm{E}-04$ & $-5.0 \mathrm{E}-04$ & $-4.8 \mathrm{E}-04$ & $-5.2 \mathrm{E}-04$ & $-5.6 \mathrm{E}-04$ & $-5.1 \mathrm{E}-04$ \\
\cline { 2 - 9 } & arco-seg & -149 & -103 & -103 & -98 & -106 & -116 & -105 \\
\cline { 2 - 9 } & $\mu \mathrm{m}$ & -195 & -135 & -135 & -128 & -139 & -152 & -137 \\
\hline
\end{tabular}

\begin{tabular}{|c|l|r|r|r|r|r|r|r|}
\cline { 2 - 9 } \multicolumn{2}{c|}{} & \multicolumn{1}{c|}{$\mathrm{P} 1$} & $\mathrm{P} 4$ & $\mathrm{P} 7$ & \multicolumn{1}{c|}{$\mathrm{P} 10$} & $\mathrm{P} 13$ & $\mathrm{P} 16$ & Pmédio \\
\hline \multirow{2}{*}{$\begin{array}{c}\text { Desvios- } \\
\text { padrão }\end{array}$} & $\begin{array}{l}\text { radianos } \\
\text { arco-seg }\end{array}$ & $1.8 \mathrm{E}-05$ & $1.8 \mathrm{E}-05$ & $1.8 \mathrm{E}-05$ & $1.8 \mathrm{E}-05$ & $1.8 \mathrm{E}-05$ & $1.8 \mathrm{E}-05$ & $1.8 \mathrm{E}-05$ \\
\cline { 2 - 9 } & $\mu \mathrm{m}$ & 4 & 4 & 4 & 4 & 4 & 4 & 4 \\
\hline
\end{tabular}


Tabela A5.21 -Valores médios do desvio de perpendicularismo, referentes às tabelas A5.13 a A5.20 (Método Minimax).

\begin{tabular}{|c|c|c|c|c|}
\hline & \multicolumn{4}{|c|}{$\begin{array}{c}\text { Resultados Médios - Desvio de perpendicularismo - Peça } 1 \\
\text { - Sistema Automatizado e Ajustagem Minimax }\end{array}$} \\
\hline & \multicolumn{3}{|c|}{ Amostra de Medição da Peça } & 01 \\
\hline & \multicolumn{3}{|c|}{ Amostra de Medição da superfície de Referência } & 01 \\
\hline & $\begin{array}{l}\text { Média Geral das } \\
\text { Combinações }\end{array}$ & $\begin{array}{l}\text { D. Padrão } \\
\text { Total }\end{array}$ & $\begin{array}{l}\text { Perfil Médio - } \\
\text { Referência } \\
\text { Média }\end{array}$ & $\begin{array}{l}\text { Desvio } \\
\text { Médio }\end{array}$ \\
\hline radianos & $-5.5 \mathrm{E}-04$ & $4.6 \mathrm{E}-05$ & --- & $-5.5 \mathrm{E}-04$ \\
\hline arco-seg & -114 & 9 & --- & -114 \\
\hline um & -149 & 12 & --- & -149 \\
\hline
\end{tabular}

\begin{tabular}{|l|r|r|r|r|}
\cline { 2 - 5 } \multicolumn{1}{c|}{} & \multicolumn{2}{l|}{ Amostra de Medição da Peça } & $\mathbf{0 1}$ \\
\cline { 2 - 5 } & \multicolumn{2}{l|}{ Amostra de Medição da superfície de Referência } & \multicolumn{1}{c|}{$\mathbf{0 3}$} \\
\cline { 2 - 5 } & $\begin{array}{c}\text { Média Geral das } \\
\text { Combinações }\end{array}$ & D. Padrão Total & $\begin{array}{c}\text { Perfil Médio } \\
\text { - Referência } \\
\text { Média }\end{array}$ & $\begin{array}{c}\text { Desvio } \\
\text { Médio }\end{array}$ \\
\hline $\begin{array}{l}\text { radianos } \\
\text { arco-seg }\end{array}$ & $-5.7 \mathrm{E}-04$ & $4.8 \mathrm{E}-05$ & $-5.7 \mathrm{E}-04$ & $-5.7 \mathrm{E}-04$ \\
\hline um & -118 & 10 & -117 & -118 \\
\hline
\end{tabular}

\begin{tabular}{|l|r|r|c|r|}
\cline { 2 - 5 } \multicolumn{1}{c|}{} & \multicolumn{2}{l|}{ Amostra de Medição da Peça } & $\mathbf{0 2}$ \\
\cline { 2 - 5 } \multicolumn{1}{c|}{ Amostra de Medição da superfície de Referência } & \multicolumn{1}{c|}{$\mathbf{0 1}$} \\
\cline { 2 - 5 } \multicolumn{1}{c|}{} & $\begin{array}{c}\text { Média Geral das } \\
\text { Combinações }\end{array}$ & $\begin{array}{c}\text { D. Padrão } \\
\text { Total }\end{array}$ & $\begin{array}{c}\text { Perfil Médio - } \\
\text { Referência } \\
\text { Média }\end{array}$ & $\begin{array}{c}\text { Desvio } \\
\text { Médio }\end{array}$ \\
\hline \multirow{2}{*}{$\begin{array}{l}\text { radianos } \\
\text { arco-seg }\end{array}$} & $-5.0 \mathrm{E}-04$ & $7.4 \mathrm{E}-05$ & --- & $-5.1 \mathrm{E}-04$ \\
\hline um & -104 & 15 & --- & -104 \\
\hline
\end{tabular}

\begin{tabular}{|l|r|r|r|r|}
\cline { 2 - 5 } \multicolumn{1}{c|}{} & \multicolumn{2}{l|}{ Amostra de Medição da Peça } & \multicolumn{1}{c|}{$\mathbf{0 2}$} \\
\cline { 2 - 5 } \multicolumn{1}{c|}{ Amostra de Medição da superfície de Referência } & \multicolumn{1}{c|}{$\mathbf{0 2}$} \\
\cline { 2 - 5 } & $\begin{array}{c}\text { Média Geral das } \\
\text { Combinações }\end{array}$ & D. Padrão Total & $\begin{array}{c}\text { Perfil Médio } \\
\text { - Referência } \\
\text { Média }\end{array}$ & $\begin{array}{c}\text { Desvio } \\
\text { Médio }\end{array}$ \\
\cline { 2 - 6 } $\begin{array}{l}\text { radianos } \\
\text { arco-seg }\end{array}$ & $-5.4 \mathrm{E}-04$ & $7.7 \mathrm{E}-05$ & $-5.1 \mathrm{E}-04$ & $-5.4 \mathrm{E}-04$ \\
\hline um & -111 & 16 & -106 & -111 \\
\hline
\end{tabular}

\begin{tabular}{|l|r|r|r|r|}
\cline { 2 - 5 } \multicolumn{1}{c|}{} & \multicolumn{2}{l|}{ Amostra de Medição da Peça } & \multicolumn{1}{c|}{$\mathbf{0 2}$} \\
\cline { 2 - 5 } \multicolumn{1}{c|}{ Amostra de Medição da superfície de Referência } & $\mathbf{0 3}$ \\
\cline { 2 - 5 } & $\begin{array}{c}\text { Média Geral das } \\
\text { Combinações }\end{array}$ & D. Padrão Total & $\begin{array}{c}\text { Perfil Médio } \\
\text { - Referência } \\
\text { Média }\end{array}$ & $\begin{array}{c}\text { Desvio } \\
\text { Médio }\end{array}$ \\
\hline $\begin{array}{l}\text { radianos } \\
\text { arco-seg }\end{array}$ & $-5.2 \mathrm{E}-04$ & $7.4 \mathrm{E}-05$ & $-5.2 \mathrm{E}-04$ & $-5.2 \mathrm{E}-04$ \\
\hline um & -108 & 15 & -106 & -108 \\
\hline
\end{tabular}


Tabela A5.21 -Valores médios do desvio de perpendicularismo, referentes às tabelas A5.13 a A5.20 (Método Minimax) - continuação.

\begin{tabular}{|l|l|l|l|r|}
\cline { 2 - 5 } & \multicolumn{3}{c}{$\begin{array}{l}\text { Resultados Médios - Desvio de perpendicularismo - Peça 1- } \\
\text { Sistema Automatizado e Ajustagem Minimax }\end{array}$} \\
\cline { 2 - 5 } & \multicolumn{3}{c|}{ Amostra de Medição da Peça } & \multicolumn{1}{c|}{$\mathbf{0 3}$} \\
\cline { 2 - 5 } & Amostra de Medição da superfície de Referência & \multicolumn{1}{c|}{$\mathbf{0 1}$} \\
\cline { 2 - 5 } & $\begin{array}{c}\text { Média Geral das } \\
\text { Combinações }\end{array}$ & $\begin{array}{c}\text { D. Padrão } \\
\text { Total }\end{array}$ & $\begin{array}{c}\text { Perfil Médio - } \\
\text { Referência Média }\end{array}$ & $\begin{array}{c}\text { Desvio } \\
\text { Médio }\end{array}$ \\
\hline radianos & $-5.3 \mathrm{E}-04$ & $8.6 \mathrm{E}-05$ & --- & $-5.3 \mathrm{E}-04$ \\
\cline { 2 - 5 } arco-seg & -108 & 18 & --- & -109 \\
\hline um & -142 & 23 & --- & -143 \\
\hline
\end{tabular}

\begin{tabular}{|l|r|r|r|r|}
\cline { 2 - 5 } \multicolumn{1}{c|}{} & \multicolumn{2}{l|}{ Amostra de Medição da Peça } & $\mathbf{0 3}$ \\
\cline { 2 - 5 } \multicolumn{1}{c|}{ Amostra de Medição da superfície de Referência } & $\mathbf{0 2}$ \\
\cline { 2 - 5 } \multicolumn{1}{c|}{} & $\begin{array}{c}\text { Média Geral das } \\
\text { Combinações }\end{array}$ & D. Padrão Total & $\begin{array}{c}\text { Perfil Médio } \\
\text { - Referência } \\
\text { Média }\end{array}$ & $\begin{array}{c}\text { Desvio } \\
\text { Médio }\end{array}$ \\
\hline radianos & $-5.6 \mathrm{E}-04$ & $8.9 \mathrm{E}-05$ & $-5.1 \mathrm{E}-04$ & $-5.6 \mathrm{E}-04$ \\
\hline arco-seg & -116 & 18 & -106 & -116 \\
\hline um & -151 & 24 & -139 & -151 \\
\hline
\end{tabular}

\begin{tabular}{|l|r|r|r|r|}
\cline { 2 - 5 } \multicolumn{1}{c|}{} & \multicolumn{2}{l|}{ Amostra de Medição da Peça } & $\mathbf{0 3}$ \\
\cline { 2 - 5 } & \multicolumn{2}{|c|}{ Amostra de Medição da superfície de Referência } & \multicolumn{1}{c|}{$\mathbf{0 3}$} \\
\cline { 2 - 5 } & $\begin{array}{c}\text { Média Geral } \\
\text { das } \\
\text { Combinações }\end{array}$ & D. Padrão Total & $\begin{array}{c}\text { Perfil Médio - } \\
\text { Referência } \\
\text { Média }\end{array}$ & $\begin{array}{c}\text { Desvio } \\
\text { Médio }\end{array}$ \\
\hline radianos & $-5.6 \mathrm{E}-04$ & $8.6 \mathrm{E}-05$ & $-5.2 \mathrm{E}-04$ & $-5.5 \mathrm{E}-04$ \\
\cline { 2 - 5 } arco-seg & -116 & 18 & -107 & -113 \\
\hline um & -152 & 23 & -140 & -148 \\
\hline
\end{tabular}


Tabela A5.22 - Desvios de perpendicularismo da Peça 1 (Sistema Automatizado e ajustagem de Mínimos Quadrados).

\begin{tabular}{|c|c|c|c|c|c|}
\hline \multicolumn{6}{|c|}{$\begin{array}{c}\text { Desvio de Perpendicularismo - Peça } 1 \text { - Medição com o Sistema } \\
\text { Automatizado - Método dos Mínimos Quadrados }\end{array}$} \\
\hline \multicolumn{2}{|c|}{$\begin{array}{l}\text { Amostra de medição da } \\
\text { Peça: }\end{array}$} & \multirow{2}{*}{\multicolumn{2}{|c|}{\begin{tabular}{c|c}
01 & $\begin{array}{c}\text { Amostra de medic } \\
\text { superfície de refer }\end{array}$ \\
Valores observados para todas \\
as combinacõos de perfis
\end{tabular}}} & $\begin{array}{l}\text { da } \\
\text { cia: }\end{array}$ & 01 \\
\hline & & & & Des & Médio \\
\hline \multirow{3}{*}{$\begin{array}{l}\text { Valores do } \\
\text { desvio }\end{array}$} & radianos & & $-5.4 \mathrm{E}-04$ & & $-5.4 \mathrm{E}-04$ \\
\hline & arco-seg & & -112 & & -112 \\
\hline & um & & -146 & & -146 \\
\hline
\end{tabular}

\begin{tabular}{|c|c|c|c|c|c|}
\hline \multicolumn{2}{|c|}{$\begin{array}{c}\text { Amostra de medição da } \\
\text { Peça: }\end{array}$} & 01 & \multicolumn{2}{|c|}{$\begin{array}{l}\text { Amostra de medição da } \\
\text { superfície de referência: }\end{array}$} & \multirow{2}{*}{$\frac{03}{\text { o Médio }}$} \\
\hline & & $\begin{array}{r}\text { Valores } \\
\text { as c }\end{array}$ & $\begin{array}{l}\text { servados para todas } \\
\text { inações de perfis }\end{array}$ & Des & \\
\hline \multirow{3}{*}{$\begin{array}{l}\text { Valores do } \\
\text { desvio }\end{array}$} & radianos & & $-5.2 \mathrm{E}-04$ & & $-5.2 \mathrm{E}-04$ \\
\hline & arco-seg & & -108 & & -108 \\
\hline & um & & -141 & & -141 \\
\hline
\end{tabular}

\begin{tabular}{|c|l|r|r|r|}
\hline \multicolumn{2}{|c|}{$\begin{array}{c}\text { Amostra de medição da } \\
\text { Peça: }\end{array}$} & \multicolumn{1}{|c|}{$\begin{array}{c}\text { Amostra de medição da } \\
\text { superfície de referência: }\end{array}$} & \multicolumn{1}{c|}{$\mathbf{0 1}$} \\
\hline \multicolumn{2}{|c|}{} & $\begin{array}{c}\text { Valores observados para todas } \\
\text { as combinações de perfis }\end{array}$ & \multicolumn{1}{c|}{ Desvio Médio } \\
\hline \multirow{2}{*}{$\begin{array}{c}\text { Valores do } \\
\text { desvio }\end{array}$} & radianos & $-5.4 \mathrm{E}-04$ & $-5.4 \mathrm{E}-04$ \\
\cline { 2 - 5 } & arco-seg & -112 & -112 \\
\cline { 2 - 5 } & um & -146 & -146 \\
\hline
\end{tabular}

\begin{tabular}{|c|c|c|c|c|c|}
\hline \multicolumn{2}{|c|}{$\begin{array}{l}\text { Amostra de medição da } \\
\text { Peça: }\end{array}$} & 02 & \multicolumn{2}{|c|}{$\begin{array}{l}\text { Amostra de medição da } \\
\text { superfície de referência: }\end{array}$} & 02 \\
\hline & & \multicolumn{2}{|c|}{$\begin{array}{c}\text { Valores observados para todas } \\
\text { as combinações de perfis }\end{array}$} & \multicolumn{2}{|c|}{ Desvio Médio } \\
\hline \multirow{3}{*}{$\begin{array}{l}\text { Valores do } \\
\text { desvio }\end{array}$} & radianos & & $-5.0 \mathrm{E}-04$ & & $-5.0 \mathrm{E}-04$ \\
\hline & arco-seg & & -104 & & -104 \\
\hline & um & & -136 & & -136 \\
\hline
\end{tabular}

\begin{tabular}{|c|c|c|c|c|c|}
\hline \multicolumn{2}{|c|}{$\begin{array}{c}\text { Amostra de medição da } \\
\text { Peça: }\end{array}$} & 02 & \multicolumn{2}{|c|}{$\begin{array}{l}\text { Amostra de medição da } \\
\text { superfície de referência: }\end{array}$} & \multirow{2}{*}{$\frac{\mathbf{0 3}}{\text { io Médio }}$} \\
\hline & & $\begin{array}{r}\text { Valores } \\
\text { as c } \\
\end{array}$ & $\begin{array}{l}\text { ervados para todas } \\
\text { inações de perfis }\end{array}$ & Des & \\
\hline \multirow{3}{*}{$\begin{array}{l}\text { Valores do } \\
\text { desvio }\end{array}$} & radianos & & $-5.2 \mathrm{E}-04$ & & $-5.2 E-04$ \\
\hline & arco-seg & & -108 & & -108 \\
\hline & um & & -141 & & -141 \\
\hline
\end{tabular}

\begin{tabular}{|c|l|r|r|r|}
\hline \multicolumn{2}{|c|}{$\begin{array}{c}\text { Amostra de medição da } \\
\text { Peça: }\end{array}$} & \multicolumn{1}{|c|}{$\begin{array}{c}\text { Amostra de medição da } \\
\text { superfície de referência: }\end{array}$} & \multicolumn{1}{c|}{$\mathbf{0 1}$} \\
\hline \multicolumn{2}{|c|}{} & $\begin{array}{c}\text { Valores observados para todas } \\
\text { as combinações de perfis }\end{array}$ & Desvio Médio \\
\hline \multirow{2}{*}{$\begin{array}{c}\text { Valores do } \\
\text { desvio }\end{array}$} & radianos & $-5.4 \mathrm{E}-04$ & $-5.4 \mathrm{E}-04$ \\
\cline { 2 - 5 } & arco-seg & -112 & -112 \\
\cline { 2 - 5 } & um & -146 & -146 \\
\hline
\end{tabular}


Tabela A5.22 - Desvios de perpendicularismo da Peça 1 (Sistema Automatizado e ajustagem de Mínimos Quadrados) - continuação.

\begin{tabular}{|c|l|r|r|r|}
\hline \multicolumn{5}{|c|}{$\begin{array}{c}\text { Desvio de Perpendicularismo - Peça 1 - Medição com o Sistema } \\
\text { Automatizado - Método dos Mínimos Quadrados }\end{array}$} \\
\hline $\begin{array}{c}\text { Amostra de medição da } \\
\text { Peça: }\end{array}$ & \multicolumn{1}{|c|}{$\mathbf{0 3}$} & $\begin{array}{c}\text { Amostra de medição da } \\
\text { superfície de referência: }\end{array}$ & $\mathbf{0 2}$ \\
\hline \multicolumn{3}{|c|}{} & $\begin{array}{c}\text { Valores observados para todas } \\
\text { as combinações de perfis }\end{array}$ & Desvio Médio \\
\hline \multirow{2}{*}{$\begin{array}{c}\text { Valores do } \\
\text { desvio }\end{array}$} & radianos & \multicolumn{1}{|c|}{$-5.0 \mathrm{E}-04$} & $-5.0 \mathrm{E}-04$ \\
\cline { 2 - 5 } & arco-seg & -104 & -104 \\
\cline { 2 - 6 } & um & -136 & -136 \\
\hline
\end{tabular}

\begin{tabular}{|c|l|r|r|r|}
\hline \multicolumn{2}{|c|}{$\begin{array}{c}\text { Amostra de medição da } \\
\text { Peça: }\end{array}$} & \multicolumn{1}{c|}{$\mathbf{0 2}$} & $\begin{array}{c}\text { Amostra de medição da } \\
\text { superfície de referência: }\end{array}$ & \multicolumn{1}{c|}{$\mathbf{0 3}$} \\
\hline \multicolumn{2}{|c|}{} & $\begin{array}{c}\text { Valores observados para todas } \\
\text { as combinações de perfis }\end{array}$ & \multicolumn{1}{c|}{ Desvio Médio } \\
\hline \multirow{2}{*}{$\begin{array}{c}\text { Valores do } \\
\text { desvio }\end{array}$} & radianos & $-5.2 \mathrm{E}-04$ & $-5.2 \mathrm{E}-04$ \\
\cline { 2 - 5 } & arco-seg & -108 & -108 \\
\cline { 2 - 5 } & um & -141 & -141 \\
\hline
\end{tabular}

Observação: os resultados referentes à combinação entre a amostra 01 de dados da peça e a amostra 02 de dados do artefato de referência foram apresentados no item 6.2.1 deste trabalho. 
242 


\section{APÊNDICE 6 - Resultados dos cálculos do desvio de perpendicularismo da Peça 2 - Amostras Adicionais}

\section{Dados obtidos utilizando-se o sistema automatizado}

\section{Amostra 02}

Tabela A6.1 - Perfis das geratrizes da Peça 2 medidos com o Sistema Automatizado.

\begin{tabular}{|c|c|c|c|c|c|c|c|}
\hline \multicolumn{8}{|c|}{$\begin{array}{c}\text { Perfil das Geratrizes da Peça } 2(\mu \mathrm{m}) \text { - Amostra } 02 \text { - Sistema } \\
\text { Automatizado - com inclinação }\end{array}$} \\
\hline G1 & G2 & G3 & G4 & G5 & G6 & G7 & G8 \\
\hline 9 & 15 & -21 & -8 & -23 & -22 & -29 & -50 \\
\hline-10 & -1 & -30 & -21 & -32 & -36 & -43 & -70 \\
\hline-28 & -17 & -39 & -34 & -43 & -49 & -58 & -91 \\
\hline-46 & -32 & -50 & -48 & -53 & -63 & -72 & -109 \\
\hline-62 & -44 & -59 & -62 & -63 & -75 & -85 & -124 \\
\hline-75 & -56 & -65 & -72 & -72 & -88 & -97 & -137 \\
\hline-84 & -66 & -72 & -80 & -82 & -97 & -108 & -148 \\
\hline-89 & -73 & -77 & -88 & -88 & -104 & -116 & -154 \\
\hline-90 & -78 & -82 & -93 & -92 & -108 & -122 & -156 \\
\hline-86 & -81 & -84 & -95 & -92 & -108 & -125 & -154 \\
\hline-79 & -81 & -85 & -93 & -92 & -105 & -125 & -149 \\
\hline-69 & -78 & -83 & -90 & -90 & -98 & -122 & -141 \\
\hline-59 & -74 & -81 & -87 & -87 & -90 & -116 & -133 \\
\hline-46 & -69 & -77 & -83 & -85 & -79 & -107 & -123 \\
\hline-32 & -63 & -73 & -79 & -82 & -68 & -98 & -110 \\
\hline-17 & -56 & -67 & -73 & -81 & -57 & -88 & -94 \\
\hline
\end{tabular}

Tabela A6.2 - Perfis das transversais da Peça 2 medidos com o Sistema Automatizado.

\begin{tabular}{|r|r|r|r|r|r|}
\hline \multicolumn{6}{|c|}{$\begin{array}{c}\text { Perfil das Transversais da Peça 2 }(\mu \mathrm{m})- \\
\text { Amostra 02 - Sistema Automatizado - com } \\
\text { inclinação }\end{array}$} \\
\hline \multicolumn{1}{|c|}{ T1 } & \multicolumn{1}{|c|}{ T4 } & \multicolumn{1}{c|}{ T7 } & \multicolumn{1}{c|}{ T10 } & \multicolumn{1}{c|}{ T13 } & \multicolumn{1}{c|}{ T16 } \\
\hline 25 & -32 & -20 & -38 & -12 & -24 \\
\hline 38 & -20 & -8 & -23 & 2 & -6 \\
\hline 39 & -15 & -3 & -18 & 9 & 5 \\
\hline 30 & -15 & -3 & -20 & 9 & 9 \\
\hline 9 & -22 & -10 & -30 & 1 & 9 \\
\hline-20 & -33 & -24 & -49 & -13 & 4 \\
\hline-59 & -49 & -43 & -76 & -34 & -7 \\
\hline-106 & -69 & -70 & -111 & -62 & -26 \\
\hline
\end{tabular}


Tabela A6.3 - Perfil de superfície da Peça 2.

\begin{tabular}{|r|r|r|r|r|r|r|r|r|r|r|r|r|r|r|r|}
\hline \multicolumn{2}{|c|}{ Perfil da superfície da Peça $2(\mu \mathrm{m})$ - Amostra 02 - Perfil 1, obtido utilizando-se a reta-base T1 } \\
\hline 0 & -19 & -37 & -55 & -71 & -84 & -93 & -98 & -98 & -94 & -87 & -78 & -67 & -55 & -41 & -25 \\
\hline 13 & -3 & -19 & -34 & -46 & -58 & -68 & -75 & -80 & -83 & -83 & -80 & -76 & -71 & -65 & -58 \\
\hline 14 & 6 & -4 & -14 & -24 & -30 & -37 & -42 & -46 & -49 & -50 & -48 & -45 & -41 & -37 & -31 \\
\hline 5 & -8 & -21 & -35 & -49 & -59 & -67 & -75 & -80 & -82 & -80 & -77 & -74 & -70 & -66 & -60 \\
\hline-16 & -25 & -36 & -46 & -55 & -65 & -74 & -81 & -85 & -85 & -84 & -83 & -80 & -77 & -75 & -73 \\
\hline-45 & -58 & -72 & -85 & -98 & -110 & -120 & -126 & -130 & -130 & -127 & -121 & -112 & -102 & -91 & -79 \\
\hline-84 & -99 & -113 & -127 & -140 & -152 & -163 & -172 & -178 & -181 & -181 & -177 & -171 & -163 & -153 & -143 \\
\hline-131 & -152 & -173 & -191 & -205 & -218 & -230 & -236 & -238 & -236 & -231 & -223 & -214 & -204 & -192 & -176 \\
\hline
\end{tabular}

Tabela A6.4 - Coeficientes dos planos ajustados aos perfis da Peça 2 (ajustagem Minimax).

\begin{tabular}{|l|r|r|r|r|r|r|r|r|}
\hline \multicolumn{7}{|c|}{ Peça 2 - Amostra 02 - Coeficientes dos planos ajustados - Sistema Automatizado - } \\
Avaliação com Método Minimax \\
\hline coeficientes & \multicolumn{1}{|c|}{ Perfil 1 } & Perfil 4 & Perfil 7 & Perfil 10 & Perfil 13 & Perfil 16 & Média & $\begin{array}{r}\text { Perfil } \\
\text { Médio }\end{array}$ \\
\hline a0 & -145 & -15 & 10 & 7 & 15 & 35 & -15 & -15 \\
a1 & $-1.7 \mathrm{E}-04$ & $-1.5 \mathrm{E}-04$ & $-1.4 \mathrm{E}-04$ & $-1.7 \mathrm{E}-04$ & $-2.1 \mathrm{E}-04$ & $-2.4 \mathrm{E}-04$ & $-1.8 \mathrm{E}-04$ & $-1.8 \mathrm{E}-04$ \\
a2 & $1.1 \mathrm{E}-03$ & $3.1 \mathrm{E}-04$ & $4.1 \mathrm{E}-04$ & $5.5 \mathrm{E}-04$ & $3.3 \mathrm{E}-04$ & $-8.3 \mathrm{E}-05$ & $4.4 \mathrm{E}-04$ & $4.4 \mathrm{E}-04$ \\
\hline
\end{tabular}

Tabela A6.5 - Coeficientes dos planos ajustados aos perfis da Peça 2 (ajustagem de Mínimos Quadrados).

\begin{tabular}{|l|r|r|r|r|r|r|r|r|}
\hline \multicolumn{7}{|c|}{ Peça 2 - Amostra 02 - Coeficientes dos planos ajustados - Sistema Automatizado - } \\
\hline \\
coeficientes & \multicolumn{1}{|c|}{ Perfil 1 } & Perfil 4 & \multicolumn{1}{|c|}{ Perfil 7 } & Perfil 10 & Perfil 13 & Perfil 16 & \multicolumn{1}{c|}{ Média } & $\begin{array}{r}\text { Perfil } \\
\text { Médio }\end{array}$ \\
\hline a0 & -134 & -12 & 16 & 11 & 17 & 33 & -11 & -11 \\
a1 & $-1.9 \mathrm{E}-04$ & $-1.9 \mathrm{E}-04$ & $-1.9 \mathrm{E}-04$ & $-1.9 \mathrm{E}-04$ & $-1.9 \mathrm{E}-04$ & $-1.9 \mathrm{E}-04$ & $-1.9 \mathrm{E}-04$ & $-1.9 \mathrm{E}-04$ \\
$\mathrm{a} 2$ & $1.1 \mathrm{E}-03$ & $3.3 \mathrm{E}-04$ & $3.8 \mathrm{E}-04$ & $5.5 \mathrm{E}-04$ & $3.7 \mathrm{E}-04$ & $3.8 \mathrm{E}-05$ & $4.6 \mathrm{E}-04$ & $4.6 \mathrm{E}-04$ \\
\hline
\end{tabular}




\section{Amostra 03}

Tabela A6.6 - Perfis das geratrizes da Peça 2 medidos com o sistema automatizado.

\begin{tabular}{|r|r|r|r|r|r|r|r|}
\hline \multicolumn{8}{|c|}{ Perfil das Geratrizes da Peça 2 $(\mu \mathrm{m})$ - Amostra 03 - Sistema } \\
\hline \multicolumn{1}{|c|}{ G1tomatizado - com inclinação } \\
\hline 13 & G2 & \multicolumn{1}{|c|}{ G3 } & \multicolumn{1}{|c|}{ G4 } & \multicolumn{1}{|c|}{ G5 } & \multicolumn{1}{c|}{ G6 } & \multicolumn{1}{c|}{ G7 } & \multicolumn{1}{c|}{ G8 } \\
\hline-9 & -19 & -32 & -10 & -34 & -19 & -28 & -54 \\
\hline-29 & -35 & -39 & -38 & -43 & -37 & -42 & -72 \\
\hline-47 & -49 & -46 & -52 & -61 & -54 & -57 & -90 \\
\hline-63 & -61 & -53 & -64 & -69 & -81 & -71 & -107 \\
\hline-74 & -71 & -59 & -74 & -78 & -93 & -98 & -122 \\
\hline-84 & -80 & -65 & -82 & -86 & -101 & -110 & -135 \\
\hline-90 & -85 & -71 & -90 & -92 & -108 & -119 & -153 \\
\hline-91 & -88 & -76 & -94 & -95 & -113 & -124 & -154 \\
\hline-89 & -87 & -80 & -95 & -97 & -112 & -126 & -153 \\
\hline-84 & -83 & -82 & -93 & -97 & -109 & -127 & -150 \\
\hline-76 & -77 & -82 & -90 & -96 & -101 & -126 & -143 \\
\hline-67 & -70 & -81 & -85 & -94 & -91 & -122 & -135 \\
\hline-55 & -60 & -80 & -80 & -88 & -79 & -116 & -124 \\
\hline-43 & -49 & -77 & -75 & -83 & -66 & -108 & -112 \\
\hline-29 & -38 & -76 & -69 & -80 & -50 & -99 & -97 \\
\hline
\end{tabular}

Tabela A6.7 - Perfis das transversais da Peça 2 medidos com o sistema automatizado.

\begin{tabular}{|c|c|c|c|c|c|}
\hline \multicolumn{6}{|c|}{$\begin{array}{c}\text { Perfil das Transversais da Peça } 2(\mu \mathrm{m})- \\
\text { Amostra 03- Sistema Automatizado - com } \\
\text { inclinação }\end{array}$} \\
\hline T1 & T4 & T7 & T10 & T13 & T16 \\
\hline 19 & -25 & -18 & -35 & -23 & -21 \\
\hline 30 & -13 & -3 & -19 & -8 & -5 \\
\hline 31 & -7 & 1 & -12 & 1 & 5 \\
\hline 23 & -7 & 0 & -15 & 3 & 8 \\
\hline 7 & -12 & -9 & -26 & -2 & 6 \\
\hline-17 & -21 & -28 & -47 & -15 & -1 \\
\hline-51 & -34 & -53 & -75 & -34 & -14 \\
\hline-92 & -51 & -86 & -111 & -59 & -33 \\
\hline
\end{tabular}

Tabela A6.8 -Perfil de superfície da Peça 2.

\begin{tabular}{|r|r|r|r|r|r|r|r|r|r|r|r|r|r|r|r|}
\hline \multicolumn{2}{|c|}{ Perfil da superfície da Peça $2(\mu \mathrm{m})$ - Amostra 03 - Perfil 1, obtido utilizando-se a reta-base T1 } \\
\hline 0 & -21 & -42 & -59 & -75 & -87 & -96 & -103 & -104 & -101 & -96 & -89 & -79 & -68 & -56 & -42 \\
\hline 11 & -7 & -24 & -38 & -49 & -60 & -69 & -74 & -76 & -76 & -72 & -66 & -58 & -49 & -38 & -27 \\
\hline 12 & 8 & 1 & -6 & -13 & -19 & -26 & -31 & -36 & -40 & -42 & -42 & -41 & -40 & -38 & -36 \\
\hline 4 & -9 & -23 & -38 & -49 & -60 & -68 & -75 & -79 & -81 & -79 & -75 & -71 & -66 & -60 & -54 \\
\hline-12 & -21 & -31 & -40 & -48 & -57 & -64 & -71 & -74 & -76 & -76 & -75 & -72 & -67 & -62 & -58 \\
\hline-36 & -54 & -71 & -85 & -99 & -110 & -119 & -126 & -130 & -130 & -126 & -119 & -108 & -97 & -84 & -68 \\
\hline-70 & -84 & -99 & -113 & -127 & -140 & -152 & -161 & -166 & -168 & -169 & -168 & -164 & -158 & -150 & -141 \\
\hline-111 & -130 & -148 & -164 & -179 & -193 & -204 & -210 & -212 & -211 & -207 & -200 & -192 & -181 & -169 & -154 \\
\hline
\end{tabular}


Tabela A6.9 - Coeficientes dos planos ajustados aos perfis da Peça 2 (ajustagem Minimax).

\begin{tabular}{|l|r|r|r|r|r|r|r|r|}
\hline \multicolumn{7}{|c|}{ Peça 2 - Amostra 03 - Coeficientes dos planos ajustados - Sistema Automatizado - } \\
Avaliação com Método Minimax \\
\hline coeficientes & \multicolumn{1}{|c|}{ Perfil 1 } & Perfil 4 & Perfil 7 & Perfil 10 & Perfil 13 & Perfil 16 & Média & $\begin{array}{r}\text { Perfil } \\
\text { Médio }\end{array}$ \\
\hline a0 & -124 & -7 & -2 & 2 & 25 & 21 & -14 & -14 \\
a1 & $-1.5 \mathrm{E}-04$ & $-1.2 \mathrm{E}-04$ & $-1.2 \mathrm{E}-04$ & $-1.3 \mathrm{E}-04$ & $-1.6 \mathrm{E}-04$ & $-2.2 \mathrm{E}-04$ & $-1.5 \mathrm{E}-04$ & $-1.5 \mathrm{E}-04$ \\
$\mathrm{a} 2$ & $8.6 \mathrm{E}-04$ & $2.4 \mathrm{E}-04$ & $5.3 \mathrm{E}-04$ & $5.9 \mathrm{E}-04$ & $2.5 \mathrm{E}-04$ & $6.4 \mathrm{E}-05$ & $4.2 \mathrm{E}-04$ & $4.2 \mathrm{E}-04$ \\
\hline
\end{tabular}

Tabela A6.10 - Coeficientes dos planos ajustados aos perfis da Peça 2 (ajustagem de Mínimos Quadrados).

\begin{tabular}{|l|r|r|r|r|r|r|r|r|}
\hline \multicolumn{7}{|c|}{ Peça 2 - Amostra 03 - Coeficientes dos planos ajustados - Sistema Automatizado - } \\
Avaliação com Método dos Mínimos Quadrados \\
\hline \\
coeficientes & Perfil 1 & Perfil 4 & Perfil 7 & Perfil 10 & Perfil 13 & Perfil 16 & Média & $\begin{array}{r}\text { Perfil } \\
\text { Médio }\end{array}$ \\
\hline a0 & -119 & -6 & 0 & 8 & 31 & 22 & -11 & -11 \\
a1 & $-1.8 \mathrm{E}-04$ & $-1.8 \mathrm{E}-04$ & $-1.8 \mathrm{E}-04$ & $-1.8 \mathrm{E}-04$ & $-1.8 \mathrm{E}-04$ & $-1.8 \mathrm{E}-04$ & $-1.8 \mathrm{E}-04$ & $-1.8 \mathrm{E}-04$ \\
$\mathrm{a} 2$ & $9.5 \mathrm{E}-04$ & $2.9 \mathrm{E}-04$ & $5.4 \mathrm{E}-04$ & $5.8 \mathrm{E}-04$ & $2.3 \mathrm{E}-04$ & $8.8 \mathrm{E}-05$ & $4.5 \mathrm{E}-04$ & $4.5 \mathrm{E}-04$ \\
\hline
\end{tabular}

\section{Dados obtidos com a medição convencional}

\section{Amostra 02}

Tabela A6.11 - Perfil das geratrizes da Peça 2 (método convencional).

\begin{tabular}{|r|r|r|r|r|r|r|r|}
\hline \multicolumn{8}{|c|}{ Perfil das Geratrizes da Peça 2 $(\mu \mathrm{m})$ - Medição Convencional - } \\
\hline \multicolumn{1}{|c|}{ G1 } & \multicolumn{1}{|c|}{ G2 } & \multicolumn{1}{c|}{ G3 } & \multicolumn{1}{c|}{ G4 } & \multicolumn{1}{c|}{ G5 } & \multicolumn{1}{c|}{ G6 } & \multicolumn{1}{c|}{ G7 } & \multicolumn{1}{c|}{ G8 } \\
\hline 60 & 65 & 65 & 70 & 70 & 70 & 75 & 80 \\
\hline 45 & 50 & 54 & 55 & 57 & 60 & 65 & 65 \\
\hline 33 & 37 & 40 & 43 & 45 & 45 & 50 & 50 \\
\hline 20 & 25 & 25 & 30 & 30 & 30 & 35 & 40 \\
\hline 8 & 10 & 15 & 17 & 20 & 20 & 23 & 25 \\
\hline-5 & 0 & 3 & 5 & 5 & 8 & 10 & 10 \\
\hline-15 & -12 & -8 & -5 & -5 & -5 & 0 & 0 \\
\hline-25 & -20 & -20 & -15 & -15 & -15 & -10 & -10 \\
\hline-30 & -30 & -25 & -25 & -24 & -22 & -20 & -20 \\
\hline-38 & -35 & -32 & -30 & -30 & -30 & -25 & -25 \\
\hline-43 & -40 & -38 & -35 & -35 & -35 & -30 & -30 \\
\hline-47 & -45 & -42 & -40 & -40 & -38 & -35 & -35 \\
\hline-50 & -50 & -46 & -45 & -45 & -43 & -40 & -38 \\
\hline-55 & -52 & -50 & -48 & -48 & -46 & -42 & -40 \\
\hline-60 & -55 & -55 & -52 & -52 & -50 & -45 & -45 \\
\hline-62 & -60 & -58 & -55 & -55 & -54 & -50 & -50 \\
\hline
\end{tabular}




\section{Amostra 03}

Tabela A6.12 - Perfil das geratrizes da Peça 2 (método convencional).

\begin{tabular}{|r|r|r|r|r|r|r|r|}
\hline \multicolumn{7}{|c|}{ Perfil das Geratrizes da Peça 2 $(\mu \mathrm{m})$ - Medição Convencional - } \\
\multicolumn{1}{|r|}{ com inclinaça - Amostra 03 } \\
\hline G1 & \multicolumn{1}{|c|}{ G2 } & \multicolumn{1}{c|}{ G3 } & \multicolumn{1}{c|}{ G4 } & \multicolumn{1}{c|}{ G5 } & \multicolumn{1}{c|}{ G6 } & \multicolumn{1}{c|}{ G7 } & \multicolumn{1}{c|}{ G8 } \\
\hline 55 & 60 & 60 & 65 & 70 & 72 & 73 & 75 \\
\hline 42 & 45 & 50 & 50 & 55 & 60 & 60 & 60 \\
\hline 30 & 30 & 35 & 40 & 40 & 45 & 45 & 48 \\
\hline 15 & 20 & 22 & 25 & 25 & 30 & 32 & 32 \\
\hline 5 & 7 & 10 & 12 & 15 & 20 & 20 & 20 \\
\hline-8 & -5 & 0 & 0 & 3 & 5 & 6 & 7 \\
\hline-20 & -15 & -12 & -10 & -8 & -5 & -5 & -5 \\
\hline-30 & -25 & -22 & -20 & -18 & -15 & -15 & -15 \\
\hline-35 & -33 & -30 & -27 & -25 & -25 & -17 & -24 \\
\hline-43 & -40 & -35 & -33 & -32 & -30 & -25 & -30 \\
\hline-47 & -45 & -40 & -40 & -38 & -35 & -30 & -35 \\
\hline-52 & -50 & -45 & -45 & -42 & -40 & -35 & -40 \\
\hline-55 & -52 & -50 & -47 & -45 & -45 & -40 & -42 \\
\hline-60 & -57 & -55 & -50 & -50 & -47 & -45 & -45 \\
\hline-63 & -60 & -58 & -55 & -55 & -50 & -50 & -50 \\
\hline-67 & -65 & -62 & -60 & -57 & -55 & -54 & -53 \\
\hline
\end{tabular}




\section{Valores do Desvio de Perpendicularismo da Peça 2 - combinações entre as amostras de dados da peça e as amostras de dados do plano de referência}

Tabela A6.13 - Desvios de perpendicularismo da Peça 2 (Sistema Automatizado e ajustagem Minimax) - Amostras 01 e 01.

\begin{tabular}{|c|c|c|c|c|c|c|c|c|c|c|}
\hline \multicolumn{11}{|c|}{$\begin{array}{l}\text { Desvio de Perpendicularismo - Peça } 2 \text { - Medição com o Sistema Automatizado - } \\
\text { Avaliação com o Método Minimax }\end{array}$} \\
\hline \multicolumn{4}{|c|}{ Amostra de medição da Peça: } & \multirow{2}{*}{$\begin{array}{c}01 \\
\mathrm{R} 1-\mathrm{P} 7\end{array}$} & \multicolumn{5}{|c|}{$\begin{array}{l}\text { Amostra de medição da superfície de } \\
\text { referência: }\end{array}$} & \multirow{2}{*}{$\begin{array}{c}01 \\
\text { Desvio } \\
\text { padrão }\end{array}$} \\
\hline Coml & nações & $\mathrm{R} 1-\mathrm{P} 1$ & $\mathrm{R} 1-\mathrm{P} 4$ & & $\mathrm{R} 1-\mathrm{P} 10$ & $\mathrm{R} 1-\mathrm{P} 13$ & $\mathrm{R} 1-\mathrm{P} 16$ & R1-PM & $\begin{array}{c}\text { Média } \\
\text { (R1) }\end{array}$ & \\
\hline \multirow{3}{*}{$\begin{array}{c}\text { Valores } \\
\text { do } \\
\text { desvio }\end{array}$} & radianos & $-5.2 E-04$ & $-5.3 \mathrm{E}-04$ & $-5.3 \mathrm{E}-04$ & $-5.7 \mathrm{E}-04$ & $-5.6 \mathrm{E}-04$ & $-6.1 \mathrm{E}-04$ & $-5.5 \mathrm{E}-04$ & $-5.6 \mathrm{E}-04$ & $3.4 \mathrm{E}-05$ \\
\hline & arco-seg & $\begin{array}{r}107 \\
\end{array}$ & -109 & -110 & -118 & -117 & -126 & -114 & -115 & 7 \\
\hline & $\mu \mathrm{m}$ & -140 & -143 & -144 & -155 & -153 & -165 & -149 & -150 & 9 \\
\hline
\end{tabular}

\begin{tabular}{|c|c|c|c|c|c|c|c|c|c|c|}
\hline \multicolumn{2}{|c|}{ Combinações } & R3-P1 & R4-P4 & $\mathrm{R} 4-\mathrm{P} 7$ & R4-P10 & R4-P13 & R4-P16 & R4-PM & $\begin{array}{l}\text { Média } \\
(\mathrm{R} 4)\end{array}$ & $\begin{array}{l}\text { Desvio } \\
\text { padrão }\end{array}$ \\
\hline \multirow{3}{*}{$\begin{array}{c}\text { Valores } \\
\text { do } \\
\text { desvio }\end{array}$} & radianos & $-5.1 E-04$ & $-5.2 E-04$ & $-5.2 E-04$ & $-5.4 E-04$ & $-5.5 E-04$ & -6.0 E-04 & $-5.4 E-04$ & $-5.4 E-04$ & 3.3E-05 \\
\hline & arco-seg & -105 & -107 & -108 & -112 & -114 & -124 & -111 & -112 & 7 \\
\hline & $\mu \mathrm{m}$ & -137 & -140 & -141 & -147 & -149 & -162 & -146 & -146 & 9 \\
\hline
\end{tabular}

\begin{tabular}{|c|c|c|c|c|c|c|c|c|c|c|}
\hline \multicolumn{2}{|c|}{ Combinações } & R5-P1 & R7-P4 & $\mathrm{R} 7-\mathrm{P} 7$ & R7-P10 & R7-P13 & R7-P16 & R7-PM & $\begin{array}{c}\text { Média } \\
(\mathrm{R} 7)\end{array}$ & $\begin{array}{l}\text { Desvio } \\
\text { padrão }\end{array}$ \\
\hline \multirow{3}{*}{$\begin{array}{c}\text { Valores } \\
\text { do } \\
\text { desvio }\end{array}$} & radianos & $-5.1 E-04$ & $-5.2 E-04$ & $-5.3 E-04$ & $-5.5 E-04$ & $-5.6 E-04$ & $-6.0 \mathrm{E}-04$ & $-5.4 \mathrm{E}-04$ & $-5.4 \mathrm{E}-04$ & 3.3E-05 \\
\hline & arco-seg & -105 & -107 & -108 & -113 & -115 & -124 & -112 & -112 & 7 \\
\hline & $\mu \mathrm{m}$ & -138 & -141 & -142 & -148 & -150 & -162 & -146 & -147 & 9 \\
\hline
\end{tabular}

\begin{tabular}{|c|l|r|r|r|r|r|r|r|}
\cline { 3 - 9 } \multicolumn{2}{c|}{} & \multicolumn{1}{c|}{$\mathrm{P} 1$} & \multicolumn{1}{c|}{$\mathrm{P} 4$} & \multicolumn{1}{c|}{$\mathrm{P} 7$} & \multicolumn{1}{c|}{$\mathrm{P} 10$} & \multicolumn{1}{c|}{$\mathrm{P} 13$} & \multicolumn{1}{c|}{$\mathrm{P} 16$} & \multicolumn{1}{c|}{ Pmédio } \\
\hline \multirow{3}{*}{ Médias } & radianos & $-5.1 \mathrm{E}-04$ & $-5.2 \mathrm{E}-04$ & $-5.3 \mathrm{E}-04$ & $-5.5 \mathrm{E}-04$ & $-5.6 \mathrm{E}-04$ & $-6.0 \mathrm{E}-04$ & $-5.4 \mathrm{E}-04$ \\
\cline { 3 - 10 } & arco-seg & -106 & -108 & -109 & -114 & -115 & -125 & -112 \\
\cline { 2 - 9 } & $\mu \mathrm{m}$ & -138 & -141 & -143 & -150 & -151 & -163 & -147 \\
\hline
\end{tabular}

\begin{tabular}{|c|l|r|r|r|r|r|r|r|}
\cline { 2 - 8 } \multicolumn{2}{c|}{} & \multicolumn{1}{c|}{$\mathrm{P} 1$} & \multicolumn{1}{c|}{$\mathrm{P} 4$} & \multicolumn{1}{c|}{$\mathrm{P} 7$} & \multicolumn{1}{c|}{$\mathrm{P} 10$} & \multicolumn{1}{c|}{$\mathrm{P} 13$} & \multicolumn{1}{c|}{$\mathrm{P} 16$} & Pmédio \\
\hline \multirow{2}{*}{$\begin{array}{c}\text { Desvios- } \\
\text { padrão }\end{array}$} & $\begin{array}{l}\text { radianos } \\
\text { arco-seg }\end{array}$ & $6.2 \mathrm{E}-06$ & $6.2 \mathrm{E}-06$ & $6.2 \mathrm{E}-06$ & $1.6 \mathrm{E}-05$ & $6.2 \mathrm{E}-06$ & $6.2 \mathrm{E}-06$ & $6.2 \mathrm{E}-06$ \\
\cline { 2 - 9 } & $\mu \mathrm{m}$ & 2 & 1 & 1 & 3 & 1 & 1 & 1 \\
\hline
\end{tabular}

Obs.: Os valores do desvio resultantes da combinação entre a amostra 01 de dados da peça e a amostra 02 de dados do artefato de referência são apresentados no capítulo 6 deste trabalho, item 6.2.2. 
Tabela A6.14 - Desvios de perpendicularismo da Peça 2 (Sistema Automatizado e ajustagem Minimax) - Amostras 01 e 03.

\begin{tabular}{|c|c|c|c|c|c|c|c|c|c|c|}
\hline \multicolumn{11}{|c|}{$\begin{array}{c}\text { Desvio de Perpendicularismo - Peça } 2 \text { - Medição com o Sistema Automatizado - } \\
\text { Avaliação com o Método Minimax }\end{array}$} \\
\hline \multicolumn{5}{|c|}{ Amostra de medição da Peça: } & \multirow{2}{*}{$\begin{array}{c}01 \\
\text { R1-P10 }\end{array}$} & \multicolumn{4}{|c|}{$\begin{array}{l}\text { Amostra de medição da superfície } \\
\text { de referência: }\end{array}$} & \multirow{2}{*}{$\begin{array}{c}\mathbf{0 3} \\
\text { Desvio } \\
\text { padrão }\end{array}$} \\
\hline Comb & inações & $\mathrm{R} 1-\mathrm{P} 1$ & $\mathrm{R} 1-\mathrm{P} 4$ & $\mathrm{R} 1-\mathrm{P} 7$ & & R1-P13 & R1-P16 & R1-PM & $\begin{array}{c}\text { Médias } \\
(\mathrm{R} 1)\end{array}$ & \\
\hline \multirow{3}{*}{$\begin{array}{c}\text { Valores } \\
\text { do } \\
\text { desvio }\end{array}$} & radianos & $-5.4 \mathrm{E}-04$ & $-5.5 \mathrm{E}-04$ & $-5.6 \mathrm{E}-04$ & $-5.8 \mathrm{E}-04$ & $-5.9 E-04$ & $-6.4 \mathrm{E}-04$ & $-5.8 \mathrm{E}-04$ & $-5.8 \mathrm{E}-04$ & 3.3E-05 \\
\hline & arco-seg & -112 & -114 & -115 & -120 & -122 & -131 & -119 & -119 & 7 \\
\hline & $\mu \mathrm{m}$ & -147 & -150 & -151 & -157 & -159 & -171 & -155 & -156 & 9 \\
\hline
\end{tabular}

\begin{tabular}{|c|c|c|c|c|c|c|c|c|c|c|}
\hline \multicolumn{2}{|c|}{ Combinações } & $\mathrm{R} 4-\mathrm{P} 1$ & R4-P4 & R4-P7 & R4-P10 & R4-P13 & R4-P16 & $\begin{array}{c}\text { R4- } \\
\text { Pmédio }\end{array}$ & $\begin{array}{l}\text { Médias } \\
\text { (R4) }\end{array}$ & $\begin{array}{l}\text { Desvio } \\
\text { padrão }\end{array}$ \\
\hline \multirow{3}{*}{$\begin{array}{l}\text { Valores } \\
\text { do } \\
\text { desvio }\end{array}$} & radianos & $-5.4 \mathrm{E}-04$ & $-5.5 \mathrm{E}-04$ & $-5.6 \mathrm{E}-04$ & $-5.8 \mathrm{E}-04$ & $-5.9 E-04$ & $-6.4 \mathrm{E}-04$ & $-5.8 \mathrm{E}-04$ & $-5.8 \mathrm{E}-04$ & 3.3E-05 \\
\hline & arco-seg & -112 & -114 & -115 & -120 & -122 & -131 & -119 & -119 & 7 \\
\hline & $\mu \mathrm{m}$ & -147 & -150 & -151 & -157 & -159 & -172 & -155 & -156 & 9 \\
\hline
\end{tabular}

\begin{tabular}{|c|c|c|c|c|c|c|c|c|c|c|}
\hline \multicolumn{2}{|c|}{ Combinações } & R7-P1 & R7-P4 & R7-P7 & R7-P10 & R7-P13 & R7-P16 & $\begin{array}{c}\text { R7- } \\
\text { Pmédio } \\
\end{array}$ & $\begin{array}{c}\text { Médias } \\
\text { (R7) }\end{array}$ & $\begin{array}{l}\text { Desvio } \\
\text { padrão }\end{array}$ \\
\hline \multirow{3}{*}{$\begin{array}{c}\text { Valores } \\
\text { do } \\
\text { desvio }\end{array}$} & radianos & $-5.3 \mathrm{E}-04$ & $-5.4 \mathrm{E}-04$ & $-5.5 \mathrm{E}-04$ & $-5.7 \mathrm{E}-04$ & $-5.8 \mathrm{E}-04$ & $-6.2 \mathrm{E}-04$ & $-5.8 \mathrm{E}-04$ & $-5.6 \mathrm{E}-04$ & 3.3E-05 \\
\hline & arco-seg & -109 & -112 & -113 & -117 & -119 & -128 & -119 & -116 & 7 \\
\hline & $\mu \mathrm{m}$ & -143 & -146 & -147 & -153 & -156 & -168 & -155 & -152 & 9 \\
\hline
\end{tabular}

\begin{tabular}{|c|c|c|c|c|c|c|c|c|c|c|}
\hline \multicolumn{2}{|c|}{ Combinações } & R10-P1 & R10-P4 & R10-P7 & R10-P10 & R10-P13 & R10-P16 & $\begin{array}{c}\text { R10- } \\
\text { Pmédio }\end{array}$ & $\begin{array}{l}\text { Médias } \\
\text { (R10) }\end{array}$ & $\begin{array}{l}\text { Desvio } \\
\text { padrão }\end{array}$ \\
\hline \multirow{3}{*}{$\begin{array}{c}\text { Valores } \\
\text { do } \\
\text { desvio }\end{array}$} & radianos & $-5.4 \mathrm{E}-04$ & $-5.5 \mathrm{E}-04$ & $-5.6 \mathrm{E}-04$ & $-5.8 \mathrm{E}-04$ & $-5.9 \mathrm{E}-04$ & $-6.4 \mathrm{E}-04$ & $-5.8 \mathrm{E}-04$ & $-5.8 \mathrm{E}-04$ & 3.3E-05 \\
\hline & arco-seg & -112 & -114 & -115 & -120 & -122 & -131 & -119 & -119 & 7 \\
\hline & $\mu \mathrm{m}$ & -147 & -150 & -151 & -157 & -159 & -171 & -155 & -156 & 9 \\
\hline
\end{tabular}

\begin{tabular}{|c|c|c|c|c|c|c|c|c|c|c|}
\hline \multicolumn{2}{|c|}{ Combinações } & R13-P1 & R13-P4 & R13-P7 & R13-P10 & R13-P13 & R13-P16 & $\begin{array}{c}\text { R13- } \\
\text { Pmédio }\end{array}$ & $\begin{array}{c}\text { Médias } \\
\text { (R13) }\end{array}$ & $\begin{array}{l}\text { Desvio } \\
\text { padrão }\end{array}$ \\
\hline \multirow{3}{*}{$\begin{array}{c}\text { Valores } \\
\text { do } \\
\text { desvio }\end{array}$} & radianos & $-5.0 \mathrm{E}-04$ & $-5.1 \mathrm{E}-04$ & $-5.2 \mathrm{E}-04$ & $-5.4 \mathrm{E}-04$ & $-5.5 E-04$ & $-5.9 \mathrm{E}-04$ & $-5.3 E-04$ & $-5.4 \mathrm{E}-04$ & 3.3E-05 \\
\hline & arco-seg & -104 & -106 & -107 & -111 & -113 & -123 & -110 & -111 & 7 \\
\hline & $\mu \mathrm{m}$ & -136 & -139 & -140 & -146 & -148 & -161 & -144 & -145 & 9 \\
\hline
\end{tabular}

\begin{tabular}{|c|r|r|r|r|r|r|r|r|r|r|}
\hline \multicolumn{2}{|c|}{$\begin{array}{c}\text { Combinações } \\
\text { RM-P1 }\end{array}$} & RM-P4 & RM-P7 & RM-P10 & RM-P13 & RM-P16 & $\begin{array}{c}\text { RM- } \\
\text { Pmédio }\end{array}$ & $\begin{array}{c}\text { Média } \\
\text { (RM) }\end{array}$ & $\begin{array}{c}\text { Desvio } \\
\text { padrão }\end{array}$ \\
\hline \multirow{2}{*}{\begin{tabular}{c} 
Valores $\begin{array}{c}\text { Ro } \\
\text { do } \\
\text { desvio }\end{array}$ \\
\cline { 2 - 13 }
\end{tabular}} & radianos & $-5.4 \mathrm{E}-04$ & $-5.5 \mathrm{E}-04$ & $-5.6 \mathrm{E}-04$ & $-5.8 \mathrm{E}-04$ & $-5.9 \mathrm{E}-04$ & $-6.4 \mathrm{E}-04$ & $-5.8 \mathrm{E}-04$ & $-5.8 \mathrm{E}-04$ & $3.3 \mathrm{E}-05$ \\
\cline { 2 - 11 } & $\mu \mathrm{m}$ & -112 & -114 & -115 & -120 & -122 & -131 & -119 & -119 & 7 \\
\hline
\end{tabular}

\begin{tabular}{|l|l|r|r|r|r|r|r|r|}
\cline { 3 - 9 } \multicolumn{2}{c|}{} & \multicolumn{1}{c|}{$\mathrm{P} 1$} & \multicolumn{1}{c|}{$\mathrm{P} 4$} & \multicolumn{1}{c|}{$\mathrm{P} 7$} & \multicolumn{1}{c|}{$\mathrm{P} 10$} & \multicolumn{1}{c|}{$\mathrm{P} 13$} & \multicolumn{1}{c|}{$\mathrm{P} 16$} & \multicolumn{1}{c|}{ Pmédio } \\
\hline \multirow{3}{*}{ Médias } & radianos & $-5.3 \mathrm{E}-04$ & $-5.4 \mathrm{E}-04$ & $-5.5 \mathrm{E}-04$ & $-5.7 \mathrm{E}-04$ & $-5.8 \mathrm{E}-04$ & $-6.2 \mathrm{E}-04$ & $-5.7 \mathrm{E}-04$ \\
\cline { 2 - 9 } & arco-seg & -110 & -112 & -113 & -118 & -119 & -129 & -117 \\
\cline { 2 - 9 } & $\mu \mathrm{m}$ & -144 & -147 & -148 & -154 & -156 & -169 & -153 \\
\hline
\end{tabular}

\begin{tabular}{|c|l|r|r|r|r|r|r|r|}
\cline { 2 - 9 } \multicolumn{2}{c|}{} & \multicolumn{1}{c|}{$\mathrm{P} 1$} & \multicolumn{1}{c|}{$\mathrm{P} 4$} & $\mathrm{P} 7$ & $\mathrm{P} 10$ & $\mathrm{P} 13$ & $\mathrm{P} 16$ & Pmédio \\
\hline \multirow{2}{*}{$\begin{array}{c}\text { Desvios- } \\
\text { padrão }\end{array}$} & $\begin{array}{l}\text { radianos } \\
\text { arco-seg }\end{array}$ & $1.8 \mathrm{E}-05$ & $1.8 \mathrm{E}-05$ & $1.8 \mathrm{E}-05$ & $1.8 \mathrm{E}-05$ & $1.8 \mathrm{E}-05$ & $1.8 \mathrm{E}-05$ & $1.8 \mathrm{E}-05$ \\
\cline { 2 - 10 } & $\mu \mathrm{m}$ & 4 & 4 & 4 & 4 & 4 & 4 & 4 \\
\hline
\end{tabular}


Tabela A6.15 - Desvios de perpendicularismo da Peça 2 (Sistema Automatizado e ajustagem Minimax) - Amostras 02 e 01.

\begin{tabular}{|c|c|c|c|c|c|c|c|c|c|c|}
\hline \multicolumn{11}{|c|}{$\begin{array}{c}\text { Desvio de Perpendicularismo - Peça } 2 \text { - Medição com o Sistema Automatizado - } \\
\text { Avaliação com o Método Minimax }\end{array}$} \\
\hline \multicolumn{4}{|c|}{ Amostra de medição da Peça: } & \multirow{2}{*}{$\begin{array}{c}02 \\
\mathrm{R} 1-\mathrm{P} 7\end{array}$} & \multicolumn{5}{|c|}{$\begin{array}{l}\text { Amostra de medição da superfície de } \\
\text { referência: }\end{array}$} & \multirow{2}{*}{$\begin{array}{c}01 \\
\text { Desvio } \\
\text { padrão }\end{array}$} \\
\hline Comb & nações & $\mathrm{R} 1-\mathrm{P} 1$ & $\mathrm{R} 1-\mathrm{P} 4$ & & $\mathrm{R} 1-\mathrm{P} 10$ & $\mathrm{R} 1-\mathrm{P} 13$ & R1-P16 & R1-PM & $\begin{array}{c}\text { Média } \\
\text { (R1) }\end{array}$ & \\
\hline \multirow{3}{*}{$\begin{array}{c}\text { Valores } \\
\text { do } \\
\text { desvio }\end{array}$} & radianos & $-5.4 \mathrm{E}-04$ & $-5.2 \mathrm{E}-04$ & $-5.1 \mathrm{E}-04$ & $-5.6 \mathrm{E}-04$ & $-5.8 \mathrm{E}-04$ & $-6.1 \mathrm{E}-04$ & \begin{tabular}{|l|}
$-5.6 \mathrm{E}-04$ \\
\end{tabular} & $-5.5 \mathrm{E}-04$ & $3.8 \mathrm{E}-05$ \\
\hline & arco-seg & -111 & -108 & -105 & -115 & -119 & -126 & -115 & -114 & 8 \\
\hline & $\mu \mathrm{m}$ & -145 & -141 & -138 & -151 & -156 & -165 & -150 & -149 & 10 \\
\hline
\end{tabular}

\begin{tabular}{|c|r|r|r|r|r|r|r|r|r|r|}
\hline \multicolumn{2}{|c|}{ Combinações } & \multicolumn{1}{|c|}{ R3-P1 } & \multicolumn{1}{c|}{ R4-P4 } & \multicolumn{1}{c|}{ R4-P7 } & R4-P10 & R4-P13 & R4-P16 & R4-PM & \multicolumn{1}{c|}{$\begin{array}{c}\text { Média } \\
\text { (R4) }\end{array}$} & $\begin{array}{c}\text { Desvio } \\
\text { padrão }\end{array}$ \\
\hline \multirow{2}{*}{$\begin{array}{c}\text { Valores } \\
\text { do } \\
\text { desvio }\end{array}$} & $\begin{array}{l}\text { radianos } \\
\text { arco-seg }\end{array}$ & $-5.3 \mathrm{E}-04$ & $-5.1 \mathrm{E}-04$ & $-5.0 \mathrm{E}-04$ & $-5.3 \mathrm{E}-04$ & $-5.7 \mathrm{E}-04$ & $-6.0 \mathrm{E}-04$ & $-5.4 \mathrm{E}-04$ & $-5.4 \mathrm{E}-04$ & $3.8 \mathrm{E}-05$ \\
\cline { 2 - 11 } & $\mu \mathrm{m}$ & -142 & -105 & -103 & -109 & -117 & -124 & -112 & -111 & 8 \\
\hline
\end{tabular}

\begin{tabular}{|c|r|r|r|r|r|r|r|r|r|r|}
\hline \multicolumn{2}{|c|}{ Combinações } & \multicolumn{1}{|c|}{ R5-P1 } & R7-P4 & R7-P7 & R7-P10 & R7-P13 & R7-P16 & R7-PM & \multicolumn{1}{c|}{$\begin{array}{c}\text { Média } \\
\text { (R7) }\end{array}$} & $\begin{array}{c}\text { Desvio } \\
\text { padrão }\end{array}$ \\
\hline $\begin{array}{c}\text { Valores } \\
\text { do } \\
\text { desvio }\end{array}$ & $\begin{array}{l}\text { radianos } \\
\text { arco-seg }\end{array}$ & $-5.3 \mathrm{E}-04$ & $-5.1 \mathrm{E}-04$ & $-5.0 \mathrm{E}-04$ & $-5.3 \mathrm{E}-04$ & $-5.7 \mathrm{E}-04$ & $-6.0 \mathrm{E}-04$ & $-5.5 \mathrm{E}-04$ & $-5.4 \mathrm{E}-04$ & $3.8 \mathrm{E}-05$ \\
\cline { 2 - 11 } & $\mu \mathrm{m}$ & -143 & -106 & -103 & -110 & -117 & -124 & -113 & -112 & 8 \\
\hline
\end{tabular}

\begin{tabular}{|c|l|r|r|r|r|r|r|r|}
\cline { 3 - 9 } \multicolumn{2}{c|}{} & \multicolumn{1}{c|}{$\mathrm{P} 1$} & \multicolumn{1}{c|}{$\mathrm{P} 4$} & \multicolumn{1}{c|}{$\mathrm{P} 7$} & \multicolumn{1}{c|}{ P10 } & \multicolumn{1}{c|}{ P13 } & \multicolumn{1}{c|}{ P16 } & \multicolumn{1}{c|}{ Pmédio } \\
\hline \multirow{3}{*}{ Médias } & radianos & $-5.3 \mathrm{E}-04$ & $-5.2 \mathrm{E}-04$ & $-5.0 \mathrm{E}-04$ & $-5.4 \mathrm{E}-04$ & $-5.7 \mathrm{E}-04$ & $-6.0 \mathrm{E}-04$ & $-5.5 \mathrm{E}-04$ \\
\cline { 3 - 10 } & arco-seg & -110 & -106 & -104 & -112 & -118 & -125 & -113 \\
\cline { 2 - 9 } & $\mu \mathrm{m}$ & -143 & -139 & -136 & -146 & -154 & -163 & -148 \\
\hline
\end{tabular}

\begin{tabular}{|c|l|r|r|r|r|r|r|r|}
\cline { 3 - 9 } \multicolumn{2}{c|}{} & \multicolumn{1}{c|}{$\mathrm{P} 1$} & \multicolumn{1}{c|}{$\mathrm{P} 4$} & \multicolumn{1}{c|}{$\mathrm{P} 7$} & \multicolumn{1}{c|}{$\mathrm{P} 10$} & $\mathrm{P} 13$ & $\mathrm{P} 16$ & Pmédio \\
\hline \multirow{2}{*}{$\begin{array}{c}\text { Desvios- } \\
\text { padrão }\end{array}$} & $\begin{array}{l}\text { radianos } \\
\text { arco-seg }\end{array}$ & $6.2 \mathrm{E}-06$ & $6.2 \mathrm{E}-06$ & $6.2 \mathrm{E}-06$ & $1.6 \mathrm{E}-05$ & $6.2 \mathrm{E}-06$ & $6.2 \mathrm{E}-06$ & $6.2 \mathrm{E}-06$ \\
\cline { 2 - 9 } & $\mu \mathrm{m}$ & 2 & 1 & 1 & 3 & 1 & 1 & 1 \\
\hline
\end{tabular}


Tabela A6.16 - Desvios de perpendicularismo da Peça 2 (Sistema Automatizado e ajustagem Minimax) - Amostras 02 e 02.

\begin{tabular}{|c|c|c|c|c|c|c|c|c|c|c|}
\hline \multicolumn{11}{|c|}{$\begin{array}{c}\text { Desvio de Perpendicularismo - Peça } 2 \text { - Medição com o Sistema Automatizado - } \\
\text { Avaliação com o Método Minimax }\end{array}$} \\
\hline \multicolumn{5}{|c|}{ Amostra de medição da Peça: } & \multirow{2}{*}{$\begin{array}{c}02 \\
R 1-P 10\end{array}$} & \multicolumn{4}{|c|}{$\begin{array}{l}\text { Amostra de medição da superfície } \\
\text { de referência: }\end{array}$} & \multirow{2}{*}{$\begin{array}{c}02 \\
\text { Desvio } \\
\text { padrão }\end{array}$} \\
\hline Comb & inações & $\mathrm{R} 1-\mathrm{P} 1$ & $\mathrm{R} 1-\mathrm{P} 4$ & $\mathrm{R} 1-\mathrm{P} 7$ & & R1-P13 & R1-P16 & R1-PM & $\begin{array}{c}\text { Médias } \\
\text { (R1) }\end{array}$ & \\
\hline \multirow{3}{*}{$\begin{array}{c}\text { Valores } \\
\text { do } \\
\text { desvio }\end{array}$} & radianos & $-6.1 \mathrm{E}-04$ & $-6.0 \mathrm{E}-04$ & $-5.9 \mathrm{E}-04$ & $-6.2 \mathrm{E}-04$ & $-6.5 \mathrm{E}-04$ & $-6.9 \mathrm{E}-04$ & $-6.3 \mathrm{E}-04$ & $-6.3 \mathrm{E}-04$ & 3.8E-05 \\
\hline & arco-seg & -127 & -123 & -121 & -127 & -135 & -142 & -130 & -129 & 8 \\
\hline & $\mu \mathrm{m}$ & -166 & -161 & -158 & -167 & -177 & -185 & -170 & -169 & 10 \\
\hline
\end{tabular}

\begin{tabular}{|c|r|r|r|r|r|r|r|r|r|r|}
\hline \multicolumn{2}{|c|}{ Combinações } & \multicolumn{1}{|c|}{ R4-P1 } & \multicolumn{1}{c|}{ R4-P4 } & R4-P7 & R4-P10 & R4-P13 & R4-P16 & R4-PM & $\begin{array}{c}\text { Média } \\
\text { (R4) }\end{array}$ & $\begin{array}{c}\text { Desvio } \\
\text { padrão }\end{array}$ \\
\hline \multirow{2}{*}{\begin{tabular}{c} 
Valores $\begin{array}{c}\text { do } \\
\text { desvio }\end{array}$ \\
\cline { 2 - 12 }
\end{tabular}} & radianos & $-5.7 \mathrm{E}-04$ & $-5.5 \mathrm{E}-04$ & $-5.4 \mathrm{E}-04$ & $-5.7 \mathrm{E}-04$ & $-6.1 \mathrm{E}-04$ & $-6.4 \mathrm{E}-04$ & $-5.8 \mathrm{E}-04$ & $-5.8 \mathrm{E}-04$ & $3.8 \mathrm{E}-05$ \\
\cline { 2 - 11 } & $\mu \mathrm{m}$ & -117 & -113 & -111 & -118 & -125 & -132 & -120 & -119 & 8 \\
\hline
\end{tabular}

\begin{tabular}{|c|r|r|r|r|r|r|r|r|r|r|}
\hline \multicolumn{2}{|c|}{ Combinações } & \multicolumn{1}{|c|}{ R4-P1 } & \multicolumn{1}{c|}{ R4-P4 } & R4-P7 & R4-P10 & R4-P13 & R4-P16 & R4-PM & $\begin{array}{c}\text { Média } \\
\text { (R4) }\end{array}$ & $\begin{array}{c}\text { Desvio } \\
\text { padrão }\end{array}$ \\
\hline \multirow{2}{*}{\begin{tabular}{c} 
Valores $\begin{array}{c}\text { do } \\
\text { desvio }\end{array}$ \\
\cline { 2 - 12 }
\end{tabular}} & $\begin{array}{l}\text { radianos } \\
\text { arco-seg }\end{array}$ & $-5.6 \mathrm{E}-04$ & $-5.4 \mathrm{E}-04$ & $-5.3 \mathrm{E}-04$ & $-5.6 \mathrm{E}-04$ & $-6.0 \mathrm{E}-04$ & $-6.3 \mathrm{E}-04$ & $-5.6 \mathrm{E}-04$ & $-5.7 \mathrm{E}-04$ & $3.8 \mathrm{E}-05$ \\
\cline { 2 - 11 } & -116 & -112 & -110 & -116 & -124 & -131 & -116 & -118 & 8 \\
\hline
\end{tabular}

\begin{tabular}{|c|c|c|c|c|c|c|c|c|c|c|}
\hline \multicolumn{2}{|c|}{ Combinações } & $\mathrm{R} 10-\mathrm{P} 1$ & R10-P4 & R10-P7 & R10-P10 & $\mathrm{R} 10-\mathrm{P} 13$ & R10-P16 & R10-PM & $\begin{array}{l}\text { Média } \\
\text { (R10) }\end{array}$ & $\begin{array}{l}\text { Desvio } \\
\text { padrão }\end{array}$ \\
\hline \multirow{3}{*}{$\begin{array}{c}\text { Valores } \\
\text { do } \\
\text { desvio }\end{array}$} & radianos & $-5.5 \mathrm{E}-04$ & $-5.3 E-04$ & $-5.2 E-04$ & $-5.5 \mathrm{E}-04$ & $-5.9 \mathrm{E}-04$ & $-6.2 \mathrm{E}-04$ & $-5.6 \mathrm{E}-04$ & $-5.6 \mathrm{E}-04$ & $3.8 \mathrm{E}-05$ \\
\hline & arco-seg & -113 & -109 & -107 & -113 & -121 & -128 & -116 & -115 & 8 \\
\hline & $\mu \mathrm{m}$ & -147 & -143 & -140 & -148 & -158 & -167 & -152 & -151 & 10 \\
\hline
\end{tabular}

\begin{tabular}{|c|c|c|c|c|c|c|c|c|c|c|}
\hline \multicolumn{2}{|c|}{ Combinações } & R13-P1 & R13-P4 & R13-P7 & R13-P10 & R13-P13 & R13-P16 & R13-PM & $\begin{array}{l}\text { Média } \\
\text { (R13) }\end{array}$ & $\begin{array}{l}\text { Desvio } \\
\text { padrão }\end{array}$ \\
\hline \multirow{3}{*}{$\begin{array}{c}\text { Valores } \\
\text { do } \\
\text { desvio }\end{array}$} & radianos & $-5.5 E-04$ & $-5.3 E-04$ & $-5.2 \mathrm{E}-04$ & $-5.5 \mathrm{E}-04$ & $-5.9 \mathrm{E}-04$ & $-6.2 \mathrm{E}-04$ & $-5.6 \mathrm{E}-04$ & $-5.6 \mathrm{E}-04$ & 3.8E-05 \\
\hline & arco-seg & -113 & -109 & -107 & -113 & -121 & -128 & -116 & -115 & 8 \\
\hline & $\mu \mathrm{m}$ & -147 & -143 & -140 & -148 & -158 & -167 & -152 & -151 & 10 \\
\hline
\end{tabular}

\begin{tabular}{|c|r|r|r|r|r|r|r|r|r|r|}
\hline \multicolumn{2}{|c|}{ Combinações } & \multicolumn{1}{|c|}{ RM-P1 } & RM-P4 & RM-P7 & RM-P10 & RM-P13 & RM-P16 & RM-PM & $\begin{array}{c}\text { Média } \\
\text { (RM) }\end{array}$ & $\begin{array}{c}\text { Desvio } \\
\text { padrão }\end{array}$ \\
\hline \multirow{2}{*}{$\begin{array}{c}\text { Valores } \begin{array}{c}\text { do } \\
\text { desvio }\end{array} \\
\text { desadianos }\end{array}$} & $-5.6 \mathrm{E}-04$ & $-5.4 \mathrm{E}-04$ & $-5.3 \mathrm{E}-04$ & $-5.6 \mathrm{E}-04$ & $-6.0 \mathrm{E}-04$ & $-6.3 \mathrm{E}-04$ & $-5.8 \mathrm{E}-04$ & $-5.7 \mathrm{E}-04$ & $3.8 \mathrm{E}-05$ \\
\cline { 2 - 13 } & $\mu \mathrm{m}$ & -115 & -112 & -110 & -116 & -124 & -131 & -119 & -118 & 8 \\
\hline
\end{tabular}

\begin{tabular}{|c|l|r|r|r|r|r|r|r|}
\cline { 3 - 9 } \multicolumn{2}{c|}{} & \multicolumn{1}{c|}{$\mathrm{P} 1$} & \multicolumn{1}{c|}{$\mathrm{P} 4$} & \multicolumn{1}{c|}{$\mathrm{P} 7$} & \multicolumn{1}{c|}{$\mathrm{P} 10$} & \multicolumn{1}{c|}{$\mathrm{P} 13$} & \multicolumn{1}{c|}{$\mathrm{P} 16$} & \multicolumn{1}{c|}{ Pmédio } \\
\hline \multirow{3}{*}{ Médias } & radianos & $-5.7 \mathrm{E}-04$ & $-5.5 \mathrm{E}-04$ & $-5.4 \mathrm{E}-04$ & $-5.7 \mathrm{E}-04$ & $-6.1 \mathrm{E}-04$ & $-6.4 \mathrm{E}-04$ & $-5.8 \mathrm{E}-04$ \\
\cline { 2 - 9 } & arco-seg & -117 & -114 & -111 & -118 & -125 & -132 & -120 \\
\cline { 2 - 9 } & $\mu \mathrm{m}$ & -153 & -149 & -145 & -154 & -164 & -173 & -157 \\
\hline
\end{tabular}

\begin{tabular}{|c|l|r|r|r|r|r|r|r|}
\cline { 2 - 9 } \multicolumn{2}{c|}{} & \multicolumn{1}{c|}{$\mathrm{P} 1$} & \multicolumn{1}{c|}{$\mathrm{P} 4$} & \multicolumn{1}{c|}{$\mathrm{P} 7$} & \multicolumn{1}{c|}{$\mathrm{P} 10$} & $\mathrm{P} 13$ & $\mathrm{P} 16$ & Pmédio \\
\hline \multirow{2}{*}{$\begin{array}{c}\text { Desvios- } \\
\text { padrão }\end{array}$} & radianos & $2.8 \mathrm{E}-05$ & $2.8 \mathrm{E}-05$ & $2.8 \mathrm{E}-05$ & $2.8 \mathrm{E}-05$ & $2.8 \mathrm{E}-05$ & $2.8 \mathrm{E}-05$ & $2.9 \mathrm{E}-05$ \\
\cline { 2 - 9 } & & 6 & 6 & 6 & 6 & 6 & 6 & 6 \\
\cline { 2 - 9 } & $\mu \mathrm{m}$ & 8 & 8 & 8 & 8 & 8 & 8 & 8 \\
\hline
\end{tabular}


Tabela A6.17 - Desvios de perpendicularismo da Peça 2 (Sistema Automatizado e ajustagem Minimax) - Amostras 02 e 03.

\begin{tabular}{|c|c|c|c|c|c|c|c|c|c|c|}
\hline \multicolumn{11}{|c|}{$\begin{array}{c}\text { Desvio de Perpendicularismo - Peça } 2 \text { - Medição com o Sistema Automatizado - } \\
\text { Avaliação com o Método Minimax }\end{array}$} \\
\hline \multicolumn{5}{|c|}{ Amostra de medição da Peça: } & \multirow{2}{*}{$\begin{array}{c}02 \\
R 1-P 10\end{array}$} & \multicolumn{4}{|c|}{$\begin{array}{l}\text { Amostra de medição da superfície } \\
\text { de referência: }\end{array}$} & \multirow{2}{*}{$\begin{array}{c}03 \\
\text { Desvio } \\
\text { padrão }\end{array}$} \\
\hline Com & inações & $\mathrm{R} 1-\mathrm{P} 1$ & R1-P4 & R1-P7 & & $\mathrm{R} 1-\mathrm{P} 13$ & R1-P16 & R1-PM & $\begin{array}{c}\text { Médias } \\
\text { (R1) }\end{array}$ & \\
\hline \multirow{3}{*}{$\begin{array}{c}\text { Valores } \\
\text { do } \\
\text { desvio }\end{array}$} & radianos & $-5.6 \mathrm{E}-04$ & $-5.5 \mathrm{E}-04$ & $-5.3 E-04$ & $-5.7 \mathrm{E}-04$ & $-6.0 \mathrm{E}-04$ & $-6.4 \mathrm{E}-04$ & $-5.8 \mathrm{E}-04$ & $-5.7 E-04$ & $3.8 \mathrm{E}-05$ \\
\hline & arco-seg & -116 & -113 & -110 & -117 & -124 & -131 & -120 & $-1.2 \mathrm{E}+02$ & $7.8 \mathrm{E}+00$ \\
\hline & $\mu \mathrm{m}$ & -152 & -148 & -144 & -153 & -163 & -172 & -157 & -155.2 & 10.2 \\
\hline
\end{tabular}

\begin{tabular}{|c|l|r|r|r|r|r|r|r|r|r|}
\hline \multicolumn{2}{|c|}{ Combinações } & & R4-P1 & R4-P4 & R4-P7 & R4-P10 & R4-P13 & R4-P16 & \multicolumn{1}{c|}{$\begin{array}{c}\text { R4- } \\
\text { Pmédio }\end{array}$} & \multicolumn{1}{c|}{$\begin{array}{c}\text { Média } \\
\text { (R4) }\end{array}$} \\
\hline \multirow{2}{*}{$\begin{array}{c}\text { Valores } \\
\text { do } \\
\text { desvio }\end{array}$} & $\begin{array}{l}\text { radianos } \\
\text { arco-seg }\end{array}$ & $-5.6 \mathrm{E}-04$ & $-5.5 \mathrm{E}-04$ & $-5.3 \mathrm{E}-04$ & $-5.7 \mathrm{E}-04$ & $-6.0 \mathrm{E}-04$ & $-6.4 \mathrm{E}-04$ & $-5.8 \mathrm{E}-04$ & $-5.8 \mathrm{E}-04$ & $3.8 \mathrm{E}-05$ \\
\cline { 2 - 11 } & $\mu \mathrm{m}$ & -116 & -113 & -110 & -117 & -124 & -131 & -120 & -118.6 & 7.8 \\
\hline
\end{tabular}

\begin{tabular}{|c|c|c|c|c|c|c|c|c|c|c|}
\hline \multicolumn{2}{|c|}{ Combinações } & & R7-P1 & R7-P4 & $\mathrm{R} 7-\mathrm{P} 7$ & $\mathrm{R} 7-\mathrm{P} 10$ & $\mathrm{R} 7-\mathrm{P} 13$ & R7-P16 & $\begin{array}{c}\text { R7- } \\
\text { Pmédio } \\
\end{array}$ & $\begin{array}{l}\text { Média } \\
\text { (R7) }\end{array}$ \\
\hline \multirow{3}{*}{$\begin{array}{c}\text { Valores } \\
\text { do } \\
\text { desvio }\end{array}$} & radianos & $-5.5 \mathrm{E}-04$ & $-5.3 E-04$ & $-5.2 \mathrm{E}-04$ & $-5.5 \mathrm{E}-04$ & $-5.9 \mathrm{E}-04$ & $-6.2 \mathrm{E}-04$ & $-5.8 \mathrm{E}-04$ & $-5.6 \mathrm{E}-04$ & $3.8 \mathrm{E}-05$ \\
\hline & arco-seg & -113 & -110 & -107 & -114 & -122 & -128 & -120 & -115.8 & 7.8 \\
\hline & $\mu \mathrm{m}$ & -148 & -144 & -141 & -149 & -159 & -168 & -157 & -151.6 & 10.2 \\
\hline
\end{tabular}

\begin{tabular}{|c|c|c|c|c|c|c|c|c|c|c|}
\hline \multicolumn{2}{|c|}{ Combinações } & & R10-P1 & R10-P4 & $\mathrm{R} 10-\mathrm{P} 7$ & R10-P10 & R10-P13 & R10-P16 & $\begin{array}{c}\text { R10- } \\
\text { Pmédio } \\
\end{array}$ & $\begin{array}{l}\text { Média } \\
\text { (R10) }\end{array}$ \\
\hline \multirow{3}{*}{$\begin{array}{c}\text { Valores } \\
\text { do } \\
\text { desvio }\end{array}$} & radianos & $-5.6 \mathrm{E}-04$ & $-5.5 \mathrm{E}-04$ & $-5.3 \mathrm{E}-04$ & $-5.7 \mathrm{E}-04$ & $-6.0 \mathrm{E}-04$ & $-6.4 \mathrm{E}-04$ & $-5.8 \mathrm{E}-04$ & $-5.7 \mathrm{E}-04$ & 3.8E-05 \\
\hline & arco-seg & -116 & -113 & -110 & -117 & -124 & -131 & -120 & -118.6 & 7.8 \\
\hline & $\mu \mathrm{m}$ & -152 & -148 & -144 & -153 & -163 & -172 & -157 & -155.2 & 10.2 \\
\hline
\end{tabular}

\begin{tabular}{|c|c|c|c|c|c|c|c|c|c|c|}
\hline \multicolumn{2}{|c|}{ Combinações } & & R13-P1 & R13-P4 & R13-P7 & R13-P10 & R13-P13 & R13-P16 & $\begin{array}{c}\text { R13- } \\
\text { Pmédio }\end{array}$ & $\begin{array}{l}\text { Média } \\
\text { (R13) }\end{array}$ \\
\hline \multirow{3}{*}{$\begin{array}{c}\text { Valores } \\
\text { do } \\
\text { desvio }\end{array}$} & radianos & $-5.2 E-04$ & $-5.1 \mathrm{E}-04$ & $-4.9 \mathrm{E}-04$ & $-5.3 \mathrm{E}-04$ & $-5.6 \mathrm{E}-04$ & $-6.0 \mathrm{E}-04$ & $-5.4 \mathrm{E}-04$ & $-5.3 E-04$ & $3.8 \mathrm{E}-05$ \\
\hline & arco-seg & -108 & -104 & -102 & -109 & -116 & -123 & -111 & -110.2 & 7.8 \\
\hline & $\mu \mathrm{m}$ & -141 & -137 & -133 & -142 & -152 & -161 & -146 & -144.3 & 10.2 \\
\hline
\end{tabular}

\begin{tabular}{|c|c|c|c|c|c|c|c|c|c|c|}
\hline \multicolumn{2}{|c|}{ Combinações } & & $\mathrm{RM}-\mathrm{P} 1$ & $\mathrm{RM}-\mathrm{P} 4$ & RM-P7 & RM-P10 & RM-P13 & RM-P16 & $\begin{array}{c}\text { RM- } \\
\text { Pmédio } \\
\end{array}$ & $\begin{array}{l}\text { Média } \\
\text { (RM) }\end{array}$ \\
\hline \multirow{3}{*}{$\begin{array}{c}\text { Valores } \\
\text { do } \\
\text { desvio }\end{array}$} & radianos & $-5.6 \mathrm{E}-04$ & $-5.5 \mathrm{E}-04$ & $-5.3 \mathrm{E}-04$ & $-5.7 \mathrm{E}-04$ & $-6.0 \mathrm{E}-04$ & $-6.4 \mathrm{E}-04$ & $-5.8 \mathrm{E}-04$ & $-5.7 E-04$ & $3.8 \mathrm{E}-05$ \\
\hline & arco-seg & -116 & -113 & -110 & -117 & -124 & -131 & -120 & -118.6 & 7.8 \\
\hline & $\mu \mathrm{m}$ & -152 & -148 & -144 & -153 & -163 & -172 & -157 & -155.2 & 10.2 \\
\hline
\end{tabular}

\begin{tabular}{|l|l|r|r|r|r|r|r|r|}
\cline { 3 - 9 } \multicolumn{2}{c|}{} & \multicolumn{1}{c|}{$\mathrm{P} 1$} & \multicolumn{1}{c|}{$\mathrm{P} 4$} & \multicolumn{1}{c|}{$\mathrm{P} 7$} & \multicolumn{1}{c|}{$\mathrm{P} 10$} & \multicolumn{1}{c|}{$\mathrm{P} 13$} & \multicolumn{1}{c|}{$\mathrm{P} 16$} & \multicolumn{1}{c|}{ Pmédio } \\
\hline \multirow{3}{*}{ Médias } & radianos & $-5.5 \mathrm{E}-04$ & $-5.4 \mathrm{E}-04$ & $-5.2 \mathrm{E}-04$ & $-5.6 \mathrm{E}-04$ & $-5.9 \mathrm{E}-04$ & $-6.3 \mathrm{E}-04$ & $-5.7 \mathrm{E}-04$ \\
\cline { 2 - 9 } & arco-seg & -114 & -111 & -108 & -115 & -122 & -129 & -118 \\
\cline { 2 - 9 } & $\mu \mathrm{m}$ & -149 & -145 & -141 & -150 & -160 & -169 & -154 \\
\hline
\end{tabular}

\begin{tabular}{|c|l|r|r|r|r|r|r|r|}
\cline { 2 - 9 } \multicolumn{2}{c|}{} & \multicolumn{1}{c|}{$\mathrm{P} 1$} & \multicolumn{1}{c|}{$\mathrm{P} 4$} & $\mathrm{P} 7$ & \multicolumn{1}{c|}{$\mathrm{P} 10$} & $\mathrm{P} 13$ & $\mathrm{P} 16$ & Pmédio \\
\hline \multirow{2}{*}{$\begin{array}{c}\text { Desvios- } \\
\text { padrão }\end{array}$} & $\begin{array}{l}\text { radianos } \\
\text { arco-seg }\end{array}$ & $1.8 \mathrm{E}-05$ & $1.8 \mathrm{E}-05$ & $1.8 \mathrm{E}-05$ & $1.8 \mathrm{E}-05$ & $1.8 \mathrm{E}-05$ & $1.8 \mathrm{E}-05$ & $1.8 \mathrm{E}-05$ \\
\cline { 2 - 9 } & 4 & 4 & 4 & 4 & 4 & 4 & 4 \\
\cline { 2 - 8 } & & 5 & 5 & 5 & 5 & 5 & 5 & 5 \\
\hline
\end{tabular}


Tabela A6.18 - Desvios de perpendicularismo da Peça 2 (Sistema Automatizado e ajustagem Minimax) - Amostras 03 e 01.

\begin{tabular}{|c|c|c|c|c|c|c|c|c|c|c|}
\hline \multicolumn{11}{|c|}{$\begin{array}{l}\text { Desvio de Perpendicularismo - Peça } 2 \text { - Medição com o Sistema Automatizado - } \\
\text { Avaliação com o Método Minimax }\end{array}$} \\
\hline \multicolumn{4}{|c|}{ Amostra de medição da Peça: } & \multirow{2}{*}{$\frac{03}{R 1-P 7}$} & \multicolumn{5}{|c|}{$\begin{array}{l}\text { Amostra de medição da superfície de } \\
\text { referência: }\end{array}$} & \multirow{2}{*}{$\begin{array}{c}01 \\
\text { Desvio } \\
\text { padrão }\end{array}$} \\
\hline \multicolumn{2}{|c|}{ Combinações } & $\mathrm{R} 1-\mathrm{P} 1$ & $\mathrm{R} 1-\mathrm{P} 4$ & & $\mathrm{R} 1-\mathrm{P} 10$ & $\mathrm{R} 1-\mathrm{P} 13$ & $\mathrm{R} 1-\mathrm{P} 16$ & $\mathrm{R} 1-\mathrm{PM}$ & \begin{tabular}{|c|} 
Média \\
$(\mathrm{R} 1)$ \\
\end{tabular} & \\
\hline \multirow{3}{*}{$\begin{array}{c}\text { Valores } \\
\text { do } \\
\text { desvio }\end{array}$} & radianos & $-5.3 E-04$ & $-4.9 \mathrm{E}-04$ & $-4.9 \mathrm{E}-04$ & $-5.2 E-04$ & $-5.4 \mathrm{E}-04$ & $-5.9 E-04$ & $-5.2 E-04$ & $-5.3 \mathrm{E}-04$ & 3.7E-05 \\
\hline & arco-seg & -109 & -101 & -101 & -107 & -111 & -122 & -108 & -108 & 8 \\
\hline & $\mu \mathrm{m}$ & -142 & -132 & -132 & -140 & -145 & -159 & -141 & -142 & 10 \\
\hline
\end{tabular}

\begin{tabular}{|c|c|c|c|c|c|c|c|c|c|c|}
\hline \multicolumn{2}{|c|}{ Combinações } & R3-P1 & R4-P4 & R4-P7 & R4-P10 & R4-P13 & R4-P16 & R4-PM & $\begin{array}{c}\text { Média } \\
\text { (R4) }\end{array}$ & $\begin{array}{l}\text { Desvio } \\
\text { padrão }\end{array}$ \\
\hline \multirow{3}{*}{$\begin{array}{c}\text { Valores } \\
\text { do } \\
\text { desvio }\end{array}$} & radianos & $-5.1 \mathrm{E}-04$ & $-4.8 \mathrm{E}-04$ & $-4.8 \mathrm{E}-04$ & $-4.9 \mathrm{E}-04$ & $-5.2 E-04$ & $-5.8 E-04$ & $-5.1 \mathrm{E}-04$ & $-5.1 \mathrm{E}-04$ & 3.8E-05 \\
\hline & arco-seg & -106 & -99 & -99 & -101 & -108 & -119 & -106 & -105 & 8 \\
\hline & $u m$ & -139 & -129 & -129 & -132 & -142 & -156 & -138 & -138 & 10 \\
\hline
\end{tabular}

\begin{tabular}{|c|c|r|r|r|r|r|r|r|r|r|}
\hline \multicolumn{2}{|c|}{ Combinações } & R5-P1 & R7-P4 & R7-P7 & R7-P10 & R7-P13 & R7-P16 & R7-PM & $\begin{array}{c}\text { Média } \\
\text { (R7) }\end{array}$ & $\begin{array}{c}\text { Desvio } \\
\text { padrão }\end{array}$ \\
\hline \multirow{2}{*}{\begin{tabular}{c} 
Valores $\begin{array}{c}\text { Ro } \\
\text { do } \\
\text { desvio }\end{array}$ \\
\cline { 2 - 12 }
\end{tabular}} & $\begin{array}{l}\text { radianos } \\
\text { arco-seg }\end{array}$ & $-5.2 \mathrm{E}-04$ & $-4.8 \mathrm{E}-04$ & $-4.8 \mathrm{E}-04$ & $-4.9 \mathrm{E}-04$ & $-5.3 \mathrm{E}-04$ & $-5.8 \mathrm{E}-04$ & $-5.1 \mathrm{E}-04$ & $-5.1 \mathrm{E}-04$ & $3.8 \mathrm{E}-05$ \\
\cline { 2 - 11 } & & -107 & -99 & -99 & -101 & -109 & -120 & -106 & -106 & 8 \\
\hline
\end{tabular}

\begin{tabular}{|c|l|r|r|r|r|r|r|r|}
\cline { 3 - 9 } \multicolumn{2}{c|}{} & \multicolumn{1}{c|}{$\mathrm{P} 1$} & \multicolumn{1}{c|}{$\mathrm{P} 4$} & \multicolumn{1}{c|}{$\mathrm{P} 7$} & \multicolumn{1}{c|}{$\mathrm{P} 10$} & \multicolumn{1}{c|}{$\mathrm{P} 13$} & \multicolumn{1}{c|}{$\mathrm{P} 16$} & \multicolumn{1}{c|}{ Pmédio } \\
\hline \multirow{3}{*}{ Médias } & radianos & $-5.2 \mathrm{E}-04$ & $-4.8 \mathrm{E}-04$ & $-4.8 \mathrm{E}-04$ & $-5.0 \mathrm{E}-04$ & $-5.3 \mathrm{E}-04$ & $-5.8 \mathrm{E}-04$ & $-5.2 \mathrm{E}-04$ \\
\cline { 2 - 9 } & arco-seg & -107 & -100 & -100 & -103 & -109 & -120 & -107 \\
\cline { 2 - 9 } & $\mu \mathrm{m}$ & -140 & -130 & -130 & -134 & -143 & -157 & -140 \\
\hline
\end{tabular}

\begin{tabular}{|c|l|r|r|r|r|r|r|r|}
\cline { 3 - 9 } \multicolumn{2}{c|}{} & \multicolumn{1}{c|}{$\mathrm{P} 1$} & \multicolumn{1}{c|}{$\mathrm{P} 4$} & $\mathrm{P} 7$ & $\mathrm{P} 10$ & $\mathrm{P} 13$ & \multicolumn{1}{c|}{$\mathrm{P} 16$} & Pmédio \\
\hline \multirow{2}{*}{$\begin{array}{c}\text { Desvios- } \\
\text { padrão }\end{array}$} & radianos & $6.2 \mathrm{E}-06$ & $6.2 \mathrm{E}-06$ & $6.2 \mathrm{E}-06$ & $1.6 \mathrm{E}-05$ & $6.2 \mathrm{E}-06$ & $6.2 \mathrm{E}-06$ & $6.2 \mathrm{E}-06$ \\
\cline { 2 - 9 } & $\mu \mathrm{m}$ & 1 & 1 & 1 & 3 & 1 & 1 & 1 \\
\cline { 2 - 9 } & & 2 & 2 & 2 & 4 & 2 & 2 & 2 \\
\hline
\end{tabular}


Tabela A6.19 - Desvios de perpendicularismo da Peça 2 (Sistema Automatizado e ajustagem Minimax) - Amostras 03 e 02.

\begin{tabular}{|c|c|c|c|c|c|c|c|c|c|c|}
\hline \multicolumn{11}{|c|}{$\begin{array}{c}\text { Desvio de Perpendicularismo - Peça } 2 \text { - Medição com o Sistema Automatizado - } \\
\text { Avaliação com o Método Minimax }\end{array}$} \\
\hline \multicolumn{5}{|c|}{ Amostra de medição da Peça: } & \multirow{2}{*}{$\begin{array}{c}03 \\
\text { R1-P10 }\end{array}$} & \multicolumn{4}{|c|}{$\begin{array}{l}\text { Amostra de medição da superfície } \\
\text { de referência: }\end{array}$} & \multirow{2}{*}{$\begin{array}{c}02 \\
\text { Desvio } \\
\text { padrão }\end{array}$} \\
\hline Comb & nações & $\mathrm{R} 1-\mathrm{P} 1$ & $\mathrm{R} 1-\mathrm{P} 4$ & R1-P7 & & $\mathrm{R} 1-\mathrm{P} 13$ & R1-P16 & R1-PM & $\begin{array}{c}\text { Médias } \\
\text { (R1) }\end{array}$ & \\
\hline \multirow{3}{*}{$\begin{array}{l}\text { Valores } \\
\text { do } \\
\text { desvio }\end{array}$} & radianos & $-6.0 \mathrm{E}-04$ & $-5.7 \mathrm{E}-04$ & $-5.7 E-04$ & $-5.7 \mathrm{E}-04$ & $-6.1 \mathrm{E}-04$ & $-6.7 \mathrm{E}-04$ & $-6.0 \mathrm{E}-04$ & $-6.0 \mathrm{E}-04$ & $3.8 \mathrm{E}-05$ \\
\hline & arco-seg & -124 & -117 & -117 & -118 & -126 & -137 & -124 & $-1.2 \mathrm{E}+02$ & $7.9 \mathrm{E}+00$ \\
\hline & $\mu \mathrm{m}$ & -163 & -153 & -153 & -155 & -165 & -180 & -162 & -161.3 & 10.4 \\
\hline
\end{tabular}

\begin{tabular}{|c|l|r|r|r|r|r|r|r|r|r|}
\hline \multicolumn{2}{|c|}{ Combinações } & \multicolumn{1}{|c|}{ R4-P1 } & \multicolumn{1}{c|}{ R4-P4 } & R4-P7 & R4-P10 & R4-P13 & R4-P16 & $\begin{array}{c}\text { R4- } \\
\text { Pmédio }\end{array}$ & $\begin{array}{c}\text { Média } \\
\text { (R4) }\end{array}$ & $\begin{array}{c}\text { Desvio } \\
\text { padrão }\end{array}$ \\
\hline \multirow{2}{*}{$\begin{array}{c}\text { Valores } \\
\text { do } \\
\text { desvio }\end{array}$} & $\begin{array}{l}\text { radianos } \\
\text { arco-seg }\end{array}$ & $-5.5 \mathrm{E}-04$ & $-5.2 \mathrm{E}-04$ & $-5.2 \mathrm{E}-04$ & $-5.3 \mathrm{E}-04$ & $-5.6 \mathrm{E}-04$ & $-6.2 \mathrm{E}-04$ & $-5.5 \mathrm{E}-04$ & $-5.5 \mathrm{E}-04$ & $3.8 \mathrm{E}-05$ \\
\cline { 2 - 11 } & $\mu \mathrm{m}$ & -114 & -107 & -107 & -109 & -116 & -127 & -114 & -113.4 & 7.9 \\
\hline
\end{tabular}

\begin{tabular}{|c|r|r|r|r|r|r|r|r|r|r|}
\hline \multicolumn{2}{|c|}{ Combinações } & \multicolumn{1}{|c|}{ R7-P1 } & \multicolumn{1}{c|}{ R7-P4 } & R7-P7 & R7-P10 & R7-P13 & R7-P16 & $\begin{array}{c}\text { R7- } \\
\text { Pmédio }\end{array}$ & $\begin{array}{c}\text { Média } \\
\text { (R7) }\end{array}$ & \multicolumn{1}{c|}{$\begin{array}{c}\text { Desvio } \\
\text { padrão }\end{array}$} \\
\hline \multirow{2}{*}{$\begin{array}{c}\text { Valores } \\
\text { do } \\
\text { desvio }\end{array}$} & $\begin{array}{l}\text { radianos } \\
\text { arco-seg }\end{array}$ & $-5.5 \mathrm{E}-04$ & $-5.1 \mathrm{E}-04$ & $-5.1 \mathrm{E}-04$ & $-5.2 \mathrm{E}-04$ & $-5.6 \mathrm{E}-04$ & $-6.1 \mathrm{E}-04$ & $-5.3 \mathrm{E}-04$ & $-5.4 \mathrm{E}-04$ & $3.8 \mathrm{E}-05$ \\
\cline { 2 - 11 } & $\mu \mathrm{m}$ & -113 & -106 & -106 & -108 & -115 & -126 & -110 & -112.3 & 7.9 \\
\hline
\end{tabular}

\begin{tabular}{|c|r|r|r|r|r|r|r|r|r|r|}
\hline \multicolumn{2}{|c|}{ Combinações } & R10-P1 & R10-P4 & R10-P7 & R10-P10 & R10-P13 & R10-P16 & $\begin{array}{c}\text { R10- } \\
\text { Pmédio }\end{array}$ & $\begin{array}{c}\text { Média } \\
\text { (R10) }\end{array}$ & \multicolumn{1}{c|}{$\begin{array}{c}\text { Desvio } \\
\text { padrão }\end{array}$} \\
\hline \multirow{2}{*}{$\begin{array}{c}\text { Valores } \\
\text { do } \\
\text { desvio }\end{array}$} & $\begin{array}{l}\text { radianos } \\
\text { arco-seg }\end{array}$ & $-5.3 \mathrm{E}-04$ & $-5.0 \mathrm{E}-04$ & $-5.0 \mathrm{E}-04$ & $-5.1 \mathrm{E}-04$ & $-5.4 \mathrm{E}-04$ & $-6.0 \mathrm{E}-04$ & $-5.3 \mathrm{E}-04$ & $-5.3 \mathrm{E}-04$ & $3.8 \mathrm{E}-05$ \\
\cline { 2 - 11 } & $\mu \mathrm{m}$ & -110 & -103 & -103 & -104 & -112 & -123 & -110 & -109.2 & 7.9 \\
\hline
\end{tabular}

\begin{tabular}{|c|r|r|r|r|r|r|r|r|r|r|}
\hline \multicolumn{2}{|c|}{ Combinações } & R13-P1 & R13-P4 & R13-P7 & R13-P10 & R13-P13 & R13-P16 & $\begin{array}{c}\text { R13- } \\
\text { Pmédio }\end{array}$ & $\begin{array}{c}\text { Média } \\
\text { (R13) }\end{array}$ & $\begin{array}{c}\text { Desvio } \\
\text { padrão }\end{array}$ \\
\hline \multirow{2}{*}{$\begin{array}{c}\text { Valores } \\
\text { do } \\
\text { desvio }\end{array}$} & $\begin{array}{l}\text { radianos } \\
\text { arco-seg }\end{array}$ & $-5.3 \mathrm{E}-04$ & $-5.0 \mathrm{E}-04$ & $-5.0 \mathrm{E}-04$ & $-5.1 \mathrm{E}-04$ & $-5.4 \mathrm{E}-04$ & $-6.0 \mathrm{E}-04$ & $-5.3 \mathrm{E}-04$ & $-5.3 \mathrm{E}-04$ & $3.8 \mathrm{E}-05$ \\
\cline { 2 - 11 } & $\mu \mathrm{m}$ & -110 & -103 & -103 & -104 & -112 & -123 & -110 & -109.2 & 7.9 \\
\hline
\end{tabular}

\begin{tabular}{|c|r|r|r|r|r|r|r|r|r|r|}
\hline \multicolumn{2}{|c|}{ Combinações } & RM-P1 & RM-P4 & RM-P7 & RM-P10 & RM-P13 & RM-P16 & $\begin{array}{c}\text { RM- } \\
\text { Pmédio }\end{array}$ & \multicolumn{1}{c|}{$\begin{array}{c}\text { Média } \\
\text { (RM) }\end{array}$} & $\begin{array}{c}\text { Desvio } \\
\text { padrão }\end{array}$ \\
\hline $\begin{array}{c}\text { Valores } \\
\text { do } \\
\text { desvio }\end{array}$ & $\begin{array}{l}\text { radianos } \\
\text { arco-seg }\end{array}$ & $-5.5 \mathrm{E}-04$ & $-5.1 \mathrm{E}-04$ & $-5.1 \mathrm{E}-04$ & $-5.2 \mathrm{E}-04$ & $-5.6 \mathrm{E}-04$ & $-6.1 \mathrm{E}-04$ & $-5.5 \mathrm{E}-04$ & $-5.4 \mathrm{E}-04$ & $3.8 \mathrm{E}-05$ \\
\cline { 2 - 11 } & $\mu \mathrm{m}$ & -148 & -138 & -106 & -107 & -115 & -126 & -112 & -112.1 & 7.9 \\
\hline
\end{tabular}

\begin{tabular}{|l|l|r|r|r|r|r|r|r|}
\cline { 3 - 9 } \multicolumn{2}{c|}{} & \multicolumn{1}{c|}{$\mathrm{P} 1$} & \multicolumn{1}{c|}{$\mathrm{P} 4$} & \multicolumn{1}{c|}{$\mathrm{P} 7$} & \multicolumn{1}{c|}{$\mathrm{P} 10$} & \multicolumn{1}{c|}{$\mathrm{P} 13$} & \multicolumn{1}{c|}{$\mathrm{P} 16$} & \multicolumn{1}{c|}{ Pmédio } \\
\hline \multirow{3}{*}{ Médias } & radianos & $-5.5 \mathrm{E}-04$ & $-5.2 \mathrm{E}-04$ & $-5.2 \mathrm{E}-04$ & $-5.3 \mathrm{E}-04$ & $-5.6 \mathrm{E}-04$ & $-6.2 \mathrm{E}-04$ & $-5.5 \mathrm{E}-04$ \\
\cline { 2 - 9 } & arco-seg & -114 & -107 & -107 & -109 & -116 & -127 & -113 \\
\cline { 2 - 9 } & $\mu \mathrm{m}$ & -150 & -140 & -140 & -142 & -152 & -167 & -148 \\
\hline
\end{tabular}

\begin{tabular}{|c|l|r|r|r|r|r|r|r|}
\cline { 2 - 9 } \multicolumn{2}{c|}{} & \multicolumn{1}{c|}{$\mathrm{P} 1$} & \multicolumn{1}{c|}{$\mathrm{P} 4$} & \multicolumn{1}{c|}{$\mathrm{P} 7$} & \multicolumn{1}{c|}{$\mathrm{P} 10$} & $\mathrm{P} 13$ & $\mathrm{P} 16$ & Pmédio \\
\hline \multirow{2}{*}{$\begin{array}{c}\text { Desvios- } \\
\text { padrão }\end{array}$} & $\begin{array}{l}\text { radianos } \\
\text { arco-seg }\end{array}$ & $2.8 \mathrm{E}-05$ & $2.8 \mathrm{E}-05$ & $2.8 \mathrm{E}-05$ & $2.8 \mathrm{E}-05$ & $2.8 \mathrm{E}-05$ & $2.8 \mathrm{E}-05$ & $2.9 \mathrm{E}-05$ \\
\cline { 2 - 9 } & & 6 & 6 & 6 & 6 & 6 & 6 & 6 \\
\hline
\end{tabular}


Tabela A6.20 - Desvios de perpendicularismo da Peça 2 (Sistema Automatizado e ajustagem Minimax)- Amostras 03 e 03.

\begin{tabular}{|c|c|c|c|c|c|c|c|c|c|c|}
\hline \multicolumn{11}{|c|}{$\begin{array}{c}\text { Desvio de Perpendicularismo - Peça } 2 \text { - Medição com o Sistema Automatizado - } \\
\text { Avaliação com o Método Minimax }\end{array}$} \\
\hline \multicolumn{5}{|c|}{ Amostra de medição da Peça: } & \multirow{2}{*}{$\frac{03}{R 1-P 10}$} & \multicolumn{4}{|c|}{$\begin{array}{l}\text { Amostra de medição da superfície } \\
\text { de referência: }\end{array}$} & \multirow{2}{*}{$\begin{array}{c}\mathbf{0 3} \\
\text { Desvio } \\
\text { padrão }\end{array}$} \\
\hline Comt & inações & $\mathrm{R} 1-\mathrm{P} 1$ & $\mathrm{R} 1-\mathrm{P} 4$ & R1-P7 & & $\mathrm{R} 1-\mathrm{P} 13$ & $\mathrm{R} 1-\mathrm{P} 16$ & R1-PM & $\begin{array}{c}\text { Médias } \\
\text { (R1) }\end{array}$ & \\
\hline \multirow{3}{*}{$\begin{array}{c}\text { Valores } \\
\text { do } \\
\text { desvio }\end{array}$} & radianos & $-5.5 \mathrm{E}-04$ & $-5.1 \mathrm{E}-04$ & $-5.1 \mathrm{E}-04$ & $-5.2 \mathrm{E}-04$ & $-5.6 \mathrm{E}-04$ & $-6.1 \mathrm{E}-04$ & $-5.5 \mathrm{E}-04$ & $-5.5 \mathrm{E}-04$ & 3.8E-05 \\
\hline & arco-seg & -114 & -106 & -106 & -108 & -116 & -127 & -113 & -113 & 8 \\
\hline & $\mu \mathrm{m}$ & -149 & -139 & -139 & -141 & -151 & -166 & -148 & -148 & 10 \\
\hline
\end{tabular}

\begin{tabular}{|c|c|c|c|c|c|c|c|c|c|c|}
\hline \multicolumn{2}{|c|}{ Combinações } & $\mathrm{R} 4-\mathrm{P} 1$ & R4-P4 & R4-P7 & R4-P10 & R4-P13 & R4-P16 & $\begin{array}{c}\text { R4- } \\
\text { Pmédio }\end{array}$ & $\begin{array}{l}\text { Média } \\
\text { (R4) }\end{array}$ & $\begin{array}{l}\text { Desvio } \\
\text { padrão }\end{array}$ \\
\hline \multirow{3}{*}{$\begin{array}{l}\text { Valores } \\
\text { do } \\
\text { desvio }\end{array}$} & \multirow{2}{*}{$\begin{array}{l}\text { radianos } \\
\text { arco-seg }\end{array}$} & & $-5.1 \mathrm{E}-04$ & $-5.1 \mathrm{E}-04$ & $-5.2 \mathrm{E}-04$ & $-5.6 \mathrm{E}-04$ & $-6.1 \mathrm{E}-04$ & $-5.5 \mathrm{E}-04$ & $-5.5 E-04$ & 4.3E-05 \\
\hline & & -114 & -106 & -106 & -108 & -116 & -127 & -113 & -113 & 8 \\
\hline & $\mu \mathrm{m}$ & -149 & -139 & -139 & -141 & -152 & -166 & -148 & -148 & 10 \\
\hline
\end{tabular}

\begin{tabular}{|c|c|c|c|c|c|c|c|c|c|c|}
\hline \multicolumn{2}{|c|}{ Combinações } & R7-P1 & R7-P4 & R7-P7 & R7-P10 & R7-P13 & R7-P16 & $\begin{array}{c}\text { R7- } \\
\text { Pmédio } \\
\end{array}$ & $\begin{array}{l}\text { Média } \\
\text { (R7) }\end{array}$ & $\begin{array}{l}\text { Desvio } \\
\text { padrão }\end{array}$ \\
\hline \multirow{3}{*}{$\begin{array}{c}\text { Valores } \\
\text { do } \\
\text { desvio }\end{array}$} & radianos & $-5.4 \mathrm{E}-04$ & $-5.0 \mathrm{E}-04$ & $-5.0 \mathrm{E}-04$ & $-5.1 \mathrm{E}-04$ & $-5.5 \mathrm{E}-04$ & $-6.0 \mathrm{E}-04$ & $-5.5 \mathrm{E}-04$ & $-5.3 \mathrm{E}-04$ & $3.8 \mathrm{E}-05$ \\
\hline & arco-seg & -111 & -103 & -103 & -105 & -113 & -124 & -113 & -110 & 8 \\
\hline & $\mu \mathrm{m}$ & -145 & -135 & -135 & -138 & -148 & -162 & -148 & -144 & 10 \\
\hline
\end{tabular}

\begin{tabular}{|c|r|r|r|r|r|r|r|r|r|r|}
\hline \multicolumn{2}{|c|}{ Combinações } & R10-P1 & R10-P4 & R10-P7 & R10-P10 & R10-P13 & R10-P16 & $\begin{array}{c}\text { R10- } \\
\text { Pmédio }\end{array}$ & $\begin{array}{c}\text { Média } \\
\text { (R10) }\end{array}$ & $\begin{array}{c}\text { Desvio } \\
\text { padrão }\end{array}$ \\
\hline \multirow{2}{*}{\begin{tabular}{c} 
Valores $\begin{array}{c}\text { do } \\
\text { desvio }\end{array}$ \\
\cline { 2 - 12 }
\end{tabular}} & \begin{tabular}{r} 
ardianos \\
\cline { 2 - 11 }
\end{tabular} & $-5.5 \mathrm{E}-04$ & $-5.1 \mathrm{E}-04$ & $-5.1 \mathrm{E}-04$ & $-5.2 \mathrm{E}-04$ & $-5.6 \mathrm{E}-04$ & $-6.1 \mathrm{E}-04$ & $-5.5 \mathrm{E}-04$ & $-5.5 \mathrm{E}-04$ & $3.8 \mathrm{E}-05$ \\
\cline { 2 - 11 } & -114 & -106 & -106 & -108 & -116 & -127 & -113 & -113 & -148 \\
\hline
\end{tabular}

\begin{tabular}{|c|c|c|c|c|c|c|c|c|c|c|}
\hline \multicolumn{2}{|c|}{ Combinações } & R13-P1 & R13-P4 & R13-P7 & R13-P10 & R13-P13 & R13-P16 & $\begin{array}{c}\text { R13- } \\
\text { Pmédio }\end{array}$ & $\begin{array}{l}\text { Média } \\
\text { (R13) }\end{array}$ & $\begin{array}{l}\text { Desvio } \\
\text { padrão }\end{array}$ \\
\hline \multirow{3}{*}{$\begin{array}{c}\text { Valores } \\
\text { do } \\
\text { desvio }\end{array}$} & radianos & $-5.1 \mathrm{E}-04$ & $-4.7 \mathrm{E}-04$ & $-4.7 \mathrm{E}-04$ & $-4.8 \mathrm{E}-04$ & $-5.2 \mathrm{E}-04$ & $-5.7 \mathrm{E}-04$ & $-5.1 \mathrm{E}-04$ & $-5.1 \mathrm{E}-04$ & $3.8 \mathrm{E}-05$ \\
\hline & arco-seg & -105 & -98 & -98 & -100 & -107 & -118 & -105 & -104 & 8 \\
\hline & $\mu \mathrm{m}$ & -138 & -128 & -128 & -130 & -140 & -155 & -137 & -137 & 10 \\
\hline
\end{tabular}

\begin{tabular}{|c|r|r|r|r|r|r|r|r|r|r|}
\hline \multicolumn{2}{|c|}{ Combinações } & \multicolumn{1}{|c|}{ RM-P1 } & RM-P4 & RM-P7 & RM-P10 & RM-P13 & RM-P16 & $\begin{array}{c}\text { RM- } \\
\text { Pmédio }\end{array}$ & $\begin{array}{c}\text { Média } \\
\text { (RM) }\end{array}$ & $\begin{array}{c}\text { Desvio } \\
\text { padrão }\end{array}$ \\
\hline \multirow{2}{*}{$\begin{array}{c}\text { Valores } \begin{array}{c}\text { do } \\
\text { desvio }\end{array} \\
\text { desadianos }\end{array}$} & $-5.5 \mathrm{E}-04$ & $-5.1 \mathrm{E}-04$ & $-5.1 \mathrm{E}-04$ & $-5.2 \mathrm{E}-04$ & $-5.6 \mathrm{E}-04$ & $-6.1 \mathrm{E}-04$ & $-5.5 \mathrm{E}-04$ & $-5.5 \mathrm{E}-04$ & $3.8 \mathrm{E}-05$ \\
\cline { 2 - 12 } & arco-seg & -114 & -106 & -106 & -108 & -116 & -127 & -113 & -113 & 8 \\
\hline
\end{tabular}

\begin{tabular}{|c|l|r|r|r|r|r|r|r|}
\cline { 3 - 9 } \multicolumn{2}{c|}{} & \multicolumn{1}{c|}{$\mathrm{P} 1$} & \multicolumn{1}{c|}{$\mathrm{P} 4$} & \multicolumn{1}{c|}{$\mathrm{P} 7$} & \multicolumn{1}{c|}{$\mathrm{P} 10$} & \multicolumn{1}{c|}{$\mathrm{P} 13$} & \multicolumn{1}{c|}{$\mathrm{P} 16$} & \multicolumn{1}{c|}{ Pmédio } \\
\hline \multirow{3}{*}{ Médias } & radianos & $-4.3 \mathrm{E}-04$ & $-5.0 \mathrm{E}-04$ & $-5.0 \mathrm{E}-04$ & $-5.1 \mathrm{E}-04$ & $-5.5 \mathrm{E}-04$ & $-6.0 \mathrm{E}-04$ & $-5.4 \mathrm{E}-04$ \\
\cline { 2 - 9 } & arco-seg & -111 & -104 & -104 & -106 & -113 & -125 & -111 \\
\cline { 2 - 9 } & $\mu \mathrm{m}$ & -146 & -136 & -136 & -138 & -149 & -163 & -146 \\
\hline
\end{tabular}

\begin{tabular}{|c|l|r|r|r|r|r|r|r|}
\cline { 2 - 9 } \multicolumn{2}{c|}{} & \multicolumn{1}{c|}{$\mathrm{P} 1$} & $\mathrm{P} 4$ & $\mathrm{P} 7$ & $\mathrm{P} 10$ & $\mathrm{P} 13$ & $\mathrm{P} 16$ & Pmédio \\
\hline \multirow{2}{*}{$\begin{array}{c}\text { Desvios- } \\
\text { padrão }\end{array}$} & $\begin{array}{l}\text { radianos } \\
\text { arco-seg }\end{array}$ & $2.4 \mathrm{E}-04$ & $1.8 \mathrm{E}-05$ & $1.8 \mathrm{E}-05$ & $1.8 \mathrm{E}-05$ & $1.8 \mathrm{E}-05$ & $1.8 \mathrm{E}-05$ & $1.8 \mathrm{E}-05$ \\
\cline { 2 - 9 } & $\mu \mathrm{m}$ & 4 & 4 & 4 & 4 & 4 & 4 & 4 \\
\hline
\end{tabular}


Tabela A6.21 -Valores médios do desvio de perpendicularismo, referentes às tabelas A6.13 a A6.20 (Método Minimax).

\begin{tabular}{|c|c|c|c|c|}
\hline & \multicolumn{4}{|c|}{$\begin{array}{c}\text { Resultados Médios - Desvio de Perpendicularismo - Peça } 2 \\
\text { - Sistema Automatizado e Ajustagem Minimax }\end{array}$} \\
\hline & \multicolumn{3}{|c|}{ Amostra de Medição da Peça } & 01 \\
\hline & \multicolumn{3}{|c|}{ Amostra de Medição da superfície de Referência } & 01 \\
\hline & $\begin{array}{l}\text { Média Geral das } \\
\text { Combinações }\end{array}$ & $\begin{array}{l}\text { D. Padrão } \\
\text { Total }\end{array}$ & $\begin{array}{l}\text { Perfil Médio - } \\
\text { Referência Média }\end{array}$ & $\begin{array}{l}\text { Desvio } \\
\text { Médio }\end{array}$ \\
\hline radianos & $-5.5 \mathrm{E}-04$ & $3.2 \mathrm{E}-05$ & --- & $-5.5 \mathrm{E}-04$ \\
\hline arco-seg & -113 & 7 & --- & -113 \\
\hline um & -148 & 9 & --- & -148 \\
\hline
\end{tabular}

\begin{tabular}{|l|r|r|r|r|}
\cline { 2 - 5 } \multicolumn{1}{c|}{} & \multicolumn{3}{l|}{ Amostra de Medição da Peça } & $\mathbf{0 1}$ \\
\cline { 2 - 5 } \multicolumn{1}{c|}{ Amostra de Medição da superfície de Referência } & \multicolumn{1}{c|}{$\mathbf{0 3}$} \\
\cline { 2 - 5 } \multicolumn{1}{c|}{} & $\begin{array}{c}\text { Média Geral das } \\
\text { Combinações }\end{array}$ & $\begin{array}{c}\text { D. Padrão } \\
\text { Total }\end{array}$ & $\begin{array}{c}\text { Perfil Médio - } \\
\text { Referência Média }\end{array}$ & $\begin{array}{c}\text { Desvio } \\
\text { Médio }\end{array}$ \\
\hline radianos & $-5.7 \mathrm{E}-04$ & $3.5 \mathrm{E}-05$ & $-5.8 \mathrm{E}-04$ & $-5.7 \mathrm{E}-04$ \\
\cline { 2 - 6 } arco-seg & -117 & 7 & -119 & -117 \\
\hline um & -153 & 9 & -155 & -153 \\
\hline
\end{tabular}

\begin{tabular}{|l|r|r|r|r|}
\cline { 2 - 5 } \multicolumn{1}{c|}{} & \multicolumn{3}{l|}{ Amostra de Medição da Peça } & $\mathbf{0 2}$ \\
\cline { 2 - 5 } \multicolumn{1}{c|}{ Amostra de Medição da superfície de Referência } & $\mathbf{0 1}$ \\
\cline { 2 - 5 } \multicolumn{1}{c|}{} & $\begin{array}{c}\text { Média Geral das } \\
\text { Combinações }\end{array}$ & $\begin{array}{c}\text { D. Padrão } \\
\text { Total }\end{array}$ & $\begin{array}{c}\text { Perfil Médio - } \\
\text { Referência Média }\end{array}$ & $\begin{array}{c}\text { Desvio } \\
\text { Médio }\end{array}$ \\
\hline radianos & $-5.4 \mathrm{E}-04$ & $3.6 \mathrm{E}-05$ & --- & $-5.5 \mathrm{E}-04$ \\
\cline { 2 - 5 } arco-seg & -112 & 7 & --- & -113 \\
\hline um & -147 & 10 & --- & -148 \\
\hline
\end{tabular}

\begin{tabular}{|l|r|r|r|r|}
\cline { 2 - 5 } \multicolumn{1}{c|}{} & \multicolumn{2}{l|}{ Amostra de Medição da Peça } & $\mathbf{0 2}$ \\
\cline { 2 - 5 } \multicolumn{1}{c|}{ Amostra de Medição da superfície de Referência } & \multicolumn{1}{c|}{$\mathbf{0 2}$} \\
\cline { 2 - 5 } \multicolumn{1}{c|}{} & $\begin{array}{c}\text { Média Geral das } \\
\text { Combinações }\end{array}$ & $\begin{array}{c}\text { D. Padrão } \\
\text { Total }\end{array}$ & $\begin{array}{c}\text { Perfil Médio - } \\
\text { Referência Média }\end{array}$ & $\begin{array}{c}\text { Desvio } \\
\text { Médio }\end{array}$ \\
\hline $\begin{array}{l}\text { radianos } \\
\text { arco-seg }\end{array}$ & $-5.8 \mathrm{E}-04$ & $4.3 \mathrm{E}-05$ & $-5.8 \mathrm{E}-04$ & $-5.8 \mathrm{E}-04$ \\
\hline um & -119 & 9 & -119 & -119 \\
\hline
\end{tabular}

\begin{tabular}{|l|r|r|r|r|}
\cline { 2 - 5 } \multicolumn{1}{c|}{} & \multicolumn{2}{l|}{ Amostra de Medição da Peça } & $\mathbf{0 2}$ \\
\cline { 2 - 5 } & \multicolumn{2}{|l|}{ Amostra de Medição da superfície de Referência } & \multicolumn{1}{c|}{$\mathbf{0 3}$} \\
\cline { 2 - 5 } & $\begin{array}{c}\text { Média Geral das } \\
\text { Combinações }\end{array}$ & D. Padrão Total & $\begin{array}{l}\text { Perfil Médio } \\
\text { - Referência } \\
\text { Média }\end{array}$ & $\begin{array}{c}\text { Desvio } \\
\text { Médio }\end{array}$ \\
\cline { 2 - 6 } $\begin{array}{l}\text { radianos } \\
\text { arco-seg }\end{array}$ & $-5.6 \mathrm{E}-04$ & $3.9 \mathrm{E}-05$ & $-5.8 \mathrm{E}-04$ & $-5.6 \mathrm{E}-04$ \\
\hline um & -116 & 8 & -120 & -116 \\
\hline
\end{tabular}


Tabela A6.21 -Valores médios do desvio de perpendicularismo, referentes às tabelas A6.13 a A6.20 (Método Minimax) - continuação.

\begin{tabular}{|c|c|c|c|c|}
\hline & \multicolumn{4}{|c|}{\begin{tabular}{|c|} 
Resultados Médios - Desvio de Perpendicularismo - Peça 2 - \\
Sistema Automatizado e Ajustagem Minimax
\end{tabular}} \\
\hline & \multicolumn{3}{|c|}{ Amostra de Medição da Peça } & 03 \\
\hline & \multicolumn{3}{|c|}{ Amostra de Medição da superfície de Referência } & 01 \\
\hline & \begin{tabular}{|c|} 
Média Geral das \\
Combinações \\
\end{tabular} & $\begin{array}{l}\text { D. Padrão } \\
\text { Total }\end{array}$ & \begin{tabular}{|c|} 
Perfil Médio - \\
Referência Média \\
\end{tabular} & Desvio Médio \\
\hline radianos & $-5.2 \mathrm{E}-04$ & $3.6 \mathrm{E}-05$ & --- & $-5.2 E-04$ \\
\hline arco-seg & -106 & 7 & --- & -107 \\
\hline um & -139 & 10 & --- & -140 \\
\hline
\end{tabular}

\begin{tabular}{|c|c|c|c|c|}
\hline & \multicolumn{3}{|c|}{ Amostra de Medição da Peça } & \multirow{3}{*}{$\begin{array}{c}03 \\
02 \\
\text { Desvio } \\
\text { Médio }\end{array}$} \\
\hline & \multicolumn{3}{|c|}{ Amostra de Medição da superfície de Referência } & \\
\hline & $\begin{array}{l}\text { Média Geral das } \\
\text { Combinações }\end{array}$ & $\begin{array}{l}\text { D. Padrão } \\
\text { Total }\end{array}$ & $\begin{array}{c}\text { Perfil Médio - } \\
\text { Referência Média }\end{array}$ & \\
\hline radianos & $-5.5 \mathrm{E}-04$ & 4.4E-05 & $-5.5 E-04$ & $-5.5 \mathrm{E}-04$ \\
\hline arco-seg & -113 & 9 & -112 & -113 \\
\hline um & -149 & 12 & -147 & -149 \\
\hline
\end{tabular}

\begin{tabular}{|l|r|r|r|r|}
\cline { 2 - 5 } \multicolumn{1}{c|}{} & \multicolumn{2}{l|}{ Amostra de Medição da Peça } & $\mathbf{0 3}$ \\
\cline { 2 - 5 } \multicolumn{1}{c|}{} & \multicolumn{1}{l|}{ Amostra de Medição da superfície de Referência } & \multicolumn{1}{c|}{$\mathbf{0 3}$} \\
\cline { 2 - 5 } \multicolumn{1}{c|}{} & $\begin{array}{c}\text { Média Geral das } \\
\text { Combinações }\end{array}$ & $\begin{array}{c}\text { D. Padrão } \\
\text { Total }\end{array}$ & $\begin{array}{c}\text { Perfil Médio - } \\
\text { Referência Média }\end{array}$ & $\begin{array}{c}\text { Desvio } \\
\text { Médio }\end{array}$ \\
\hline radianos & $-5.4 \mathrm{E}-04$ & $1.1 \mathrm{E}-04$ & $-5.5 \mathrm{E}-04$ & $-5.4 \mathrm{E}-04$ \\
arco-seg & -111 & 8 & -113 & -111 \\
\hline um & -145 & 11 & -148 & -145 \\
\hline
\end{tabular}


Tabela A6.22 - Desvios de perpendicularismo da Peça 2 (Sistema Automatizado e ajustagem de Mínimos Quadrados).

\begin{tabular}{|c|l|r|r|r|}
\hline \multicolumn{5}{|c|}{$\begin{array}{c}\text { Desvio de Perpendicularismo - Peça 2 - Medição com o Sistema } \\
\text { Automatizado - Método dos Mínimos Quadrados }\end{array}$} \\
\hline $\begin{array}{c}\text { Amostra de medição da } \\
\text { Peça: }\end{array}$ & \multicolumn{1}{|c|}{$\begin{array}{c}\text { Amostra de medição da } \\
\text { superfície de referência: }\end{array}$} & \multicolumn{1}{c|}{$\mathbf{0 1}$} \\
\hline \multicolumn{2}{|c|}{} & $\begin{array}{c}\text { Valores observados para todas } \\
\text { as combinações de perfis }\end{array}$ & Desvio Médio \\
\hline \multirow{2}{*}{$\begin{array}{c}\text { Valores do } \\
\text { desvio }\end{array}$} & radianos & \multicolumn{1}{c|}{$-5.8 \mathrm{E}-04$} & $-5.8 \mathrm{E}-04$ \\
\cline { 2 - 5 } & arco-seg & -120 & -120 \\
\cline { 2 - 5 } & um & -157 & -157 \\
\hline
\end{tabular}

Observação: os resultados referentes à combinação entre a amostra 01 de dados da peça e a amostra 02 de dados do artefato de referência foram apresentados no item 6.2.2 deste trabalho.

\begin{tabular}{|c|l|r|r|r|}
\hline \multicolumn{2}{|c|}{$\begin{array}{c}\text { Amostra de medição da } \\
\text { Peça: }\end{array}$} & \multicolumn{1}{|c|}{$\begin{array}{c}\text { Amostra de medição da } \\
\text { superfície de referência: }\end{array}$} & \multicolumn{1}{c|}{$\mathbf{0 3}$} \\
\hline \multicolumn{2}{|c|}{} & $\begin{array}{c}\text { Valores observados para todas } \\
\text { as combinações de perfis }\end{array}$ & \multicolumn{1}{c|}{ Desvio Médio } \\
\hline \multirow{2}{*}{$\begin{array}{c}\text { Valores do } \\
\text { desvio }\end{array}$} & radianos & $-5.6 \mathrm{E}-04$ & $-5.6 \mathrm{E}-04$ \\
\cline { 2 - 5 } & arco-seg & -116 & -116 \\
\cline { 2 - 5 } & um & -152 & -152 \\
\hline
\end{tabular}

\begin{tabular}{|c|c|c|c|c|c|}
\hline \multicolumn{2}{|c|}{$\begin{array}{l}\text { Amostra de medição da } \\
\text { Peça: }\end{array}$} & 02 & \multicolumn{2}{|c|}{$\begin{array}{l}\text { Amostra de medição da } \\
\text { superfície de referência: }\end{array}$} & \multirow{2}{*}{$\frac{01}{\text { Médio }}$} \\
\hline & & $\begin{array}{r}\text { Valore } \\
\text { as c }\end{array}$ & $\begin{array}{l}\text { ervados para todas } \\
\text { nações de perfis }\end{array}$ & Des & \\
\hline \multirow{3}{*}{$\begin{array}{l}\text { Valores do } \\
\text { desvio }\end{array}$} & radianos & & $-5.8 \mathrm{E}-04$ & & $-5.8 E-04$ \\
\hline & arco-seg & & -120 & & -120 \\
\hline & um & & -157 & & -157 \\
\hline
\end{tabular}

\begin{tabular}{|c|c|c|c|c|c|}
\hline \multicolumn{2}{|c|}{$\begin{array}{c}\text { Amostra de medição da } \\
\text { Peça: }\end{array}$} & 02 & \multicolumn{2}{|c|}{$\begin{array}{l}\text { Amostra de medição da } \\
\text { superfície de referência: }\end{array}$} & 02 \\
\hline & & $\begin{array}{r}\text { Valores } \\
\text { as C } \\
\end{array}$ & $\begin{array}{l}\text { iervados para todas } \\
\text { inações de perfis }\end{array}$ & Des & Médio \\
\hline \multirow{3}{*}{$\begin{array}{l}\text { Valores do } \\
\text { desvio }\end{array}$} & radianos & & $-5.4 \mathrm{E}-04$ & & $-5.4 \mathrm{E}-04$ \\
\hline & arco-seg & & -112 & & -112 \\
\hline & um & & -147 & & -147 \\
\hline
\end{tabular}

\begin{tabular}{|c|l|r|r|r|}
\hline \multicolumn{2}{|c|}{$\begin{array}{c}\text { Amostra de medição da } \\
\text { Peça: }\end{array}$} & \multicolumn{1}{|c|}{$\begin{array}{c}\text { Amostra de medição da } \\
\text { superfície de referência: }\end{array}$} & \multicolumn{1}{c|}{$\mathbf{0 3}$} \\
\hline \multicolumn{2}{|c|}{} & $\begin{array}{c}\text { Valores observados para todas } \\
\text { as combinações de perfis }\end{array}$ & \multicolumn{2}{c|}{ Desvio Médio } \\
\hline \multirow{2}{*}{$\begin{array}{c}\text { Valores do } \\
\text { desvio }\end{array}$} & radianos & $-5.6 \mathrm{E}-04$ & $-5.6 \mathrm{E}-04$ \\
\cline { 2 - 5 } & arco-seg & -116 & -116 \\
\cline { 2 - 5 } & um & -152 & -152 \\
\hline
\end{tabular}


Tabela A6.23 - Desvios de perpendicularismo da Peça 2 (Sistema Automatizado e ajustagem de Mínimos Quadrados) - continuação.

\begin{tabular}{|c|l|r|r|r|}
\hline \multicolumn{5}{|c|}{$\begin{array}{c}\text { Desvio de Perpendicularismo - Peça 2 - Medição com o Sistema } \\
\text { Automatizado - Método dos Mínimos Quadrados }\end{array}$} \\
\hline $\begin{array}{c}\text { Amostra de medição da } \\
\text { Peça: }\end{array}$ & $\mathbf{0 3}$ & $\begin{array}{c}\text { Amostra de medição da } \\
\text { superfície de referência: }\end{array}$ & \multicolumn{1}{|c|}{$\mathbf{0 1}$} \\
\hline \multicolumn{2}{|c|}{} & $\begin{array}{c}\text { Valores observados para todas } \\
\text { as combinações de perfis }\end{array}$ & Desvio Médio \\
\hline \multirow{2}{*}{$\begin{array}{c}\text { Valores do } \\
\text { desvio }\end{array}$} & radianos & $-5.7 \mathrm{E}-04$ & $-5.7 \mathrm{E}-04$ \\
\cline { 2 - 5 } & arco-seg & -118 & -118 \\
\cline { 2 - 6 } & um & -154 & -154 \\
\hline
\end{tabular}

\begin{tabular}{|c|l|r|r|r|}
\hline \multicolumn{2}{|c|}{$\begin{array}{c}\text { Amostra de medição da } \\
\text { Peça: }\end{array}$} & \multicolumn{1}{|c|}{$\begin{array}{c}\text { Amostra de medição da } \\
\text { superfície de referência: }\end{array}$} & \multicolumn{1}{c|}{$\mathbf{0 2}$} \\
\hline \multicolumn{2}{|c|}{} & $\begin{array}{c}\text { Valores observados para todas } \\
\text { as combinações de perfis }\end{array}$ & Desvio Médio \\
\hline \multirow{2}{*}{$\begin{array}{c}\text { Valores do } \\
\text { desvio }\end{array}$} & radianos & $-5.7 \mathrm{E}-04$ & $-5.7 \mathrm{E}-04$ \\
\cline { 2 - 5 } & arco-seg & -118 & -118 \\
\cline { 2 - 5 } & um & -154 & -154 \\
\hline
\end{tabular}

\begin{tabular}{|c|c|c|c|c|c|}
\hline \multicolumn{2}{|c|}{$\begin{array}{l}\text { Amostra de medição da } \\
\text { Peça: }\end{array}$} & 03 & \multicolumn{2}{|c|}{$\begin{array}{l}\text { Amostra de medição da } \\
\text { superfície de referência: }\end{array}$} & 03 \\
\hline & & $\begin{array}{r}\text { Valores } \\
\text { as cc }\end{array}$ & $\begin{array}{l}\text { ervados para todas } \\
\text { nações de perfis }\end{array}$ & Desi & o Médio \\
\hline \multirow{3}{*}{$\begin{array}{l}\text { Valores do } \\
\text { desvio }\end{array}$} & radianos & & $-5.5 \mathrm{E}-04$ & & $-5.5 E-04$ \\
\hline & arco-seg & & -114 & & -114 \\
\hline & um & & -149 & & -149 \\
\hline
\end{tabular}


260 


\section{APÊNDICE 7 - Resultados dos cálculos do desvio de perpendicularismo da peça 3 - Amostras adicionais}

\section{Dados obtidos utilizando-se o sistema automatizado}

\section{Amostra 02}

Tabela A7.1 - Perfis das geratrizes da Peça 3 medidos com o sistema automatizado.

\begin{tabular}{|r|r|r|r|r|}
\hline \multicolumn{6}{|c|}{ Perfil das Geratrizes da Peça 3 $(\mu \mathrm{m})$ - } \\
Amostra 02 - Sistema Automatizado - \\
com inclinação \\
\hline G1 & \multicolumn{1}{|c|}{ G2 } & \multicolumn{1}{c|}{ G3 } & \multicolumn{1}{c|}{ G4 } & \multicolumn{1}{c|}{ G5 } \\
\hline-12 & -9 & -1 & -14 & -27 \\
\hline-17 & -11 & 0 & -13 & -26 \\
\hline-14 & -8 & 2 & -8 & -22 \\
\hline-4 & -1 & 7 & 0 & -15 \\
\hline 13 & 9 & 16 & 12 & -6 \\
\hline 38 & 23 & 28 & 27 & 6 \\
\hline 69 & 40 & 42 & 44 & 20 \\
\hline 106 & 60 & 58 & 64 & 37 \\
\hline
\end{tabular}

Tabela A7.2 - Perfis das transversais da Peça 3 medidos com o sistema automatizado.

\begin{tabular}{|r|r|r|r|}
\hline \multicolumn{4}{|c|}{ Perfil das Transversais da Peça } \\
$3(\mu \mathrm{m})$ - Amostra 02 - Sistema \\
Automatizado - com inclinação \\
\hline T1 & \multicolumn{1}{|c|}{ T3 } & \multicolumn{1}{c|}{ T5 } & \multicolumn{1}{c|}{ T7 } \\
\hline 17 & 56 & 78 & 115 \\
\hline 0 & 55 & 80 & 111 \\
\hline-2 & 44 & 67 & 102 \\
\hline 11 & 23 & 40 & 89 \\
\hline 39 & -10 & -1 & 72 \\
\hline
\end{tabular}

Tabela A7.3 - Perfil de superfície da Peça 3

\begin{tabular}{|c|c|c|c|c|c|c|c|}
\hline \multicolumn{8}{|c|}{$\begin{array}{c}\text { Perfil da superfície da Peça } 3 \text { - Amostra } 02 \text { - Perfil de } \\
\text { superfície 01, obtido utilizando-se a reta-base T1 - } \\
\text { Sistema Automatizado }\end{array}$} \\
\hline 0 & -4 & -1 & 8 & 25 & 50 & 81 & 118 \\
\hline-17 & -19 & -16 & -9 & 1 & 15 & 32 & 52 \\
\hline-19 & -19 & -16 & -11 & -2 & 9 & 23 & 40 \\
\hline-7 & -5 & -1 & 7 & 19 & 35 & 52 & 72 \\
\hline 22 & 23 & 27 & 33 & 43 & 55 & 69 & 85 \\
\hline
\end{tabular}


Tabela A7.4 - Coeficientes dos planos ajustados aos perfis da Peça 3 (ajustagem Minimax).

\begin{tabular}{|l|r|r|r|r|r|r|}
\hline \multicolumn{7}{|c|}{ Peça 3 - Amostra 02 - Coeficientes dos planos ajustados - Sistema } \\
Automatizado - Avaliaca com o Método Minimax \\
\hline coeficientes & \multicolumn{1}{|c|}{ Perfil 1 } & \multicolumn{1}{|c|}{ Perfil 3 } & \multicolumn{1}{|c|}{ Perfil 5 } & \multicolumn{1}{|c|}{ Perfil 7 } & \multicolumn{1}{c|}{ Média } & Perfil Médio \\
\hline a0 & -2.4 & -4.0 & -21.7 & -80.3 & -27.1 & -35.6 \\
a1 & $6.5 \mathrm{E}-04$ & $7.6 \mathrm{E}-04$ & $6.6 \mathrm{E}-04$ & $7.0 \mathrm{E}-04$ & $6.9 \mathrm{E}-04$ & $8.1 \mathrm{E}-04$ \\
a2 & $-2.1 \mathrm{E}-04$ & $-1.0 \mathrm{E}-03$ & $-1.0 \mathrm{E}-03$ & $-1.3 \mathrm{E}-04$ & $-6.0 \mathrm{E}-04$ & $-5.4 \mathrm{E}-04$ \\
\hline
\end{tabular}

Tabela A7.5 - Coeficientes dos planos ajustados aos perfis da Peça 3 (ajustagem de Mínimos Quadrados).

\begin{tabular}{|c|c|c|c|c|c|c|}
\hline \multicolumn{7}{|c|}{$\begin{array}{l}\text { Peça } 3 \text { - Amostra } 02 \text { - Coeficientes dos planos ajustados - Sistema } \\
\text { Automatizado - Avaliação com Método dos Mínimos Quadrados }\end{array}$} \\
\hline coeficientes & Perfil 1 & Perfil 3 & Perfil 5 & Perfil 7 & Média & Perfil Médio \\
\hline $\mathrm{a} 0$ & & & & & & \\
\hline a1 & & & & & & $6.2 \mathrm{E}-04$ \\
\hline a2 & $2.0 \mathrm{E}-04$ & $-1.1 \mathrm{E}-03$ & $-1.2 \mathrm{E}-03$ & $-3.7 E-04$ & $-6.2 \mathrm{E}-04$ & $-6.2 \mathrm{E}-04$ \\
\hline
\end{tabular}

\section{Amostra 03}

Tabela A7.6 - Perfis das geratrizes da Peça 3 medidos com o sistema automatizado.

\begin{tabular}{|r|r|r|r|r|}
\hline \multicolumn{6}{|c|}{$\begin{array}{c}\text { Perfil das Geratrizes da Peça 3 }(\mu \mathrm{m}) \text { - } \\
\text { Amostra 03 - Sistema automatizado - } \\
\text { com inclinação }\end{array}$} \\
\hline \multicolumn{6}{|c|}{ G1 } & \multicolumn{1}{|c|}{ G3 } & \multicolumn{1}{c|}{ G4 } & \multicolumn{1}{c|}{ G5 } \\
\hline-36 & -35 & -9 & -41 & -52 \\
\hline-5 & -13 & 3 & -16 & -27 \\
\hline 20 & 6 & 13 & 4 & -6 \\
\hline 40 & 20 & 21 & 19 & 9 \\
\hline 55 & 30 & 26 & 28 & 20 \\
\hline 64 & 35 & 28 & 34 & 25 \\
\hline 68 & 37 & 28 & 37 & 27 \\
\hline 64 & 34 & 27 & 34 & 23 \\
\hline
\end{tabular}

Tabela A7.7 - Perfis das transversais da Peça 3 medidos com o sistema automatizado.

\begin{tabular}{|c|c|c|c|}
\hline \multicolumn{4}{|c|}{$\begin{array}{l}\text { Perfil das Transversais da Peça } \\
\mathbf{3}(\mu \mathrm{m}) \text { - Amostra } 03 \text { - Sistema } \\
\text { Automatizado - com inclinação }\end{array}$} \\
\hline T1 & T3 & T5 & T7 \\
\hline 26 & 51 & 74 & 111 \\
\hline 13 & 49 & 75 & 108 \\
\hline 7 & 40 & 63 & 98 \\
\hline 8 & 23 & 38 & 81 \\
\hline 15 & -3 & -1 & 57 \\
\hline
\end{tabular}


Tabela A7.8 - Perfil de superfície da Peça 3.

\begin{tabular}{|c|c|c|c|c|c|c|c|}
\hline \multicolumn{8}{|c|}{$\begin{array}{c}\text { Perfil da superfície da Peça } 3 \text { - Amostra } 03 \text { - Perfil de } \\
\text { superfície 01, obtido utilizando-se a reta-base T1 - } \\
\text { Sistema Automatizado }\end{array}$} \\
\hline 0 & 31 & 56 & 75 & 91 & 100 & 104 & 100 \\
\hline-13 & 10 & 28 & 43 & 52 & 58 & 60 & 57 \\
\hline-19 & -6 & 4 & 11 & 16 & 19 & 19 & 18 \\
\hline-17 & 7 & 27 & 42 & 51 & 57 & 60 & 57 \\
\hline-11 & 15 & 36 & 51 & 62 & 67 & 69 & 65 \\
\hline
\end{tabular}

Tabela A7.9 - Coeficientes dos planos ajustados aos perfis da Peça 3 (ajustagem Minimax).

\begin{tabular}{|l|r|r|r|r|r|r|}
\hline \multicolumn{7}{|c|}{ Peça 3 - Amostra 03 - Coeficientes dos planos ajustados - Sistema } \\
\hline \multicolumn{1}{|c|}{ Automatizado - Avaliano com o Método Minimax } \\
\hline Coeficientes & \multicolumn{1}{|c|}{ Perfil 1 } & \multicolumn{1}{|c|}{ Perfil 3 } & \multicolumn{1}{c|}{ Perfil 5 } & \multicolumn{1}{|c|}{ Perfil 7 } & \multicolumn{1}{c|}{ Média } & Perfil Médio \\
\hline a0 & 34 & -32 & -53 & -69 & -30 & -40 \\
a1 & $3.1 \mathrm{E}-04$ & $6.1 \mathrm{E}-04$ & $6.0 \mathrm{E}-04$ & $6.0 \mathrm{E}-04$ & $5.3 \mathrm{E}-04$ & $6.2 \mathrm{E}-04$ \\
a2 & $-4.5 \mathrm{E}-04$ & $-6.5 \mathrm{E}-04$ & $-7.8 \mathrm{E}-04$ & $-4.1 \mathrm{E}-04$ & $-5.7 \mathrm{E}-04$ & $-5.4 \mathrm{E}-04$ \\
\hline
\end{tabular}

Tabela A7.10 - Coeficientes dos planos ajustados aos perfis da Peça 3 (ajustagem de Mínimos Quadrados).

\begin{tabular}{|l|r|r|r|r|r|r|}
\hline \multicolumn{7}{|c|}{ Peça 3 - Amostra 03 - Coeficientes dos planos ajustados - Sistema } \\
Automatizado - Avaliação com Método dos Mínimos Quadrados \\
\hline coeficientes & \multicolumn{1}{|c|}{ Perfil 1 } & \multicolumn{1}{|c|}{ Perfil 3 } & \multicolumn{1}{|c|}{ Perfil 5 } & \multicolumn{1}{|c|}{ Perfil 7 } & \multicolumn{1}{c|}{ Média } & Perfil Médio \\
\hline a0 & 14 & -17 & -39 & -56 & -25 & -25 \\
a1 & $5.6 \mathrm{E}-04$ & $5.6 \mathrm{E}-04$ & $5.6 \mathrm{E}-04$ & $5.6 \mathrm{E}-04$ & $5.6 \mathrm{E}-04$ & $5.6 \mathrm{E}-04$ \\
a2 & $-2.9 \mathrm{E}-04$ & $-8.1 \mathrm{E}-04$ & $-1.0 \mathrm{E}-03$ & $-6.5 \mathrm{E}-04$ & $-6.9 \mathrm{E}-04$ & $-6.9 \mathrm{E}-04$ \\
\hline
\end{tabular}

\section{Dados obtidos com a medição convencional}

\section{Amostra 02}

Tabela A7.11 - Perfil da superfície da Peça 3 medido com o sistema convencional.

\begin{tabular}{|r|r|r|r|r|r|r|r|}
\hline \multicolumn{1}{|c|}{ Perfil da superfície da Peça 3 - Sistema Convencional - } \\
\hline-8 & -6 & -5 & -2.5 & -1.5 & 0 & 2.5 & 3 \\
\hline-6 & -4.5 & -3 & -2 & -0.5 & 2 & 4 & 5.5 \\
\hline-4 & -3.5 & -2 & -0.5 & 1.5 & 4 & 6 & 6.5 \\
\hline-3.5 & -2.5 & -1 & 2 & 2 & 4 & 5.5 & 7 \\
\hline-2 & -3 & -1 & 0.5 & 2.5 & 7 & 8 & 9 \\
\hline
\end{tabular}




\section{Amostra 03}

Tabela A7.12 - Perfil da superfície da Peça 3 medido com o sistema convencional.

\begin{tabular}{|r|r|r|r|r|r|r|r|}
\hline \multicolumn{1}{|c|}{ Perfil da superfície da Peça 3 - Sistema Convencional - } \\
\hline-7 & -4.5 & -5 & -3 & -2 & 0.5 & 1.5 & 3 \\
\hline-7 & -5.5 & -2.5 & -1.5 & -0.5 & 2 & 4.5 & 5 \\
\hline-5.5 & -4.5 & -2.5 & -1 & 1 & 4 & 5 & 6.5 \\
\hline-4 & -4 & -2.5 & 0 & 1 & 3 & 4.5 & 6.5 \\
\hline-5.5 & -3.5 & -2.5 & -1 & 1.5 & 5 & 4 & 7.5 \\
\hline
\end{tabular}




\section{Valores do Desvio de Perpendicularismo da Peça 1 - combinações entre as amostras de dados da peça e as amostras de dados do plano de referência}

Tabela A7.13 - Desvios de perpendicularismo da Peça 3 (Sistema Automatizado e ajustagem Minimax) - Amostras 01 e 01.

\begin{tabular}{|c|c|c|c|c|c|c|c|c|}
\hline \multicolumn{9}{|c|}{$\begin{array}{c}\text { Desvio de Perpendicularismo - Peça } 3 \text { - Medição com o Sistema Automatizado - } \\
\text { Avaliação com o Método Minimax }\end{array}$} \\
\hline \multicolumn{3}{|c|}{$\begin{array}{l}\text { Amostra de medição da } \\
\text { Peça: }\end{array}$} & \multirow{2}{*}{$\begin{array}{c}01 \\
\mathrm{R} 1-\mathrm{P} 3 \\
\end{array}$} & \multicolumn{4}{|c|}{$\begin{array}{l}\text { Amostra de medição da superfície de } \\
\text { referência: }\end{array}$} & \multirow{2}{*}{$\begin{array}{c}01 \\
\text { D. padrão }\end{array}$} \\
\hline Combin & ações & $\mathrm{R} 1-\mathrm{P} 1$ & & R1-P5 & R1-P7 & R1-PM & $\begin{array}{l}\text { Médias } \\
\text { (R1) }\end{array}$ & \\
\hline \multirow{3}{*}{$\begin{array}{l}\text { Valores do } \\
\text { desvio }\end{array}$} & radianos & $1.8 \mathrm{E}-04$ & 1.8E-04 & $1.8 \mathrm{E}-04$ & $1.8 \mathrm{E}-04$ & $1.8 \mathrm{E}-04$ & $1.8 \mathrm{E}-04$ & $0.0 \mathrm{E}+00$ \\
\hline & arco-seg & 37 & 37 & 37 & 37 & 37 & 37 & 0 \\
\hline & um & 28 & 28 & 28 & 28 & 28 & 28 & 0 \\
\hline
\end{tabular}

\begin{tabular}{|c|r|r|r|r|r|r|r|r|}
\hline \multicolumn{2}{|c|}{ Combinações } & R3-P1 & \multicolumn{1}{|c|}{ R3-P3 } & R3-P5 & R3-P7 & R3-PM & $\begin{array}{c}\text { Médias } \\
\text { (R3) }\end{array}$ & D. padrão \\
\hline \multirow{2}{*}{$\begin{array}{c}\text { Valores do } \\
\text { desvio }\end{array}$} & $\begin{array}{l}\text { radianos } \\
\text { arco-seg }\end{array}$ & $1.9 \mathrm{E}-04$ & $1.9 \mathrm{E}-04$ & $1.9 \mathrm{E}-04$ & $1.9 \mathrm{E}-04$ & $1.9 \mathrm{E}-04$ & $1.9 \mathrm{E}-04$ & $1.4 \mathrm{E}-20$ \\
\cline { 2 - 9 } & um & 30 & 40 & 40 & 40 & 40 & 40 & 0 \\
\hline
\end{tabular}

\begin{tabular}{|c|r|r|r|r|r|r|r|r|}
\hline \multicolumn{2}{|c|}{ Combinações } & R5-P1 & \multicolumn{1}{|c|}{ R5-P3 } & R5-P5 & R5-P7 & R5-PM & $\begin{array}{c}\text { Médias } \\
\text { (R5) }\end{array}$ & D. padrão \\
\hline \multirow{2}{*}{$\begin{array}{c}\text { Valores do } \\
\text { desvio }\end{array}$} & $\begin{array}{l}\text { radianos } \\
\text { arco-seg }\end{array}$ & $1.9 \mathrm{E}-04$ & $1.9 \mathrm{E}-04$ & $1.9 \mathrm{E}-04$ & $1.9 \mathrm{E}-04$ & $1.9 \mathrm{E}-04$ & $1.9 \mathrm{E}-04$ & $0.0 \mathrm{E}+00$ \\
\cline { 2 - 9 } & um & 39 & 39 & 39 & 39 & 39 & 39 & 0 \\
\hline
\end{tabular}

\begin{tabular}{|l|l|r|r|r|r|r|}
\cline { 3 - 7 } \multicolumn{2}{c|}{} & \multicolumn{1}{c|}{$\mathrm{P} 1$} & \multicolumn{1}{c|}{$\mathrm{P} 3$} & \multicolumn{1}{c|}{$\mathrm{P} 5$} & \multicolumn{1}{c|}{$\mathrm{P} 7$} & \multicolumn{1}{c|}{ Pmédio } \\
\hline \multirow{3}{*}{ Médias } & radianos & $1.9 \mathrm{E}-04$ & $1.9 \mathrm{E}-04$ & $1.9 \mathrm{E}-04$ & $1.9 \mathrm{E}-04$ & $1.9 \mathrm{E}-04$ \\
\cline { 2 - 7 } & arco-seg & 39 & 39 & 39 & 39 & 39 \\
\cline { 2 - 7 } & (um) & 30 & 30 & 30 & 30 & 30 \\
\hline
\end{tabular}

\begin{tabular}{|c|l|r|r|r|r|r|}
\cline { 3 - 7 } \multicolumn{2}{c|}{} & \multicolumn{1}{c|}{$\mathrm{P} 1$} & \multicolumn{1}{c|}{$\mathrm{P} 3$} & \multicolumn{1}{c|}{$\mathrm{P} 5$} & \multicolumn{1}{c|}{$\mathrm{P} 7$} & Pmédio \\
\hline \multirow{2}{*}{$\begin{array}{c}\text { Desvios- } \\
\text { padrão }\end{array}$} & radianos & $6.2 \mathrm{E}-06$ & $6.2 \mathrm{E}-06$ & $6.2 \mathrm{E}-06$ & $6.2 \mathrm{E}-06$ & $6.2 \mathrm{E}-06$ \\
\cline { 2 - 7 } & arco-seg & 1 & 1 & 1 & 1 & 1 \\
\cline { 2 - 7 } & um & 1 & 1 & 1 & 1 & 1 \\
\hline
\end{tabular}


Tabela A7.14 - Desvios de perpendicularismo da Peça 3 (Sistema Automatizado e ajustagem Minimax) - Amostras 01 e 03.

\begin{tabular}{|c|c|c|c|c|c|c|c|c|}
\hline \multicolumn{9}{|c|}{$\begin{array}{c}\text { Desvio de Perpendicularismo - Peça } 3 \text { - Medição com o Sistema Automatizado - } \\
\text { Avaliação com o Método Minimax }\end{array}$} \\
\hline \multicolumn{4}{|c|}{ Amostra de medição da Peça: } & \multirow{2}{*}{$\frac{01}{\mathrm{R} 1-\mathrm{P} 5}$} & \multicolumn{3}{|c|}{$\begin{array}{l}\text { Amostra de medição da superfície } \\
\text { de referência: }\end{array}$} & \multirow{2}{*}{$\frac{03}{\text { D. padrão }}$} \\
\hline Comk & inações & $\mathrm{R} 1-\mathrm{P} 1$ & $\mathrm{R} 1-\mathrm{P} 3$ & & $\mathrm{R} 1-\mathrm{P} 7$ & $\mathrm{R} 1-\mathrm{PM}$ & Médias (R1) & \\
\hline \multirow{3}{*}{$\begin{array}{c}\text { Valores } \\
\text { do } \\
\text { desvio }\end{array}$} & radianos & $1.6 \mathrm{E}-04$ & $1.6 \mathrm{E}-04$ & $1.6 \mathrm{E}-04$ & 1.6E-04 & 1.6E-04 & 1.6E-04 & $0.0 \mathrm{E}+00$ \\
\hline & arco-seg & 32 & 32 & 32 & 32 & 32 & 32 & 0 \\
\hline & $\mu \mathrm{m}$ & 25 & 25 & 25 & 25 & 25 & 25 & 0 \\
\hline
\end{tabular}

\begin{tabular}{|c|l|r|l|r|r|r|r|r|}
\hline \multicolumn{2}{|c|}{ Combinaçes } & \multicolumn{1}{c|}{ R4-P1 } & R4-P3 & R4-P5 & R4-P7 & R4-PM & Médias (R4) & D. padrão \\
\hline \multirow{2}{*}{$\begin{array}{c}\text { Valores } \\
\text { do } \\
\text { desvio }\end{array}$} & radianos & $1.6 \mathrm{E}-04$ & $1.6 \mathrm{E}-04$ & $1.6 \mathrm{E}-04$ & $1.6 \mathrm{E}-04$ & $1.6 \mathrm{E}-04$ & $1.6 \mathrm{E}-04$ & $0.0 \mathrm{E}+00$ \\
\cline { 2 - 10 } & arco-seg & 32 & 32 & 32 & 32 & 32 & 32 & 0 \\
\cline { 2 - 10 } & & 25 & 25 & 25 & 25 & 25 & 25 & 0 \\
\hline
\end{tabular}

\begin{tabular}{|c|l|r|l|r|r|r|r|r|}
\hline \multicolumn{2}{|c|}{ Combinac̃es } & \multicolumn{1}{|c|}{ R7-P1 } & R7-P3 & R7-P5 & R7-P7 & R7-PM & Médias (R7) & D. padrão \\
\hline \multirow{2}{*}{$\begin{array}{c}\text { Valores } \\
\text { do } \\
\text { desvio }\end{array}$} & radianos & $1.7 \mathrm{E}-04$ & $1.7 \mathrm{E}-04$ & $1.7 \mathrm{E}-04$ & $1.7 \mathrm{E}-04$ & $1.6 \mathrm{E}-04$ & $1.7 \mathrm{E}-04$ & $6.0 \mathrm{E}-06$ \\
\cline { 2 - 9 } & arco-seg & 35 & 35 & 35 & 35 & 32 & 34 & 1 \\
\cline { 2 - 9 } & & 27 & 27 & 27 & 27 & 25 & 26 & 1 \\
\hline
\end{tabular}

\begin{tabular}{|c|l|r|r|r|r|r|r|r|}
\hline \multicolumn{2}{|c|}{ Combinães } & R10-P1 & R10-P3 & R10-P5 & R10-P7 & R10-PM & Médias (R10) & D. padrão \\
\hline \multirow{2}{*}{$\begin{array}{c}\text { Valores } \\
\text { do } \\
\text { desvio }\end{array}$} & radianos & $1.6 \mathrm{E}-04$ & $1.6 \mathrm{E}-04$ & $1.6 \mathrm{E}-04$ & $1.6 \mathrm{E}-04$ & $1.6 \mathrm{E}-04$ & $1.6 \mathrm{E}-04$ & $0.0 \mathrm{E}+00$ \\
\cline { 2 - 9 } & arco-seg & 32 & 32 & 32 & 32 & 32 & 32 & 0 \\
\cline { 2 - 9 } & & 25 & 25 & 25 & 25 & 25 & 25 & 0 \\
\hline
\end{tabular}

\begin{tabular}{|c|l|r|r|r|r|r|r|r|}
\hline \multicolumn{2}{|c|}{ Combinães } & R13-P1 & R13-P3 & R13-P5 & R13-P7 & R13-PM & Médias (R13) & D. padrão \\
\hline \multirow{2}{*}{\begin{tabular}{c} 
Valores $\begin{array}{c}\text { do } \\
\text { desvio } \\
\text { desvio }\end{array}$ \\
\cline { 2 - 9 }
\end{tabular}} & arco-seg & $2.0 \mathrm{E}-04$ & $2.0 \mathrm{E}-04$ & $2.0 \mathrm{E}-04$ & $2.0 \mathrm{E}-04$ & $2.0 \mathrm{E}-04$ & $2.0 \mathrm{E}-04$ & $0.0 \mathrm{E}+00$ \\
\cline { 2 - 9 } & 40 & 40 & 40 & 40 & 40 & 40 & 0 \\
\hline
\end{tabular}

\begin{tabular}{|c|c|c|c|c|c|c|c|c|}
\hline \multicolumn{2}{|c|}{ Combinações } & RM-P1 & RM-P3 & RM-P5 & RM-P7 & RM-PM & Médias (RM) & D. padrão \\
\hline \multirow{3}{*}{$\begin{array}{c}\text { Valores } \\
\text { do } \\
\text { desvio }\end{array}$} & radianos & $1.6 \mathrm{E}-04$ & 1.6E-04 & $1.6 \mathrm{E}-04$ & 1.6E-04 & 1.6E-04 & 1.6E-04 & $0.0 \mathrm{E}+00$ \\
\hline & arco-seg & 32 & 32 & 32 & 32 & 32 & 32 & 0 \\
\hline & $\mu \mathrm{m}$ & 25 & 25 & 25 & 25 & 25 & 25 & 0 \\
\hline
\end{tabular}

\begin{tabular}{|l|l|r|r|r|r|r|}
\cline { 3 - 7 } \multicolumn{2}{c|}{} & \multicolumn{1}{c|}{$\mathrm{P} 1$} & \multicolumn{1}{c|}{$\mathrm{P} 3$} & \multicolumn{1}{c|}{$\mathrm{P} 5$} & \multicolumn{1}{c|}{$\mathrm{P} 7$} & \multicolumn{1}{c|}{ Pmédio } \\
\hline \multirow{3}{*}{ Médias } & radianos & $1.7 \mathrm{E}-04$ & $1.7 \mathrm{E}-04$ & $1.7 \mathrm{E}-04$ & $1.7 \mathrm{E}-04$ & $1.6 \mathrm{E}-04$ \\
\cline { 2 - 7 } & arco-seg & 34 & 34 & 34 & 34 & 34 \\
\cline { 2 - 7 } & $\mu \mathrm{m}$ & 26 & 26 & 26 & 26 & 26 \\
\hline
\end{tabular}

\begin{tabular}{|c|l|r|r|r|r|r|}
\cline { 3 - 7 } \multicolumn{2}{c|}{} & \multicolumn{1}{c|}{$\mathrm{P} 1$} & \multicolumn{1}{c|}{$\mathrm{P} 3$} & $\mathrm{P} 5$ & $\mathrm{P} 7$ & Pmédio \\
\hline \multirow{2}{*}{$\begin{array}{c}\text { Desvios- } \\
\text { padrão }\end{array}$} & $\begin{array}{l}\text { radianos } \\
\text { arco-seg }\end{array}$ & $1.8 \mathrm{E}-05$ & $1.8 \mathrm{E}-05$ & $1.8 \mathrm{E}-05$ & $1.8 \mathrm{E}-05$ & $1.8 \mathrm{E}-05$ \\
\cline { 2 - 7 } & $\mu \mathrm{m}$ & 4 & 4 & 4 & 4 & 4 \\
\hline
\end{tabular}


Tabela A7.15 - Desvios de perpendicularismo da Peça 3 (Sistema Automatizado e ajustagem Minimax) - Amostra 02 e 01.

\begin{tabular}{|c|c|c|c|c|c|c|c|c|}
\hline \multicolumn{9}{|c|}{$\begin{array}{c}\text { Desvio de Perpendicularismo - Peça } 3 \text { - Medição com o Sistema Automatizado - } \\
\text { Avaliação com o Método Minimax }\end{array}$} \\
\hline \multicolumn{3}{|c|}{$\begin{array}{l}\text { Amostra de medição da } \\
\text { Peça: }\end{array}$} & \multirow{2}{*}{$\begin{array}{c}02 \\
R 1-P 3\end{array}$} & \multicolumn{4}{|c|}{$\begin{array}{l}\text { Amostra de medição da superfície de } \\
\text { referência: }\end{array}$} & \multirow{2}{*}{$\begin{array}{c}01 \\
\text { D. padrão }\end{array}$} \\
\hline Combin & ações & $\mathrm{R} 1-\mathrm{P} 1$ & & R1-P5 & $\mathrm{R} 1-\mathrm{P} 7$ & R1-PM & $\begin{array}{l}\text { Médias } \\
\text { (R1) }\end{array}$ & \\
\hline \multirow{3}{*}{$\begin{array}{l}\text { Valores do } \\
\text { desvio }\end{array}$} & radianos & $2.8 \mathrm{E}-04$ & $3.9 \mathrm{E}-04$ & $2.9 \mathrm{E}-04$ & $3.2 \mathrm{E}-04$ & 4.4E-04 & $3.4 \mathrm{E}-04$ & 6.8E-05 \\
\hline & arco-seg & 57 & 81 & 60 & 67 & 90 & 71 & 14 \\
\hline & um & 43 & 62 & 46 & 51 & 69 & 54 & 11 \\
\hline
\end{tabular}

\begin{tabular}{|c|r|r|r|r|r|r|r|r|}
\hline \multicolumn{2}{|c|}{$\begin{array}{c}\text { Combinações } \\
\text { R3-P1 }\end{array}$} & R3-P3 & R3-P5 & R3-P7 & R3-PM & $\begin{array}{c}\text { Médias } \\
\text { (R3) }\end{array}$ & D. padrão \\
\hline \multirow{2}{*}{$\begin{array}{c}\text { Valores do } \\
\text { desvio }\end{array}$} & $\begin{array}{l}\text { radianos } \\
\text { arco-seg }\end{array}$ & $2.9 \mathrm{E}-04$ & $4.0 \mathrm{E}-04$ & $3.0 \mathrm{E}-04$ & $3.4 \mathrm{E}-04$ & $4.5 \mathrm{E}-04$ & $3.6 \mathrm{E}-04$ & $6.8 \mathrm{E}-05$ \\
\cline { 2 - 9 } & um & 49 & 83 & 62 & 69 & 92 & 73 & 14 \\
\hline
\end{tabular}

\begin{tabular}{|c|r|r|r|r|r|r|r|r|}
\hline \multicolumn{2}{|c|}{ Combinações } & R5-P1 & \multicolumn{1}{|c|}{ R5-P3 } & R5-P5 & R5-P7 & R5-PM & $\begin{array}{c}\text { Médias } \\
\text { (R5) }\end{array}$ & D. padrão \\
\hline \multirow{2}{*}{$\begin{array}{c}\text { Valores do } \\
\text { desvio }\end{array}$} & $\begin{array}{l}\text { radianos } \\
\text { arco-seg }\end{array}$ & $2.8 \mathrm{E}-04$ & $4.0 \mathrm{E}-04$ & $3.0 \mathrm{E}-04$ & $3.3 \mathrm{E}-04$ & $4.4 \mathrm{E}-04$ & $3.5 \mathrm{E}-04$ & $6.8 \mathrm{E}-05$ \\
\cline { 2 - 9 } & $\mathrm{5m}$ & 83 & 62 & 69 & 92 & 73 & 14 \\
\hline
\end{tabular}

\begin{tabular}{|l|l|r|r|r|r|r|}
\cline { 3 - 7 } \multicolumn{2}{c|}{} & \multicolumn{1}{c|}{$\mathrm{P} 1$} & \multicolumn{1}{c|}{ P3 } & \multicolumn{1}{c|}{ P5 } & \multicolumn{1}{c|}{ P7 } & Pmédio \\
\hline \multirow{3}{*}{ Médias } & radianos & $2.8 \mathrm{E}-04$ & $4.0 \mathrm{E}-04$ & $3.0 \mathrm{E}-04$ & $3.3 \mathrm{E}-04$ & $4.4 \mathrm{E}-04$ \\
\cline { 2 - 7 } & arco-seg & 58 & 82 & 61 & 68 & 91 \\
\cline { 2 - 7 } & (um) & 45 & 63 & 47 & 52 & 70 \\
\hline
\end{tabular}

\begin{tabular}{|c|l|r|r|r|r|r|}
\cline { 3 - 7 } \multicolumn{2}{c|}{} & \multicolumn{1}{c|}{$\mathrm{P} 1$} & \multicolumn{1}{c|}{$\mathrm{P} 3$} & \multicolumn{1}{c|}{$\mathrm{P} 5$} & \multicolumn{1}{c|}{$\mathrm{P} 7$} & Pmédio \\
\hline \multirow{2}{*}{$\begin{array}{c}\text { Desvios- } \\
\text { padrão }\end{array}$} & radianos & $6.2 \mathrm{E}-06$ & $6.2 \mathrm{E}-06$ & $6.2 \mathrm{E}-06$ & $6.2 \mathrm{E}-06$ & $6.2 \mathrm{E}-06$ \\
\cline { 2 - 7 } & arco-seg & 1 & 1 & 1 & 1 & 1 \\
\cline { 2 - 7 } & um & 1 & 1 & 1 & 1 & 1 \\
\hline
\end{tabular}


Tabela A7.16 - Desvios de perpendicularismo da Peça 3 (Sistema Automatizado e ajustagem Minimax) - Amostras 02 e 02.

\begin{tabular}{|c|c|c|c|c|c|c|c|c|}
\hline \multicolumn{9}{|c|}{$\begin{array}{c}\text { Desvio de Perpendicularismo - Peça } 3 \text { - Medição com o Sistema Automatizado - } \\
\text { Avaliação com o Método Minimax }\end{array}$} \\
\hline \multicolumn{4}{|c|}{ Amostra de medição da Peça: } & \multirow{2}{*}{$\frac{02}{\mathrm{R} 1-\mathrm{P} 5}$} & \multicolumn{3}{|c|}{$\begin{array}{l}\text { Amostra de medição da superfície } \\
\text { de referência: }\end{array}$} & \multirow{2}{*}{$\frac{02}{\text { D. padrão }}$} \\
\hline Comk & inações & $\mathrm{R} 1-\mathrm{P} 1$ & R1-P3 & & $\mathrm{R} 1-\mathrm{P} 7$ & $\mathrm{R} 1-\mathrm{PM}$ & Médias (R1) & \\
\hline \multirow{3}{*}{$\begin{array}{c}\text { Valores } \\
\text { do } \\
\text { desvio }\end{array}$} & radianos & $2.0 \mathrm{E}-04$ & $3.2 \mathrm{E}-04$ & 2.2E-04 & $2.5 \mathrm{E}-04$ & 3.6E-04 & $2.7 \mathrm{E}-04$ & $6.8 \mathrm{E}-05$ \\
\hline & arco-seg & 41 & 65 & 44 & 51 & 74 & 55 & 14 \\
\hline & $\mu \mathrm{m}$ & 32 & 50 & 34 & 39 & 57 & 42 & 11 \\
\hline
\end{tabular}

\begin{tabular}{|c|l|r|r|r|r|r|r|r|}
\hline \multicolumn{2}{|c|}{ Combinaçes } & \multicolumn{1}{|c|}{ R4-P1 } & R4-P3 & R4-P5 & R4-P7 & R4-PM & Médias (R4) & D. padrão \\
\hline \multirow{2}{*}{$\begin{array}{c}\text { Valores } \\
\text { do } \\
\text { desvio }\end{array}$} & radianos & $2.5 \mathrm{E}-04$ & $3.6 \mathrm{E}-04$ & $2.6 \mathrm{E}-04$ & $3.0 \mathrm{E}-04$ & $4.1 \mathrm{E}-04$ & $3.2 \mathrm{E}-04$ & $6.8 \mathrm{E}-05$ \\
\cline { 2 - 10 } & arco-seg & 51 & 75 & 54 & 61 & 84 & 65 & 14 \\
\cline { 2 - 10 } & & 39 & 57 & 42 & 47 & 64 & 50 & 11 \\
\hline
\end{tabular}

\begin{tabular}{|c|l|r|r|r|r|r|r|r|}
\hline \multicolumn{2}{|c|}{ Combinac̃es } & \multicolumn{1}{|c|}{ R7-P1 } & R7-P3 & R7-P5 & R7-P7 & R7-PM & Médias (R7) & D. padrão \\
\hline \multirow{2}{*}{$\begin{array}{c}\text { Valores } \\
\text { do } \\
\text { desvio }\end{array}$} & radianos & $2.5 \mathrm{E}-04$ & $3.7 \mathrm{E}-04$ & $2.7 \mathrm{E}-04$ & $3.0 \mathrm{E}-04$ & $4.3 \mathrm{E}-04$ & $3.2 \mathrm{E}-04$ & $7.3 \mathrm{E}-05$ \\
\cline { 2 - 9 } & arco-seg & 52 & 76 & 55 & 62 & 88 & 67 & 15 \\
\cline { 2 - 9 } & $\mu \mathrm{m}$ & 40 & 58 & 42 & 48 & 68 & 51 & 12 \\
\hline
\end{tabular}

\begin{tabular}{|c|c|c|c|c|c|c|c|c|}
\hline \multicolumn{2}{|c|}{ Combinações } & R10-P1 & R10-P3 & R10-P5 & R10-P7 & R10-PM & Médias (R10) & D. padrão \\
\hline \multirow{3}{*}{$\begin{array}{c}\text { Valores } \\
\text { do } \\
\text { desvio }\end{array}$} & radianos & 2.7E-04 & $3.8 \mathrm{E}-04$ & $2.8 \mathrm{E}-04$ & 3.2E-04 & 4.3E-04 & 3.4E-04 & 6.8E-05 \\
\hline & arco-seg & 55 & 79 & 58 & 65 & 88 & 69 & 14 \\
\hline & $\mu \mathrm{m}$ & 42 & 61 & 45 & 50 & 68 & 53 & 11 \\
\hline
\end{tabular}

\begin{tabular}{|c|l|r|r|r|r|r|r|r|}
\hline \multicolumn{2}{|c|}{ Combinães } & R13-P1 & R13-P3 & R13-P5 & R13-P7 & R13-PM & Médias (R13) & D. padrão \\
\hline \multirow{2}{*}{$\begin{array}{c}\text { Valores } \\
\text { do } \\
\text { desvio }\end{array}$} & radianos & $2.7 \mathrm{E}-04$ & $3.8 \mathrm{E}-04$ & $2.8 \mathrm{E}-04$ & $3.2 \mathrm{E}-04$ & $4.3 \mathrm{E}-04$ & $3.4 \mathrm{E}-04$ & $6.8 \mathrm{E}-05$ \\
\cline { 2 - 9 } & arco-seg & 55 & 79 & 58 & 65 & 88 & 69 & 14 \\
\cline { 2 - 9 } & 42 & 61 & 45 & 50 & 68 & 53 & 11 \\
\hline
\end{tabular}

\begin{tabular}{|c|l|r|r|r|r|r|r|r|}
\hline \multicolumn{2}{|c|}{ Combinac̃es } & RM-P1 & RM-P3 & RM-P5 & RM-P7 & RM-PM & Médias (RM) & D. padrão \\
\hline \multirow{2}{*}{$\begin{array}{c}\text { Valores } \begin{array}{c}\text { do } \\
\text { desvio }\end{array} \\
\text { desadianos }\end{array}$} & $2.5 \mathrm{E}-04$ & $3.7 \mathrm{E}-04$ & $2.7 \mathrm{E}-04$ & $3.0 \mathrm{E}-04$ & $4.1 \mathrm{E}-04$ & $3.2 \mathrm{E}-04$ & $6.8 \mathrm{E}-05$ \\
\cline { 2 - 9 } & $\mu \mathrm{m}$ & 52 & 76 & 56 & 62 & 85 & 66 & 14 \\
\hline
\end{tabular}

\begin{tabular}{|l|l|r|r|r|r|r|}
\cline { 3 - 7 } \multicolumn{2}{c|}{} & \multicolumn{1}{c|}{$\mathrm{P} 1$} & \multicolumn{1}{c|}{$\mathrm{P} 3$} & \multicolumn{1}{c|}{$\mathrm{P} 5$} & \multicolumn{1}{c|}{$\mathrm{P} 7$} & \multicolumn{1}{c|}{ Pmédio } \\
\hline \multirow{3}{*}{ Médias } & radianos & $2.5 \mathrm{E}-04$ & $3.6 \mathrm{E}-04$ & $2.6 \mathrm{E}-04$ & $3.0 \mathrm{E}-04$ & $4.1 \mathrm{E}-04$ \\
\cline { 2 - 7 } & arco-seg & 51 & 75 & 54 & 61 & 85 \\
\cline { 2 - 7 } & $\mu \mathrm{m}$ & 39 & 57 & 42 & 47 & 65 \\
\hline
\end{tabular}

\begin{tabular}{|c|l|r|r|r|r|r|}
\cline { 3 - 7 } \multicolumn{2}{c|}{} & \multicolumn{1}{c|}{$\mathrm{P} 1$} & \multicolumn{1}{c|}{$\mathrm{P} 3$} & $\mathrm{P} 5$ & \multicolumn{1}{c|}{$\mathrm{P} 7$} & \multicolumn{1}{c|}{ Pmédio } \\
\hline \multirow{2}{*}{$\begin{array}{c}\text { Desvios- } \\
\text { padrão }\end{array}$} & $\begin{array}{l}\text { radianos } \\
\text { arco-seg }\end{array}$ & $2.8 \mathrm{E}-05$ & $2.8 \mathrm{E}-05$ & $2.8 \mathrm{E}-05$ & $2.8 \mathrm{E}-05$ & $2.9 \mathrm{E}-05$ \\
\cline { 2 - 7 } & $\mu \mathrm{m}$ & 6 & 6 & 6 & 6 & 6 \\
\hline
\end{tabular}


Tabela A7.17 - Desvios de perpendicularismo da Peça 3 (Sistema Automatizado e ajustagem Minimax) - Amostras 02 e 03.

\begin{tabular}{|c|c|c|c|c|c|c|c|c|}
\hline \multicolumn{9}{|c|}{$\begin{array}{c}\text { Desvio de Perpendicularismo - Peça } 3 \text { - Medição com o Sistema Automatizado - } \\
\text { Avaliação com o Método Minimax }\end{array}$} \\
\hline \multicolumn{4}{|c|}{ Amostra de medição da Peça: } & \multirow{2}{*}{$\frac{02}{\mathrm{R} 1-\mathrm{P} 5}$} & \multicolumn{3}{|c|}{$\begin{array}{l}\text { Amostra de medição da superfície } \\
\text { de referência: }\end{array}$} & \multirow{2}{*}{$\frac{03}{\text { D. padrão }}$} \\
\hline Comk & inações & $\mathrm{R} 1-\mathrm{P} 1$ & $\mathrm{R} 1-\mathrm{P} 3$ & & $\mathrm{R} 1-\mathrm{P} 7$ & $\mathrm{R} 1-\mathrm{PM}$ & Médias (R1) & \\
\hline \multirow{3}{*}{$\begin{array}{c}\text { Valores } \\
\text { do } \\
\text { desvio }\end{array}$} & radianos & $2.5 \mathrm{E}-04$ & $3.7 \mathrm{E}-04$ & 2.7E-04 & $3.0 \mathrm{E}-04$ & 4.1E-04 & $3.2 \mathrm{E}-04$ & $6.8 \mathrm{E}-05$ \\
\hline & arco-seg & 52 & 76 & 55 & 62 & 85 & 66 & 14 \\
\hline & $\mu \mathrm{m}$ & 40 & 58 & 42 & 47 & 65 & 50 & 11 \\
\hline
\end{tabular}

\begin{tabular}{|c|l|r|r|r|r|r|r|r|}
\hline \multicolumn{2}{|c|}{ Combinaçes } & \multicolumn{1}{|c|}{ R4-P1 } & R4-P3 & R4-P5 & R4-P7 & R4-PM & Médias (R4) & D. padrão \\
\hline \multirow{2}{*}{$\begin{array}{c}\text { Valores } \\
\text { do } \\
\text { desvio }\end{array}$} & radianos & $2.5 \mathrm{E}-04$ & $3.7 \mathrm{E}-04$ & $2.7 \mathrm{E}-04$ & $3.0 \mathrm{E}-04$ & $4.1 \mathrm{E}-04$ & $3.2 \mathrm{E}-04$ & $6.8 \mathrm{E}-05$ \\
\cline { 2 - 9 } & arco-seg & 52 & 76 & 55 & 62 & 85 & 66 & 14 \\
\cline { 2 - 9 } & $4 \mathrm{~m}$ & 40 & 58 & 42 & 47 & 65 & 50 & 11 \\
\hline
\end{tabular}

\begin{tabular}{|c|c|c|c|c|c|c|c|c|}
\hline \multicolumn{2}{|c|}{ Combinações } & R7-P1 & R7-P3 & R7-P5 & R7-P7 & R7-PM & Médias (R7) & D. padrão \\
\hline \multirow{3}{*}{$\begin{array}{c}\text { Valores } \\
\text { do } \\
\text { desvio }\end{array}$} & \multirow{2}{*}{$\begin{array}{l}\text { radianos } \\
\text { arco-seg }\end{array}$} & $2.6 \mathrm{E}-04$ & $3.8 \mathrm{E}-04$ & $2.8 \mathrm{E}-04$ & $3.1 \mathrm{E}-04$ & $4.1 \mathrm{E}-04$ & 3.3E-04 & 6.4E-05 \\
\hline & & 54 & 78 & 58 & 65 & 85 & 68 & 13 \\
\hline & $\mu \mathrm{m}$ & 42 & 60 & 44 & 49 & 65 & 52 & 10 \\
\hline
\end{tabular}

\begin{tabular}{|c|l|r|r|r|r|r|r|r|}
\hline \multicolumn{2}{|c|}{ Combinações } & R10-P1 & R10-P3 & R10-P5 & R10-P7 & R10-PM & Médias (R10) & D. padrão \\
\hline \multirow{2}{*}{$\begin{array}{c}\text { Valores } \\
\text { do } \\
\text { desvio }\end{array}$} & radianos & $2.5 \mathrm{E}-04$ & $3.7 \mathrm{E}-04$ & $2.7 \mathrm{E}-04$ & $3.0 \mathrm{E}-04$ & $4.1 \mathrm{E}-04$ & $3.2 \mathrm{E}-04$ & $6.8 \mathrm{E}-05$ \\
\cline { 2 - 9 } & arco-seg & 52 & 76 & 55 & 62 & 85 & 66 & 14 \\
\hline
\end{tabular}

\begin{tabular}{|c|c|c|c|c|c|c|c|c|}
\hline \multicolumn{2}{|c|}{ Combinações } & R13-P1 & R13-P3 & R13-P5 & R13-P7 & R13-PM & Médias (R13) & D. padrão \\
\hline \multirow{3}{*}{$\begin{array}{c}\text { Valores } \\
\text { do } \\
\text { desvio }\end{array}$} & radianos & $2.9 \mathrm{E}-04$ & 4.1E-04 & $3.1 \mathrm{E}-04$ & $3.4 \mathrm{E}-04$ & 4.5E-04 & 3.6E-04 & 6.8E-05 \\
\hline & arco-seg & 60 & 84 & 63 & 70 & 93 & 74 & 14 \\
\hline & $\mu \mathrm{m}$ & 46 & 64 & 48 & 54 & 71 & 57 & 11 \\
\hline
\end{tabular}

\begin{tabular}{|c|c|c|c|c|c|c|c|c|}
\hline \multicolumn{2}{|c|}{ Combinações } & RM-P1 & RM-P3 & RM-P5 & RM-P7 & RM-PM & Médias (RM) & D. padrão \\
\hline \multirow{3}{*}{$\begin{array}{c}\text { Valores } \\
\text { do } \\
\text { desvio }\end{array}$} & radianos & $2.5 \mathrm{E}-04$ & 3.7E-04 & 2.7E-04 & $3.0 \mathrm{E}-04$ & $4.1 \mathrm{E}-04$ & 3.2E-04 & 6.8E-05 \\
\hline & arco-seg & 52 & 76 & 55 & 62 & 85 & 66 & 14 \\
\hline & $\mu \mathrm{m}$ & 40 & 58 & 42 & 47 & 65 & 50 & 11 \\
\hline
\end{tabular}

\begin{tabular}{|l|l|r|r|r|r|r|}
\cline { 3 - 7 } \multicolumn{2}{c|}{} & \multicolumn{1}{c|}{$\mathrm{P} 1$} & \multicolumn{1}{c|}{$\mathrm{P} 3$} & \multicolumn{1}{c|}{$\mathrm{P} 5$} & \multicolumn{1}{c|}{$\mathrm{P} 7$} & \multicolumn{1}{c|}{ Pmédio } \\
\hline \multirow{3}{*}{ Médias } & radianos & $2.6 \mathrm{E}-04$ & $3.8 \mathrm{E}-04$ & $2.8 \mathrm{E}-04$ & $3.1 \mathrm{E}-04$ & $4.2 \mathrm{E}-04$ \\
\cline { 2 - 7 } & arco-seg & 54 & 78 & 57 & 64 & 86 \\
\cline { 2 - 7 } & $\mu \mathrm{m}$ & 41 & 60 & 44 & 49 & 66 \\
\hline
\end{tabular}

\begin{tabular}{|c|l|r|r|r|r|r|}
\cline { 3 - 7 } \multicolumn{2}{c|}{} & \multicolumn{1}{c|}{$\mathrm{P} 1$} & \multicolumn{1}{c|}{$\mathrm{P} 3$} & $\mathrm{P} 5$ & $\mathrm{P} 7$ & \multicolumn{1}{c|}{ Pmédio } \\
\hline \multirow{2}{*}{$\begin{array}{c}\text { Desvios- } \\
\text { padrão }\end{array}$} & radianos & $1.8 \mathrm{E}-05$ & $1.8 \mathrm{E}-05$ & $1.8 \mathrm{E}-05$ & $1.8 \mathrm{E}-05$ & $1.8 \mathrm{E}-05$ \\
\cline { 2 - 7 } & arco-seg & 4 & 4 & 4 & 4 & 4 \\
\cline { 2 - 7 } & $\mu \mathrm{m}$ & 3 & 3 & 3 & 3 & 3 \\
\hline
\end{tabular}


Tabela A7.18 - Desvios de perpendicularismo da Peça 3 (Sistema Automatizado e ajustagem Minimax) - Amostras 03 e 01.

\begin{tabular}{|c|c|c|c|c|c|c|c|c|}
\hline \multicolumn{9}{|c|}{$\begin{array}{l}\text { Desvio de Perpendicularismo - Peça } 3 \text { - Medição com o Sistema Automatizado - } \\
\text { Avaliação com o Método Minimax }\end{array}$} \\
\hline \multicolumn{3}{|c|}{ Amostra de medição da Peça: } & \multirow{2}{*}{$\frac{03}{\mathrm{R} 1-\mathrm{P} 3}$} & \multicolumn{4}{|c|}{$\begin{array}{l}\text { Amostra de medição da superfície de } \\
\text { referência: }\end{array}$} & \multirow{2}{*}{$\frac{01}{\text { D. padrão }}$} \\
\hline Combir & ações & $\mathrm{R} 1-\mathrm{P} 1$ & & R1-P5 & $\mathrm{R} 1-\mathrm{P} 7$ & R1-PM & $\begin{array}{l}\text { Médias } \\
\text { (R1) }\end{array}$ & \\
\hline \multirow{3}{*}{$\begin{array}{l}\text { Valores do } \\
\text { desvio }\end{array}$} & radianos & $-6.7 \mathrm{E}-05$ & $2.4 \mathrm{E}-04$ & $2.2 \mathrm{E}-04$ & $2.2 \mathrm{E}-04$ & $2.5 \mathrm{E}-04$ & 1.7E-04 & $1.4 \mathrm{E}-04$ \\
\hline & arco-seg & -14 & 49 & 46 & 46 & 52 & 36 & 28 \\
\hline & um & -11 & 38 & 35 & 35 & 40 & 27 & 21 \\
\hline
\end{tabular}

\begin{tabular}{|c|l|r|r|r|r|r|r|r|}
\hline \multicolumn{2}{|c|}{ Combinações } & \multicolumn{1}{|c|}{ R3-P1 } & R3-P3 & R3-P5 & R3-P7 & R3-PM & $\begin{array}{c}\text { Médias } \\
\text { (R3) }\end{array}$ & D. padrão \\
\hline \multirow{2}{*}{$\begin{array}{c}\text { Valores do } \\
\text { desvio }\end{array}$} & radianos & $-5.5 \mathrm{E}-05$ & $2.5 \mathrm{E}-04$ & $2.4 \mathrm{E}-04$ & $2.4 \mathrm{E}-04$ & $2.6 \mathrm{E}-04$ & $1.9 \mathrm{E}-04$ & $1.4 \mathrm{E}-04$ \\
\cline { 2 - 9 } & arco-seg & -11 & 52 & 49 & 49 & 54 & 38 & 28 \\
\cline { 2 - 10 } & um & -9 & 40 & 37 & 37 & 42 & 29 & 21 \\
\hline
\end{tabular}

\begin{tabular}{|c|l|r|r|r|r|r|r|r|}
\hline \multicolumn{2}{|c|}{ Combinações } & \multicolumn{1}{|c|}{ R5-P1 } & R5-P3 & R5-P5 & R5-P7 & R5-PM & $\begin{array}{c}\text { Médias } \\
\text { (R5) }\end{array}$ & D. padrão \\
\hline \multirow{2}{*}{$\begin{array}{c}\text { Valores do } \\
\text { desvio }\end{array}$} & $\begin{array}{l}\text { radianos } \\
\text { arco-seg }\end{array}$ & $-5.8 \mathrm{E}-05$ & $2.5 \mathrm{E}-04$ & $2.3 \mathrm{E}-04$ & $2.3 \mathrm{E}-04$ & $2.6 \mathrm{E}-04$ & $1.8 \mathrm{E}-04$ & $1.4 \mathrm{E}-04$ \\
\cline { 2 - 9 } & $\mathrm{um}$ & -12 & 51 & 48 & 48 & 54 & 38 & 28 \\
\hline
\end{tabular}

\begin{tabular}{|l|l|r|r|r|r|r|}
\cline { 3 - 7 } \multicolumn{2}{c|}{} & \multicolumn{1}{c|}{$\mathrm{P} 1$} & \multicolumn{1}{c|}{$\mathrm{P} 3$} & \multicolumn{1}{c|}{$\mathrm{P} 5$} & \multicolumn{1}{c|}{$\mathrm{P} 7$} & Pmédio \\
\hline \multirow{3}{*}{ Médias } & radianos & $-6.0 \mathrm{E}-05$ & $2.5 \mathrm{E}-04$ & $2.3 \mathrm{E}-04$ & $2.3 \mathrm{E}-04$ & $2.6 \mathrm{E}-04$ \\
\cline { 2 - 7 } & arco-seg & -12 & 51 & 48 & 48 & 53 \\
\cline { 2 - 7 } & (um) & -10 & 39 & 36 & 36 & 41 \\
\hline
\end{tabular}

\begin{tabular}{|c|l|r|r|r|r|r|}
\cline { 3 - 7 } \multicolumn{2}{c|}{} & \multicolumn{1}{c|}{$\mathrm{P} 1$} & \multicolumn{1}{c|}{$\mathrm{P} 3$} & \multicolumn{1}{c|}{$\mathrm{P} 5$} & \multicolumn{1}{c|}{$\mathrm{P} 7$} & Pmédio \\
\hline \multirow{2}{*}{$\begin{array}{c}\text { Desvios- } \\
\text { padrão }\end{array}$} & radianos & $6.2 \mathrm{E}-06$ & $6.2 \mathrm{E}-06$ & $6.2 \mathrm{E}-06$ & $6.2 \mathrm{E}-06$ & $6.2 \mathrm{E}-06$ \\
\cline { 2 - 7 } & arco-seg & 1 & 1 & 1 & 1 & 1 \\
\cline { 2 - 7 } & um & 1 & 1 & 1 & 1 & 1 \\
\hline
\end{tabular}


Tabela A7.19 - Desvios de perpendicularismo da Peça 3 (Sistema Automatizado e ajustagem Minimax) - Amostras 03 e 02.

\begin{tabular}{|c|c|c|c|c|c|c|c|c|}
\hline \multicolumn{9}{|c|}{$\begin{array}{c}\text { Desvio de Perpendicularismo - Peça } 3 \text { - Medição com o Sistema Automatizado - } \\
\text { Avaliação com o Método Minimax }\end{array}$} \\
\hline \multicolumn{4}{|c|}{ Amostra de medição da Peça: } & \multirow{2}{*}{$\frac{03}{\mathrm{R} 1-\mathrm{P} 5}$} & \multicolumn{3}{|c|}{$\begin{array}{l}\text { Amostra de medição da superfície } \\
\text { de referência: }\end{array}$} & \multirow{2}{*}{$\begin{array}{c}02 \\
\text { D. padrão } \\
\end{array}$} \\
\hline Comk & inações & $\mathrm{R} 1-\mathrm{P} 1$ & $\mathrm{R} 1-\mathrm{P} 3$ & & $\mathrm{R} 1-\mathrm{P} 7$ & $\mathrm{R} 1-\mathrm{PM}$ & Médias (R1) & \\
\hline \multirow{3}{*}{$\begin{array}{c}\text { Valores } \\
\text { do } \\
\text { desvio }\end{array}$} & radianos & $-1.4 \mathrm{E}-04$ & $1.6 \mathrm{E}-04$ & $1.5 \mathrm{E}-04$ & $1.5 \mathrm{E}-04$ & $1.8 \mathrm{E}-04$ & 9.9E-05 & $1.4 \mathrm{E}-04$ \\
\hline & arco-seg & -29 & 34 & 31 & 31 & 36 & 20 & 28 \\
\hline & $\mu \mathrm{m}$ & -23 & 26 & 23 & 23 & 28 & 16 & 21 \\
\hline
\end{tabular}

\begin{tabular}{|c|l|r|r|r|r|r|r|r|}
\hline \multicolumn{2}{|c|}{ Combinaçes } & \multicolumn{1}{c|}{ R4-P1 } & R4-P3 & R4-P5 & R4-P7 & R4-PM & Médias (R4) & D. padrão \\
\hline \multirow{2}{*}{$\begin{array}{c}\text { Valores } \\
\text { do } \\
\text { desvio }\end{array}$} & radianos & $-9.5 \mathrm{E}-05$ & $2.1 \mathrm{E}-04$ & $2.0 \mathrm{E}-04$ & $2.0 \mathrm{E}-04$ & $2.2 \mathrm{E}-04$ & $1.5 \mathrm{E}-04$ & $1.4 \mathrm{E}-04$ \\
\cline { 2 - 9 } & arco-seg & -20 & 43 & 40 & 40 & 46 & 30 & 28 \\
\cline { 2 - 10 } & & -15 & 33 & 31 & 31 & 35 & 23 & 21 \\
\hline
\end{tabular}

\begin{tabular}{|c|c|c|c|c|c|c|c|c|}
\hline \multicolumn{2}{|c|}{ Combinações } & R7-P1 & R7-P3 & R7-P5 & R7-P7 & R7-PM & Médias (R7) & D. padrão \\
\hline \multirow{3}{*}{$\begin{array}{c}\text { Valores } \\
\text { do } \\
\text { desvio }\end{array}$} & radianos & $-8.9 E-05$ & $2.2 \mathrm{E}-04$ & $2.0 \mathrm{E}-04$ & $2.0 \mathrm{E}-04$ & 2.4E-04 & 1.5E-04 & 1.4E-04 \\
\hline & arco-seg & -18 & 45 & 42 & 42 & 50 & 32 & 28 \\
\hline & $\mu \mathrm{m}$ & -14 & 34 & 32 & 32 & 38 & 24 & 22 \\
\hline
\end{tabular}

\begin{tabular}{|c|c|c|c|c|c|c|c|c|}
\hline \multicolumn{2}{|c|}{ Combinações } & R10-P1 & R10-P3 & R10-P5 & R10-P7 & R10-PM & Médias (R10) & D. padrão \\
\hline \multirow{3}{*}{$\begin{array}{c}\text { Valores } \\
\text { do } \\
\text { desvio }\end{array}$} & radianos & $-7.5 \mathrm{E}-05$ & 2.3E-04 & 2.2E-04 & $2.2 \mathrm{E}-04$ & 2.4E-04 & 1.7E-04 & 1.4E-04 \\
\hline & arco-seg & -15 & 48 & 45 & 45 & 50 & 34 & 28 \\
\hline & $\mu \mathrm{m}$ & -12 & 36 & 34 & 34 & 38 & 26 & 21 \\
\hline
\end{tabular}

\begin{tabular}{|c|c|c|c|c|c|c|c|c|}
\hline \multicolumn{2}{|c|}{ Combinações } & R13-P1 & R13-P3 & R13-P5 & R13-P7 & R13-PM & Médias (R13) & D. padrão \\
\hline \multirow{3}{*}{$\begin{array}{c}\text { Valores } \\
\text { do } \\
\text { desvio }\end{array}$} & radianos & $-7.5 \mathrm{E}-05$ & 2.3E-04 & 2.2E-04 & 2.2E-04 & $2.4 \mathrm{E}-04$ & 1.7E-04 & $1.4 \mathrm{E}-04$ \\
\hline & arco-seg & -15 & 48 & 45 & 45 & 50 & 34 & 28 \\
\hline & $\mu \mathrm{m}$ & -12 & 36 & 34 & 34 & 38 & 26 & 21 \\
\hline
\end{tabular}

\begin{tabular}{|c|l|r|r|r|r|r|r|r|}
\hline \multicolumn{2}{|c|}{ Combinações } & \multicolumn{1}{|c|}{ RM-P1 } & RM-P3 & RM-P5 & RM-P7 & RM-PM & Médias (RM) & D. padrão \\
\hline \multirow{2}{*}{$\begin{array}{c}\text { Valores } \begin{array}{c}\text { codianos } \\
\text { desvio }\end{array} \\
\text { desvio }\end{array}$} & arco-seg & -18 & 45 & 42 & 42 & 47 & 31 & 28 \\
\cline { 2 - 9 } & $\mu \mathrm{m}$ & -14 & 34 & 32 & 32 & 36 & 24 & 21 \\
\hline
\end{tabular}

\begin{tabular}{|c|c|c|c|c|c|c|}
\hline & & P1 & P3 & P5 & P7 & Pmédio \\
\hline \multirow{3}{*}{ Médias } & radianos & $\begin{array}{r}-9.5 \mathrm{E}- \\
05 \\
\end{array}$ & $2.1 \mathrm{E}-04$ & 2.0E-04 & 2.0E-04 & 2.3E-04 \\
\hline & arco-seg & -20 & 43 & 40 & 40 & 47 \\
\hline & $\mu \mathrm{m}$ & -15 & 33 & 31 & 31 & 36 \\
\hline
\end{tabular}

\begin{tabular}{|c|l|r|r|r|r|r|}
\cline { 3 - 7 } \multicolumn{2}{c|}{} & \multicolumn{1}{c|}{$\mathrm{P} 1$} & \multicolumn{1}{c|}{$\mathrm{P} 3$} & \multicolumn{1}{c|}{$\mathrm{P} 5$} & \multicolumn{1}{c|}{$\mathrm{P} 7$} & \multicolumn{1}{c|}{ Pmédio } \\
\hline \multirow{2}{*}{$\begin{array}{c}\text { Desvios- } \\
\text { padrão }\end{array}$} & radianos & $2.8 \mathrm{E}-05$ & $2.8 \mathrm{E}-05$ & $2.8 \mathrm{E}-05$ & $2.8 \mathrm{E}-05$ & $2.9 \mathrm{E}-05$ \\
\cline { 2 - 7 } & arco-seg & 6 & 6 & 6 & 6 & 6 \\
\cline { 2 - 7 } & $\mu \mathrm{m}$ & 4 & 4 & 4 & 4 & 5 \\
\hline
\end{tabular}


Tabela A7.20 - Desvios de perpendicularismo da Peça 3 (Sistema Automatizado e ajustagem Minimax) - Amostras 03 e 03.

\begin{tabular}{|c|c|c|c|c|c|c|c|c|}
\hline \multicolumn{9}{|c|}{$\begin{array}{c}\text { Desvio de Perpendicularismo - Peça } 3 \text { - Medição com o Sistema Automatizado - } \\
\text { Avaliação com o Método Minimax }\end{array}$} \\
\hline \multicolumn{4}{|c|}{ Amostra de medição da Peça: } & \multirow{2}{*}{$\begin{array}{c}03 \\
R 1-P 5\end{array}$} & \multicolumn{3}{|c|}{$\begin{array}{l}\text { Amostra de medição da superfície } \\
\text { de referência: }\end{array}$} & \multirow{2}{*}{$\frac{03}{\text { D. padrão }}$} \\
\hline Comk & inações & $\mathrm{R} 1-\mathrm{P} 1$ & $\mathrm{R} 1-\mathrm{P} 3$ & & \begin{tabular}{|l|}
$\mathrm{R} 1-\mathrm{P} 7$ \\
\end{tabular} & $\mathrm{R} 1-\mathrm{PM}$ & Médias (R1) & \\
\hline \multirow{3}{*}{$\begin{array}{c}\text { Valores } \\
\text { do } \\
\text { desvio }\end{array}$} & radianos & $-9.2 E-05$ & $2.1 \mathrm{E}-04$ & $2.0 \mathrm{E}-04$ & $2.0 \mathrm{E}-04$ & $2.3 \mathrm{E}-04$ & 1.5E-04 & $1.4 \mathrm{E}-04$ \\
\hline & arco-seg & -19 & 44 & 41 & 41 & 47 & 31 & 28 \\
\hline & $\mu \mathrm{m}$ & -14 & 34 & 31 & 31 & 36 & 24 & 21 \\
\hline
\end{tabular}

\begin{tabular}{|c|l|r|r|r|r|r|r|r|}
\hline \multicolumn{2}{|c|}{ Combinações } & \multicolumn{1}{|c|}{ R4-P1 } & \multicolumn{1}{c|}{ R4-P3 } & \multicolumn{1}{c|}{ R4-P5 } & R4-P7 & R4-PM & Médias (R4) & D. padrão \\
\hline \multirow{2}{*}{$\begin{array}{c}\text { Valores } \begin{array}{c}\text { do } \\
\text { desvio }\end{array} \\
\text { desadianos }\end{array}$} & $-9.2 \mathrm{E}-05$ & $2.1 \mathrm{E}-04$ & $2.0 \mathrm{E}-04$ & $2.0 \mathrm{E}-04$ & $2.3 \mathrm{E}-04$ & $1.5 \mathrm{E}-04$ & $1.4 \mathrm{E}-04$ \\
\cline { 2 - 9 } & $\mathrm{arco}-\mathrm{seg}$ & -19 & 44 & 41 & 41 & 47 & 31 & 28 \\
\cline { 2 - 10 } & & -15 & 34 & 31 & 31 & 36 & 24 & 21 \\
\hline
\end{tabular}

\begin{tabular}{|c|c|c|c|c|c|c|c|c|}
\hline \multicolumn{2}{|c|}{ Combinações } & R7-P1 & R7-P3 & R7-P5 & R7-P7 & R7-PM & Médias (R7) & D. padrão \\
\hline \multirow{3}{*}{$\begin{array}{c}\text { Valores } \\
\text { do } \\
\text { desvio }\end{array}$} & radianos & $-7.8 E-05$ & $2.3 \mathrm{E}-04$ & $2.1 \mathrm{E}-04$ & $2.1 \mathrm{E}-04$ & $2.3 \mathrm{E}-04$ & 1.6E-04 & 1.3E-04 \\
\hline & arco-seg & -16 & 47 & 44 & 44 & 47 & 33 & 28 \\
\hline & $\mu \mathrm{m}$ & -12 & 36 & 34 & 34 & 36 & 25 & 21 \\
\hline
\end{tabular}

\begin{tabular}{|c|c|c|c|c|c|c|c|c|}
\hline \multicolumn{2}{|c|}{ Combinações } & R10-P1 & R10-P3 & R10-P5 & R10-P7 & R10-PM & Médias (R10) & D. padrão \\
\hline \multirow{3}{*}{$\begin{array}{c}\text { Valores } \\
\text { do } \\
\text { desvio }\end{array}$} & radianos & $-9.2 E-05$ & 2.1E-04 & 2.0E-04 & 2.0E-04 & 2.3E-04 & 1.5E-04 & 1.4E-04 \\
\hline & arco-seg & -19 & 44 & 41 & 41 & 47 & 31 & 28 \\
\hline & $\mu \mathrm{m}$ & -14 & 34 & 31 & 31 & 36 & 24 & 21 \\
\hline
\end{tabular}

\begin{tabular}{|c|l|r|r|r|r|r|r|r|}
\hline \multicolumn{2}{|c|}{ Combinações } & R13-P1 & R13-P3 & R13-P5 & R13-P7 & R13-PM & Médias (R13) & D. padrão \\
\hline \multirow{2}{*}{$\begin{array}{c}\text { Valores } \begin{array}{c}\text { do } \\
\text { desvio }\end{array} \\
\text { desianos }\end{array}$} & $-5.1 \mathrm{E}-05$ & $2.5 \mathrm{E}-04$ & $2.4 \mathrm{E}-04$ & $2.4 \mathrm{E}-04$ & $2.7 \mathrm{E}-04$ & $1.9 \mathrm{E}-04$ & $1.4 \mathrm{E}-04$ \\
\cline { 2 - 9 } & $\mu \mathrm{m}$ & -11 & 52 & 49 & 49 & 55 & 39 & 28 \\
\cline { 2 - 9 } & -8 & 40 & 38 & 38 & 42 & 30 & 21 \\
\hline
\end{tabular}

\begin{tabular}{|c|c|c|c|c|c|c|c|c|}
\hline \multicolumn{2}{|c|}{ Combinações } & RM-P1 & RM-P3 & RM-P5 & RM-P7 & RM-PM & Médias (RM) & D. padrão \\
\hline \multirow{3}{*}{$\begin{array}{c}\text { Valores } \\
\text { do } \\
\text { desvio }\end{array}$} & radianos & $-9.2 E-05$ & $2.1 \mathrm{E}-04$ & $2.0 \mathrm{E}-04$ & 2.0E-04 & 2.3E-04 & 1.5E-04 & $1.4 \mathrm{E}-04$ \\
\hline & arco-seg & -19 & 44 & 41 & 41 & 47 & 31 & 28 \\
\hline & $\mu \mathrm{m}$ & -14 & 34 & 31 & 31 & 36 & 24 & 21 \\
\hline
\end{tabular}

\begin{tabular}{|l|l|r|r|r|r|r|}
\cline { 3 - 7 } \multicolumn{2}{c|}{} & \multicolumn{1}{c|}{$\mathrm{P} 1$} & \multicolumn{1}{c|}{$\mathrm{P} 3$} & \multicolumn{1}{c|}{$\mathrm{P} 5$} & \multicolumn{1}{c|}{$\mathrm{P} 7$} & \multicolumn{1}{c|}{ Pmédio } \\
\hline \multirow{3}{*}{ Médias } & radianos & $-8.1 \mathrm{E}-05$ & $2.2 \mathrm{E}-04$ & $2.1 \mathrm{E}-04$ & $2.1 \mathrm{E}-04$ & $2.3 \mathrm{E}-04$ \\
\cline { 2 - 7 } & arco-seg & -17 & 46 & 43 & 43 & 48 \\
\cline { 2 - 7 } & $\mu \mathrm{m}$ & -13 & 35 & 33 & 33 & 37 \\
\hline
\end{tabular}

\begin{tabular}{|c|l|r|r|r|r|r|}
\cline { 2 - 7 } \multicolumn{2}{c|}{} & \multicolumn{1}{c|}{$\mathrm{P} 1$} & \multicolumn{1}{c|}{$\mathrm{P} 3$} & $\mathrm{P} 5$ & $\mathrm{P} 7$ & Pmédio \\
\hline \multirow{2}{*}{$\begin{array}{c}\text { Desvios- } \\
\text { padrão }\end{array}$} & $\begin{array}{l}\text { radianos } \\
\text { arco-seg }\end{array}$ & $1.8 \mathrm{E}-05$ & $1.8 \mathrm{E}-05$ & $1.8 \mathrm{E}-05$ & $1.8 \mathrm{E}-05$ & $1.8 \mathrm{E}-05$ \\
\cline { 2 - 7 } & $\mu \mathrm{m}$ & 4 & 4 & 4 & 4 & 4 \\
\hline
\end{tabular}


Tabela A7.21 - Valores médios do desvio de perpendicularismo, referentes às tabelas A7.13 a A7.20 (Método Minimax).

\begin{tabular}{|l|l|l|c|r|}
\cline { 2 - 5 } & \multicolumn{4}{c|}{$\begin{array}{c}\text { Valores Médios - Desvio de perpendicularismo - Peça 3 - } \\
\text { Sistema Automatizado e Ajustagem Minimax }\end{array}$} \\
\cline { 2 - 5 } & \multicolumn{3}{c|}{$\mathbf{0 1}$} \\
\cline { 2 - 5 } & Amostra de Medição da Peça & \multicolumn{1}{c|}{$\mathbf{0 1}$} \\
\cline { 2 - 5 } & $\begin{array}{c}\text { Média Geral das } \\
\text { Combinações }\end{array}$ & $\begin{array}{c}\text { D. Padrão } \\
\text { Total }\end{array}$ & $\begin{array}{c}\text { Perfil Médio - } \\
\text { Referência Média }\end{array}$ & $\begin{array}{c}\text { Desvio } \\
\text { Médio }\end{array}$ \\
\hline \multirow{2}{*}{$\begin{array}{l}\text { radianos } \\
\text { arco-seg }\end{array}$} & $1.9 \mathrm{E}-04$ & $5.2 \mathrm{E}-06$ & --- & $1.8 \mathrm{E}-04$ \\
\hline um & 39 & 1 & --- & 38 \\
\hline
\end{tabular}

\begin{tabular}{|l|r|r|r|r|}
\cline { 2 - 5 } \multicolumn{1}{c|}{} & \multicolumn{3}{l|}{ Amostra de Medição da Peça } & $\mathbf{0 1}$ \\
\cline { 2 - 5 } \multicolumn{1}{c|}{ Amostra de Medição da superfície de Referência } & \multicolumn{1}{c|}{$\mathbf{0 3}$} \\
\cline { 2 - 5 } \multicolumn{1}{c|}{} & $\begin{array}{c}\text { Média Geral das } \\
\text { Combinações }\end{array}$ & $\begin{array}{c}\text { D. Padrão } \\
\text { Total }\end{array}$ & $\begin{array}{c}\text { Perfil Médio - } \\
\text { Referência Média }\end{array}$ & $\begin{array}{c}\text { Desvio } \\
\text { Médio }\end{array}$ \\
\hline radianos & $1.7 \mathrm{E}-04$ & $1.6 \mathrm{E}-05$ & $1.6 \mathrm{E}-04$ & $1.7 \mathrm{E}-04$ \\
\cline { 2 - 6 } arco-seg & 34 & 3 & 32 & 34 \\
\hline um & 5 & 3 & 25 & 26 \\
\hline
\end{tabular}

\begin{tabular}{|l|r|r|r|r|}
\cline { 2 - 5 } \multicolumn{1}{c|}{} & \multicolumn{2}{l|}{ Amostra de Medição da Peça } & $\mathbf{0 2}$ \\
\cline { 2 - 5 } \multicolumn{1}{c|}{ Amostra de Medição da superfície de Referência } & \multicolumn{1}{c|}{$\mathbf{0 1}$} \\
\cline { 2 - 5 } \multicolumn{1}{c|}{} & $\begin{array}{c}\text { Média Geral das } \\
\text { Combinações }\end{array}$ & $\begin{array}{c}\text { D. Padrão } \\
\text { Total }\end{array}$ & $\begin{array}{c}\text { Perfil Médio - } \\
\text { Referência Média }\end{array}$ & $\begin{array}{c}\text { Desvio } \\
\text { Médio }\end{array}$ \\
\hline radianos & $3.5 \mathrm{E}-04$ & $6.3 \mathrm{E}-05$ & --- & $3.2 \mathrm{E}-04$ \\
\cline { 2 - 5 } arco-seg & 72 & 13 & --- & 67 \\
\hline um & 55 & 10 & --- & 51 \\
\hline
\end{tabular}

\begin{tabular}{|l|r|r|r|r|}
\cline { 2 - 5 } \multicolumn{1}{c|}{} & \multicolumn{2}{l|}{ Amostra de Medição da Peça } & \multicolumn{1}{c|}{$\mathbf{0 2}$} \\
\cline { 2 - 5 } \multicolumn{1}{c|}{ Amostra de Medição da superfície de Referência } & \multicolumn{1}{c|}{$\mathbf{0 2}$} \\
\cline { 2 - 5 } \multicolumn{1}{c|}{$\begin{array}{c}\text { Média Geral das } \\
\text { Combinações }\end{array}$} & $\begin{array}{c}\text { D. Padrão } \\
\text { Total }\end{array}$ & $\begin{array}{c}\text { Perfil Médio - } \\
\text { Referência Média }\end{array}$ & $\begin{array}{c}\text { Desvio } \\
\text { Médio }\end{array}$ \\
\hline $\begin{array}{l}\text { radianos } \\
\text { arco-seg }\end{array}$ & $3.2 \mathrm{E}-04$ & $6.8 \mathrm{E}-05$ & $4.1 \mathrm{E}-04$ & $2.9 \mathrm{E}-04$ \\
\hline um & 65 & 14 & 85 & 60 \\
\hline
\end{tabular}

\begin{tabular}{|l|r|r|r|r|}
\cline { 2 - 5 } \multicolumn{1}{c|}{} & \multicolumn{2}{l|}{ Amostra de Medição da Peça } & $\mathbf{0 2}$ \\
\cline { 2 - 5 } \multicolumn{1}{c|}{ Amostra de Medição da superfície de Referência } & $\mathbf{0 3}$ \\
\cline { 2 - 5 } \multicolumn{1}{c|}{$\begin{array}{c}\text { Média Geral das } \\
\text { Combinações }\end{array}$} & D. Padrão Total & $\begin{array}{c}\text { Perfil Médio } \\
\text { - Referência } \\
\text { Média }\end{array}$ & $\begin{array}{c}\text { Desvio } \\
\text { Médio }\end{array}$ \\
\hline radianos & $3.3 \mathrm{E}-04$ & $6.4 \mathrm{E}-05$ & $4.1 \mathrm{E}-04$ & $3.1 \mathrm{E}-04$ \\
\hline arco-seg & 68 & 13 & 85 & 63 \\
\hline um & 10 & 10 & 65 & 48 \\
\hline
\end{tabular}


Tabela A7.21 - Valores médios do desvio de perpendicularismo, referentes às tabelas A7.13 a A7.20 (Método Minimax) - continuação.

\begin{tabular}{|c|c|c|c|c|}
\hline & \multicolumn{4}{|c|}{$\begin{array}{c}\text { Valores médios - Desvio de perpendicularismo - Peça } 3 \text { - } \\
\text { Sistema Automatizado e Ajustagem Minimax }\end{array}$} \\
\hline & \multicolumn{3}{|c|}{ Amostra de Medição da Peça } & \multirow{2}{*}{\begin{tabular}{|l|}
03 \\
01 \\
\end{tabular}} \\
\hline & \multicolumn{3}{|c|}{ Amostra de Medição da superfície de Referência } & \\
\hline & $\begin{array}{c}\text { Média Geral das } \\
\text { Combinações }\end{array}$ & $\begin{array}{l}\text { D. Padrão } \\
\text { Total }\end{array}$ & $\begin{array}{c}\text { Perfil Médio - } \\
\text { Referência Média }\end{array}$ & Desvio Médio \\
\hline radianos & $1.8 \mathrm{E}-04$ & 1.3E-04 & --- & 1.6E-04 \\
\hline arco-seg & 37 & 26 & $-\cdots$ & 33 \\
\hline um & 29 & 20 & --- & 25 \\
\hline
\end{tabular}

\begin{tabular}{|l|r|r|r|r|}
\cline { 2 - 5 } \multicolumn{1}{c|}{} & \multicolumn{2}{l|}{ Amostra de Medição da Peça } & $\mathbf{0 3}$ \\
\cline { 2 - 5 } \multicolumn{1}{c|}{ Amostra de Medição da superfície de Referência } & \multicolumn{1}{c|}{$\mathbf{0 2}$} \\
\cline { 2 - 5 } \multicolumn{1}{c|}{} & $\begin{array}{c}\text { Média Geral das } \\
\text { Combinações }\end{array}$ & $\begin{array}{c}\text { D. Padrão } \\
\text { Total }\end{array}$ & $\begin{array}{c}\text { Perfil Médio - } \\
\text { Referência Média }\end{array}$ & $\begin{array}{c}\text { Desvio } \\
\text { Médio }\end{array}$ \\
\hline \multirow{2}{*}{$\begin{array}{l}\text { radianos } \\
\text { arco-seg }\end{array}$} & $1.5 \mathrm{E}-04$ & $1.3 \mathrm{E}-04$ & $2.3 \mathrm{E}-04$ & $1.3 \mathrm{E}-04$ \\
\hline um & 30 & 26 & 47 & 26 \\
\hline
\end{tabular}

\begin{tabular}{|c|c|c|c|c|}
\hline & \multicolumn{3}{|c|}{ Amostra de Medição da Peça } & \multirow{2}{*}{$\begin{array}{l}03 \\
03 \\
\end{array}$} \\
\hline & \multicolumn{3}{|c|}{ Amostra de Medição da superfície de Referência } & \\
\hline & $\begin{array}{c}\text { Média Geral das } \\
\text { Combinações } \\
\end{array}$ & $\begin{array}{l}\text { D. Padrão } \\
\text { Total }\end{array}$ & $\begin{array}{c}\text { Perfil Médio - } \\
\text { Referência Média } \\
\end{array}$ & $\begin{array}{l}\text { Desvio } \\
\text { Médio }\end{array}$ \\
\hline radianos & $1.6 \mathrm{E}-04$ & $1.2 \mathrm{E}-04$ & $2.3 \mathrm{E}-04$ & 1.4E-04 \\
\hline arco-seg & 33 & 26 & 47 & 29 \\
\hline um & 5 & 20 & 36 & 22 \\
\hline
\end{tabular}


Tabela A7.22 - Desvios de perpendicularismo da Peça 3 (Sistema Automatizado e ajustagem de Mínimos Quadrados).

\begin{tabular}{|c|l|r|r|r|}
\hline \multicolumn{5}{|c|}{$\begin{array}{c}\text { Desvio de Perpendicularismo - Peça 3 - Medição com o Sistema } \\
\text { Automatizado - Método dos Mínimos Quadrados }\end{array}$} \\
\hline $\begin{array}{c}\text { Amostra de medição da } \\
\text { Peça: }\end{array}$ & \multicolumn{1}{|c|}{$\mathbf{0 1}$} & $\begin{array}{c}\text { Amostra de medição da } \\
\text { superfície de referência: }\end{array}$ & \multicolumn{1}{c|}{$\mathbf{0 1}$} \\
\hline \multicolumn{3}{|c|}{} & $\begin{array}{c}\text { Valores observados para todas } \\
\text { as combinações de perfis }\end{array}$ & Desvio Médio \\
\hline \multirow{2}{*}{$\begin{array}{c}\text { Valores do } \\
\text { desvio }\end{array}$} & radianos & $2.4 \mathrm{E}-04$ & $2.4 \mathrm{E}-04$ \\
\cline { 2 - 5 } & arco-seg & 49 & 49 \\
\cline { 2 - 5 } & um & 38 & 38 \\
\hline
\end{tabular}

Observação: os resultados referentes à combinação entre a amostra 01 de dados da peça e a amostra 02 de dados do artefato de referência foram apresentados no item 6.2.3 deste trabalho.

\begin{tabular}{|c|c|c|c|c|c|}
\hline \multicolumn{2}{|c|}{$\begin{array}{l}\text { Amostra de medição da } \\
\text { Peça: }\end{array}$} & 01 & \multicolumn{2}{|c|}{$\begin{array}{l}\text { Amostra de medição da } \\
\text { superfície de referência: }\end{array}$} & 03 \\
\hline & & \multicolumn{2}{|c|}{$\begin{array}{c}\text { Valores observados para todas } \\
\text { as combinações de perfis }\end{array}$} & \multicolumn{2}{|c|}{ Desvio Médio } \\
\hline \multirow{3}{*}{$\begin{array}{l}\text { Valores do } \\
\text { desvio }\end{array}$} & radianos & & 2.6E-04 & & 2.6E-04 \\
\hline & arco-seg & & 53 & & 53 \\
\hline & um & & 41 & & 41 \\
\hline
\end{tabular}

\begin{tabular}{|c|c|c|c|c|c|}
\hline \multicolumn{2}{|c|}{$\begin{array}{c}\text { Amostra de medição da } \\
\text { Peça: }\end{array}$} & \multirow{2}{*}{\multicolumn{2}{|c|}{\begin{tabular}{c|c}
02 & $\begin{array}{c}\text { Amostra de mediç } \\
\text { superfície de refer }\end{array}$ \\
Valores observados para todas \\
as combinações de perfis
\end{tabular}}} & $\begin{array}{l}\text { da } \\
\text { cia: }\end{array}$ & \multirow{2}{*}{01} \\
\hline & & & & Des & \\
\hline \multirow{3}{*}{$\begin{array}{c}\text { Valores do } \\
\text { desvio }\end{array}$} & radianos & & 2.3E-04 & & 2.3E-04 \\
\hline & arco-seg & & 48 & & 48 \\
\hline & um & & 37 & & 37 \\
\hline
\end{tabular}

\begin{tabular}{|c|c|c|c|c|c|}
\hline \multicolumn{2}{|c|}{$\begin{array}{l}\text { Amostra de medição da } \\
\text { Peça: }\end{array}$} & 02 & \multicolumn{2}{|c|}{$\begin{array}{l}\text { Amostra de medição da } \\
\text { superfície de referência: }\end{array}$} & 02 \\
\hline & & $\begin{array}{r}\text { Valores } \\
\text { as c } \\
\end{array}$ & $\begin{array}{l}\text { ervados para todas } \\
\text { nações de perfis }\end{array}$ & Des & Médio \\
\hline \multirow{3}{*}{$\begin{array}{l}\text { Valores do } \\
\text { desvio }\end{array}$} & radianos & & 2.7E-04 & & 2.7E-04 \\
\hline & arco-seg & & 56 & & 56 \\
\hline & um & & 43 & & 43 \\
\hline
\end{tabular}

\begin{tabular}{|c|c|c|c|c|c|}
\hline \multicolumn{2}{|c|}{$\begin{array}{l}\text { Amostra de medição da } \\
\text { Peça: }\end{array}$} & \multirow{2}{*}{\multicolumn{2}{|c|}{\begin{tabular}{c|c}
02 & $\begin{array}{c}\text { Amostra de mediç } \\
\text { superfície de refer }\end{array}$ \\
Valores observados para todas \\
as combinações de perfis
\end{tabular}}} & $\begin{array}{l}\text { da } \\
\text { cia: }\end{array}$ & 03 \\
\hline & & & & Des & Médio \\
\hline \multirow{3}{*}{$\begin{array}{l}\text { Valores do } \\
\text { desvio }\end{array}$} & radianos & & $2.5 \mathrm{E}-04$ & & 2.5E-04 \\
\hline & arco-seg & & 52 & & 52 \\
\hline & um & & 40 & & 40 \\
\hline
\end{tabular}


Tabela A7.23 - Desvios de perpendicularismo da Peça 3 (Sistema Automatizado e ajustagem de Mínimos Quadrados) - continuação.

\begin{tabular}{|c|c|c|c|c|c|}
\hline \multicolumn{6}{|c|}{$\begin{array}{c}\text { Desvio de Perpendicularismo - Peça } 3 \text { - Medição com o Sistema } \\
\text { Automatizado - Método dos Mínimos Quadrados }\end{array}$} \\
\hline \multicolumn{2}{|c|}{$\begin{array}{l}\text { Amostra de medição da } \\
\text { Peça: }\end{array}$} & \multirow{2}{*}{\multicolumn{2}{|c|}{\begin{tabular}{c|c}
$\mathbf{0 3}$ & $\begin{array}{c}\text { Amostra de medic } \\
\text { superfície de refer }\end{array}$ \\
Valores observados para todas \\
as combinacões de perfis
\end{tabular}}} & da & 01 \\
\hline & & & & Des & Médio \\
\hline \multirow{3}{*}{$\begin{array}{l}\text { Valores do } \\
\text { desvio }\end{array}$} & radianos & & 1.7E-04 & & $1.7 \mathrm{E}-04$ \\
\hline & arco-seg & & 36 & & 36 \\
\hline & um & & 27 & & 27 \\
\hline
\end{tabular}

\begin{tabular}{|c|c|c|c|c|c|}
\hline \multicolumn{2}{|c|}{$\begin{array}{c}\text { Amostra de medição da } \\
\text { Peça: }\end{array}$} & 03 & \multicolumn{2}{|c|}{$\begin{array}{l}\text { Amostra de medição da } \\
\text { superfície de referência: }\end{array}$} & 02 \\
\hline & & $\begin{array}{r}\text { Valores } \\
\text { as cc } \\
\end{array}$ & $\begin{array}{l}\text { ervados para todas } \\
\text { inações de perfis }\end{array}$ & Des & Médio \\
\hline \multirow{3}{*}{$\begin{array}{l}\text { Valores do } \\
\text { desvio }\end{array}$} & radianos & & $2.1 \mathrm{E}-04$ & & 2.1E-04 \\
\hline & arco-seg & & 44 & & 44 \\
\hline & um & & 34 & & 34 \\
\hline
\end{tabular}

\begin{tabular}{|c|l|r|r|r|}
\hline \multicolumn{2}{|c|}{$\begin{array}{c}\text { Amostra de medição da } \\
\text { Peça: }\end{array}$} & \multicolumn{1}{c|}{$\mathbf{0 3}$} & $\begin{array}{c}\text { Amostra de medição da } \\
\text { superfície de referência: }\end{array}$ & \multicolumn{1}{c|}{$\mathbf{0 3}$} \\
\hline \multicolumn{2}{|c|}{} & $\begin{array}{c}\text { Valores observados para todas } \\
\text { as combinações de perfis }\end{array}$ & \multicolumn{1}{c|}{ Desvio Médio } \\
\hline \multirow{2}{*}{$\begin{array}{c}\text { Valores do } \\
\text { desvio }\end{array}$} & radianos & & $1.9 \mathrm{E}-04$ & $1.9 \mathrm{E}-04$ \\
\cline { 2 - 5 } & arco-seg & & 40 & 40 \\
\cline { 2 - 5 } & um & & 30 & 30 \\
\hline
\end{tabular}

